
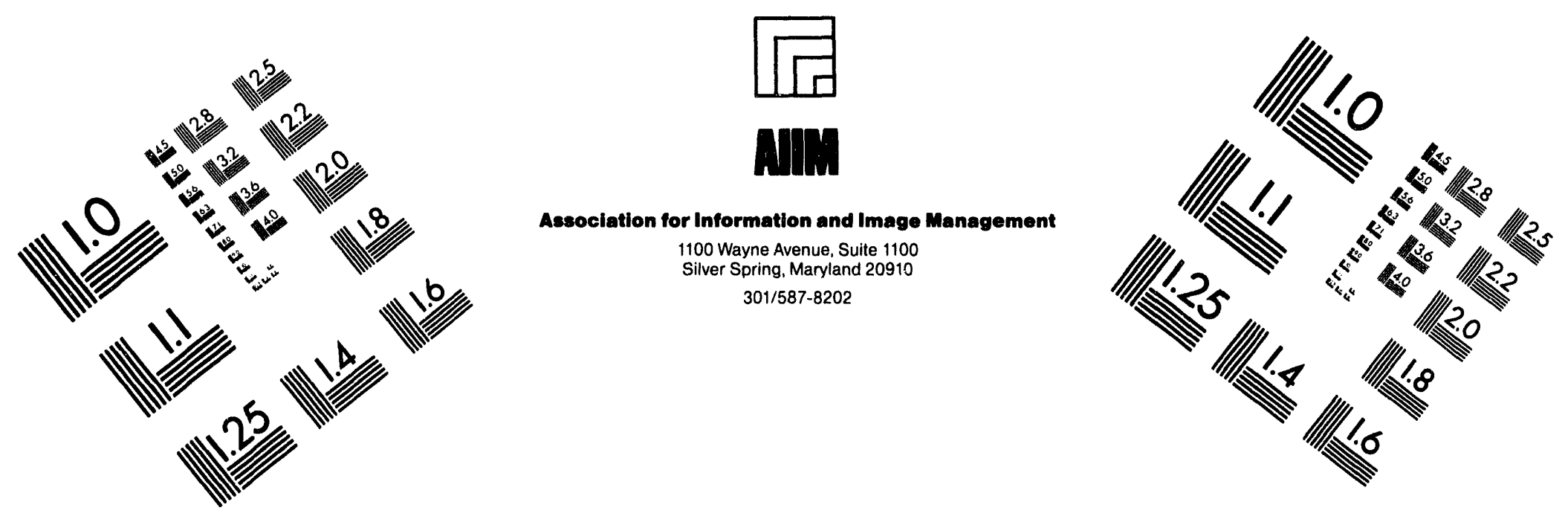

\title{
Centimeter
}

$\begin{array}{llllllllllllllll}1 & 2 & 3 & 4 & 5 & 6 & 7 & 8 & 9 & 10 & 11 & 12 & 13 & 14 & 15 & \mathrm{~mm}\end{array}$

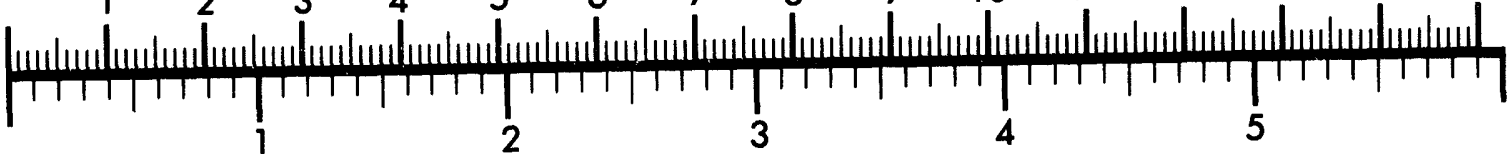
Inches

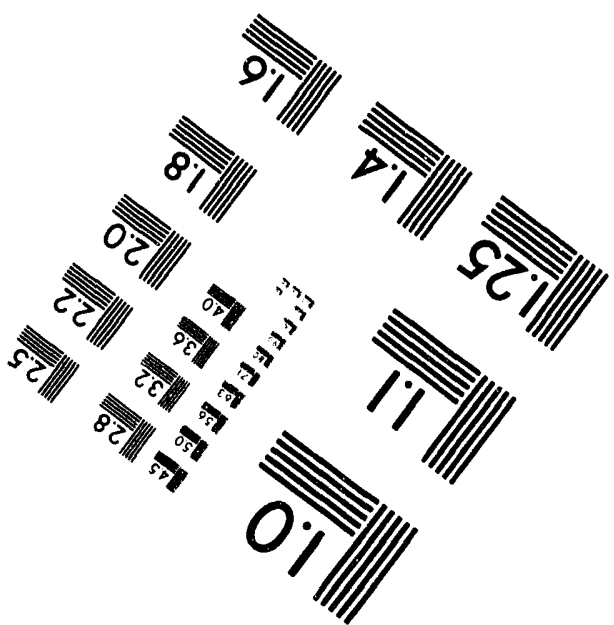

MANUFACTURED TO AIIM STANDARDS BY APPLIED IMAGE, INC.

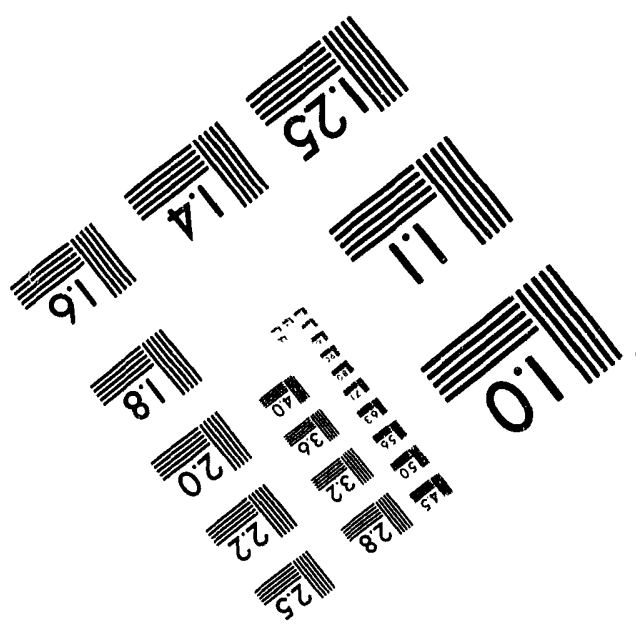



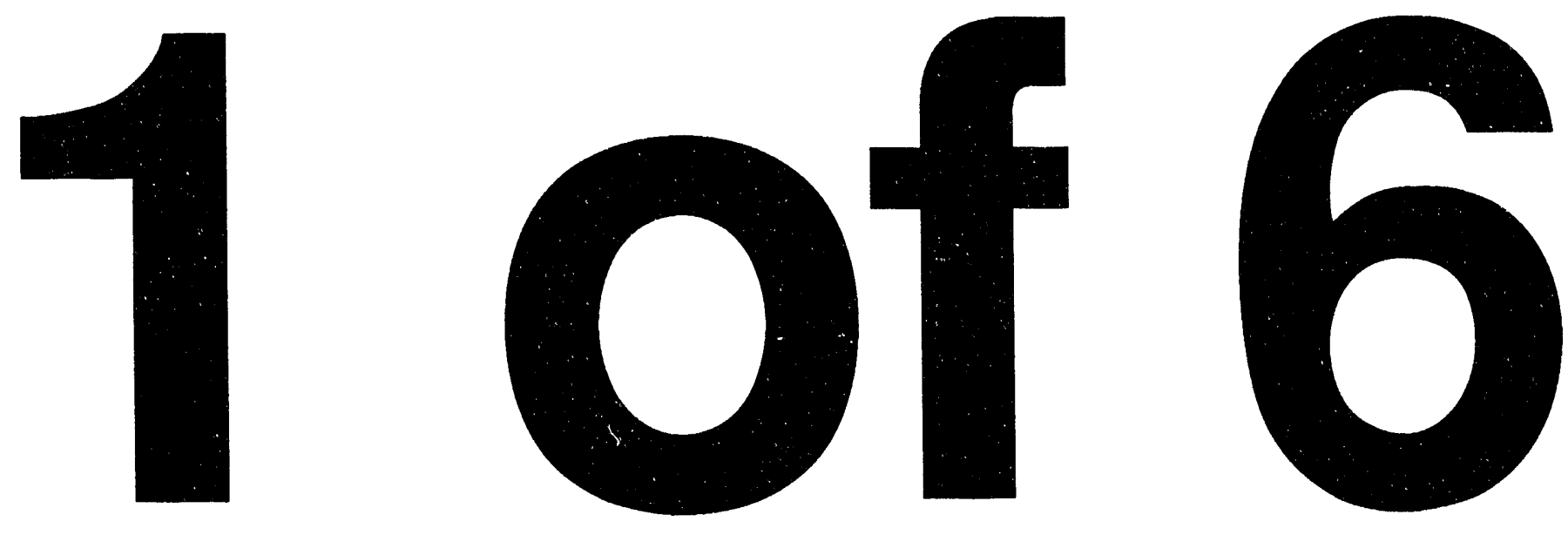


\section{WRAP 2A ADVANCED CONCEPTUAL DESIGN REPORT}

The Final Advanced Conceptual Design Report is submitted to the Westinghouse Hanford Company in accordance with the Statement of Work for Off-Site Architect-Engineer Services, Revision 4D.

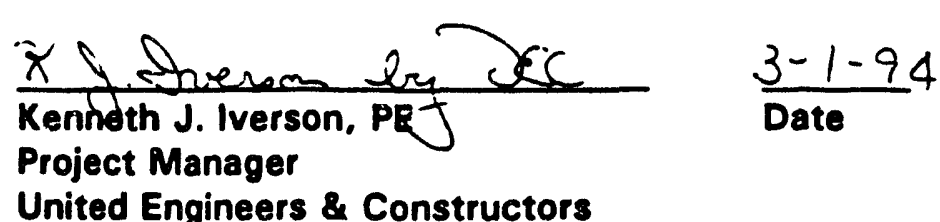

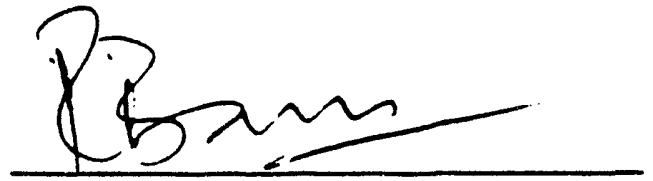

Rathin Basu, PE

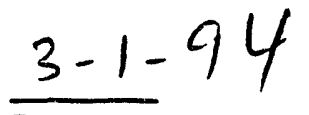

Date

Project Engineering Manager

United Engineers \& Constructors

\section{NOTICE}

This report was prepared as an account of work sponsored by the United States Government and not for the purpose of reliance by any third party. Neither the United States nor the Department of Energy, nor any of their employees, nor any of their contractors, subcontractors. or their employees, make any warranty, express or implied, or assume any logal liability or responsibility for the accuracy, completeness, or usefulness of any information, apparatus, product or process disclosed or represent that its use would not infringe privately-owned rights. Reference herein to any specific commercial product, process, or service by trade name, mark, manufacturer, or otherwise, does not necessarily constitute or imply its endorsement, recommendation, or fovoring by the United States Government or any agency thereof nor any contractor, subcontractor, or their employees. The views and opinions of authors expressed herein do not necessarily state or reflect those of the United States Government or any agency thereof, nor any contractor, subcontractor, or their employees. Use of any part of this report shall be at the user's sole risk and shall constitute a relesse and an agreement to defend and indemnity the United States, the Department of Energy and/or any of their employees, contractors, subcontractors, and/or their employees, against any and all liability in connection therewith, regordless of fault or negligence.

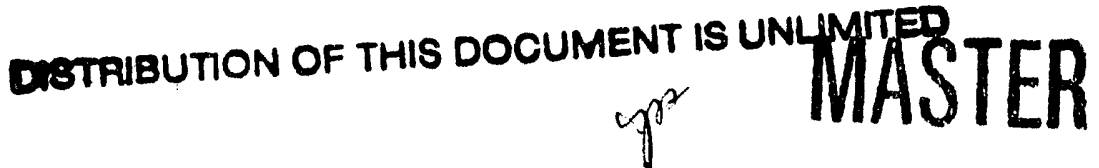




\section{VOLUME I \\ WRAP 2A \\ ADVANCED CONCEPTUAL DESIGN REPORT}

\section{TABLE OF CONTENTS}

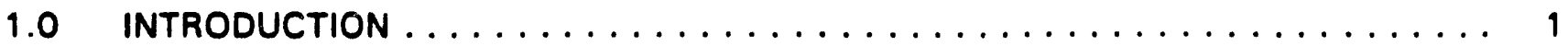

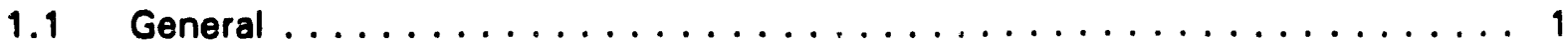

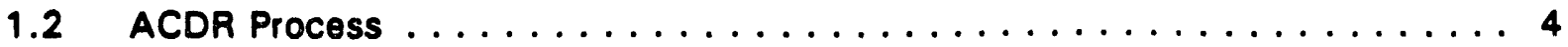

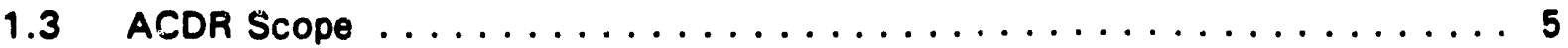

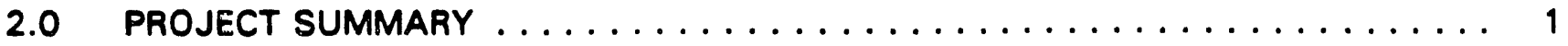

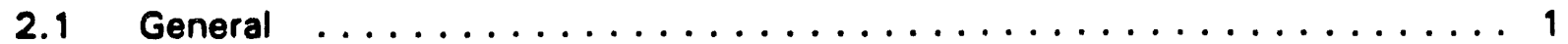

2.2 Waste Treatment Technologies ....................6

2.3 Facility Overview ........................... 21

2.4 WRAP $2 A$ Conceptual Design Comparison ................ 21

3.0 ENGINEERING ASSESSMENTS SUMMARY $\ldots \ldots \ldots \ldots \ldots \ldots \ldots \ldots$

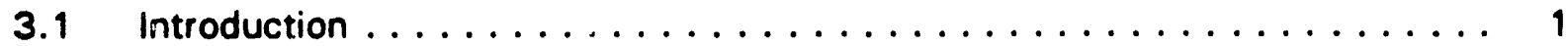

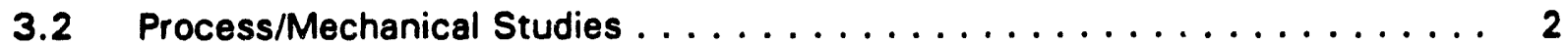

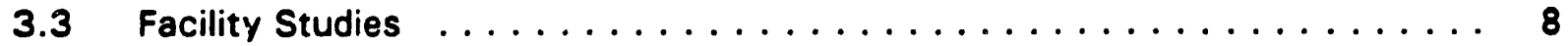

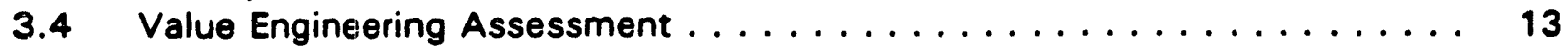

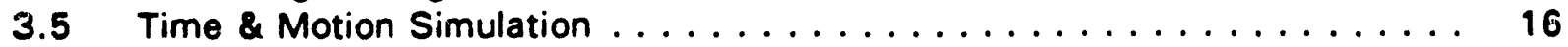

3.6 Hazards and Operability Review $\ldots \ldots \ldots \ldots \ldots \ldots \ldots \ldots$

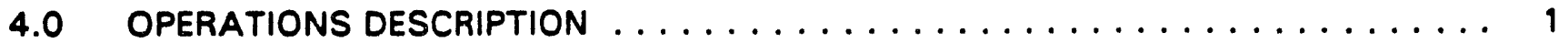

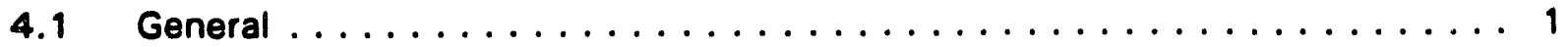

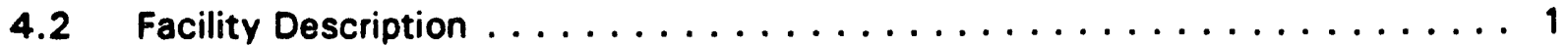

4.3 General Layout . . . . . . . . . . . . . . . . . . . . 7

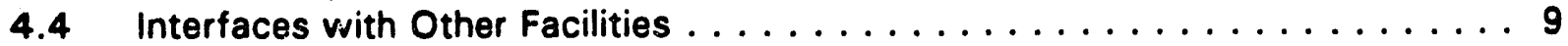

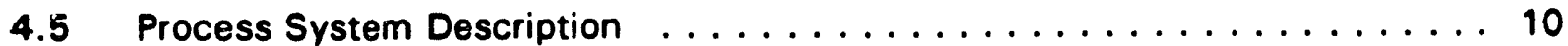

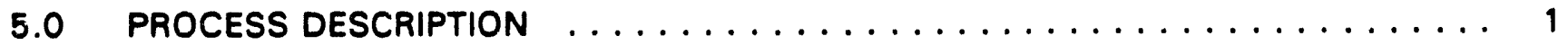

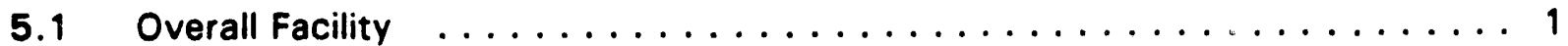

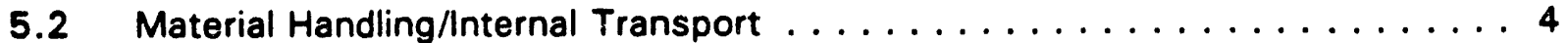

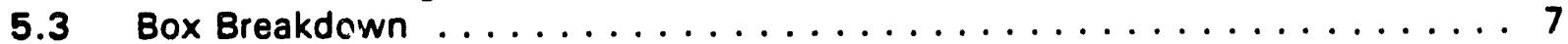

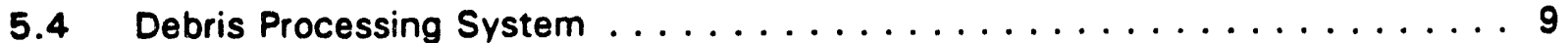

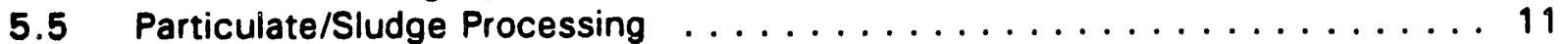

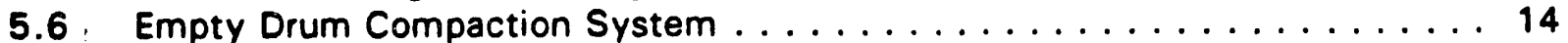

5.7 Polyethylene Encapsulation System $\ldots \ldots \ldots \ldots \ldots \ldots \ldots \ldots \ldots$

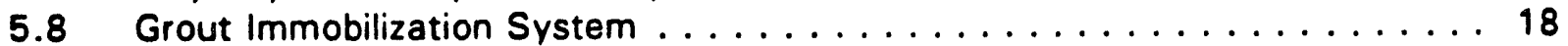

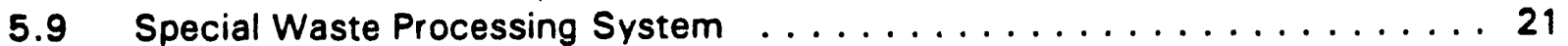

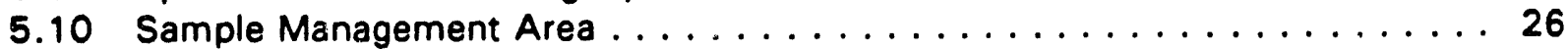

5.11 Secondary Waste Processing System . . . . . . . . . . . . 27 


\section{VOLUME I \\ WRAP 2A \\ ADVANCED CONCEPTUAL DESIGN REPORT}

\section{TABLE OF CONTENTS (Continued)}

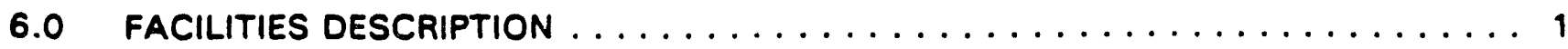

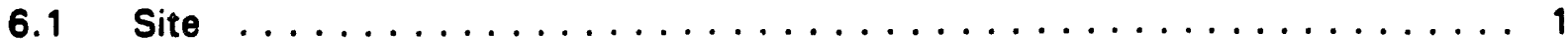

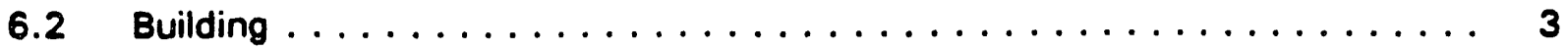

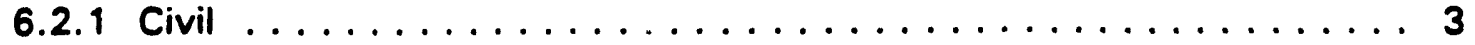

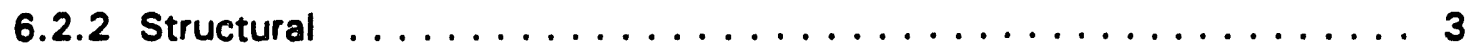

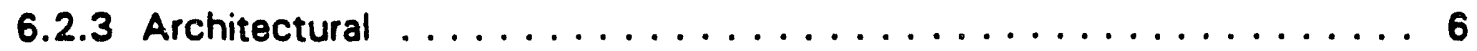

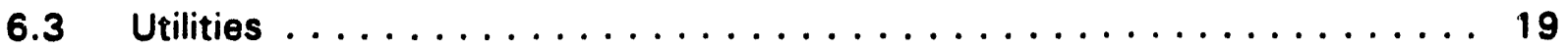

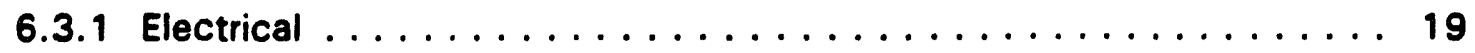

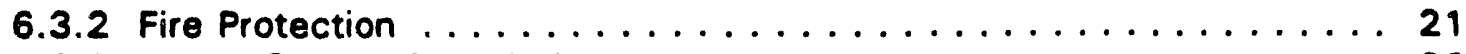

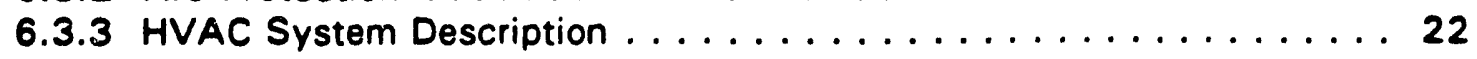

6.3.4 Potable Water . . . . . . . . . . . . . . . . . 29

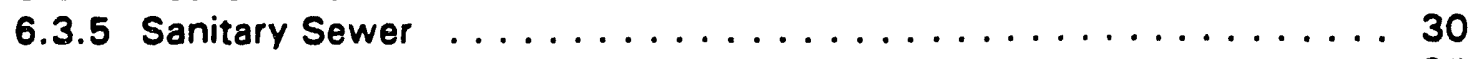

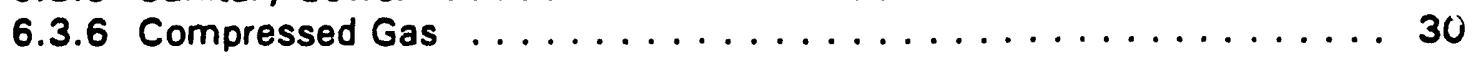

6.3.7 Process Water . . . . . . . . . . . . . . . . . 31

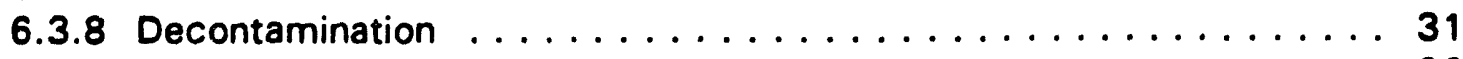

6.3.9 Chemical Storage . . . . . . . . . . . . . . . . 32

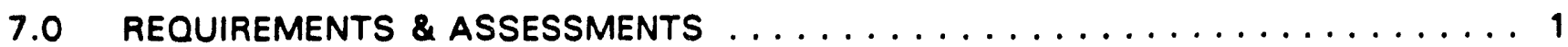

7.1 Project Criteria $\ldots \ldots \ldots \ldots \ldots \ldots \ldots \ldots \ldots \ldots \ldots \ldots \ldots$

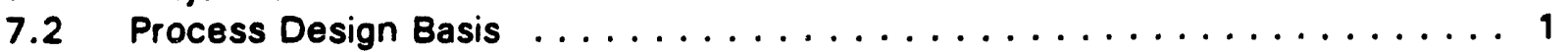

7.2 .1 Overall Facility . . . . . . . . . . . . . . . . . . 1

7.2.2 Material Handling/Internal Transport System ............. 10

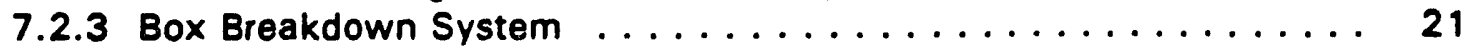

7.2 .4 Debris Processing System . . . . . . . . . . . . . . 27

7.2.5 Particulate/Sludge Processing System . . . . . . . . . . . 34

7.2.6 Empty Drum Compaction System . . . . . . . . . . . . . 41

7.2.7 Polyethylene Encapsulation System . . . . . . . . . . . 46

7.2.8 Grout Immobilization System .................. 56

7.2.9 Special Waste Processing System . . . . . . . . . . . . 69

7.2.10 Sample Management Area . . . . . . . . . . . . . 85

7.2.11 Secondary Waste Processing System . . . . . . . . . . . . . . 99

7.3 Confinement, Operations, Decontamination \& Maintenance . . . . . . . . . 109

7.4 WRAP 2A Shielding and Gamma Dose Source Term Assessment . . . . . . 113

8.0 IDENTIFICATION \& ANALYSIS OF UNCERTAINTIES $\ldots \ldots \ldots \ldots \ldots \ldots \ldots$

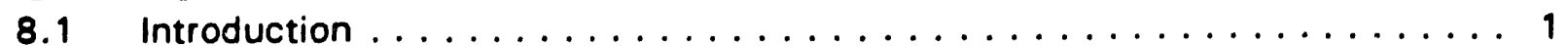

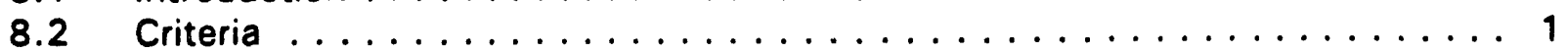

8.3 Summary of Uncertainties $\ldots \ldots \ldots \ldots \ldots \ldots \ldots \ldots \ldots \ldots \ldots$ 


\section{VOLUME II \\ WRAP 2A ACDR \\ PROJECT COST ESTIMATE}

1.0 INTRODUCTION \& SCOPE

2.0 DESIGN TO COST

3.0 ESTIMATE BASIS

3.1 General Approach

3.2 Quantity Basis

3.3 Pricing Basis

3.4 Labor

3.5 Indirects, Overheads, \& Expenses

3.6 Other TEC Cost

3.7 Escalation

3.8 Contingency

3.9 Exclusions

3.10 Assumptions \& Qualifications

4.0 UE\&C CODE OF ACCOUNTS

5.0 TOTAL ESTIMATED COST

6.0 CONSTRUCTION SCHEDULE

\subsection{Schedule Basis}

6.2 Construction and Procurement Strategies

6.3 Technical Basis for Cost and Schedule

6.4 Assumptions and Qualifications

7.0 CONSTRUCTION SCHEDULE

\section{APPENDICES}

Appendix A KEH Craft Wage Rates

Appendix B Escalation Tables

Appendix C Module 2A ACDR Estimate Detail 


\section{VOLUME III \\ WRAP 2A ACDR \\ DESIGN INPUT/ASSESSMENTS/VALIDATION}

\section{TABLE OF CONTENTS}

APPENDIX A APPENDIX B APPENDIX C

APPENDIX D

APPENDIX E APPENDIX $F$ APPENDIX G
WRAP 2A WASTE FEED CHARACTERIZATION DATA

PROCESS EQUIPMENT DATA SHEETS

ENGINEERING STUDIES

1. Open/Sort/Size Reduction

2. Sludge Repack

3. Process Sampling

4. Waste Mixing

5. Single Immobilization

6. WFO Treatability

7. Plant Maintainability FACILITY ASSESSMENTS

1. Preliminary Building Fire Hazard/Classification Assessment

2. Preliminary Process Area NEC Classification Assessment

3. Preliminary HVAC Confinement Assessment

VALUE ENGINEERING ASSESSMENT

HAZOP STUDY REPORTS

TIME \& MOTION SIMULATION 


\section{VOLUME IV \\ WRAP 2A \\ ADVANCED CONCEPTUAL DESIGN DRAWINGS}

\section{TABLE OF CONTENTS}

INDEX

PROCESS FLOW DIAGRAMS

EQUIPMENT GENERAL ARRANGEMENTS

FACILITY DRAWINGS 


\section{ABBREVIATIONS \& ACRONYMS}

\begin{tabular}{|c|c|}
\hline $\begin{array}{l}\text { ACD } \\
\text { ACDR } \\
\text { AGV } \\
\text { ALARA } \\
\text { AMU } \\
\text { ANS } \\
\text { ANSI } \\
\text { ARM } \\
\text { ASCE } \\
\text { ASHRAE } \\
\text { AS/RS } \\
\text { ASTM } \\
\text { BDAT } \\
\text { BFD } \\
\text { BFS } \\
\text { BNFL } \\
\text { CAM } \\
\text { CCTV } \\
\text { CDR } \\
\text { CF/CFT } \\
\text { CFM } \\
\text { CFR } \\
\text { CH } \\
\text { CHLLMW } \\
\text { CMAA } \\
\text { DB } \\
\text { DBA } \\
\text { DBE } \\
\text { DCS } \\
\text { DMS } \\
\text { DOE } \\
\text { DOE-RL } \\
\text { DOT } \\
\text { EPA } \\
\text { ERDA } \\
\text { ES\&H } \\
\text { FACP } \\
\text { FDC } \\
\text { FLT } \\
\text { FM } \\
\text { FY } \\
\text { GEA } \\
\text { GPD } \\
\text { HAZOP } \\
\text { HCWC } \\
\text { HDW-EIS } \\
\text { HEL }\end{array}$ & 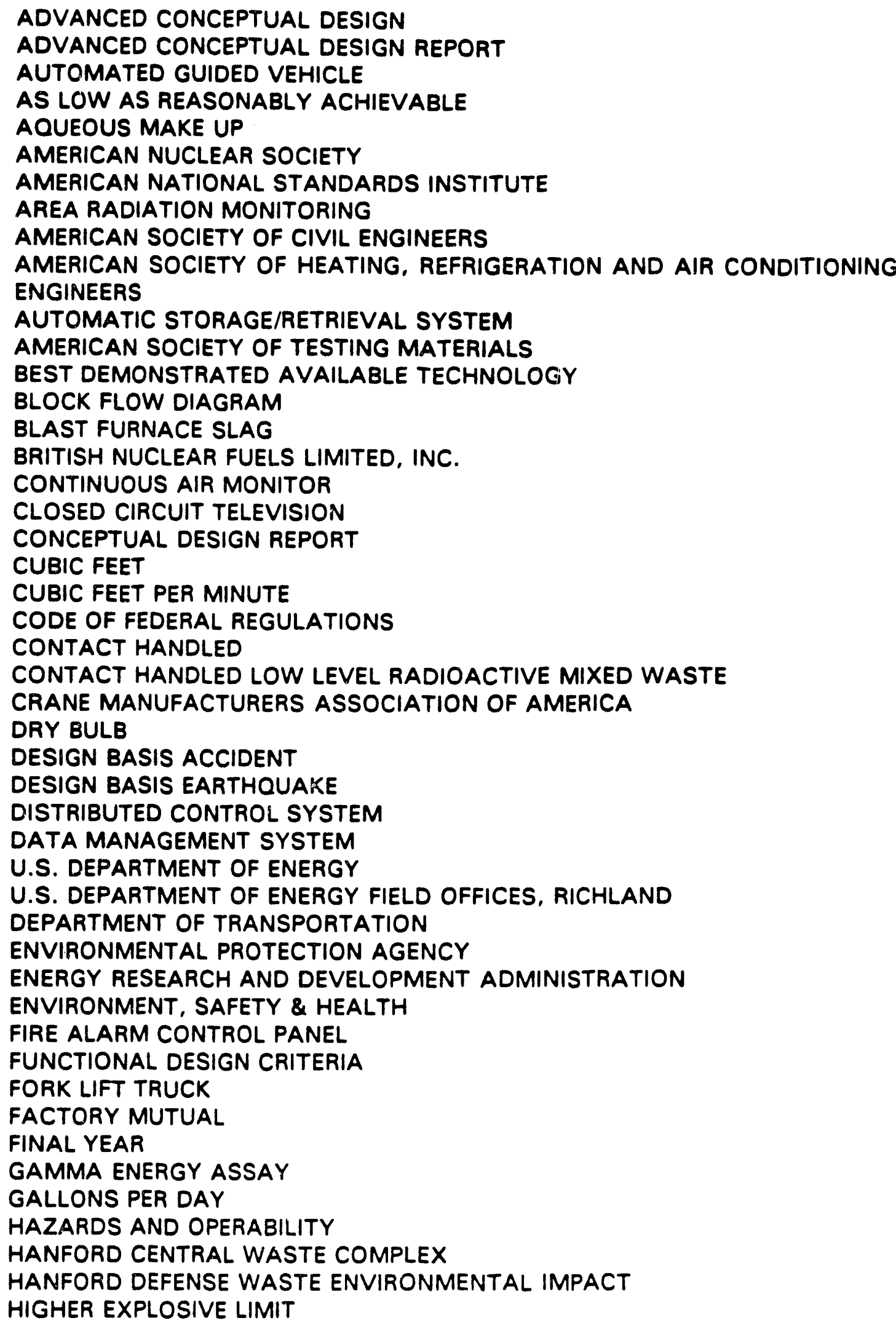 \\
\hline
\end{tabular}




\section{ABBREVIATIONS \& ACRONYMS}

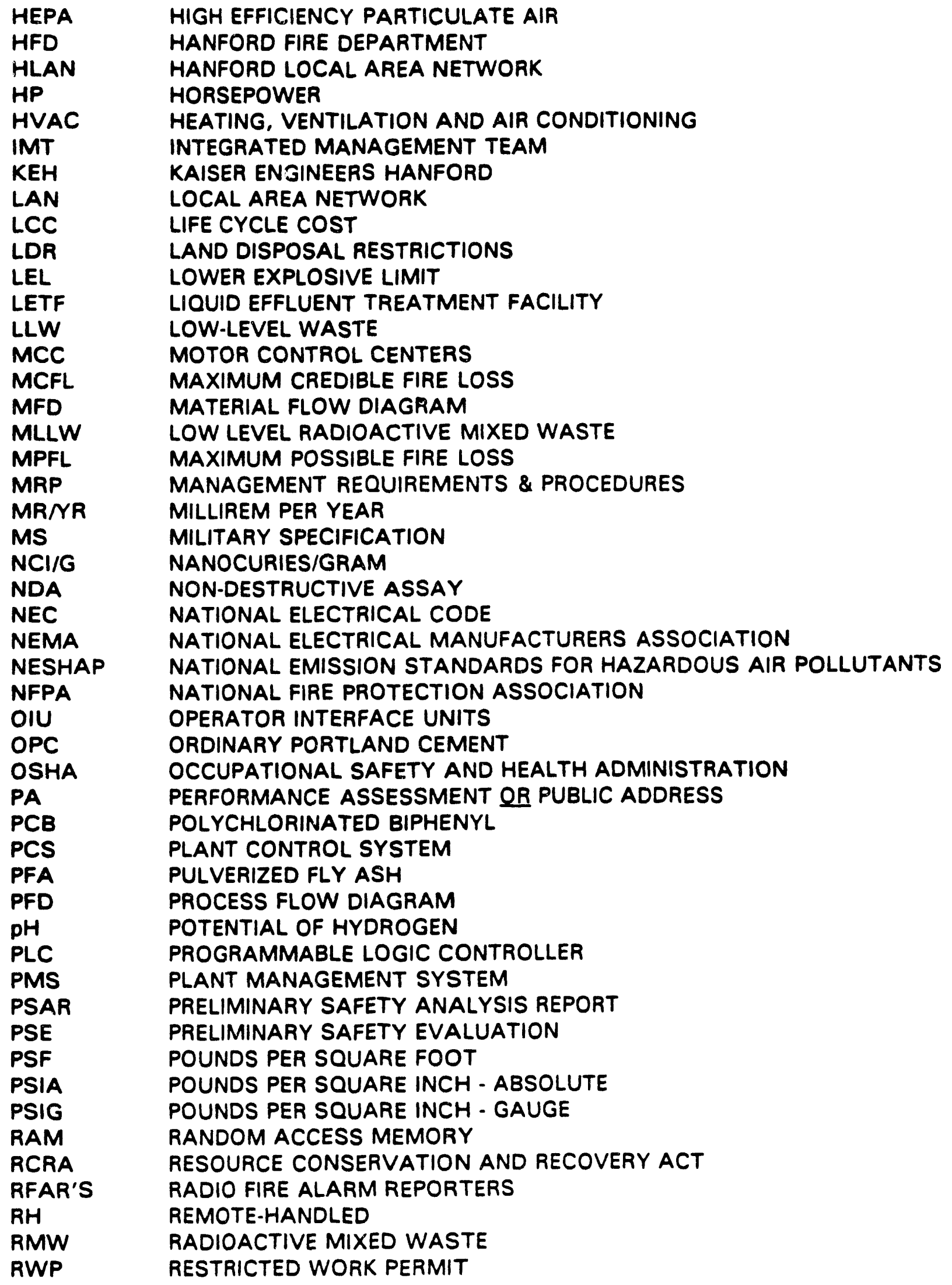




\section{ABBREVIATIONS \& ACRONYMS}

\begin{tabular}{|c|c|}
\hline $\begin{array}{l}\text { TA } \\
\text { TB } \\
\text { TC } \\
\text { TC } \\
\text { TE } \\
\text { TE } \\
\text { TL } \\
\text { TP } \\
\text { TR } \\
\text { TS } \\
\text { TT } \\
\text { UB } \\
\text { UC } \\
\text { UE } \\
\text { UK } \\
\text { UL } \\
\text { UP } \\
\text { UP } \\
\text { VE } \\
\text { VE } \\
\text { VE } \\
\text { VE }\end{array}$ & 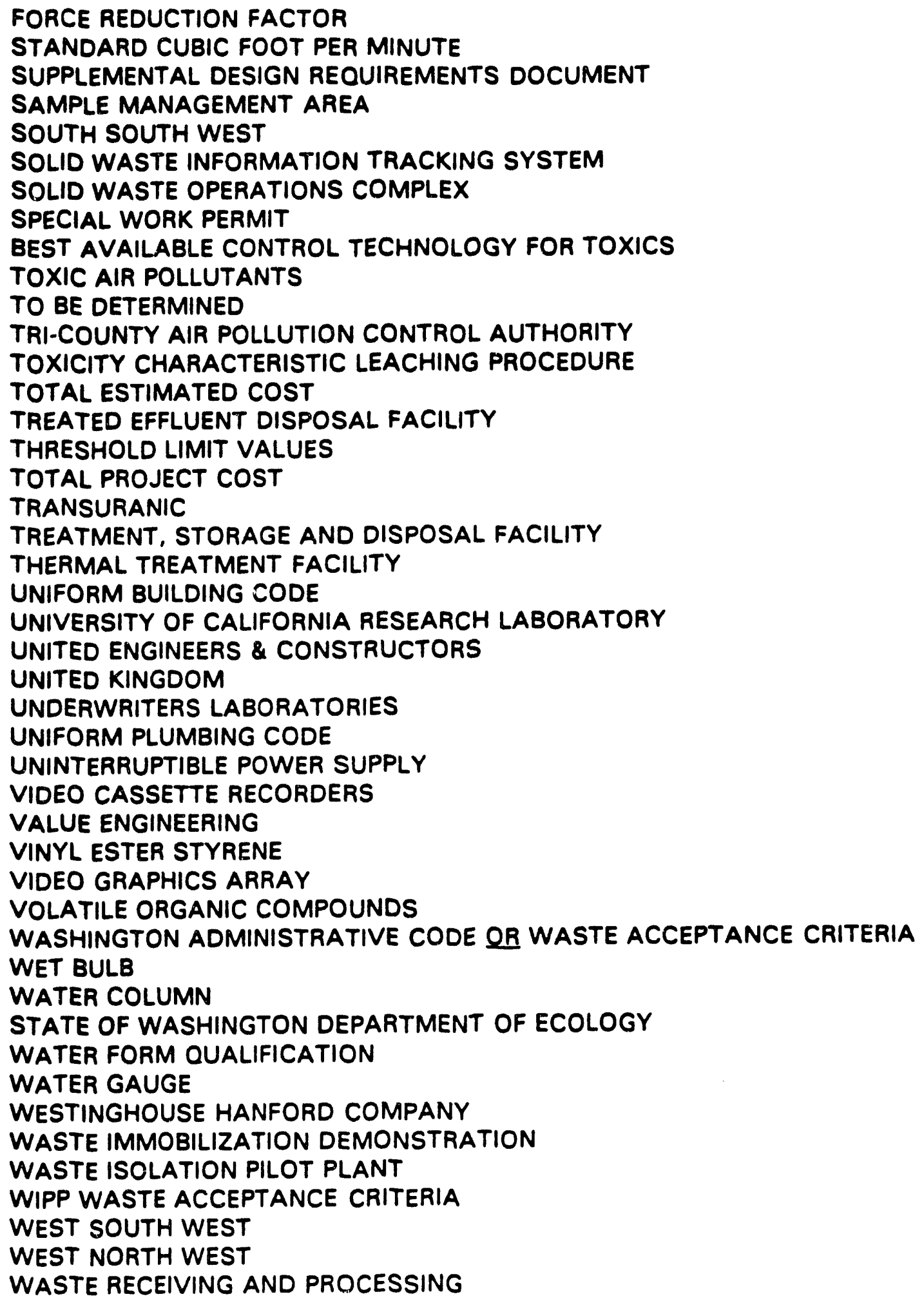 \\
\hline
\end{tabular}




\section{APPENDIX E \\ VALUE ENGINEERING STUDY}

\section{TABLE OF CONTENTS}

Section 1.0 - Value Engineering Assessment

Section 2.0 - Resolution of Value engineering Assessment Actions

2.1 - Final Product Container

2.2 - Box Breakdown Scope Definition

2.3 - Extruder Alternatives

2.4 - Equipment Commonality

2.5 - WHC Response To Value Engineering Assessment Actions

Section $\quad 3.0$ - Resolution Of Post Value Engineering Assessment Actions

3.1 - Sludge Dryer For Grout Line

3.2 - Core Sampling

3.3 - Material Handling Internal Transport System Basis For Advanced Conceptual Design Approach

3.4 - Mercury Containing Waste Retort Equipment

3.5 - Out of Drum vs. In-Drum Mixing 


\section{SECTION 1.0 WRAP 2A VALUE ENGINEERING ASSESSMENT}


LIST OF ATTACHMENTS

ATTACHMENT 1 SCOPE STATEMENT SHEET

ATTACHMENT 2 MANAGEMENT PRESENTATION

ATTACHMENT 3 BACKGROUND

ATTACHMENT 4 KEYWORDS

ATTACHMENT 5 F.A.S.T. DIAGRAM

ATTACHMENT 6 BRAINSTORMING LISTS

ATTACHMENT 7 EVALUATION CRITERIA

ATTACHMENT 8 FINAL BRAINSTORMED LISTS

ATTACHMENT 9 BLOCK FLOW DIAGRAMS

ATTACHMENT 10 MEMORIES, ASSUMPTIONS AND INFORMATION NEEDED ITEMS

ATTACHMENT 11 SESSION AGENDA 
ATTACHMENT 1

SCOPE STATEMENT SHEET 
Project Title: WRAP 2A PROCESS ENGINEERING ASSESSMENT Location of VE Session: 1818 Terminal Drive Conference Room Dates: October 11-15, 1993 Team Briefing Meeting: NA Date:

TEAM MEMBERS

NAME

\section{Payroll}

PHONE MSIN

DISCIPLINE

Co.

DL (DARRYL) LAMBERD (Team Lead) 2-0845 H1-60

$\star-2682$

$\star-2590$

JP (JOHN) BUCKLE

DA (DEWEY) BURBANK

2-0855

2-0792

LEAD SYSTEMS ENGINEER

WHC

RM (BOB) HORGOS

OL (OWEN) KRUGER

$2-1463$

2-1463

2-0922

TR (TOM) PAULY

*-3361

$A$ (ANDREW) SHARPE

*-3056

$R$ (BOB) VOKE

KM (KENT) WEINGARDT

2-0772

ENGR MGR

MECH ENGR/LAYOUT

H1-60 WST IMMOBILIZATION DEMO

H1 -60

MECHANICAL LEAD

H5-33

SOLID WASTE PROGRAM

H5-33

SOLID WASTE PROGRAM

H1-60

LEAD PROCESS ENGR

PROCESS ENGR

PROCESS ENGR

H1-60

PROCESS ENGR

UE3C

WHC

WHC

WHC

WHC

WHC

UE\&C

UEZC

WHC

PHONE \#s: * is a (303)843 prefix to the extension shown

PART TIME
EJ (ERIC) BERGLIN
GF (GARY) BOOTHE
TA (TERRY) CARLSON
WR (WALT) SWITA
JR (JIM) WEBER

NAME

MD (MICHELLE) LECLAIR

SL (SUSANNE) KOOIKER
Payroll

$\begin{array}{rr}6-0983 & G 6-46 \\ 6-0158 & G 6-46 \\ 843-3650 & G 6-46 \\ 6-0031 & G 6-46 \\ 6-0366 & G 6-46\end{array}$

FACILITATOR

No.

$\begin{array}{lll}\frac{\text { PHONE }}{2-1246} & \frac{\text { MSIN }}{H 1-60} & \text { DISCIPLINE } \\ 6-0133 & \text { G6-46 } & \text { MECH ENGR } \\ & & \end{array}$

$\mathrm{CO}$.

WHC WHC

- WRAP 2A PROCESS AND PLANT LAYOUT

- IMMOBILIZATION TECHNOLOGIES

- PE \& GROUT

- PROCESSING BY FEEDSTREAM

- CONFINEMENT OF PROCESS

- PROCESS LAYOUT CONCEPT 


\section{OBJECTIVES}

- ACHIEVE CONSENSUS ON TECHNICAL APPROACH TO PROCEED WITH TITLE I DESIGN

- DEFINE PREFERRED IMMOBILIZATION TECHNOLOGIES

- REFINE PROCESS DESIGN FEATURES AND PLANT LAYOUT CONCEPT

- IMPROVE CONFINEMENT FEATURES

\section{DELIVERABLES}

- PREFERRED IMMOBILIZATION TECHNOLOGIES

- ASSOCIATED BLOCK FLOW DIAGRAM

- ASSOCIATED PLANT LAYOUT CONCEPT

- aCTION PLAN TO:

- REFINE ASSOCIATED PFD'S

- IMPLEMENT RECOMMENDATIONS

- ADDRESS UNCERTAINTIES AND MINIMIZE IMPACT ON THE COST AND SCHEDULE

- PROVIDE DELIVERABLES TO SUPPORT TITLE I DESIGN START 


\section{ATTACHMENT 2}

\section{MANAGEMENT PRESENTATION}



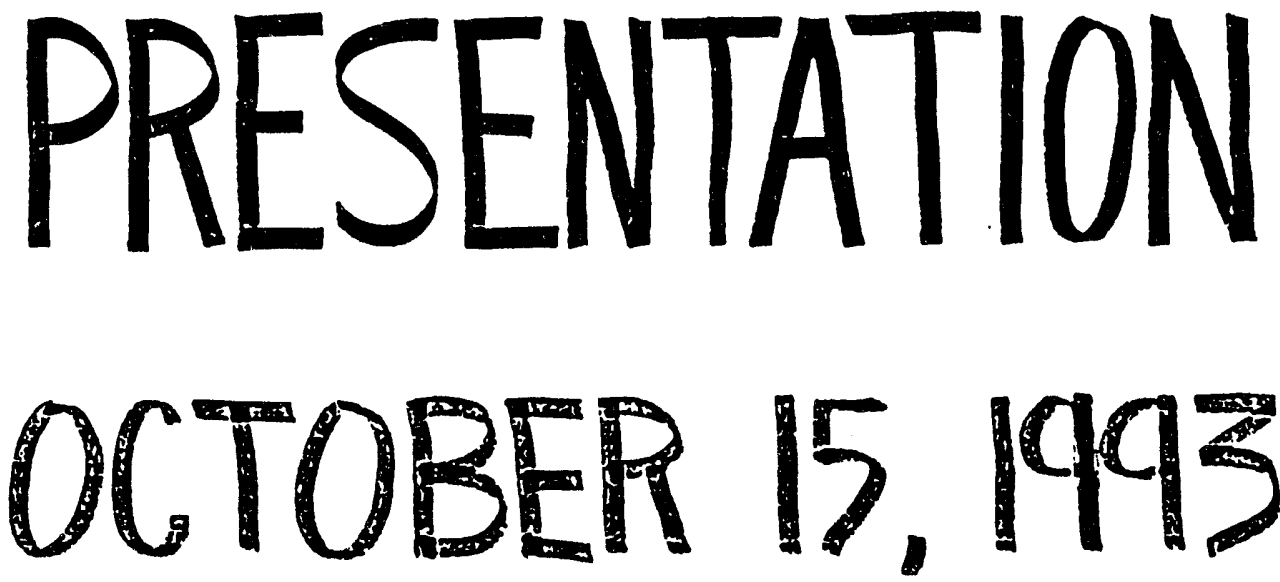
AGENDA

3 WelCOME/AgendA

- Purpose

- Engineering Assessment Process

S TEAM Presentation

REVIEW

Bask Background

Review Scope Statement Sheet

I INTRODUCTIONS

- Sumnary/Assumptions

:-1:- Detailed Proposals

- Implementation Plan

-.: Summarize

Q Question and Answer 


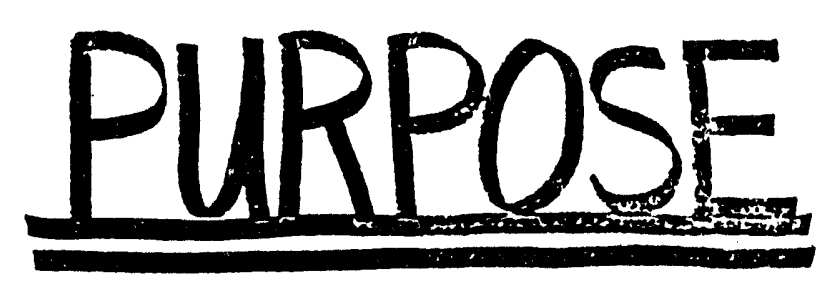

INFORM YOU OF THE

Engineering Assement Team's

Consensus on the WRAP 2A Process Design Basis. 
BACKGROUND

- Evolution of DESIGN Process

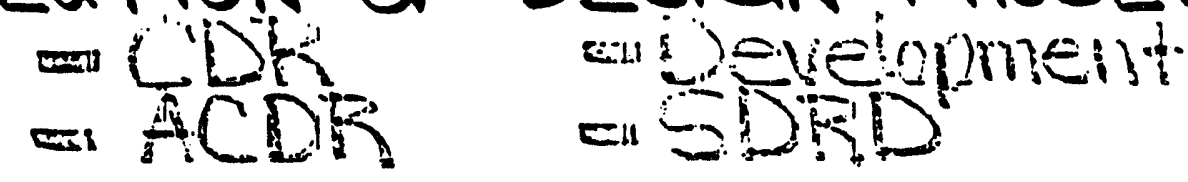

- Team Review of Process Could Lead to An IMPROVED, SAFer Design = Fodghtrom $\Rightarrow$ MID

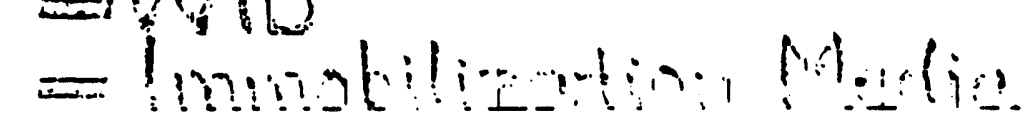

- Close Interaction Witt Team Suggested a Consensus for ACDR Prior to TitLe was NeEDED.

- Simultaneous Activities Included: WHO TEAM EFFORT REVIEW OF ACDR PROCESS FOR EACH FEED STREAM UE \&C REVIEW OF Confinement AND LAYOUT FOR PROCESS 
- BACKGROUND (CONT

- INTERACTIVENESS OF THE ACTIVITES TO INTEGRATE ACTIVITIES LEADING TO
CONSENSUS ON THE TOTAL PROCESS DESIGN BASIS<smiles>CC=CCC</smiles> 


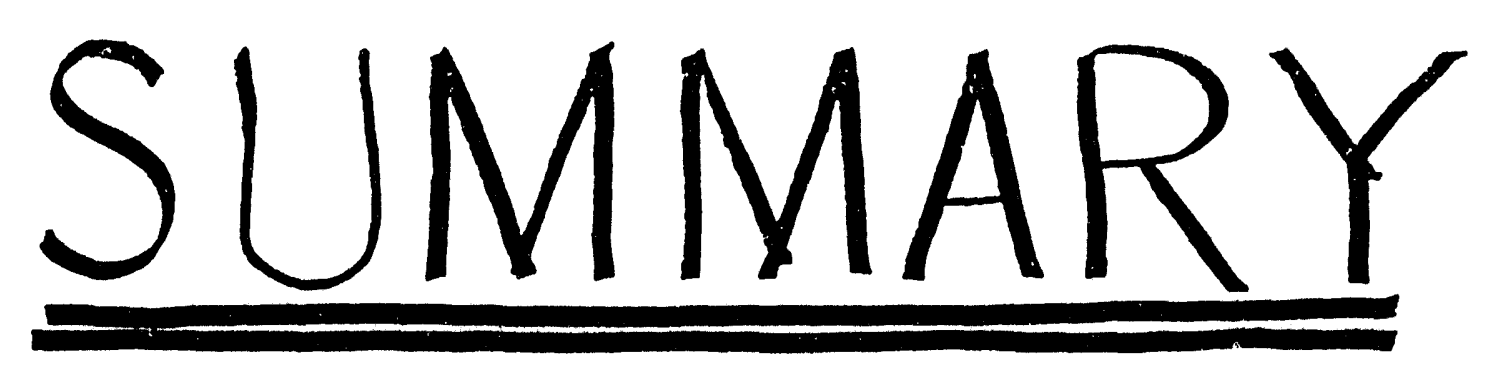

\section{CONSENSUS ON:}

-DEBRIS WST TREAT IN GROUT - PARTICULATE WSTTREAT INGROUT - PARTICULATE WSTTREAT IN PE - ZONE I CONFINEMENT CONCEPT - IN-DRUM VERSUS OUT OF DRUM - VERTICAL PLANT LAYOUT 


\section{$\triangle \exists Y J H d \exists C \mathrm{VI} \perp \mathrm{N} \cap$}

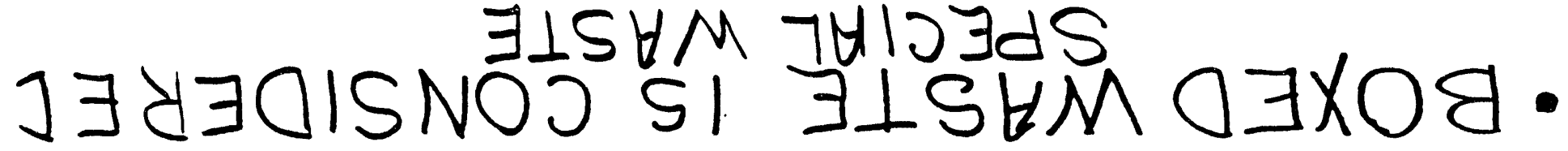
$7 \forall \forall \mid y \exists \perp \forall M \quad \exists \perp S \forall M$ AN

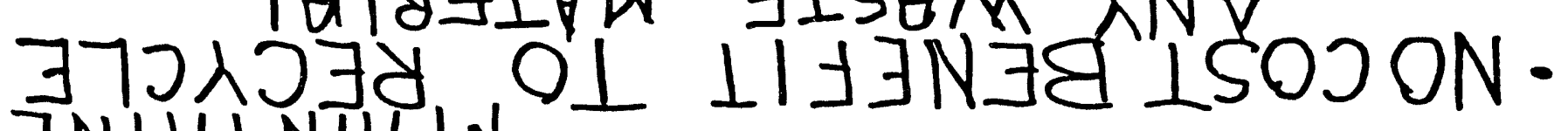

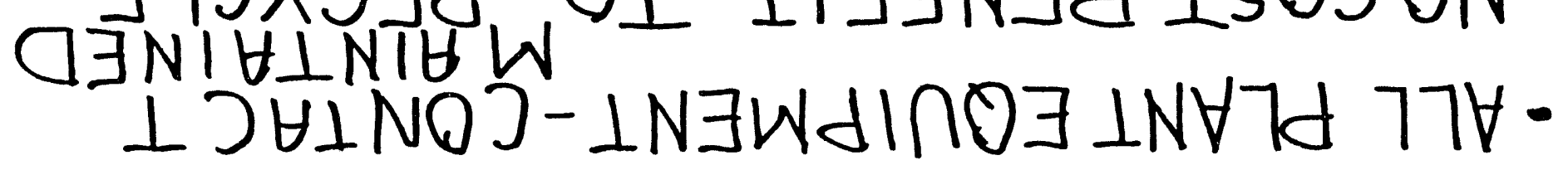

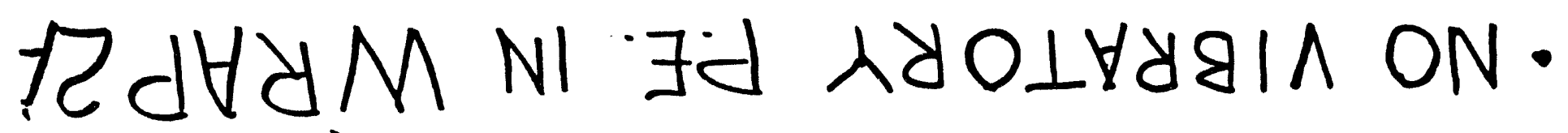

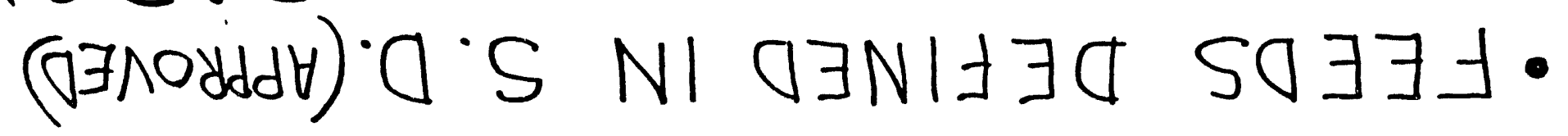
$\exists \cdot d$ onH LIOYS

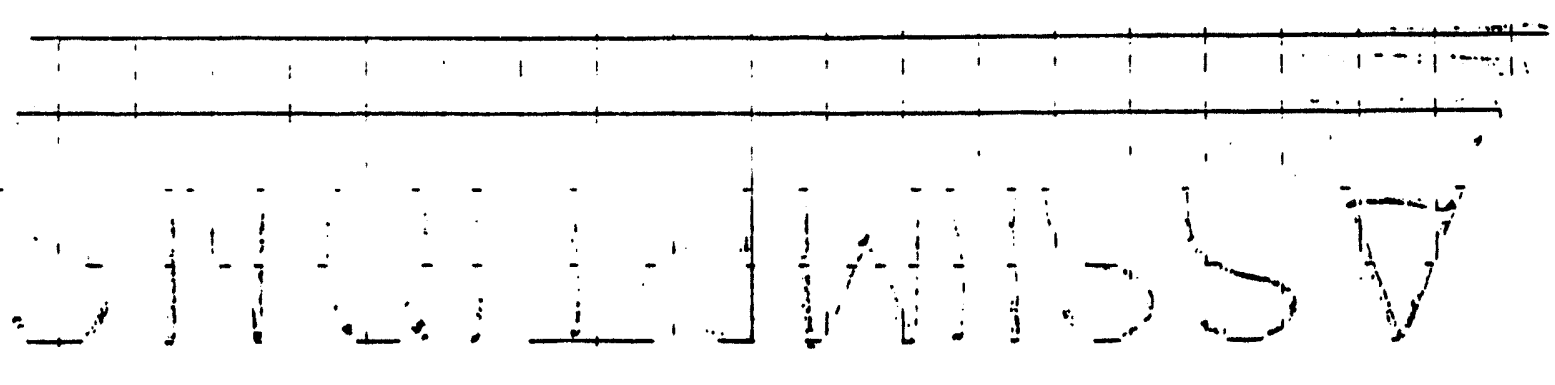


Particulate In Grout

- Out-of-Drum Mixing

- Continuous Device

- High Speed Pug Mill

- Accomodates Any Final Container

- Ensures Complete Fill of Container

- Potential Reduction Life Cycle Cost - No Lost Paddle

- Limited Custom Design

- Generates Active Waste Water

- Maintenance of Active Equipment 
Particulate In P.E.

- Suitable for use With PARTICULATES AND SLUDGES

- Wet WASTE WILl BE DRIED PRIOR TO MIXING WITH P.E.

- PRODUCES ACTIVE WASTEWATER

- ACCOMODATES ANY FINAL CONTAINER

- Size Reduction/deagglomeration BY CRUSHING DRY PARTICULATES - MUST REMOVE NON - FRIABLE METAL ITEMS 
- PROVIDES CAPABILITY FOR CHEMICAL ADDITION FOR ENHANCED PERFORMANCE

- Potential to use less EXPENSIVE MACHINE FOR MIXING/MELTING 


\section{PARTICULATE IN P.E.}

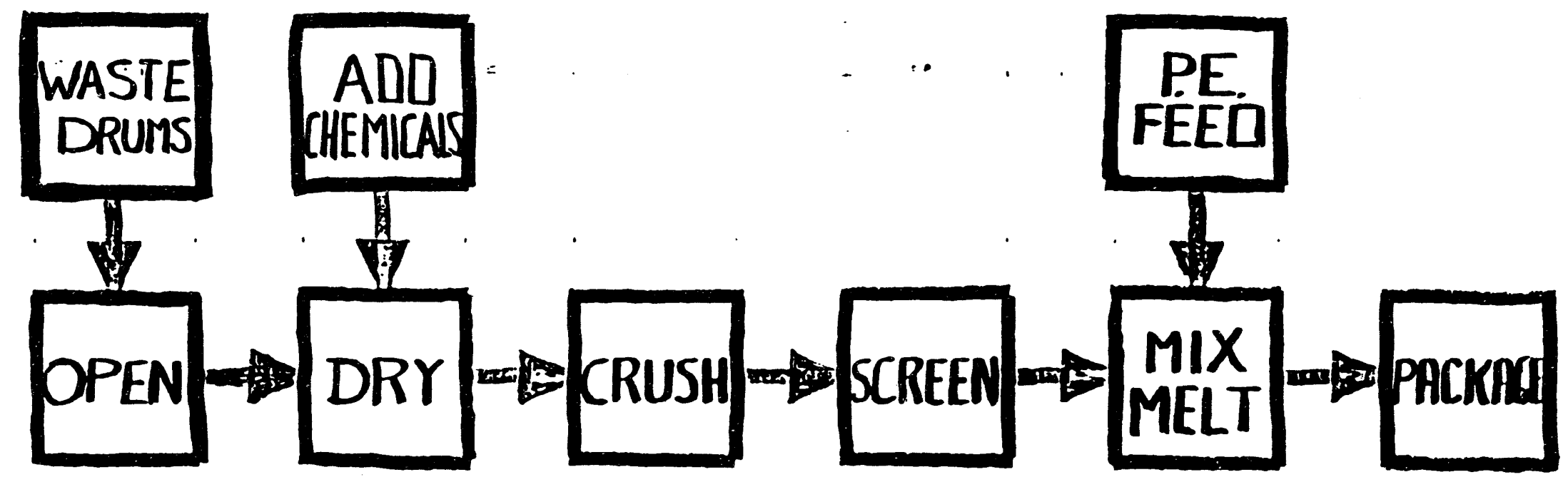


- DEBRIS IN GROUT.

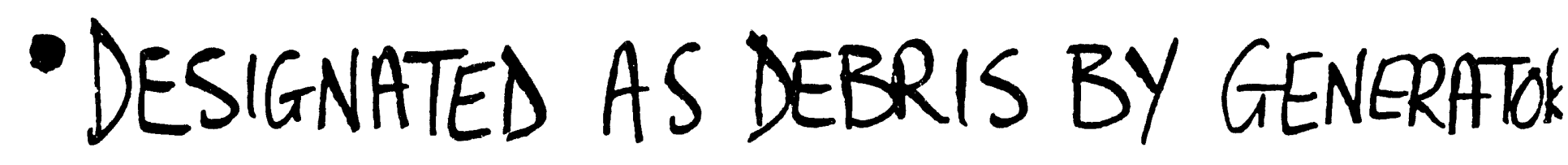

- All incoming Debris Macro Encap in Great

- Shredding provides:

- good packing efficiencies

- good surface coating.

- volume Reduction

- Minimized active grouting Equip.

- SHREDDING UNOPENED DRUMS. - SUPER COMPACTION OF UNOPENED DRUM
FOLLIES BY MACRENCAP SULATION. 


\section{DEBRIS IN GROUT}

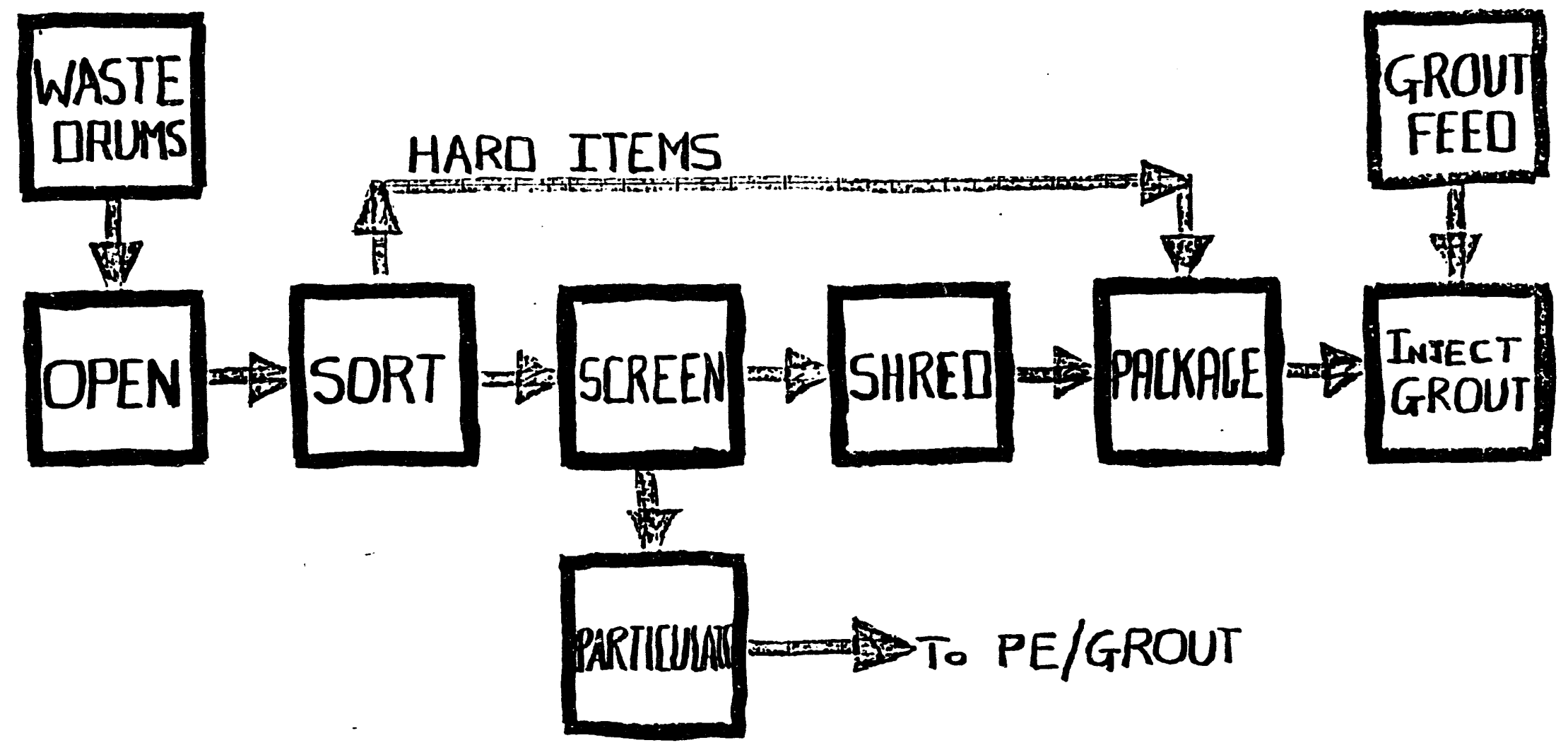




\section{- Wrap 2 a plant layout CONCEPT}

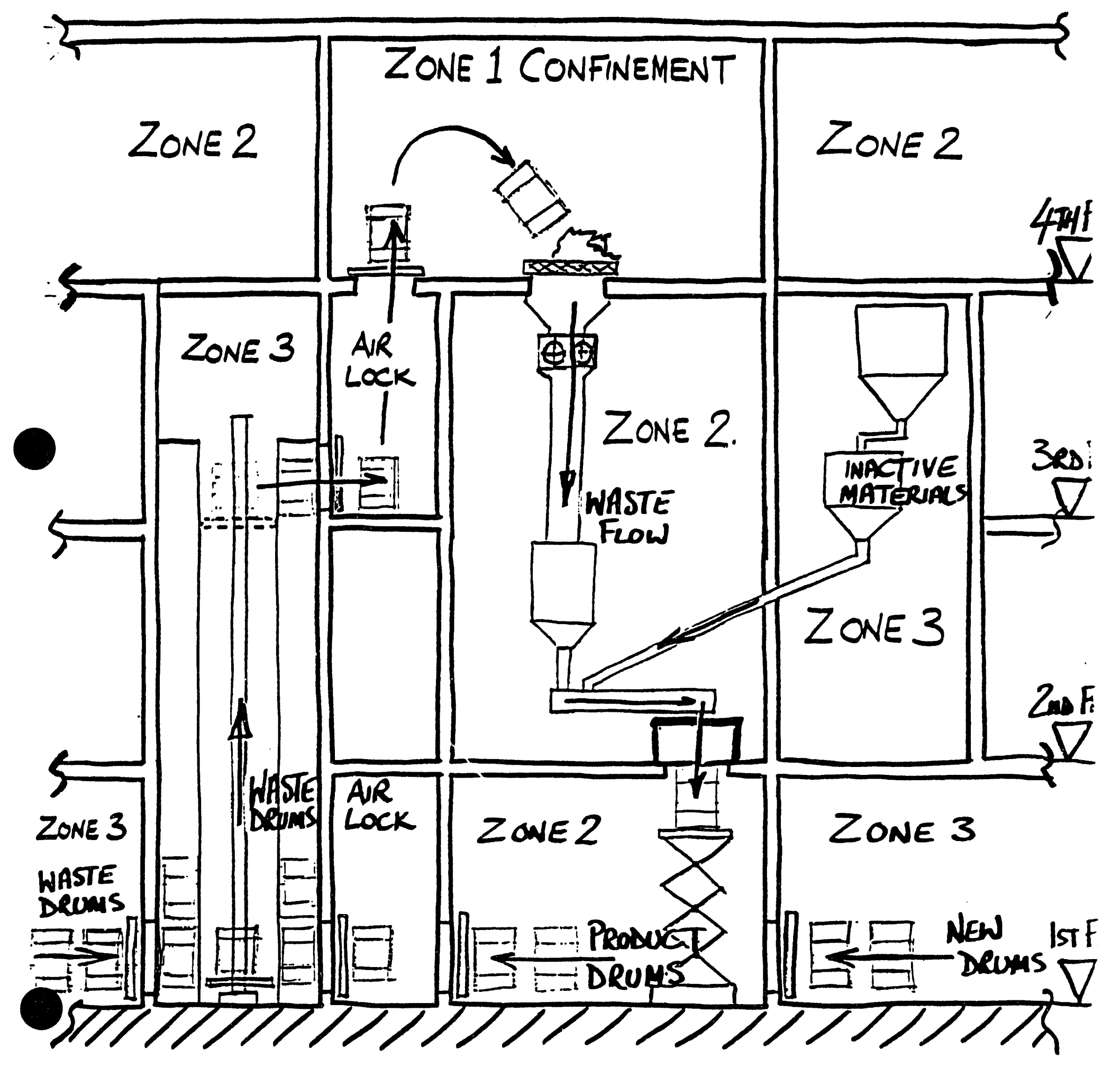




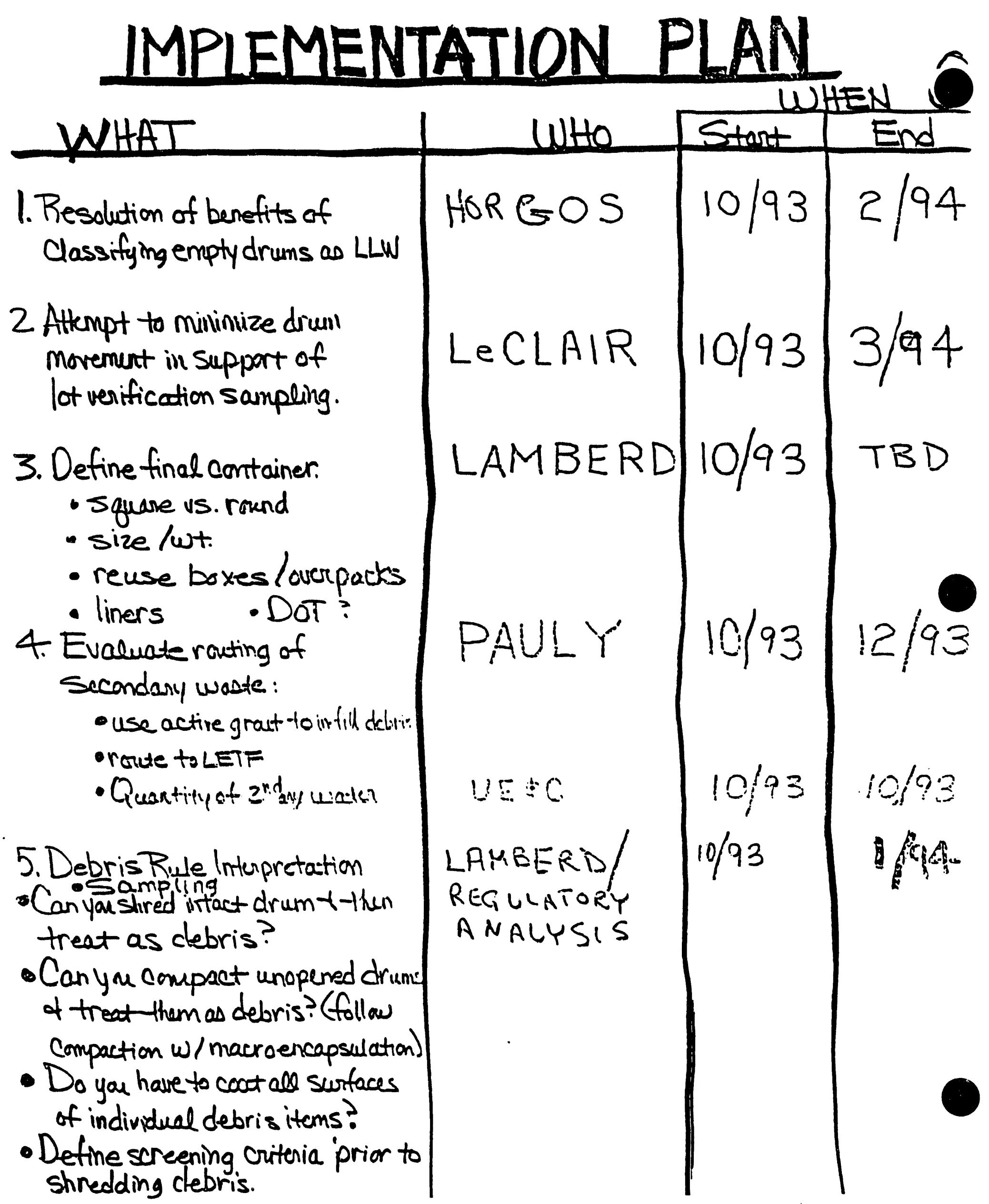




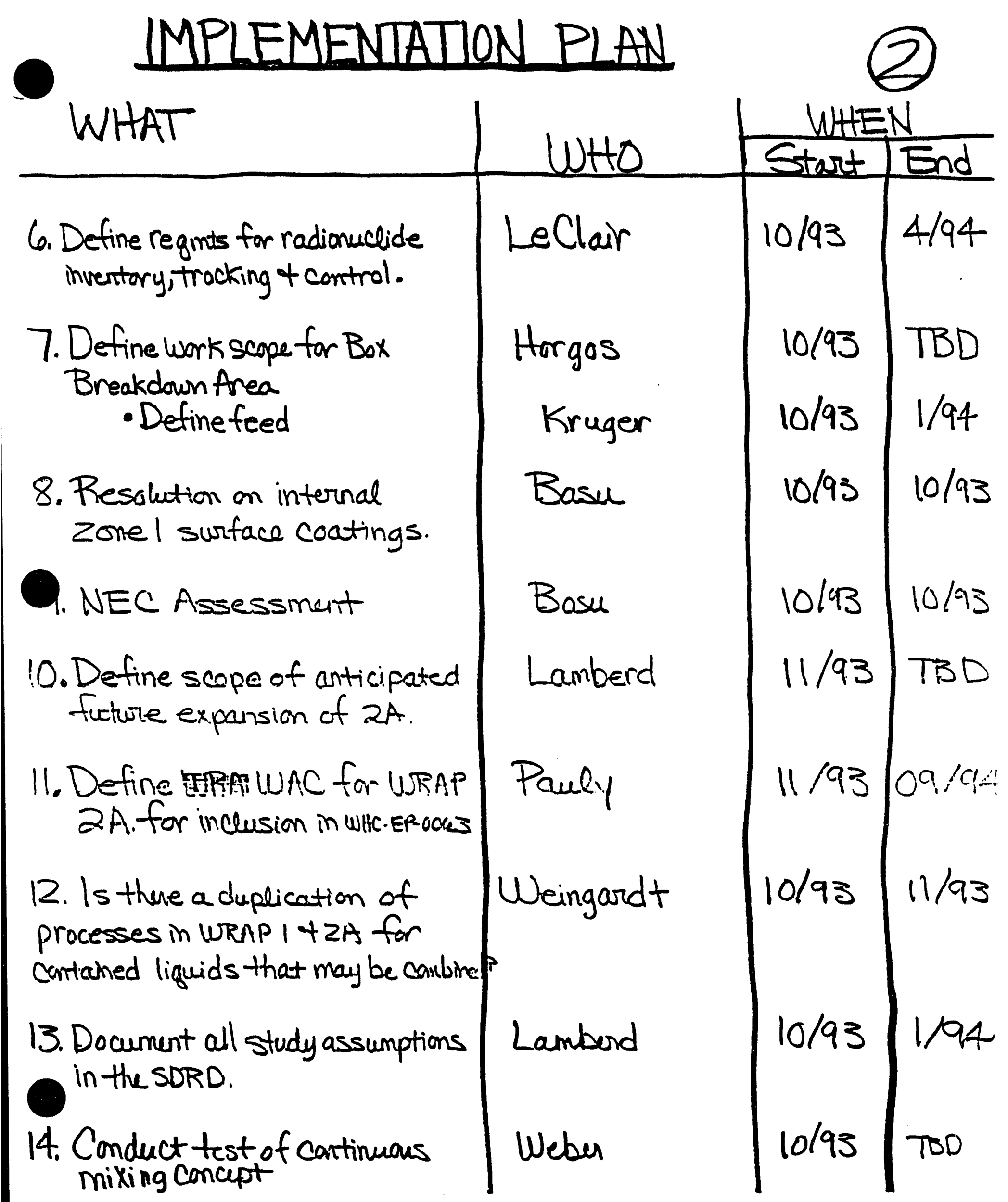


IMPIEMENTATTON PLAN

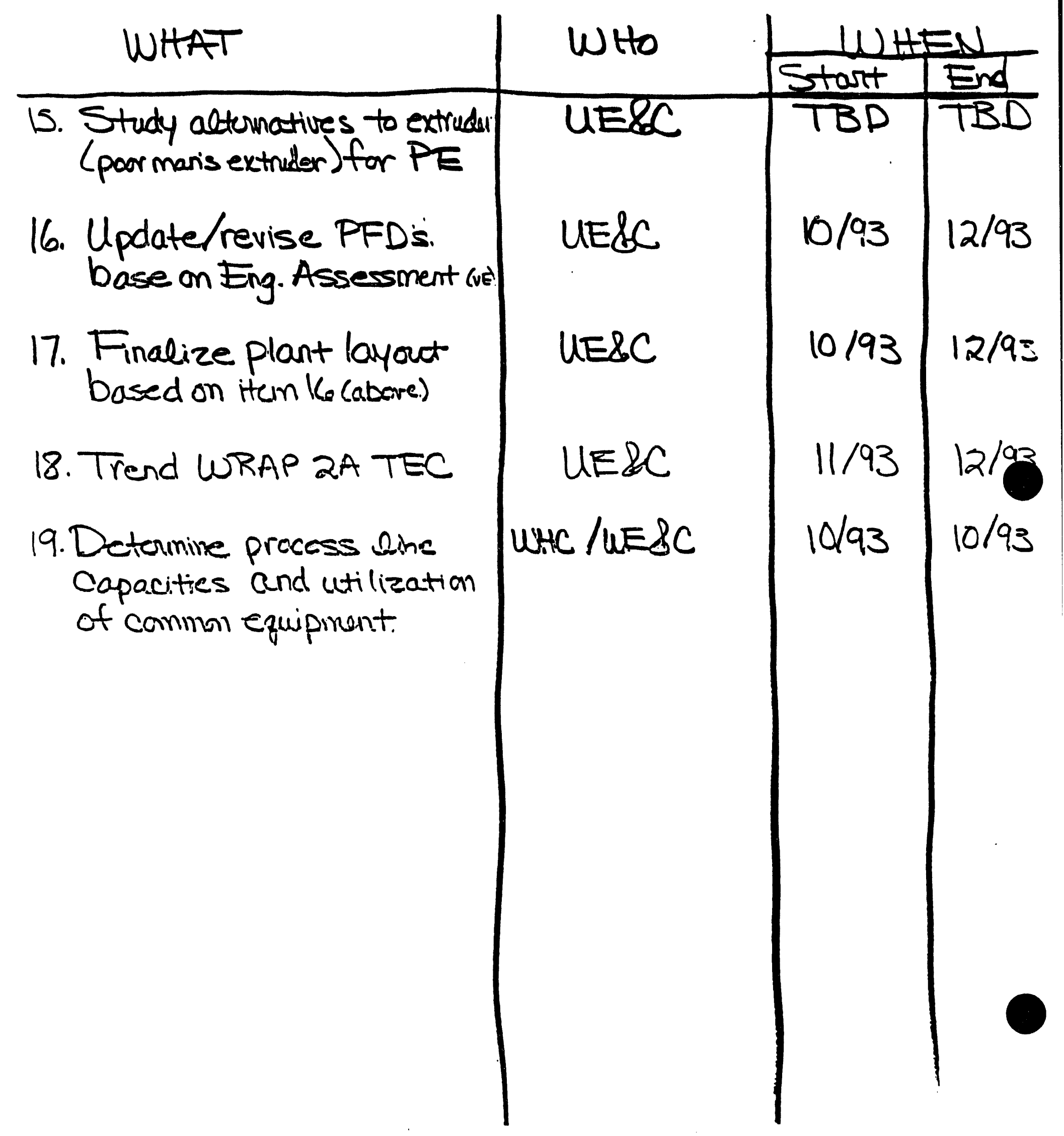


CONCLUSIONS

Results of Assessment $+$

Action Plan Implementation

$\downarrow$

Update design Media

$\downarrow$

Solid URAP 2A Design Basis $\downarrow$

Efficient Title Design Start. 
ATTACHMENT 3

\section{BACKGROUND}

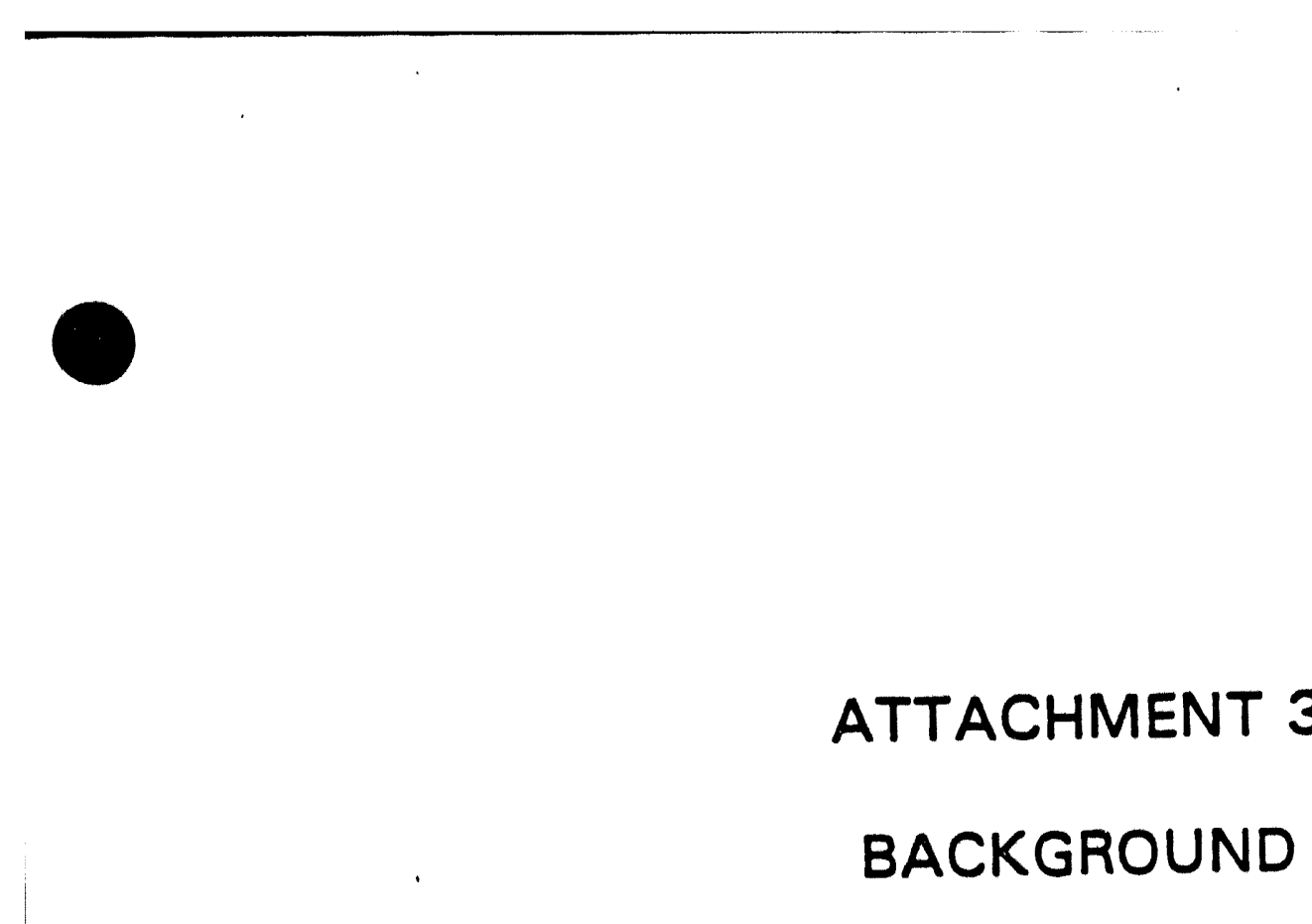


BACKGROUND

(1)

- R. Roberts wants to make the VES/PE decision based on Giteria evaluation. This is CA Peterseris action.

- ER has sent a Hr. to SW which potentially imposes a large $\uparrow$ in the projection of Contaminated soils for processing in UTIAP ZA.

- This effort is to consolidate our efforts to simplify to process before starting Tithe 1.

- About 2 mos. ago we started to bol@ process t make an attempt to remove artificial constraints. Wanted to also make proc. flexible so that ur would nit fall into an twWP-type trap. Are there simple mods. that cold be made to dbl triple thru pt? Prevent a bottleneck?

- Fresh look was being taken wi reg and to fac. layaut/configuration. Need to marriage this wp the WHC efforts on process simplificathen.

- WRAP I $\rightarrow$ reviewed glovebox dsgn; maintenance Costs, fabrication costs, etc and saw same dish in WRAP XA. Could a cell concept be used in lieu of the glavebox concept in URAP $2 A$ ? 
BACKGROUND

- What type of contauriers in + out of WRAP $2 A$

- 85\% of waste info is a best guess

- Desire plant to handle a wider variety of feeds than documented due to possibility of changes.

- Cell is flexible in handling different types/ sizes of containers

- Ky basic types of feedstreams.' solids, liquids, particulate: solids are large, shall, shredded. 


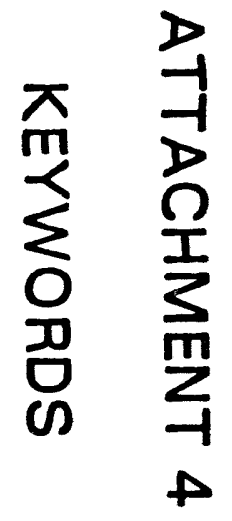


•

•

• 
KEY WORDS

$\checkmark$ WASTE DEEINITION

- Debris: - Feed Stream Definition

14 Contramers

- Incoming; - Product

$\checkmark$ EDC CRIERIA

6Throughput Criteria

LSingle vs. Muttiple Shifts

- TECHNOLOGY OETINAS

1 PRETREATMENT/NASTECONDITIANING,

$\checkmark$ PROCESS DESIGN FERTLEES

Special Waste Treatanent

ICOMFINEMENT Containes filling.

Oretamian Consineratuns.

Mantenance Consinesatinns.

Propuct Cebtificatial

I Decontamination

Facility Hazatid Classieication

Safety Consider andins - Secondory Ulst 


$$
\text { WASTE DEFINITION }
$$

(1)

- Categories: 1) Heterogeneous solids

2) Particulate / granular

- Descriptors: - wet/dry

(physical) - shreddable/ronstrreddable

- See Overhead.

- Friability

Treatability Groups

- Descriptors (Chemical): Is it PE or Grout compatible

- Vanadium Rentaoxide in' feed streams 6 have a specific treatment std. associated wit them.

- Feedstream 2A -addition of sulfide to Stabilize TC ${ }^{99}$. $=4 \mathrm{Hg}$.

- What form are the contained liquids / L ab packs s coming into the facility I

- Is there enough alpha to create a fresh ais atmosphere regent?

- Now assuming that debris can be treated as anyothes wist. coming into the plant.

- Amt of particulate associated (in) debris may drive the process. 
- Waste Definition Cons.

(2)

- Are there any time remit for debris that are different than other wist?

- If containers is labeled as debris and the particulate can be separated fran debris, the debris can then be shredded.

- Debris-material that $D<50 \%$ particulate.

- Advantage to classifying uss. as debris - no post -process sampling

Performance assessment defines that cat. 1 of cat 3 uss will be treated differently in the disposal site.

1 What precludes mixing of 2 categories of wist? Into. needed. 
Containers

(1)

Incoming: 55 gal drums w 55 gal in $85 \mathrm{gal}$ over packs boxes

$\approx 15 \%$ are currently in existence of which (according to SW II) 89+ are overpacked.

Containers Categories (Incoming waste)

$-55 \mathrm{gal}$

- 55 gal in 85 gal overupactis

- 85 gal drums

- Boxes

- $110 \mathrm{gal}$.

- 30 gal inside of a 55 gal drum

$w-\| z \rightarrow C a n$ handle 55 gal

boxes 85 gal up to 12,000 of $5 \times 5 \times 9^{\prime}$

- \# of boxes is anticipate to $\uparrow$ bey md that specified in the CDS.

- B25 (4x4x7) boxes are the only boxes approved by DOT.

$35-4$ this is not in the FDC/SBRD

- 35-40 boxes/yr. expected in 2A. per Oven.

- Per SWITS-only have 17 boxes presently that are candidates for URAP $2 A$ processing. 
CONTAINERS

(2)

- Is it acceptable to size reduce etc.

- 85 gal drums, 110 gal, drums to 55 -gal drums in the Box Breakdown Area?

- Presently expecting 12 boxes/yr. - throughput for WRAP $2 A$.

- Liners - might be bags (10 or $30 \mathrm{~m}$ frigid ( 90 mil or $110 \mathrm{mil}$ ). Will be routine to have liners.

- Activity underway to standardize the liner for future generate us ts. - no status.

- Are bags inside of the liners. eg. 8" dir. glovebox bags

- Rigid liner sealing - several concepts one of which fuses/bonds the figigigid liner lid onto the liner.

- 55 gal drums (not cues packed) will meet DOT structural regimes

- All contains recd@ ZA ur ill be structurally "sound".

- RTV was used to attach lids. Can be expect this? Doit know for sure, but can expect that lids will be difficult to remove.

- If wot is designated as acutely hazardous, drums once empty, can not be released as LLW or reused unless it has been triple rinsed.

- Acutely hazardous empty drums will be treated as mixed wot. 
CONTANERS

(3)

- Drum Receipt fran w-112-use tret trucks that can deliver drums into racks or onto a Conveyor. Can deliver into fac. like as in WRAP 1.

- Boxes to be delivered by fork truck.

- Pallet storage space is needed. if pallets are used.

- Potentially there may be a need to econ pallets (if they are used?

Product Colones:

$\rightarrow$ ted ${ }^{2}$ to be

- If in -drum mixing is used, it needs to be cylindrical

- 12,000 *titi is base on FDC. Probably to $u t$. limit for battery powered fork trucks. If yugo to gasoline pourer fork trucks, you create a fire hazards issue.

- Outgoing containers wt. Innit is dictated by W-025 acceptance criteria

- $F D C$ : enteringlexiting containers as $\lg$ as $5 \times 5 \times 9^{\circ}$ weighing 12,000 lb of 110 gal drums weighing 300 o lb.

based on filling a 55 gal drum $1 / 2$ flue w/ Pb. 
Contantess

(4)

PropuctComanter

-W-025 Giteria: $4500 \mathrm{lb} / \mathrm{ft}^{2}$ static load on the liner. $w /$ a $35^{\prime}$ vertical height (including waste contents t over burden?

Assuming $120^{16} / \mathrm{ft}^{3}$ oven a 35 vertical column.

- Interface bur larantaime 4 condiment

- needs to be considered for contamination control.

- Transfer back to w-11z is on a contaiverby- Container basis

FDC Armenia

Throughput

- Delivery of drums to 5 from $2 A$ is over an 8 hr shift.

- ie. W. $1 / 2$ needs to deliver lot of Containers for processing by the end of the st proceeding the processing shift.

- 30 drums sol it incoming 60 drums/dshift outgoing.

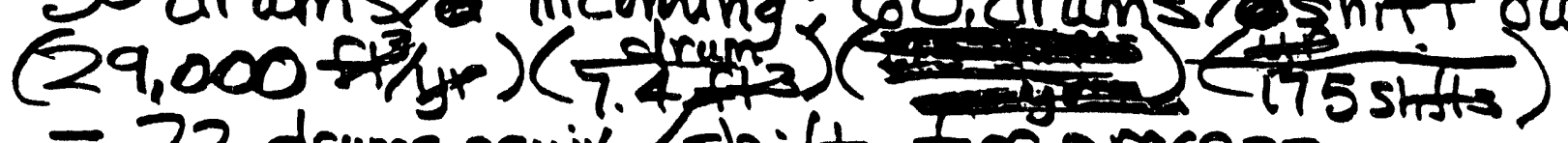
$=22$ drum equivi/shitt for process

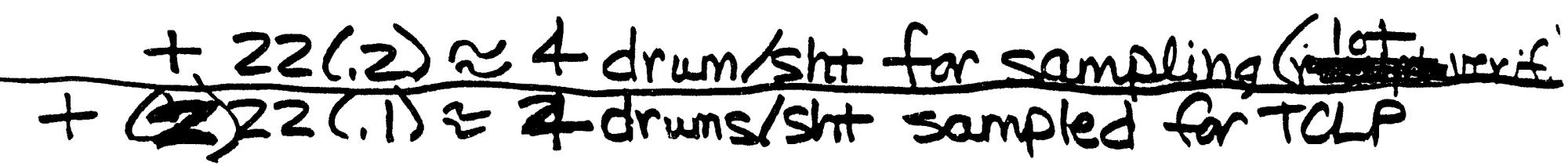

Campaigning Strategy

Special Wat. Vol $=4300 \mathrm{A3} / \mathrm{Hr}$ Pb o Hg t contained liquid: for $1-3$ yrs of processing. ( $4300 \mathrm{As} / \mathrm{y} r$ is included in the 29,000 yr y no. for these 1-3 yrs. that special wist. will be processed. 
FEC CRITERIA

Special Waste - smaller wist. streams that may tret other than the main line treatment.

Specialty Irma Ares onsies t tosses.

Lead -may be a special est but does not necessarily require specialty tret.

Campaign Strategy - will 2 different wist. lots be. treated concurrently in $2 A$ ? Yes.

Lot Sizes? highly variable. May game into play if cleanup is reg'd blum lots. Will cleanup be reg'd bum lots? Need to consider wist. categories test. Codes, listed usia, etc.

- On a shy - what is length of sift?

- Multiple sit operation implies multiple throughput. (\# of operation has is proportional to $\#$ of drums.)

Technology options

See Assumptions. $\rightarrow$ Grout of PE. 
(1)

Preatmanthet Condoning

PE- drying of wat.

- Calcium oxide addition - adjust PH of tractate to assist in mtg wist. criteria

- size reduce to 0 . Kodasize max

- size control leg. screenings.

- delump

Extrudes:

material to be 1/10" size max. w/ either single or twin screw. Heat transfer 4 material jamming are both factors for this size determination. Extrusion nozzle is about a $40: 1$ reduction @ the high end.

Appears that an extruder is needed somewhere on the processing line just to melt the PE pellets.

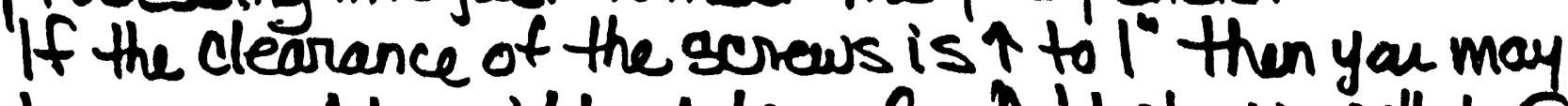
have a problem w/. heat transfer. Add plastic pellets@ front end to act as lubricant of then add wist. part way down the line.

Moisture-canit take more than $1 \%$ w/ single screw. U/ twin screw can take 10-15\% moisture content.

Mixing -can probably be accomplished w/ single screw, but al ot more optionsw/twin screw

Singer $12^{\prime \prime} \phi$ for 5 tons/thr Twin $-6-B^{4}$ ia. for 5 tons $/ \mathrm{hr}$. \$3-4 million complete en
cost $-3 x$ that of single 
(2)

ZF-IREATMENT

Extrude (cont) - startup t shut-down is not impacting to the equip.

$1800-1200 \mathrm{HP}$ to run

$$
0.15 \text { Kw } \mathrm{hr} / \mathrm{kg}
$$

Working life - screw $\Delta$ every 6 mos. -2 yrs. $\$ 5000-\$ 20,000$

Capacity - 5 tons/ hr $\rightarrow$ based on 29,000 $\mathrm{HH} / \mathrm{gr}$ thru put: Cost is not directly proportional to size $\$ 1 / 2-2 M$ for $51 / 2-6^{\prime}$ ia. Single screw.

- 30\% of all feed will need to be dryer prior to treatment in $P E$

- How much drying is required?

$$
80 \% \rightarrow<10 \%
$$

- Extruder is not the right place to dry feed. 
(3)

- GTROUT Agitated Re treatment

- Water to be added. (integral to grouting

- Addition of chemicals

- Size reduce + size control up to $5 \mathrm{~mm}$

- Paddle needs to be designed for largest particle to be treated

Delump

14 Vibratory 1 Prot Pretreatment

- Size control to make void spaces cucialable * to fit into a drum. $90 \%$ or greater of material is $>5 \mathrm{~m}$

- repack: drums, basket, framework - soft vs hard waste : Conditioning may be
different for each

- No pretreatment for macro PE 
Batch processing -discrete operations If you switch btw on batch 4 continuous processing, lag storage will be need. W/ a fully continuous process, lag storage bruin process steps is eliminated.

Wist. tracking may be more of an issue w/ a fully continuous process.

W/Continuaus process, each unit op must operate @ the same feed throughput rate.

In -drum mixing is inherently a batch process.

Sampling io minimized w/ continuous processing.

Common Equipment, $/$ for flexibility.

Mixing - In -drum w/ or who lost paddle Out-of-drum continua us but-of-drum batch

Batch size for mixing-shoeld it 55-gal or larger.

W-1R cant accommodate 110 gal drums presently due to size restriction.

Vertical us. horizontal plant 
special Waste treatment beyond the mail line treatment

WstConditioning - performed all wat prior to immobilization

Waste Pretreatment - clone to make wist. amenable to treatment in the main line. This is then followed by wat. conditioning.

Specialty Ireatment-BDAT treatment of the special wastes (egg. Hg retort) amalgamation.)

Do you have to immobilize amalgamated mercury? If it is class 3 , it may require immobilization.

Mecury salts can sublime in the retort (specifically $\mathrm{H}_{9} \mathrm{NO}_{3}+\mathrm{HgCl}_{2}$ ) \& lower temps than the mercury itself Specifically applies to stream $5 A Z$

Contained liquids - feed stream 9C. - make it like URAP 1. Manpower t analytically intensive. - Consider sending it to URAP I.

Treated on a batch basis. Probably more like a laboratory w/ hand on treatment. (Probably horizontal orientation.)

Probable will not tip t dump drum. Some Hg. is in glass. 
(1)

Orontamination - G. Booth

- Is there a significant ant of feed that will require a ctr l? Assume bounding case -some drums will have 99 nanocuries $/ \mathrm{gm}$. of Pu. One solution to get around designing the plant for the conservative situation might be to impose administrative curls on incoming drums.

- Can we get away from an a confinement glarbox or are the source terms such that y al are stuck $\omega /$ this approach?

- At what pt are alpha controls reg'd? Gary has never seen any info. that excludes $\alpha$ from UR AP 2 A.2A is an alpha facility and needs to be designed as such. Is there a diminimis o \# (egg. in picocuries $/ g m$ ) that below which you would not be considered to have $\alpha$ Contamination? Yes, but they are very low. $100 n C^{\prime} u=.16 \mu \mathrm{\mu g}$

$$
\begin{aligned}
& 10 \mathrm{nCu} / \mathrm{g}=22,000 \mathrm{dpm} \\
& \text { Spread over } 1000 \mathrm{~cm}^{2} \rightarrow 22 \quad \mathrm{dpm}
\end{aligned}
$$

Conclusion: it is not inconceivable to have $\alpha$ levels above Ctr l limits.

WHC-Cm-7-5 $\rightarrow$ limit of $60 \mathrm{pCi} / \mathrm{gm} \alpha$ in soil.

Releasing drums: Allowable removal ie surface contain. $26 \mathrm{dpm} / 1 \mathrm{a}$ Allowable fixed removable contamination: $500 \mathrm{~d}$ pm $/ 100 \mathrm{cli}$ : 


\section{TABLE 1}

TYPE OF CONTROL
$\begin{aligned} & \text { Allowable removable } \\ & \text { surface contanination' }\end{aligned}$$\frac{\begin{array}{l}\text { CONTROL LIMIT } \\ \text { ALPHA PRESENT }\end{array}}{20 \mathrm{dpm} / 100 \mathrm{~cm}^{2}} \frac{\begin{array}{l}\text { CONTROL LIMIT } \\ \text { MO ALPHA PRESENT }\end{array}}{1000 \mathrm{dpa} / 100 \mathrm{~cm}^{2}}$

Allowable fixed and resovable contanination

$500 \mathrm{dpm} / 100 \mathrm{~cm}^{2} \quad 5000 \mathrm{dpa} / 100 \mathrm{~cm}^{2}$

Allowable workplace air $3 E-13$ UCI/CC concentrations ${ }^{2}$

Allowable stack concentrations

Allowable liquid discharge

$3 E-8 u C i / c c$

$2 E-14 u C i / C e$

$2 E-12 u C i / c c$

$2 E-10 u C I / C C$

(E-12 uCi/ce

$1 E-6 u C 1 / C e$

NOTES: 1. Based on the release 1 imits of HHC-CH-1-6

2. 10\% of the Derived Air Concentration (DAC) of DOE Order 5480.11

3. Based on the Derived Concentration Guides (DCG) of HHC- it-7-5

4. Based on the DCG for liquid effluents

\author{
DESIGN \\ IMPLICATIONS \\ FOR ALPHA \\ Decon oper- \\ ations, pro- \\ cess layout
}

Decon operations, process layout

Seals, glovebox protection factor, HVAC, personnel protection, monftoring

Filters, effsysir-ns, sampling systems

Liquid eiflucontrol luer $t$ control 
(2)

Contamination - G.Bcothe

- If we have 99 drums of paper 41 drum of acetone. why doit we eliminate the Idrum of acetone? (Relatively speaking, acetone is likened to drums containing $99 n C i / g m$.

- If we have a fac. capable of handling up to $99 \mathrm{Ci} / \mathrm{gm}$ the wat. That will cone to it is probably way beyond what we are presently anticipating.

- CONFINEMENT

- Choice btu big gloveboxes and confined rooms.

- Objective of confinement is to protect personel, not to protect the equip.

- Based on what Bootle is telling us, we need to confine the process to control $\alpha$.

- WRAP $2 A$ dian should have personnel in respiratory protection only for maintenance or off-normal situations. Not acceptable to require porsomel to be in respiratory protection for normal operation.

- Only at times when airborne $\uparrow$ to to airborne limits, will respiratory protection be reg'd when performing maintenance
$w /$ in the confinement. 
CONFINEMENT

- Captrinevelocity

Confinement requires air flaws of 125 linearft/mir \pm 25 linear $\mathrm{ft}$ min. in the absence of a physical barrier (reg'd over any opening.)

ie. We can work in a govebox wy an opening as long as these air flows are maintained.

Operator Conslomsamons

- No mask

- Typically if you have a surface contamination area (SEA) you wite have whites on

- In a RCA, whites are not needed. (Rad. Ctr Area).

- All Zone 2 will be SW P area.

- SuPs in the ctr l room area? Right now ctr rm is not zone? No SW PS in ctr l $r m$ is preferable

- Will Special waste operations be done w/ manipulators or in a glovebox (we glove hand ga): FDC-remote op. of enclosure shade be provided but minimal hands -on op. may be reg'd.

- Seem pointless to have manipulators if there is a door that can be popped open for manual operations.

- Incoming drum handling occurs in a Zone 3. Outgoing drums are the same.

- Considering a pod glcuebox in the Box Breakdown Area. Due the sizes of material passing thru this ocrea, it will most beiremote application. 
Maintenance Considerations

Repair or replace - based on cost.

- Acceptable to plan on maintenance on mask.

- Equip. Selection will drive the type of maintenance that will have to be performed.

- Consider areas of laydown need to $\Delta$ out equipment. OPERATION CONSIDERATIONS

- Box Breakdown Area is being vieured as the area to handle all the special cases. It is to be flexible - can $H$ be if applications are all remote.

- Use of downdraft tables for Pu handling to make transition from $\alpha$ containment -used at PFP wERe containers have surface contamination.

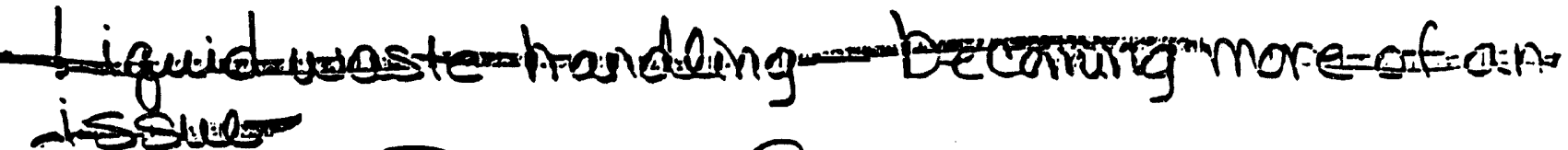

ProDuct CERTIFICATION

- A requirement.

- Probably nothing more than a quality ctr program.

- Can radionuclide inventory be determined for outgoing drums if a bulks: up process is used.

- Strong influence of batching/loting on prod. cert.

- What is the impact of prod. Cert. On the PCS OMS system? 
- Product Cermeication

- Can asingle incoming lot be partially processed in grout ot partially processed in PE? Yes if you sublet the lot.

- May graupdrums for processing by wat code

- Radionuclide category is determined for prod drums

- Need to dian. for deco of fac. @ closure.

- Maintenance decor - may be important if complete enclosures are not used.

$-20 \mathrm{dpm} / 100 \mathrm{~cm}^{2}$ o $<1000 \mathrm{dpm} / 100 \mathrm{~cm}^{2}(\beta, \gamma)$ requirement for drums exiting the fac.

- Celconcept is room that would have to be lined wi stain tess - Rothin

- May be an issue $w /$ performance of a paint based on an interpretation of 6430.1A.

- Drum decon-cottempt to minimize or eliminate drum decor. ThY.

- For practice purposes, if drum has any detectable. It will be decamped even if initially below the release lime - Even w/ French can, you get a ring of contamination \& the top of the drum during the filling process.

- Need to strive to minimize contamination-controlled exits ss.

- Once uss is mixed w/ binder - potential for contamination is reduced over potential w/ dry wist.

- Smear 4 drum count could take $/ 2$ ho.

- Survey can be done on an accumulated lot of drums. (Not I drum e) 
Decontamination

- Put both cst. + binder into drum@ same time will reduce contamination - this presents some problem W/ PE due to cratering effect. Could be prevented if moisture in wist. is remove l bond before addition to PE.

EAchity hazARD ClASSiFICATION

- Needs to be low.

- NEC Hazard Classification -Yes. Divil or DiTz. of $N E C$ Class 1 .

- Div. I if not routinely opening containers w/ VOC.

- Acetone tother elements in the feed spec are of concern.

- An NEC assessment was performed. The dian will not influence the NEC class - solely based on feed spec. Design can manipulate btw n Div 1 \& Div. $=$ but the NEC Class wont $\Delta$.

- Can we eliminate from feed stream all components in feed ape which give rise to it.

- \$6000/enclosure difference btw Div.19Div.2-prelimin Safety Considerations

- Arlen Shade views PE as solidified naphtha.

- WHC has review use of PEW/ safety org.

- Nothing > than SC 3 .

- Sdidified PE is viewed no different than paper; not a source office.

- MPFL has yet to be performed. Starting into that soon - Shredder-highrest fire frequency 
ATTACHMENT 5

F.A.S.T. DIAGRAM 


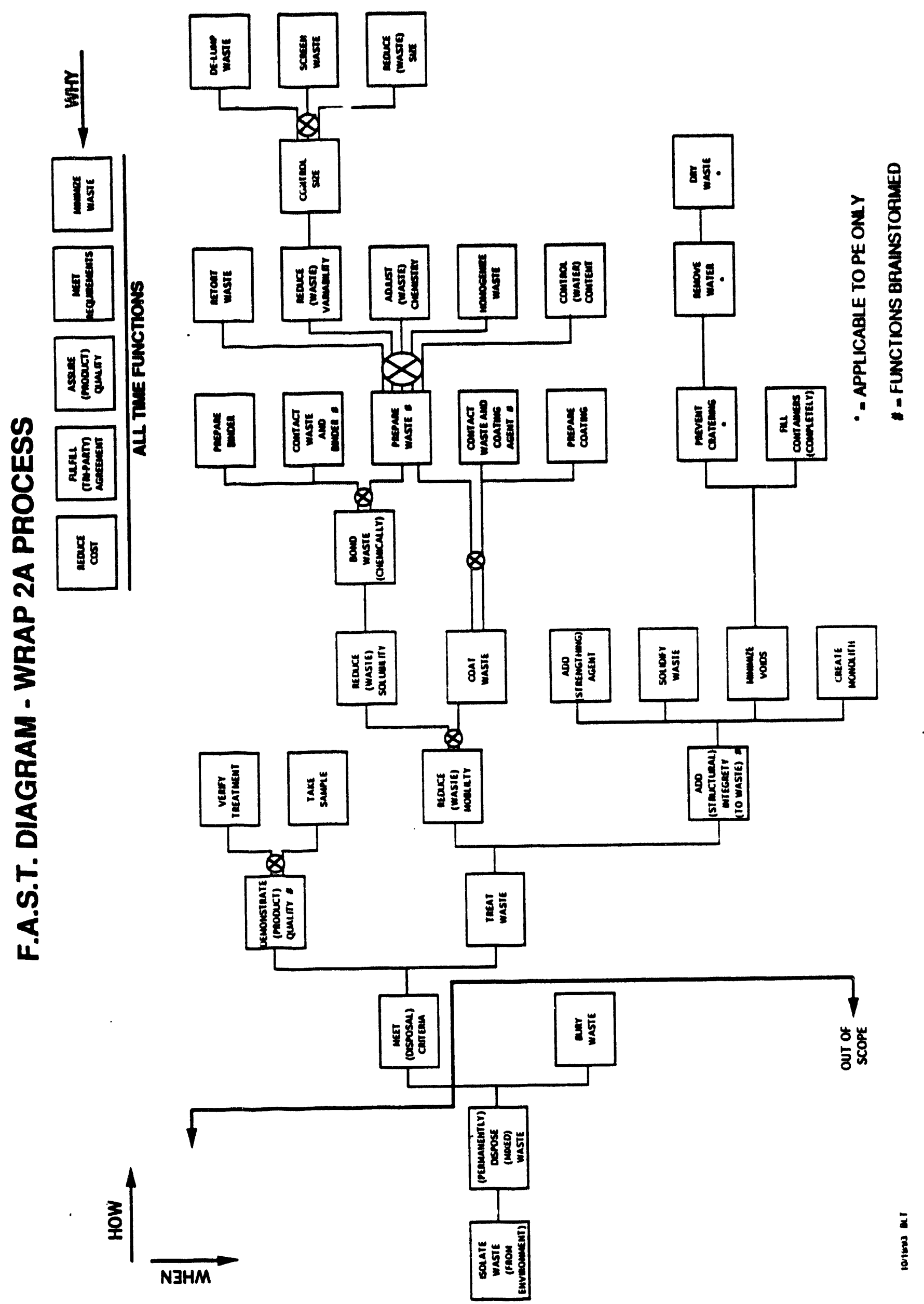



- Function Statements

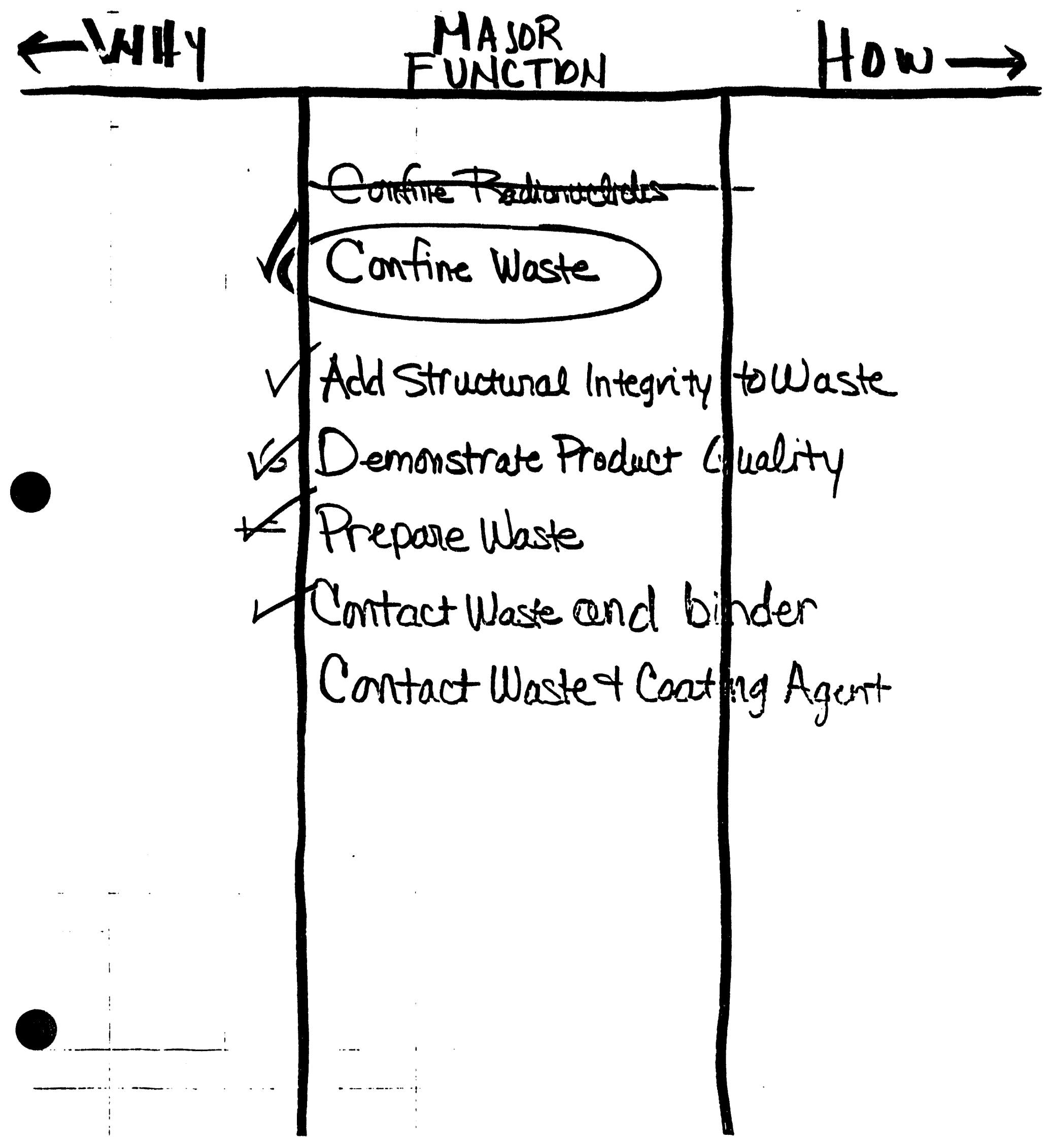




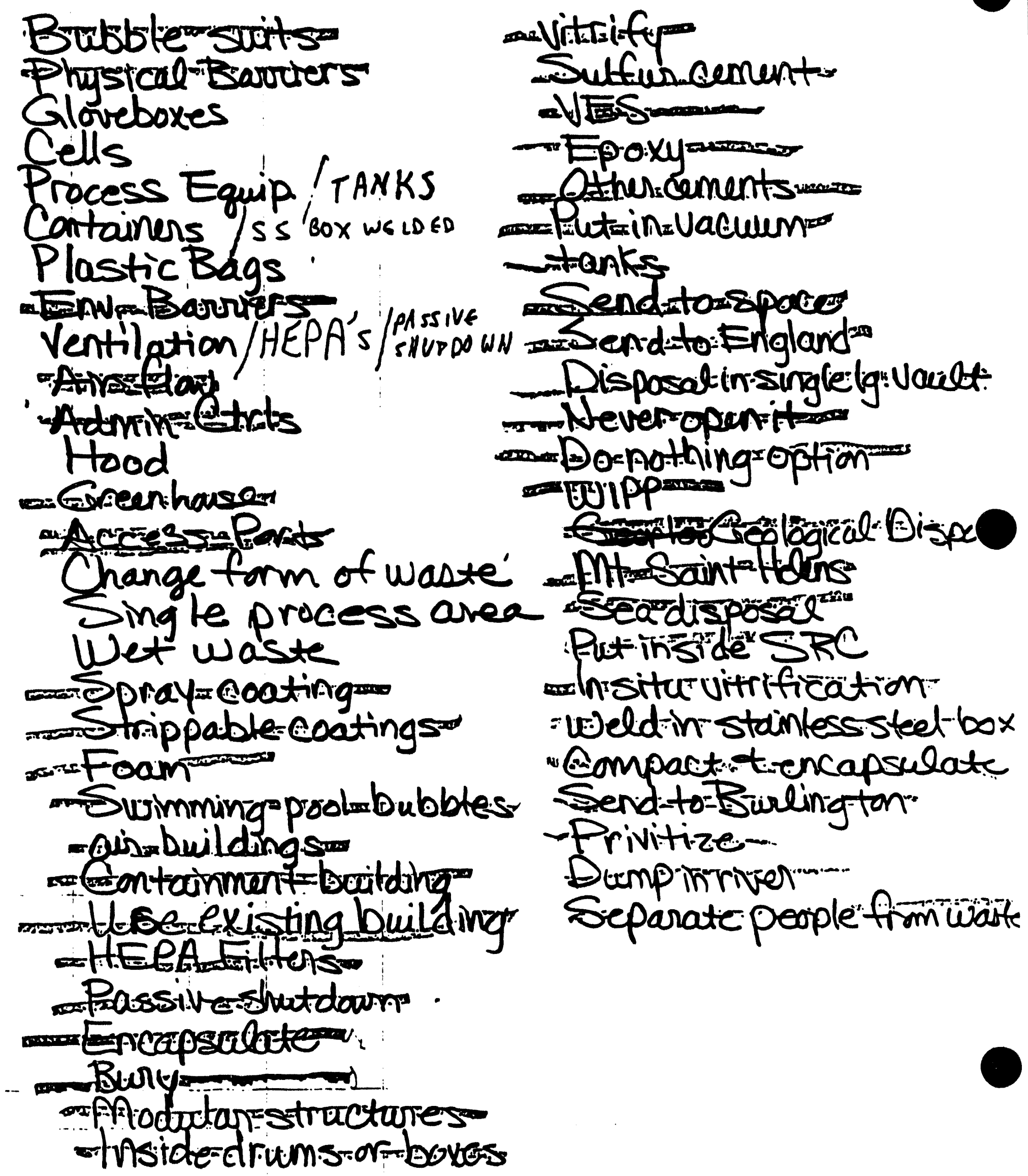


(1)

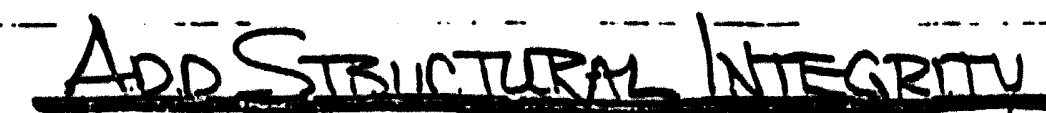

$-\cdots \cdot-\cdots$

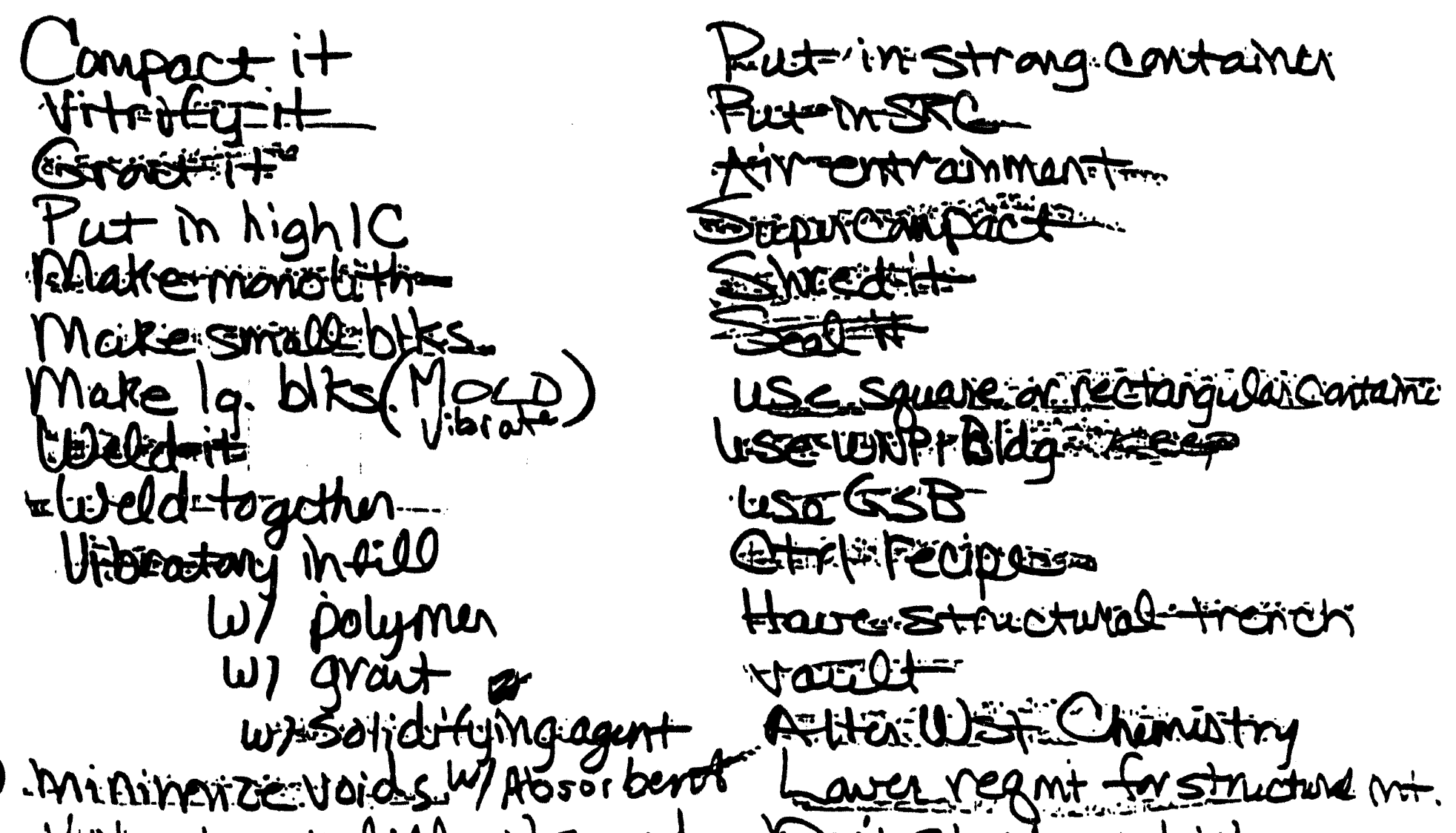

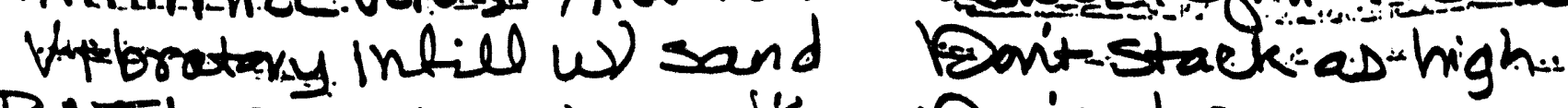

* BNFL seciet recipe * F mont drive...

Melt = it:

Exiteit

Prressurize it

Dumpinatrenchst-drive our

w)-back hoc

incor porate into loldg materials.

Baterit

Voevoum infolo

use-fixtall

Sor lod

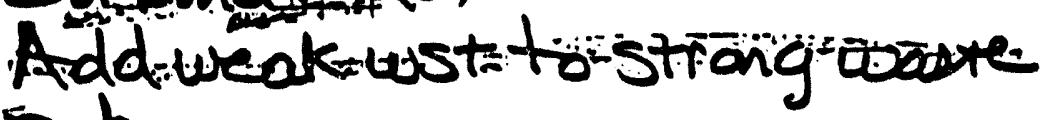
Febar.

Uśsustitead

Exposetökryptonite

trradiate if

freze-

- Acmentite

tumble mixer.

Ex asphalist

putrait on highulay

Sortuifi-

Spreadivery thinney.

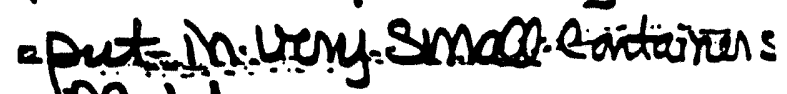

Pfoted

Makeitagouttagency.

Cure it.

- Maltinstageopliggs.

Ret=intioney combistruature 
(2)

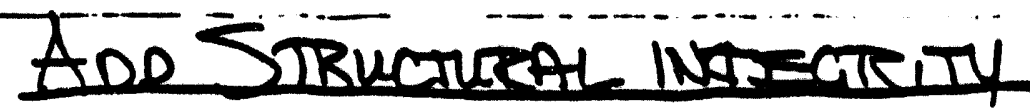

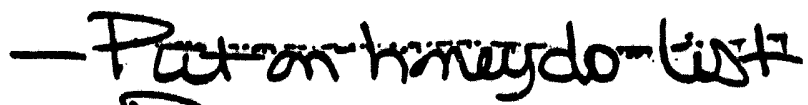

-Pu Fin

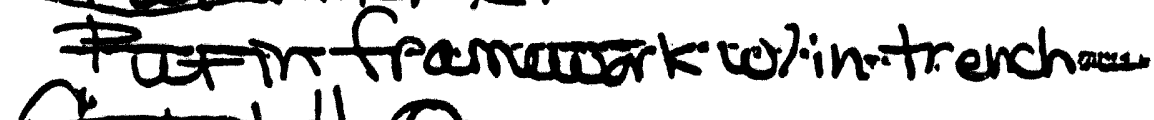

cilitot 0

Freare-ins swrpiss pu

Mix-w\%-ceranteblindat - low tempifires

Cabcine-it

Add'steel-shot

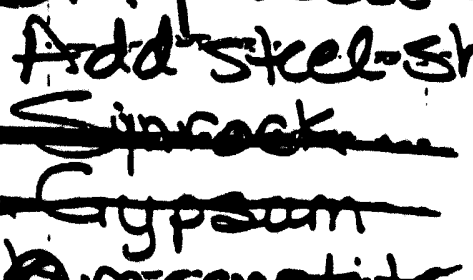

8 magnetite

Id pozeslon mat'

Vibrate after filling mold

1

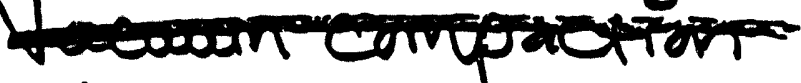

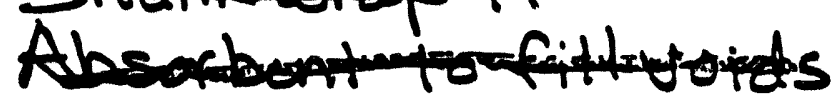


(1)

Demars Product Qunity

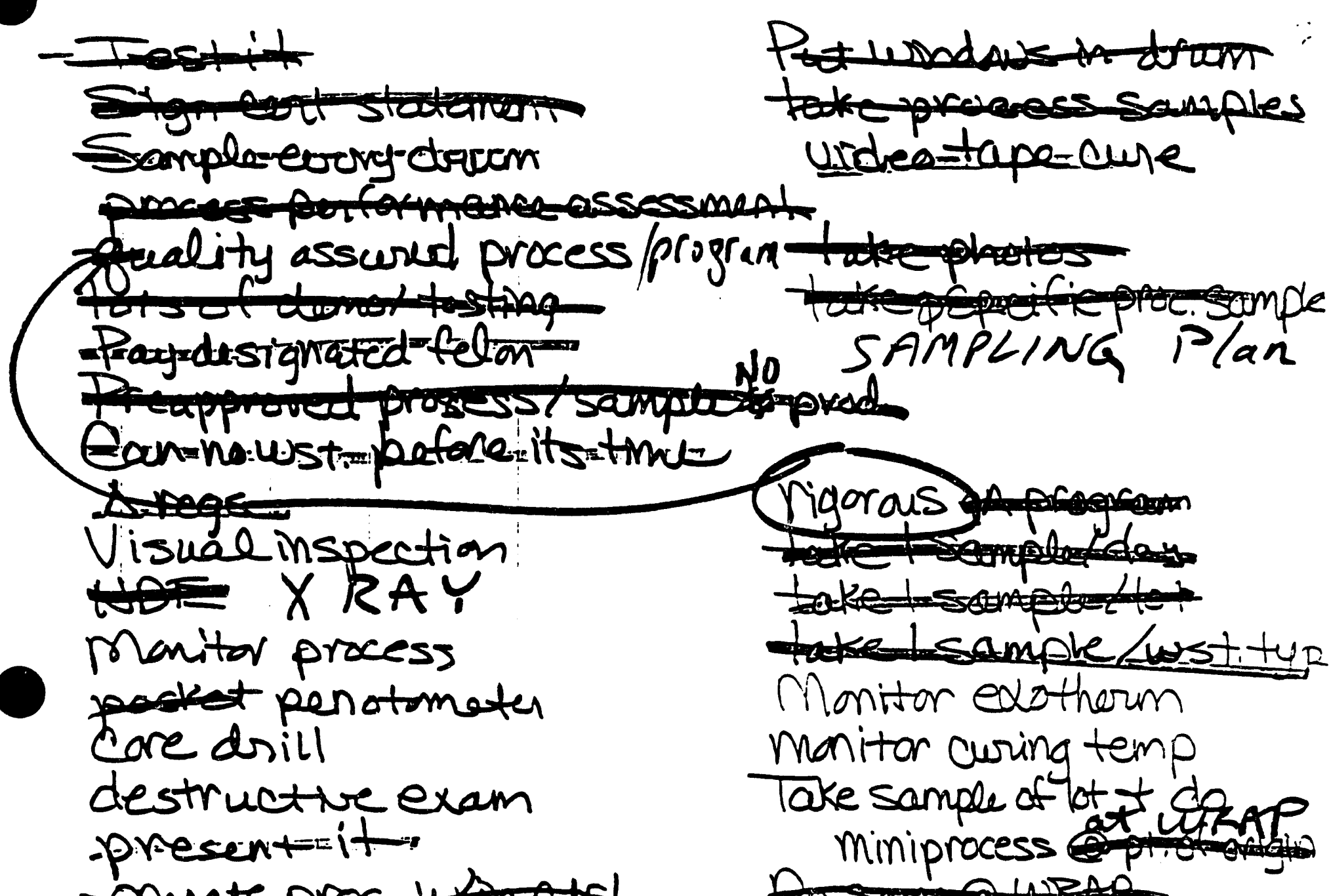

opuser pras

openate pros unctit

Do som ar

and sompong

destructuelej examevery drum tese-abhel-tapper's hammeruttrasonic - troun to. of nom onditions folly has KEEP

Manitor surface contamination of drum

imbed monitoring devices in prod.

diepose-innormigrationtare-

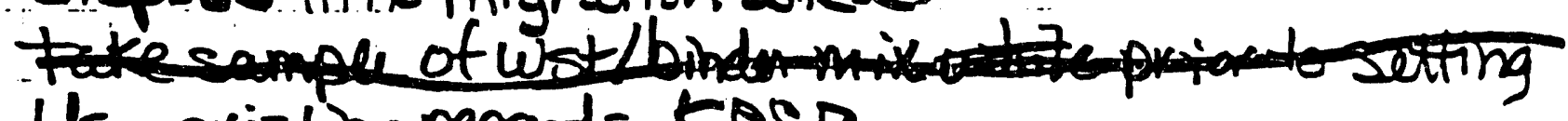

Itseeris gendr KeCP 
(2)

Demonstrate Product Quartic

- Impressive strength on entirecdrum

Fivecommencial

sent?

PR

Do TCLP test

AT of tamacesensible and

Soldif(t)

Sendelidrumplok to Olympia

Take no samples

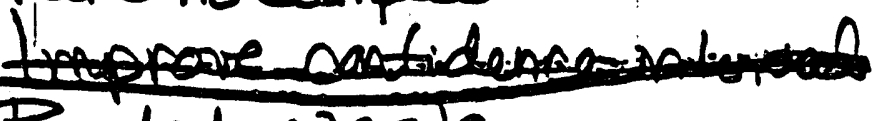

Batch waste

Do wt, balance w/vibro in fell

To med me

Use quality feed (raw matts's)

Prat test (toxicity test)-

Sponsor full -time. Ecology inspector...

Drape prod nc

Trace drum Contents thru process

Assay on a sample

Parmentosepy-

XRF

XR chrystolography

Inspect for \& free water

taseroblation.

$\forall$ isuatinspection

-. par 
(1)

Prepare Waste

Turbo destructor Antimere

Heated pugmill

Extradurom

Ball mill

Compacter

Shredder

Delumper

Sugmill/RotARY/VIBRO/Finer Cone of SCrew to homogenize

Sort Grizols Btow)itueves

Air flow dryer

Air is

- Openedruna:

Hammer mill

Roll

Wet Waste

Stir it up in great big tank Retort

Stilt up in the drum Empty-centainetr:

Shake the dorm

Gyratory crusher

Use porcupine

Shred whole things
Bun nit

Anlett-H

- Adedrum

oratory server en.

Rroditue

DIscover

Centrifuge $1<4 c c 0 N$

$\checkmark$ mixer

- Plat borehole: Qtestisite

Enzyme digest.

Wuidizedibod fer astor

Amalgamate

menivitize.

Guts feathers of all.

(a)

Ribbon Blender

Anetivatesurface

Jack Hammer

basin

Stade-trammer-

Shear

Magnetic separation

Directly repack 


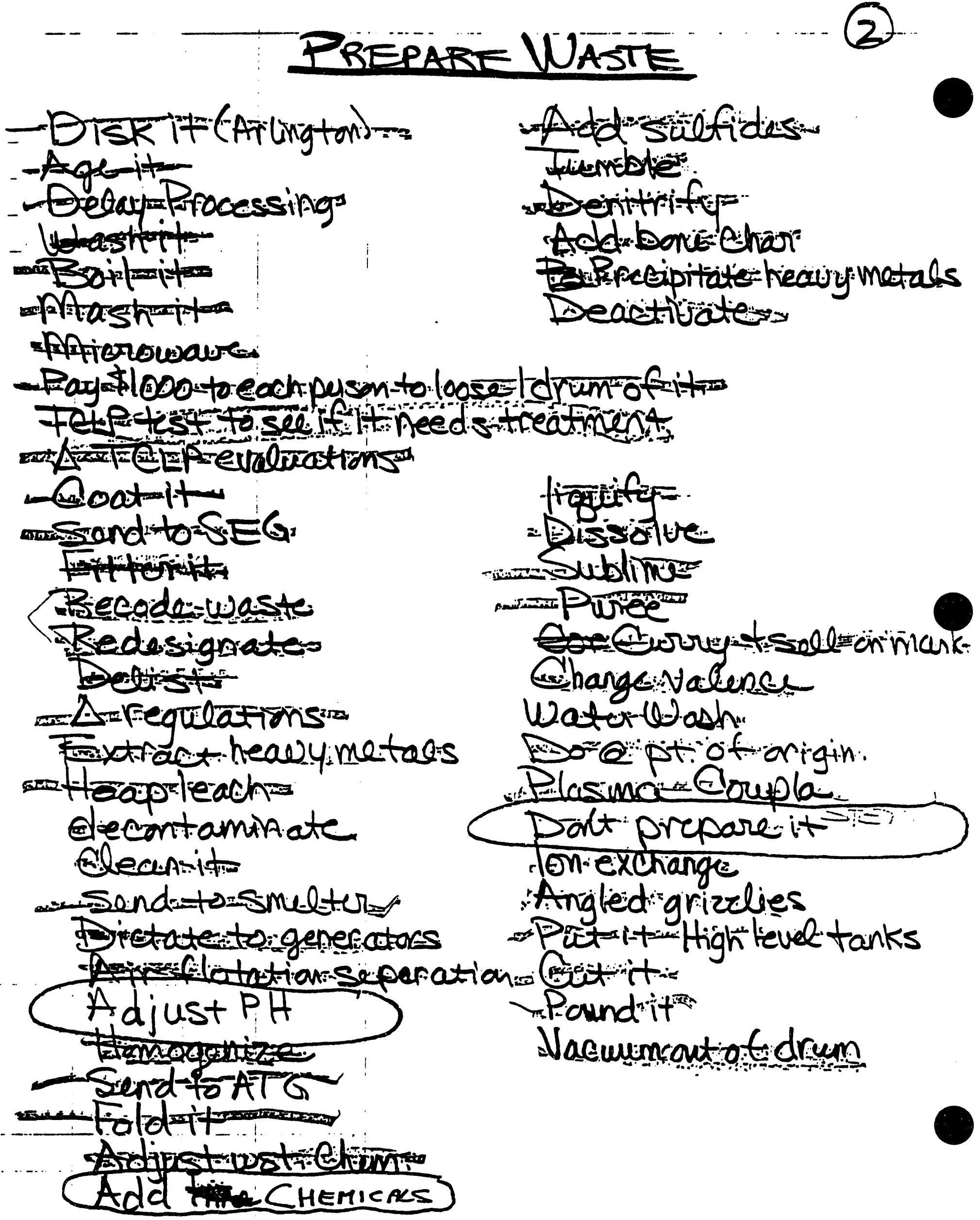


Contact Waste And Binder (Chemical)

Littleford Mixer

Mixitdry then liquifgLUR:

Mix dry then heat (PE)

Mix it

Antroment

- Indium

Slurry w st then add dry binds

drum batch

do dol planetary

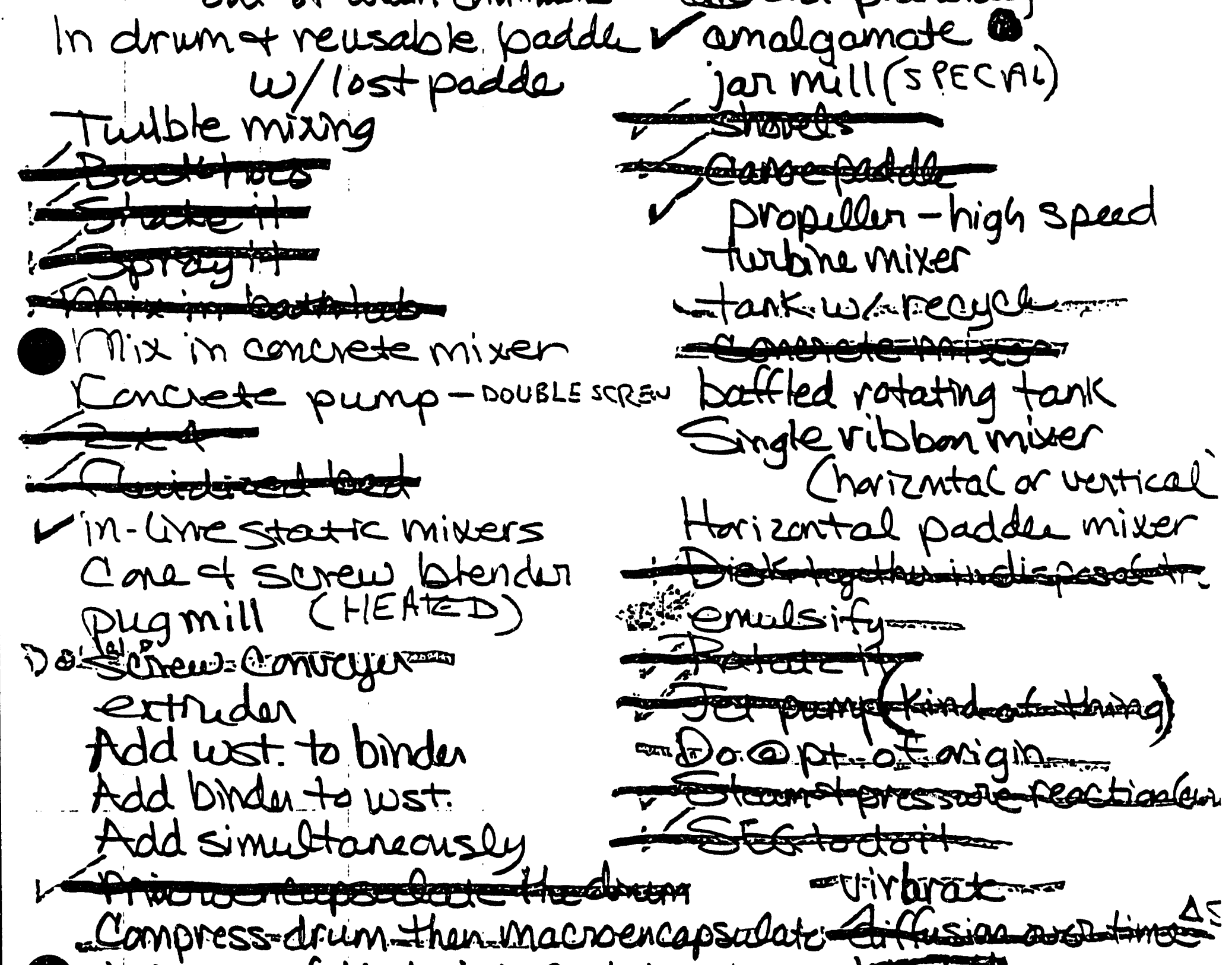

-injection of binder into containers

Slurry it.

hold paddle, rotate drum. 
- Contact Waste o Cantina Asset

- Dip it/ conT

paint it

High speed continuous mixer sup ort

- brushinitan

huge heated tank of PE

plow mixer

trowel-itan-

In-drum tumble mixer

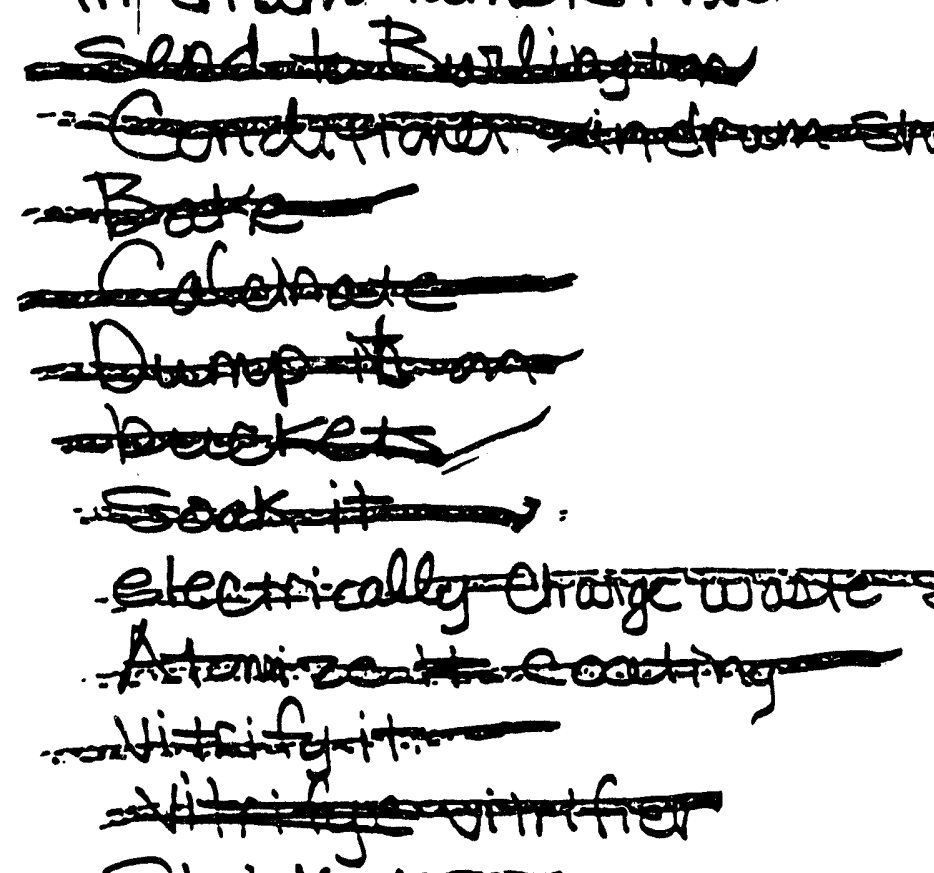

r -Shrink wowapas

Encapulate whole drum

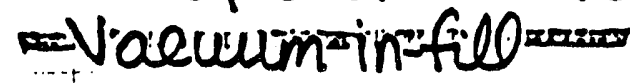

Hapor-par

-plan

-injection=moldow

pull through coating g media

fit trench wa binderstathrowaid drums

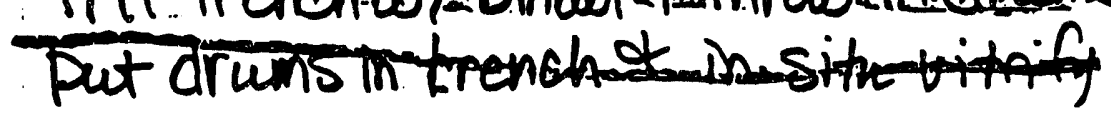

Put binder in drum of bad in w st.

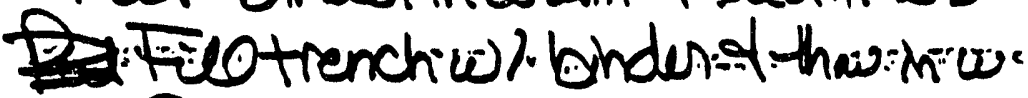
ex eoctrites

Mix it in -drum

Mix it out of drum continually Mix it out of drum batch In -drum w/ reuseable paddle In -drum w/ lost paddle

Tumble Mixing (out Dave)

Shake it

Sprayeit

Mix in concrete mixer Concrete pump

cone + screw blender pugmill

screw conveyor extruder

Add wist. to binder Add binder to wot. Add simultaneous sly ramaeroencapsulate the dream Compress drum then macroencapsulat. Injection of binder into container Slurry it.

- Pull -binder three w st: wo / vacuum 
SHOT GUN $115 T$

Drum tippes/orusher/dumper

Paysomeone-else-to-do-something-wh-it

Pavitize-

Putindowntown-LA-doverniter

wet process empty

Benefits of classifying drums as $L W$

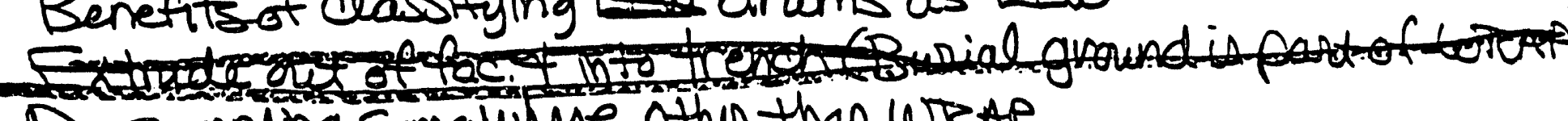

Do sampling some where other than WT RAP

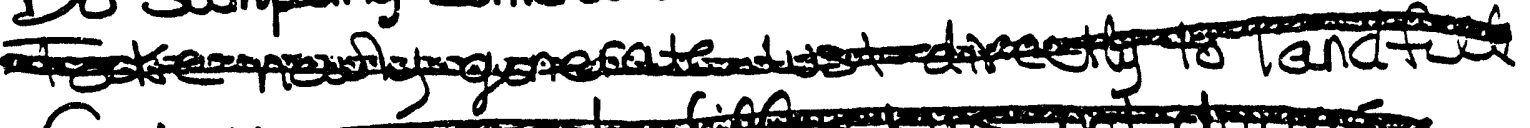

10 o rs

Utilize only a grout process

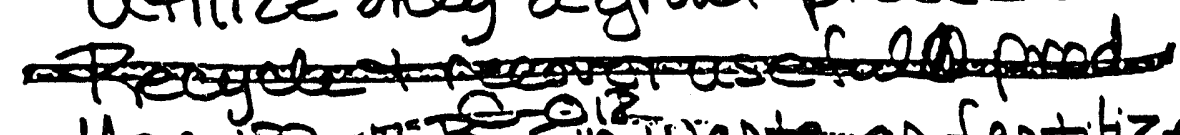

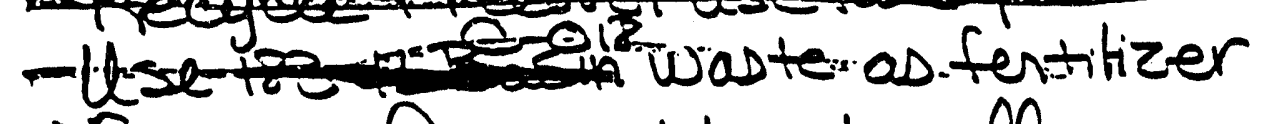

- Gnomes from mold s ot sell.

- tesemidges

- Common equipinent

- Powrdown-sewer...

- Container sire t shape

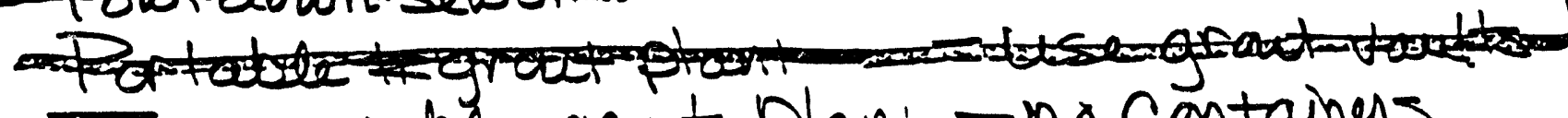
I - no Containers SEt prolate plant - reuse boxes Sit econ 4 send to commencialetso: - Ho-containment - separate/distinct proc. limes. Utilize gravity versicle plant no containment - exclude $\checkmark$ af expand f as utilize horizontal plant.

Keep scientists off der work.

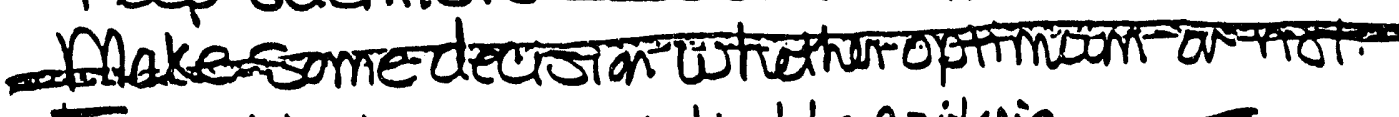

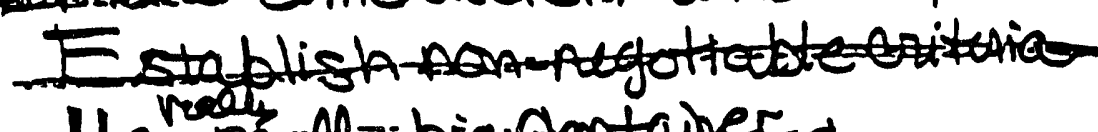

H -wstwaten to LEIF 

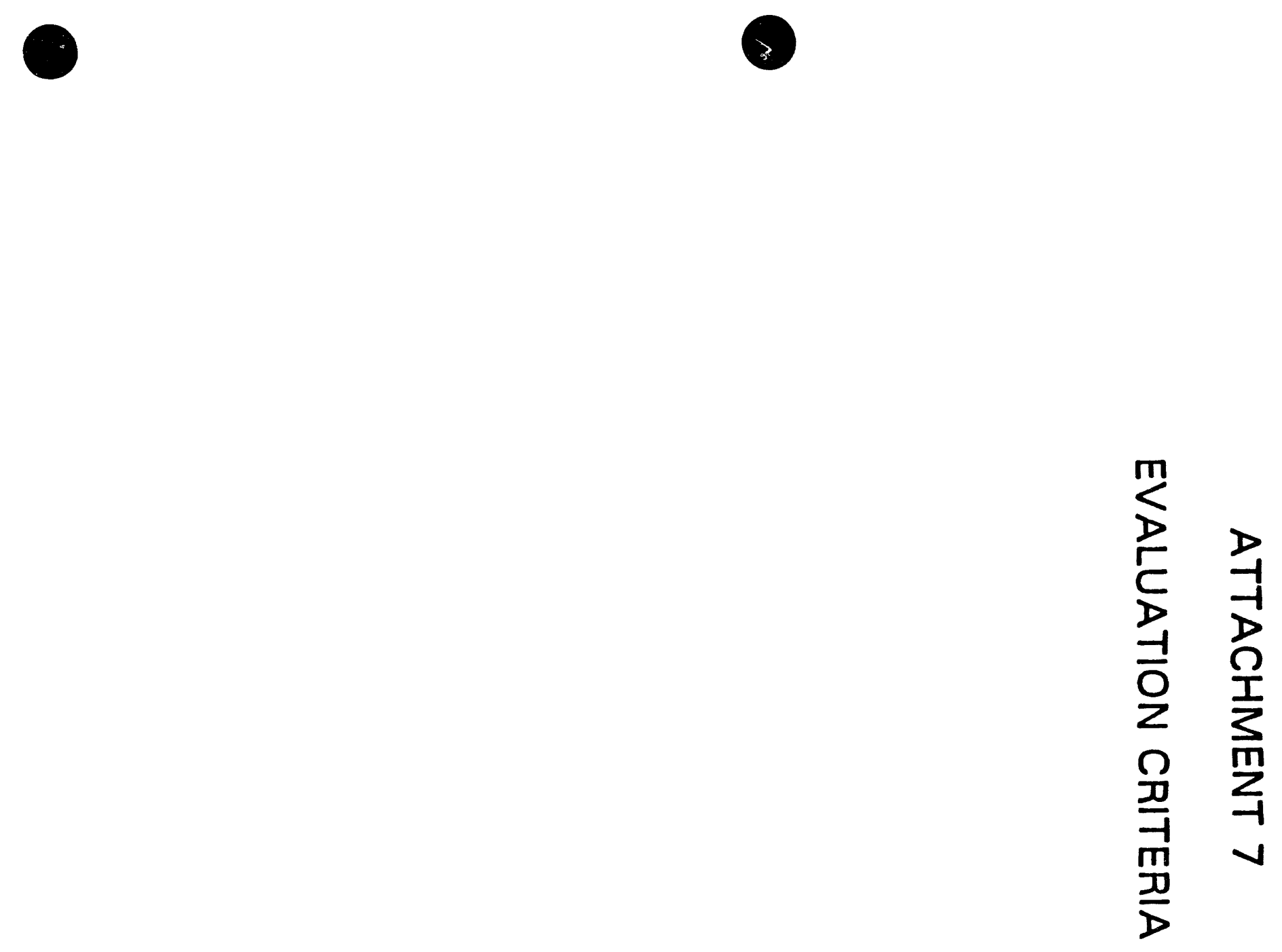
.014496, am 2nLropy)

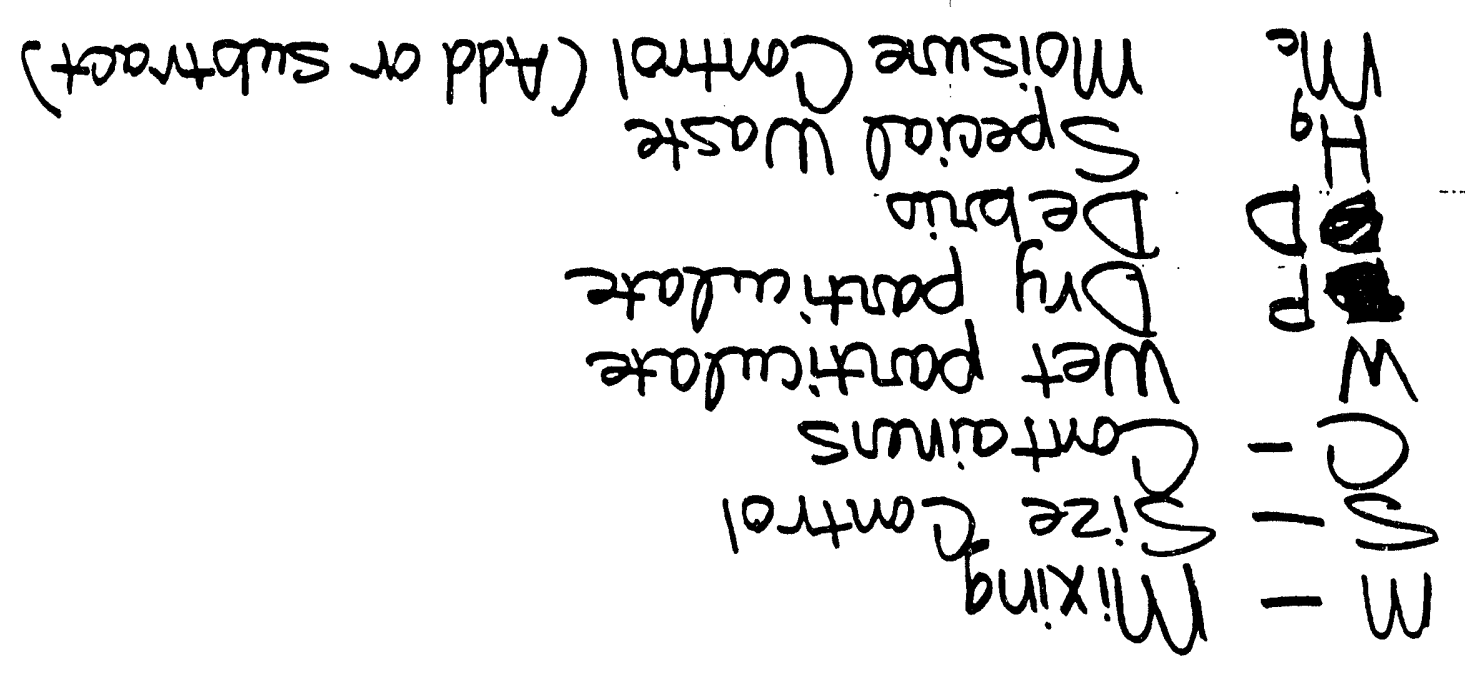

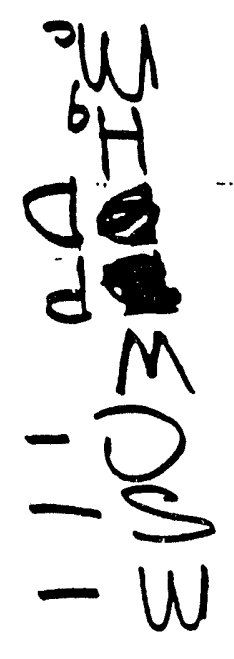

$$
\text { mol }-7
$$

umpsau - $u$

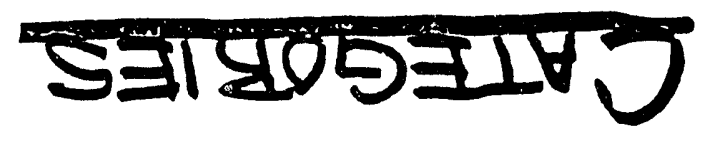

ronatsodw! 4 b!y - H

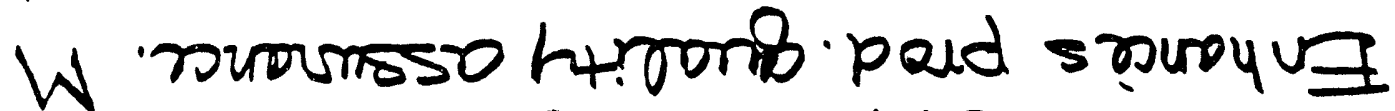

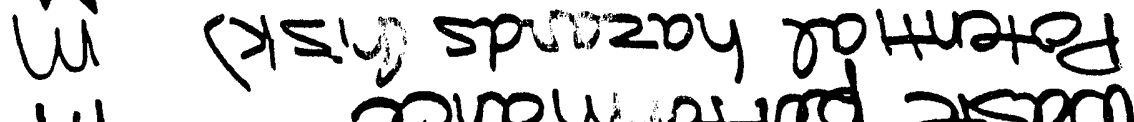

WI rovouingind assom

heolanpat

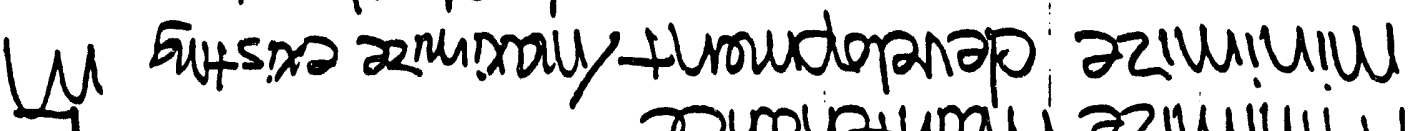

surpurturau azmulu! W'

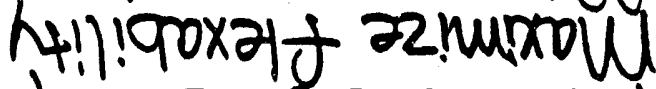

W

chuopuosastipoud' atsorn ar !mululu ssosoud pay!lchils

mdy onoult zziuixaulu

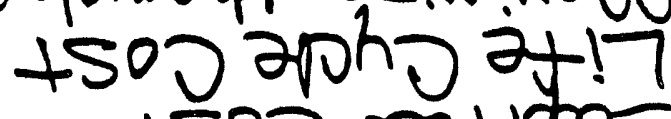

H +50 $00+1000$ : 


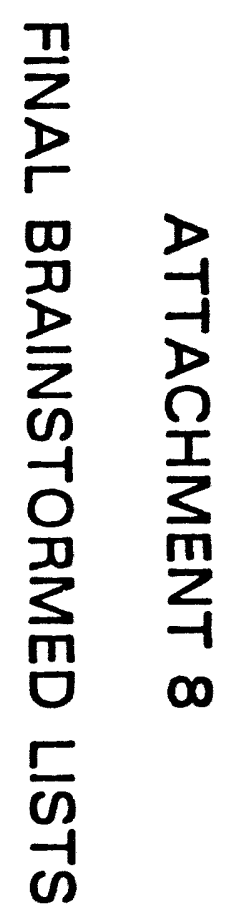


Gloveboyes

Cell 3

Process Equip / tanks

Containers/ss box welded

plastic logs

ventilation/HEPA/passive shut down

Hood

Change form of waste

Single process area

wet waste 


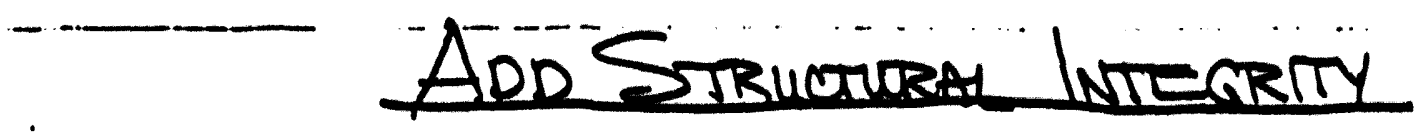

Compact it

Put in a high, integrity container

make lg. bilks (vibrate, mold)

Infill w/ polymer

w/ grout

w/ absorbent

W/ Sand

BNFL Secret recipe
Cure it 
Demonstrate Panic Quality

PR

DoTCuP test

Take no samples

Batch the waste

Do weight balance w/ vibrio infill

Use quality feed (row mat' ss)

Tracedrum contents through process

Assay on a sample

$X R F$

XR Crystallography

Inspect for free water

Rigorous quality assured process/program

Visual inspection

Pray

Monitor process

Renotometer

Core Drill

Destructive Exam

Ultrasonic

Monitor surface contamination of drum

Imbed monitoring devices in product

Follow sampling plan

Monitor. Exotherm

Monitor Curing temperature

Take sample of lot + do miniprocess @ URAP

Fully Characterize the waste

use existing records 
Prepare WAste

Turbo destructor s Heated Pugmill D/S Ball Mill's Compacter. Shredder Delumpers 5

Pugmill 5

Siren (rotany/Vibro/Filten/Grizzlies) s (3) Sort $S$ \&

Air Flowdryen D Hammer mill roll crusher 5 wet waste

Stir it up in great big tank "1 "in drum

Gyratory crusher $S$

Slurry it

Chop it up w/ backhoe in big basin

Continuous dryer D

Batch Dryer D

use porcupine $S / D$

Centrifuge/ Cyclone

Cone t Screw to homogenize $\checkmark$ mixer

Amalgamate

Retort

Shred whole thing guts, feathers tall S (3)

... Ribbon blenders 5 jack ham mir

Shear

Adjust PH
Magnetic separation $\leq S$ Directly repack (3)

Add chemicals

Donn prepare it 


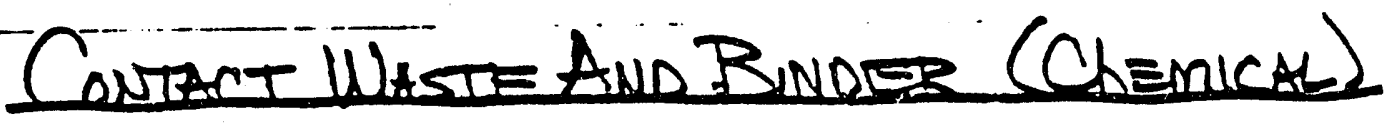
$\left[\begin{array}{rl}\text { Mix it } & \text { in drum } \\ \text { out of drum botch } \\ \text { out of drum continuous }\end{array}\right.$

In drum mixing $W /$ reusebble paddle ${ }^{4} \frac{B}{B}$

Tumble mixing

mix in concrete mixer

Concrete pump -db/ screw (4) In-line static mixer $4^{\circ}$ Cone Screw Blendes (4)

Pugmill (4)

Extruder

$\frac{c}{c / 0}$

Add waste to Binder

Add binder to waste

Add waste t binder simultaneously

Littleford mixer (4)

B lo

Mix dry then slurry

Mix dry then heat (PE)

Slurry waste then add dry lo finder

sol planetary mixer Amalgamate

Jar mu (special wot)

Propeller - high speed (4)

Turbine Mixer 401

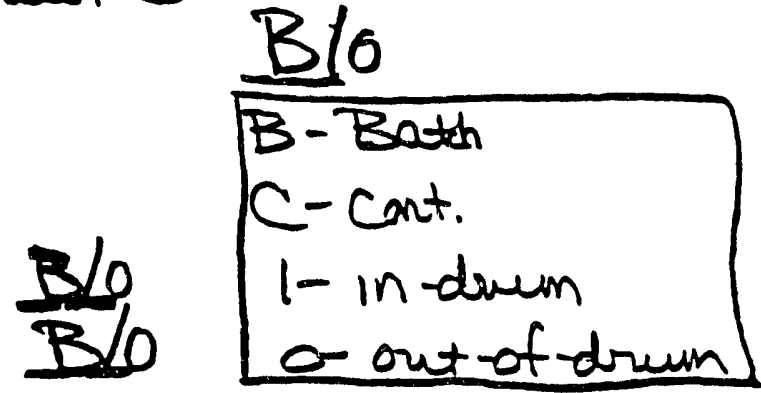

Baffled rotary tank

Single ribbon mixer (horizontal or vertical) $4^{\circ}$

Horizontal paddle mixer

$\frac{C}{B / 0}$ Hold paddle, rotate drum 
Contact Waste And Coating Agent

Dip it / Coot Ht (1)

High speed continuous mixer

t Sg heated tank of PE Q

Plow Mixer

In-drum tumble mixer (3)

Showy uss. then add dry binder

Double planetary

Jar Mill

- Pull waste through coating media Turbine Mixer

Put Baffled rotating tank

Single ribbon mixer Choriz.ervent)

Mix it out of drum continuously Horizontal paddle mixer (3) pax it out of -drum batch Vibrate (3)

In. drum w/ reuseable paddle

Hold paddle, rotate drum.

ln-drum w/ lost paddle

Tumble mixing (out of drum).

Shake it (3)

Tumble mix out -of drum (3)

Mix in concrete mixer

Concrete pump

Cone of screw blender

Pugmill (2) (Heated)

Screw Conveyor

- Extruder (10) (2)

Add Waste to binder 10

Add binder to waste (1) (1)

Add binder t waste simultaneously

Compress drum then macroencaps

Injection of binder into container (1) (3)

Slurry it:

Litteford Mixer

Mix it dry then slurry

Mix dry then heat $(P E)$

3 
Contact Waste And Coating Agent

Little ford Mixer

Mix it dry then for fy SLUR R

Mix dry then heat (PE)

Slurry wat. then add dry binder

Dbl planetary

- Jar mill (mercian)

Turbine Mixer

Jan kw werrecyete

Baffled rotating tank

Single ribbon mixer (horizontal or vertical)

Horizontal paddle mixer

ativenulsify

H. Qu point of origin. Vibrate

Hold paddle, rotate brim 
SHot Guv list

$\rightarrow$ Drum tippes/crusher/dumper Wet Process

$\checkmark$ Benefits of classifying empty drums as LLW.

Do sampling somewhere other than WRAP.

$\checkmark$ Utilize only a grout process

Utilize gravity -vertical plant

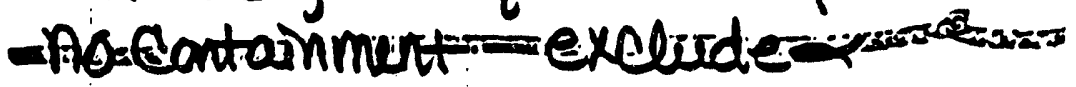
utilize horizontalsplanteresos

$\checkmark$ Common equipment

$\checkmark$ Containers size t shape

No containers
Reuse boxes
Separate/distinct process lines os of

Ex Waste water to LEIF

Dry mix wst/PE of then heat inline

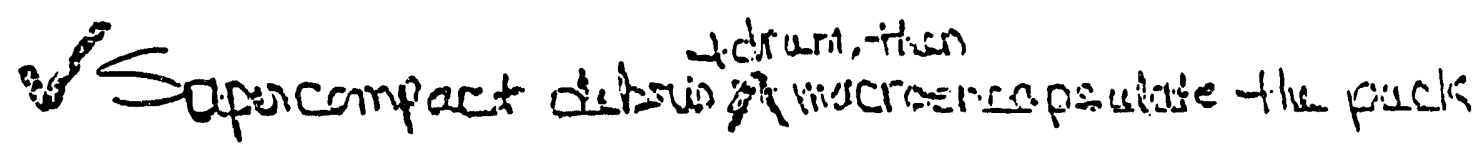




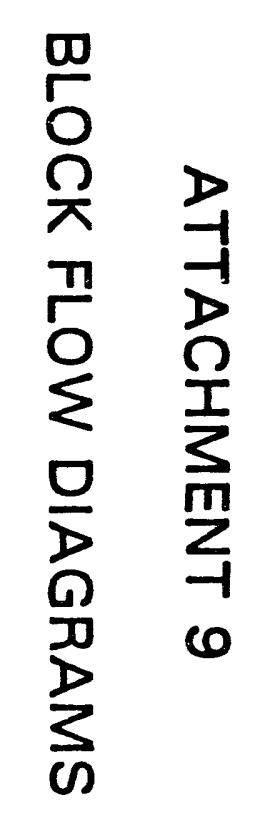




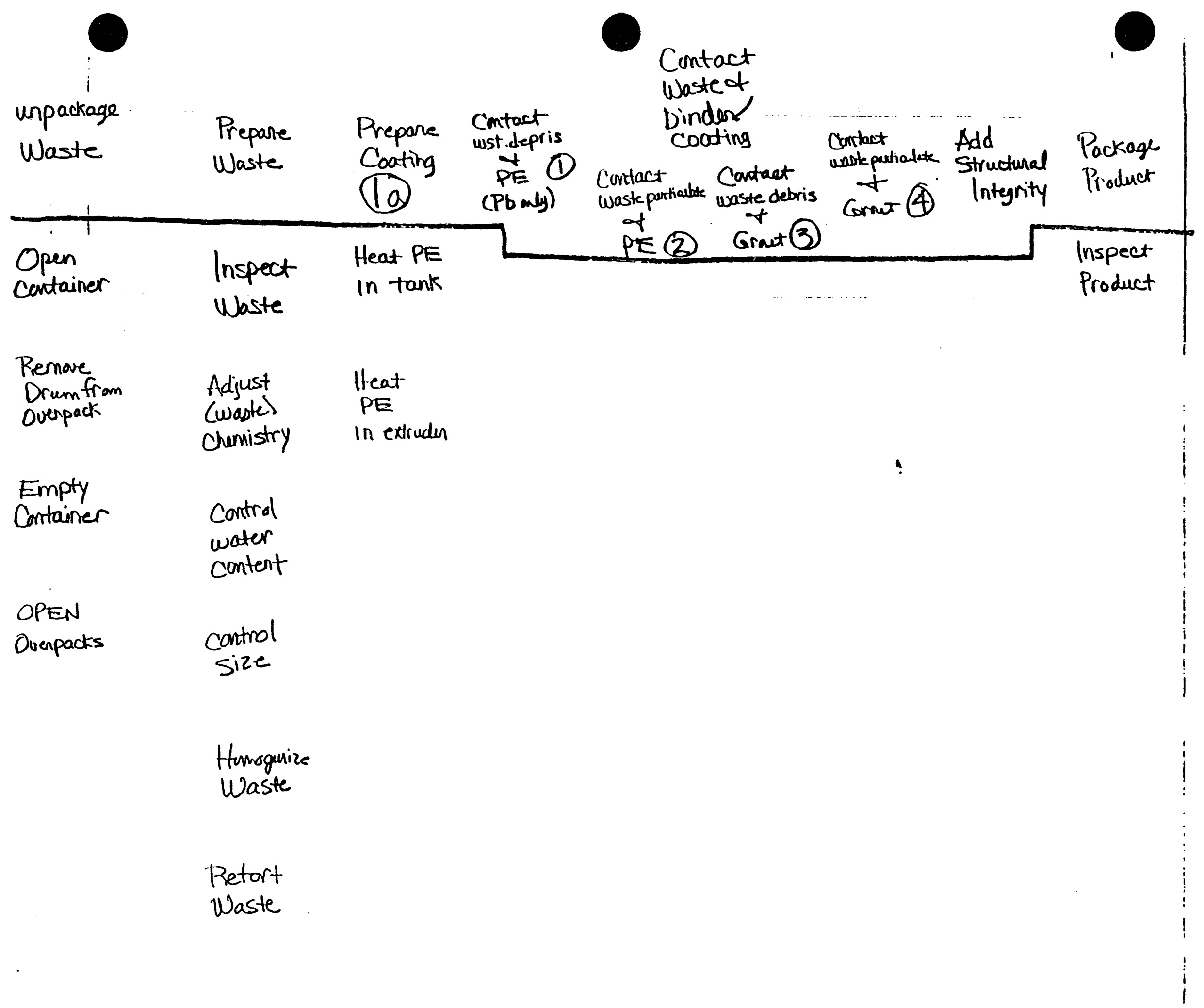



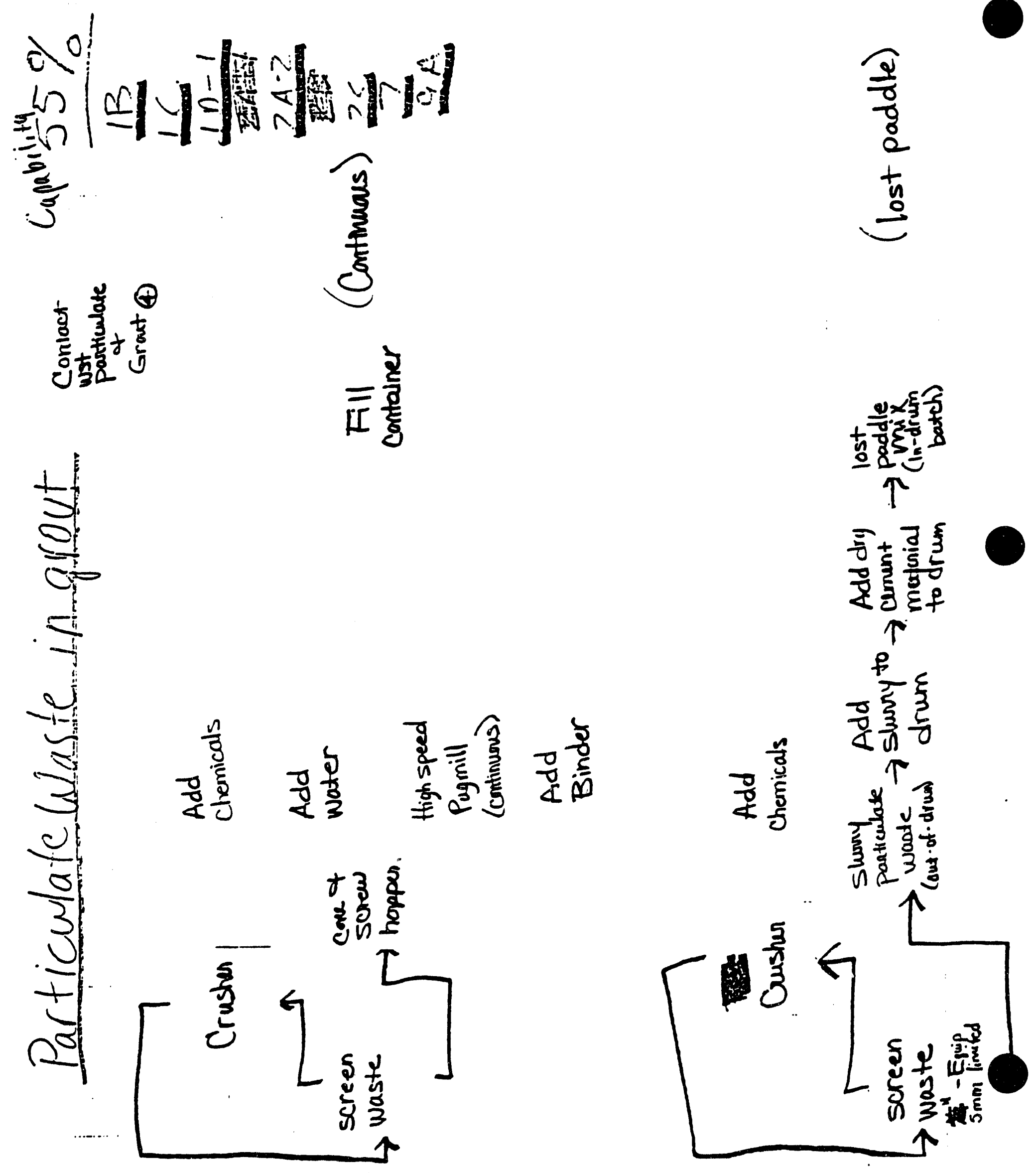


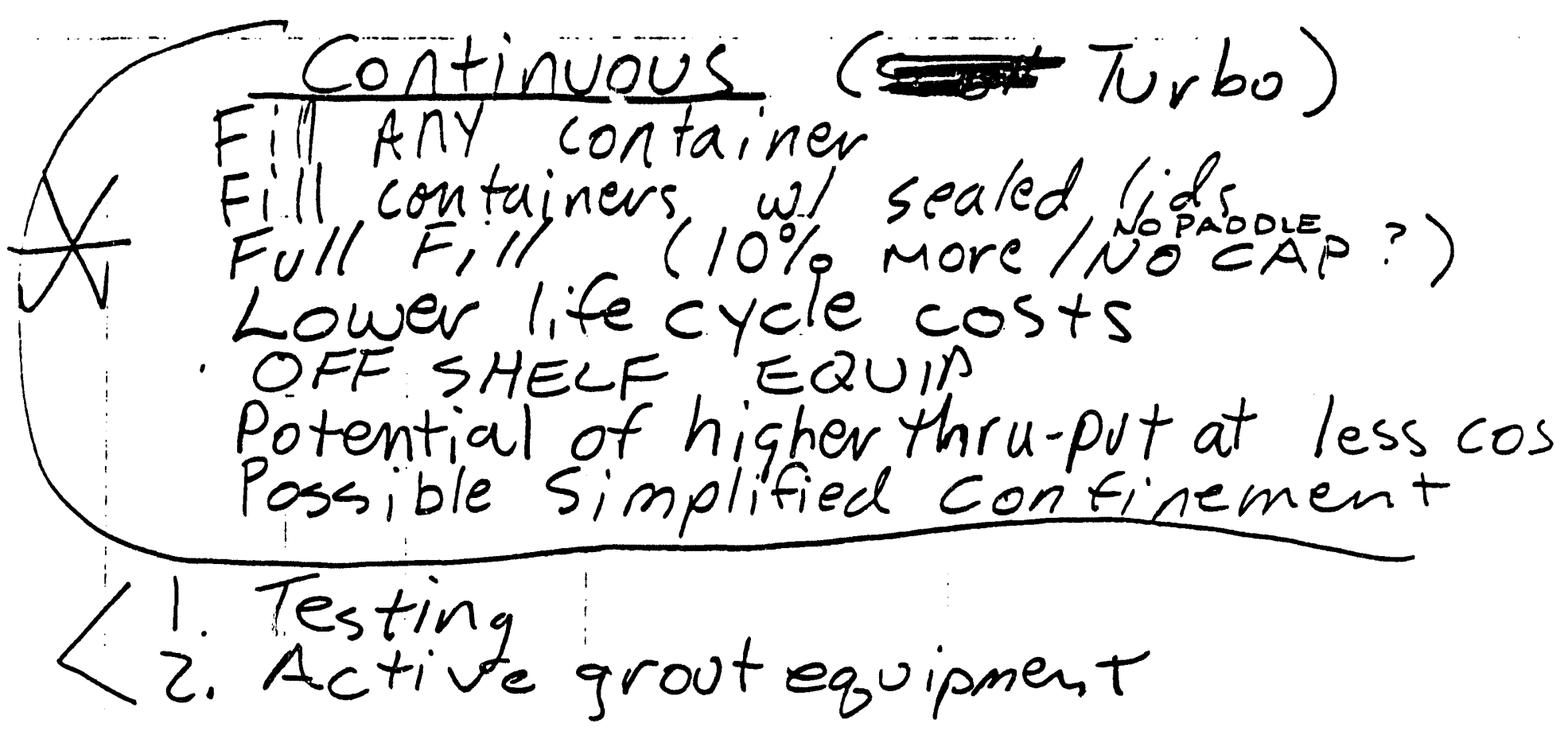

Lost Paddle

No Active grout equipment (other than drum Demonstrated technology specific to $2 A$ less clean up 

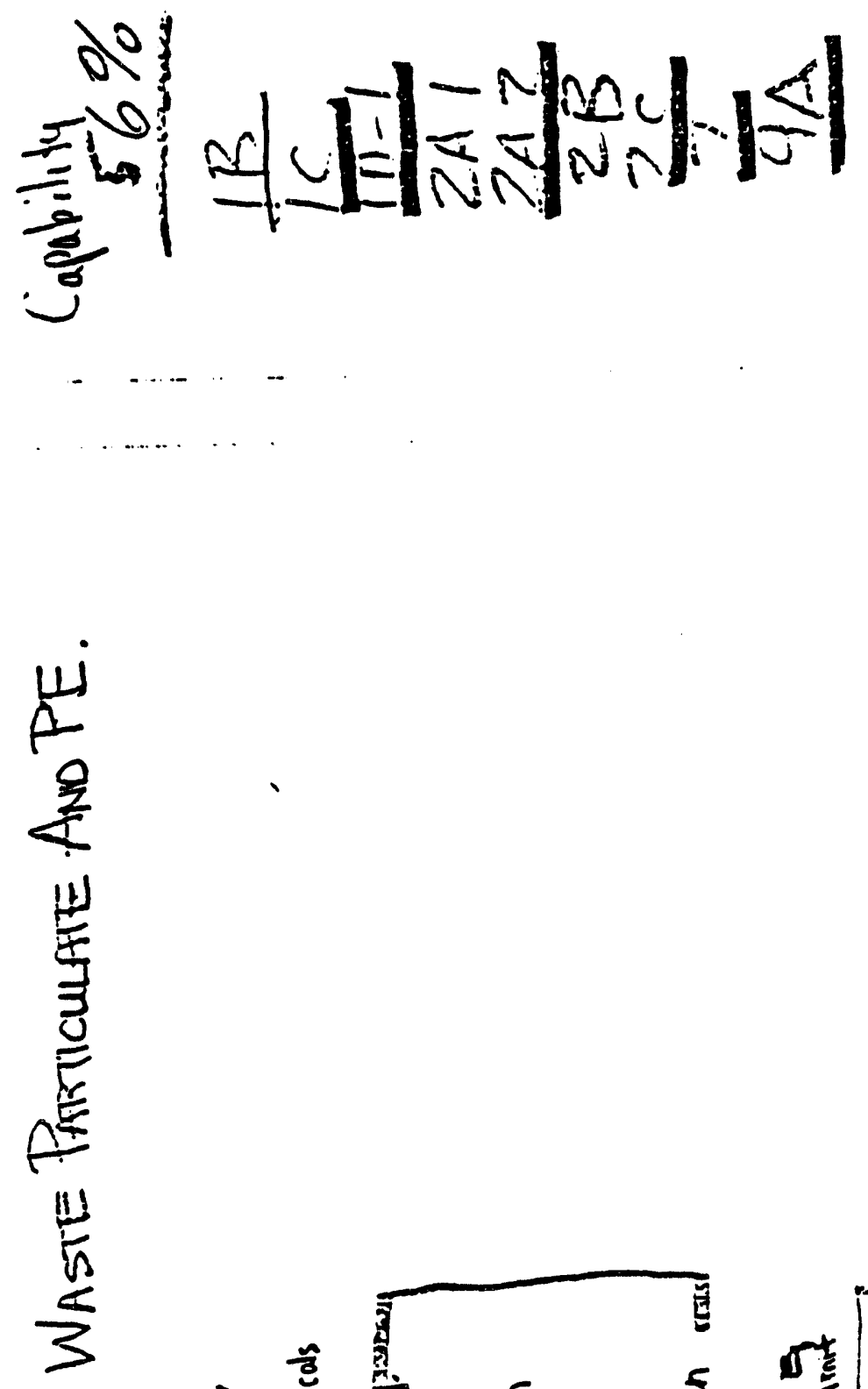

$\frac{5}{3}$
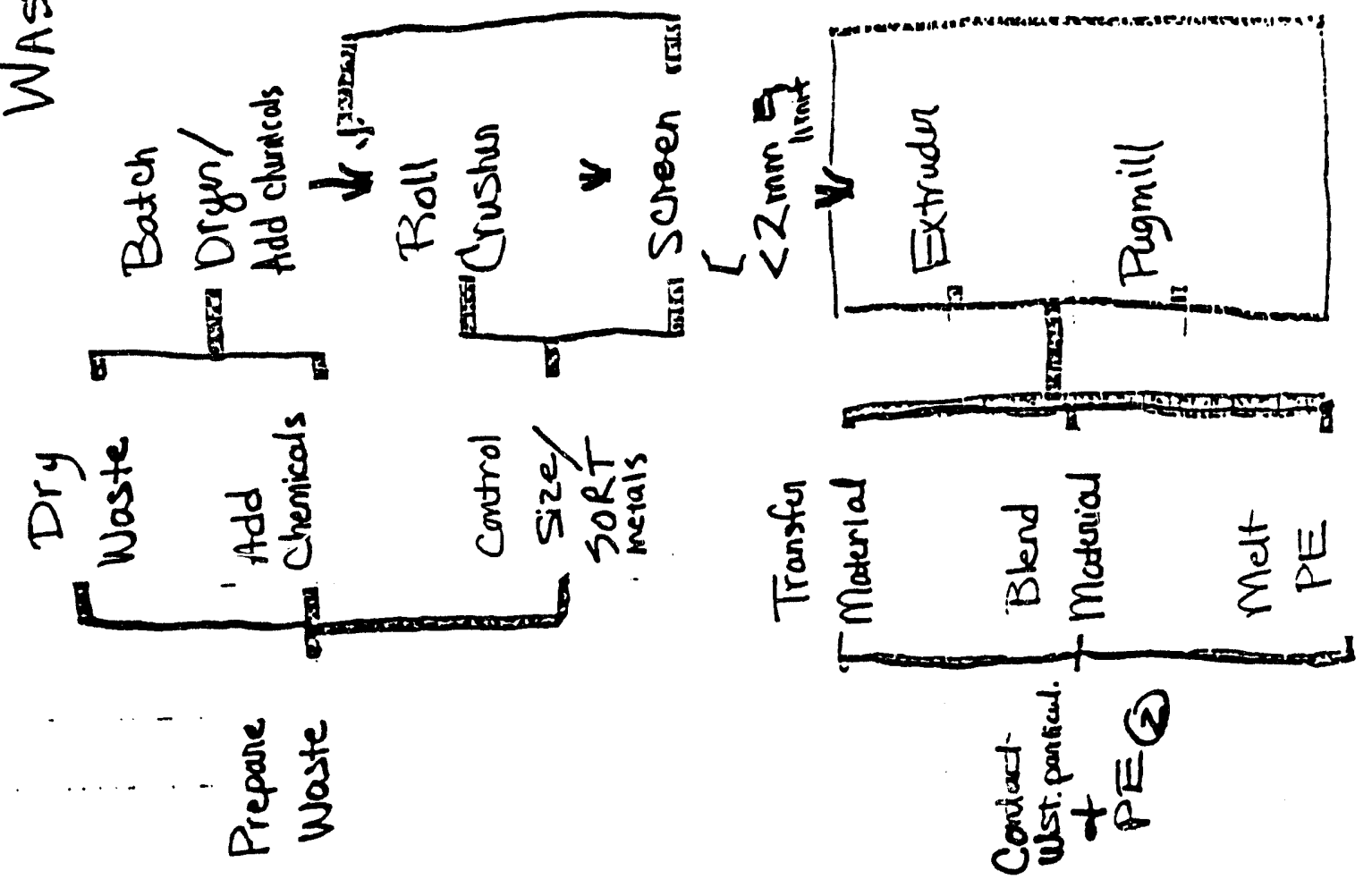
2700

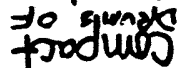

stosropsow

irryt

umop/tism

55201400

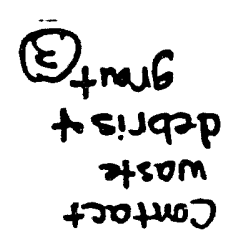

2500

suocts dd

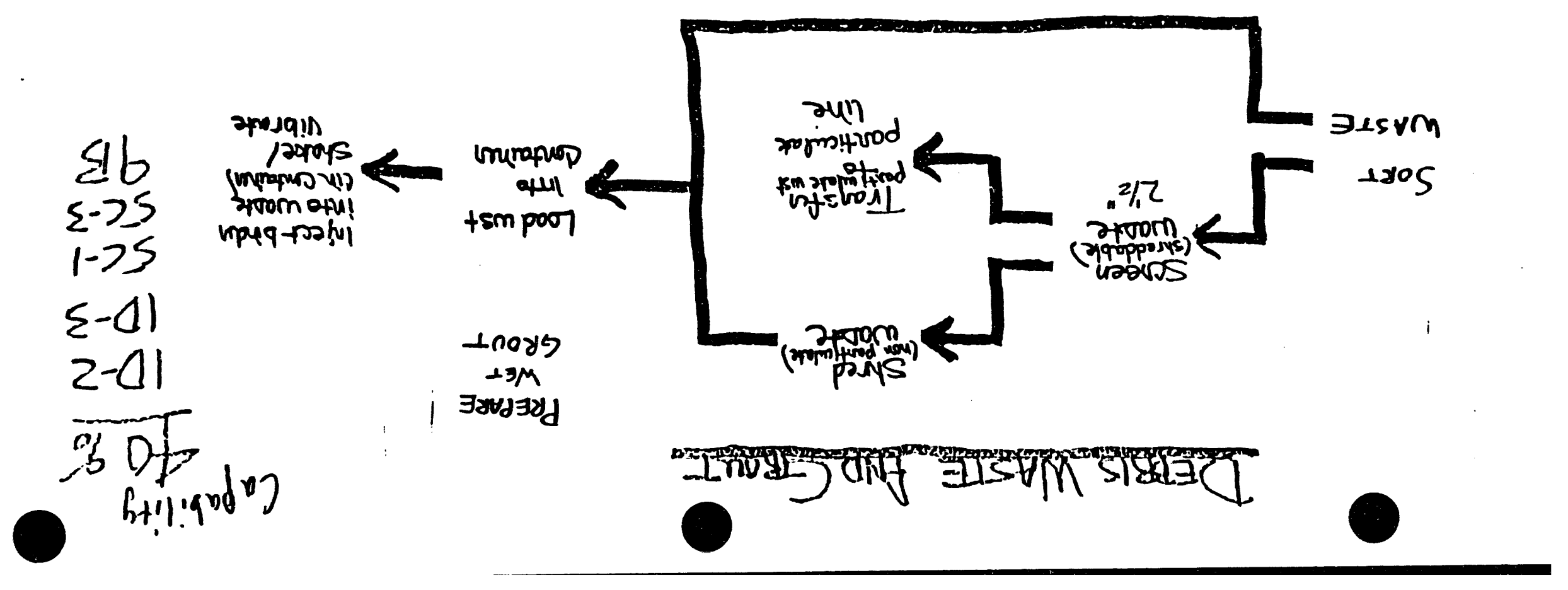




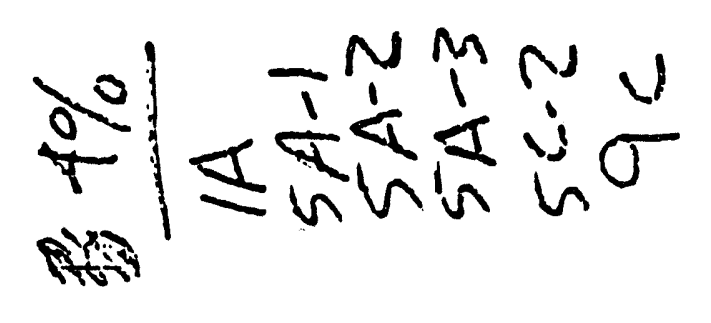

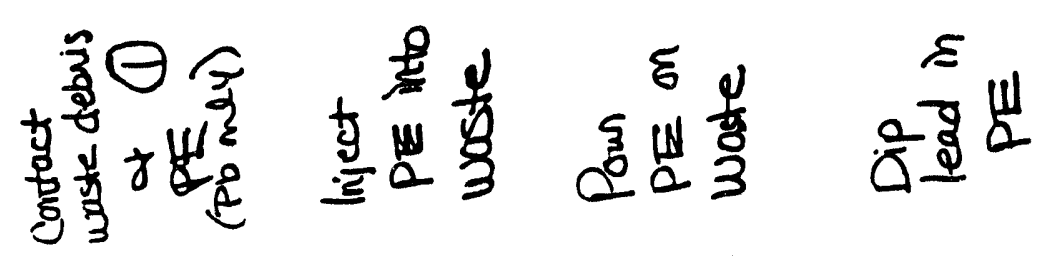

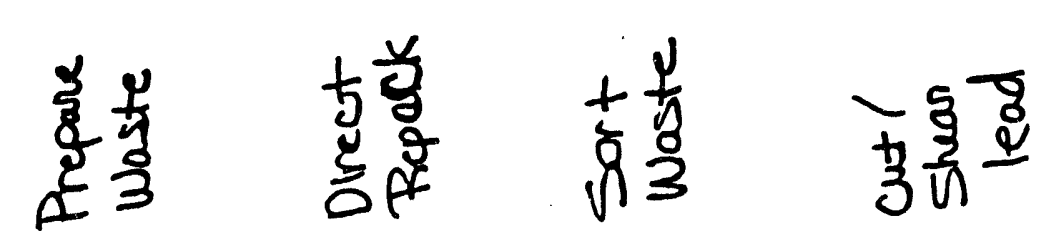

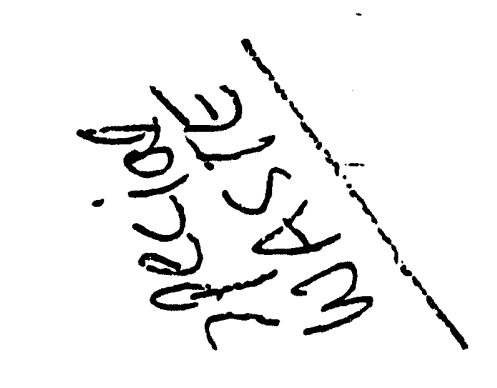




\section{ATTACHMENT 10}

\section{MEMORIES, ASSUMPTIONS AND INFORMATION NEEDED ITEMS}


Need to address R. Robert's concern re: decision to use PE t notVES

1 Computability of lead a cement.

Ask prog. office to impose acceptance Criteria on the generator on our behalf.

1 No sampling of macroencapsulated product is reed. - TRUE $\rightarrow$ Doc. in Treatment/ Disposal Compliance

$\checkmark$ Contained liquids routed to UTEAP I On WTTAP $2 A$ :

1 Stabilization - EPA def. is to reduce mobility of toxic te. components.

1 Use of square or rectangular container wo wd minimize voids 4 provide better utilization of -the land fill.

14 Blaine Stang call on W.025 trench translates to a 60 psi compressive strength regt for waste prod. (included in ZA prod. spec.).

Y Sell different test (other than TCLP).

Y USE OTHER containers than BOX OR DRUM 
ASSUMPTIONS

- WRAP ZA will be a PE/ Grout Fac.

1 WRAP 2A feed is that which is in the feed Spec. doc. [SD version that has been signed but which is being held for release.]

- If particulate can be spanged. from debris, then the debris can be shredded. (Action \#5.

$\checkmark$ If wist. comes in as category I or category? it will go out as some category. (This is based on no mixing blum categories:

- No incoming contains will be reused. including overpacks (Action \#3)

1 Not restricted to paltetizing drums fa transport to of from $w-112$.

* Prod. Container needs to be a DOT approves Container. Prod. Containers will be used. Actions:

$\checkmark$ Cleanup baum campaigns will occur

1 outside of the 175 operating days. SDRD

- Vibratory polymer processing will not be done in WISAP ZA. late W/ polymer Still will exist Container.) SORD

- All amalgamated moncerry will require immobilization SPED 

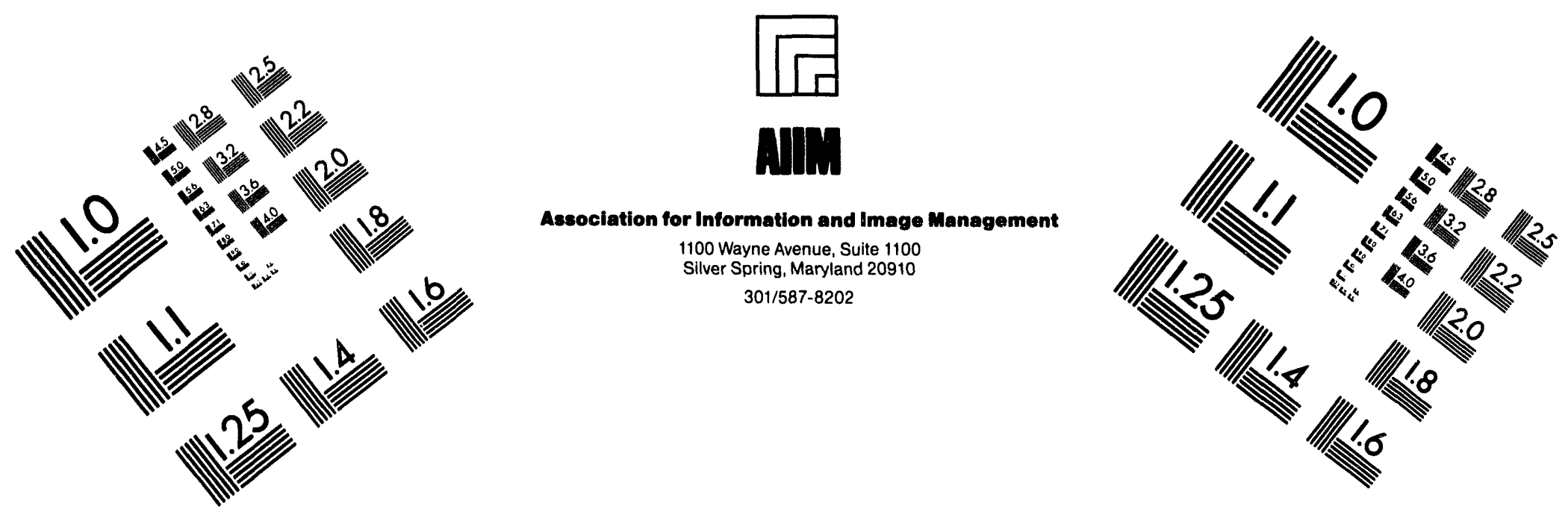

\section{Centimeter}

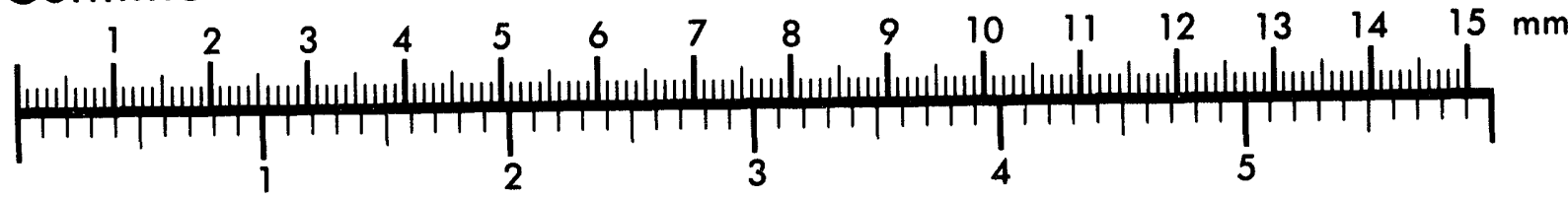
Inches
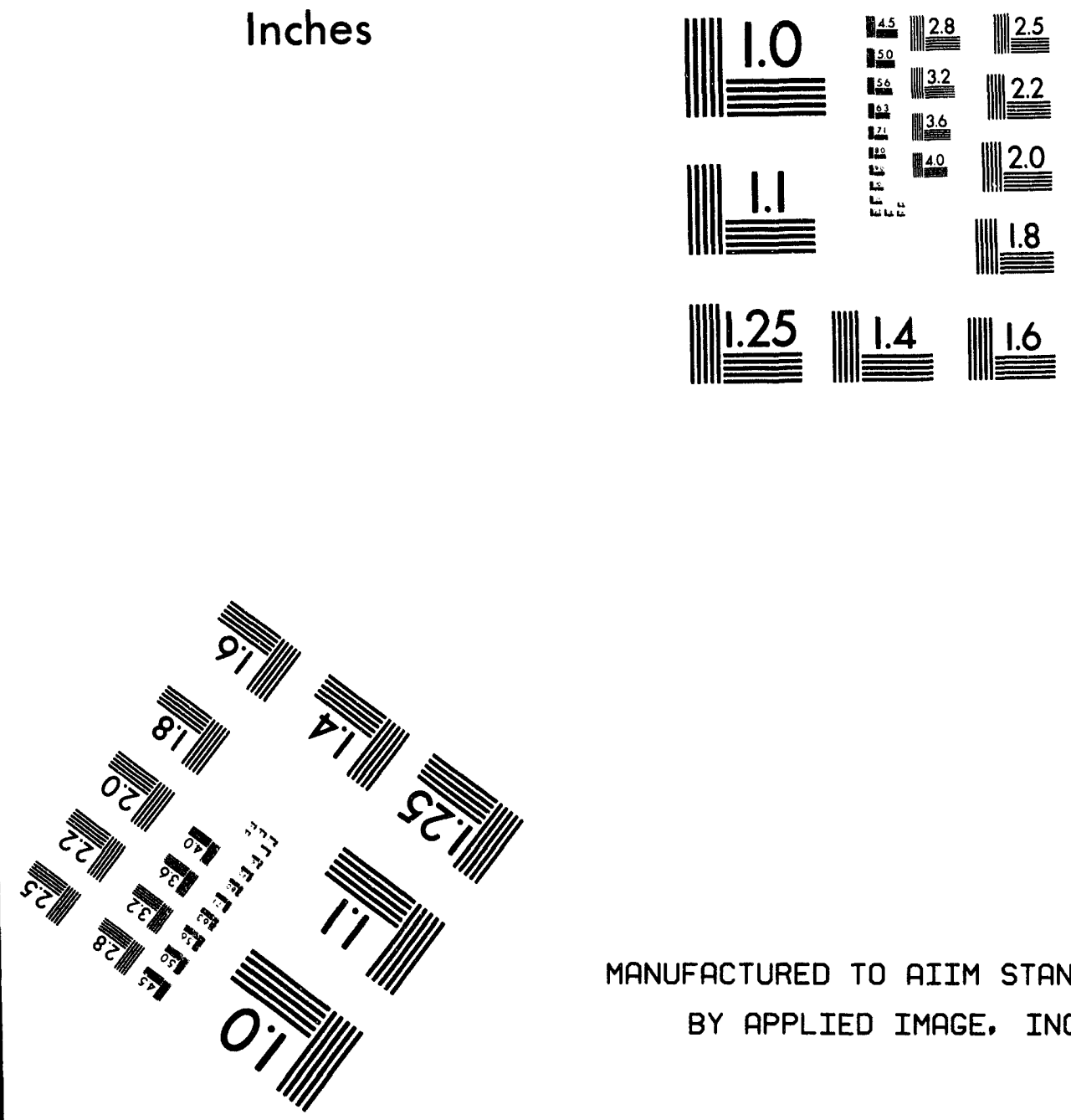

MANUFACTURED TO AIIM STANDARDS BY APPLIED IMAGE, INC.

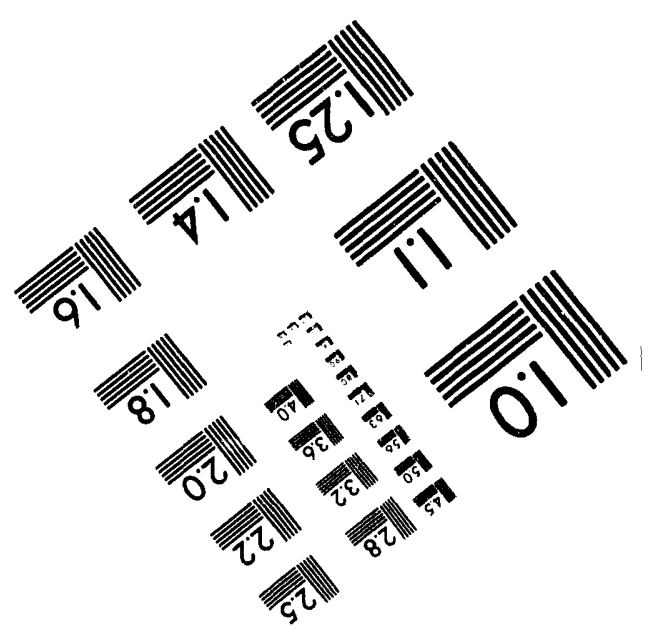



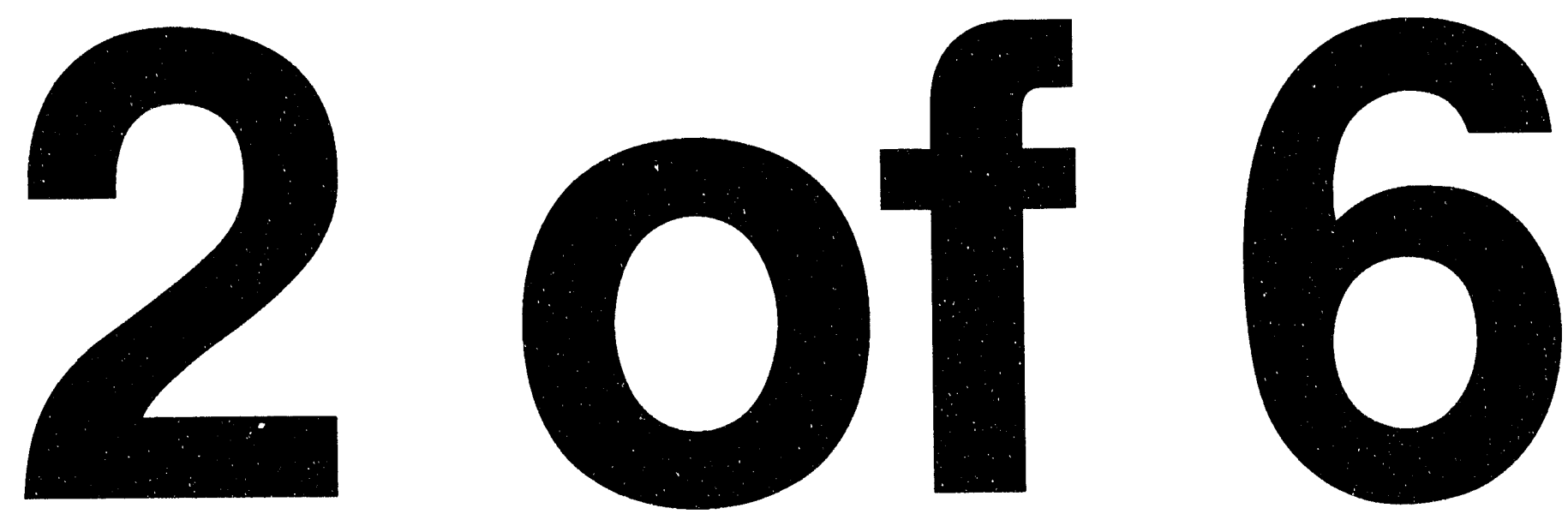
ASSUMPTIONS

(2)

- All plant equip. requires contact maintenance.

- Treated wist. must meet physical strength regime.

- There is not cost benefit to recycling materials in the

* WRAP $2 A$ wist (egg. Pb,Cu.etc.)

* w/ newly generated wat, we will know whether or not it is

- debris based, on paper work. (Action \#11)

26- Boxed wist is "special waste" by virtue of its size.

(Action 77 ) 
INFORMATION NEEDED (1)

What do yadow/non-friable items 3 3/2 dias. ? (eeg. bolts.)

Level of $\alpha$ that requires airborne contamination control (Bootle)

Can you shed intact drew then treat as debris. Do you have to cant all debris $\uparrow$

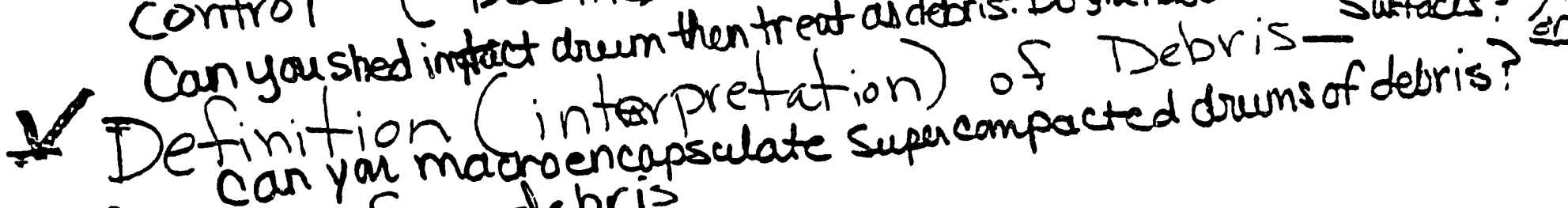

L process for debris

12

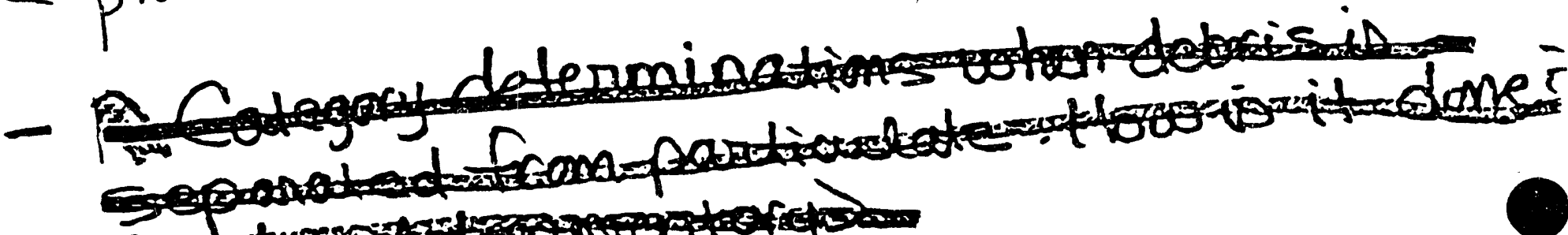

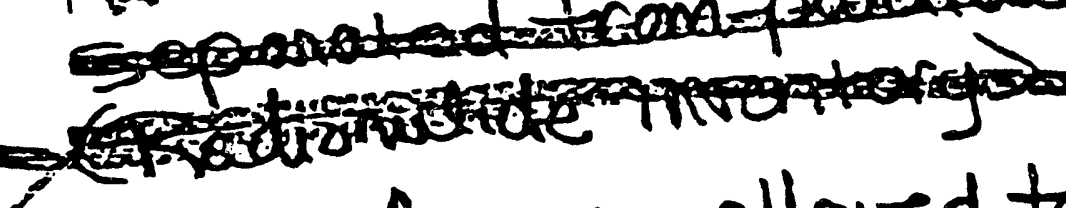

Define you allowed to mix cat. 143 wat? Define regents for radionuclide inventory, tracking $f$ control. (Include subloting approach.)

- Tom Paly - How many 183-4t basin drums have been over packed? 1600 as if and Fit: a (Need to doC the associated assumptions

$\checkmark$ Need wist. acceptance criteria for w-02s (specifically container wt ts size)

Are liners need ain prod. drums?

$=$ Other mew ns of netting plastic

- Definition of $10 \%$ void in product drums.

¿ Define work scope for the Box Breakdown Area. 
STUDIES NEEDED

Extruder us. Pugmill for FE.

MEARMATIDU NEEDED (2)

I $6430.1 \mathrm{~A}$ interpretation w/ regard to surface coatings for concrete that are amenable to future dear

1 Provide NEC Assessment to WHC - Rothin.

$\checkmark$ Scope of anticipated future expansion.

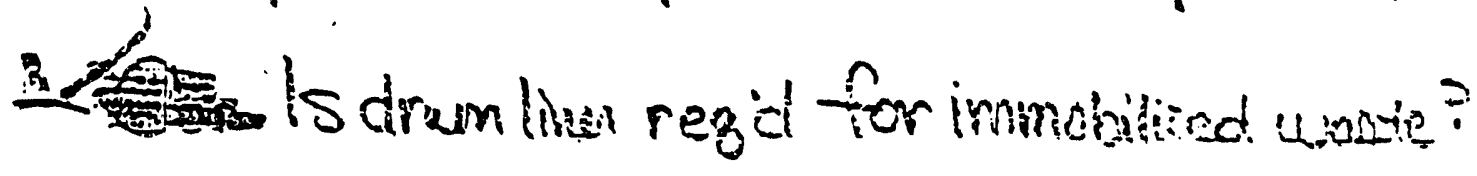

REQUIREMENTS.

$\checkmark$ Confinement is regild.

SW Ps reid in zone 2

1 Meet disposal trench acceptance criteria.

- If you-shred-debris-you first must separate out =c

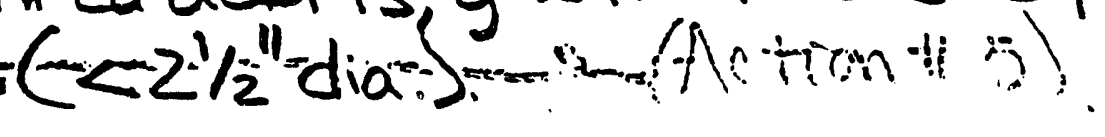




\section{ATTACHMENT 11 \\ SESSION AGENDA}




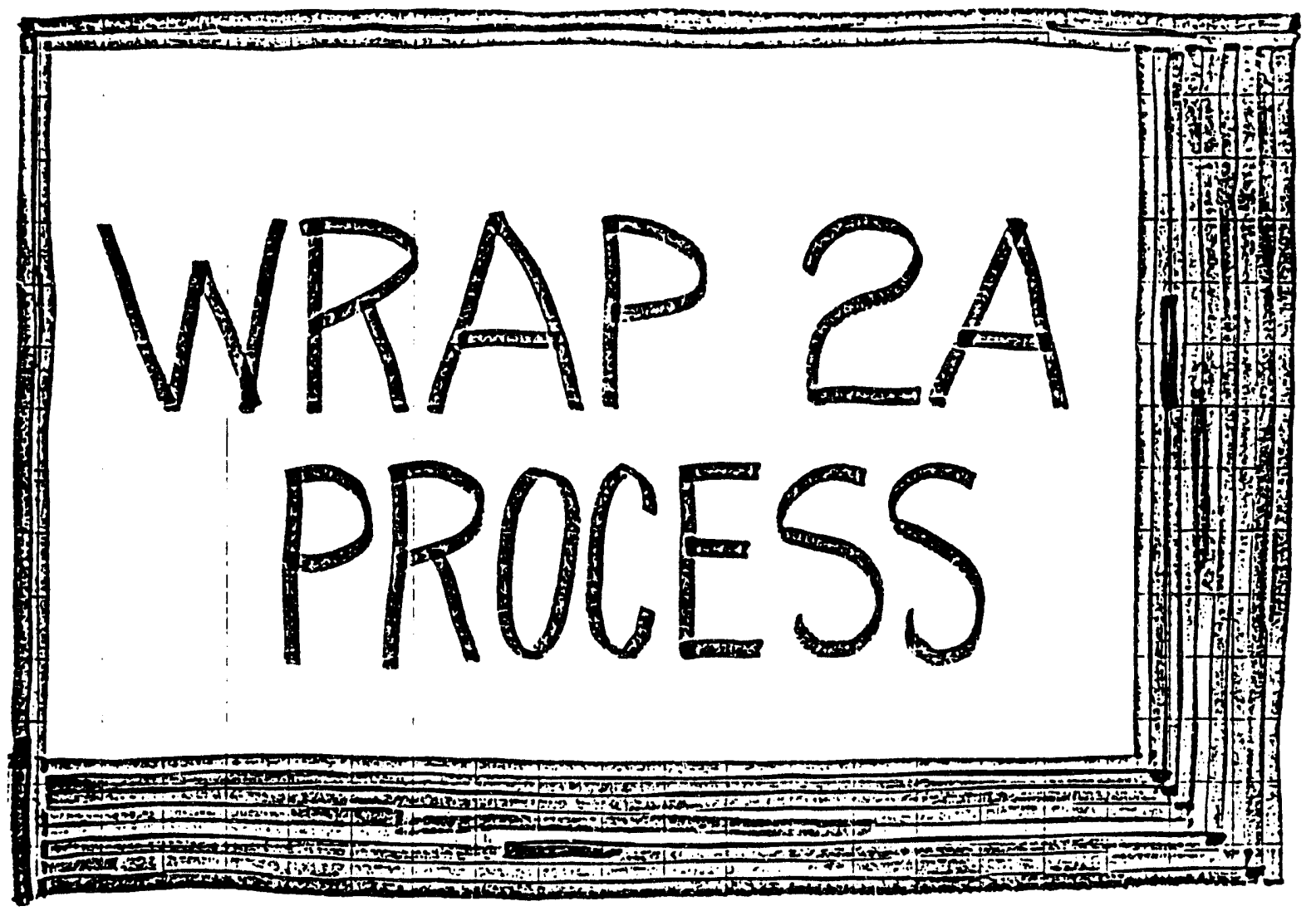

An Engineering Assessment

in a Value Engmeering Format

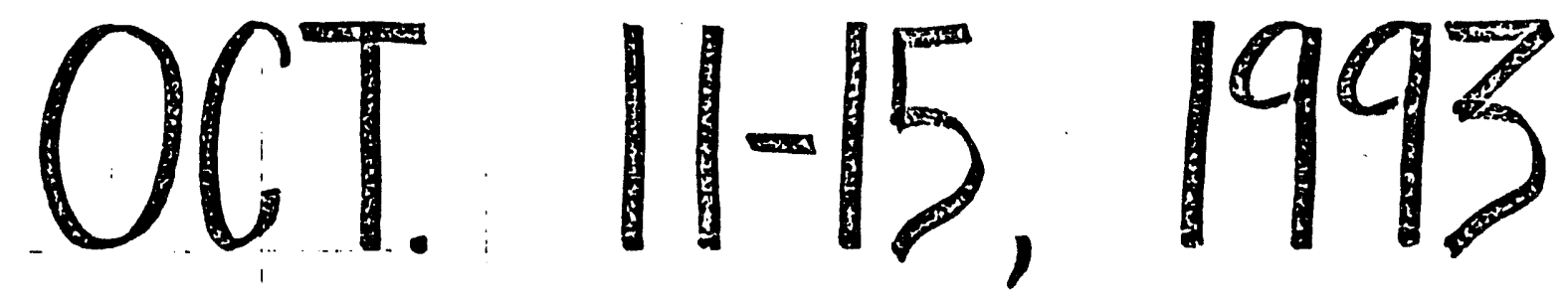


DAY 1

8:00 - WEI COME/AGENDA

- GUIDELINES/ EXPECTATIONS

- BRIEF PROCESS REVIEW

- REVIEW SCOPE STATEMENT SHEET

- BEVIEW INFORMATION PHASE./KEYwor

$8: 30$ - BEGIN KEY WORDS

$9: 30$ - BREAK

$9: 45$ - CONTINUE KEY WORDS

11:30 - BREAK/ LUNCH

12:30 - CONTINUE KEY WORDS

2:30 - BREAK

2:45 - CONTINUE KEYWORDS

$3: 30$ - REVIEW FUNCTIONS

- DEVELOP MAJOR FUNCTIONS

4:30 = FINISH DAY

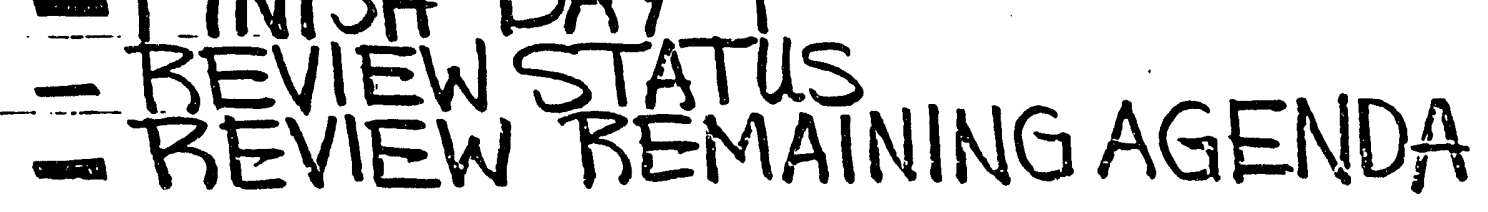


DAY 2

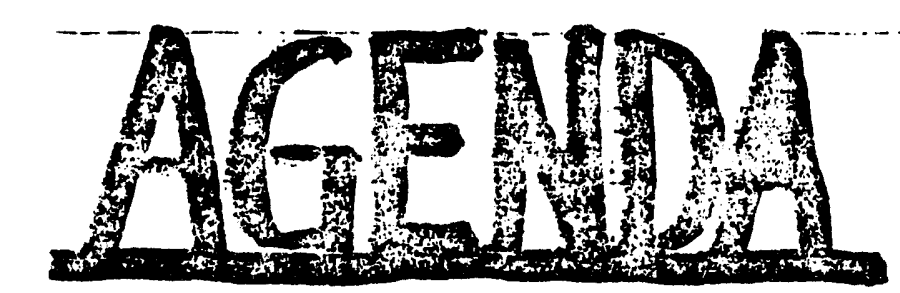

$$
\begin{aligned}
& 7: 30 \text { - REVIEW DAY 2 AGENDA /SSS } \\
& 7: 40 \text { - Continue Keywords T. DIAGRAMMING } \\
& \text { - DEVELOP F.A.S.T. } \\
& 9: 30 \text { BREAK } \\
& 9: 45=\text { CONTINUE FAST.T. DIAGRAMMING } \\
& 11: 30=1 \text { LuNCH } \\
& 12: 30 \text { - REVIEW/FINALIZE FAST. } \\
& 1: 30 \text { = SElECT FUnCTIONS TO } \\
& \text { 2:30 }=\text { BREAK } \\
& 2: 45 \text { - REVIEW BRAINSTORMING } \\
& \text { 4:30-FINISHDAY? } \\
& \text { - REVIEW STATUS } \\
& \text { - REVIEW REMAINING AGENDA }
\end{aligned}
$$




\section{AGENDA}

\section{DAY 3}

$7: 30$ - REVIEW AGENDA/SSS

$7: 40$ - CONTINUE BRAINSTOBMING $9: 00$ - REVIEW EVALLATION PHASE

$9: 30$ - BREAK

$9: 45$ - CONTINUE ROUND! EVALUATKK $11.30-14 N C H$ 12:30- CONTINUE EVALUATION-BOUND $1: 30$ - ROUND 2 EVALUATION - DEVELOP

$2: 30$ - BREAK CRITERIA

2:45 - CONTINUE EVALUATION-ROUAD 2 4:30 - FINISH DAY 3

- REVIEW STATUS - REVIEW REMAINING AGENDA 


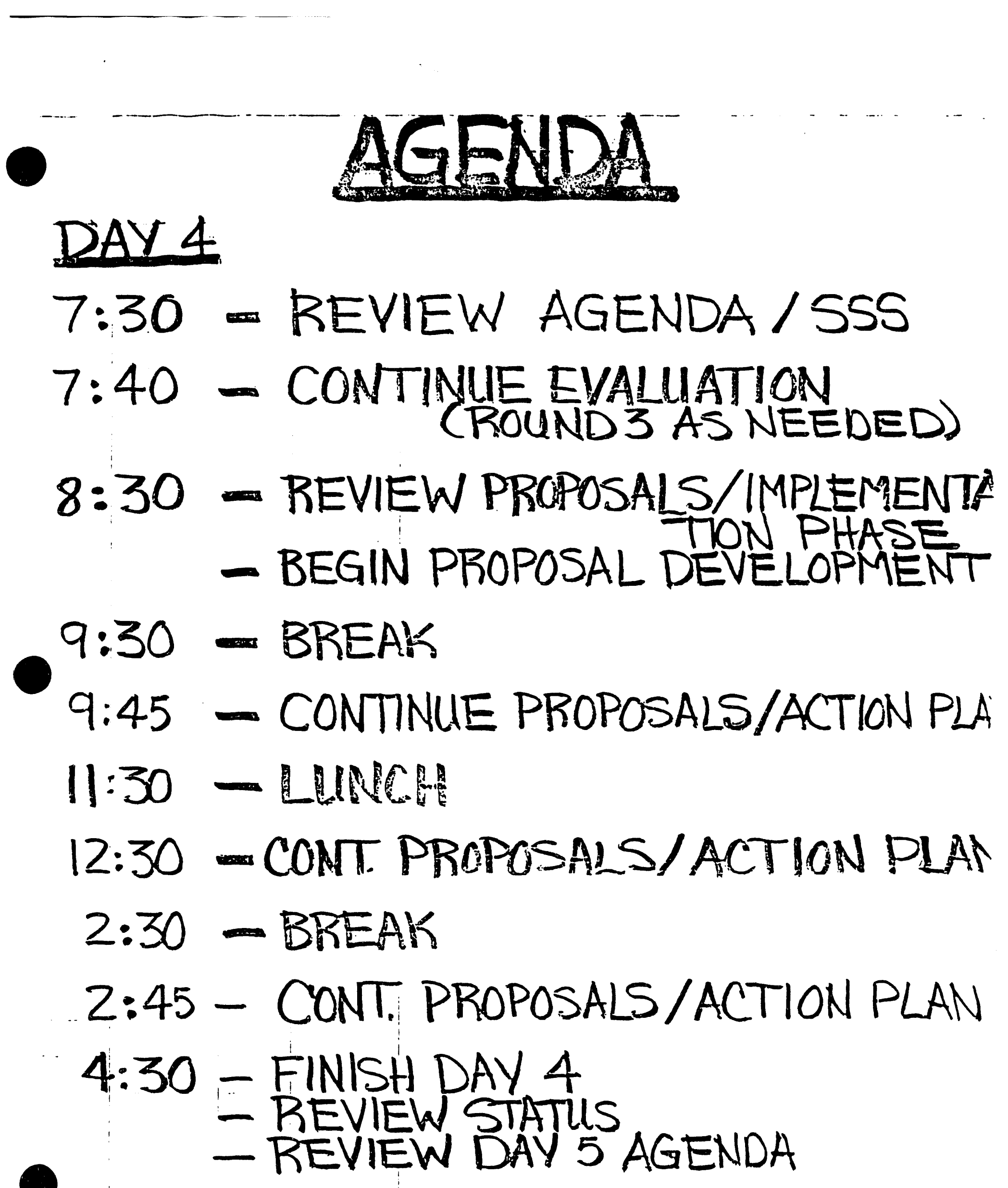




\section{Lpnts ys!u! $]=\infty$ -}

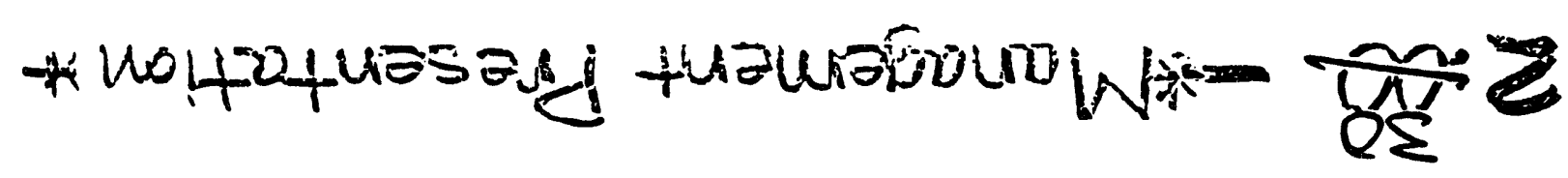

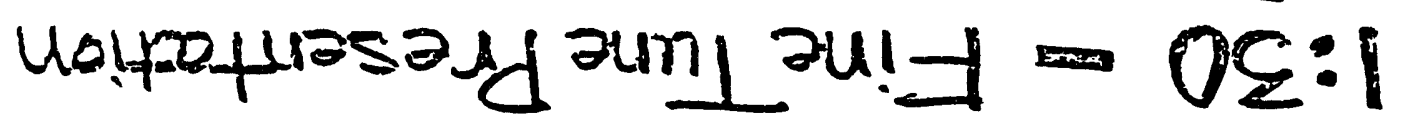

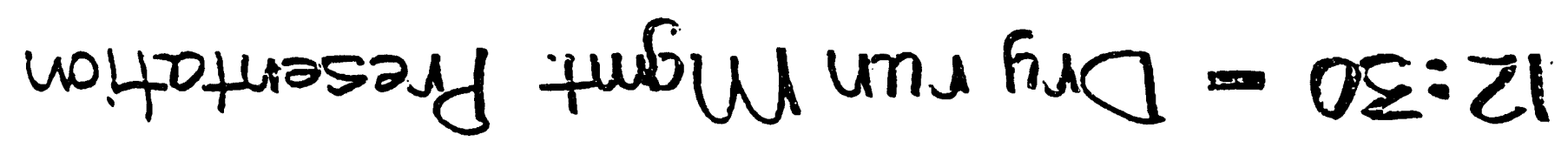
HONMT - OE:II

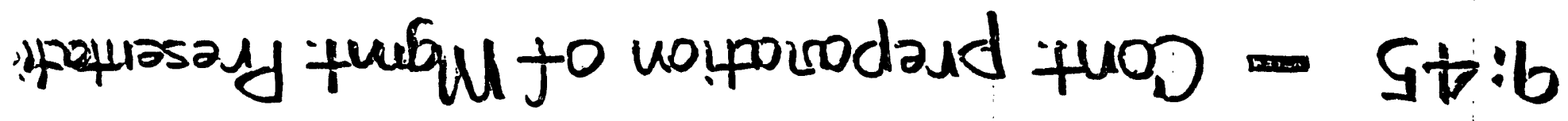
$\lambda \forall \forall 4 d=0 \varepsilon: b$

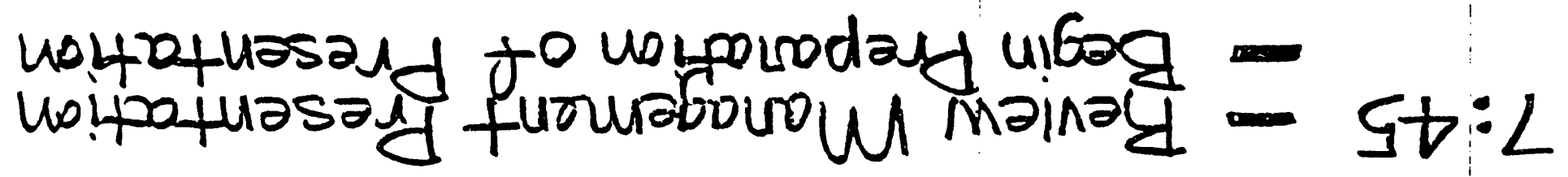

$$
\begin{aligned}
& \text { SSS/ opurb } \forall \text { glo g ma!nay - OE:L } \\
& \text { दरणव }
\end{aligned}
$$




\section{ysmbuits!c}

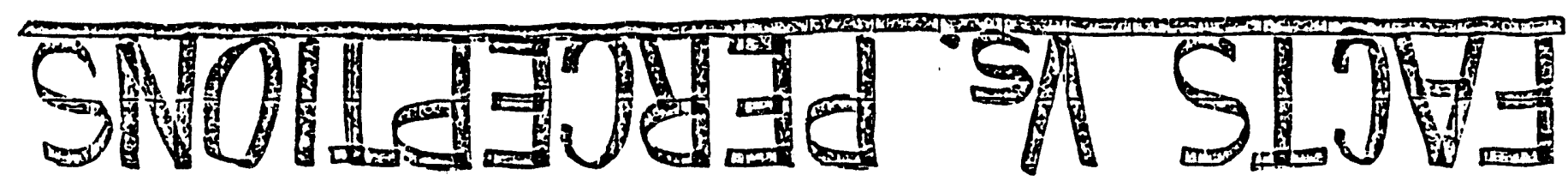

$$
\begin{aligned}
& \text { noupofialumso } 0 \\
& \text { Uo!ssas Gupnin ajuanajay }
\end{aligned}
$$

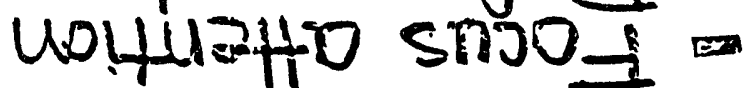

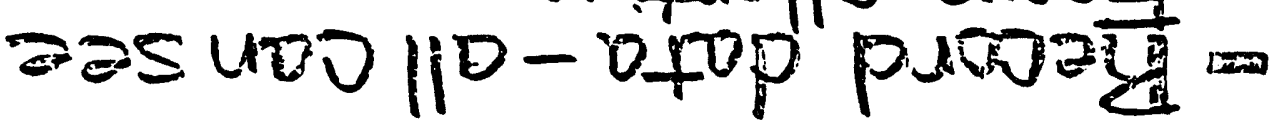

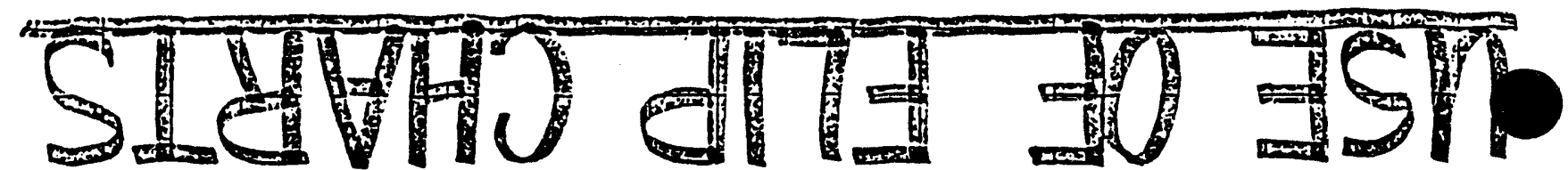

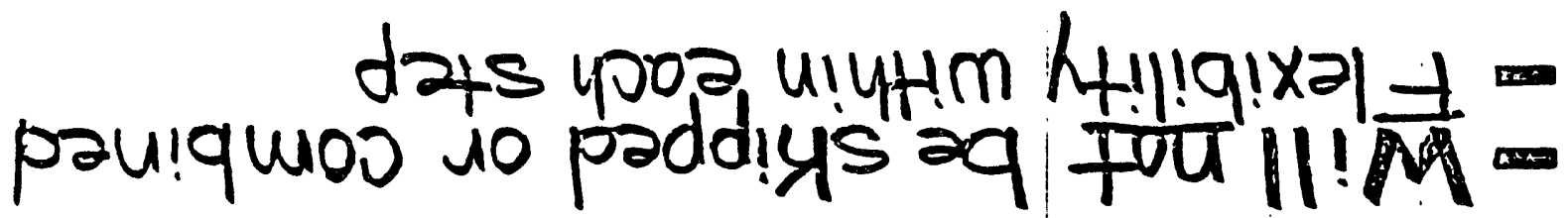

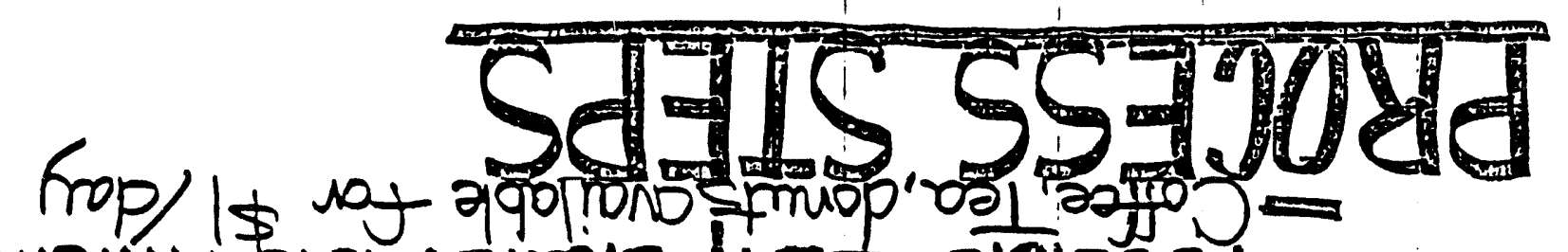

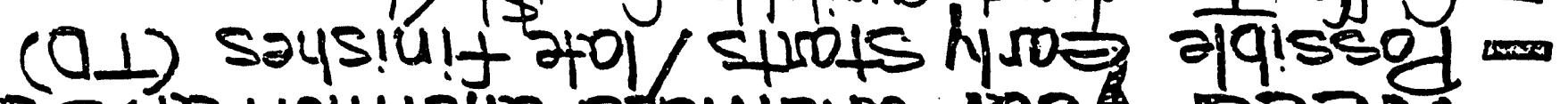

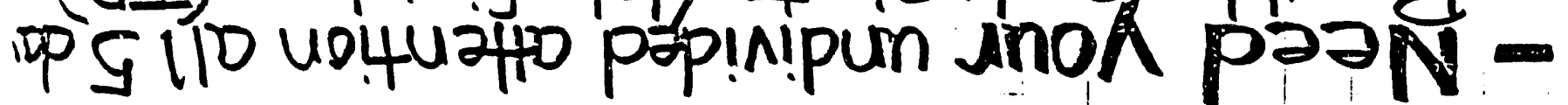
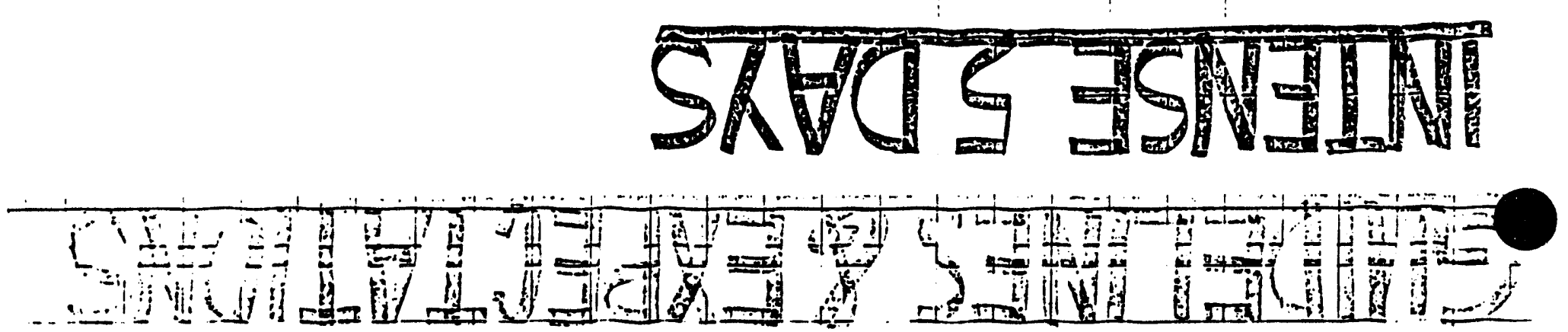

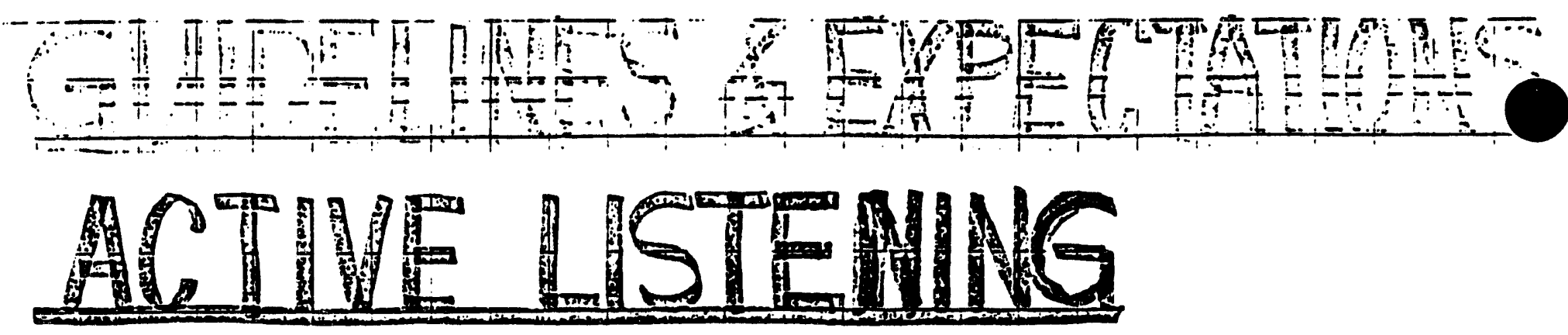

- LetPerson finish before questioning

- Question for clarity not objection (doit have to necessarily agree)
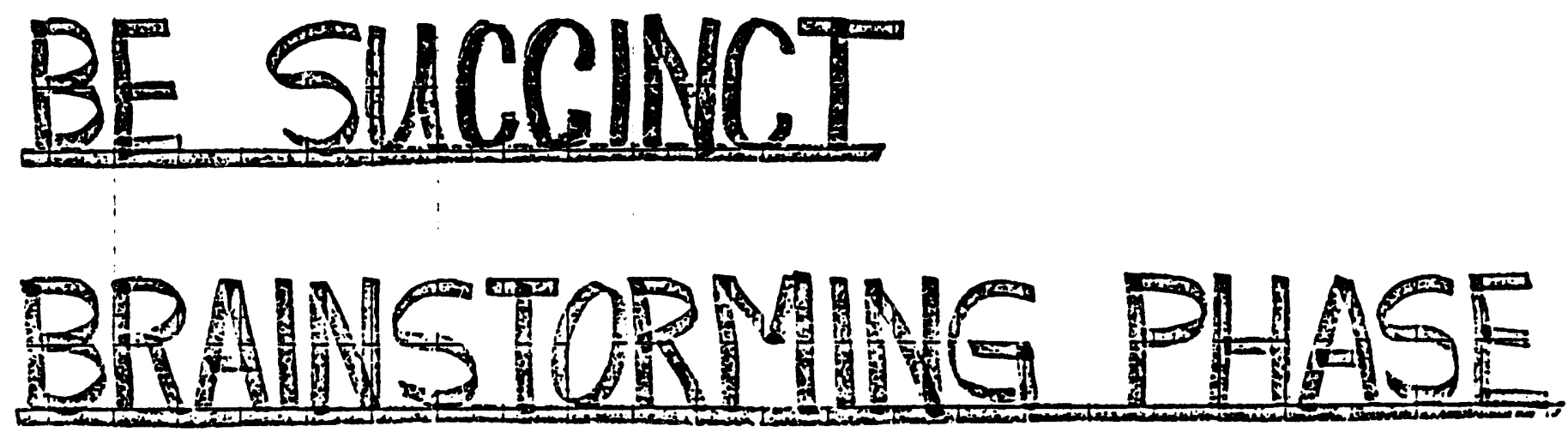

$$
\begin{aligned}
& \approx \text { No Questions } \\
& \text { * No Evaluations }
\end{aligned}
$$

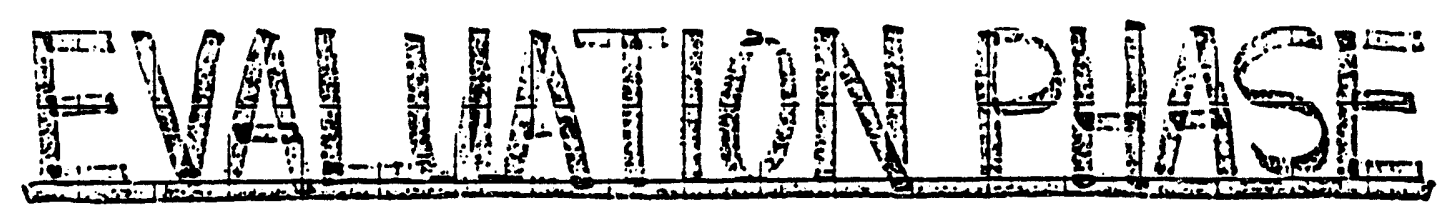

- Evaluate ideas not people

$\rightarrow$ OH on filters 


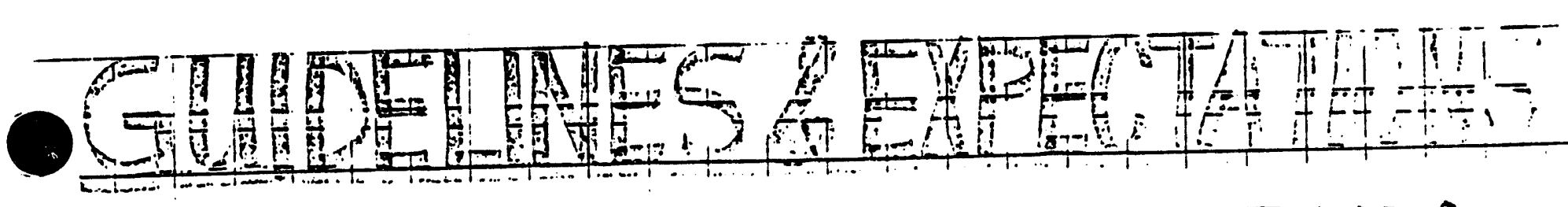

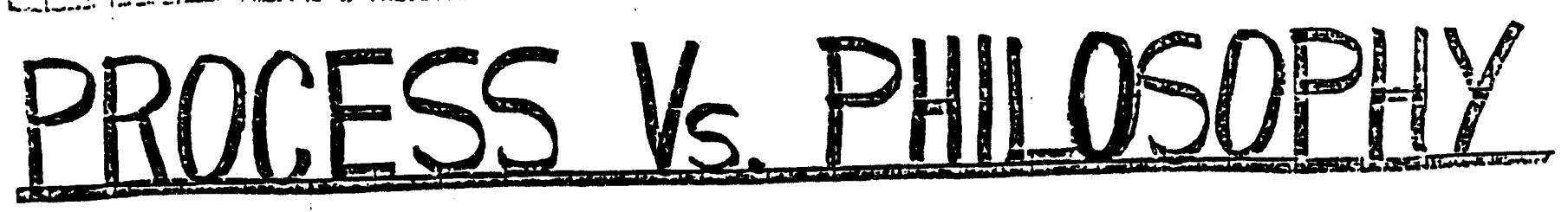

- Doing nOT training

- Facilitator guides the process
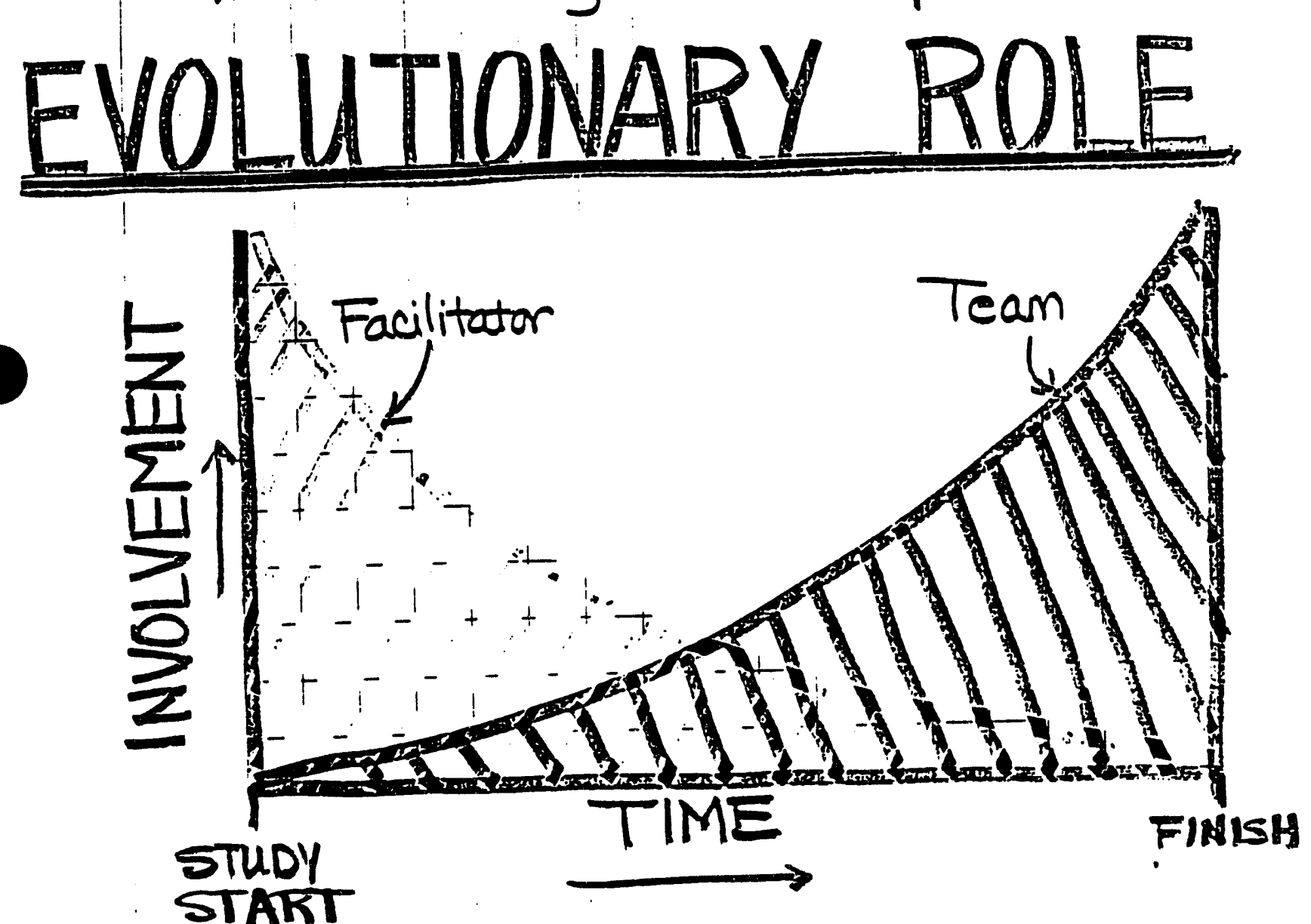

MANAGEMENT PRESEMTIION

$$
\begin{aligned}
& \text { - FriDAY, } 10 / 15 / 93 \\
& \text { - } 2: 30 \mathrm{PM} \\
& \text { - Vitro, Rm 206 }
\end{aligned}
$$


(1)
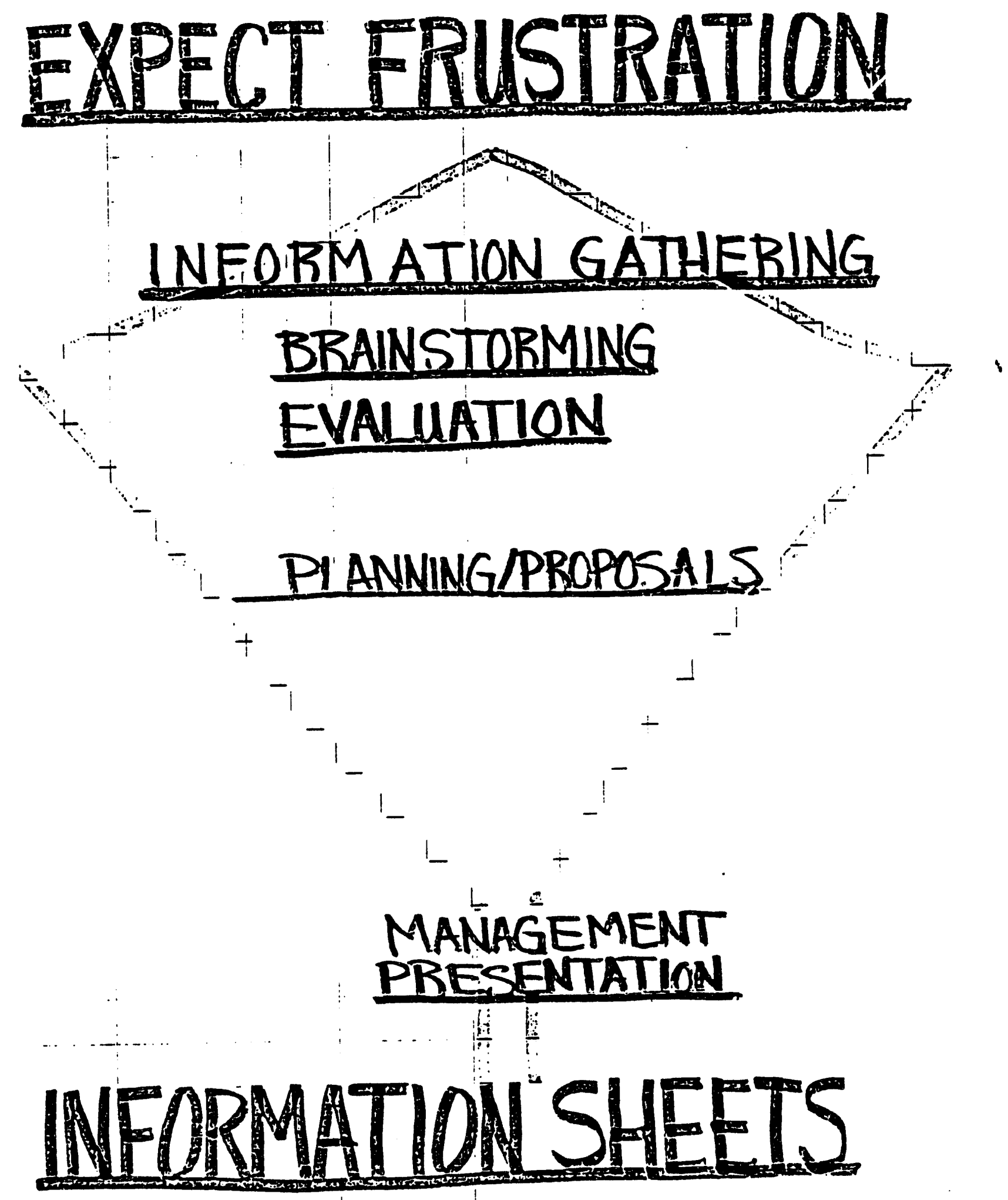

- MEMORIES -REQUIREMENTS -AssUMPTIONS I INFORMATION NEEDED :SHOT GUN "STUDIES NEEDED 


\section{SECTION 2.0 RESOLUTION OF VALUE ENGINEERING ASSESSMENT ACTIONS (WHITE PAPER)}




\section{SECTION 2.1 \\ FINAL PRODUCT CONTAINER WHITE PAPER}


EINAL PRODUCT CONTAINER

White Paper

\subsection{BACKGROUND}

1.1 The 55 gallon drum has been the essential standard container for radioactive waste disposal since the inception of the nuclear industry. The use of square drum though, permits storage efficiencies well beyond those of the conventional drum. The fundamental relationship between packaging geometry and storage efficiency places the advantage clearly with the square container.

1.2 Conventional storage of 55 gallon drums in a 6 pack array, although convenient, is inefficient in its use of available space. A 16-Pack' of 55 gallon drums occupies $100 \%$ of

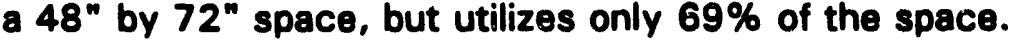

1.3 A square container of the same cross section (width and length that of the diameter) and height dimensions as the conventional $\mathbf{5 5}$ gallon drum fits in the same space as the round drum. Since the corners have been 'filed in', 9-1/2 $\mathrm{ft}^{3}$ of material can be stored in the same space occupied by the $7-12 / \mathrm{ft}^{3}$ of material in the 55 gallon drum. The square container provides, therefore, the optimum utilization of available space, occupying $100 \%$ of the space and utilizing $90 \%$ of the space.

1.4 The space utilization of conventional 55 gallon drums and square containers having the same cross section is shown in Figure A of Attachment 1.

\subsection{ACDR REQUIREMENTS}

2.1 The ACDR product container requirements were initially approximately defined as follows:

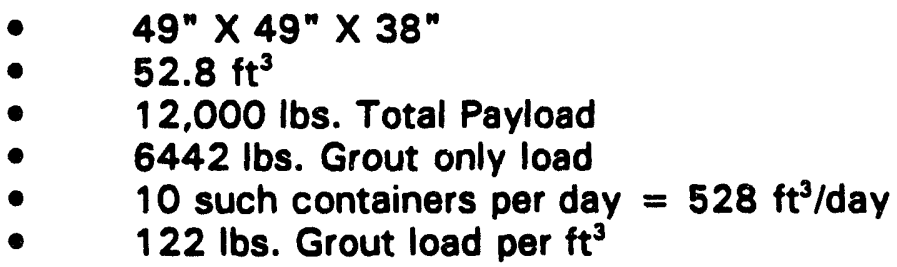

2.2 In the course of evaluation of the WRAP 2A grouting container needs, one requirement became a confining constraint. Filling the container will liquid grout weighing 122 pounds per cubic foot produces a hydraulic load on the container side walls (hoop stress). This load must be resisted so the container will keep it's shape. If the container is allowed to deform, the container lid will not be able to be removed and replace reliably.

2.3 To illustrate the impact of these requirements, the strongest container that was evaluated, the B-52 Strong Tight from Container Products has a standard only a $4000 \mathrm{lb}$. maximum payload limit, this container is illustrated in Figure B, Attachment 1. To meet our requirement of a $12,000 \mathrm{lb}$. payload and to withstand the hoop stresses of the grout before setup, Container Products will modify the container with heavier structural sections in the wall and floor and will use 10ga. material instead of $12 \mathrm{ga}$. 


\subsection{ASSESSMENT}

3.1 To fully evaluate the feasibility of using a square container to replace the standard drum container, first a supply of a container which meets the requirements must be identified. Secondly, cost effectiveness must be demonstrated. And lastly, a concept for container relidding/delidding must be demonstrated. See Attachment 2 for a comparison of options.

3.2 Three options for square containers were identified. First was a direct replacement for the 55 gallon drum, a 71 gallon with the same dimensions as a 55 gallon drum, 21.5" $\times 21.5^{\prime \prime}$ square and 33" tall, manufactured by Packaging Specialties, Inc.. The container can meet the payload requirements "off the shelf" with 4 different head options. Cost in mild steel, painted, and with lid, $\$ 58$ per container.

3.3 The second container found is a model B-52 Strong Tight, manufactured by Container Products Corporation. This container is $49^{\prime \prime}$ square by $38^{\prime \prime}$ tall. The standard containers can not meet the payload requirements, having a maximum load rate of 4000 pounds, but CPC will modify the design with increase wall thickness and added structure to support the 6442 pound hydraulic load from the concrete and 12,000 pound total payload. Cost in mild steel, painted, and with lid, $\$ 600$ per container.

3.4 The third option was suggested through conversations with Starpak, Inc. The suggestion is to design and fabricate a $48^{\prime \prime} \times 48^{\prime \prime} \times 48^{\prime \prime}$ container from light weight 16ga. materials to provide a containment only. Structural strength until the grout has set would be provided by a design and fabricated casting container which fits around the light weight container. The light weight containers are inserted into the casting container and the group introduced into the process. The grout is poured into the light weight container and allowed to cure. The casing and the light weight container are then removed from the casting container with the light weight container providing the casting's containment. Enough casting containers would be built to support the throughput of the plant and would be reused as the casting is removed with the light weight container. Cost in mild steel, painted, and with lid, $\$ 300$ per light weight container and $\$ 1200$ for each casting container.

3.5 Three other manufacturers of corrugated steel containers were contacted, Steelcrate, MINCO, and Streator Dependable. All three currently manufacture containers in the size range, but none have an "off the shelf" container to meet the payload requirements. All did, however, have containers "off the shelf" to meet the light weight container requirements of above. Steelcrate, for example, has a container that is $48^{\prime \prime} \times 48^{\prime \prime} \times 24^{\text {" }}$ deep, $32 \mathrm{ft}^{3}$, made from 12ga. mild steel, their model 90050. Cost painted with no lid, $\$ 176$. Cost with a lid to our specification would be "considerable more" on the order of twice as much.

3.6 In discussions with Greg Kasler at Container Products Corporation, the subject of lidding of the B-52 container was brought up. He suggested a modification to the lid design to accommodate the current WRAP 1 Lidder concept: manufacturing both the container and lid with a simple straight edge lip, a crimped clip can be spotted in 12 places around the perimeter to close the container. The basic design of the Lidder/Delidder can be kept with only modification to the transversing mechanism to move the equipment around the container. 


\subsection{CONCLUSIONS}

4.1 Changing from a $\mathbf{5 5}$ gallon drum to a square container generates a $21 \%$ saving in storage area.

4.2 The most cost effective method of implementation is to provide permanent casting containers on the plant's conveyor system. These structure steel boxes would provide a rigid casting housing for the grouted waste. Light weight disposal containers would be purchased as plant supply to act as a mold lining and final containment for the set up grouted waste. The final produce would then be removed from the mold by forklift and moved out of the process. 


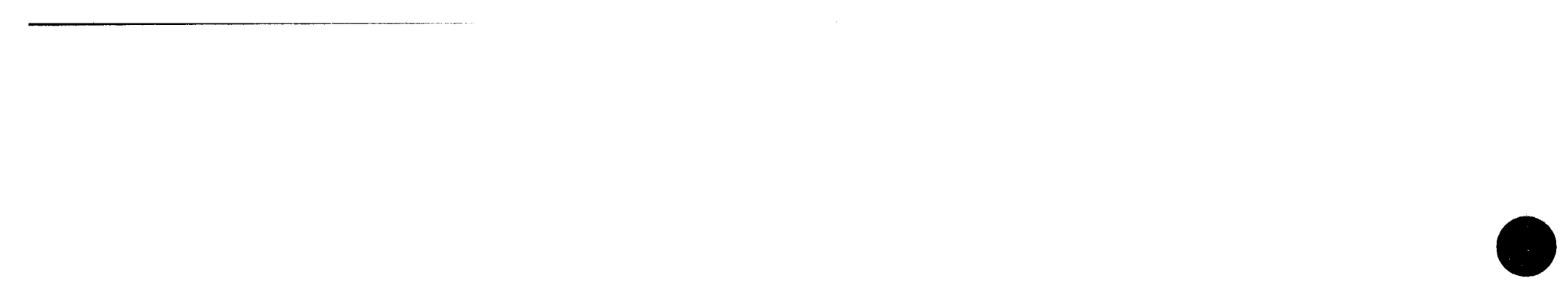

-

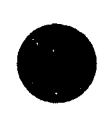

• 


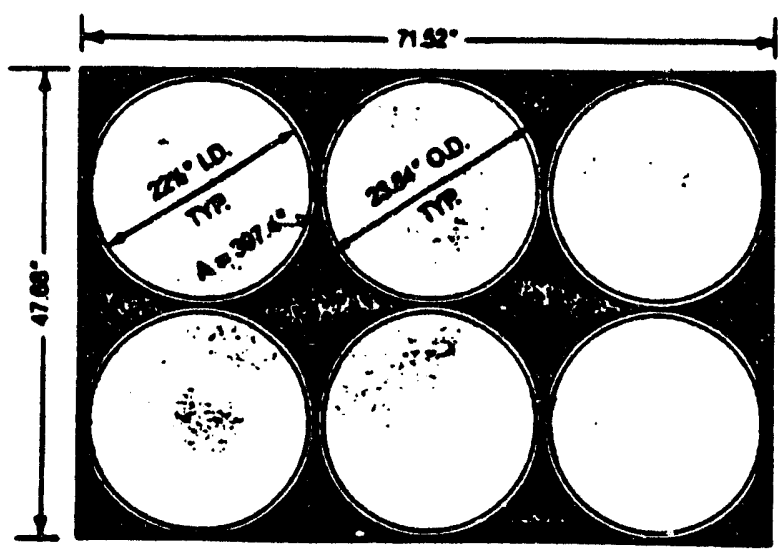

$E=69 \%$

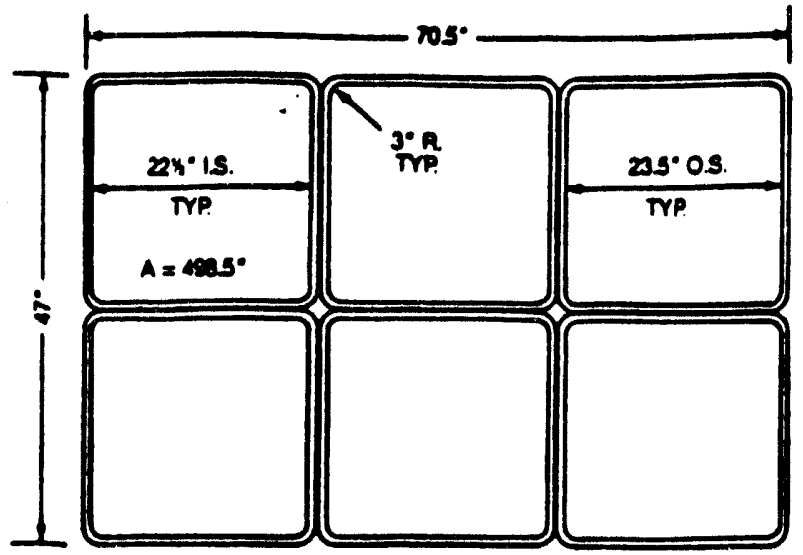

$E=90 \%$

Eigure A - 55 Gal Drum And Samer Conmander. Packine EfFicieney

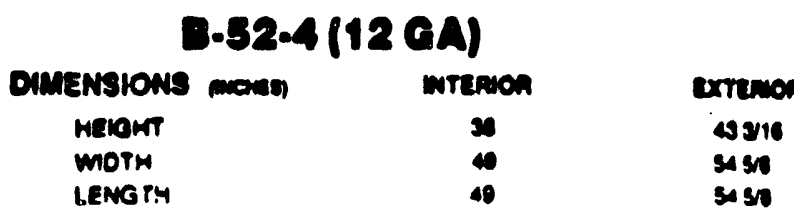

\section{Descaption}

Clasegtication Iropa Contanner

Pectuege Trpe - Coniainat

Cepectity $25 \mathrm{eu} . \mathrm{h}$

Materwi 12 as astmasos

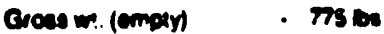

Partoed $\quad 4,000100$

Max loesed on $\quad .4775$ mo

Shnelding adional

\section{AOOITIONAL INFORMATION}

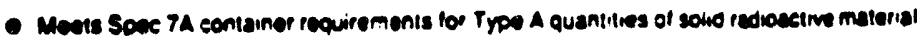

- Exctusive "eas loc" positive closure srstem to orec'ude inacreitent coening

- Find grotuctivo inisn to ment customer requirements

- Aro usod as 4 drum overpeck.

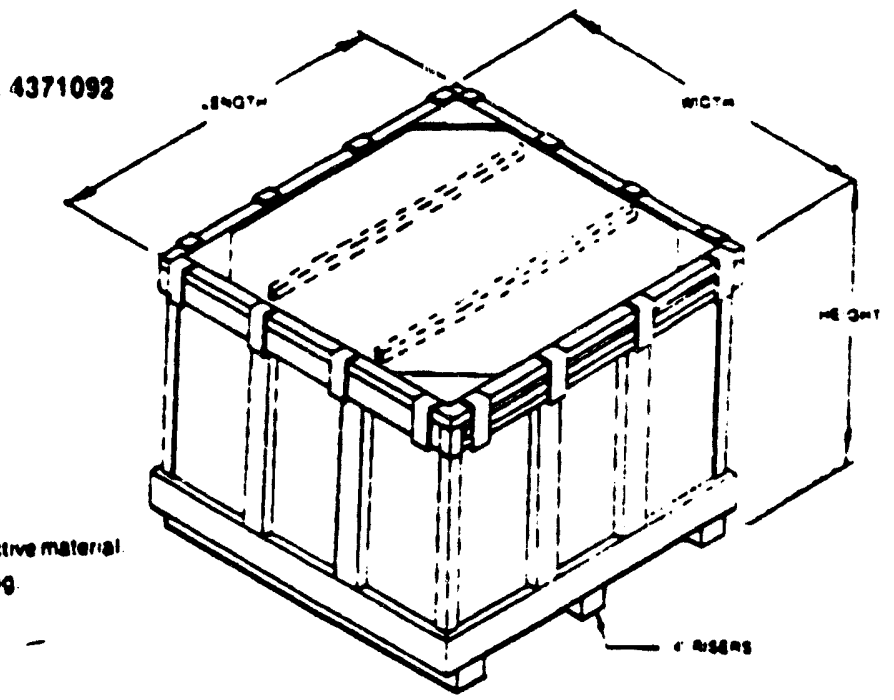

B.52.4 (12 OA)

CONTAINER PAODUCTS CORPOAATION O DOZ 3767 • Wilming1On, NC 20406919.292 .6100

Figure B - B52 Container 


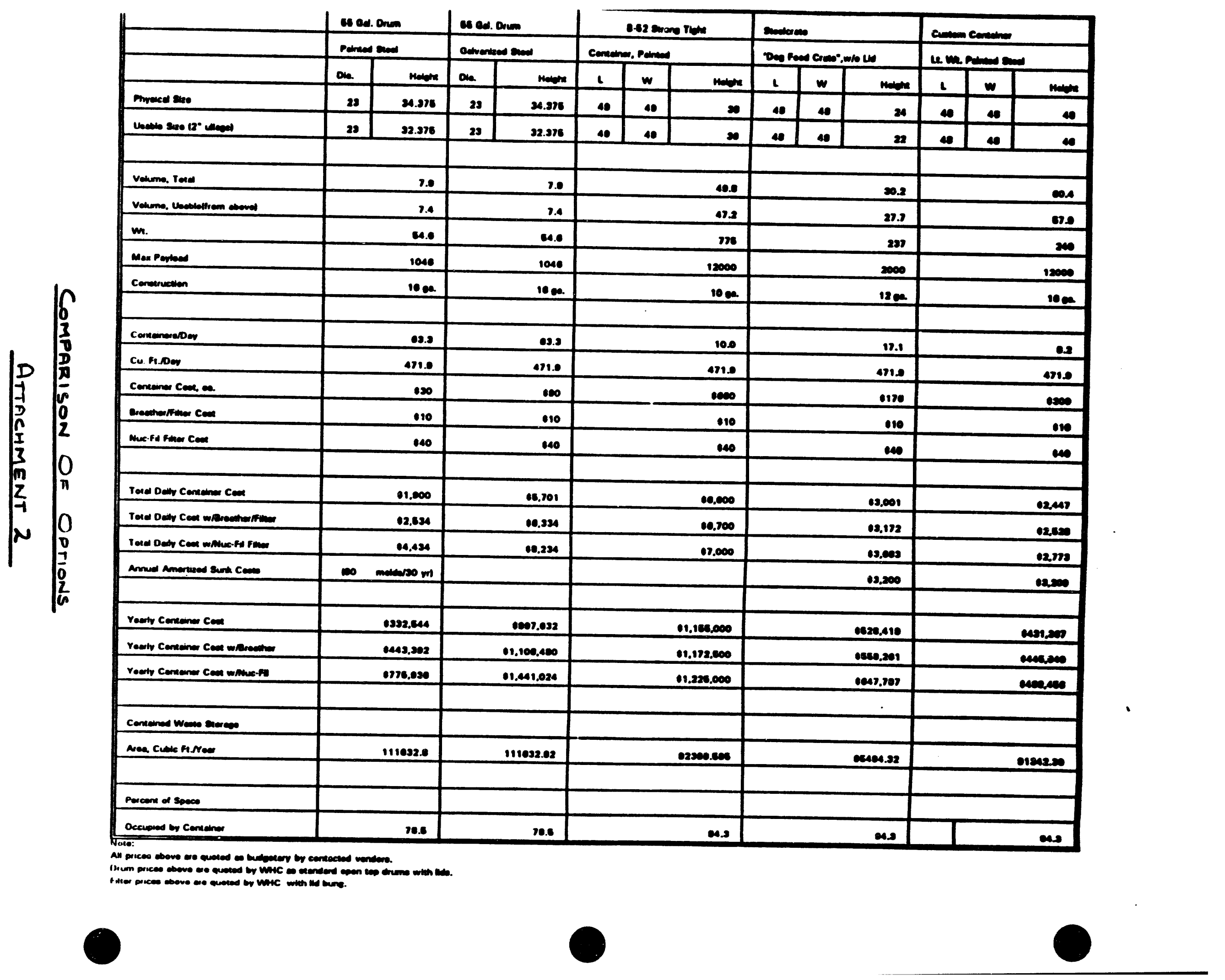




\section{SECTION 2.2 BOX BREAKDOWN SCOPE DEFINITION WHITE PAPER}




\section{BOX BREAKDOWN SCOPE DEFINITION \\ White Papor}

\subsection{Background}

1.1 The CDR design basis for the box breakdown cell was to process 12 boxes per year and to destructively examine $1 \%$ of the WRAP 2A product. As a result of the flexibility and low throughput of the box breakdown enclosure, it was assumed a number of other non routine operations could be carried out in box breakdown i.e. maintenance activities, 110 gallon drums, drums outside the scope of the main process etc. These additional tasks were only partially identified and never quantified. The WRAP 2A Value Engineering Study concentrated on evaluating the main process, considering the box breakdown process as lower risk and lower throughput, in relative terms. The Value Engineering Study did however recognize the requirement to define the scope of the box breakdown enclosure.

\subsection{Discussion}

2.1 WHC have defined the average annual throughput requirements for the box breakdown area as follows:

40 boxes/year $\left(5^{\prime} \mathrm{H} \times 5^{\prime} \mathrm{W} \times 9^{\prime} \mathrm{L}, 12,000 \mathrm{lb}\right)$

100 overpacked drums/year $(85$ gallon overpacks)

10 overweight drums/year (55 gallon drums)

$1 \%$ of WRAP $2 A$ product for destructive examination

$1 \%$ of WRAP $2 A$ product as failed product for reprocessing

The term "boxes" includes 110 gallon drums

2.2 The intent of the box breakdown area is to allow the main process area to handle only $\mathbf{5 5}$ gallon drums less than $1000 \mathrm{lb}$ in weight, in order to simplify the design of drum handling and opening equipment. The box breakdown enclosure will have the capability of processing and repacking the above feeds into either 55 gallon drums for further treatment in the main process, or product containers for vibro encapsulation.

2.3 The box breakdown manipulator is heavy duty piece of equipment intended size reduction operations, and will not have the dexterity to perform maintenance activities. Maintenance operations will, hence, not be carried out in the box breakdown area.

2.4 Core sampling of product containers will not be carried out in box breakdown because in order to core sample the product container would have to enter the box breakdown enclosure, thus contaminating the outside of the container. The container would then require decontamination before it left the box breakdovin enclosure. 


\section{SECTION 2.3 EXTRUDER ALTERNATIVES}




\section{EXTRUDER ALTERNATIVES \\ White Paper}

\subsection{Summary}

1.1 A review of plausible alternatives to the twin screw extruder concluded that none offer any clear benefits or advantages over it. This review was precipitated during the Value Engineering sessions by a suggestion that an alternative to a twin screw extruder might be found that was less costly (capital), and more tolerant of larger or more abrasive waste particles. It now appears that the alternatives (i.e.. using separate equipment for the melting and mixing functions, or replacing the extruder with another piece of equipment) do not offer any significant cost advantages, and are no more tolerant to larger or more abrasive waste items. In addition, the twin screw extruder is a more mature technology. is more widely used, and more readily available than the alternatives.

1.2 Reduced service life expectancy of a twin screw extruder due to the potentially abrasive nature of some of the wastes processed in WRAP 2A, although a valid concern, is more than outweighed by the advantages of the twin screw extruder compared to the alternatives. If early wear-out of an extruder is a governing concern, most of the potentially abrasive waste streams handled in WRAP 2A could be processed using Grout instead of polyethylene (PE) without significant cost penalties; indeed, the only two feeds (Feedstreams $2 A$ and $2 B$ ) for which PE encapsulation is the preferred treatment are not highly abrasive.

\subsection{Separate Melting and Mixing Operations}

\subsection{Uncertainty}

Is it better to melt PE in one operation, and then mix with waste in second operation, or to melt \& mix in a single operation?

\subsection{Conclusion}

Either alternative could probably be configured to accomplish the identified objectives. However, the alternative of separate melting and mixing does not offer any significant advantages compared to the combined melt/mix alternative, while the melt/mix alternative appears to offer several significant advantages over separate melting and mixing. The advantages/disadvantages of these alternatives are presented in Table 1.

\subsection{Replace Extruder with Another Type of Equipment}

\subsection{Uncertainty}

Is an extruder or a kneader (or some other piece of equipment) best for the application of melting PE and mixing with waste in single operation? 


\subsection{Conclusion}

Either a kneader or an extruder could probably be configured to accomplish the identified objectives. However, kneaders do not offer any significant advantages compared to extruders for this particular application, while extruders (particularly twin screw vented extruders) appear to offer several significant advantages over kneaders and other currently identified melt/mix equipment. The advantages/disadvantages of these alternatives are presented in Table 2. 


\begin{tabular}{|c|c|c|}
\hline & SEPARATE MELT \& MIX & COMBWED MELT \& MIX \\
\hline Cost & \multicolumn{2}{|c|}{ Neither alternative appears to have a significant cost edvantage over the other. } \\
\hline Molting & 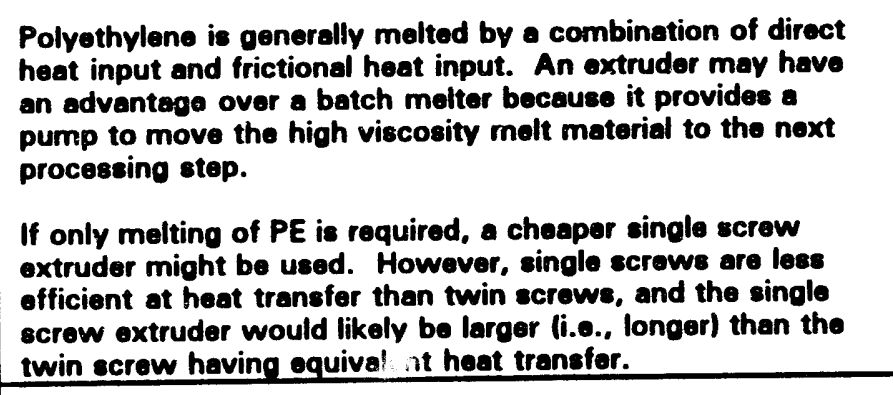 & $\begin{array}{l}\text { Twin scrow extruders are very suiteble equipment for } \\
\text { melting polyothylone since thoy provide oxcellent frictional } \\
\text { heat input os woll as direct heat input through heated } \\
\text { jeckets around the barrel. }\end{array}$ \\
\hline Mixing & $\begin{array}{l}\text { Most polyethylone has a relatively high viecosity in the } \\
\text { molten state. A higher viscosity will increase shear, with } \\
\text { high shear being necessary for good mixing. It is not cleat } \\
\text { that a separate mixer can provide the high shear mixing of a } \\
\text { high viscosity meterial without hoving close tolorances } \\
\text { betwoen mixer bledes. As the mixer blades become closer, } \\
\text { the mixer device begins to rosemble on oxtruder, which } \\
\text { appears to oliminate the advantege of having a separate } \\
\text { device for mixing. }\end{array}$ & $\begin{array}{l}\text { A twin scrow extruder is expectod to provide good mixing } \\
\text { because it provides good shear and olongation, both of } \\
\text { which are noceseary to disperse poler selte into non-polar } \\
\text { PE'. }\end{array}$ \\
\hline Maturity of Technology & $\begin{array}{l}\text { The tochnology of using an extruder for molting PE is well } \\
\text { developed and understood. } \\
\text { Mixing tochnology/procese equipment is well ostablishod in } \\
\text { generol, however, the mixing of solid waste with molten PE } \\
\text { is not a typical application for procese mixing oquipment and } \\
\text { therefore cannot be correlated directly to oxisting processes. } \\
\text { There is little experience with oquipment other than } \\
\text { extruders for mixing particulate waste into molten PE or } \\
\text { similar thermoplastics. }\end{array}$ & 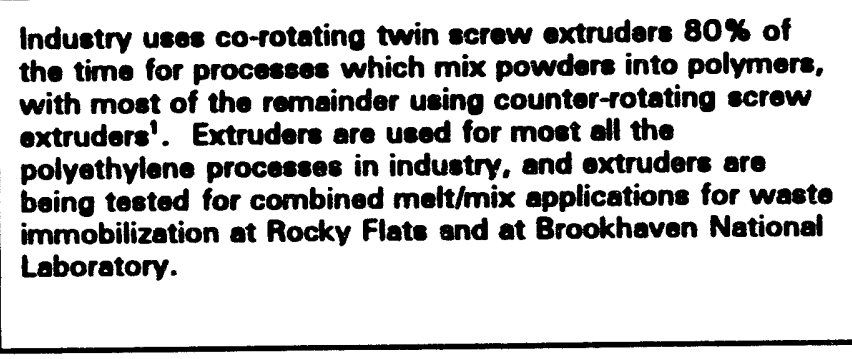 \\
\hline Feed Perticle Size & $\begin{array}{l}\text { If it is necessery to have close tolerances between b| } \\
\text { requirements for the separate mixer will be the seme } \\
\text { the } 3 \mathrm{~mm} \text { maximum tolerated by extruders would lik }\end{array}$ & $\begin{array}{l}\text { des to achieve the desired mixing, the particle size } \\
\text { for the combined melter/mixer. Also, perticles lerger then } \\
\text { threaten failure of TCLP teete. }\end{array}$ \\
\hline \multirow[t]{2}{*}{ Expected service Life } & $\begin{array}{l}\text { The separate msalter would be expected to have a longer } \\
\text { service life than the mixer or the combined mixer/melter. }\end{array}$ & \\
\hline & \multicolumn{2}{|c|}{$\begin{array}{l}\text { If it necessary to have close tolerances between blades to achiove the desired mixing, there is no reason to } \\
\text { oxpect that the service life of a separate mixer would exceed that of a combined melter/mixer. }\end{array}$} \\
\hline
\end{tabular}




\begin{tabular}{|c|c|c|}
\hline & ExTRUDERs & KREADERs \\
\hline Cost & $\begin{array}{l}\text { Twin scrow extrudere average about } 2-3 \times \text { the cost of single } \\
\text { ecrow extruders for seme throughput capebilitios'. }\end{array}$ & $\begin{array}{l}\text { The cepital coet for a kneader is not expected to be } \\
\text { significently difforent then for a twin screw extruder with } \\
\text { the same throughput cepability. }\end{array}$ \\
\hline $\begin{array}{l}\text { Availability of Units } \\
\text { and Replacement } \\
\text { Parts }\end{array}$ & $\begin{array}{l}\text { There are several US manufacturere and evailability of units } \\
\text { or replacement parts does not appear to be difficult. For a } \\
\text { twin-screw extruder, the screwe are mede up in sections. } \\
\text { This means that customized screwe can be made by } \\
\text { assembling different combinations of standard parte, as } \\
\text { opposed to single screw extruders where the spare part for a } \\
\text { screw coneiste of a single-piece unit which might be a } \\
\text { custom-design instead of a stendard scrow. }\end{array}$ & $\begin{array}{l}\text { Only one menufacturer has yot been identified and they } \\
\text { are located in Europe. }\end{array}$ \\
\hline Mixing & $\begin{array}{l}\text { Twin screw oxtruders offer more shear mixing through } \\
\text { movement of the scrows and elongationd mixing by forcing } \\
\text { the molt through gaps between the scrowe. Single scrow } \\
\text { extruders provide little shear mixing end virtually no } \\
\text { elongational mixing'. }\end{array}$ & $\begin{array}{l}\text { Since the kneeder is basicelly a veriation of a single } \\
\text { screw extruder }{ }^{2} \text {, it would be expected to offer the same } \\
\text { mixing charactoristics as a single screw extrudor. }\end{array}$ \\
\hline Waste Feeding & $\begin{array}{l}\text { The modular desion of a twin-ecrew extruder allows the foed } \\
\text { port to be located in several (including multipla) locetions and } \\
\text { configured in several woye c.0. downstream of the PE melt } \\
\text { zone using a side feed port'. }\end{array}$ & $\begin{array}{l}\text { Single ecrow extruders and kneadere ere not as flexible in } \\
\text { regards to locetion of multiplo feed porte. }\end{array}$ \\
\hline Self-Cleaning & $\begin{array}{l}\text { With a twin screw extruder, the leading odoe of one screw's } \\
\text { flighte fully wipe the trailing edoe of the other screw's } \\
\text { flights. Each screw then fully wipes the other scrow. The } \\
\text { celf-cleaning action provents buildup of the polymer on the } \\
\text { screws and prevente retention of the product in the extruder. } \\
\text { Since two screws are required for self-wiping to be possible, } \\
\text { this feature is available only on twin scrow fully intermeshing } \\
\text { extruders'. }\end{array}$ & $\begin{array}{l}\text { It is likely that more PE will be required to "flush" a } \\
\text { knoader than a comparable twin screw oxtruder. }\end{array}$ \\
\hline Venting & $\begin{array}{l}\text { Devolatization and degassing are importent both to remove } \\
\text { any moisture still in the waste, and also to allow removal of } \\
\text { air trapped in the waste which can inhibit mixing and reduce } \\
\text { woste performance. Devolatization and degeseing are more } \\
\text { officient in twin extruders than single screw oxtrudere } \\
\text { beceuse of better mixing and heat trensfer. Twin screw } \\
\text { oxtruders also offer more flexibility in the plecement of vent } \\
\text { ports. }\end{array}$ & \\
\hline
\end{tabular}




\begin{tabular}{|c|c|c|}
\hline & EXTRUDERS & KNEADERS \\
\hline $\begin{array}{l}\text { Industry } \\
\text { Usage/Consistency } \\
\text { with other DOE sites }\end{array}$ & $\begin{array}{l}\text { There are currently around } 3,000 \text { twin screw extruders in } \\
\text { operation in the US }{ }^{2} \text {. Rocky Flate and Brookhaven Nationel } \\
\text { Labe have ovaluated methods for combined melting/mixing } \\
\text { operatione and both have concluded that extruders are the } \\
\text { best alternative. It is not immediately clear whether the } \\
\text { Rocky Flats and Brookhaven rigorously evaluated alternatives } \\
\text { to extruders. }\end{array}$ & $\begin{array}{l}\text { There are probably lese than } 100 \text { kneeders in operation in } \\
\text { the U.S. The market in which kneadere heve the most } \\
\text { applications is in PVC proceseing". Other types of } \\
\text { equipment (e.e., thin film oveporatora) can claim fow if } \\
\text { any applications similar to mixing particulate into PE. }\end{array}$ \\
\hline Expected Service Life & $\begin{array}{l}\text { Estimates of screw life range from } 40,000 \text { operating hours } \\
\text { for pure PE to a low of } 2,000 \text { hours when mixing abrasive } \\
\text { materiale (it is not certain what is considered "abrasive"). } \\
\text { As a rule of thumb, the Barrel is expected to last for about } 3 \\
\text { screw changes. Rocky Flats is planning on using an extruder } \\
\text { to mix PE with nitrate salts from a Thin Film Evaporator (not } \\
\text { unlike our C-018 waete) and has decided that the } \\
\text { abrasivenese of this waste will not cause uracceptable } \\
\text { equipment wear. This determination was based on the fact } \\
\text { that, with a twin scrow extruder, the waete feed port cen be } \\
\text { located downstream of the PE molt zone, and the molten PE } \\
\text { acts as a lubricant to reduce equipment wear. Brookhaven } \\
\text { has on extruder that has been used for testing of PE/waste } \\
\text { mixing without screw or barrel woer-out. }\end{array}$ & $\begin{array}{l}\text { Because the clearences between barrel and screw are } \\
\text { dictoted by mixing shear requirements, they will be } \\
\text { oesentially the seme clearances es for extruders. } \\
\text { Therefore, oxpected equipment life is about the seme as } \\
\text { for an extruder. }\end{array}$ \\
\hline Maintenance & $\begin{array}{l}\text { The screws in a twin screw oxtruder are made in sections, } \\
\text { which can be replaced individually or altogether. The } \\
\text { sectional nature of the twin screws offers more flexibility in } \\
\text { assembly/disassembly as well as reconfiguration. }\end{array}$ & \\
\hline
\end{tabular}

1 Equipment Evaluation for Low Density Polyethylene Encapsulated Nitrate Salt Waste at the Rocky Flats Plant, Interim Report, August 30, 1993

2 Telecon notes, Eric Berglin with Dan Mielcarek, November 16, 1993 


\section{UTILIZATION OF COMMON EQUIPMENT EVALUATION \\ White Paper}

\subsection{Background}

1.1 The Value Engineering Study identified the requirement for two process systems for treating particulates and sludges:
a. Particulate/sludge immobilization in grout
b. Particulate/sludge immobilization in polyethylene

In addition to the particulate/sludge processing requirements, the value engineering study identified the need for a separate debris processing enclosure.

1.2 The pretreatment of the waste prior to immobilization in either grout or polyethylene (PE) requires similar process operations i.e. drum opening, waste screening, waste crushing etc. Consequently, an action item arising from the value engineering study was identification of the degree of commonality of equipment for the two processes. This assessment evaluates and identifies the utilization of common equipment for the processes.

\subsection{Description of Options}

2.1 An illustration of the options evaluated is give in Attachment 1, these options are briefly described as follows:

\subsection{Option 1}

a. This option proposes individual lines for each of the three processes particulate/sludge in grout, particulate/sludge in PE and debris processing. No commonality of equipment is provided in this option.

\subsection{Option 2}

a. This option provides a separate particulate in PE line and combines the grout facilities for the particulate/sludge in grout and the vibro grout process of the debris line. Pretreatment facilities for the particulate/sludge in grout process and the debris process are not combined.

\subsection{Option 3}

a. This option provides a separate debris process line and combines the open, tip, screen/sort and crushing activities for the waste prior to being diverted to either the grout immobilization or PE immobilization process. 


\subsection{Option 4}

a. This provides the same combination of pretreatment activities as for option 3 (open, tip, screen/sort and crushing) prior to being diverted to either the grout immobilization or PE immobilization process. However this option combines the grout process for both the debris process and the particulate/sludge in grout process.

\subsection{Option 5}

a. This option provides a separate debris process and combines the pretreatment activities of open, tip, screen/sort, dry and crush for the particulate/sludge in grout and the particulate in PE processes. However, the option exists to allow dry particulate past the dryer.

2.7 All options provide the capability to transfer debris in particulate/sludge waste to the debris process line and particulate/sludge in debris waste to the particulate/sludge process line

\subsection{Options Screened from Further Evaluation}

3.1 Option 1 offers a workable solution although the considerable duplication of equipment will result in high costs.

3.2 Options 2 and 4 utilize common grouting and drum loading equipment for vibro grouting of debris and grout mixing particulate/sludge. These options will give rise to throughput problems and cause additional complexity in switching between mixing grout for vibro grouting and mixing cement/particulate/water (particulate/sludge in grout) using common equipment.

3.3 Options 1, 2 and 4 are screened from further evaluation. The reasons described for screening the options were discussed and agreed with WHC as documented in Attachment 2.

\subsection{Evaluation of Options 3 and 5}

4.1 Options 3 and 5 have the same process stages and are very similar in principle, the only difference being the stage at which the waste is diverted to the grout or PE processes. In order to fully establish the most suitable of the two options it is necessary to consider the impacts of engineering the process stages into the building layout. In order to select between the two options, engineering sketches were produced for each. Engineering sketches for options 3 and 5 is shown in Attachments 3 and 4 respectively.

4.2 Examination of the engineering sketches Option 3 is preferred over option 5 for the following reasons:

a. The building height is $18^{\prime}$ less for option 3 than for option 5 . This equates to a cost saving of approximately $\$ 120 \mathrm{~K}$, as estimated in Attachment 5 . 
b. The dryer is also intended to mix and homogenize the waste and when required to mix the waste with calcium oxide. If waste is diverted around the dryer mixing is not achieved.

c. Although option 5 provides additional operational flexibility, it provides no additional process flexibility than option 3.

\subsection{Conclusions}

5.1 Option 3 to route all particulate/sludge waste requiring immobilization in either grout or PE through the open, tip, screen/sort and crush equipment is considered the optimum utilization of common equipment. After passing through this equipment the waste should be diverted either directly to the grout immobilization process or through the dryer to the PE process.

\subsection{Recommondations}

6.1 The WRAP 2A Title design should proceed on the basis that all particulate/sludge waste requiring immobilization in either grout or PE should be routed through the open, tip, screen/sort and crush equipment. After passing through this equipment the waste should be diverted either directly to the grout immobilization process or through the dryer to the PE process. 


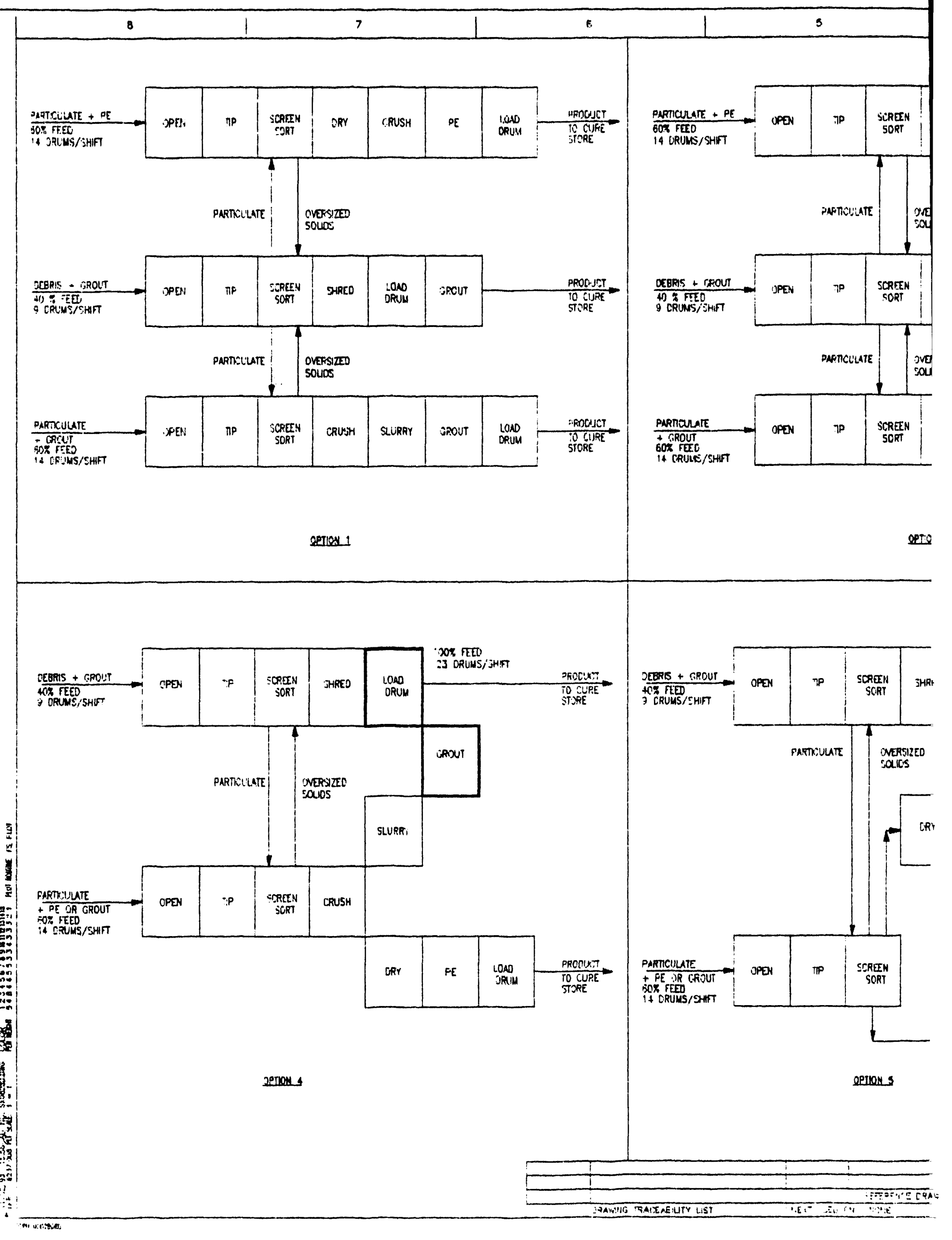




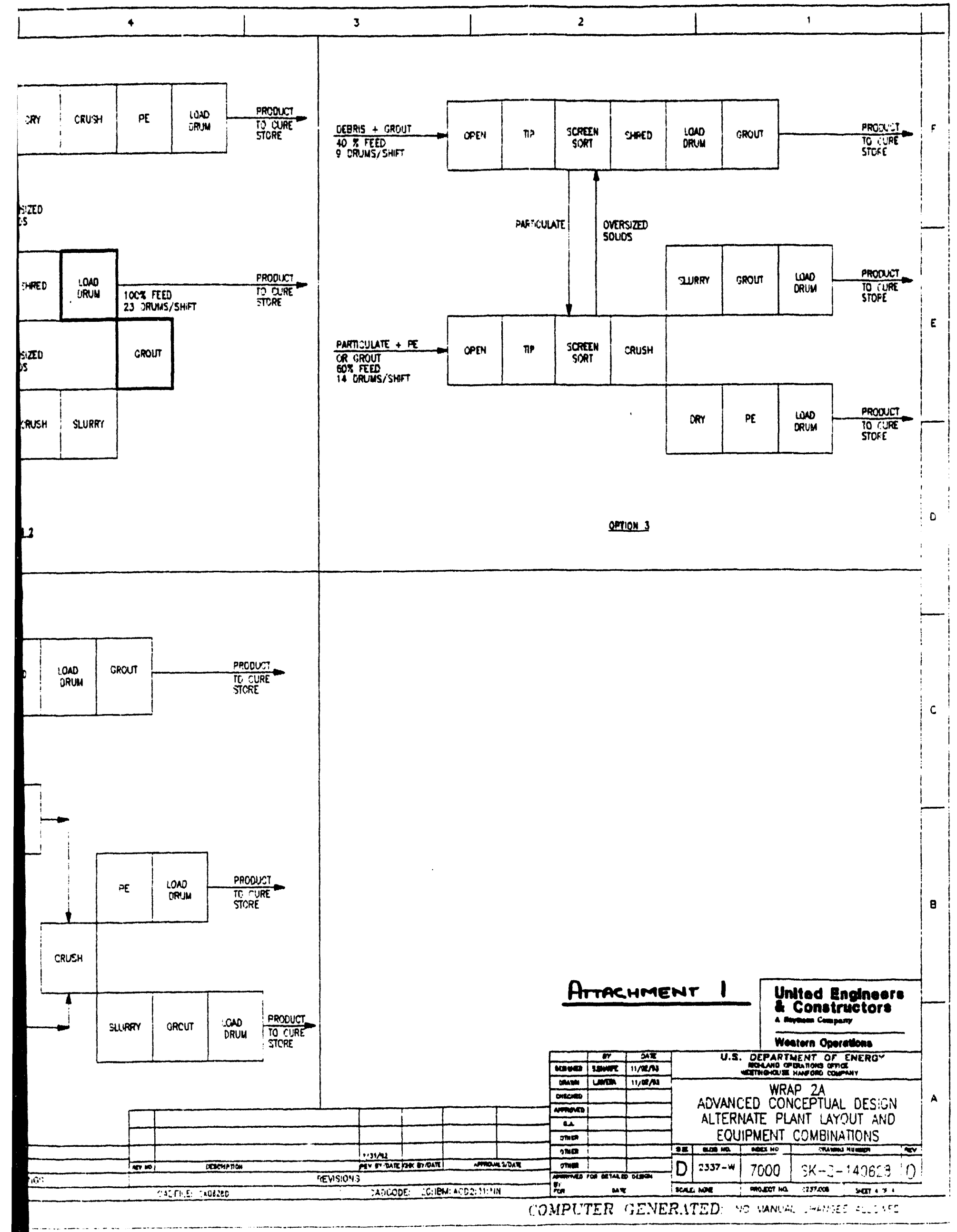




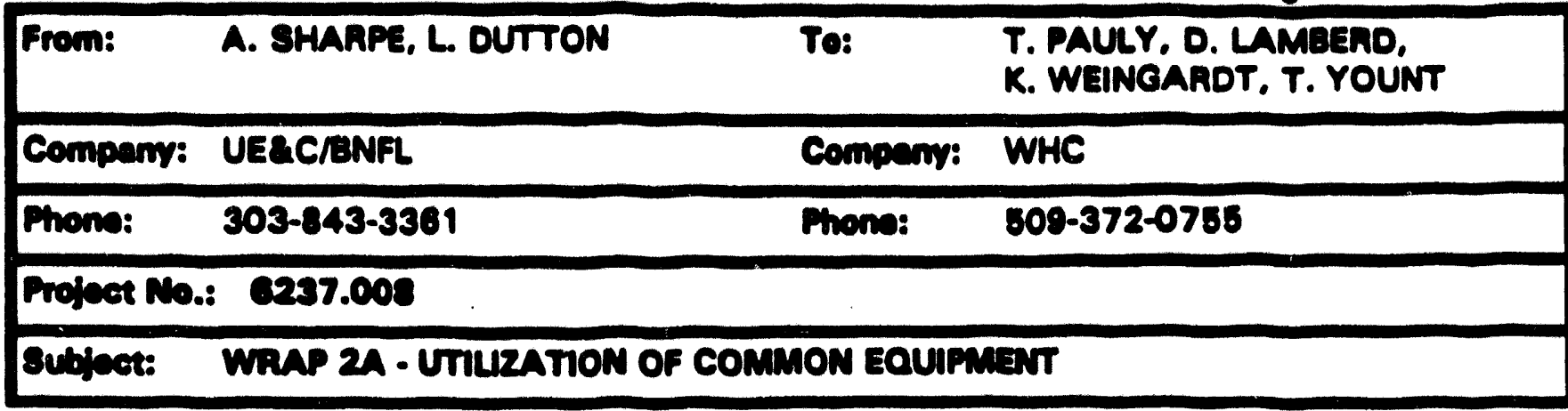

\section{Topices of Convereation:}

1. The purpose of the telecen was to discuss the elternative equipment combinations (Attachmemt 1 ) and select the most suitable option on which to proceed with the design.

2. Option 1 offers a workable solution although it was considered that the considerable duplication of equipment would result in high cost.

3. Options 2 and 4 utilize common grouting and drum loading equipment for vibro grouting of debris and grout mixing particulate/sludge. It was considered that these options would result in throughput problems and gave additional operational complexity in switching between mixing grout for vibro grouting and mixing coment/particulate/water (particulate processing in grout) using common equipment.

4. Options 3 and 5 were considered to provide economy over Option 1 because of the utilization of some commen equipment. Options 3 and 5 reduced the operational complexity and risk to throughput than that of Options 2 and 4.

5. Options 3 and 5 were considered to be very similar in principle, the only difference being the stage at which the waste was diverted to orout or polyethylene. WHC identified the additional flexibility that WRAP 2A would have if it would be possible to divert waste around any piece of equipment. UE\&C pointed out that this would prove difficult to build into the equipment and plant layout.

6. Both UEEC and WHC had made preliminary engineering sketches of how the equipment in Options 3 and 5 could be arranged. It was agreed that before advancing to a decision on the preferred option, the additional information/ideas shown on these sketches should be assess, and a further telecon arranged within the next few days to select between the options.

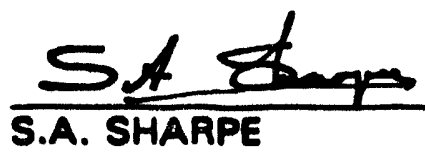

cc: C. Dicky 


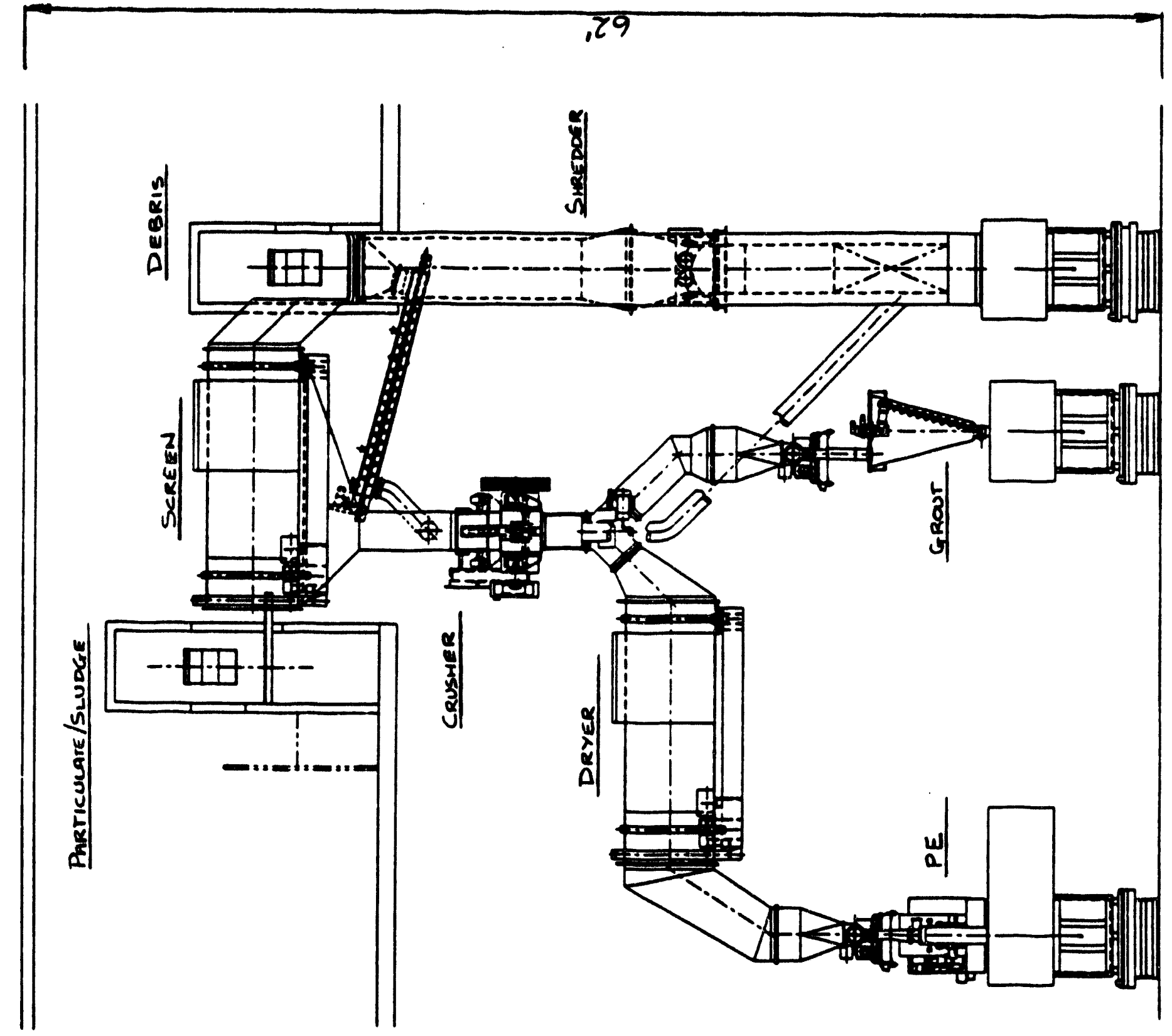

OPTION 3-ROUTE AL WASTE THROVGM DRYER For PE 

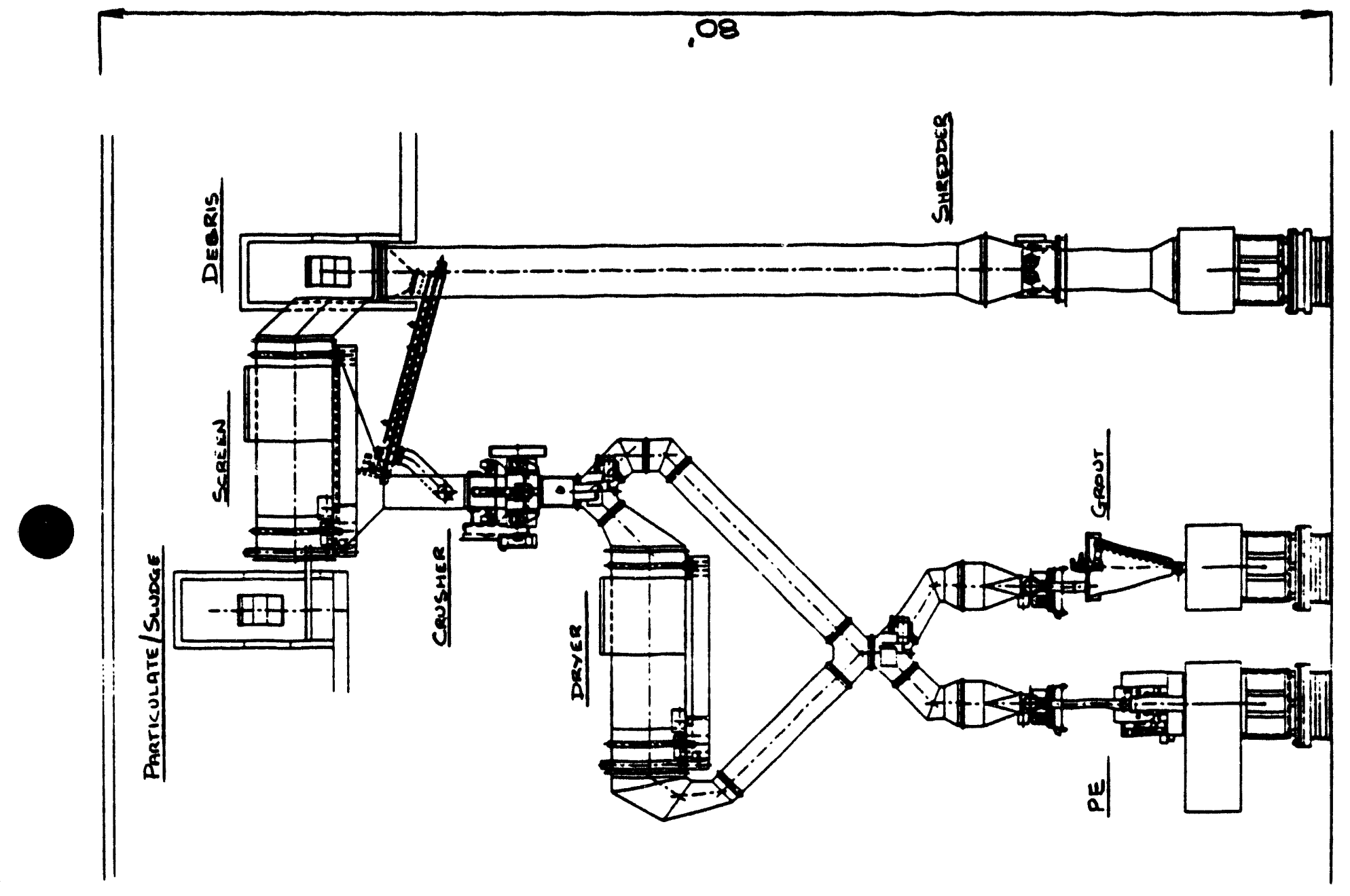

Option 5 - Capapility To Divert Waste Around DRver for PE

Attachment 4 


\section{calculate the additional building cost for increase in height of the building}

The area affected by the increase in height of the building is a $60^{\prime} \times 60^{\prime}$ section of the process area.

Calculate building cost for $10^{\prime}$ height of the $60^{\prime} \times 60^{\prime}$ section

$\begin{aligned} \text { Wall area }=60^{\prime} \times 4 & =240 \mathrm{ft}^{2} \text { e } 10 \mathrm{lb} / \mathrm{ft}^{2} \\ 240^{\prime} \times 10^{\prime} & =2,400 \mathrm{ft}^{2} \text { a } 10 \mathrm{lb} / \mathrm{ft}^{2} \\ & =24,000 \mathrm{lbs} \\ & =12 \text { Tons a } \$ 2,500 / \text { Ton } \\ & =\$ 30,000 \text { per } 10^{\prime} \text { height }\end{aligned}$

Calculate structural steel cost for $10^{\prime}$ height of the $60^{\prime} \times 60^{\prime}$ section

steel $=10^{\prime} \times 4=40^{\prime}$ e $25 \mathrm{lb} / \mathrm{ft}$

$=1,0001 \mathrm{bs}$

$=0.5$ Tons e $\$ 2,000 /$ Ton

$=\$ 1,000$ per $10^{\prime}$ height

Architectural

$=\$ 5,000$ per $10^{\prime}$ height

Waste containment chutes $=\$ 28,000$ per $10^{\prime}$ height

Total $=30,000+1,000+5,000+28,000$

$=\$ 64,000$ per $10^{\prime}$ height

Height increase of $18^{\prime}=1.8 \times 64,000$

$=\$ 115,200$ Total

Atrachment 5 


\section{SECTION 2.5 \\ WHC-RESPONSE TO VALUE ENEINEERING ASSESSMENT ACTIONS}


P.O. Box 1970 Richland, WA 99352

November 2, 1993

\section{WRAP PROJECT 93594}

Mr. M. J. Nolters, WRAP Project Manager United Engineers \& Constructors Mestern Operatians Division 5555 Greenwood Plaza Boulevard Englewood, Colorado 80111

Dear Mr. Wolters:

Date Recoived $11 / 3 / 93$

Recoived From $6 H \mathrm{HC}$ - Hand

lwULO 0185

Received By

WASTE RECEIVING AND PROCESSING MODULE 2A ENGINEERING ASSESSMENT IMPLEMENTATION PLAN RESPONSES

Attachment 1 to this letter contains responses to the Implementation Plan Actions developed during the Value Engineering assessment. This information will be used as the bases for the remainder of the Advanced Conceptual Design Report activities. This information will be incorporated into the next draft of the Supplemental Design Requirements Document (SDRD) in the format shown.

Transmittal of this attachment resolves Action Items 191, 93, \$94, 197, \$100, 103, 109 on the United Engineers \& Constructors (UE\&C) Waste Receiving and Processing (WRAP) Module 2A Action Item List.

If you require further information, please contact Mr. D. L. Lamberd at (509) 372-0845.

Very truly yours,<smiles>CCOC(=O)C1CCCCC1</smiles>

UE\&C

berceni-ai

D. R. Lúcas, Manager

NOV 031993

WRAP Project Engineering

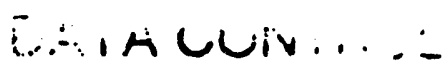

san

Attachment

RL - R. E. Bley 
RESPONSES TO ENGINEERING ASSESSMENT IMPLEMENTATION PLAN ACTION ITEMS

\section{Action Iten 91}

Imolementation Plan Iten 1: Classification and Treatment of Empty Drums

\section{Requirements:}

1. WRAP $2 A$ shall have the capability to compact 30 empty drums per shift to be managed as Low Level Waste.

2. WRAP $2 A$ shall have the capability to shred 30 empty drums per shift to be managed as debris.

Action Item $\$ 93$

Imolementation Plan Item 3: Preferred Final Container Definition

Requirements:

1. WRAP $2 A$ shall have capability to place all treated waste into 55 gallon drums for disposal.

\section{Action Item $\$ 94$}

Imolementation Plan Item 4: Secondary Waste Treatment

No additional design requirements beyond the FDC, Revision 2, and SDRD Revision A.

\section{Action Item $\$ 95$}

Implementation Plan Item 5: Debris Rule Interoretation

Requirements:

1. Treatment of waste defined as debris shall be grout macroencapsulated as defined in 40 CFR 261.

2. WRAP $2 A$ shall have the capability to perform visual inspection of all waste defined as debris to ensure that it is debris prior to treatment. Debris definition is as stated in 40 CFR 260 and WAC 173303. 
9359453

Attachment

Page 2

RESPONSES TO ENGINEERING ASSESSMENT IMPLEMENTATION PLAN ACTION ITEMS

3. URAP $2 A$ shall provide vibratory screening or other mechanical means to remove any process residues, sotls, caked solls, or other matertals less than $60 \mathrm{~min}$ in size from debris.

4. Debris and non-debris wastes shall be kept physically segregated from each other.

5. After non debris removal, size limitations are dictated by the subsequent treatment process. Demonstration testing will verify what size reduction can be accomplished and still ensure that the debris can be adequately encapsulated. Proceed on the basis that a shredded debris size of $60 \mathrm{~mm}$ can be adequately treated.

6. Following size reduction, the debris will be vibratory encapsulated in grout. Based on the available treatment technologies, WRAP 2A will use the microencapsulation and macroencapsulation technologies for treatment of debris.

7. The facility design must provide the capability to transfer any materials removed from debris to either the Grout Immobilization line or the Polyethylene Microencapsulation line. The facility design must al so provide the capability to transfer any debris materials separated from either of the particulate lines to the debris line for treatment by Grout Macroencapsulation.

8. Treatment of debris is a technology based standard and has no concentration based standards (TCLP) to meet; therefore sampling of treated debris, treated to one of the alternative technology standards, is not required provided that separation of non debris from debris waste has occurred.

Action Item \#97

\section{Implementation Plan Item 7: Box Breakdown Area Scope}

The scope of the box breakdown area shall remain the same as the conceptual design and the work completed during the ACDR. The throughput requirements for the box breakdown area are as follows.

Requirements:

1. The box breakdown area shall be capable of handling a total of 40 boxes per year. Information contained in the feed specification shall be used for waste description of boxes in the box breakdown area. 
RESPONSES TO ENGINEERING ASSESSMENT IMPLEMENTATION PLAN ACTION ITEMS

\section{Action Item $\$ 100$}

\section{Imolementation Plan Item 10: URAP 2A Expanston Capability}

\section{Requirements:}

1. An area the size of the transfer corridor shall be maintained free of obstructions in the process area for future expansion capability. The opening size shall be 40 feet wide by 20 feet high.

Action Item $\# 103$

\section{Imolementation Plan Item 13: Documentation of Study Assumotions}

The following assumptions are a part of or will be acded to the SDRD as part of the next revision draft scheduled to be issued 11/15/93.

Requirements:

1) The two immobilization processes in WRAP $2 A$ shall be grout and Polyethylene.

2) Supporting Document WHC-SD-RD-001 contains all descriptions of the incoming feeds and will be referenced in the SDRD.

3) There is no defined need for a vibratory polyethylene process to encapsulate any waste stream. However, the capability shall be provided to fill product containers with polyethylene without preheat or vibration.

4) Segregation of waste by radionuclides category (no mixing of $\mathrm{Cl}$ ass 1 and Class 3 waste) shall be maintained throughout the waste treatment in WRAP 2A. Designation shall be based on category established as waste enters WRAP 2A.

5) Reuse of any incoming waste containers shall not be allowed.

6) Waste will be designated as debris prior to receipt at WRAP 2A. In addition, inspection at WRAP 2A of incoming non-debris waste could reveal the presence of waste that meets the definition of debris. All such wastes, whether categorized as debris by the generator or at WRAP 2A, shall be managed as debris. Revision 4 of EP-0063 includes a checklist for debris.

7) Plant maintenance activities on process equipment shall be undertaken as a contact handled activity. 
RESPONSES TO ENGINEERING ASSESSMENT IMPLEMEKTATION PLAN ACTION ITEMS

8) Any non operational activities shall be performed during operating planned downtimes, 1.e., during the $30 \%$ of the 250 days per year $(-75$ days per year) the factility is not required to be operational. This shall include all rout ine maintenance, necessary cleanout of equipment between campaigns of waste, reconfiguration of process lines and other activities not directly associated with process operations.

Action Item $* 109$

Imolementation Plant Item 19: Process Line Capacities

Requirements:

See next two pages 
•

•

- 


\begin{tabular}{|c|c|c|c|}
\hline \multicolumn{4}{|c|}{ RESPONSES TO ENGINEERING ASSESSHENT IMPLEMENTATION PLAN ACTION ITENS } \\
\hline \multicolumn{4}{|c|}{ MRAP 2 single Shift Throughput Requirements } \\
\hline $\begin{array}{l}\text { Grout } \\
\text { Macroencepeulation }\end{array}$ & 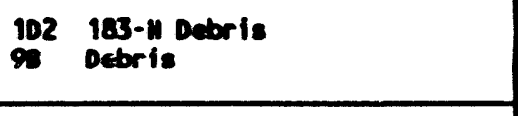 & 11,600 & 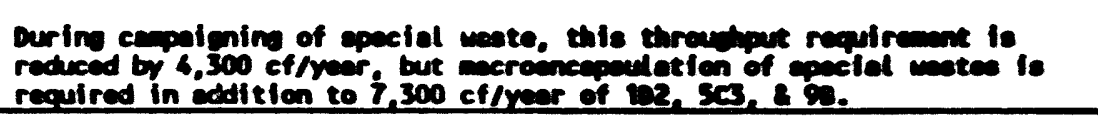 \\
\hline Grout & 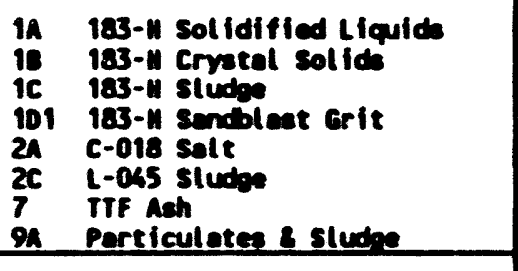 & 17.600 & \multirow{2}{*}{ 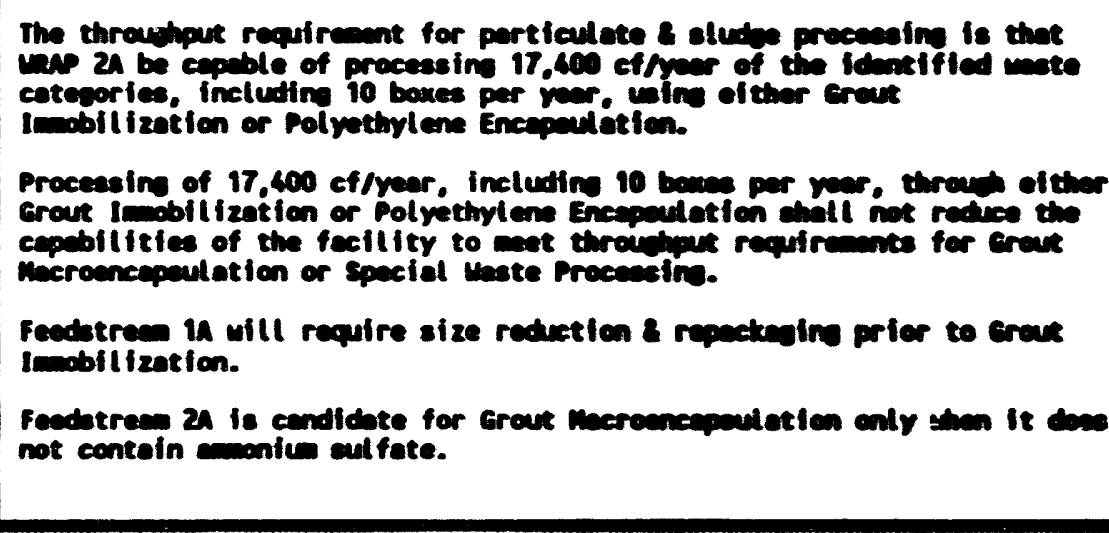 } \\
\hline $\begin{array}{l}\text { Polyethylene } \\
\text { Microencepeulation }\end{array}$ & 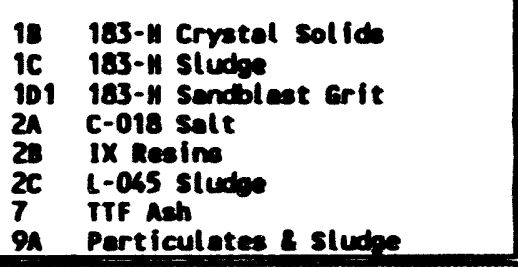 & 17,400 & \\
\hline \multicolumn{2}{|r|}{ Prifory vaste subtotal } & 22,000 & 3.8 \\
\hline \multirow{8}{*}{$\begin{array}{l}\text { Speciel Weste } \\
\text { Processing }\end{array}$} & 5 A) Elemental Marcary & 140 & 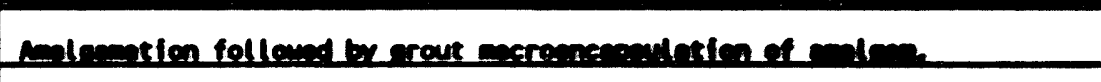 \\
\hline & 5,2 Mercury Cheaicals & $\boldsymbol{\infty}$ & mair follond by erout meroencopouletion. \\
\hline & $5 R 3$ Meterosenous Merary & 600 & 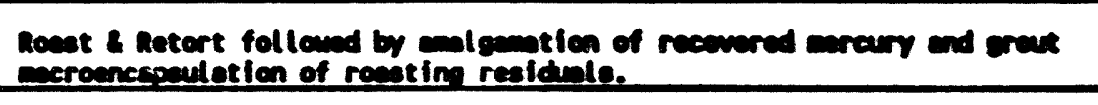 \\
\hline & Sc1 flementel leat & 1.270 & Great mexrensadenintione. \\
\hline & $5 \mathrm{C} 2$ Leed chearicals & 60 & ear folland by reut ecroencepouletion. \\
\hline & SC3 Heterorenous Leed & 0.8 & Grout meroencerauletion. \\
\hline & $x$ conteined 2 nbeorted Lievid & 1.160 & par folland by reat meroencepoul intican \\
\hline & Speciel mate subtotel & 4,300 & \\
\hline Eox sreakdown & 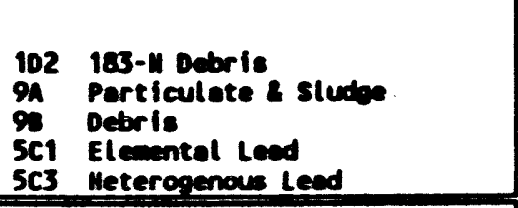 & $\begin{array}{cc}\text { erimax } & \text { soncinl } \\
9.5 & \vdots \\
29.7 & \vdots \\
: & 5.1 \\
& 0.8 \\
\end{array}$ & 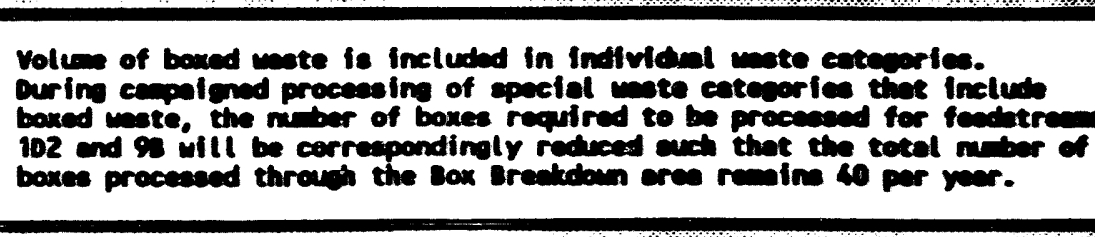 \\
\hline & Box Areakdoun subtotal & 40 & 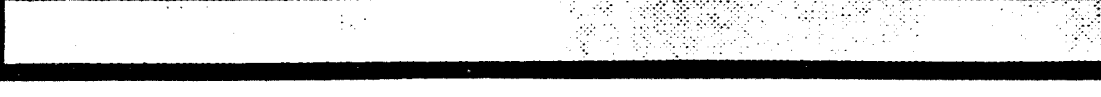 \\
\hline
\end{tabular}


RESPONSES TO ENGINEERING ASSESSHENT IMPLEMENTATION PLAN ACTION ITENS

Special Uaste Campatening Single Shift Requirements

verates creft

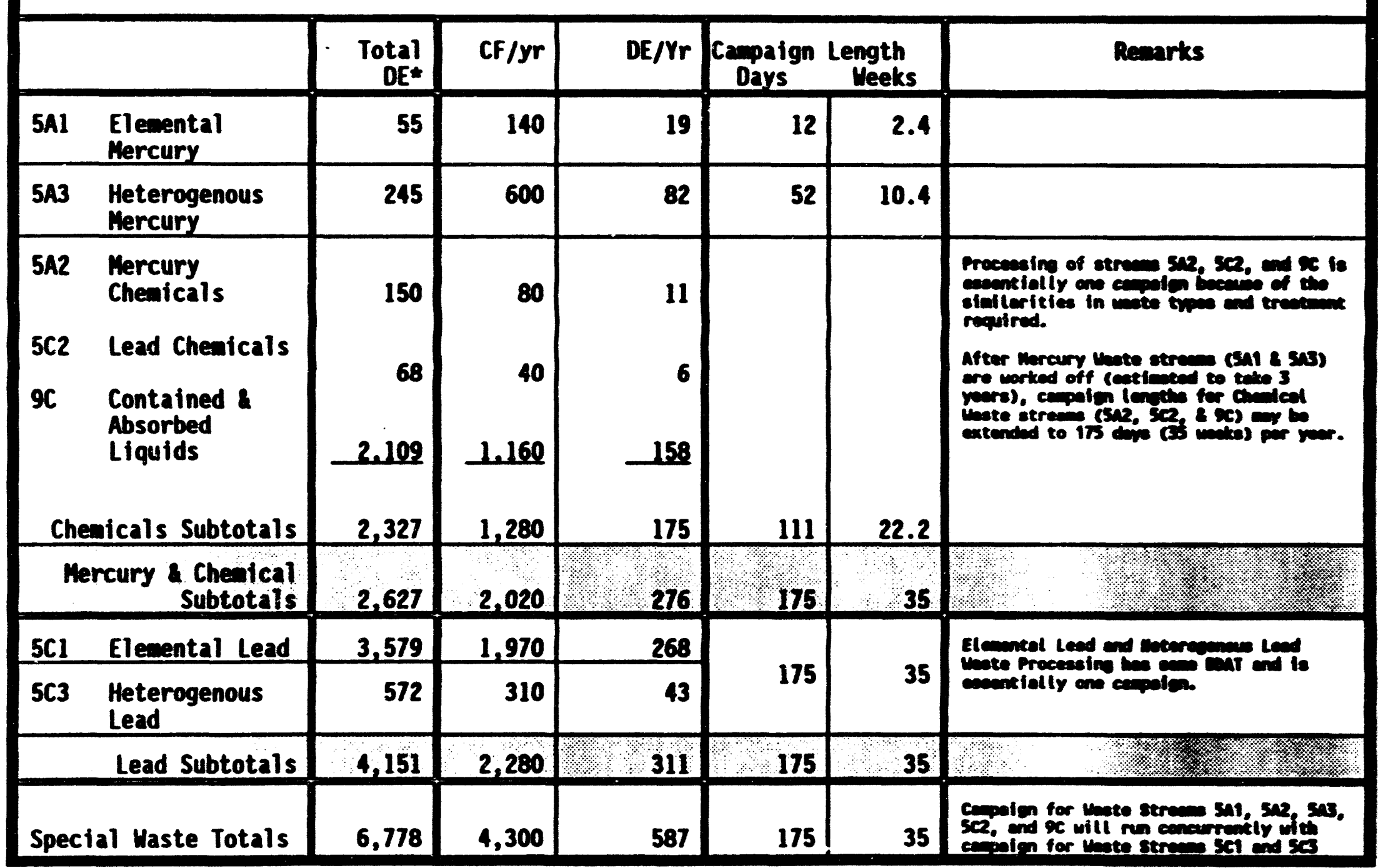

* 30 year projection from Feedspec. 


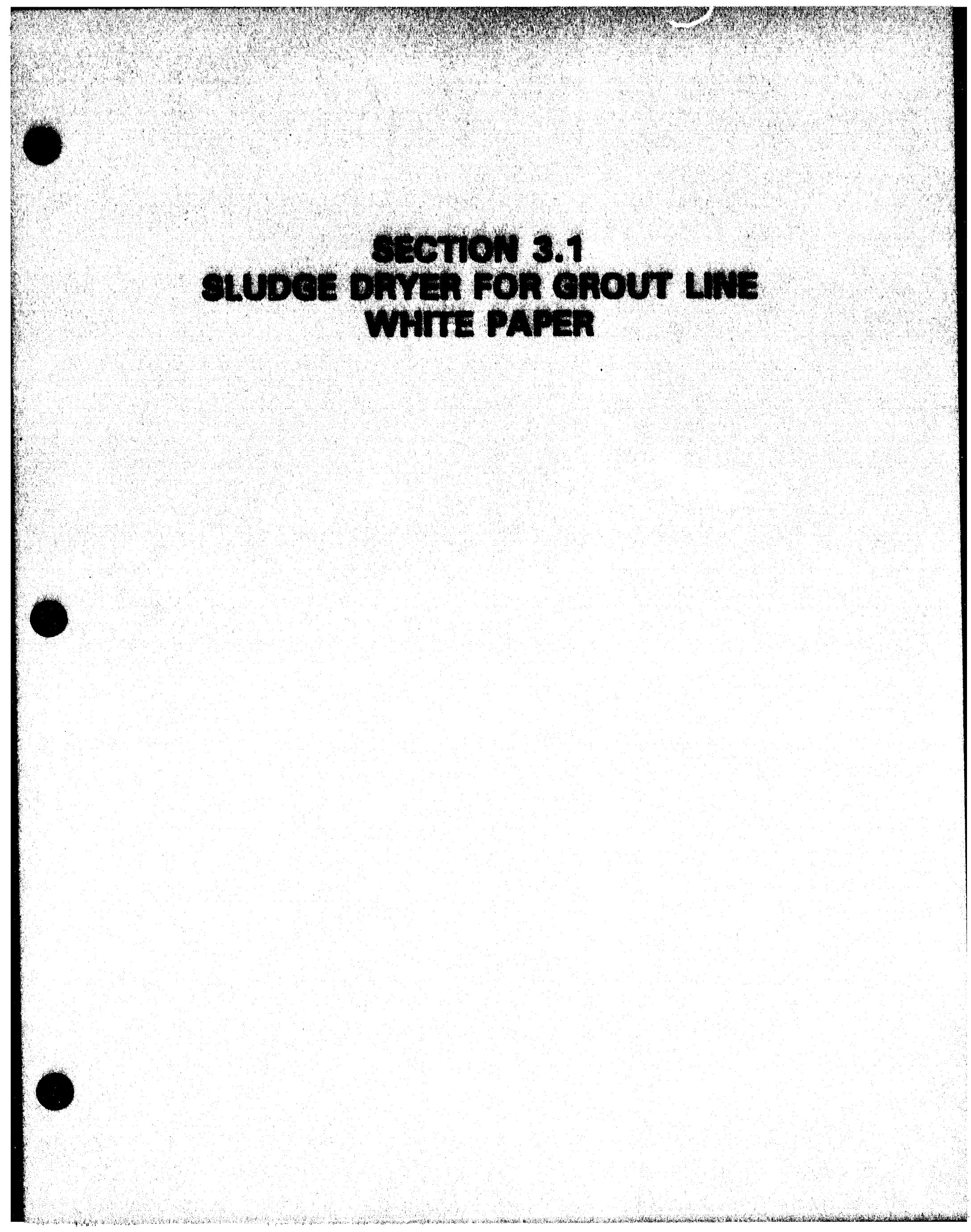




\subsection{BACKOROUND}

1.1 As part of the Value Engineering Assessment, it was proposed that a continuous mixer (Turbo-mixer) be used to prepare the grouted waste product. In using this type of equipment, it was recognized that waste and grout feed materials would have to be metered to the equipment to a relatively high degree of accuracy. Discussions with vendors indicated that dry powders and liquids could easily be metered using conventional equipment, but sludges could not be easily metered. As the Value Engineering Assessment also identified the need to dry sludge prior to encapsulation in polyethylene, the possibility of using the same dryer to dry the sludge, and hence, simplify and increase the accuracy of metering sludge to the continuous mixer.

\subsection{DIscussion}

2.1 since this issue was raised, the design of the grout process for sludge/particulate wastes has changed and now uses a batch mixer. This effectively removes the problem because the rate of feeding waste to the mixer will no longer be important. All that will need to be known in order to determine the amount of grout and the grout formulation required for product quality will be: how much waste has been fed to the mixer and the chemical composition/water content of the waste. Hence, it will not be necessary to dry sludges or particulate wastes which are to be grouted. 


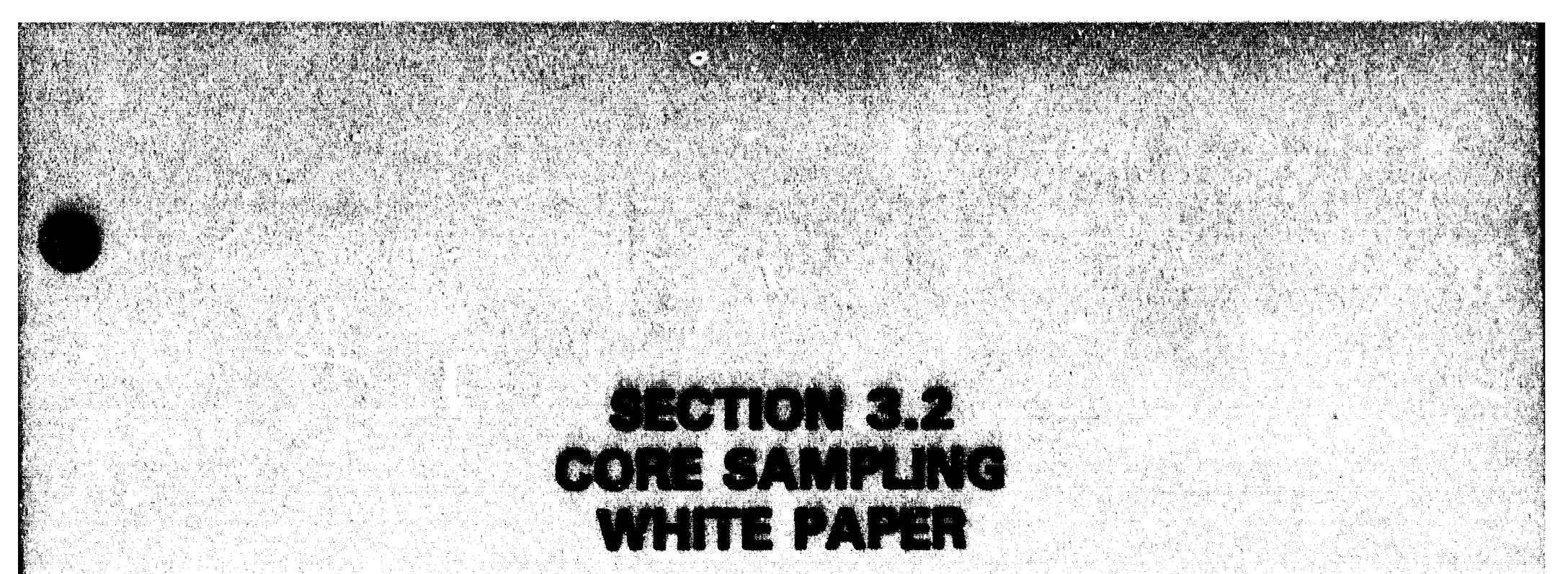

. 


\title{
CORE SAMPLING
}

\author{
White Papor
}

\subsection{BACKGROUND}

1.1 It was recognized that it would be possible to sample the grout product while it was being fed to the product container from the batch mixer and incoming solid wastes could be sampled in the Box Breakdown Area. Hence, the need to provide the ability to core sample in WRAP $2 A$ was questioned.

\subsection{Discussion}

2.1 Core sampling will still be required in WRAP 2A, but will only be used to take samples from product containers in the event that the results from the in-line samples prove to be inconclusive and additional analysis is cost beneficial when compared to batch/lot reprocessing.

2.2 The core sample needs only to be large enough to support TCLP analysis. Previously the

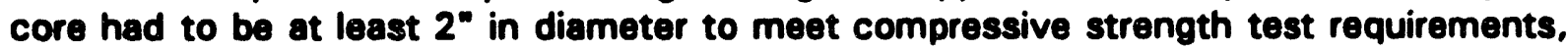
however, the geometry of the sample for TCLP is not relevant. The sampling for compressive strength testing will some from in-line sampling. 


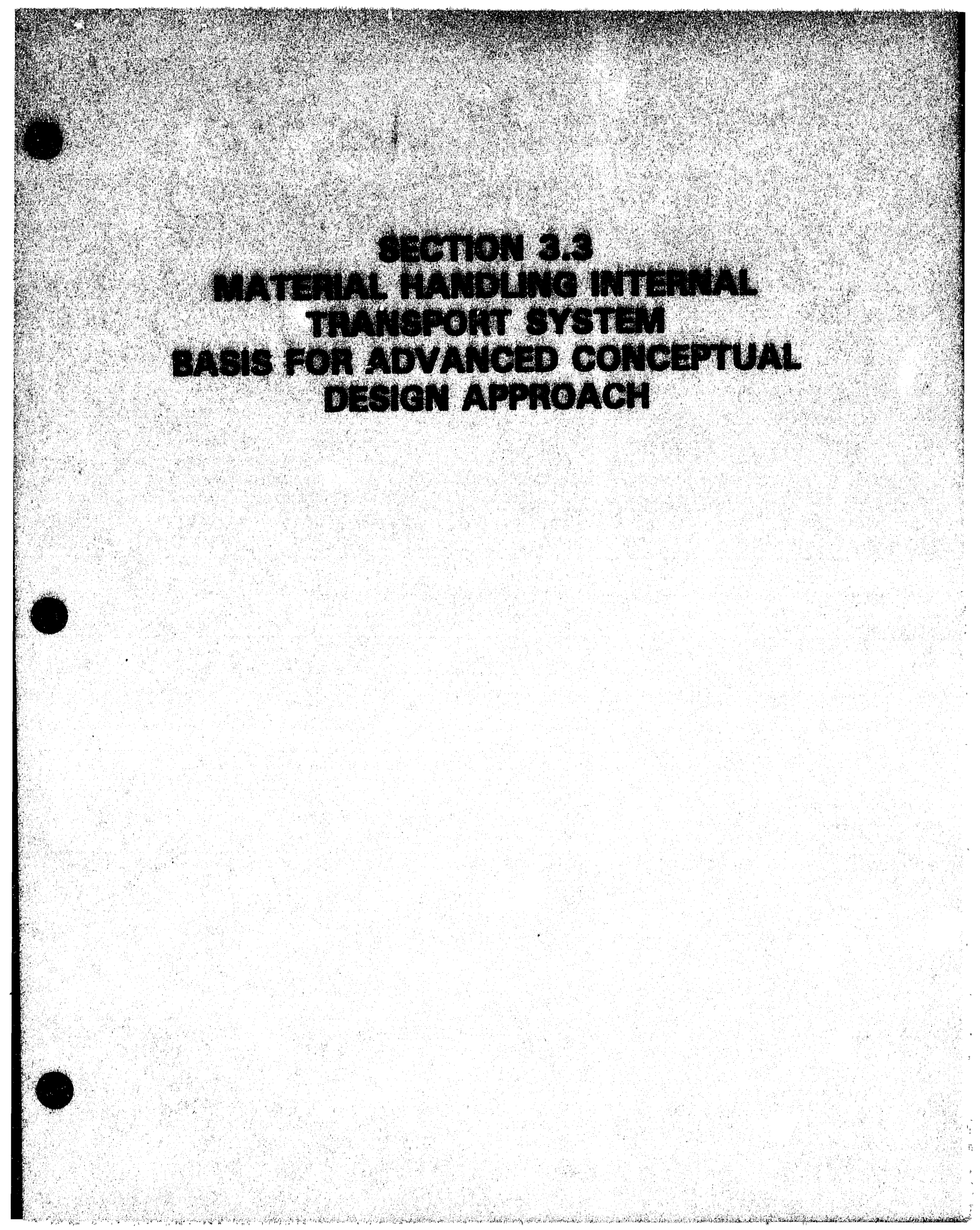




\section{MATERIAL HANDLINC INTERNAL TRANSPORT SYSTEM BASISFOR ADYANCED CONCEPTUAL DESICN APPROACH White Paper}

\subsection{BACKOROUND}

1.1 The purpose of this white paper is to briefly present the criteria utilized in a review process to select the major components of a container handling system for WRAP 2A ACDR.

\subsection{DISCUSSION}

2.1 To facilitate this review it is helpful to break the Material Handling Internal Transport System requirements into the three main zones of function identified in the ACDR:

(1) Receipt/Lag Store

(2) Internal Transport

(3) Cure Store/Ship

These functional zones represent an integration of the CDR functions of receiving, lag storage, staging, internal transport, curing free water removal, visual inspection, radiological survey, and shipping. In the initial WRAP 2A CDR, these physically separate functions were integrated by utilizing automatically guided vehicles (AGV) for all internal transport. The AGV's were initially utilized in the CDR because of requirements for large numbers of individual trips to multiple separate locations. For example, the size reduction and repackage areas discharged drums to five different pick and drop points. These drums were then picked up, transported to, and dropped off at a controlled lag storage area. When follow on process systems were available; specific drums were repicked by an AGV and transported to one of 6 process points, 4 NDA points or the cure/store area.

2.2 This resulted in frequent trips and multiple pick ups of unique drums. The current proposed ACDR configuration combines the repackaging areas with the process areas and a container is now filled with waste and treated without requiring internal transport. This eliminates the need for two additional transport and one storage step. Additionally, as waste product containers are now significantly upsized (approximately eight waste drums to one product container) the number of product containers requiring transport has been reduced by a factor of eight. These significant changes; reduction in numbers of trips, elimination of lag storage/retrieval of unique drums after repackaging, and the significant reduction in numbers of product containers, allow the material handling and internal transport systems to be simplified significantly as follows:

\subsection{FUNCTIONAL ZONE (1) RECEIPT/LAG STORAGE}

3.1 The current proposal is to allow incoming waste drums to accumulate on dedicated conveyors in the waste receipt area and eliminate the repackaged waste lag storage area. This system could be configured in a carousel arrangement to provide required storage density and adequate selectivity in a horizontal configuration, without the unique position selectivity and resulting complexities and expenses of a vertically configured AS/RS. 


\subsection{FUNCTIONAL ZONE (2) INTERNAL TRANBPORT}

4.1 The significantly reduced numbers of pick and drop points, fixed transfer routes, and reduced throughput of product containers, allows the elimination of the AGV system. Required product container transfers can be achieved with a system of powered roller conveyors and lift tables.

\subsection{FUNCTIONAL ZONE (3) CUAE STORE/SHIP}

5.1 Due to limited throughput of product containers, the cure store can be configured as an accumulating conveyor system using a first in first out philosophy. (The major impact results from a requirement to size cure store to support 3 shift operations).

\subsection{CONClusion}

6.1 This proposal eliminates the AS/RS and AGV Systems for a gross reduction of 900K in equipment costs. The conveyor upgrades are priced at $500 \mathrm{~K}$ for a net reduction of $400 \mathrm{~K}$. 


\title{
MERCURY CONTAININC WASTE RETORT EOUIPMENT
}

\author{
Whito Papers
}

\subsection{BACKGROUND}

1.1 Both tray-type ovens and rotating double-cone dryers are being evaluated for retorting mercury contaminated waste. One type of equipment may be easier to load/unload; one or both may require testing/development.

\subsection{DISCussion}

2.1 The final selection of type of mercury retort will be made during Title 1 design. However, at this time it appears that a rotating double cone dryer type design may be optimal. This type of dryer is slightly more expensive than a tray-type oven, however the loading and unloading equipment is greatly simplified. Besides total system cost, other factors to be considered include:

- Type of heat transfer: a tray-type oven would probably use electric heat and a rotating double-cone dryer may require a separate fluid heat transfer system.

- Effectiveness of mercury evaporation: both types should be equally effective.

- Ease of decontamination: a tray-type would probably be much easier to decontaminate due to the easier access to the interior.

- Layout requirements: a tray-type may require slightly less space. 
SECTION 3.5

OUT OF DRUM vS.

IN-DRUM MIXINE 
1. A Value Engineering study of WRAP 2A took place in Richland, WA, on October 11-15, 1993. The study involved WHC, UE\&C and BNFL. The criteria perceived as most important for the design of the sludge/particulate grouting area were capital cost and the need to have a simplified process. The need to minimize the volume of product/secondary waste generated and to minimize maintenance requirements for the facility were only considered to be of low importance.

2. Based on the above criteria, out of drum mixing was compared with in-drum mixing. The out-of-drum mixing technique chosen for evaluation was a continuous high speed pug mill. The benefits of each system were as follows:

\section{Out-of-Drum Mixer}

- Accommodates any final Container

- Ensures complete fill of a container

- Potential reduction in life cycle costs - no lost paddle

- Limited custom design
In-Drum Mixer

- Does not generate active grout washings

- Does not require maintenance of active equipment

3. Although the out-of-drum mixing technique would create active grout washings, the volume of these secondary wastes was believed to be small, and therefore, not an important decision factor. It was also believed that maintenance of an out-of-drum mixer could be performed with minimal dose uptake by personnel. Hence, it was decided that the design of WRAP 2A should incorporate an out-of-drum technique for mixing sludges and particulates with grout.

4. Subsequent to the Value Engineering study there was a concern raised that the continuous mixer could not be controlled with sufficient accuracy to ensure product quality. Hence, it was decided that the process should be performed in a batch mixing vessel. Batch mixing only requires the quantities of materials to be controlled, not the rate of addition. 
TITL: WRAP 2A GPECLAL WASTE PMOCESSINO MAZOP STUDY REPORT

Roviaion: 0

Submitted to:

\section{UMUTED STATES}

DepaATMEart Of ENEROY

Richland, Wechington

Propered by:

UNITED ENGINEans

\& constauctons

A Raythoon Compeny

Weotom Operectione 


\section{TABLE OF CONTENTS}

Page

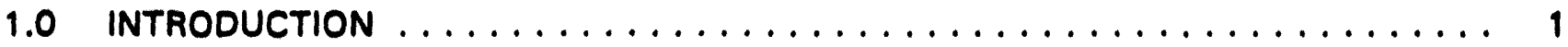

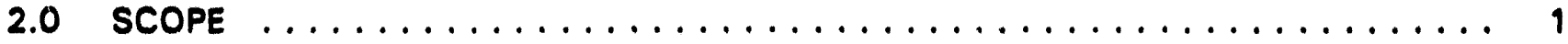

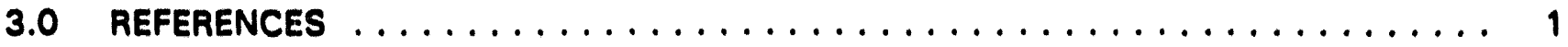

4.0 DESCRIPTION OF SPECIAL WASTE PROCESSING SYSTEM $\ldots \ldots \ldots \ldots \ldots \ldots \ldots$

4.1 Design Basis Summary . . . . . . . . . . . . . . . . . . . 2

4.2 Process Description Summary . . . . . . . . . . . . . . . . 2

5.0 STUDY CRITERIA AND METHODOLOGY $\ldots \ldots \ldots \ldots \ldots \ldots \ldots \ldots \ldots$

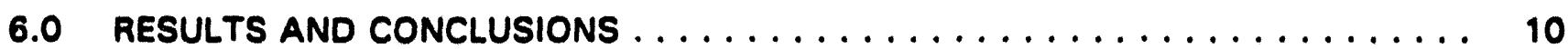


MTAP 2A

\section{BPFCIAL MAETE PAOGFARMO}

\section{HA7OP ETUPYAFPOAT}

\subsection{INTAODUCTION}

A preliminary HAZOP study was performed on the advanced conceptual design of the Special Waste Processing Systom. The HAZOPS team mot on August 4-5, 1993 and consisted of the following members

Name

Larry Walkor

Tom Nolson

Les Dutton

Bill Copoda

BIII Schrador

Gary Booth

Bob Horges

Owen Kruegar

John Moyers

Tom Pauley
Comonny

REC

REC

BNFL

REC

REC

WHC

WHC

WHC

WHC

WHC

\section{Bolo/Exonnting}

Leader, scribe, safoty

Process

Machanical/Operations

Instrumentation and Controls

Radiological

Radiological

Mechanical

Operations

Maintainability

Projects

The purpose of the HAZOPS is to identify major safety and operability problems which can best be resolved during completion of the advanced conceptual desion.

\subsection{BCOPE}

This HAZOPS encompassed the Special Waste Processing System, as shown on Process Flow Diagrams H-2-14-649 through H-2-14065 1 (Rov. E).

\subsection{REFERENCES}

1. WHC-SD-W100-FDC-001 Rev. 2A, Functional Design Criteria Waste Receiving And Processing Facility Module $2 \mathrm{~A}$.

2. WHC-SD-W100-SDRD-001 Rev. A, Waste Receiving and Processing Facility Module $2 A$ Supplemental Design Requirements Document. 


\subsection{DEsCAIPTION OF 8PECIAL WA8TE PAOCESBNO SYSTEM}

\subsection{Deden Bade summary}

1. Special wastes will be protreated by BDAT techniques in compliance with RCRA regulations and to allow compatibility with final encapsulation process.

2. Special wastes will be campaigned in a specialty enclosure using non-thermal treatment techniques ( $\left.<800^{\circ} \mathrm{F}\right)$.

3. The special waste area will be designed for an annual throughput of 4300 cubic feet per year. Mercury/morcury contaminated waste load/ead contaminated waste and contained liquid wastes will be campaigned separately.

4. All elomental mercury will be amalgamated. This includes elemental morcury separated from the bulk waste on the sorting table and elemental mercury recovered from the mercury ovaporator. The amalgamated morcury in bottles will be loaded into drums for encapaulation in polymor.

b. Bulk mercury contaminated solids shall be size reduced via shredding and then treated in the morcury evaporator.

6. Morcury waste which is ionitable, corrosive or reactive will be chemically treated to remove the characteristics of ignitability, corrosivity or reactivity, followed by absorption in diatomacesous earth or similar material, and then sent to the mercury evaporator for recovery of elemental morcury.

7. Lead bricks will be placed in baskots and then loaded in drums for encapsulation in polymor.

8. Bulk lead contaminated waste (oloves, aprons, blankets, otc.) will be size reduced by shredding and loaded into drums for encapsulation in grout.

9. Contained liquids and lead containing waste which is ignitable, corrosive or reactive will be chemically treated to remove the characteriatics of ignitability, corrosivity or reactivity, followed by absorption in diatomaceous earth or similar material. This waste will then be packaged in containers and loaded into drums for encapsulation in grout.

10. Waste separated from the contained liquid waste (packing material, etc.) will be size reduced by shredding and loaded into drums for encapsulation in grout.

\subsection{Process Description Summary}

1. The Special Waste Processing System includes facilities to pretreat and redrum special waste. This waste will be treated in campaigris prior to final encapsulation in polymer or grout for disposal. Special waste to be processed at WRAP 2A includes mercury, lead, ignitable, corrosive or reactive wastes. These wastes must be treated in compliance with RCRA regulations for hazardous waste prior to landfill disposal. 
The Special Waste Processing System will be designed to process 4300 cubic feet per year of waste. Three types of special waste to be processed in separate campaigns include:

Mercury: Feedstream 5A1 - elemental mercury

Feedstream 5A2 - mercury chemicals/solutions

Feedstream $5 \mathrm{~A} 3$ - mercury contaminated heterogeneous solids

Lead: Feedstream 5C1 - elemental lead

Feedstream 5C2 - lead chemicals/solutions

Feedstream 5C3 - lead contaminated heterogeneous solids

Contained

Liquids: Feedstream 9C - contained liquids

Sorting and size reduction operations are shown on PFD H-2-140649. Mercury waste pretreatment (consisting of mercury evaporation and amalgamation) and deactivation of ignitable, corrosive and reactive wastes is shown on PFD H-2-140650. Off-gas scrubbing is shown on PFD H-2-140651.

\section{Drum Entry}

Special waste is transported from interim storage in 55-gallon drums by transfer car to the Shredder Enclosure (GB-06-101). The drums are loaded onto the Lift Table - Drum Entry (LT-06-101). The drum is lifted through a simple double lid into the enclosure by use of the lift table and Transfer Crane (CR-06-101). The crane transfers the drum from the double lid entry port to the Sliding Hatch (DO-06-103) where it is lowered through the hatch from the entry box onto the Drum Pusher (CY-06-101) conveyor. The drum is transferred along the conveyor by the pusher to the Drum Handler/Tipper (DH-06-102).

\section{Sorting}

The contents of each drum is tipped onto Sorting/Tipping Table (ST-06-101) for inspection and removal of items incompatible for shredding. An overhead Manipulator Assembly (EM06-1011) is used to pick out lead bricks, mercury flasks and containers of ignitable, corrosive and reactive waste. Lead bricks are placed in the Lead Brick Transfer Basket (X-06-101). Mercury flasks and containers of ignitable, corrosive and reactive waste are picked out by the manipulator and transferred out of the shredder enclosure by gloveports through the Special Waste Bagless Transfer (D0-06-104).

\section{Size Reduction}

After removal of lead bricks, mercury flasks and other containers, the bulk contaminated waste is fed to the Shredder (SH-056-101) by tipping the Sorting Table. The solids are shredded and discharged into one of the Shredder Discharge Bins (T-06-101 A, B). The shredded material is then inspected and a determination is made whether the material size distribution is proper for direct loadout to a 55-9allon drum on the drum exit lift table. If the material requires further shredding, the Shredder Discharge Bin is transferred to the Shredder inlet by the Bin Transfer Cart (XX-06-102) and Bin Hoist (CR-06-102). 
Marcury contaminated bulk solids are shredded in a manner similar to other bulk solids. These shredded solids are transferred to the mercury ovaporator in a discharge bin via the bin hoist.

\section{Mercury Wente Protrentment}

Elemental morcury is recovered from mercury contaminated bulk solids in the Mercury Evaporator (H-06-201). This will be a batch, once par day, oparation. A bin of shredded mercury contaminated solids is transferred from the shredder to a location above the Mercury Waste Eelt Feeder (Y-06-201) by the bin Hoiat (CR-06-102). The solids are dumped from the discharge gate on the bottom of the bins onto the bolt feeder, and metered onto trave as the trays are retracted onto the Mercury Evaporator Rack With Trays $(X-06-202)$ by the Tray Positioner (X-06-203). The reck is then lowered 9 inches by the Evaporator Rack Hoist (CR-06-202) and the tray positionar pushos another tray into position bolow the feeder. This process will be repeated until all 10 trays are fillod and loaded onto the rack. The rack is then lowered into the evaporator by the hoist and the Mercury Evaporator Door (00-06-205) is closed.

The evaporator operates at $500^{\circ} \mathrm{F}$ (or less) and under vacuum to ovaporate elemental mercury and mercury compounds from the waste. The evaporator is purged with inert nitrogen gas to avoid combustion of any organic compounds in the waste. The eveporator will go through a programmed warm-up, soak and cool-down cycle. Vapors from the ovaporator flow to the Evaporator Condenser (E-06-201) and then to the Mercury Decant Veseal (V-06-201). The condenser is cooled with chilled water at a supply temperature of $42^{\circ} \mathrm{F}$. The chilled water flow rate is controlled based upon condenser discharge temperature. Noncondensables, such as nitrogen purge gas, flow to the Morcury Evaporator Vacuum Pump (C-06-201) and then are routed to the chemical scrubbar. The vacuum pump will maintain the evaporator pressure at approximately 1 paia $(2 \mathrm{inch} \mathrm{Hg})$.

Water will be ovaporated first and will be collected in the decant vessel. Recovered Water Pump (P-06-201) pumps the water to the Active Water collection Tank for further processing. Elemental liquid mercury will collect in the decant vessel until the evaporation cycle is complete and the vacuum pump is turned off. The mercury will then be weighed into bottles containing pre-measured amalgamating chemical. Elemental morcury in flasks from the sorting operation will also be weighed into bottles containing pre-measured amalgamating chemical. Each bottle is capped and placed on the Jar Mill (X-06-201A or B). Each jar mill is capable of mixing 2 one-liter bottles at a time. The amalgamated mercury in bottles may be stored in the special waste treating enclosure until there are enough bottles to fill a drum. The bottles will be loaded onto the Special Waste Transfer Basket (XX-06-201) and lowered into a drum by Treated Waste Hoist (CR-06-201). The drums are exterior to the enclosure and are loaded through pivoting simple double lid. The drums are transferred to the polymer encapsulation area via Treated Waste Lift Table Drum Exit (LT-06-202) and Treated Waste Discharge Conveyor (CV-06-202).

After the solids have been treated in the mercury evaporator, the mercury evaporator door is opened and the mercury evaporator rack is raised to the fist tray position by the evaporator rack hoist. The tray of treated waste is pushed by the tray positioner onto the Mercury Waste Tray Dumper (EM-06-201). The tray dumper holds the tray and rotates down to dump the solids into the Mercury Waste Dump Hopper (T-06-201). The tray dumper rotates up and the tray is moved back onto the rack by the tray positioner. The 
rack is lifted up to the next tray position and this process continues until all trays have been dumped. The solids are then dumped into drums via the Dump Hopper Discharge Gate (Y. 06-202) through a simple double lid. the filling of the drums is controlled by a drum level controller. The drums are transferred to the grout encapsulation area via the Mercury Waste Lift Table - Drum Exit (LT-06-202) and Evaporator Discharge Conveyor (CV-06-202).

Mercury contaminated waste which is ignitable, corrosive or reactive will be separated from the bulk waste on the sorting table and transferred to the special waste treating enclosure via the special waste bagless transfer. This waste will be primarily bottles of chemicals and liquids separated from lab packs (feedstream 5A2). Refer to the following deactivation process description for a discussion of how the characteristics of ignitability, corrosivity and reactivity are removed from the waste (deactivated). After this waste has been deactivated it will still need to be processed for mercury recovery. Due to the volume increase resulting from the deactivation process, it would be impractical to transfer this waste back through the bagless transfer. Therefore, it will be loaded into drums and transferred into the shredder enclosure via the drum entry box. The waste is then shredded and fed to the mercury evaporator.

\section{Load Warte Protrentment}

All lead and lead conteminated waste will enter the special waste enclosure in 55-gallon drums. Lead waste from boxes (such as oversize lead sheets) will never enter the special waste enclosure. This lead will be size reduced and repacked in the Box Breakdown area.

Lead bricks are separated from the sorting/tipping table by the manipulator assembly and placed in the lead brick transfer basket. The lead bricks in baskets are placed in now 55gallon drums using Basket Transfer Crane (CR-06-103). The now drums are located on Lift Table - Drum Exit (LT-06-102) and are external to the enclosure. The repacked lead in drums is then transferred to the polymer encapsulation area.

Lead contaminated waste which is ignitable, corrosive or reactive will be separated from he bulk waste on the sorting table and transferred to the special wastc treating enclosure via the special waste bagless transfer. This waste will be primarily bottles of chemicals and liquids separated from lab packs (feedstream 5C2). Refer to the following deactivation process description for a discussion of how the characteristics of ignitability, corrosivity and reactivity are removed from the waste (deactivated). After this waste has been deactivated it will be loaded into drums and transferred to the grout encapsulation area.

Lead contaminated bulk waste will be shredded, loaded into drums and transferred to the grout encapsulation area.

\section{Deactivation}

Waste which is ignitable, corrosive or reactive (as defined by RCRA regulations) must be treated to remove the characteristics of ignitability, corrosivity and reactivity prior to final disposal. This "deactivation" will take place by treating the waste with appropriate chemicals in the Deactivation Reactor (V-06-201). Most of this waste will be separated from lab packs or be contained liquids (feedstreams 5A2.5C2 and 9C). 
A specific chemical treatment must be determined for each particular waste. Based on the proliminary waste characteristics and components which have been identified at this time, a number of possible chemical treatments have been identified. Low temperature, aqueous phase processes will be used to minimize potential hazards. Additional studies are required to determine the best chemical treatments for all wastes. For the ignitable waste which is an oxidizer, chemical reduction with a reagent, such as formic acid, will be used. The deactivation reactor will be provided with a mixer and cooling jacket. Some reactions will require cooling from chilled water to remove heat of reaction.

In addition to the deactivation chemicals, some reactions will require dilution water to be added. After the deactivation reaction is complete, an equal weight of absorbent will be mixed with the aqueous reaction products to absorb all free liquids and give a semi-solid product. This material will be loaded into one gallon containers and may be stored in the special waste treating enclosure until there are enough containers to fill a drum. The bottles will be loaded into the special waste transfer basket and lowered into a drum by the treated waste hoist.

\section{Chomical Sorubber}

Because of potential generation of noxious off-gases, the special waste treating enclosure and nitrogen purge from the mercury evaporator will be vented to the Chemical Scrubber (V-06-301). The chemical scrubber is a packed bed scrubber which contracts the off-gas with a dilute caustic solution to absorb and neutralize acid gases.

Liquid recirculation to the scrubber is supplied by the Scrubber Circulation Pump (P-06-301). The circulating liquid can be cooled by indirect exchange with chilled water at $42^{\circ} \mathrm{F}$ using Scrubber Circulation Cooler (E-06-301). Process water makeup to the scrubber is accomplished via level control while pH is controlled by separate caustic makeup from the AMU. Blowdown from the scrubber circulation loop is controlled by a conductivity controller (with a minimum flow) and is directed to the active waste water collection and treatment system.

Treated off-gas from the scrubber, which is saturated air at approximataly $80^{\circ} \mathrm{F}$, is heated $10^{\circ} \mathrm{F}$ by Off-Gas Reheater (H-06-301) to prevent condensation and corrosion of the ductwork. Scrubber Off-Gas Blower (C-06-301) routes the off-gas to the Off-Gas Treatment System. 


\subsection{STUDY CRITERIA AND METHODOLOGY}

This HAZOPS has utilized a predetermined set of process deviations/upset conditions to be analyzed by the HAZOPS team. For each process deviation, possible courses were postulated and worst case consequences (without benefit of any safeguards) were determined. Existing safeguards (design and procedural) were then identified. Those safeguards which could be reasonably expected to be present in the final design were assumed to be existing and were so documented in the HAZOPS. For each cause and effect, hazard severity and probability were qualitatively assessed (taking credit for existing safeguards which reduce hazard probability) using the criteria shown in Table 1. The overall risk rating for each hazard was then determined using the risk ranking matrix shown on Table 2. Recommendations were proposed by the HAZOPS team in instances required by the implementation criteria shown in Table 2. 
TABLE 1

HAZARD SEVERITY AND PROBABILITY CLASSIFICATION CRITERIA

\begin{tabular}{|c|c|c|c|c|}
\hline \multirow{2}{*}{ Target Hazard } & \multicolumn{4}{|c|}{ Severity Class (Worst-case Scenario) } \\
\hline & Catastrophic (1) & Extensive (2) & Moderate (3) & Operational (4) \\
\hline Community & $\begin{array}{l}\text { Multiple irreversible } \\
\text { injuries; may include a } \\
\text { fatality }\end{array}$ & $\begin{array}{l}\text { Single irreversible or } \\
\text { several reversible injuries } \\
\text { (no fatalities) } \\
\text { OR }\end{array}$ & $\begin{array}{l}\text { Several reversible injuries } \\
\text { OR }\end{array}$ & \\
\hline Workers & $\begin{array}{l}\text { Fatalities or irreversible } \\
\text { injuries } \\
\text { OR }\end{array}$ & $\begin{array}{l}\text { Several injuries } \\
\text { OR }\end{array}$ & $\begin{array}{l}\text { Single injury } \\
\text { OR } \\
\end{array}$ & \\
\hline Facility & $\begin{array}{l}\text { Partial or full demolition of } \\
\text { facility } \\
\text { OR }\end{array}$ & $\begin{array}{l}\text { Rupture or similar loss of } \\
\text { containment } \\
\text { OR } \\
\end{array}$ & $\begin{array}{l}\text { Major equipment damage } \\
\text { leading to one month or } \\
\text { more facility downtime } \\
\text { OR }\end{array}$ & $\begin{array}{l}\text { Equipment damage } \\
\text { leading to several days of } \\
\text { facility downtime or other } \\
\text { operational penalty } \\
\text { OR }\end{array}$ \\
\hline Environment & $\begin{array}{l}\text { Major environmental } \\
\text { impact with significant } \\
\text { cleanup/liability costs }\end{array}$ & $\begin{array}{l}\text { Groundwater, soil, or } \\
\text { public sewer } \\
\text { contamination }\end{array}$ & $\begin{array}{l}\text { Minor spill or release } \\
\text { resulting in permit violation }\end{array}$ & \\
\hline
\end{tabular}

\section{LIKELIHOOD CLASSIFICATION}

\begin{tabular}{|l|l|}
\hline Highly Likely (1) & $\begin{array}{l}\text { Event has occurred at this facility - or - other facility - or - is expected to occur several times during the } \\
\text { next } 10 \text { years. }\end{array}$ \\
\hline Likely (2) & $\begin{array}{l}\text { Event has occurred at this facility - or - is possible to occur at this facility several times during the next } \\
30 \text { years. }\end{array}$ \\
\hline Unlikely (3) & $\begin{array}{l}\text { Event may have occurred at another facility - or - is possible to occur at this facility at least once in the } \\
\text { next } 50 \text { years. }\end{array}$ \\
\hline Extremely Unlikely (4) & $\begin{array}{l}\text { Event is not likely to ever occur in this facility, given a continuation of the current levels of training, } \\
\text { procedures, maintenance, inspection, testing, and other applicable process safety management system } \\
\text { support. }\end{array}$ \\
\hline
\end{tabular}


TABLE 2

RISK RANKING MATRIX AND IMPLEMENTATION CRITERIA

\begin{tabular}{|c|c|c|c|c|}
\hline Likelihood & & & & \\
\hline Highly Likely (1) & 4 & 2 & 1 & 1 \\
\hline Likely (2) & 5 & 3 & 2 & 1 \\
\hline Unlikely (3) & 6 & 4 & 3 & 2 \\
\hline Extremely Unlikely (4) & 7 & 6 & 5 & 4 \\
\hline & Operational (4) & Moderate (3) & Extensive (2) & Catastrophic (1) \\
\cline { 2 - 5 }
\end{tabular}

\section{RISK RANKING IMPLEMENTATION}

\begin{tabular}{|c|l|}
\hline Risk Ranking & \multicolumn{1}{c|}{ Implication } \\
\hline 1 & $\begin{array}{l}\text { Risk level - Very significant } \\
\text { Recommendation = Required from the HAZOPS team }\end{array}$ \\
\hline 2 & $\begin{array}{l}\text { Risk level - Significant } \\
\text { Recommendation = Required from the HAZOPS team }\end{array}$ \\
\hline 3 & $\begin{array}{l}\text { Risk level - Not very significant } \\
\text { Recommendation = Required from the HAZOPS team }\end{array}$ \\
\hline 4 & $\begin{array}{l}\text { Risk level - Not significant, but may be an operational problem } \\
\text { Recommendation = At the discretion of the HAZOPS team }\end{array}$ \\
\hline 5,6, or 7 & $\begin{array}{l}\text { Risk level - Negligible, but may be an operational problem } \\
\text { Recommendation = At the discretion of the HAZOPS team }\end{array}$ \\
\hline
\end{tabular}




\subsection{RESULTS AND CONCLUSIONS}

Because this HAZOPS is performed relatively early in the design phase, existing safeguards have not been fully documented on the process flow diagrams (these would mostly be shown on the P\&ID's developed during Title Design). However, the HAZOPS team assumed specific safeguards would be present in the final design if it appear reasonable to expect this. These assumed safeguards are documented on the HAZOPS worksheets and credit was taken for these presumed safeguards when assessing risk. During Title Design, the presence of these safeguards need to be verified to validate the conclusions of this HAZOPS.

Fifty-three potential safety and operability problems were identified and evaluated in the HAZOPS. Of these, 44 were assessed to have a negligible risk level. The remaining 9 involve potential hazards having a risk ranking of between significant and not significant. For these potential hazards, the HAZOPS team has recommended that additional safeguards be evaluated and incorporated into the WRAP 2A design. Table 3 presents a summary of changes to be made in the process flow diagram, assumed design safeguards, and additional safeguards to be evaluated for incorporation into the design.

In several instances, the need for human factors analyses and reliability/availability/maintainability analyses during Title Design was highlighted by the HAZOPS team to achieve negligible risk levels. The HAZOPS assumed that such analyses would be performed and that the necessary design requirements/modifications are incorporated. The performance of the design analyses are considered to be open issues to be resolved during Title Design. Similarly, the HAZOPS team identified the need for a maintainability analysis to develop requirements for warm maintenance at the WRAP $2 A$ Facility.

The HAZOPS is documented in the attached HAZOPS worksheets. 


\section{TABLE 3}

SPECIAL WASTE PROCESSING HAZOPS SUMMARY

\section{PROCESS FLOW DIAGRAM CHANGES}

1. Add bypass line around chemical scrubber.

2. Add sampling ports for glovebox.

3. Replace bagless transfer port with airlock door between gloveboxes.

4. Verify 1200 CFM flow rate through shredder.

5. Provide demister at top of chemical scrubber.

\section{ASSUMED DESIGN SAFEGUARDS}

1. See size reduction list.

2. Vent line from deactivation reactor.

3. Pressure relief for evaporator (sudden gas formation from container).

4. Sump in glovebox (chemical resistant materials of construction).

5. Insulated surface of evaporator.

6. Fittings used for equipment for changeout during life of facility.

7. Site glass on mercury decant vessel.

8. Monitoring of 12-hour batch cycle for evaporator.

9. Method to routinely check pH at scrubber.

\section{EVALUATE/INCORPORATE INTO TITLE I DESIGN}

1. Method to empty drum on sort table without breaking mercury glass containers.

2. Limit discharge hopper size (e.g., $1 / 2$ volume of drum volume) with level/weight indication.

3. Local HVAC hood at deactivation area inside glovebox.

4. Drum filling/loadout port (air tight containment).

5. Greater containment factor for glovebox. 


\section{TABLE.3}

SPECIAL WASTE PROCESSING HAZOPS SUMMARY (CONTINUED)

6. Calculate glovebox's capability to withstand explosion blastwave.

7. Collection pot in vent line from deactivation reactor.

8. Exothermic possibility of mercury amalgamation.

9. Locate motors outside glovebox when feasible.

10. Back up nitrogen supply for evaporator purging.

11. Glovebox fire protection/suppression.

12. Separation of incompatible chemicals present in glovebox.

13. Sloping of glovebox floor toward sump.

14. Latent heat from evaporator causing glovebox positive pressure upon loss of glovebox HVAC.

15. Vacuum system for glovebox cleanup (glass on floor).

16. Glovebox materials of construction (chemical resistant)

17. Additional drum loadout port(s) for operating flexibility (simultaneous operations).

18. Avoid shredding lead objects (jams up shredder).

19. Capability to evaporate mercury compounds.

20. Ease of maintenance for evaporator heater element.

21. Capability to test hoist inside glovebox (or replace hoist).

22. Hot maintenance requirements with decontamination.

23. Human factors engineering.

24. Ease of maintenance for shredder (e.g., hoist outside glovebox).

25. Sampling at sort table (turnaround time, waste storage) and at glovebox sump, and special waste treating enclosure.

26. Ion exchange in waterline in active waste collection for mercury.

27. Eliminate off-gas blower (provide redundant blower?).

28. Fail safe overflow of scrubber (relative to heights of glovebox off gas line and HVAC line). 


\section{SPECIAL WASTE PROCESSING HAZOPS SUMMARY (CONTINUED)}

29. Capability to drain scrubber for extended shutdown.

30. Separate vacuum discharge line and glovebox off gas line (glovebox pressure control).

31. Capability to sample scrubber blowdown (automatic water sampler).

32. Closed circuit TV for glovebox operations.

33. Glovabox horizontal arrangement versus vertical arrangement.

34. Evaporator off gas smoking ( $\mathrm{CO}$ and $\mathrm{CO}_{2}$ explosion (loss of nitrogen purge).

35. Eyewash/safety shower for work aroa handling chemicals.

36. Purging at shredder. 


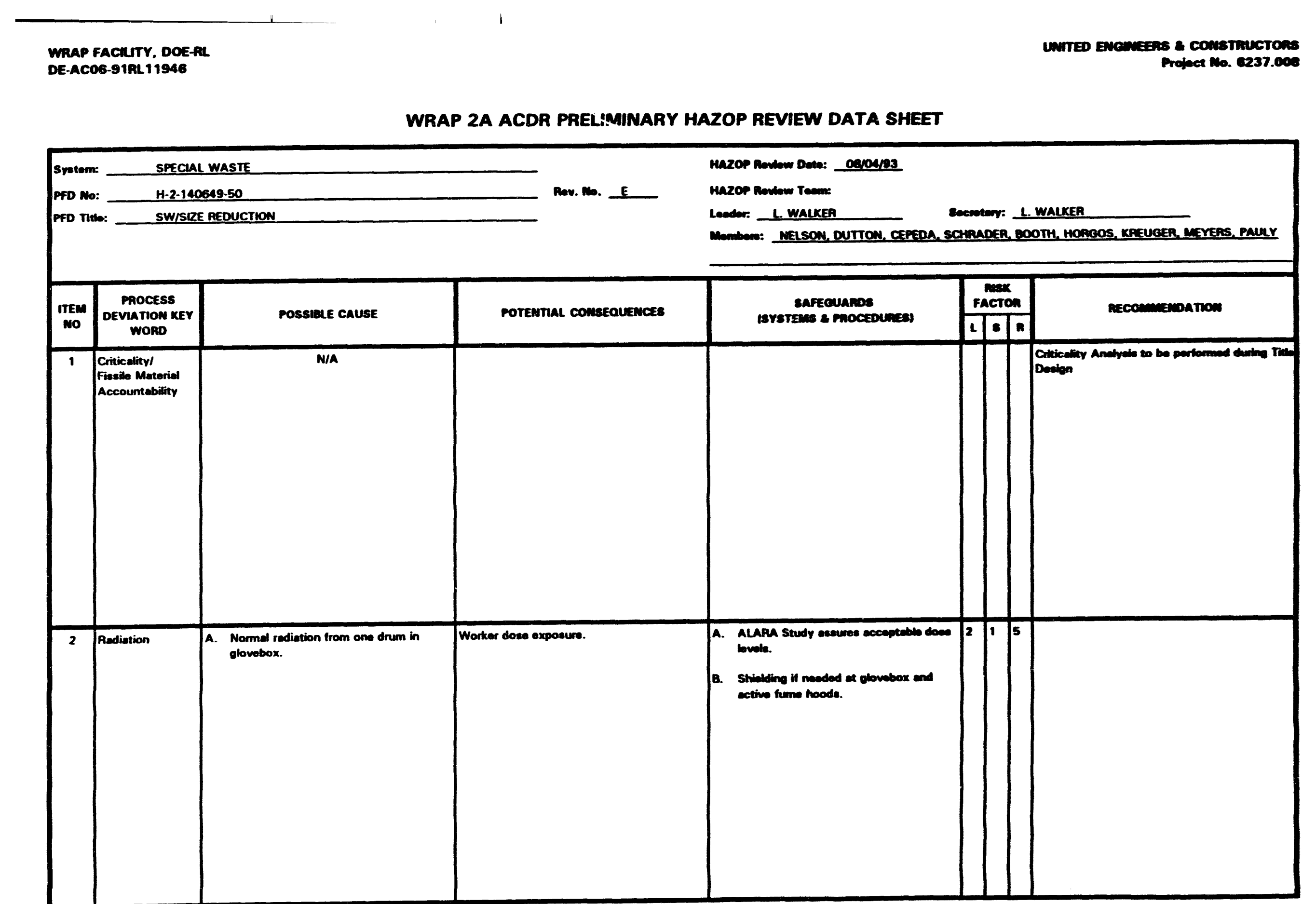




\section{WRAP 2A ACDR PRELIMINARY HAZOP REVIE DATA SHEET}

\begin{tabular}{|c|c|c|c|c|c|c|c|}
\hline 3 & $\begin{array}{l}\text { Aedionecelide } \\
\text { Contsinment }\end{array}$ & $\begin{array}{l}\text { A. Overim losdout dnum at 00-08-102 and } \\
\text { Do-06-201 }\end{array}$ & 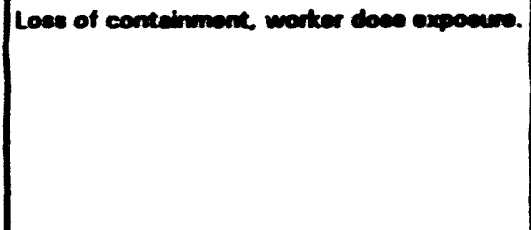 & 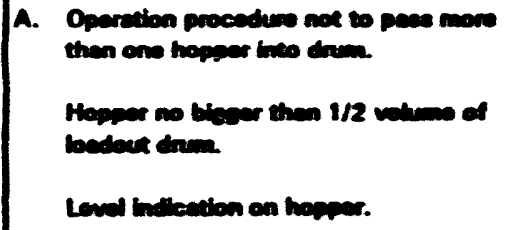 & 42 & 5 & \\
\hline 4 & 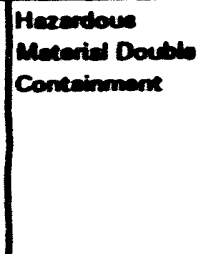 & 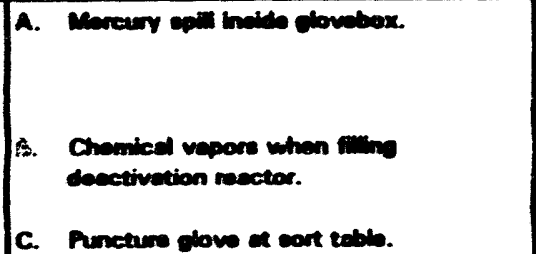 & 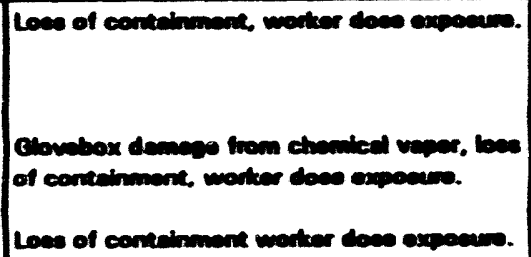 & 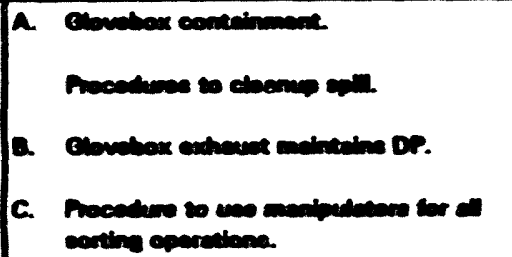 & $4 \int_{2}^{2}$ & 6 & 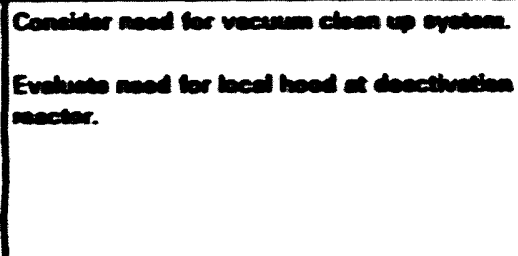 \\
\hline
\end{tabular}


WRAP 2A ACDR PRELMIMARY HAZOP REMEW DATA SHEET

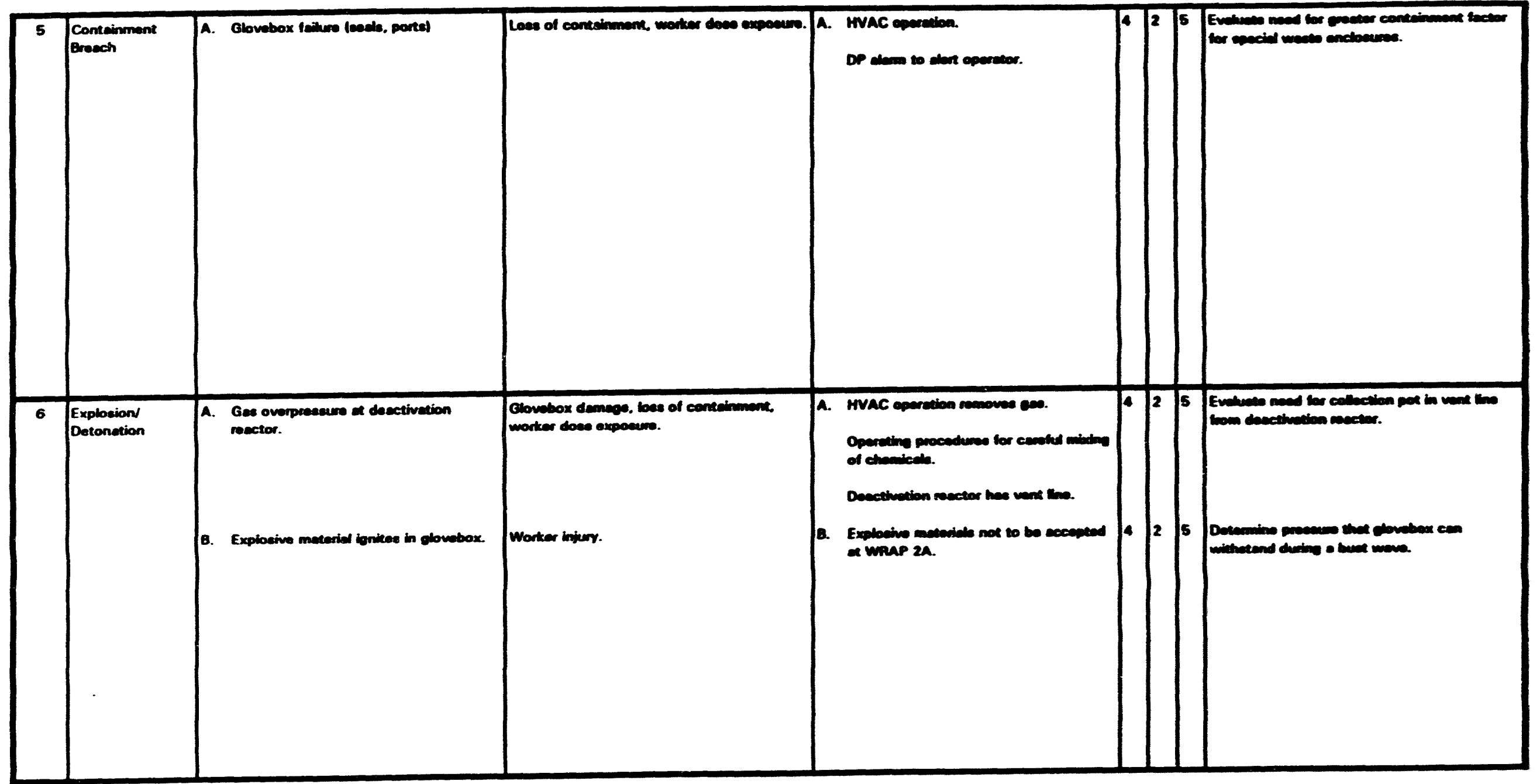




\section{WRAP 2A ACDR PRELIMIMARY HAZOP REVIEW DATA SHEET}

\begin{tabular}{|c|c|c|c|c|c|c|c|}
\hline 7 & Fine & 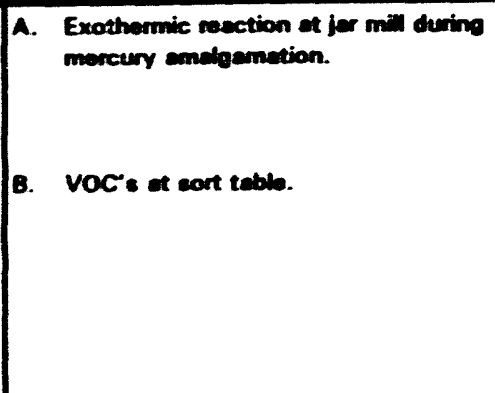 & 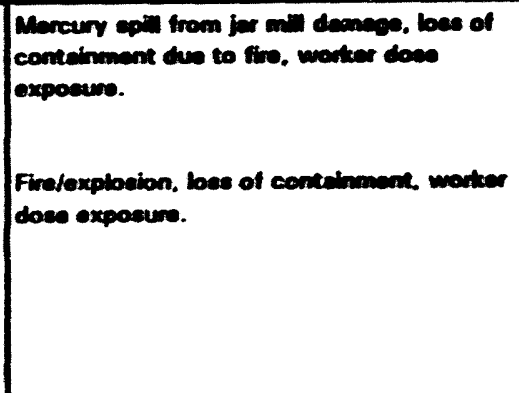 & 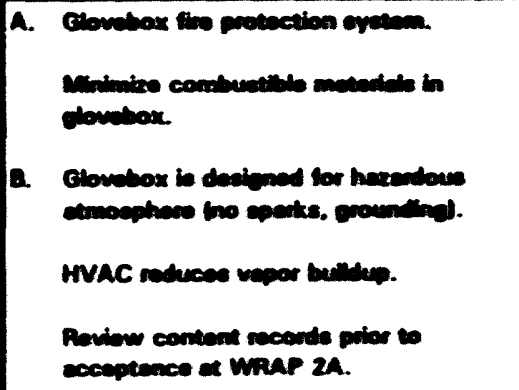 & $4]^{2}$ & 5 & 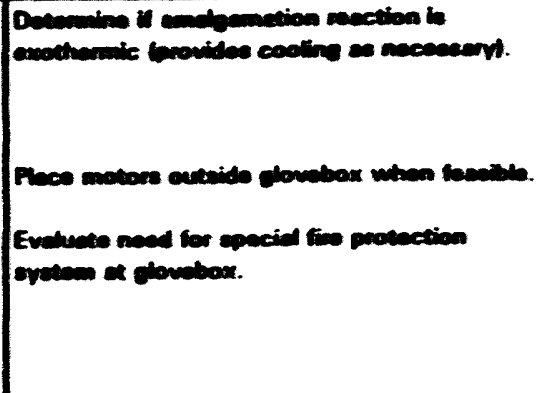 \\
\hline 8 & $\begin{array}{l}\text { Flommable } \\
\text { Meterielal } \\
\text { Combuatible } \\
\text { Atmoephere }\end{array}$ & 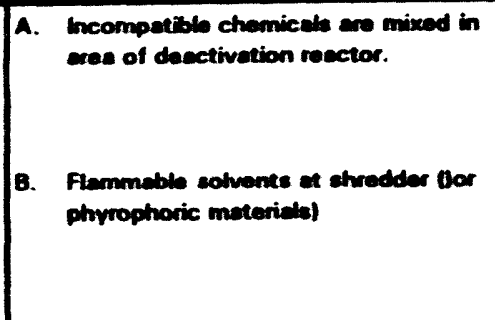 & 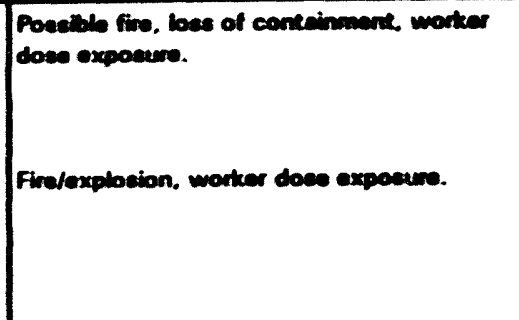 & 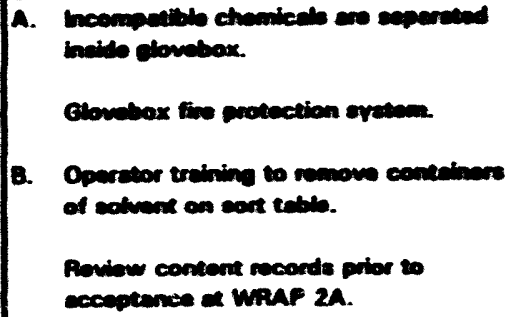 & $3 / 2$ & 3 & 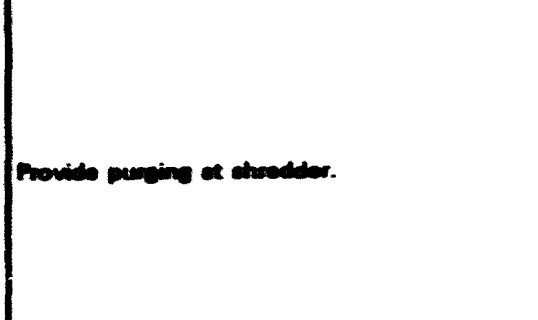 \\
\hline
\end{tabular}


WRAP $2 A$ ACDR PRELUMUARY HAZOP REMEW DATA SHEET

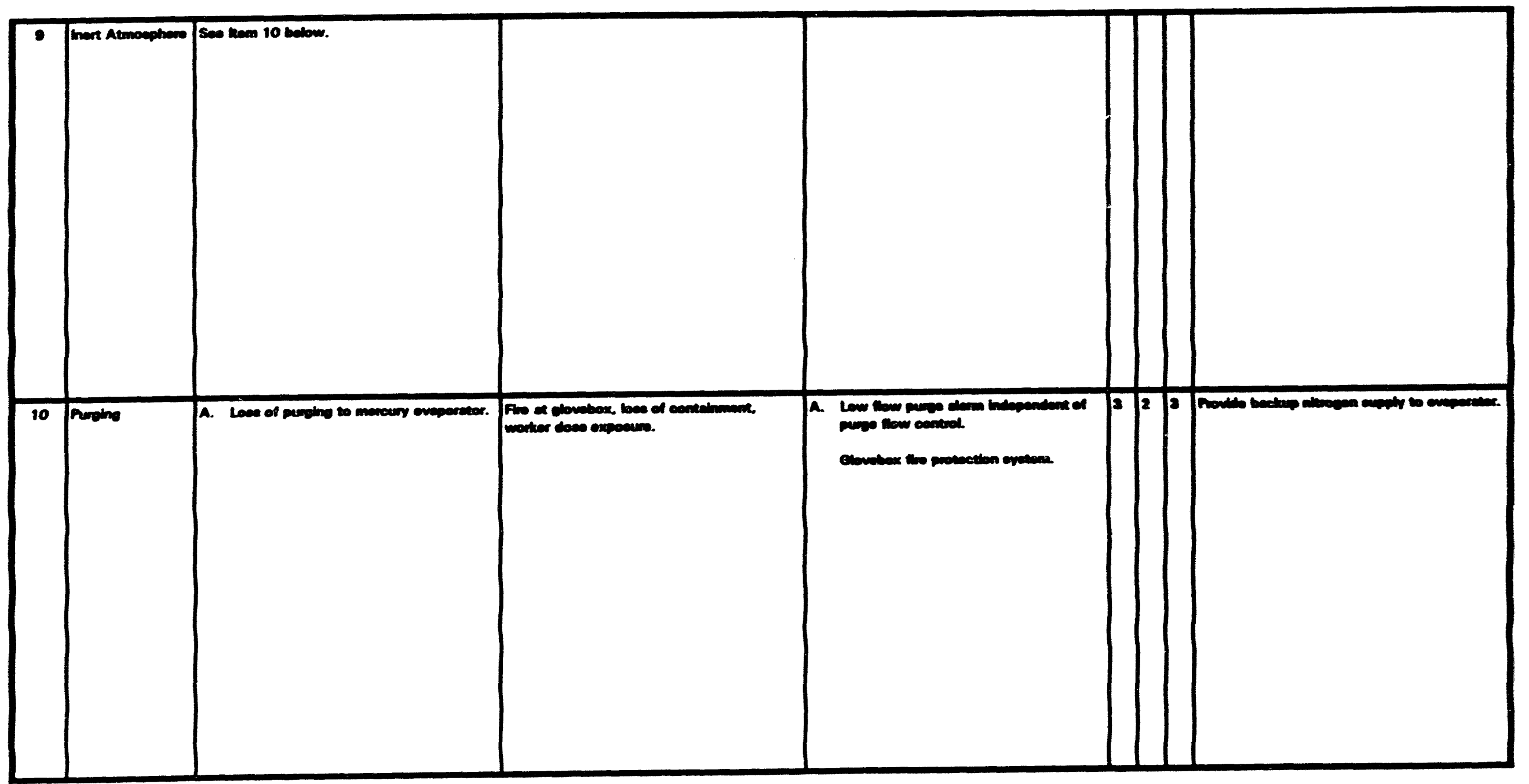




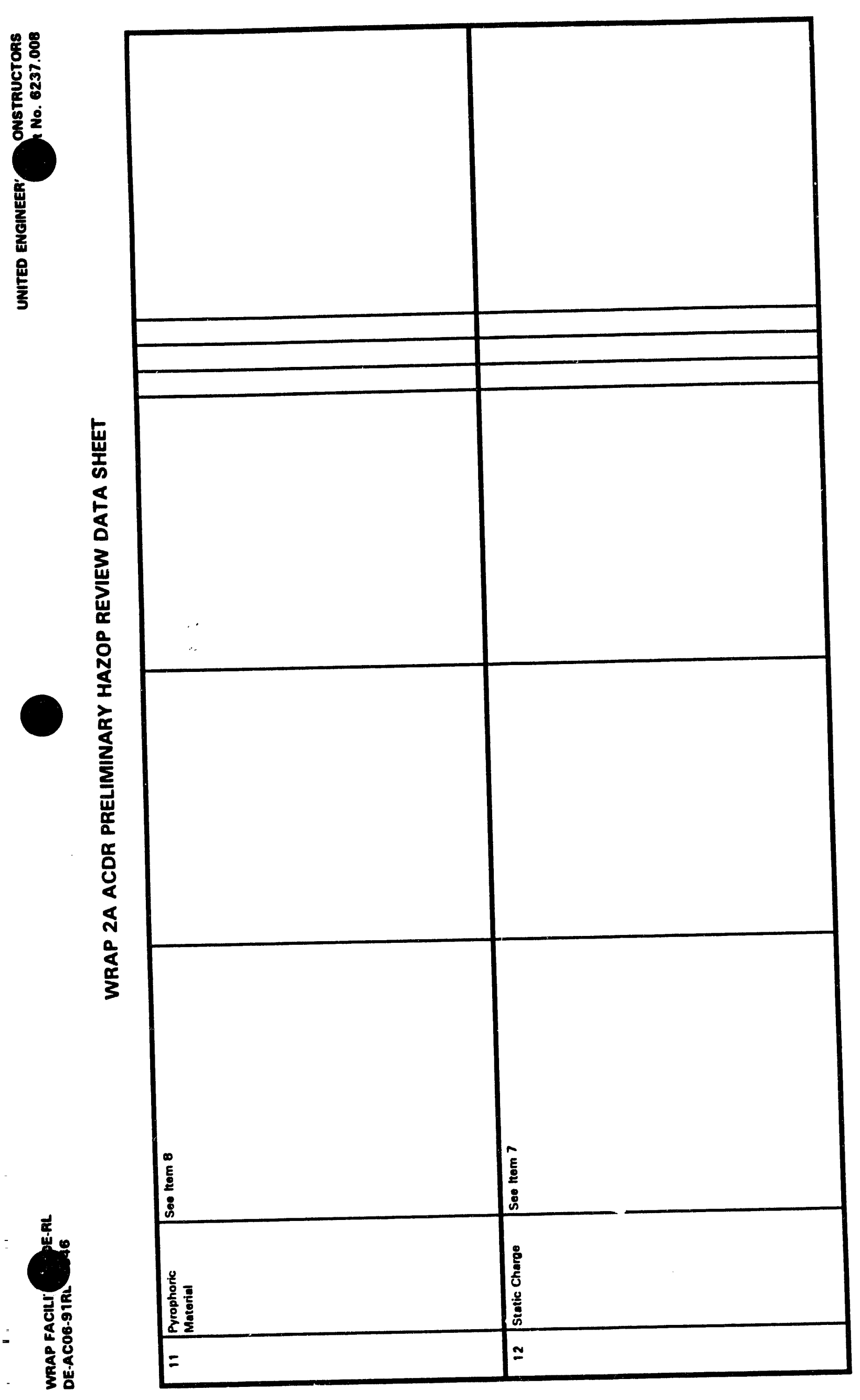




\section{WRAP 2A ACDR PRELIMINARY HAZOP REVIEW DATA SHEET}

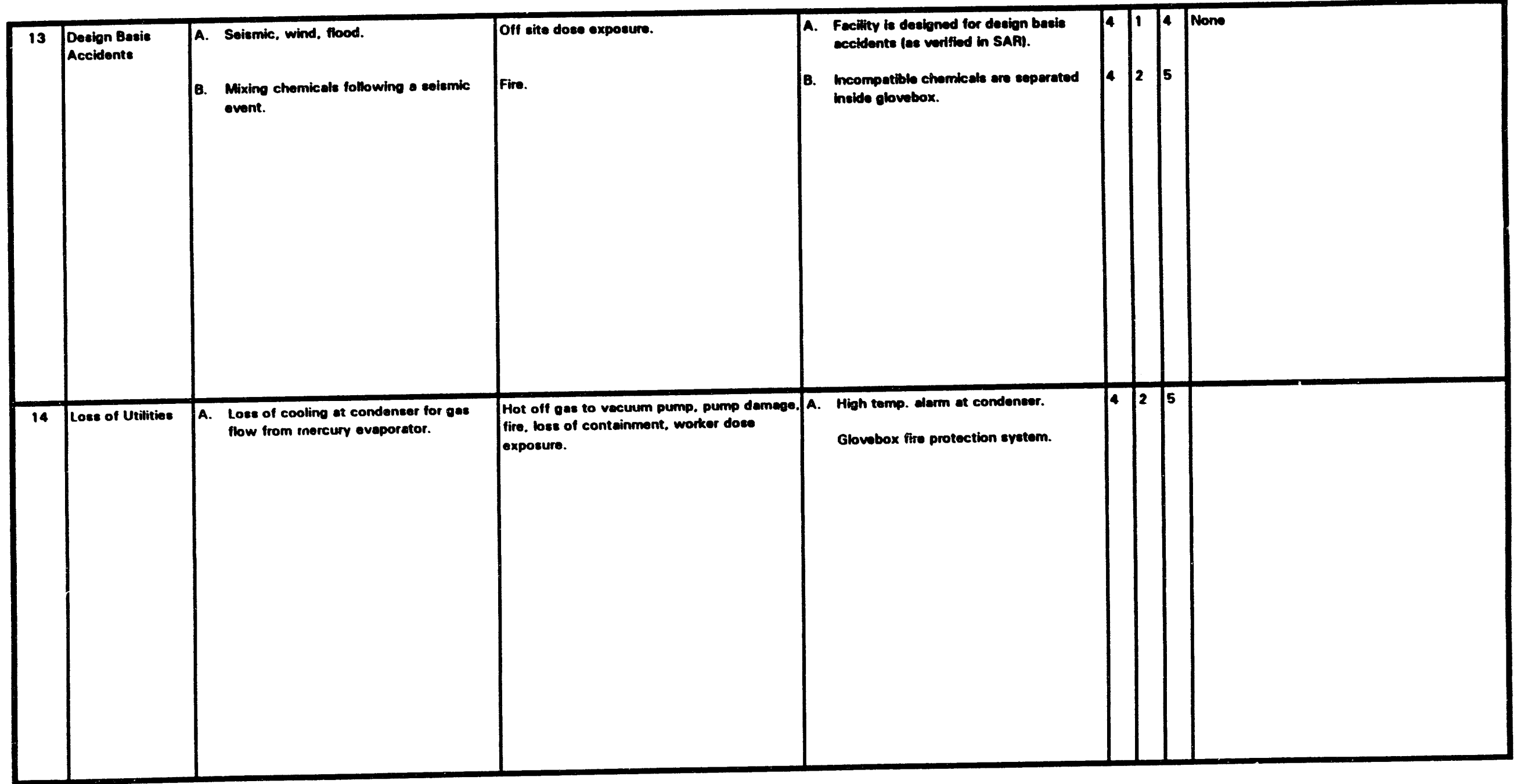


WRAP 2A ACDR PRELIMINARY HAZOP REVIEW DATA SHEET

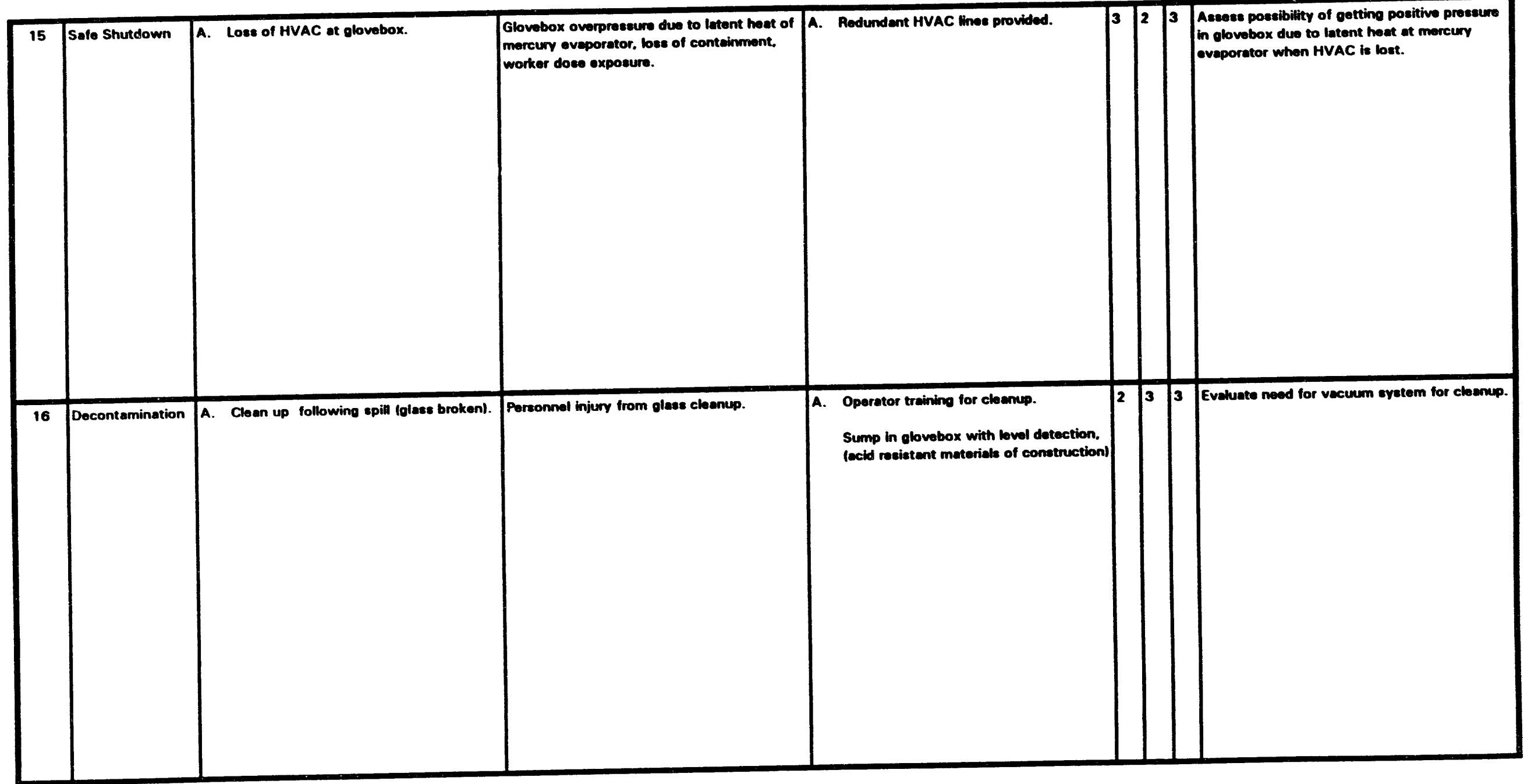


WRAP 2A ACDR PRELIMINARY HAZOP REVIEW DATA SHEET

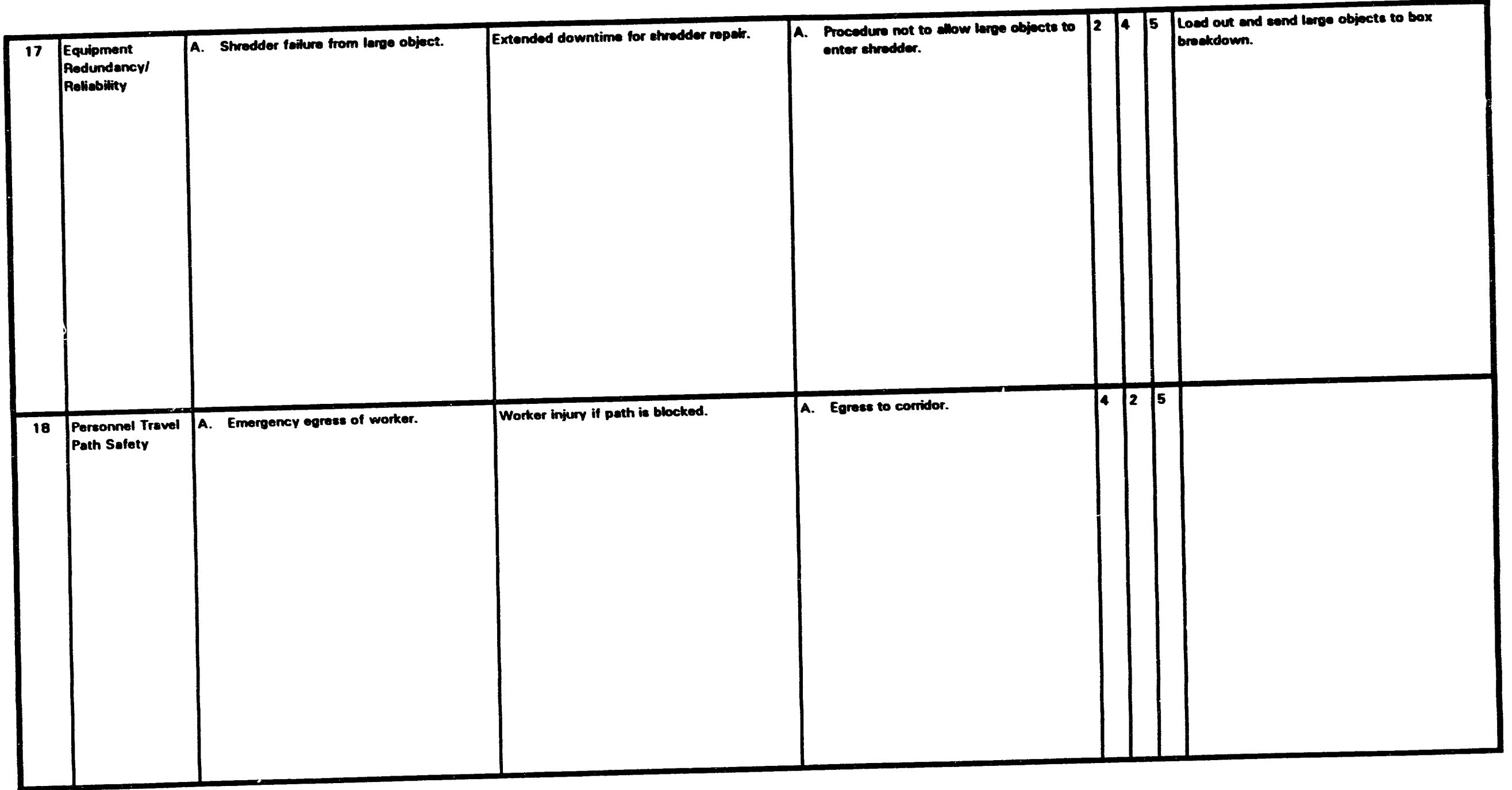


WRAP 2A ACDR PRELIMINARY HAZOP REVIEW DATA SHEET

\begin{tabular}{|c|c|c|c|c|c|c|c|}
\hline 21 & \begin{tabular}{|l|} 
Toxicityl \\
Dose Upteke
\end{tabular} & No edditional hazerds identifiod. & & & & & \\
\hline 22 & Noise & $\begin{array}{l}\text { A. Noize oenerated by mochenical } \\
\text { equipment le.9.. strodder) }\end{array}$ & Worker discomfort, possible injury. & 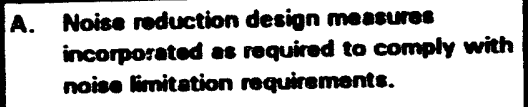 & \begin{tabular}{ll|}
4 & 3
\end{tabular} & 6 & \\
\hline
\end{tabular}




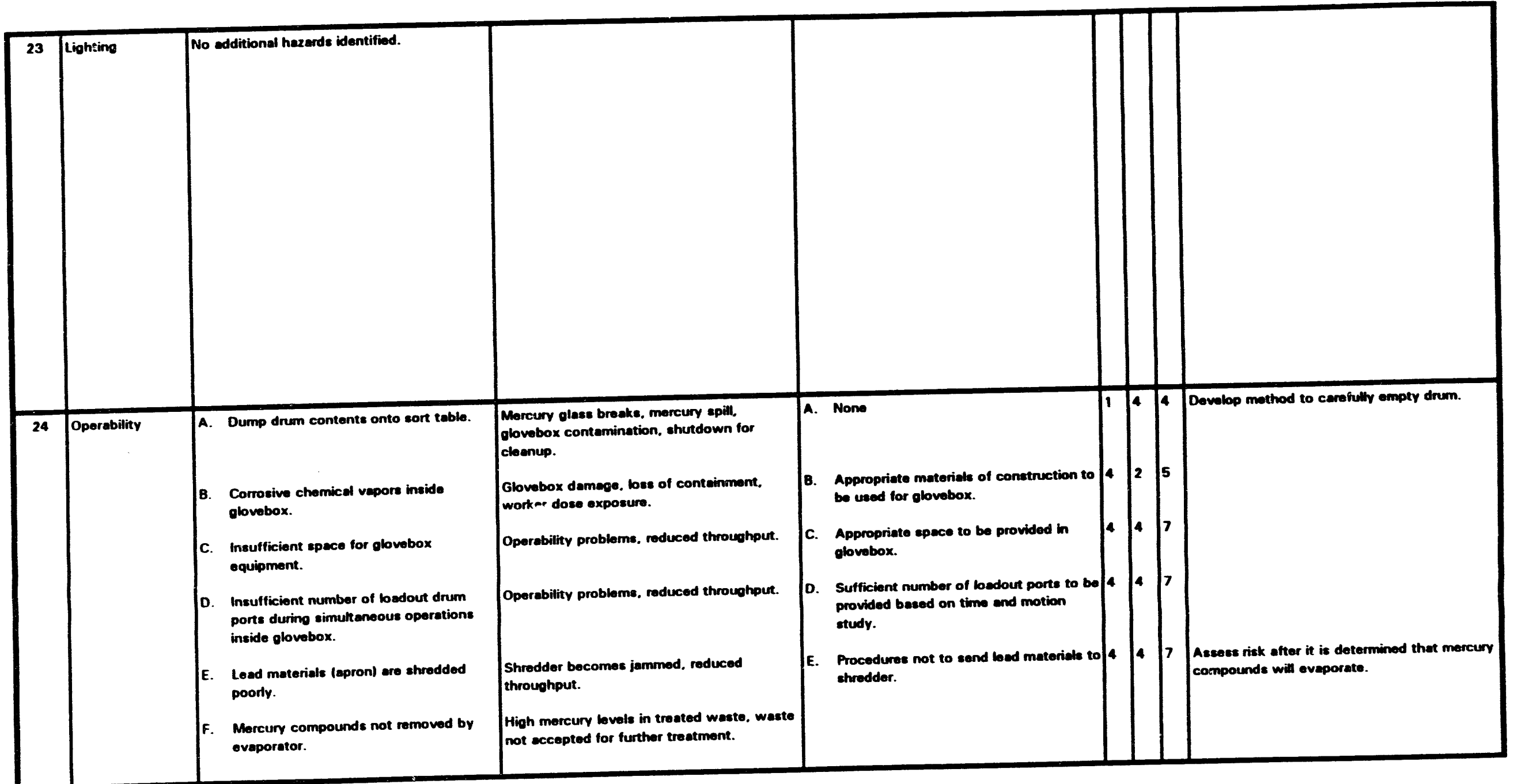


WRAP 2A ACDR PRELIMINARY HAZOP REVIEW DATA SHEET

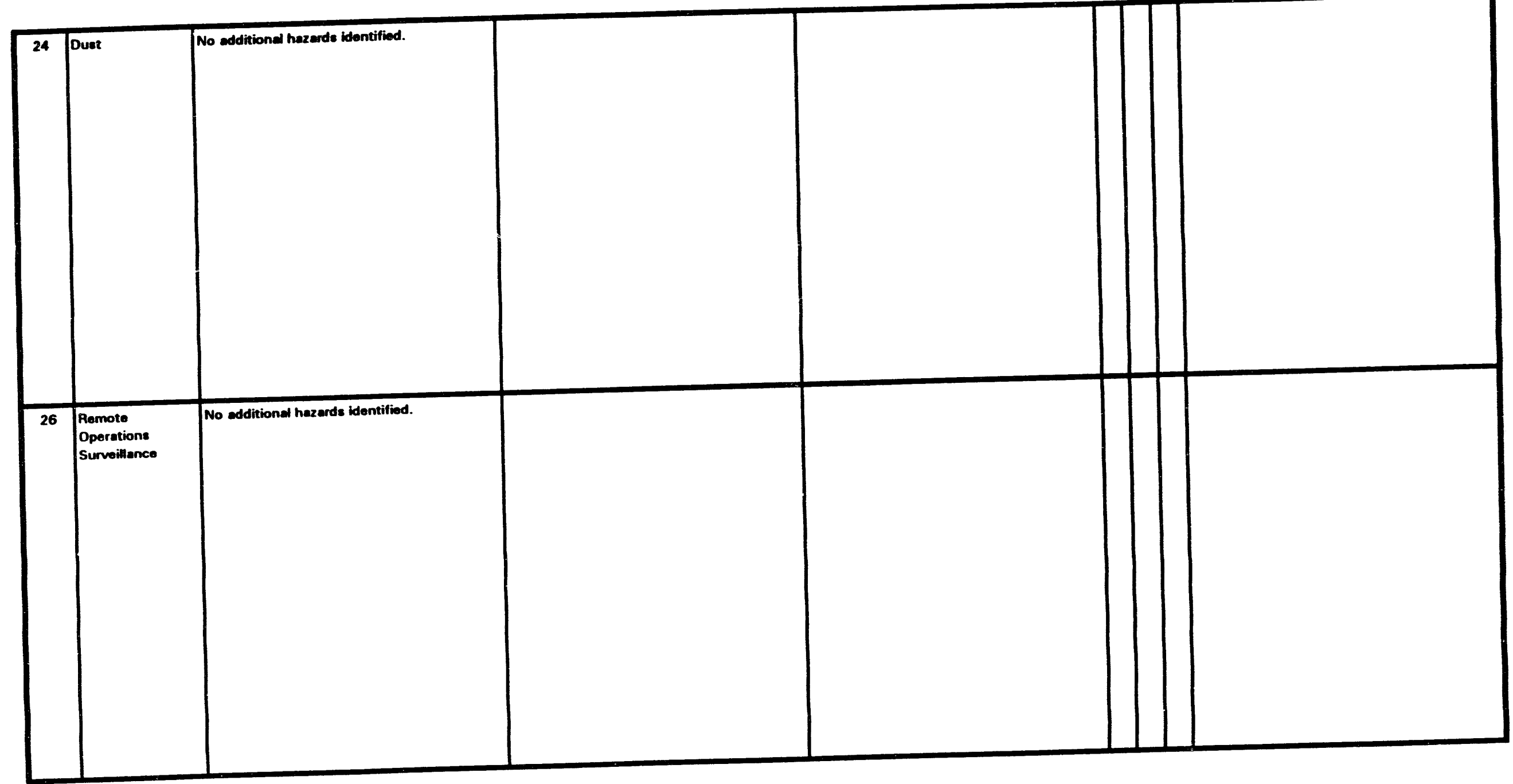


WRAP 2A ACDR PRELIMINARY HAZOP REVIEW DATA SHEET

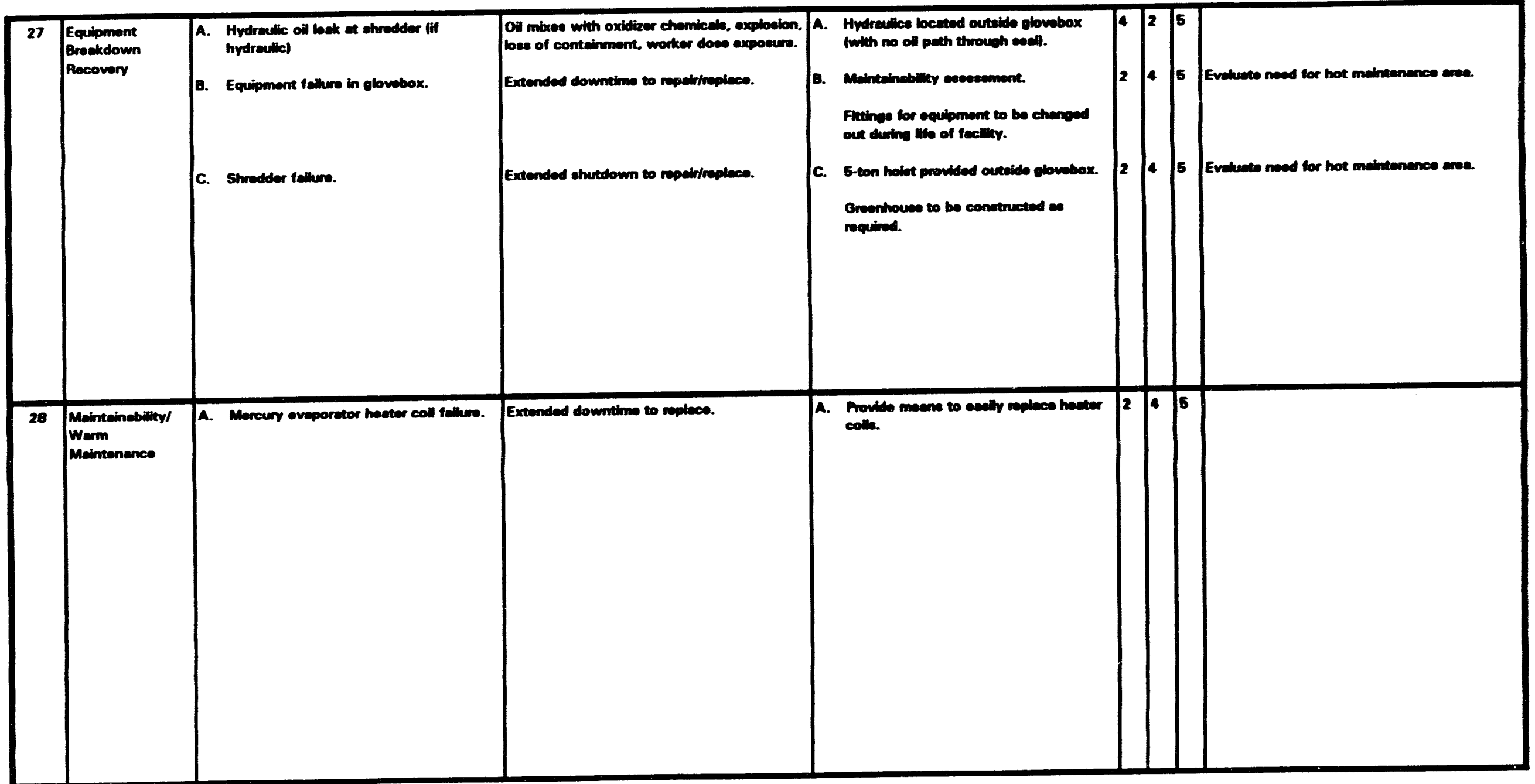




\section{WRAP 2A ACDR PRELIMINARY HAZOP REVIEW DATA SHEET}

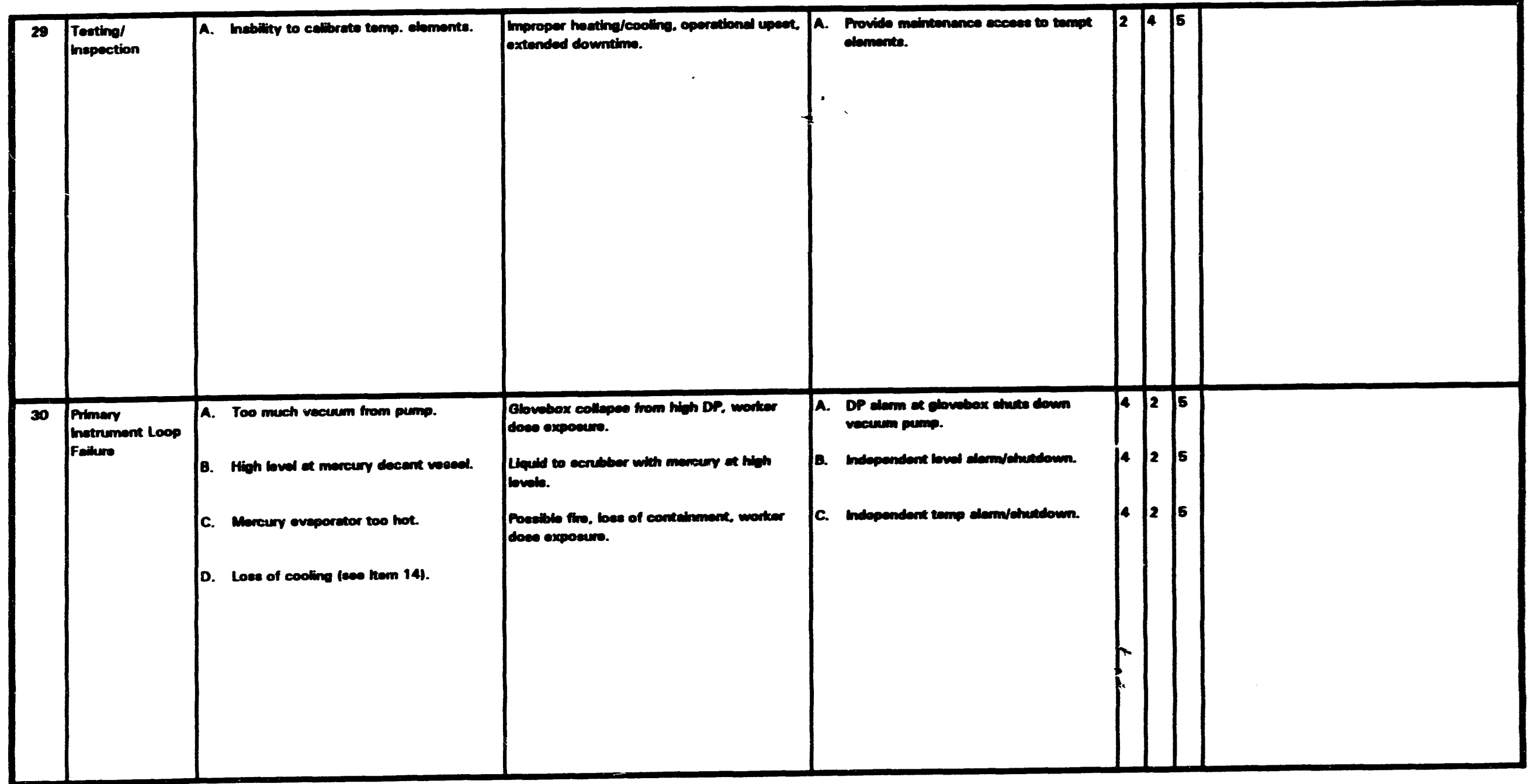



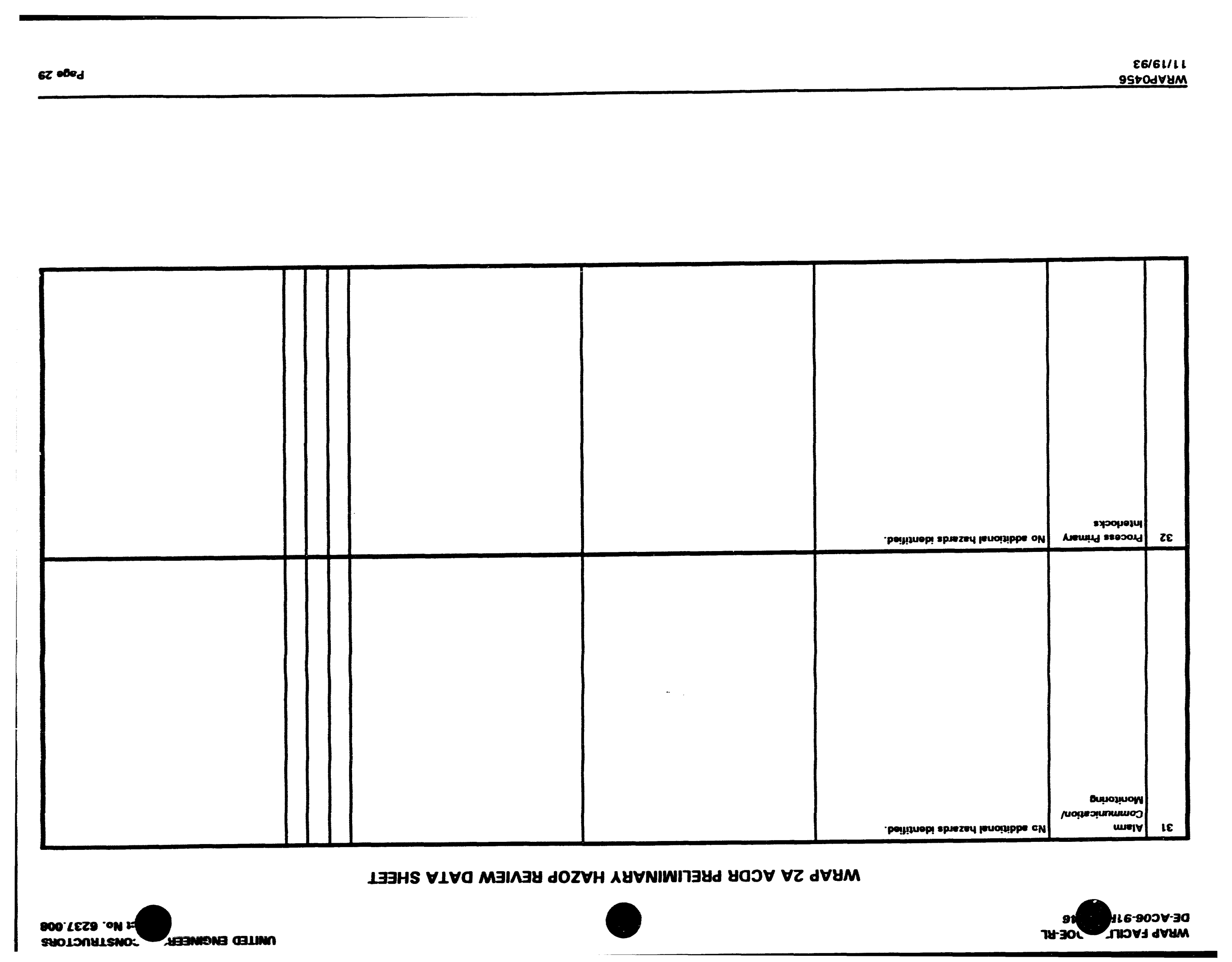
WRAP 2A ACDR PRELIMINARY HAZOP REVIEW DATA SHEET

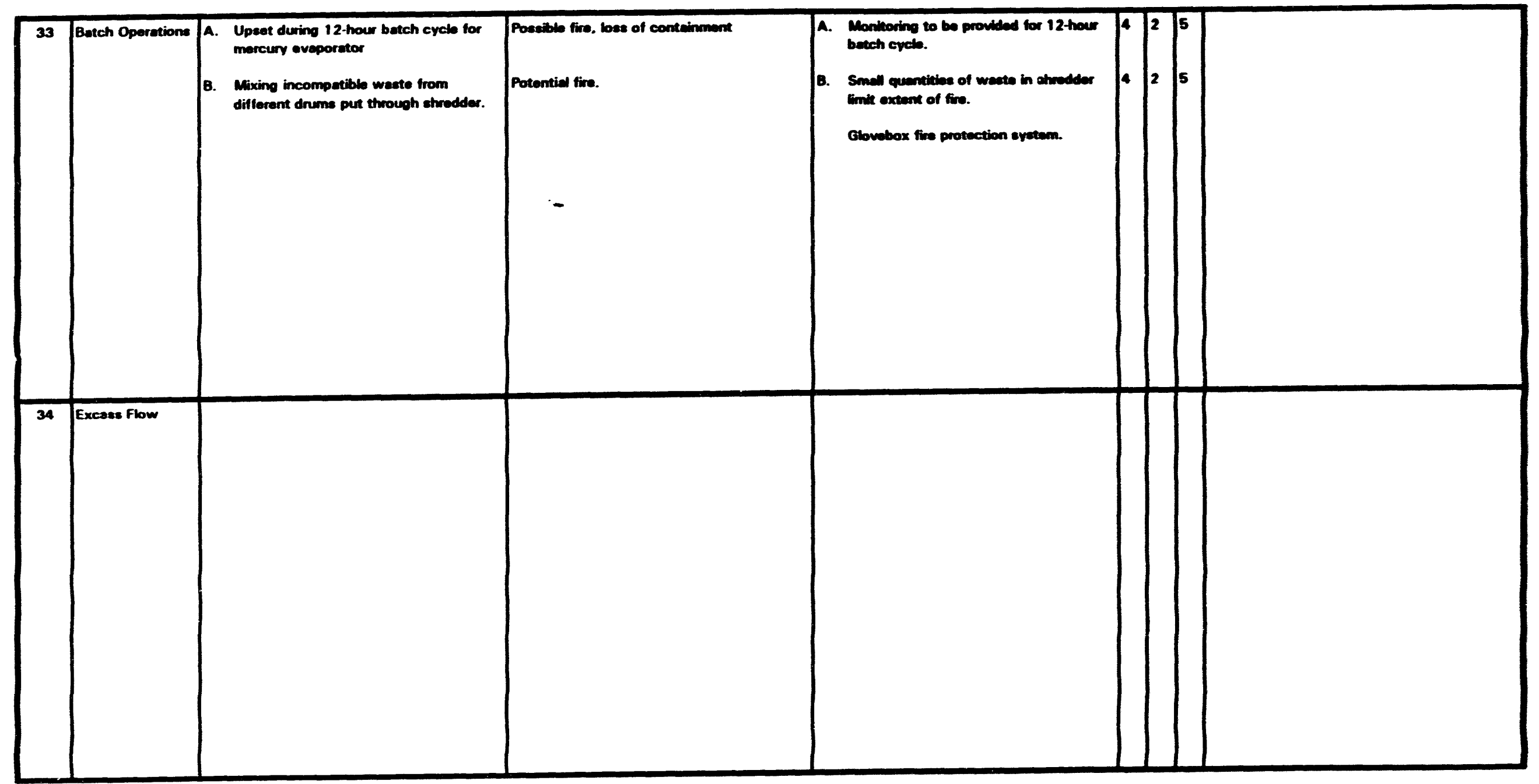


WRAP 2A ACDR PRELIMINARY HAZOP REVIEW DATA SHEET

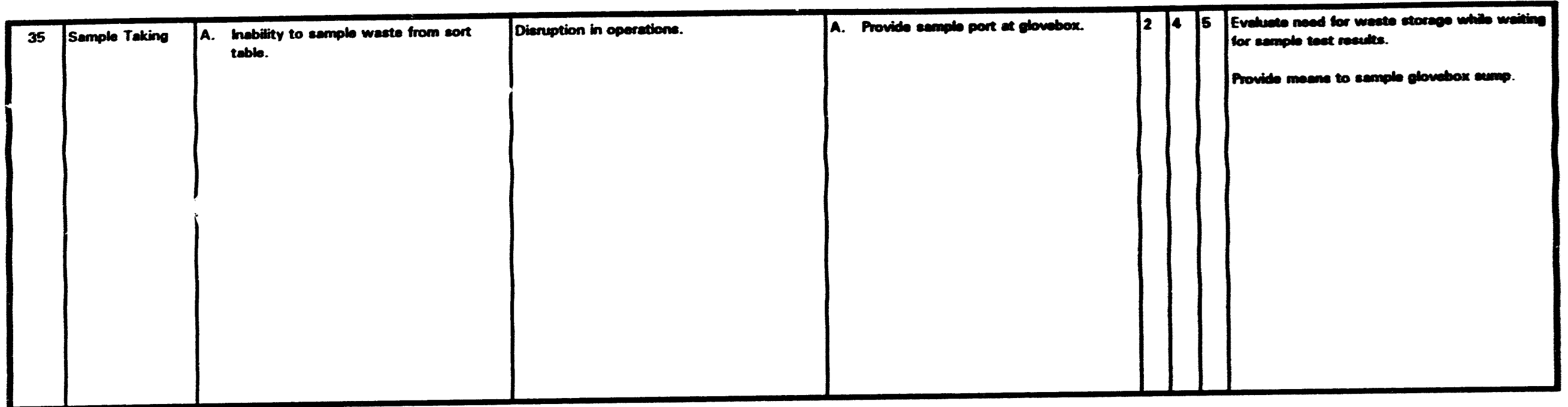




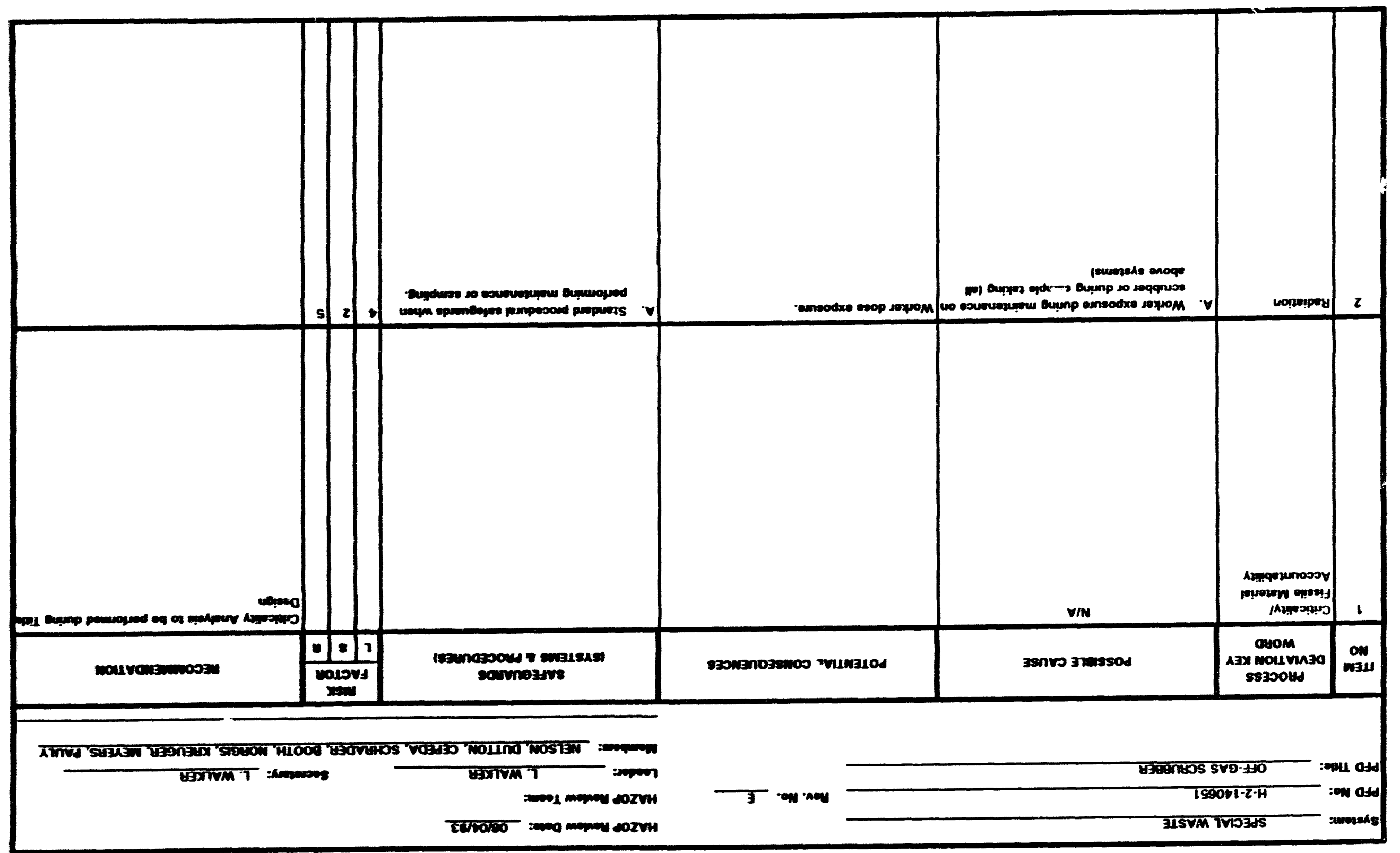



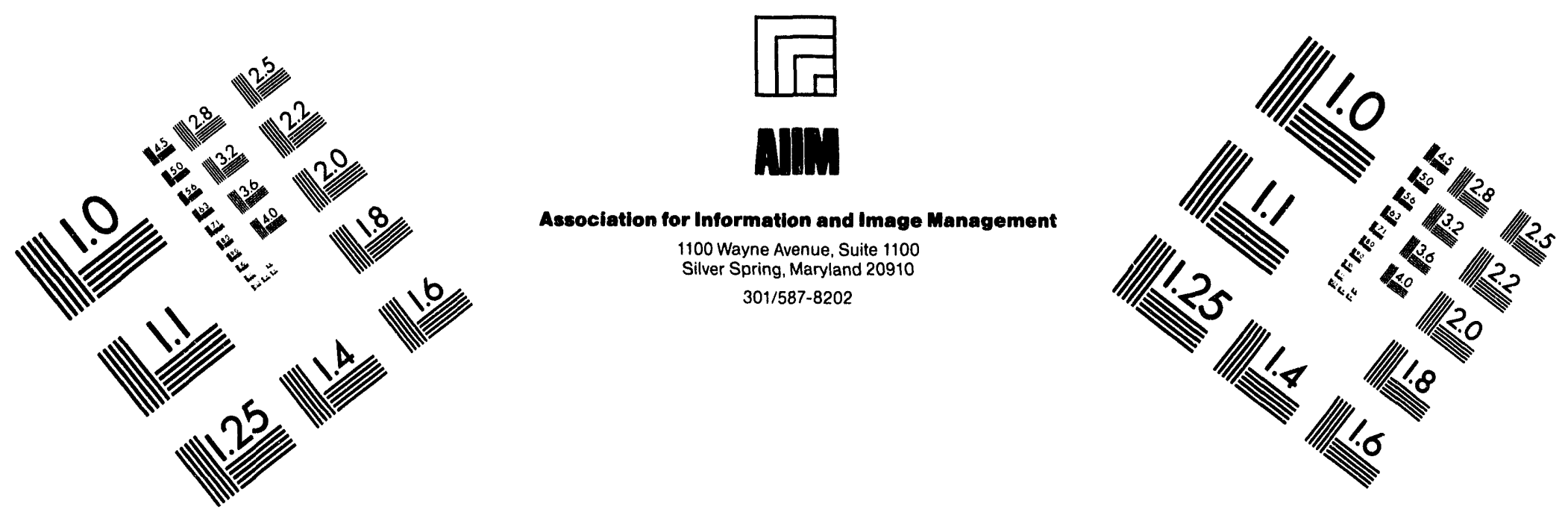

\section{Centimeter}

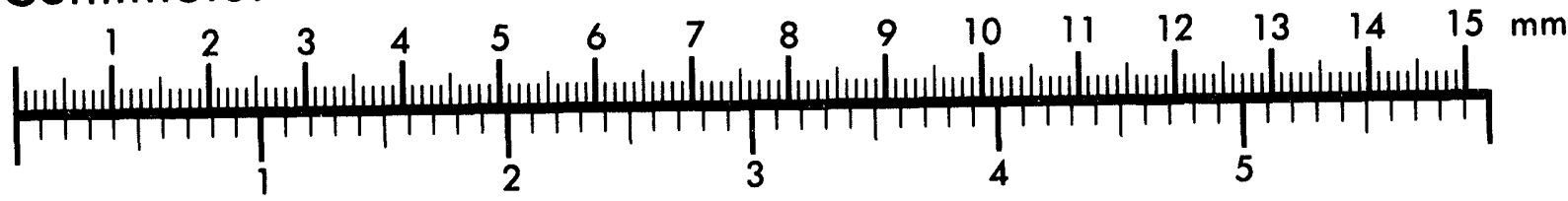
Inches
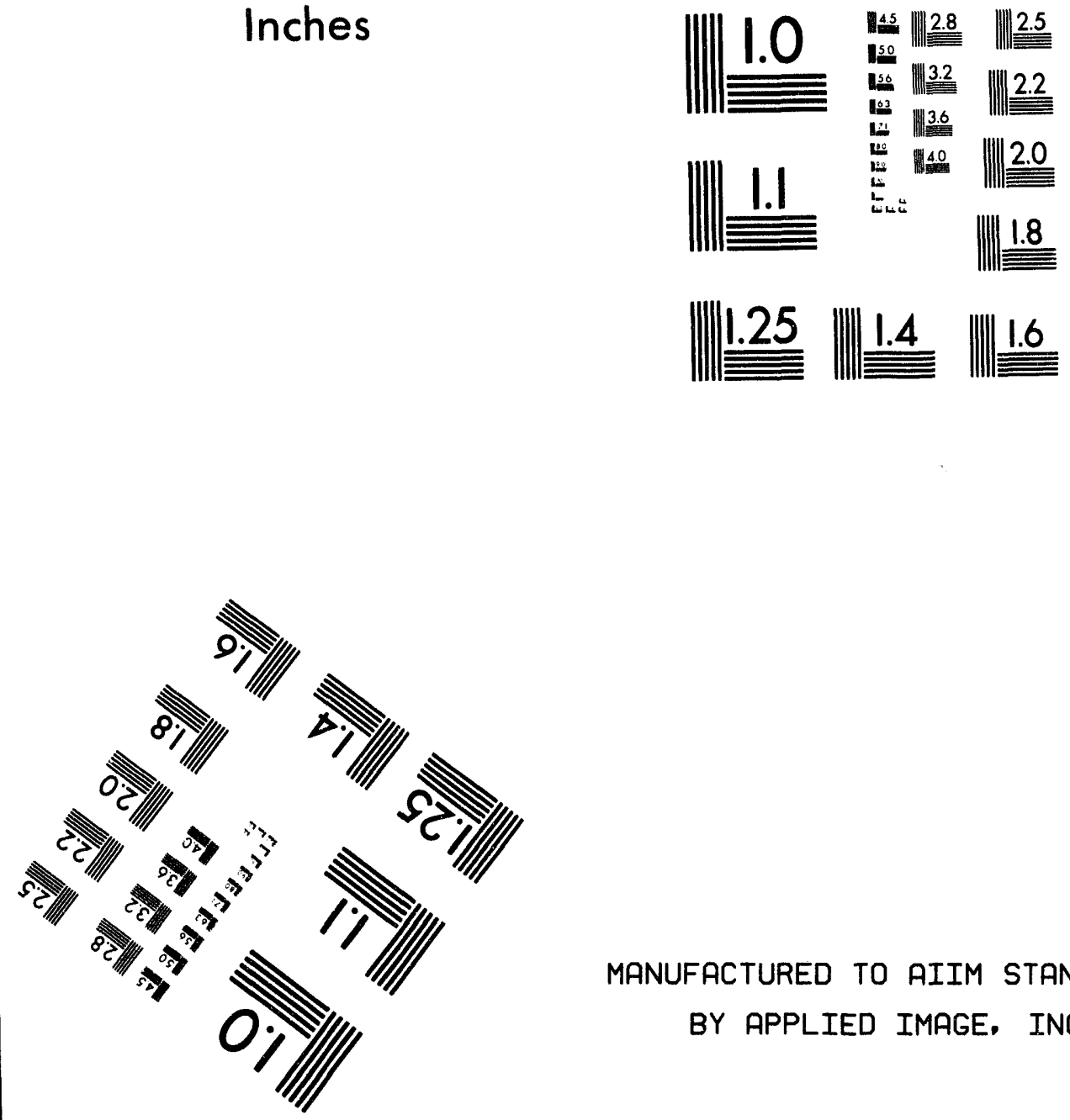

MANUFACTURED TO AIIM STANDARDS

BY APPLIED IMAGE, INC.

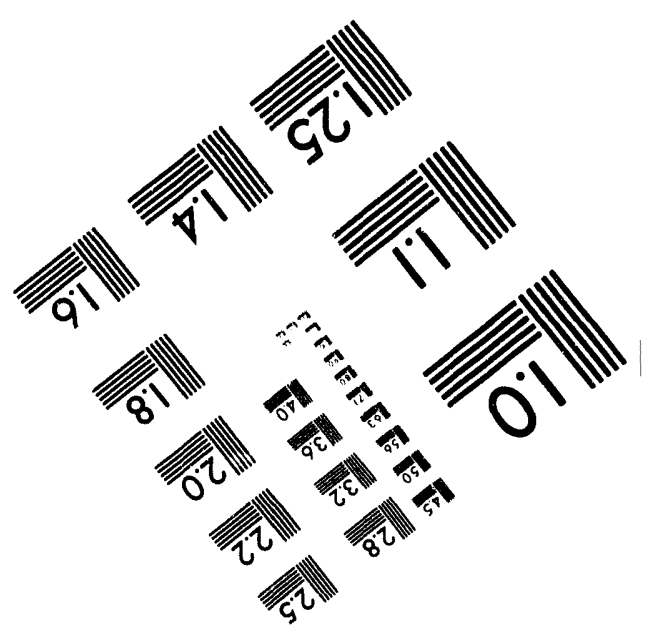



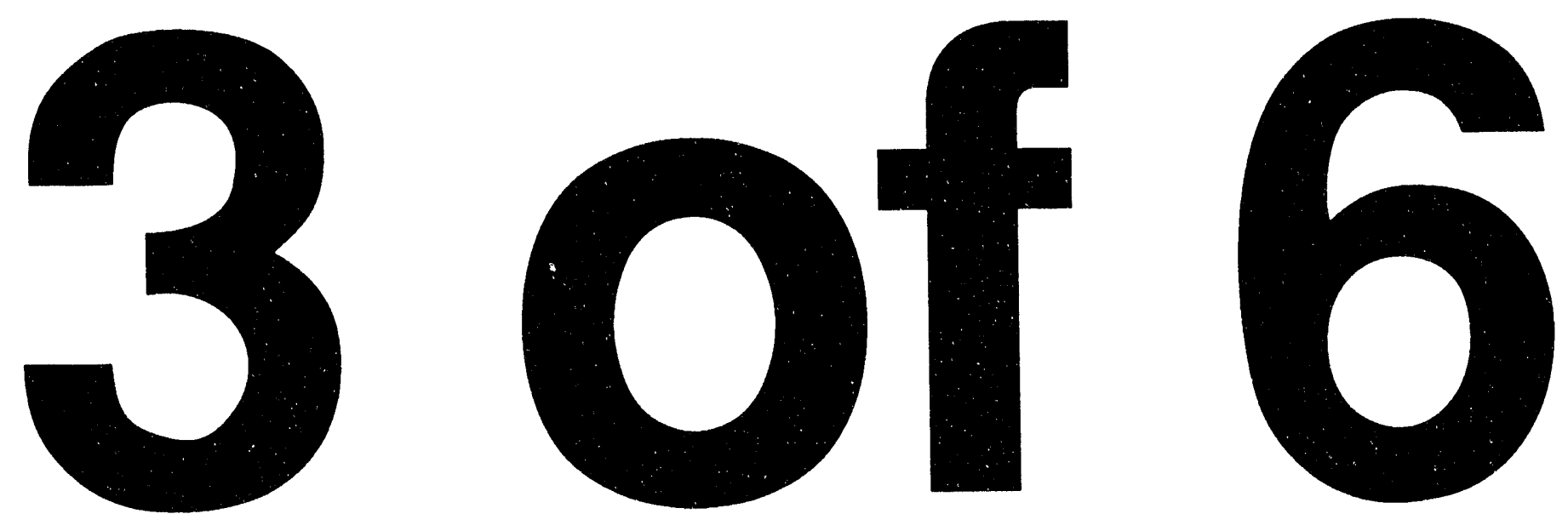
WRAP 2A ACDR PRELIMINARY HAZOP REVIEW DATA SHEET

\begin{tabular}{|c|c|c|c|c|c|c|c|c|}
\hline 3 & \begin{tabular}{|l|} 
Radionuclide \\
Containment
\end{tabular} & $\begin{array}{l}\text { A. Loss of scrubbing operation (scrubbes } \\
\text { runs } d r y \text { ) } \\
\text { B. Scrubber exhaust fan failure. }\end{array}$ & $\begin{array}{l}\text { Radionetive Mercury of extive material past } \\
\text { scrubber, worker dose exposuro. } \\
\text { onvironmental roloses. } \\
\text { Loss of glovebox DP. worker dose exposure. }\end{array}$ & $\begin{array}{l}\text { A. HEPA fiters downstream of scrubber. } \\
\text { Independent lovel alerm at scrubber. } \\
\text { B. Main HVAC inns downstream may } \\
\text { maintein negative preseure at olovebox } \\
\text { (controls to be defined). }\end{array}$ & 2 & 2 & 2 & $\begin{array}{l}\text { Evaluate need for backup scrubber exhaust fan } \\
\text { or can this fan be eliminated due to } \\
\text { appropriate aizing/control of main HVAC fans. }\end{array}$ \\
\hline 4 & $\begin{array}{l}\text { Hazardour } \\
\text { Material Double } \\
\text { Containment }\end{array}$ & A. Leak in off-gas oxhaust line. & Worker dose exposure. & $\begin{array}{l}\text { A. HVAC operation mainteins negative } \\
\text { pressure. } \\
\text { Radiation monitoring in work area. }\end{array}$ & 14 & 2 & 5 & \\
\hline
\end{tabular}


WRAP 2A ACDR PRELIMINARY HAZOP REVIEW DATA SHEET

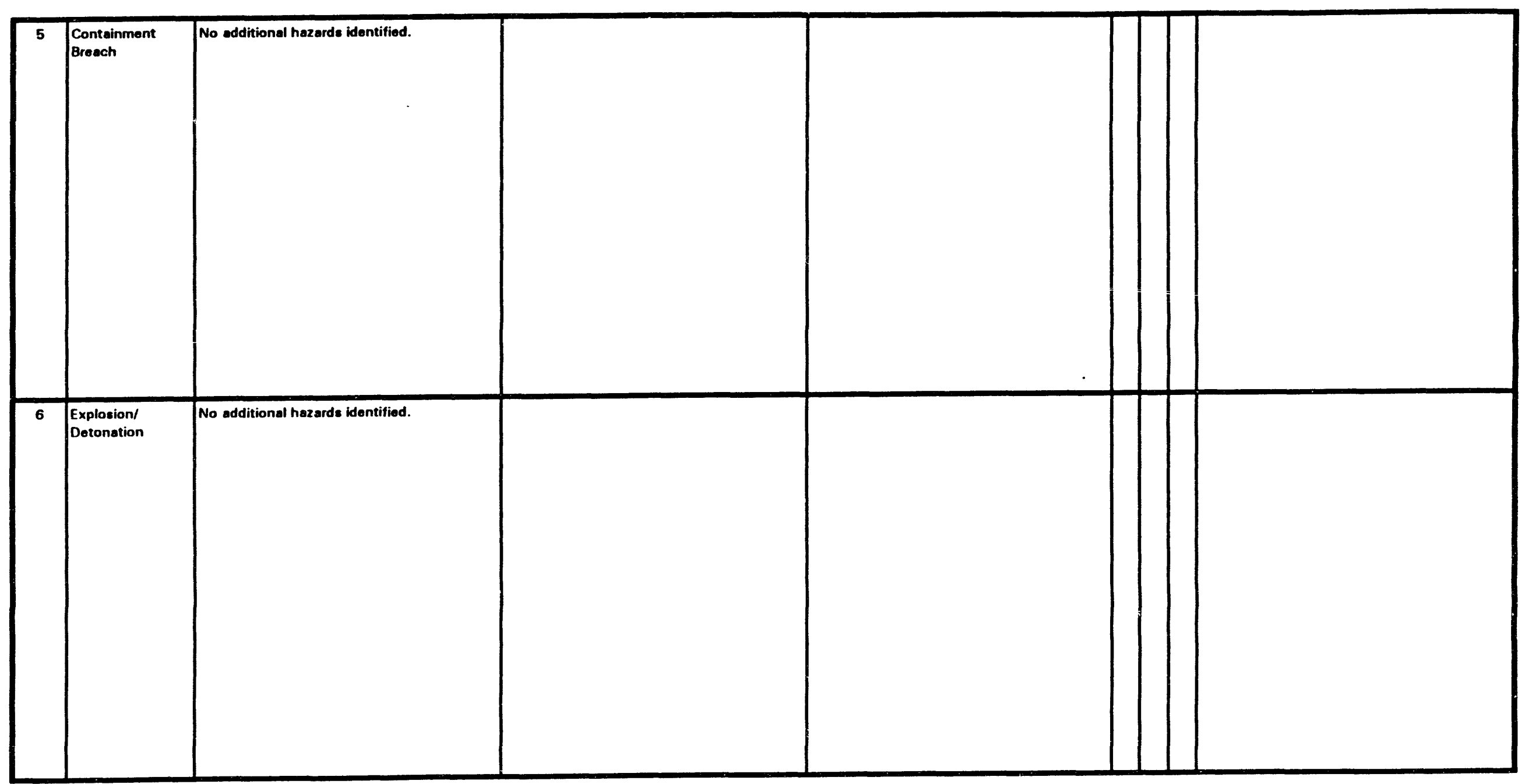


WRAP 2A ACDR PRELIMINARY HAZOP REVIEW DATA SHEET

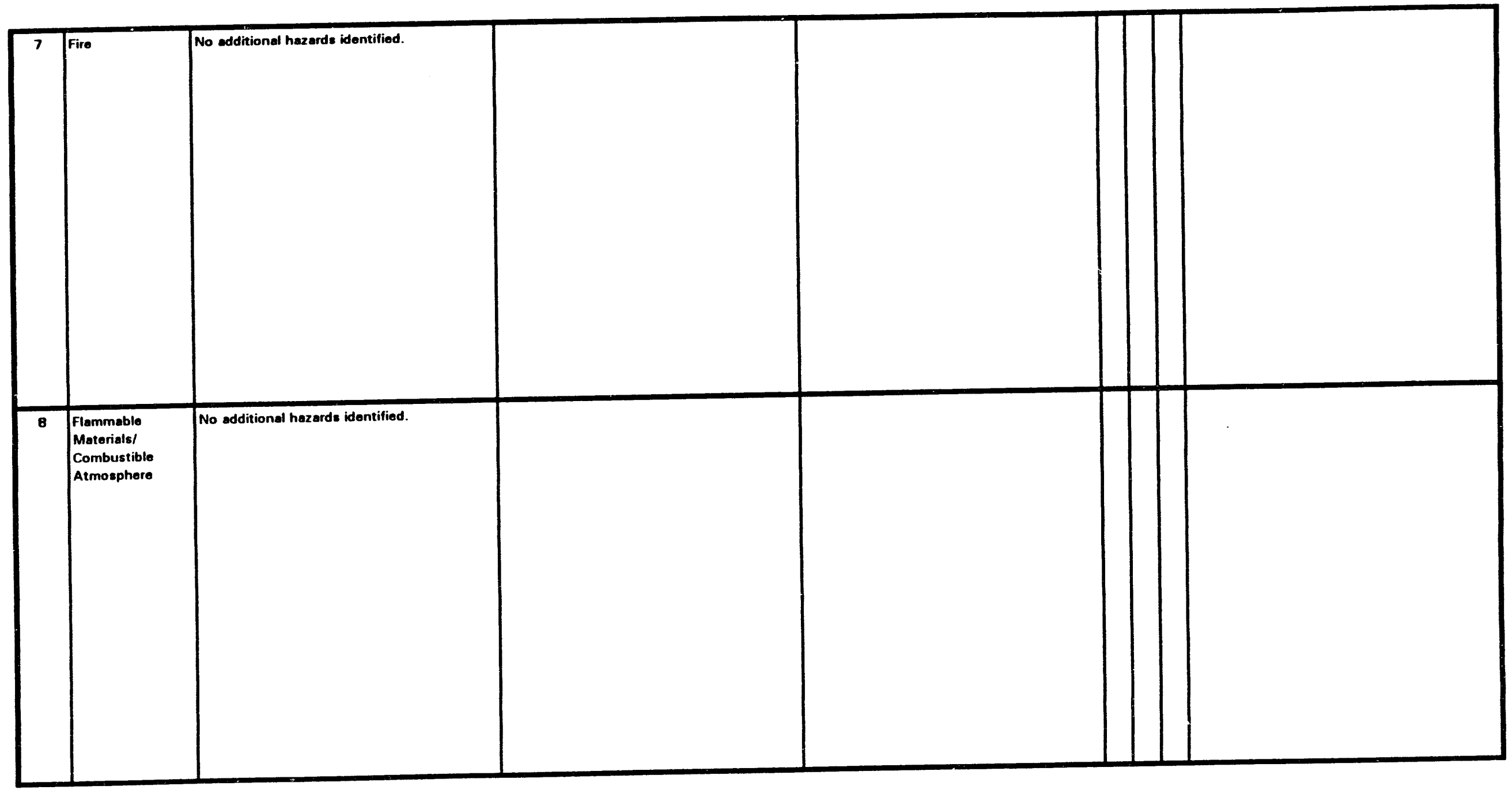


WRAP 2A ACDR PRELIMINARY HAZOP REVIEW DATA SHEET

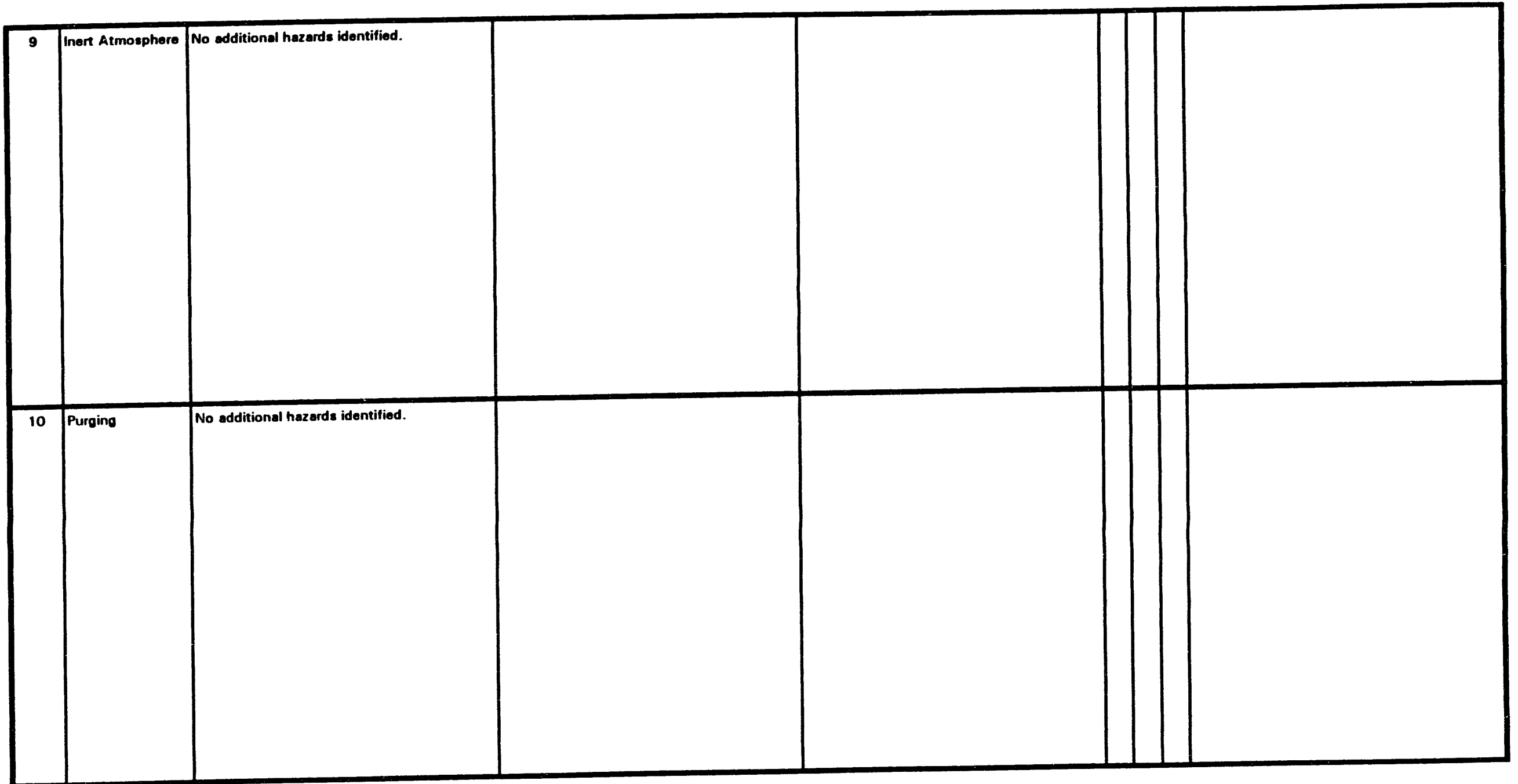





\section{WRAP 2A ACDR PRELIMINARY HAZOP REVIEW DATA SHEET}

\begin{tabular}{|c|c|c|c|c|c|c|c|}
\hline 13 & \begin{tabular}{|l} 
Design Basis \\
Accidents
\end{tabular} & $\begin{array}{l}\text { No odditional hazards identified. } \\
\text { B. Mixing chomicals following a seliemic } \\
\text { ovent. }\end{array}$ & & & & & \\
\hline 14 & Loss of Utilities & $\begin{array}{l}\text { A. Loss of chillod water flow to scrubber } \\
\text { circulating cooler. }\end{array}$ & $\begin{array}{l}\text { Saturatod off-gas. HEPA fiters plugeod, lose } \\
\text { of glovebox DP, worker dose exposure. }\end{array}$ & $\begin{array}{l}\text { A. Rodundant HEPA filters provided with } \\
\text { fitter DP alorm. } \\
\text { Glovobox DP slarm. } \\
\text { Indopondent tlow/tempt alorm. }\end{array}$ & \begin{tabular}{|l|l|l|}
4 & 2
\end{tabular} & 5 & \\
\hline
\end{tabular}




$$
7
$$


WRAP 2A ACDR PRELIMINARY HAZOP REVIEW DATA SHEET

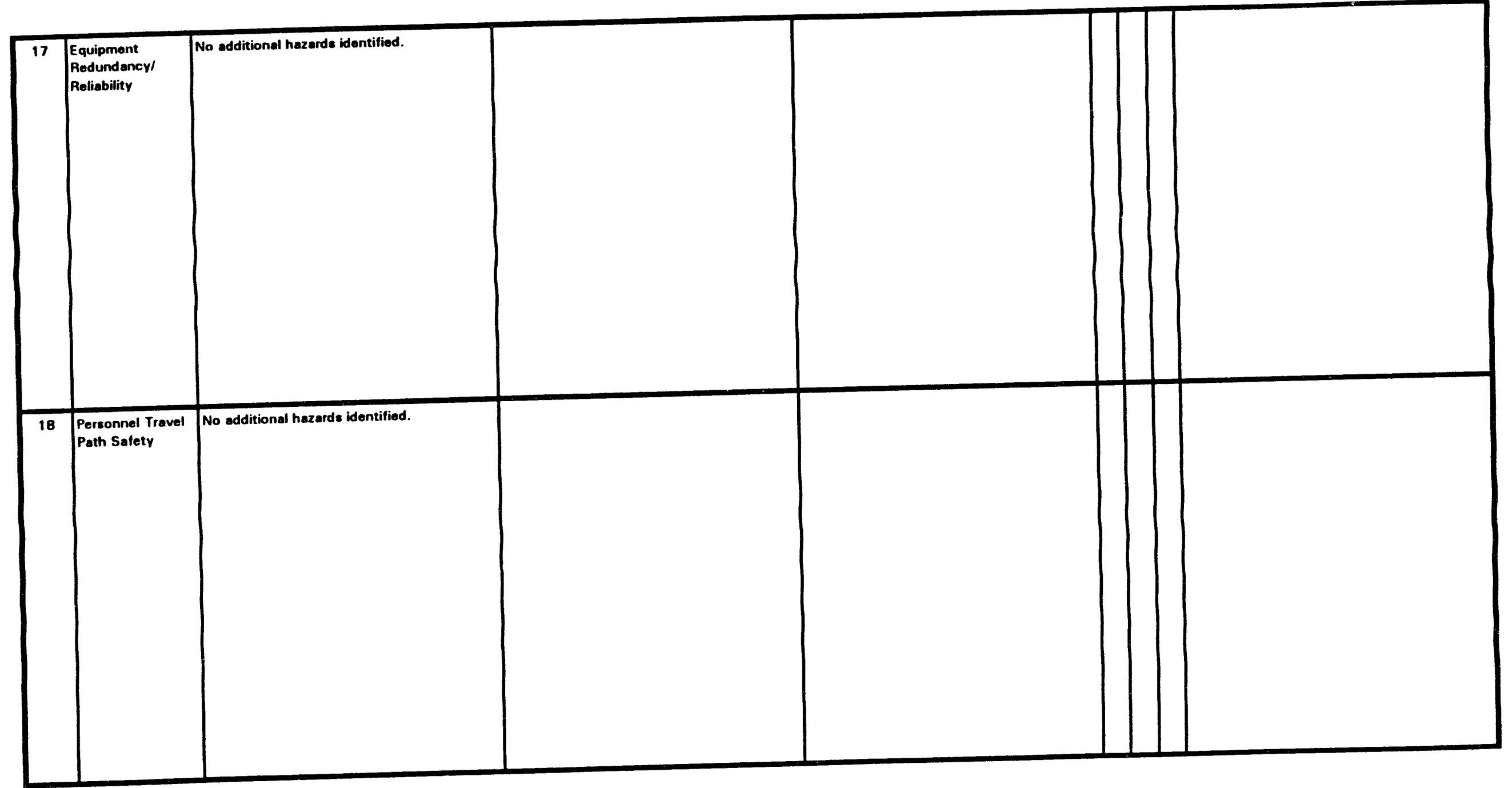


WRAP 2A ACDR PRELIMINARY HAZOP REVIEW DATA SHEET

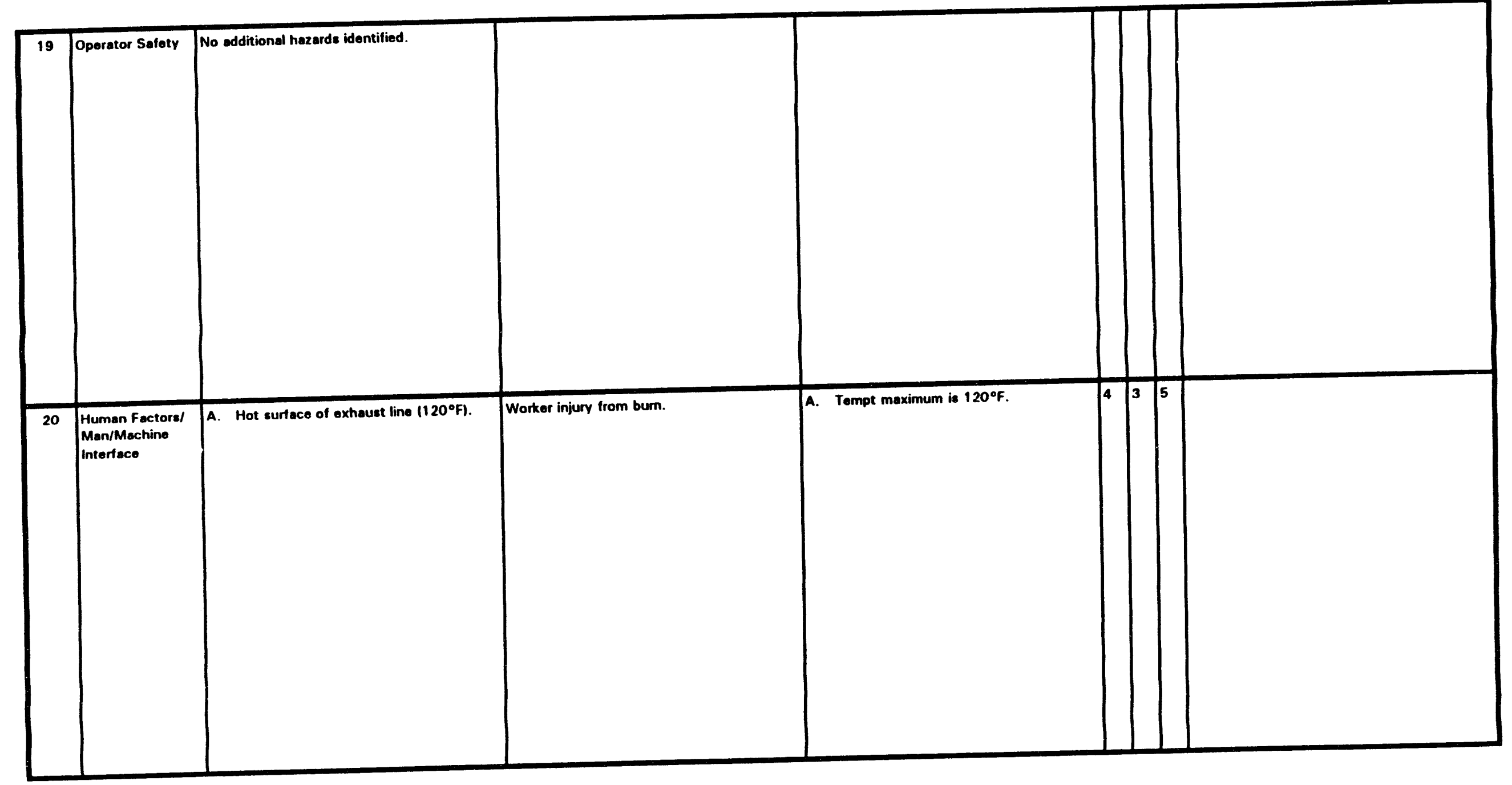




\section{WRAP FACILITY. DOE-RL}

UNITED ENGINEERS \& CONSTRUCTOAS

DE-AC06-91RLI 1946

WRAP 2A ACDR PRELIMINARY HAZOP REVIEW DATA SHEET

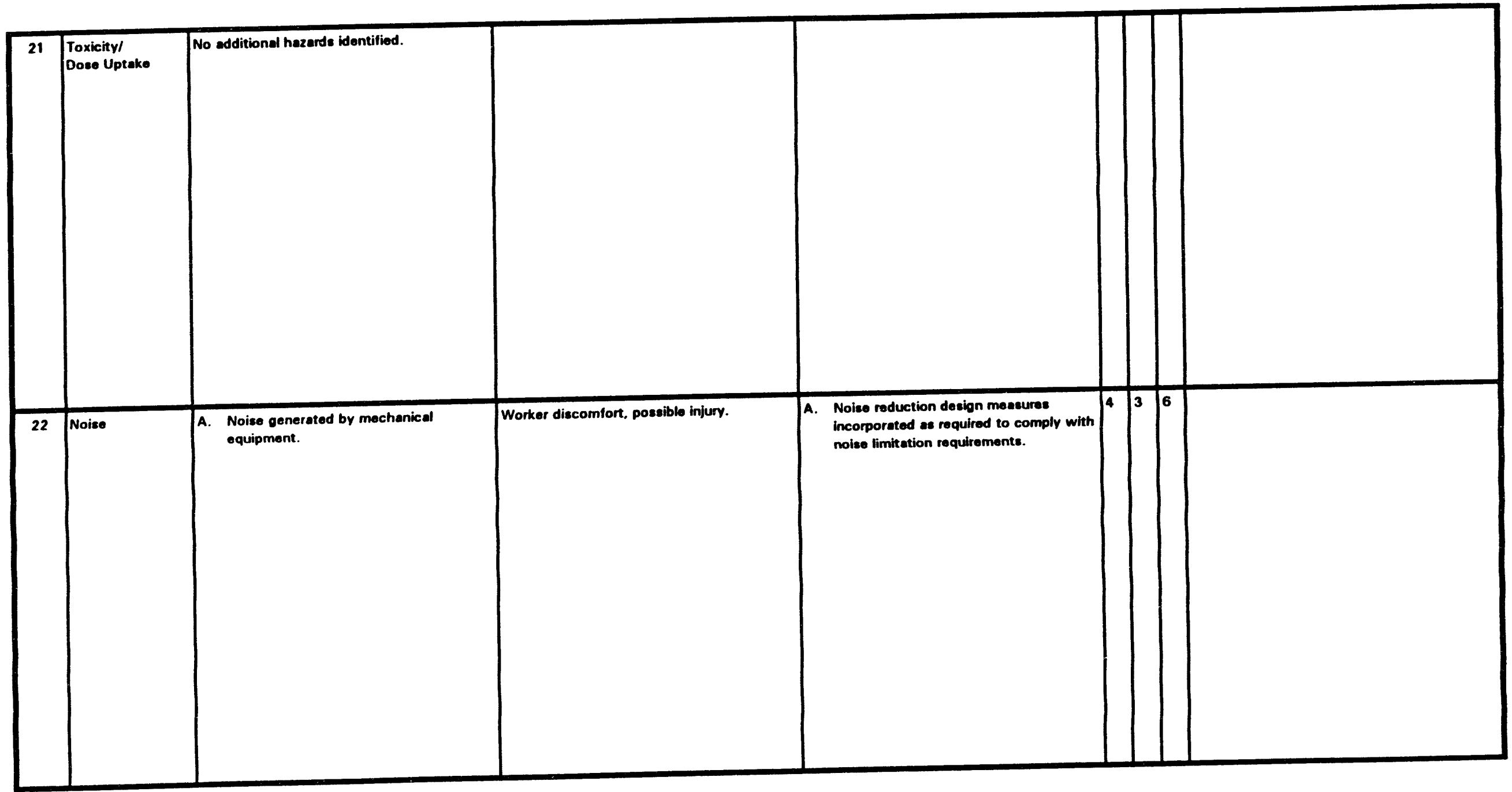


WRAP 2A ACDR PRELIMINARY HAZOP REVIEW DATA SHEET

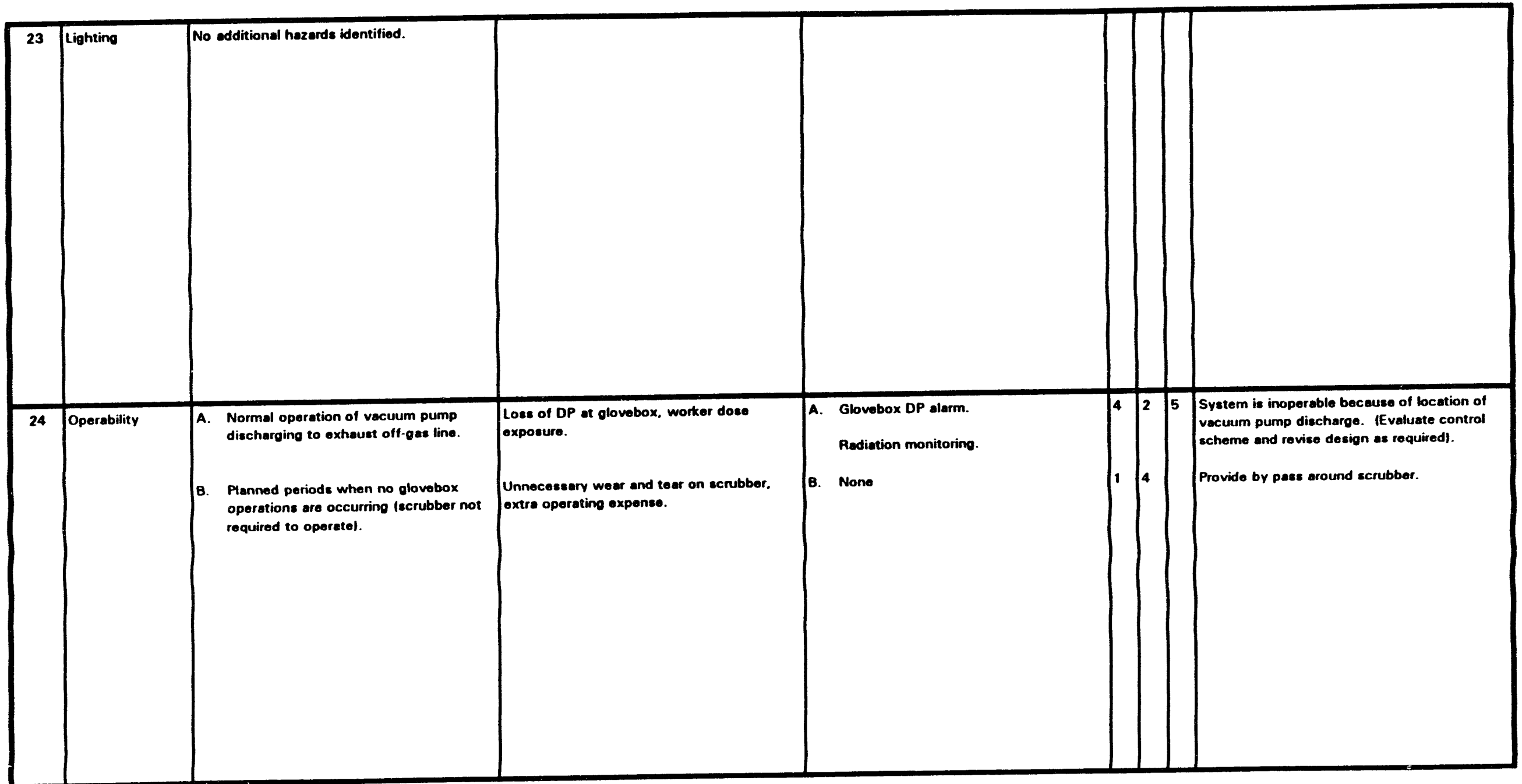


WRAP 2A ACDR PRELIMINARY HAZOP REVIEW DATA SHEET

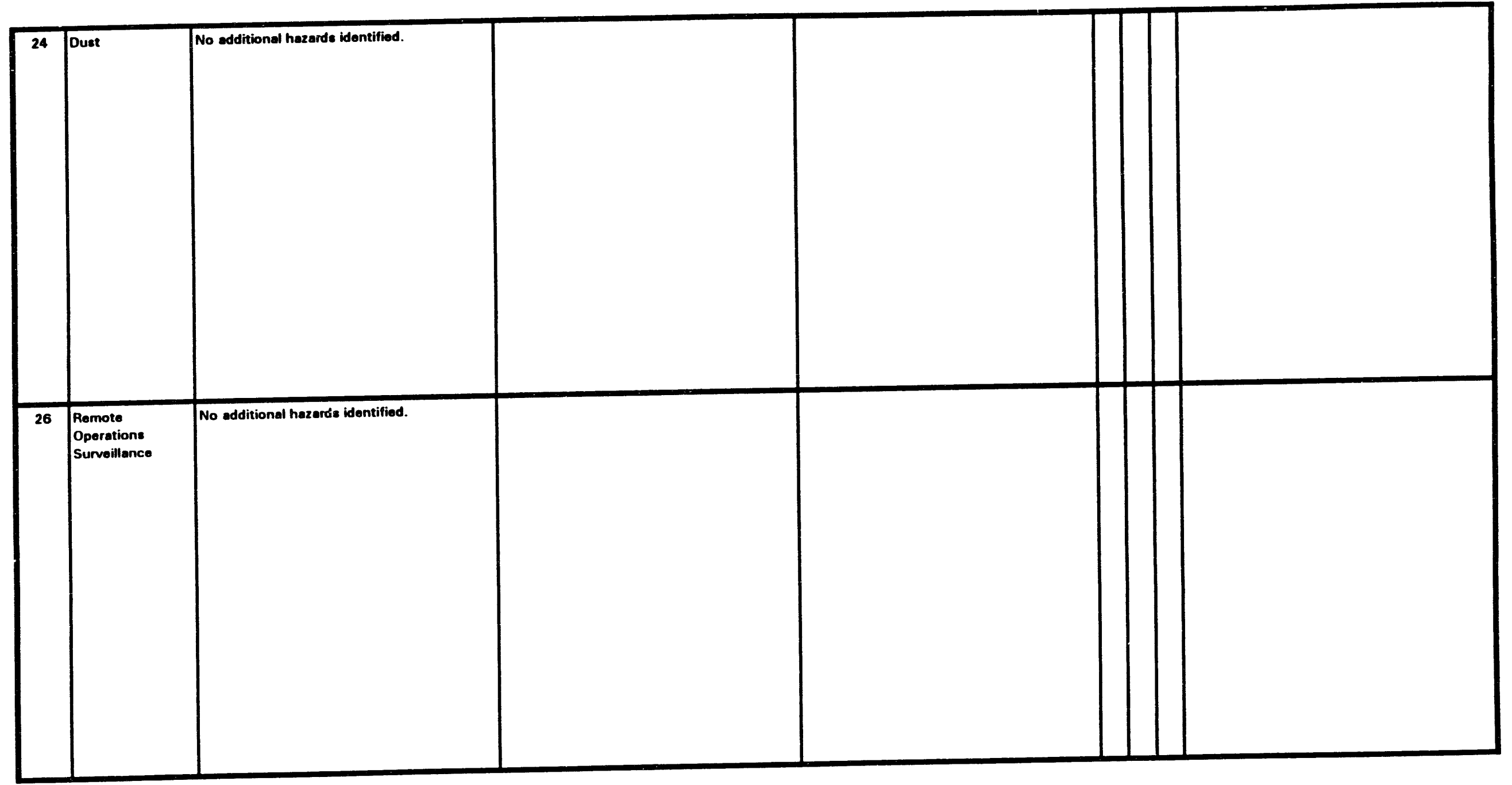




$$
57
$$


WRAP 2A ACDR PRELIMINARY HAZOP REVIEW DATA SHEET

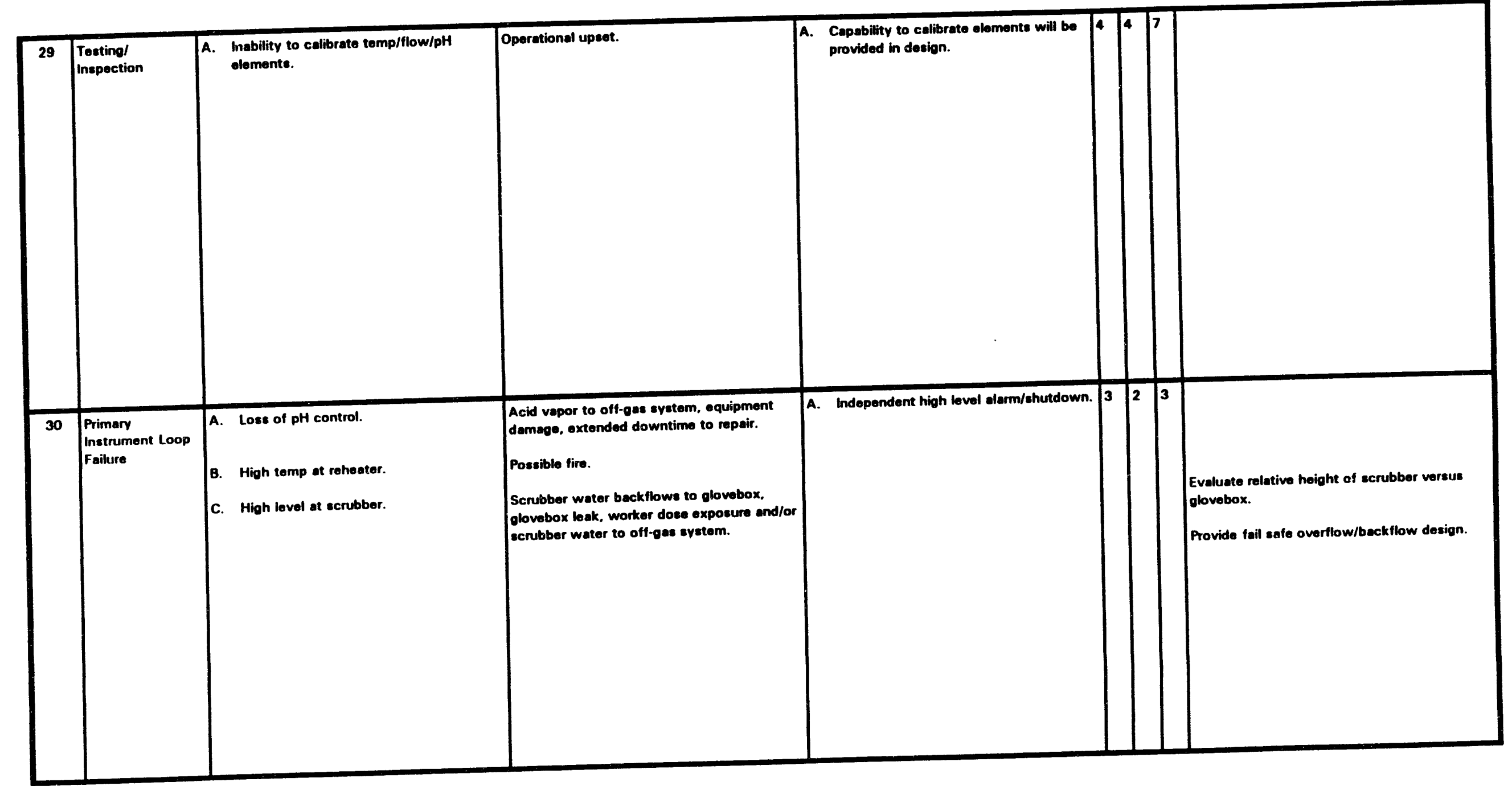




$$
\square+1
$$




\section{WRAP 2A ACDR PRELIMINARY HAZOP REVIEW DATA SHEET}

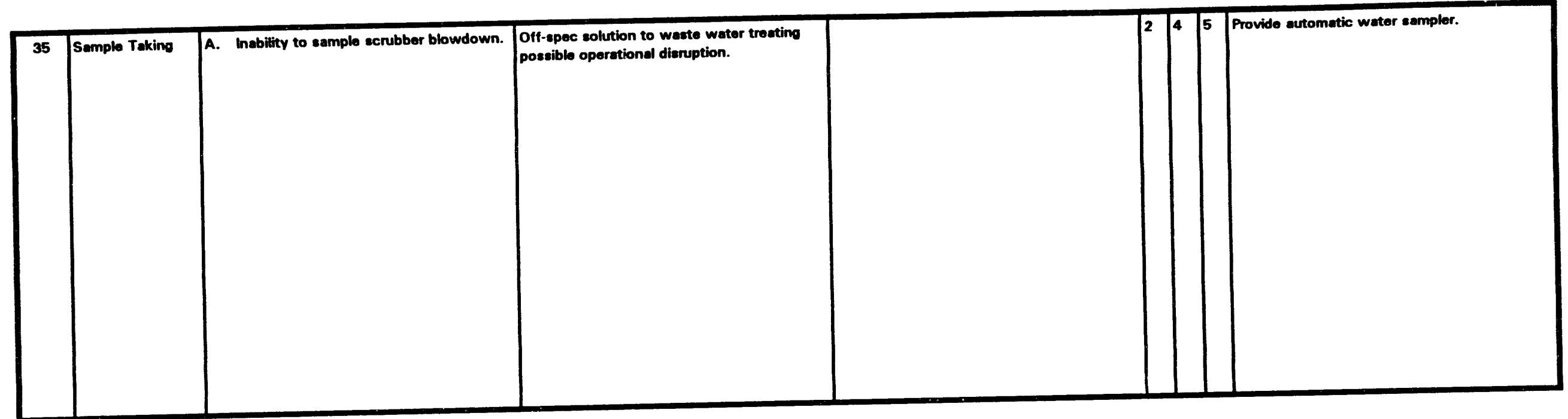


WASTE

RECEIVING

AND

PROCESSING FACILITY

TITLE: WRAP 2A RECEIVING AND SHIPPINGMATERIAL HANDLINO SYSTEM

HAZOP STUDY REPORT

Rovision: 0

Submitted to:

UNITED STATES

DEPARTMENT OF ENERGY

Richland, Washington

Propared by:

UNITED ENOINEERS

a CONSTRUCTORS

A Raytheon Compeny

Weveen Operedione 


\section{TABLE OF CONTENTS}

\section{Fage}

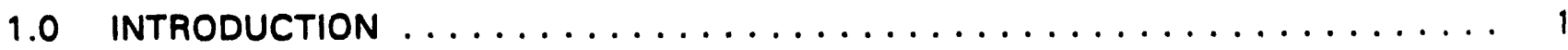

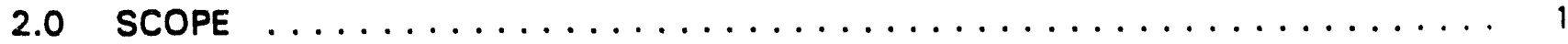

3.0 REFERENCES $\ldots \ldots \ldots \ldots \ldots \ldots \ldots \ldots \ldots \ldots \ldots \ldots \ldots \ldots \ldots \ldots \ldots$

4.0 DESCRIPTION OF RECEIVING/SHIPPING AND INTERNAL TRANSPORT SYSTEM . . . 2

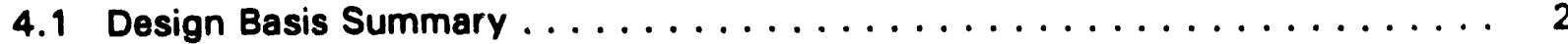

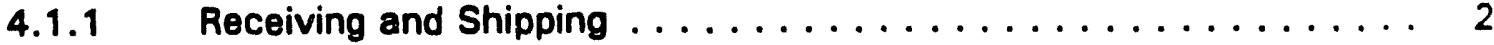

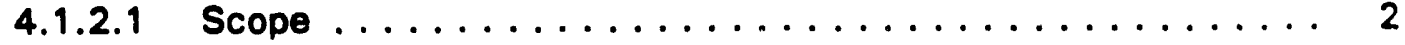

4.1.2.2 Design Goals ....................... 2

4.1.2.3 Functional Requirements .................. 2

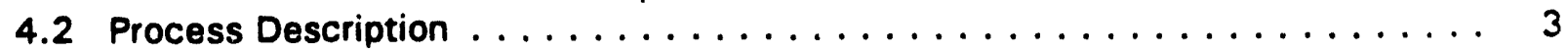

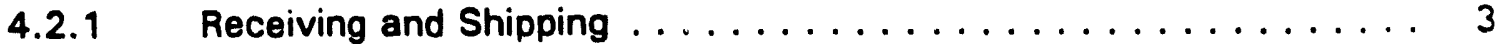

4.2.1.1 Waste Drum Handling ................... 3

4.2.1.2 New Drum Handling .................... 3

4.2.1.3 Waste Box Handling ................... 4

4.2.1.4 Waste Drum Shipping ................... 4

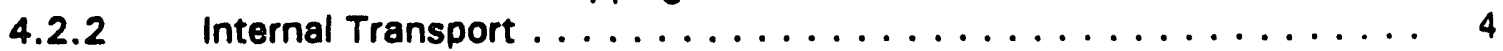

4.2.2.1 Internal Transfers ..................... 4

4.2.2.2 Waste Drum Handling .................. 5

4.2.2.3 New Drum Handling ................... 5

4.2.2.4 Waste Drum Storage .................. 5

5.0 STUDY CRITERIA AND METHODOLOGY $\ldots \ldots \ldots \ldots \ldots \ldots \ldots$

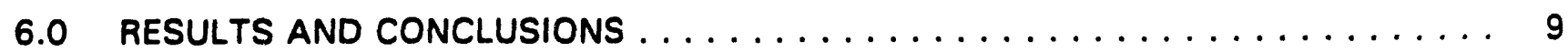


WRAP $2 A$

\section{RECEIVING AND SHIPPING/MATERIAL HANDLING SYSTEM}

\section{HAZOP STUDY REPORT}

\subsection{INTRODUCTION}

A HAZOP study was performed on the advanced conceptual design of the Receiving and Shipping and the Internal Transport Systems. The HAZOPS team met on 8 and 22 September 93, and consisted of the following members:

\begin{tabular}{|c|c|c|}
\hline Name & Company & Role/Expertise \\
\hline $\begin{array}{l}\text { Larry Walker } \\
\text { Doug Chapin } \\
\text { William Cepeda } \\
\text { Valerie Walker } \\
\text { Bernard Davies } \\
\text { Milt Hayward" } \\
\text { Ron Kolodzej" } \\
\text { Dave Mentz" } \\
\text { Bob Horgos }\end{array}$ & $\begin{array}{l}\text { UE\&C } \\
\text { UE\&C } \\
\text { UE\&C } \\
\text { BNFL } \\
\text { BNFL } \\
\text { WHC } \\
\text { WHC } \\
\text { WHC } \\
\text { WHC }\end{array}$ & $\begin{array}{l}\text { Leader, Scribe, Safety } \\
\text { Process } \\
\text { Instrumentation and Controls } \\
\text { Radiological } \\
\text { Process } \\
\text { W/R Interface, Material Handling } \\
\text { Nuclear Safety } \\
\text { Mechanical/Process } \\
\text { Mechanical }\end{array}$ \\
\hline
\end{tabular}

- Not present 22 September 93

The purpose of the HAZOPS is to identify major safety and operability problems which can best be resolved during completion of the advanced conceptual design.

\subsection{SCOPE}

This HAZOPS encompassed the Receiving and Shipping operation, and the Internal Transport System as shown on Process Flow Diagrams H-2-140670 (Rev. E) and 140644 (Rev. A) respectively.

\subsection{REFERENCES}

1. WHC-SD-W100-FDC-001 Rev. 2A, Functional Design Criteria Waste Receiving And Processing Facility Module $2 \mathrm{~A}$.

2. WHC-SD-W100-SDRD-001 Rev. A, Waste Receiving and Processing Facility Module $2 A$. 


\subsection{DESCRIPTION OF RECEIVING/SHIPPING AND INTERNAL TRANSPORT SYSTEM}

\subsection{Design Basis Summary}

\subsubsection{Recoiving and Shipping}

(later)

\subsubsection{Internal Transport}

\subsubsection{Scope}

1. The workscope includes the supply and transfer of drums within the process area and between the process enclosures.

2. Storage of drums during the curing process and for lag storage is covered.

3. The transfer of empty and waste filled drums are included.

\subsubsection{Decign Goals}

1. Proven Materials Handling Technology will be used where available.

2. The system shall be designed to ensure safe transportation of drums to their destination.

3. The system shall utilize an integrated design approach to ensure a compatible interface with the other process areas of the WRAP 2A facility.

4. The storage system will be sized to provide the necessary capacity for Cure and Lag storage in accordance with the FDC.

5. The system design will maintain consideration for human factors, the principles of ALARA and eventual decontamination and decommissioning.

\subsubsection{Functional Requirements}

1. Receipt and handling of empty and waste filled $\mathbf{5 5}$ gallon and 85 gallon drums.

2. Conveyor and Transfer Car equipment for the routing of drums to the appropriate locations within the process area.

3. Interface with process conveyors.

4. Cure storage for 2 days in accordance with the FDC.

5. Lag storage for 2 days in accordance with the FDC.

6. The system shall abe designed to handle the average daily throughput. 


\subsection{Process Description}

\subsubsection{Receiving and Shipping}

\subsubsection{Waste Drum Handling}

1. A battery powered Forklift Truck (FT-09-101) is used to unload pallets of four waste drums and boxes from the W-112 transfer vehicle. The design load capacity and travel speed for the forklift used to transport containers is 12,000 pounds and $8.0 \mathrm{mph}$ unloaded (6.7 mph loaded).

2. Each pallet of waste drums is transferred from the forklift to the Pallet Accumulation Conveyor (CV-09-101). At the front of the conveyor, the drums and pallets are radiologically surveyed for surface contamination. The pallet accumulation conveyor provides storage for six pallets of waste drums. This conveyor storage plus the drums awaiting to be transferred to the drum size reduction area provides the one day of required storage. This gravity powered conveyor can accumulate pallets weighing up to 12,000 pounds each. A concrete shield wall is provided along the length of the conveyor in accordance with ALARA requirements.

3. Once the pallet has reached the end of the pallet accumulation conveyor, the waste drums are depalletized. Depalletization is accomplished by an operator using a manual controlled Drum Jib Crane (CR-09-101), which has a capacity of 2 tons. Individual waste drums are placed onto the Drum Scale/Conveyor (CV-09-105). At this point, the bar code label is read on the drum or attached if not present, and the information concerning the incoming waste drum is entered into the DMS. Sensors detect the drum on the scale/conveyor and the scale weighs the drum. The weight of the drum is shown on an L.E.D. display and the amount is recorded. The operator signals via a push button to transfer the drum from the scale/conveyor to the Drum Feed Conveyor (CV-09-102). At the discharge end of the conveyor, sensors detect the drum, which initiates a signal to the automatic control system to open the airlock door and transfer the drum to the Airlock (AL05-101).

\subsubsection{New Drum Handling}

1. New empty 55-gallon and 85-gallon drums, used for repacking waste and compacted 55-gallon drums, are delivered to the WRAP 2A facility at the new drum storage and receiving area dock. The new drums are delivered by flatbed trucks nonpalletized. The battery powered forklift attached with a fork truck Dual Drum Gripper (X-09-101) unloads two new drums at a time off the flatbed truck, adds a bar code label to the drums and places them into storage. The storage area can accommodate sufficient new 55-gallon drums, stacked three high and four high, to provide storage for two weeks operations. 
2. After the truck is unloaded, the forklift transfers the new drums to the new Drum Feed Conveyor (CV-09-103). The conveyor includes two sections connected at a right angle and a 90 degree chain transfer device between the two sections. The drum feed conveyor detects the drums and conveys them to the end of the first section. The 90 degree chain transfer device transfers a drum to the second section which conveys the drum to the discharge end. At the discharge end, a sensor detects the drum and transfers it to the processing area via the Airlock Conveyors (CV-08-501 and CV-08-502).

\subsubsection{Waste Box Handling}

1. Waste boxes are unloaded from the W-112 transfer vehicle using the battery powered forklift. Each waste box is transported via the forklift to the Box Breakdown Airlock (AL-05-561) and the bar code label is read. At this point, the waste box is transferred into the box size reduction area for processing.

\subsubsection{Waste Drum Shipping}

1. Waste drums (55 gallon) are transported out of the processing area into the shipping and receiving area by the AGV (GV-08-102) and Airlock Transfer Conveyors (CV-08-503 and CV-08-504). At the discharge end of the airlock conveyor, the conveyor initiates a signal to the automatic control system to open the airlock door and transfer the drum to the Drum Discharge Conveyor (CV-09-104).

2. At the drum discharge conveyor, each waste drum is radiologically surveyed for external contamination. The drum is conveyed to the discharge end and transferred to the Drum Scale/Conveyor (CV-09-106) where it is weighed and its bar code label read. A Drum Jib Crane (CR-09-102) equipped with a drum gripper is used by a local operator to remove a drum from the scale/conveyor and places it on a pallet (4 waste drums per pallet). After the drums are palletized, the forklift picks up the pallet and transfers the pallet to the $W$ 112 transfer corridor. The forklift transfers the pallet to the $W-112$ vehicle which takes the pallet back to W-112 for future on-site disposal.

\subsubsection{Internal Transport}

\subsubsection{Internal Transfers}

1. The Internal Transfer system moves 55 and 85 Gallon drums between the processing and storage areas of the WRAP $2 A$ process area using Conveyors, Transfer Cars and Storage/Retrieval Stacker equipment. W112 waste drums and empty drums from the Receiving facility are introduced to the process area through Airlocks and are distributed to the designated locations. Drums of immobilized waste are removed from the Lag/Cure Store for return to W112, through the Airlock and Shipping facility.

2. Transfer of drums between the waste filling locations at the processing enclosures and the grout/polymer filling locations, is carried out within a process enclosure, the interfaces between these transfers and the Internal Transport System are Grout and Polymer Feed Conveyors. 


\subsubsection{Waste Drum Hiandling}

1. W112 Waste drums from the Receiving Facility are transferred through Airlock AL-09-101, onto the Process Feed Conveyor CV-08-501. The drums are routed, on the Conveyor to the Solid Waste Conditioning, Sludge/Particulate Conditioning and the Special Waste processes, as necessary, where they are loaded onto the Process Enclosure Lift Tables.

2. Drums of waste from the Box Breakdown process are transferred from the Lift Table at the Box Breakdown loading port onto the Transfer Car TC-08-501 which is routed to the Process Feed Conveyor CV-08-501. The drums are transferred to the Solid Waste Conditioning Enclosure Lift Table LT-05-521, the Sludge/Particulate Conditioning Enclosure Lift Table LT-05-541 or the Special Waste Enclosure Lift Table LT-LT-06-101, depending on the waste material type. Breakdown drums containing sorted waste in a suitable form are routed directly to the Grout/Polymer Process Enclosure using Transfer Car TC-08-501 to transfer drums to the Immobilization Process Transfer Car TC-08-502.

\subsubsection{New Drum Handling}

1. New empty 55 gallon drums, used for repacked waste and subsequent immobilization, are transferred through Airlock AL-09-102 onto the New Drum Conveyor CV-08-502. Drums for Box Breakdown are transferred from the New Drum Conveyor to Transfer Car TC-08-501 and routed to the waste filling location. Drums required for the waste filling and immobilization process are transferred from the New Drum Conveyor to the Transfer Car TC-08-502 and routed to the Grout Inlet Conveyor CV-08-504 or the Polymer Inlet Conveyor CV-08-505, depending on the process requirements.

2. New $\mathbf{8 5}$ gallon drums are required as overpacks for the compacted $\mathbf{5 5}$ gallon drums and use the same entry route as the new 55 gallon drums i.e., through Airlock AL-09-102 and onto the New Drum Conveyor CV-08-502. The Transfer Car TC-08-502 is used to route the drums from the New Drum Conveyor to the Aisle Stacker CR-08-501, which then delivers the empty drum to the Drum Compactor Inlet Conveyor.

\subsubsection{Waste Drum Storage}

1. The drum store, consists of a tiered rack system, in which each drum has a dedicated storage position which can be accessed at any time by a Narrow Aisle Stacker CR-08-501, the Stacker travels the full length of the store to access any of the storage locations. Interfaces between the Stacker and the transfer systems, which deliver drums to the store, are located at the ends of the rack system and at intermediate locations within the rack system. The storage location is recorded in the Plant Control Computer, using the drum bar code as the method of identification. The store is divided into two sections, a Cure Store and a Lag Store, the cure area is enclosed to enable a cooling air flow to be provided to remove the heat generated during the curing process.

2. The Cure Store receives drums directly from the immobilization processes to allow curing to take place over a period of 48 hours, as specified by the FDC. When the cure period is complete, the drums ar transferred by the Aisle Stacker to either the Lag Storage section, or directly to Shipping using conveyor CV-08-505. 
3. The inlet for the Aisle Stacker into the Cure Store Enclosure is shaped to slow a nominal clearance for the Stacker to pass through, the opening profile is designed to accept the loaded Stacker with the drum in the lowered position to provide the minimum opening area for controlled ventilation flow. Ventilation flows to the cure store enclosure are provided to meet the cooling requirements of the drums during the cure period.

4. The Lag Store receives drums from the drum compactor and from the cure store, if transport is not available from the Shipping facility. Under normal operating conditions, when transport is available to remove drums to W112, most of the Lag Store will remain empty to provide the necessary buffer in the event of the Shipping transport not being available.

\subsection{STUDY CRITERIA AND METHODOLOGY}

This HAZOPS has utilized a predetermined set of process deviations/upset conditions to be analyzed by the HAZOPS team for each process deviation, possible courses were postulated and worst case consequences (without benefit of any safeguards were determined. Existing safeguards (design and procedural) were then identified. Those safeguards which could be reasonably expected to be present in the final design were assumed to be existing and were so documented in the HAZOPS. For each cause and effect, hazard severity and probability were qualitatively assessed (taking credit for existing safeguards which reduce hazard probability) using the criteria shown in Table 1. The overall risk rating for each hazard was then determined using the risk ranking matrix shown on Table 2. Recommendations were proposed by the HAZOPS team in instances required by the implementation criteria shown in Table 2. 
TABLE 1

HAZARD SEVERITY AND PROBABILITY CLASSIFICATION CRITERIA

\begin{tabular}{|c|c|c|c|c|}
\hline \multirow{2}{*}{ Target Hazard } & \multicolumn{4}{|c|}{ Severity Class (Worst-case Scenario) } \\
\hline & Catastrophic (1) & Extensive (2) & Moderate (3) & Operational (4) \\
\hline Community & $\begin{array}{l}\text { Multiple irreversible } \\
\text { injuries; may include a } \\
\text { fatality } \\
\text { OR } \\
\end{array}$ & $\begin{array}{l}\text { Single irreversible or } \\
\text { several reversible injuries } \\
\text { (no fatalities) } \\
\text { OR }\end{array}$ & $\begin{array}{l}\text { Several reversible injuries } \\
\text { OR }\end{array}$ & \\
\hline Workers & \begin{tabular}{|l}
$\begin{array}{l}\text { Fatalities or irreversible } \\
\text { injuries } \\
\text { OR }\end{array}$ \\
\end{tabular} & $\begin{array}{l}\text { Several injuries } \\
\text { OR } \\
\end{array}$ & $\begin{array}{l}\text { Single injury } \\
\text { OR }\end{array}$ & \\
\hline Facility & $\begin{array}{l}\text { Partial or full demolition of } \\
\text { facility }\end{array}$ & $\begin{array}{l}\text { Rupture or similar loss of } \\
\text { containment } \\
\text { OR }\end{array}$ & \begin{tabular}{|l|} 
Major equipment damage \\
leading to one month or \\
more facility downtime \\
OR
\end{tabular} & $\begin{array}{l}\text { Equipment damage } \\
\text { leading to several days of } \\
\text { facility downtime or other } \\
\text { operational penalty } \\
\text { OR }\end{array}$ \\
\hline Environment & $\begin{array}{l}\text { Major environmental } \\
\text { impact with significant } \\
\text { cleanup/liability costs }\end{array}$ & $\begin{array}{l}\text { Groundwater, soil, or } \\
\text { public sewer } \\
\text { contamination }\end{array}$ & \begin{tabular}{|l|} 
Minor spill or release \\
resulting in permit violation
\end{tabular} & \\
\hline
\end{tabular}

\section{LIKELIHOOD CLASSIFICATION}

\begin{tabular}{|l|l|}
\hline Highly Likely (1) & $\begin{array}{l}\text { Event has occurred at this facility - or - other facility - or - is expected to occur several times during the } \\
\text { next } 10 \text { years. }\end{array}$ \\
\hline Likely (2) & $\begin{array}{l}\text { Event has occurred at this facility - or - is possible to occur at this facility several times during the next } \\
30 \text { years. }\end{array}$ \\
\hline Unlikely (3) & $\begin{array}{l}\text { Event may have occurred at another facility - or - is possible to occur at this facility at least once in the } \\
\text { next } 50 \text { years. }\end{array}$ \\
\hline Extremely Unlikely (4) & $\begin{array}{l}\text { Event is not likely to ever occur in this facility, given a continuation of the current levels of training, } \\
\text { procedures, maintenance, inspection, testing, and other applicable process safety management system } \\
\text { support. }\end{array}$ \\
\hline
\end{tabular}


TABLE 2

RISK RANKING MATRIX AND IMPLEMENTATION CAITERIA

\begin{tabular}{|c|c|c|c|c|}
\hline Likelihood & & & & \\
\hline Highly Likely (1) & 4 & 2 & 1 & 1 \\
\hline Likely (2) & 5 & 3 & 2 & 1 \\
\hline Unlikely (3) & 6 & 4 & 3 & 2 \\
\hline \multirow[t]{3}{*}{ Extremely Unlikely (4) } & 7 & 6 & 5 & 4 \\
\hline & Operational (4) & Moderate (3) & Extensive (2) & Catastrophic (1) \\
\hline & \multicolumn{4}{|c|}{ SEVERITY } \\
\hline
\end{tabular}

\section{RISK RANKING IMPLEMENTATION}

\begin{tabular}{|c|l|}
\hline Risk Ranking & \multicolumn{1}{c|}{ Implication } \\
\hline 1 & $\begin{array}{l}\text { Risk level - Very significant } \\
\text { Recommendation = Required from the HAZOPS team } \\
\text { Implementation - Begins immediately }\end{array}$ \\
\hline 2 & $\begin{array}{l}\text { Risk level - Significant } \\
\text { Recommendation = Required from the HAZOPS team } \\
\text { Implementation - Begins within three months }\end{array}$ \\
\hline 3 & $\begin{array}{l}\text { Risk level - Not very significant } \\
\text { Recommendation = Required from the HAZOPS team } \\
\text { Implementation - Begins within one year }\end{array}$ \\
\hline 4 & $\begin{array}{l}\text { Risk level - Not significant, but may be an operational problem } \\
\text { Recommendation = At the discretion of the HAZOPS team } \\
\text { Implementation - As soon as practical, not later than the next major plant turnaround }\end{array}$ \\
\hline 5,6, or 7 & $\begin{array}{l}\text { Risk level - Negligible, but may be an operational problem } \\
\text { Recommendation = At the discretion of the HAZOPS team } \\
\text { Implementation - To be evaluated by management }\end{array}$ \\
\hline
\end{tabular}




\subsection{RESULTS AND CONCLUSIONS}

Because this HAZOPS is performed relatively early in the design phase, existing safeguards have not been fully documented on the process flow diagrams (these would mostly be shown on the P\&ID's developed during Title Design). However, the HAZOPS team assumed specific safeguards would be present in the final design if it appear reasonable to expect this. These assumed safeguards are documented on the HAZOPS worksheets and credit was taken for these presumed safeguards when assessing risk. During Title Design, the presence of these safeguards need to be verified to validate the conclusions of this HAZOPS.

For the Receiving and Shipping System, twenty-seven potential safety and operability problems were identified and evaluated in the HAZOPS. Of these, twenty were assessed to have a negligible risk level. The remaining seven involve potential safety and operational problems having a risk ranking classified as between significant and not significant. For these potential safety and operational problems, the HAZOPS team has recommended that additional safeguards be evaluated and incorporated into the WRAP 2A design. Table 3 presents a summary of changes to be made in the process flow diagram, assumed design safeguards, and additional safeguards to be evaluated for incorporation into the design of the design of the Receiving and Shipping System.

For Internal Transport System, nine potential safety and operational problems were determined to have a risk ranking classified as between not very significant and not significant. For those potential problems, additional safeguards have been recommended for evaluation and incorporation, as summarized in Table 4.

In several instances, the need for human factors analyses and reliability/availability/maintainability analyses during Title Design was highlighted by the HAZOPS team to achieve negligible risk levels. The HAZOPS assumed that such analyses would be performed and that the necessary design requirements/modifications are incorporated. The performance of these design analyses are considered to be open issues to be resolved during Title Design. Similarly, the HAZOPS team identified the need for a maintainability analysis to develop requirements for warm maintenance at the WRAP $2 A$ Facility.

The HAZOPS is documented in the attached HAZOPS worksheets. 


\section{TABLE3}

RECEIVING/SHIPPING HAZOPS SUMMARY

\section{PROCESS FLOW DIAGRAM CHANGES}

1. Add note at CV-09-106 that drums are weighed and bar code is read.

2. Show flow of outgoing drums to box breakdown for sampling/examination (see \#14 for Title Design).

\section{ASSUMED DESIGN SAFEGUARDS}

1. General design basis requirements (e.g., shielding at work stations, forklifts).

2. Mechanism to off load drums on failed conveyors (if forklift is to be used, provide access space).

3. Mechanism to open/close failed airlock door (hand crank).

4. Mechanism to interlock/seal loading door with truck.

5. AGV sensors stop AGV travel prior to impact with object (prevent personnel injury).

6. Mechanism limits Jib Crane ARC travel (prevent drum impact with shield wall).

7. Mechanism to prevent vapor buildup at battery recharging station (see \#4 for Title Design).

8. Control system alerts operator of discrepancy with incoming waste drum data (bar code number, weight) and WNZ data.

\section{EVALUATEIINCORPORATE INTO DESIGN}

1. Need for isolation door between WRAP 2A and W112 to prevent contamination spread (spill).

2. Rearrange layout to avoid forklift travel paths crossing each other (accidents).

3. Evaluate layout for travel paths interferences between forklifts/AGV's and personnel (worker injury).

4. Evaluate requirements for battery recharging station lenclosure with local exhaust, fire protection, OSHA standards).

5. Evaluate possibility of new drums (in storage) blocking personnel egress paths following seismic event.

6. Evaluate possibility of outgoing (treated) waste drums contributing to fire hazard.

7. Evaluate need for alarm when conveyor starts.

8. Verify that new drums can be safely stacked/unstacked 4 drums high loperator visual interface).

9. Evaluate need for periodically deinventorying new drums (avoid last in last out). 


\section{EVALUATE/INCORPORATE INTO DESIGN (CONTINUED)}

10. Evaluate how the empty pallet on CV-09-105 drum scale/conveyor can be removed by operator and determine pallet routing.

11. Evaluate pallet storage location for outgoing drums (can new drums enter WRAP 2A on pallets).

12. Evaluate number of forklifts required (time \& motion) and provide additional layout space as necessary.

13. Evaluate sending 83 gallon drums to box breakdown instead of to size reduction and repack.

14. Evaluate mechanism/route to send outgoing drums to box breakdown (for sampling).

15. Evaluate need for closed circuit TV surveillance.

16. Provide capability to locate "lost" drum (portable bar code reader?).

17. Provide capability to return "wrong" drum to W112. 


\section{INTERNAL TRANSPORT HAZOPS SUMMARY}

\section{PROCESS FLOW DIAGRAM CHANGES}

1. Add inspection of cured drums as a distinct process operation to be serviced by internal transport.

2. Show transfer cars serving CV-05-632.

3. Show conveyor in feedstream \#16.

4. Correct notation on feedstream \#16 (delete "\& polymer encapsulation").

5. Verify purpose/need for CV-05-632 flow path and flow path to H-2-140633.

\section{ASSUMED DESIGN SAFEGUARDS}

1. General design basis requirements (e.g., shielding at process areas).

2. Drum lid is securely fastened during transport outside of enclosures.

3. HVAC operation for cure storage keeps vapor concentration below explosive limit (VES polymer option) when vapors are vented from drums during curing.

4. Stacker/retriever is designed to retain load upon loss of power.

5. Closed circuit TV monitoring of transport operations.

6. Mechanism to manually operate stacker/retriever and conveyors for equipment repair.

7. Mechanism to off load drums from failed transport equipment (some drums are hot).

8. Capability to load test stacker/retriever.

9. Probe with interlock at stacker/retriever prevents attempt to place a drum in an already occupied position.

10. Bar code reader is located at each process area.

\section{EVALUATE/INCORPORATE INTO DESIGN}

1. Reserve lower rows of lag storage for untreated waste drums (6 foot drop height limit) and for drums weighing more than 1,000 lbs.

2. Provide drum stops on cure/lag storage racks to prevent drum movement (seismic event).

3. Evaluate adequacy of drum vent size to relieve gas pressure formed during curing.

4. Evaluate shutting down stacker/retriever upon loss of HVAC for cure storage area (only for VES encapsulation option) to eliminate source of gas ignition.

5. Evaluate quantity of organic vapors released form untreated waste drum vents when waste drums arg near vicinity of hot curing drums or in cure storage.

6. - andysis to determine need for redundant stacker/retriever. 


\section{TABLE 4}

\section{INTERNAL TRANSPORT HAZOPS SUMMARY (CONTINUED)}

\section{EVALUATEINCORPORATE INTO DESIGN (CONTINUED)}

7. Evaluate adding direct transport route from receiving to lag storage. Clarify FDC requirement for 3 days lag storage (e.g., 1 day incoming, 1 day outgoing?).

8. Bar code reader at stacker/retriever.

9. Evaluate method of locating lost drum (e.g. portable bar code reader). 
WRAP 2A ACDR PRELIMINARY HAZOP REVIEW DATA SHEET

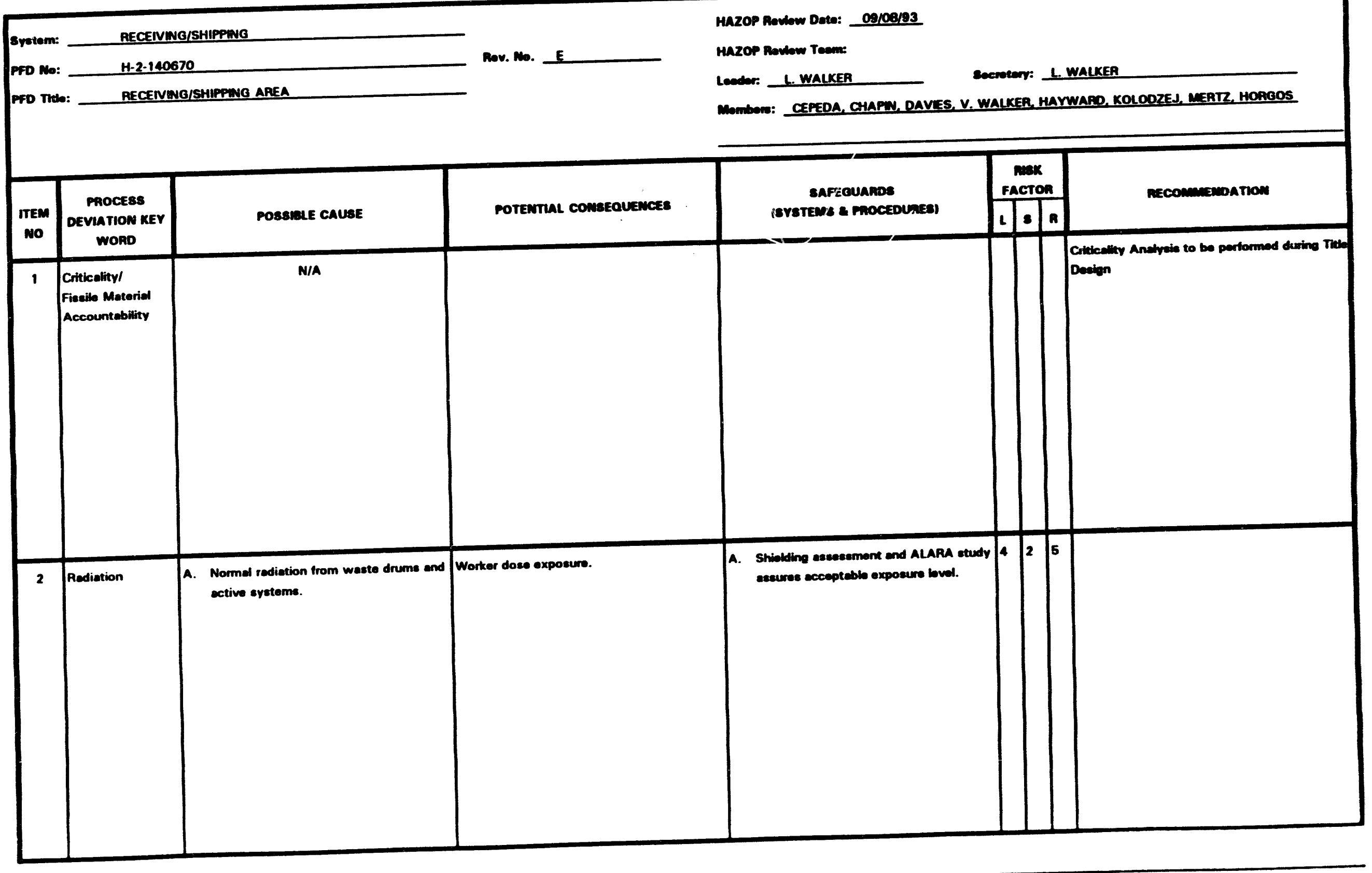



WRAP 2A ACDR PRELIMINARY HAZOP REVIEW DATA SHEET

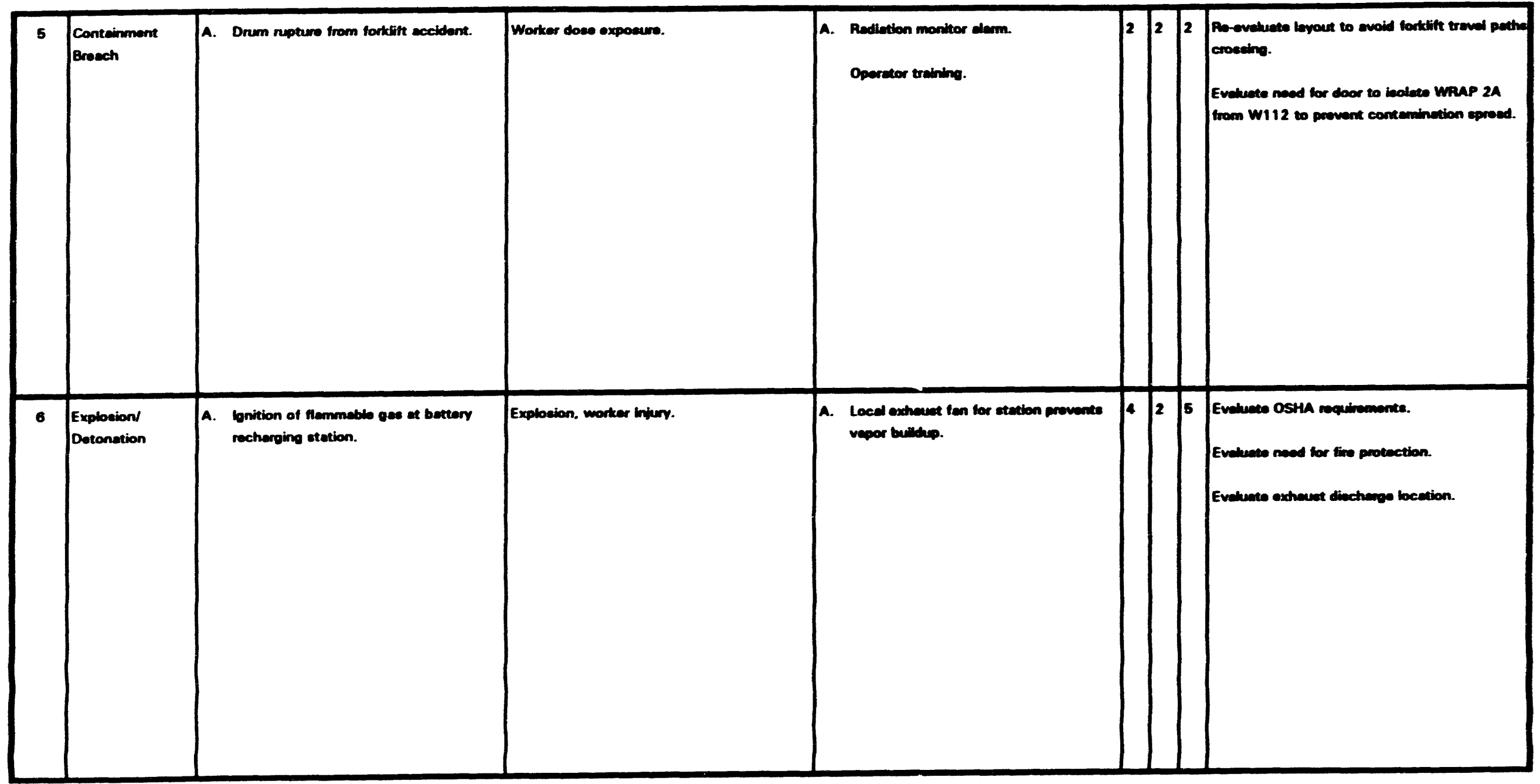


WRAP 2A ACDR PRELIMINARY HAZOP REVIEW DATA SHEET

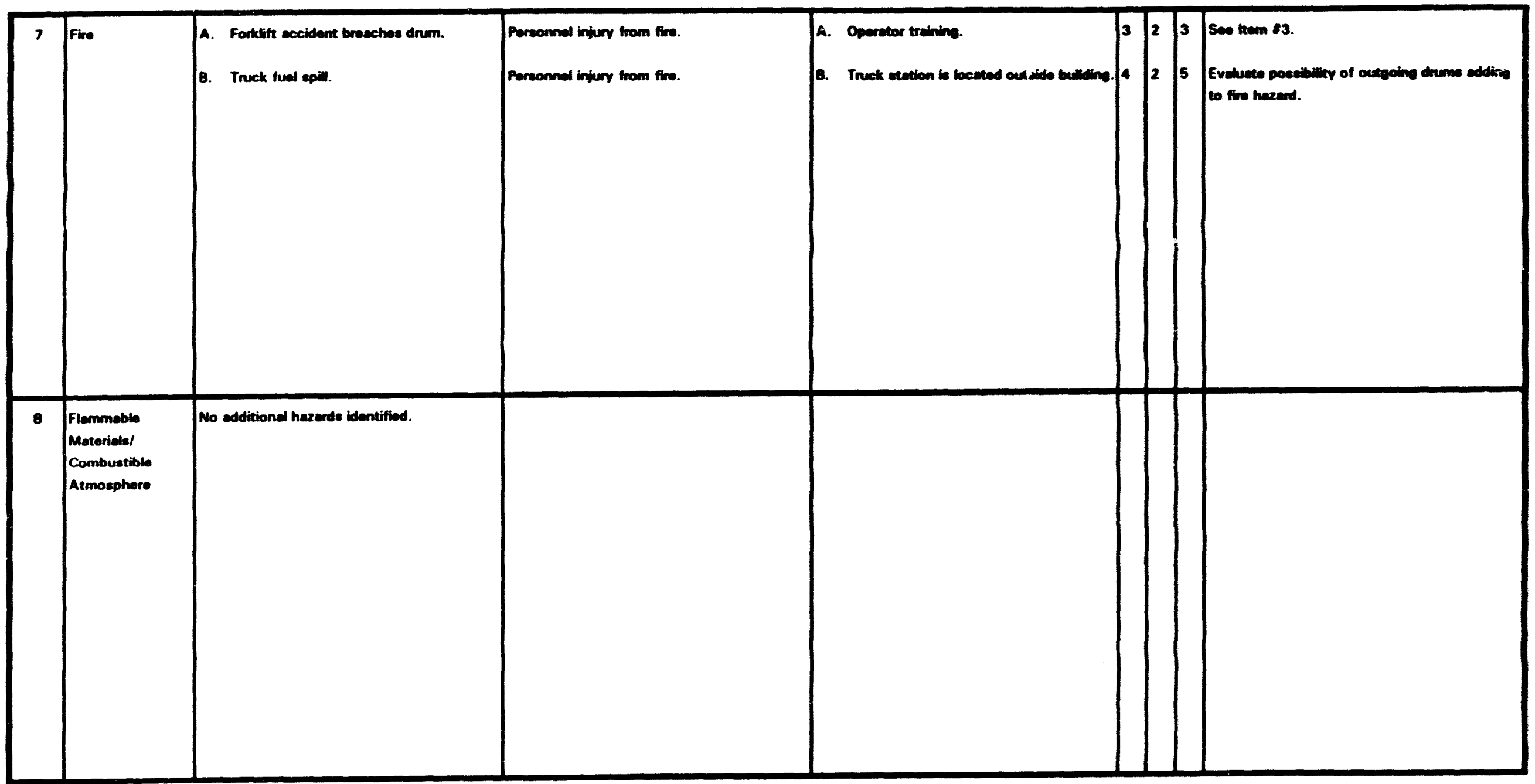


WhaP FACUITY, DOER

DE-ACOS-91RL11948

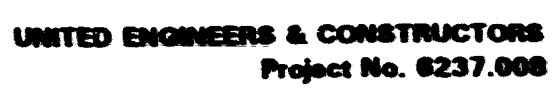

WRAP IA ACDR PRELIMINARY HAZOP REVIEW DATA SHEET

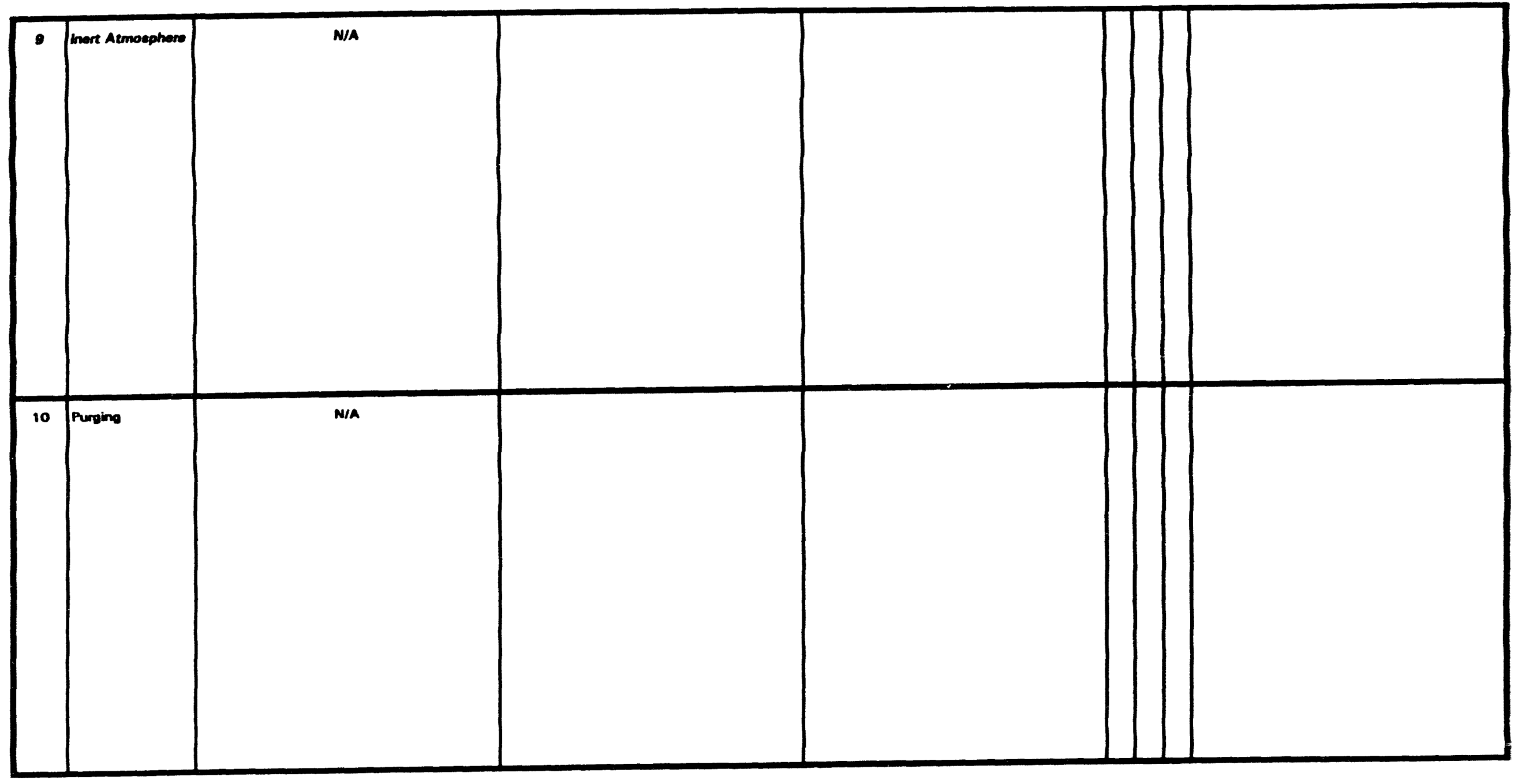

WQAPO463

Page 18

$12 / 01 / 93$ 


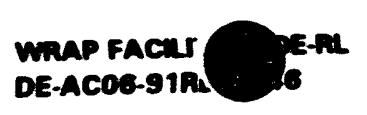

WRAP LA ACDR PRELIMINARY HAZOP REVIEW DATA SHEET

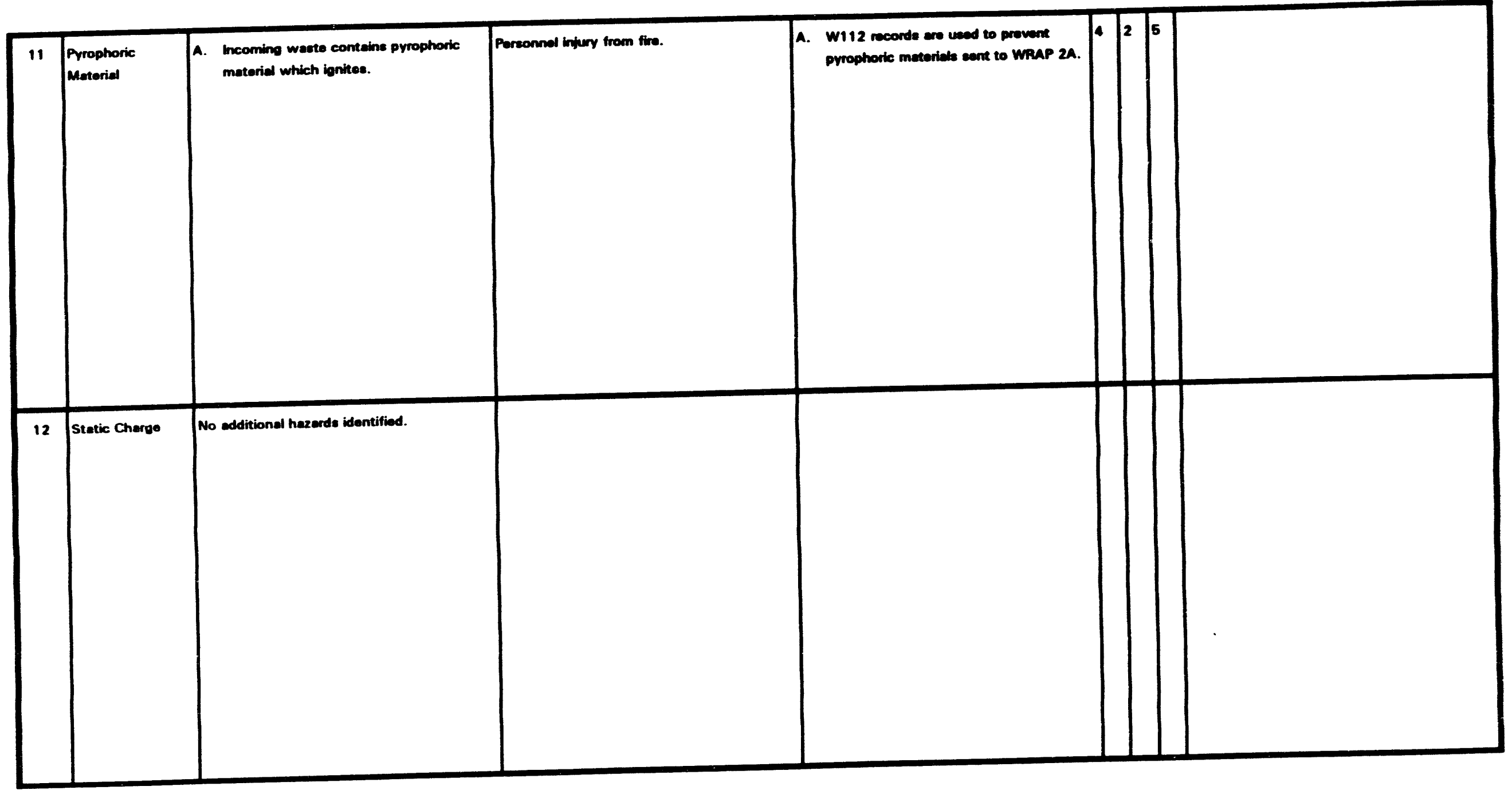

WQ9.9.453
$12 / 01 / 93$

Page 19 
WRAP 2A ACDR PRELIMINARY HAZOP REVIEW DATA SHEET

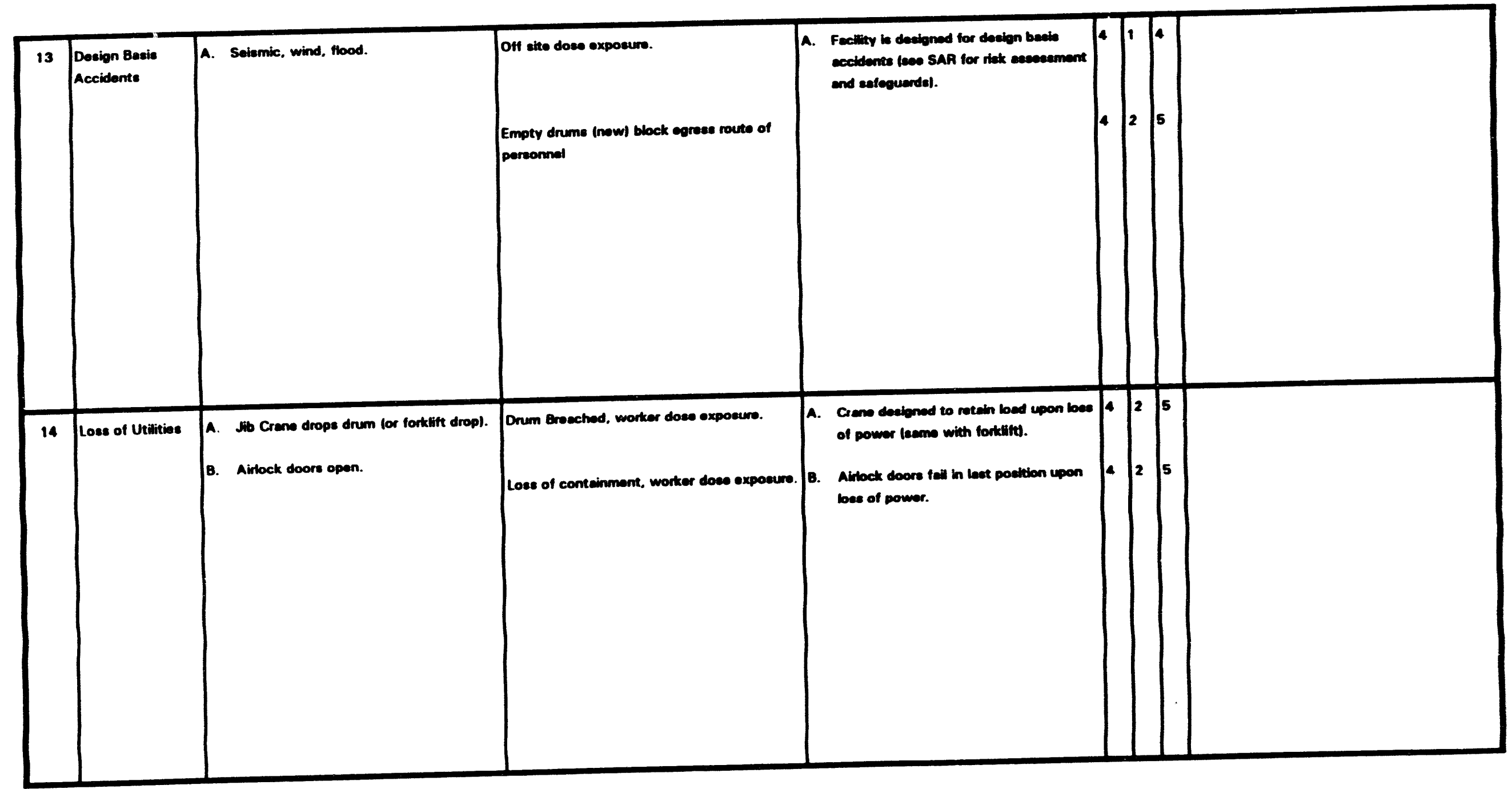



WRAP 2A ACDR PRELIMINARY HAZOP REVIEW DATA SHEET

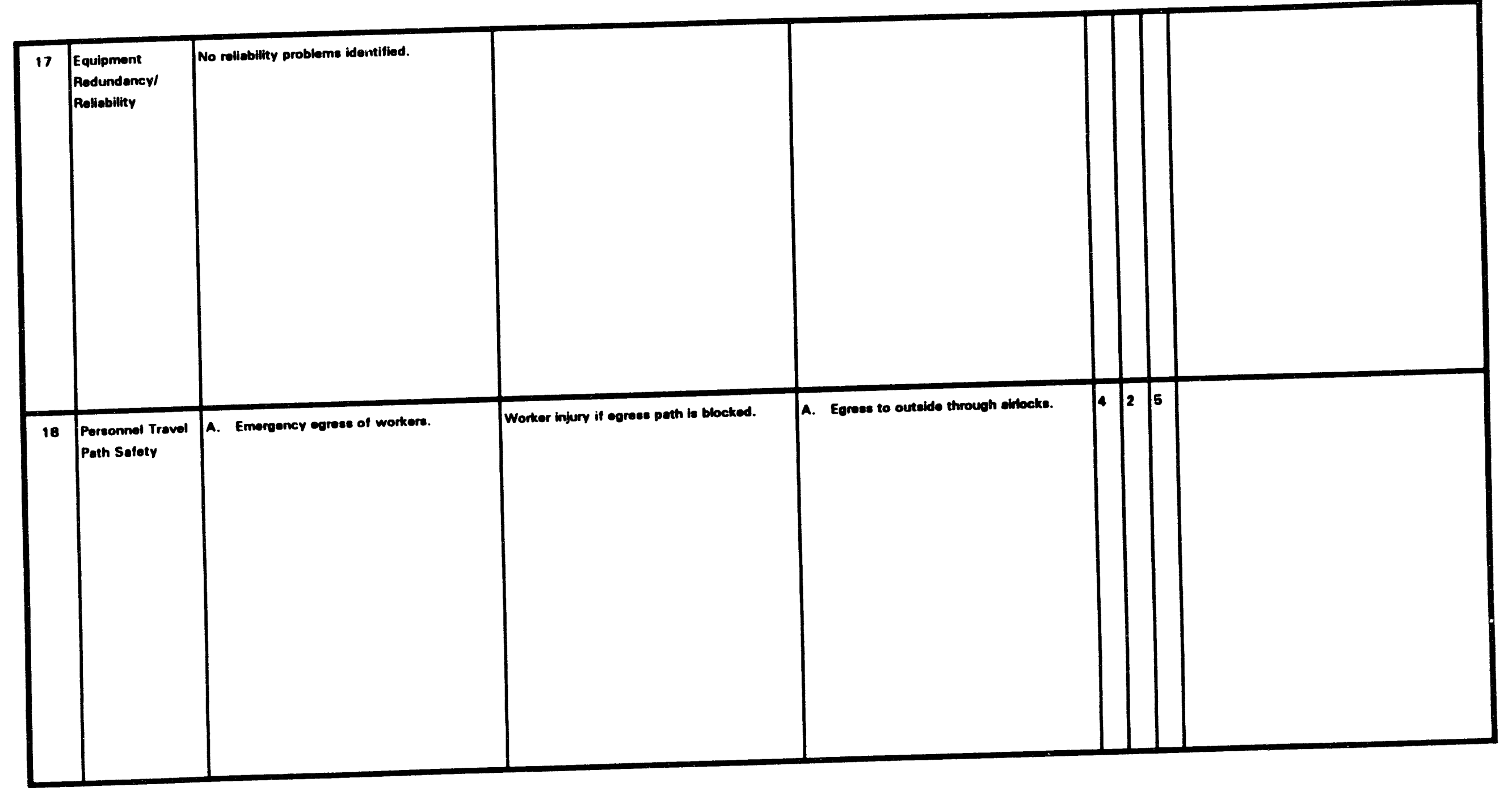




\section{WRAP 2A ACDR PRELIMINARY HAZOP REVIEW DATA SHEET}

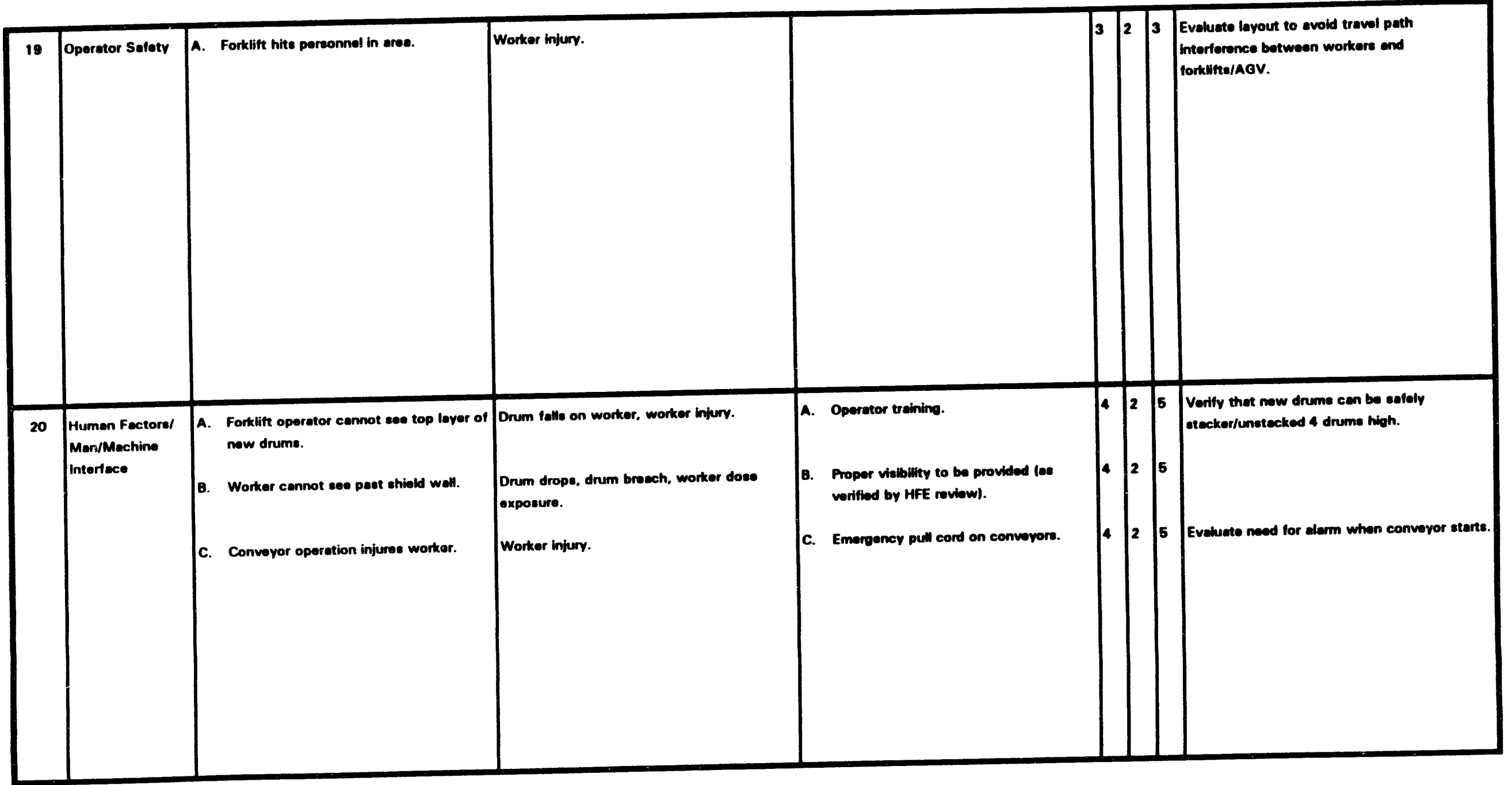


WRAP 2A ACDR PRELIMINARY HAZOP REVIEW DATA SHEET

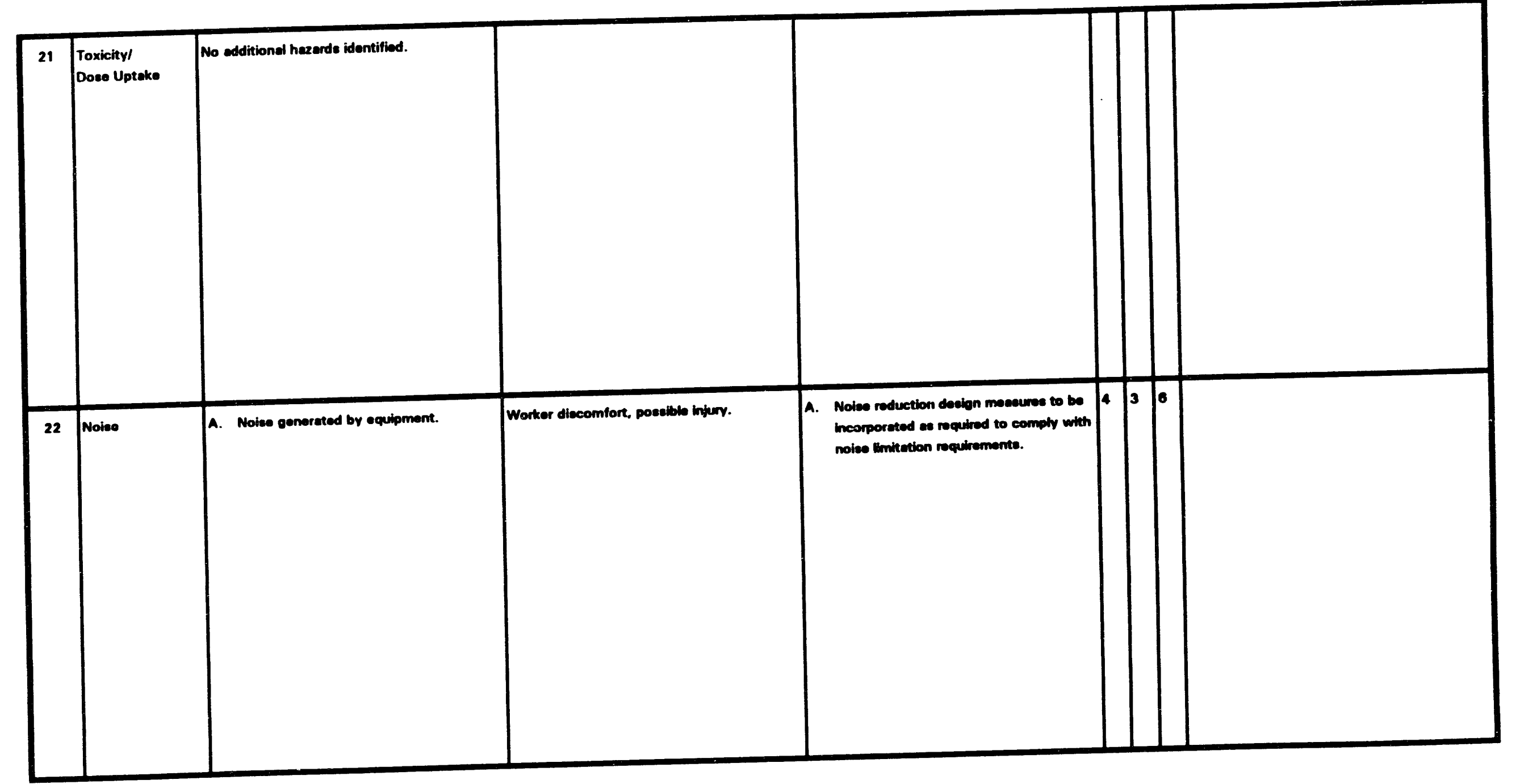




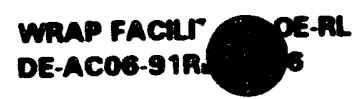

UNITED ENG WEER

onstavetons

No. 6237.000

WRAP LA ACDR PRELIMINARY HAZOP REVIEW DATA SHEET

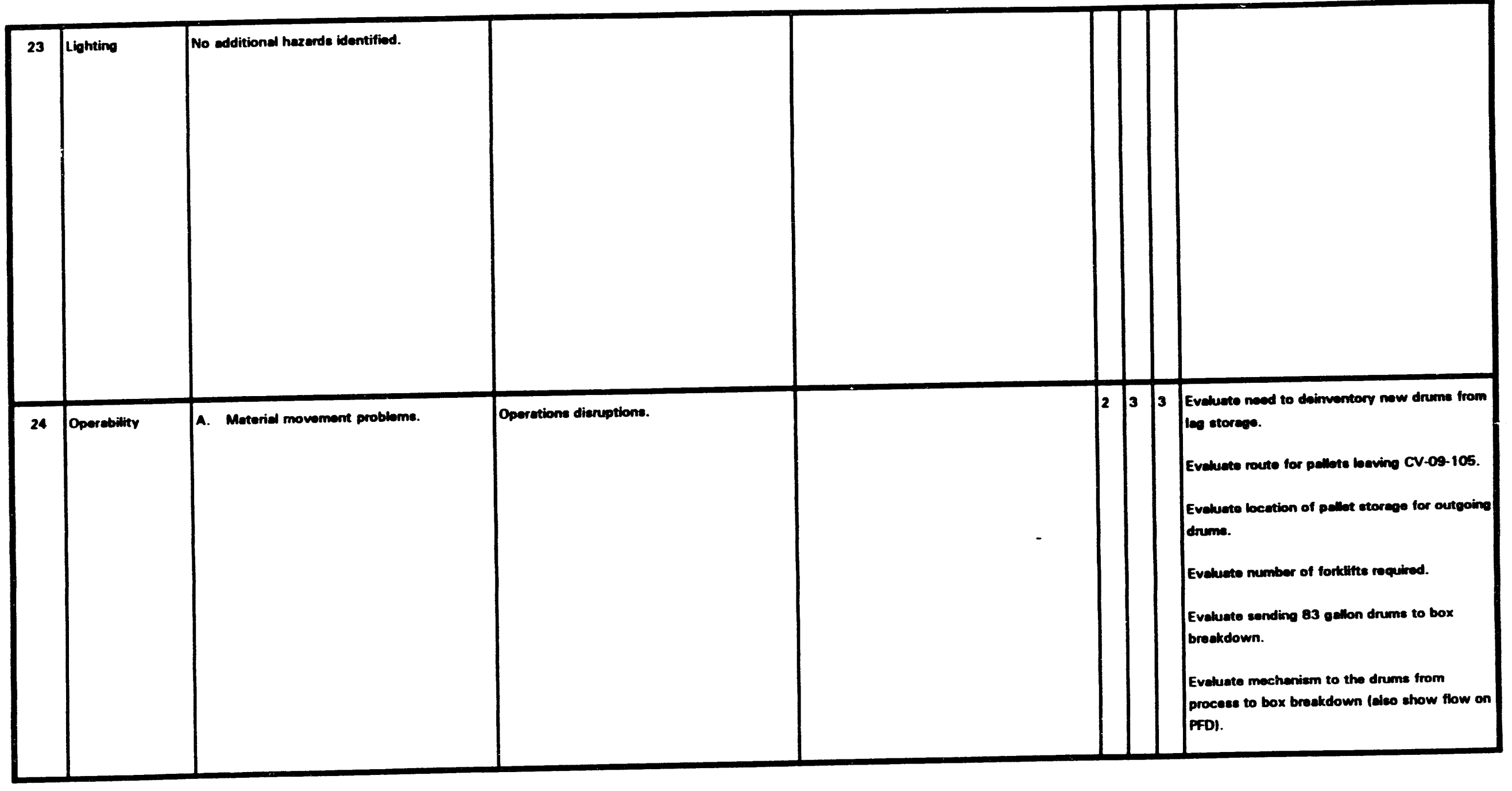

WRAD463

Page 25

$12,01 / 93$ 


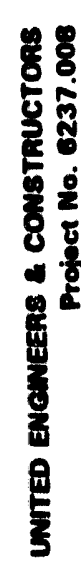

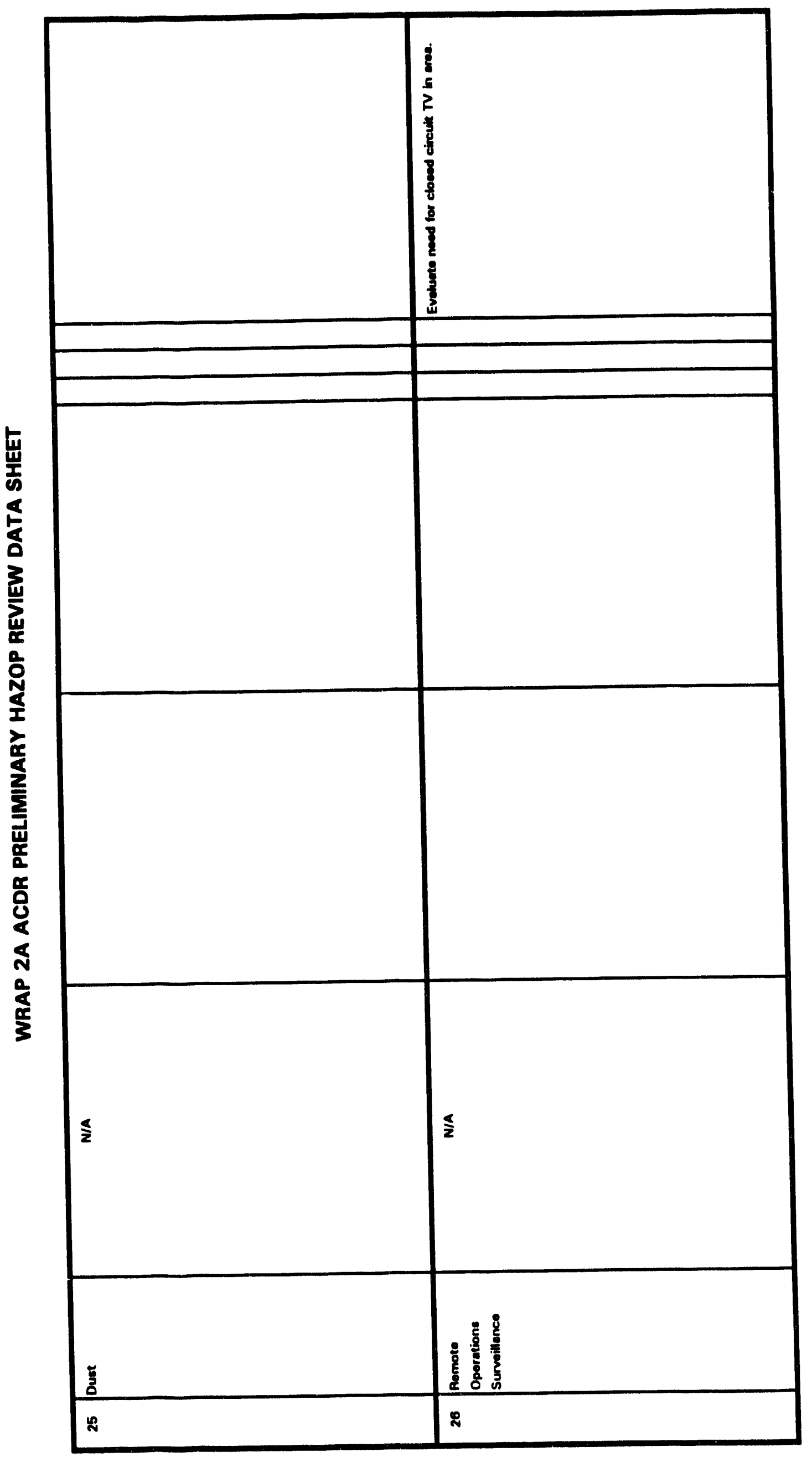




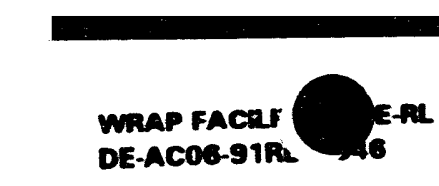

WRAP 2A ACDR PRELIMINARY HAZOP REVIEW DATA SHEET

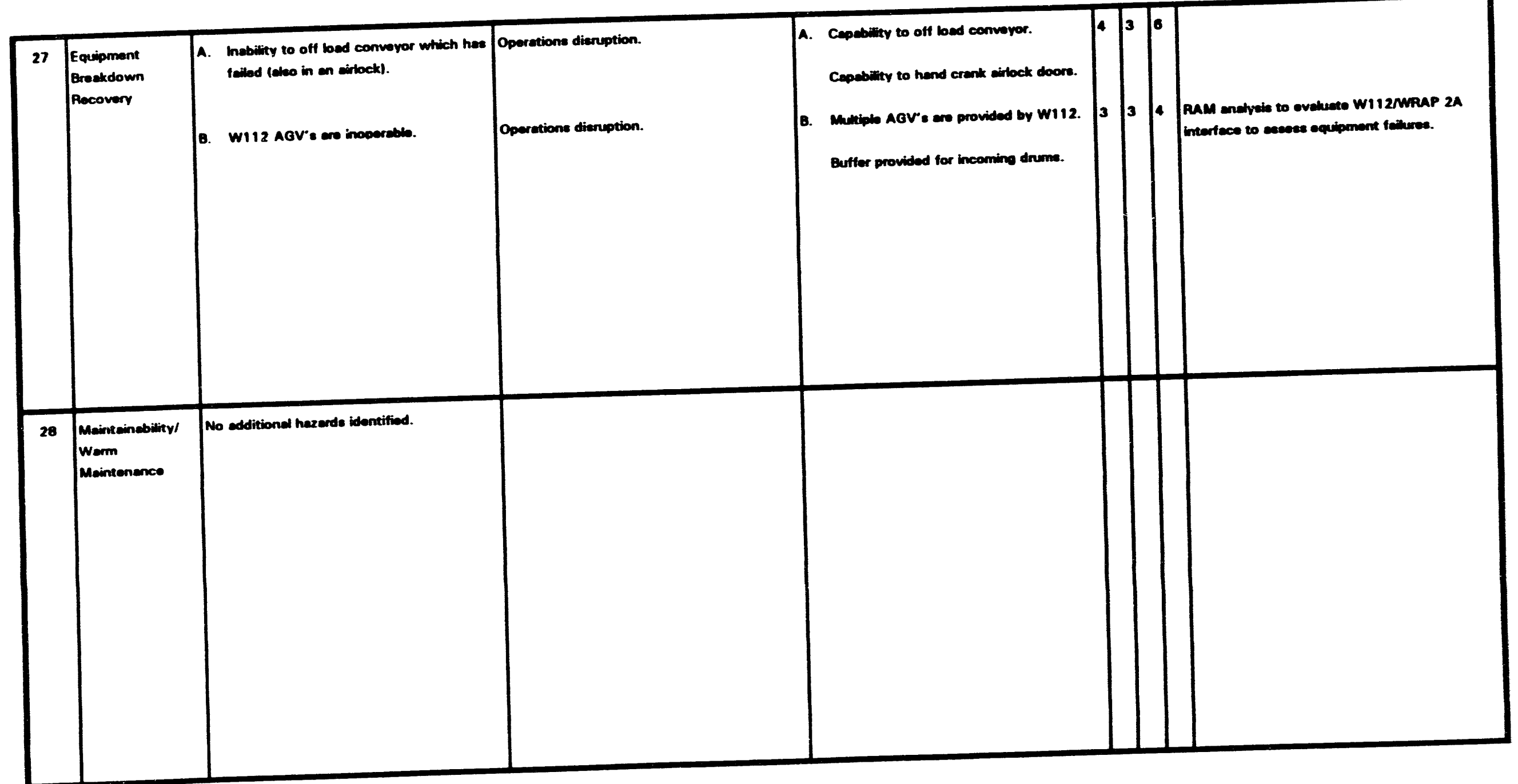


WRAP 2A ACDR PRELIMINARY HAZOP REVIEW DATA SHEET

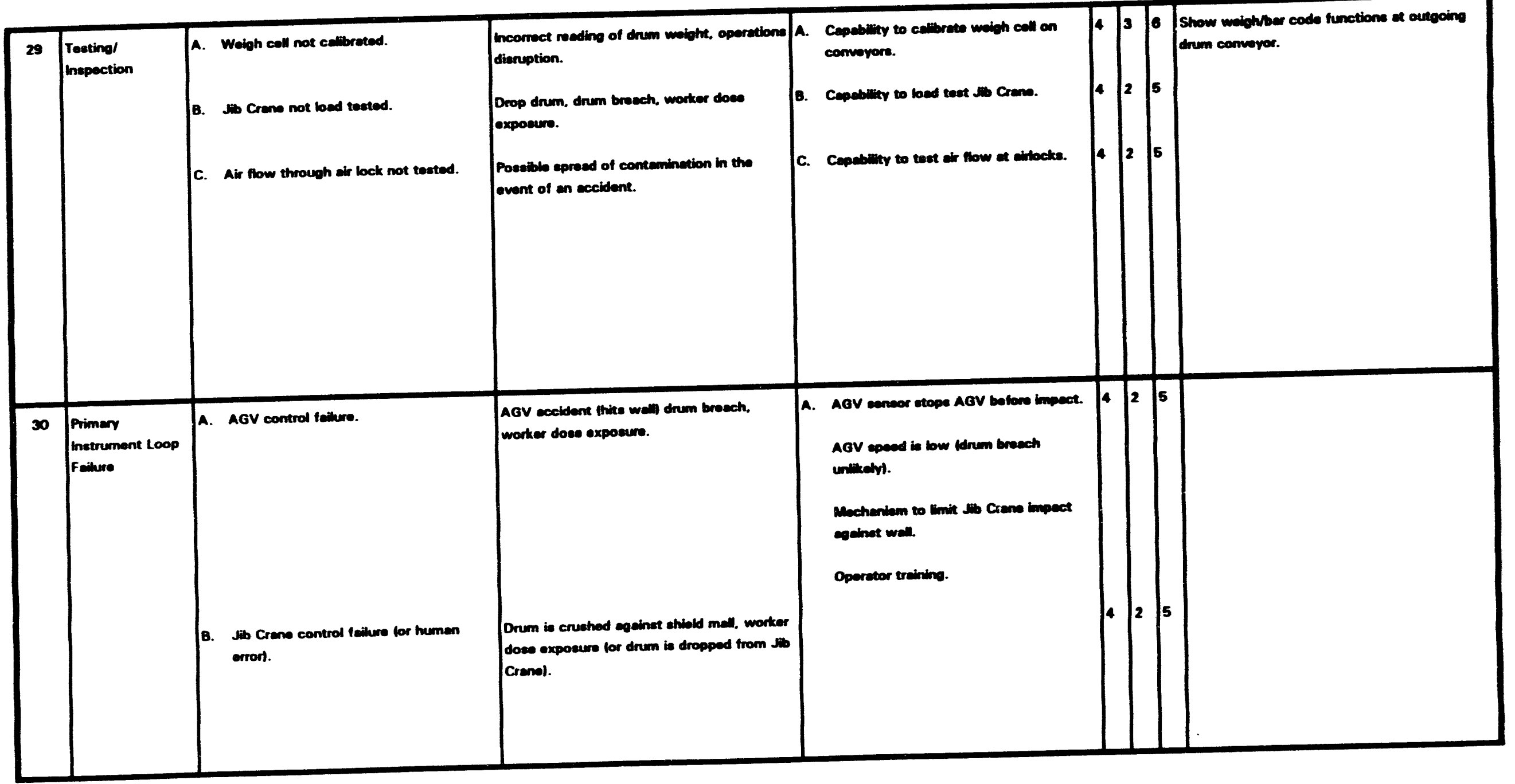




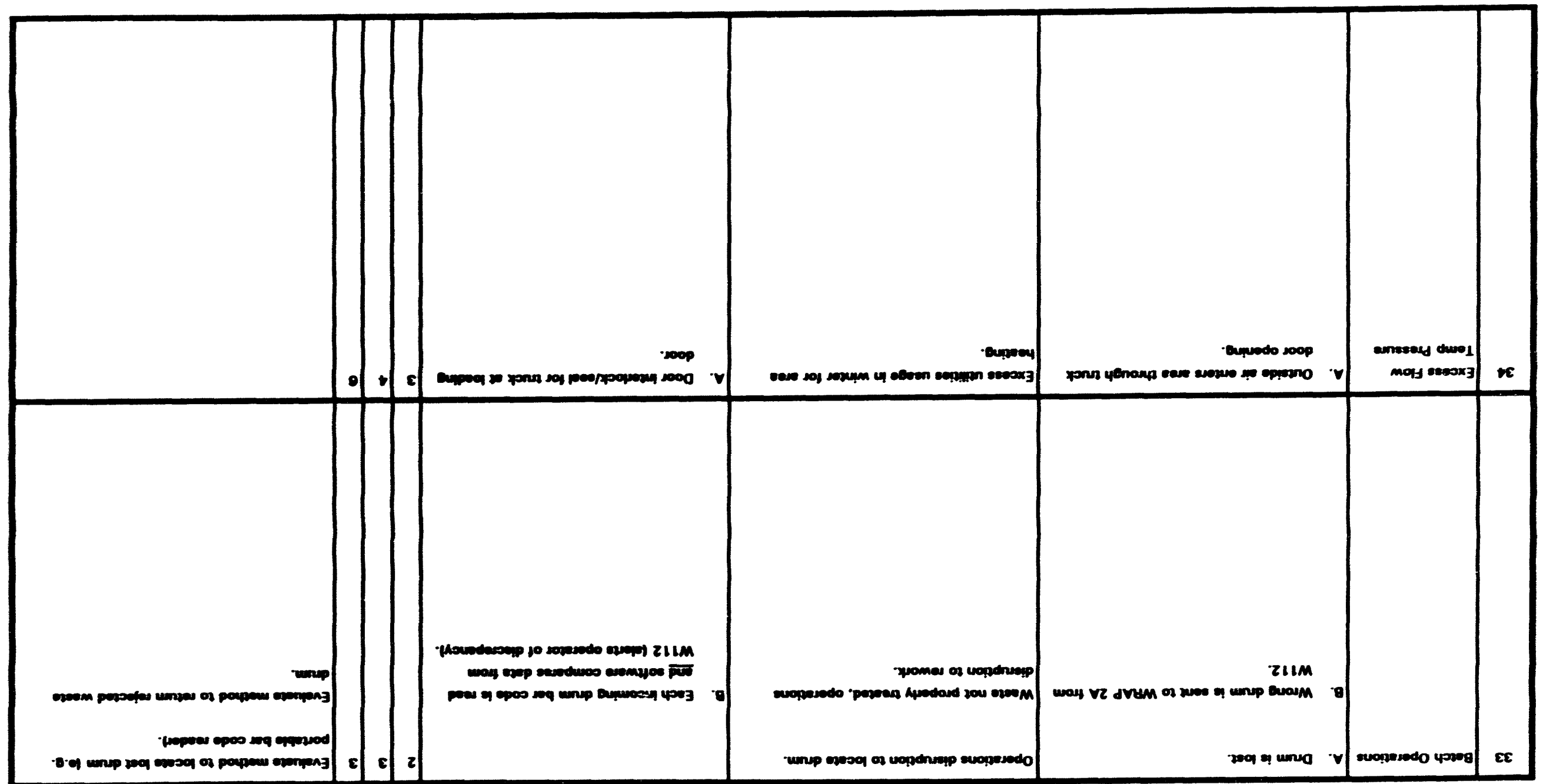

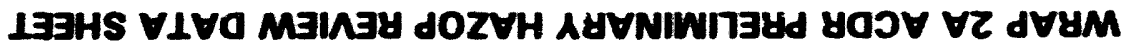




\section{WRAP 2A ACDR PRELIMINARY HAZOP REVIEW DATA SHEET}

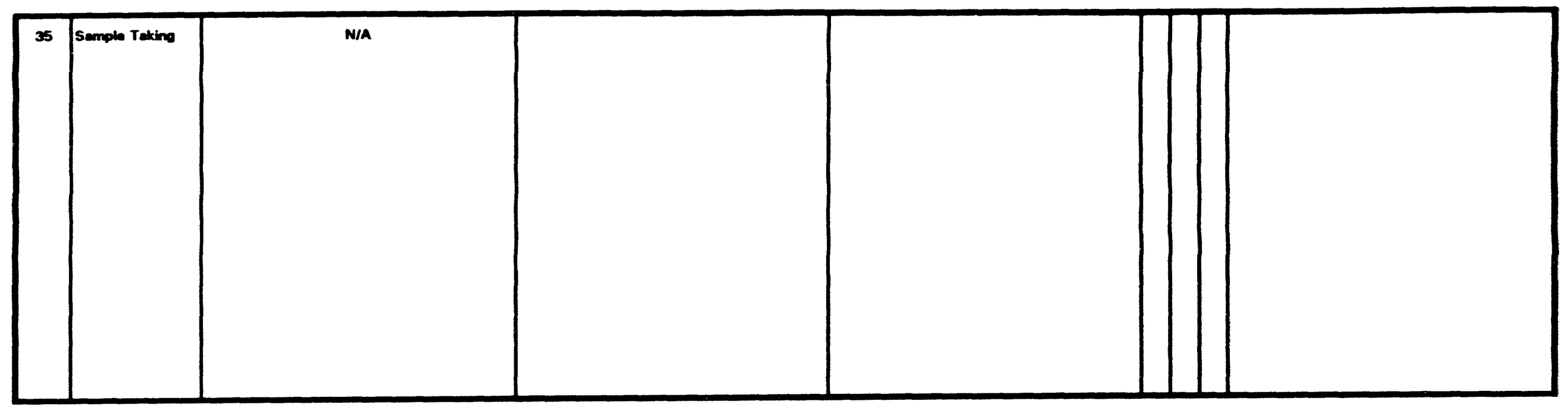




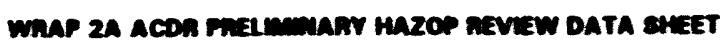

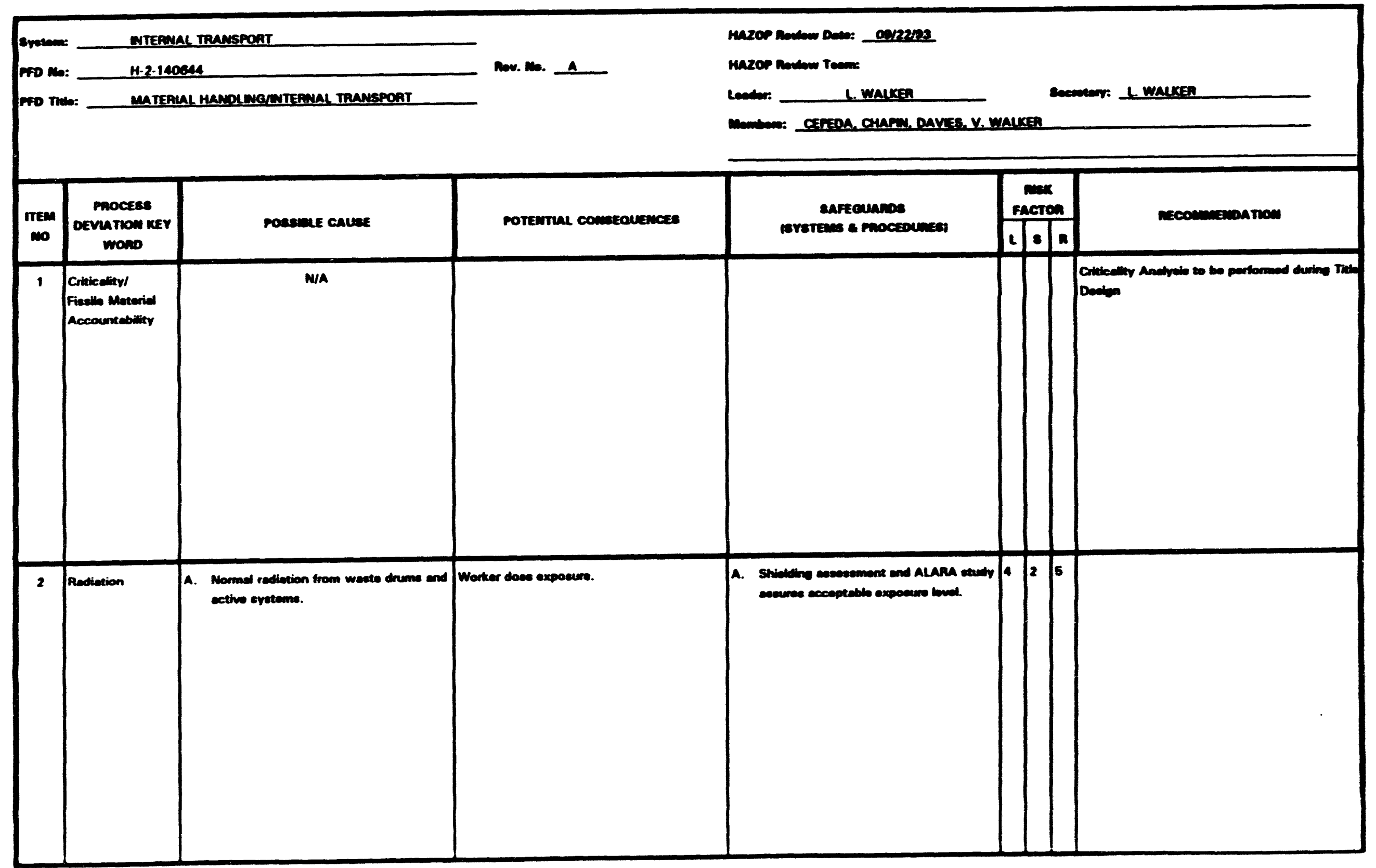




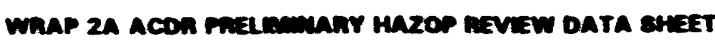

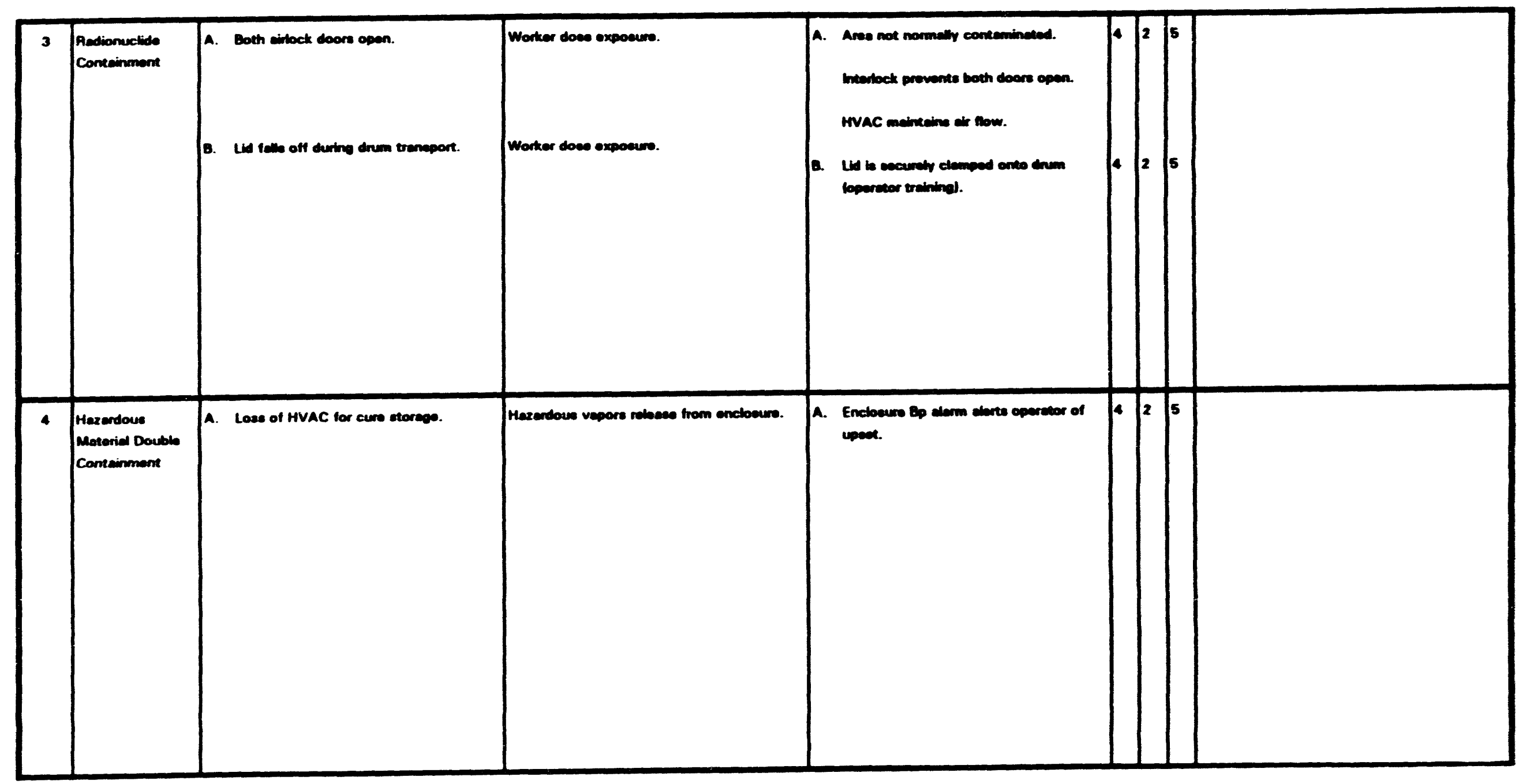




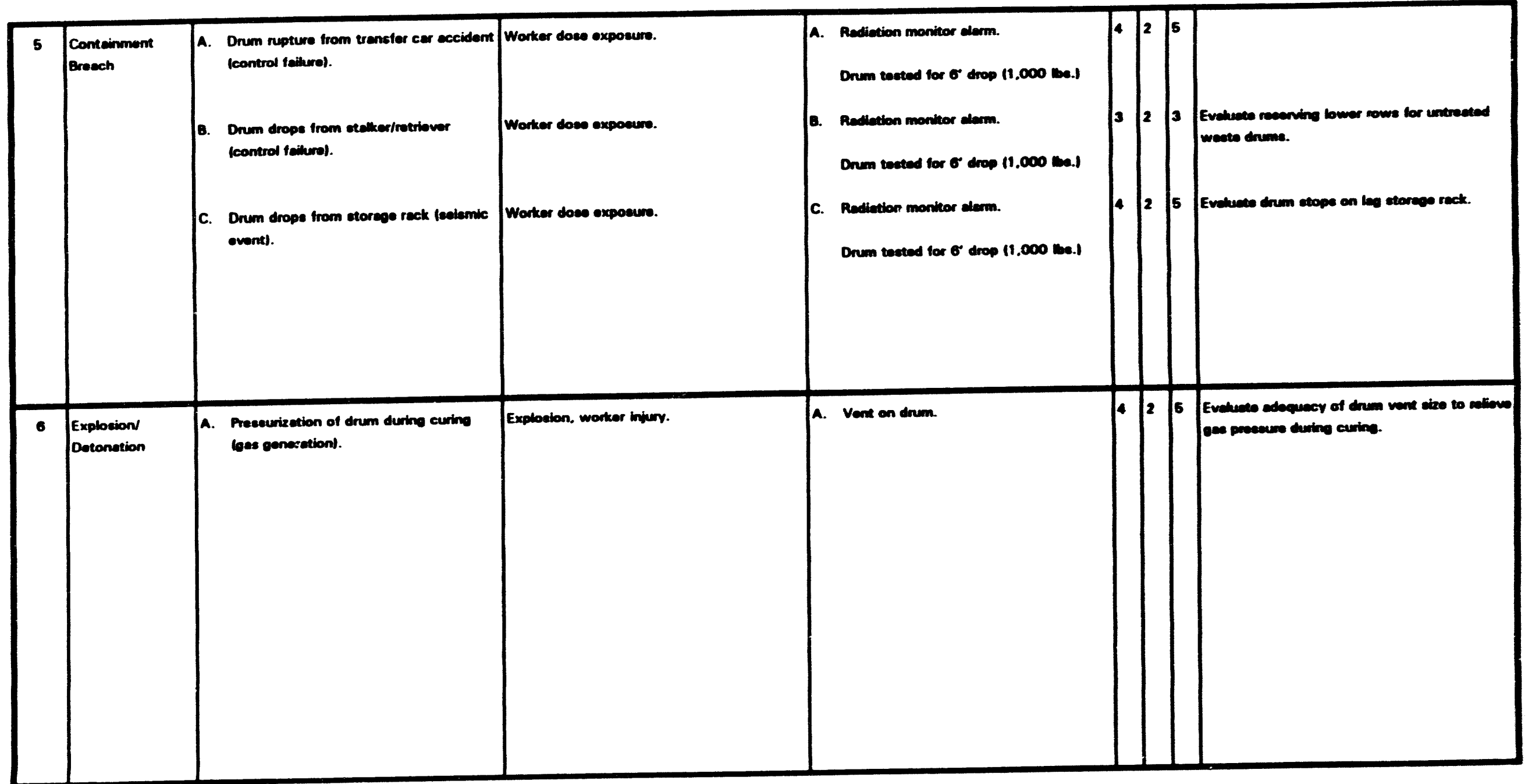




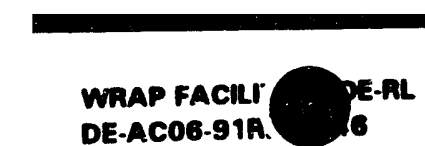

\begin{tabular}{|c|c|c|c|c|c|c|c|c|}
\hline 7 & Fire & $\begin{array}{l}\text { A. Traneter car eccident broeches drum. } \\
\text { B. Eloctrical firo. }\end{array}$ & $\begin{array}{l}\text { Poreonnel injury from fire lopitlod wante } \\
\text { ignition). } \\
\text { Local fire couseos equipment demege. }\end{array}$ & $\begin{array}{l}\text { 8. Linted amount of combusetlito material } \\
\text { prosent. }\end{array}$ & 3 & 3 & 4 & \\
\hline 8 & $\begin{array}{l}\text { Flemmable } \\
\text { Motorials/ } \\
\text { Combuetible } \\
\text { Atmosphere }\end{array}$ & $\begin{array}{l}\text { A. Vepor ovolution from curing drume IVES } \\
\text { only) normal. } \\
\text { B. Vepor evolution from untronted waete } \\
\text { drums honted up by curino drume in } \\
\text { near vicinity. }\end{array}$ & 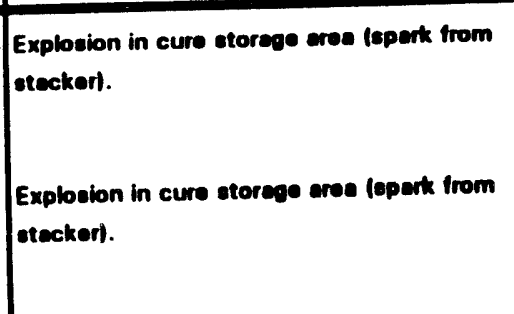 & 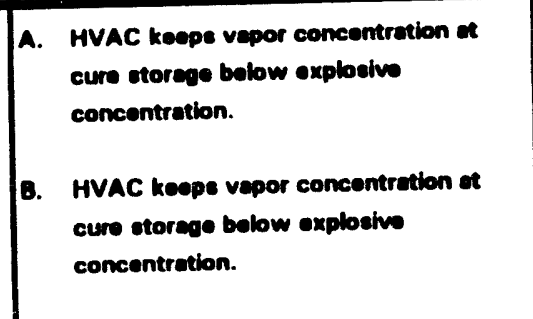 & 3 & 2 & 3 & 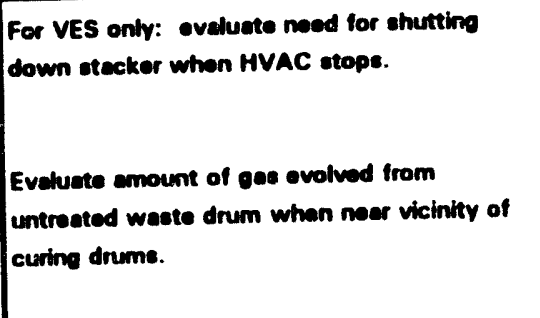 \\
\hline
\end{tabular}





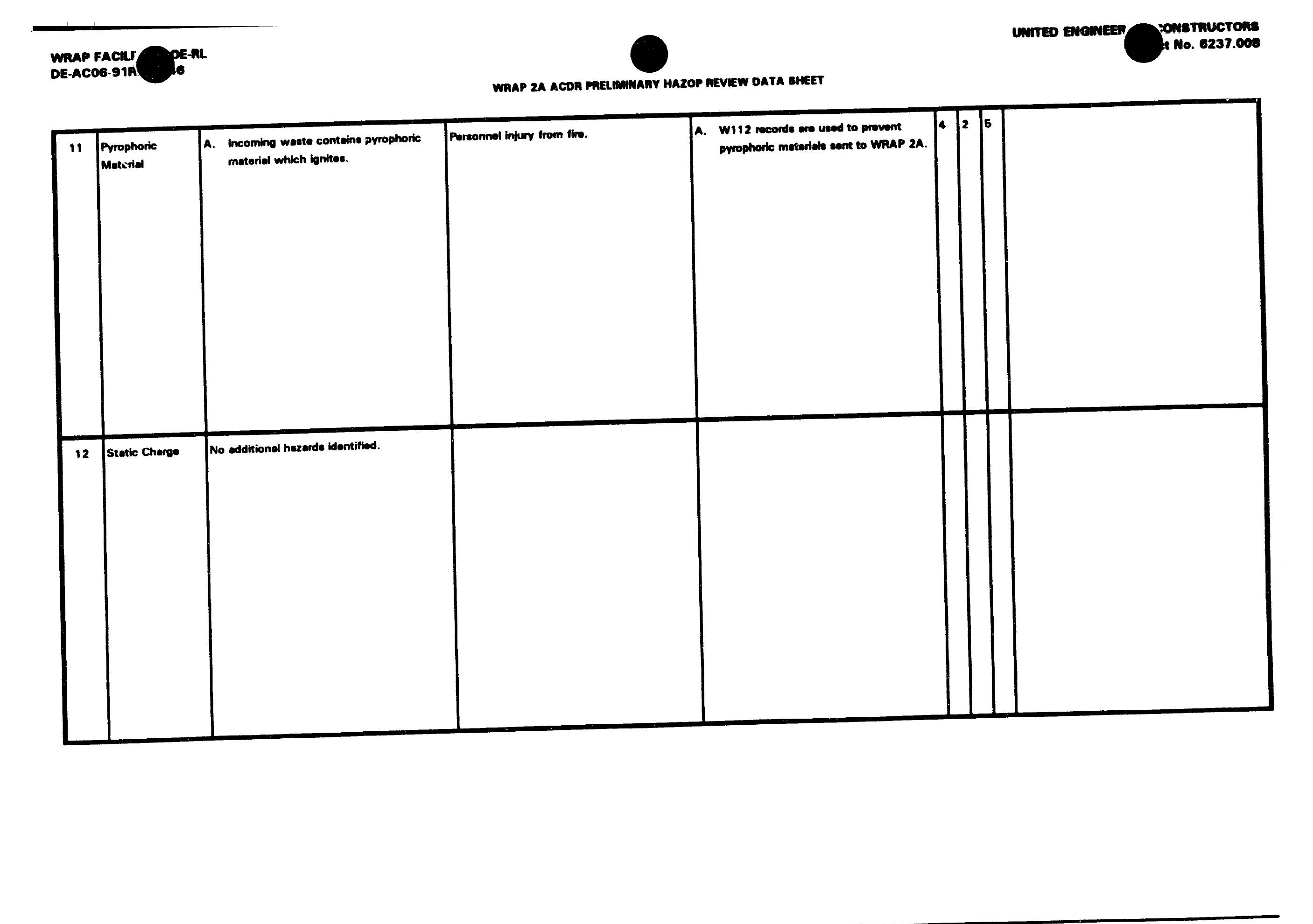




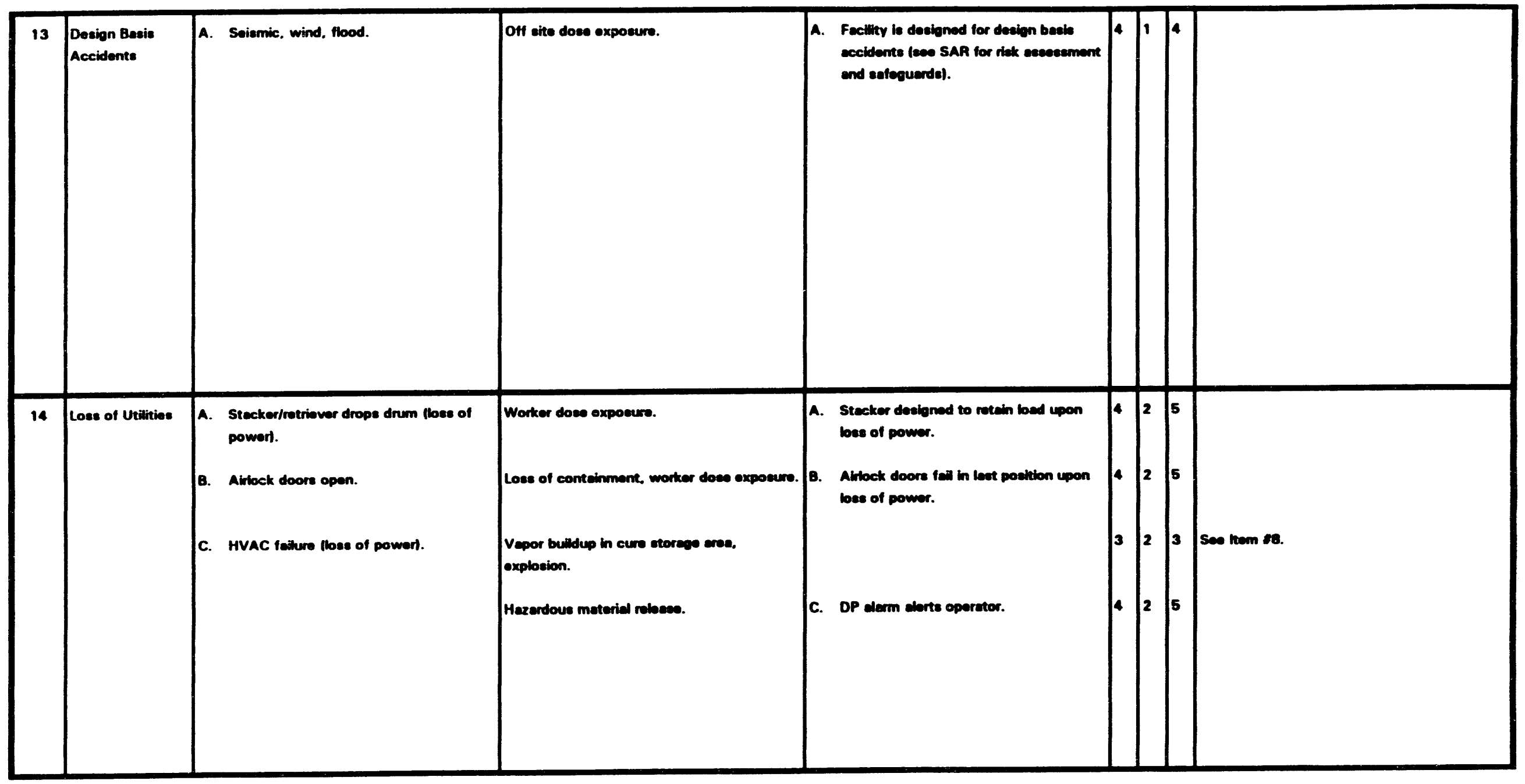



WAAP $2 A$ ACDA PAELMMULARY MAZOP REVEW DATA SHEET

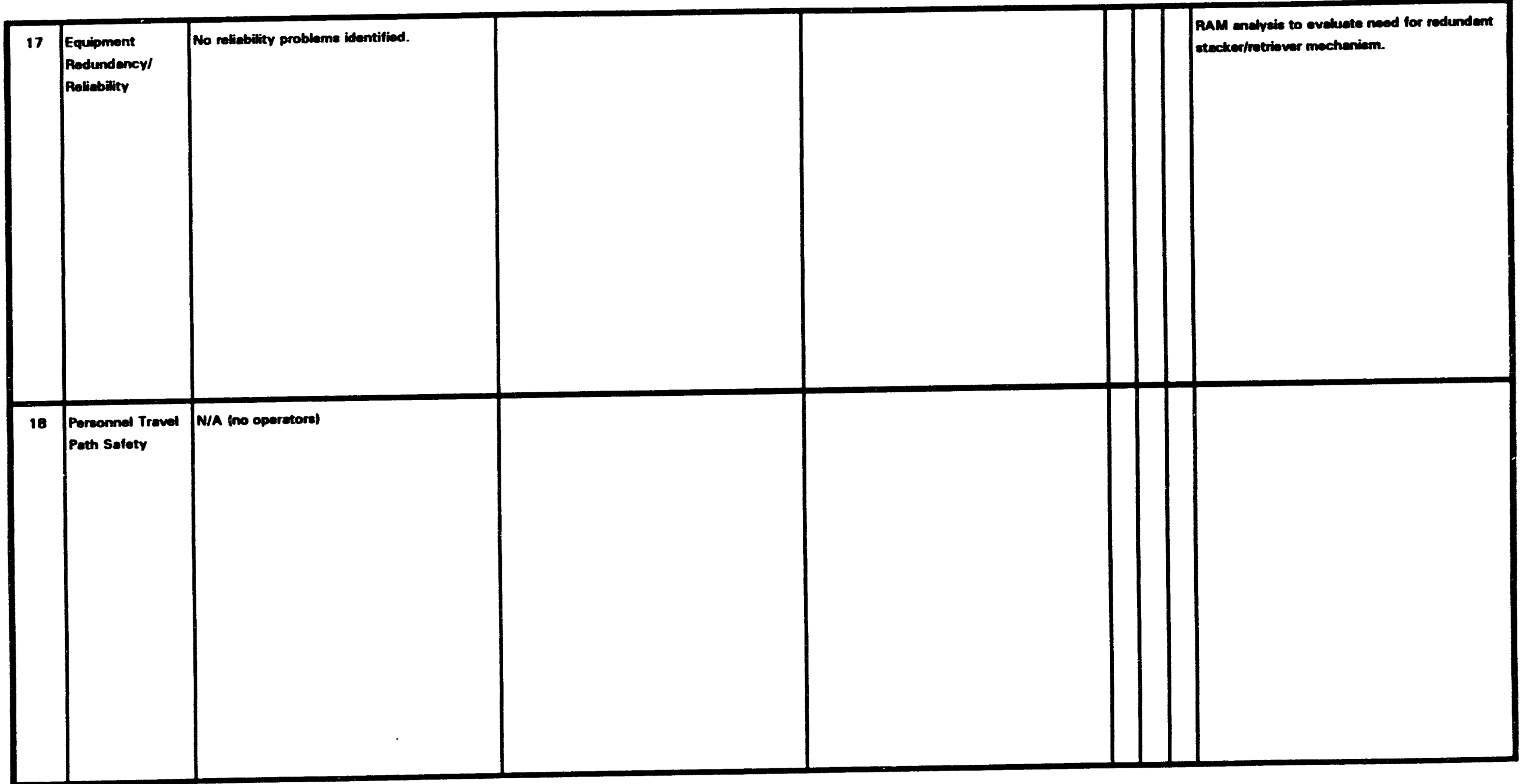




\begin{tabular}{|c|c|c|c|c|c|c|}
\hline 19 & Operator Saffety & 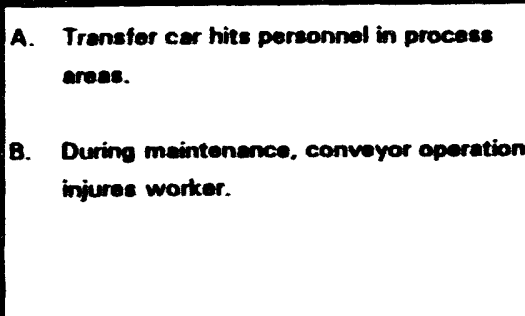 & $\begin{array}{l}\text { Worter intury. } \\
\text { Worter invery. }\end{array}$ & 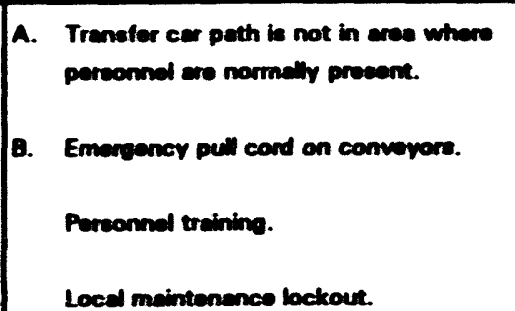 & $44_{4}^{4} 2^{2} 5$ & 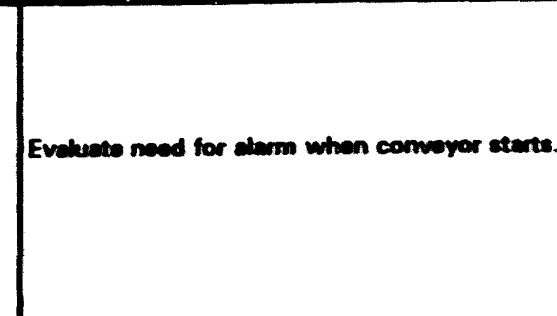 \\
\hline 20 & \begin{tabular}{|l} 
Human Fectorel \\
Man/Machine \\
Interfece
\end{tabular} & N/A & & & & \\
\hline
\end{tabular}


WRAP $2 A$ ACOA PRELUMMARY HAZOP REVEY DATA SHEET

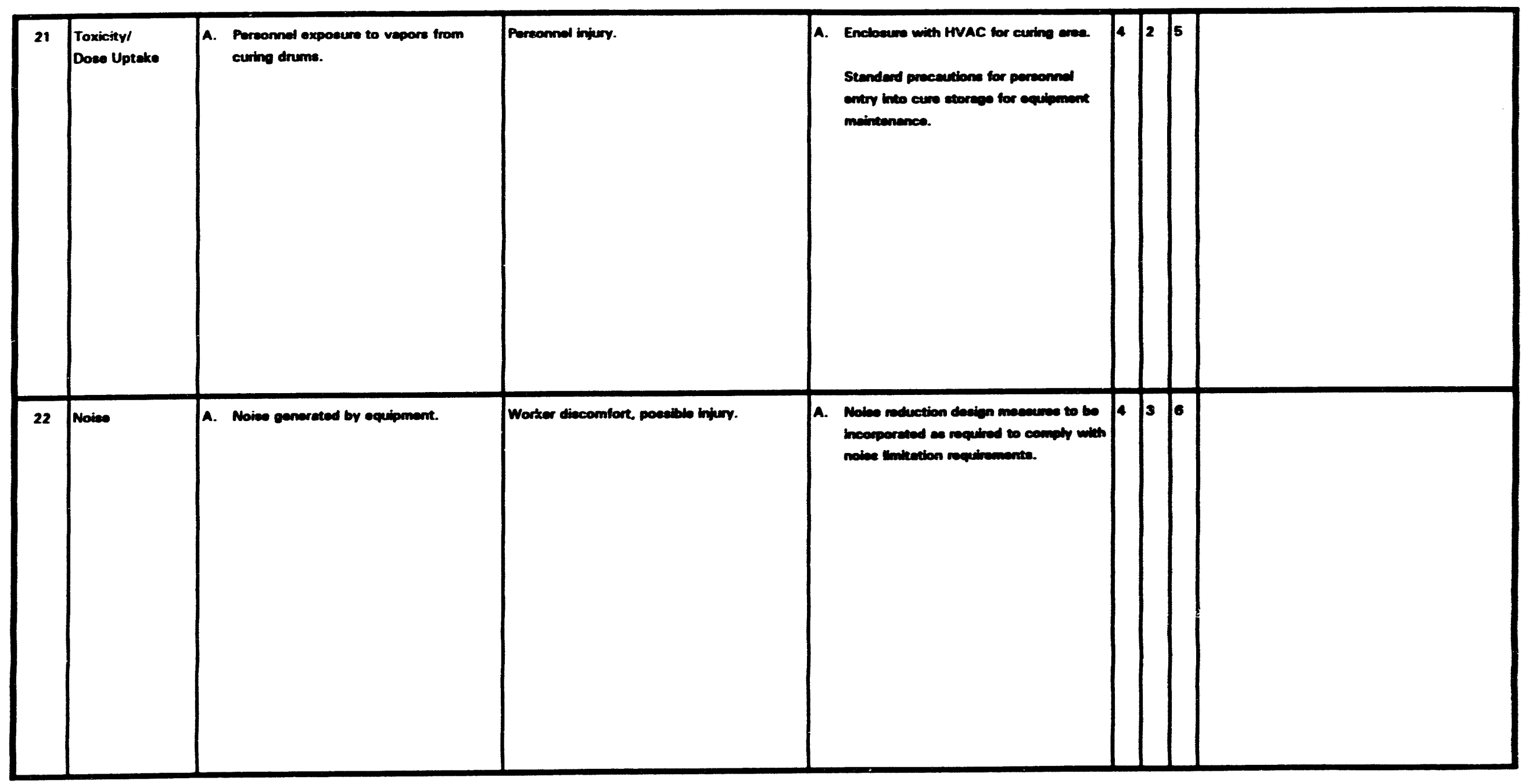


WAAP $2 A$ ACOA PAELIMUMARY MAZOP REVEZW DATA SHEET

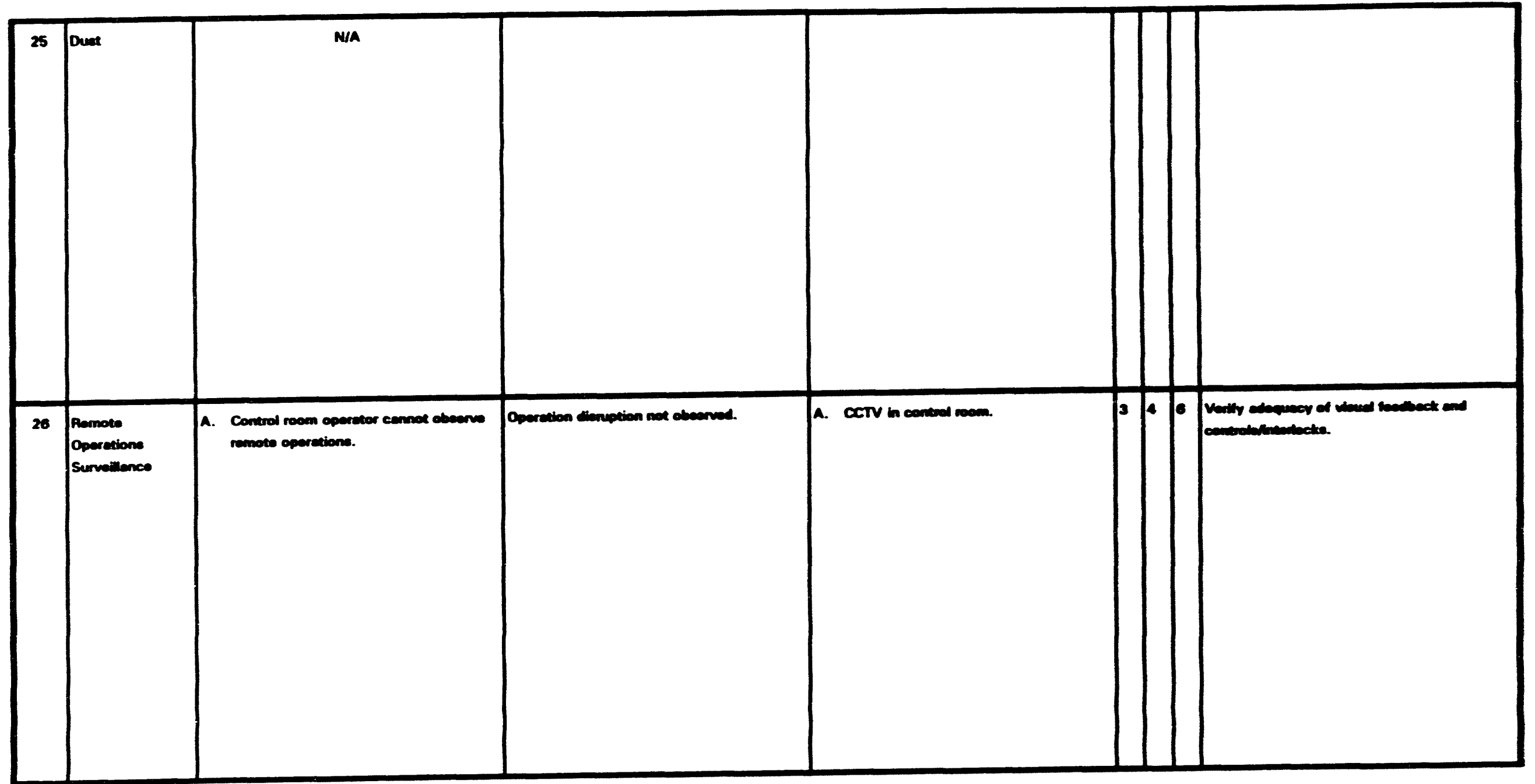




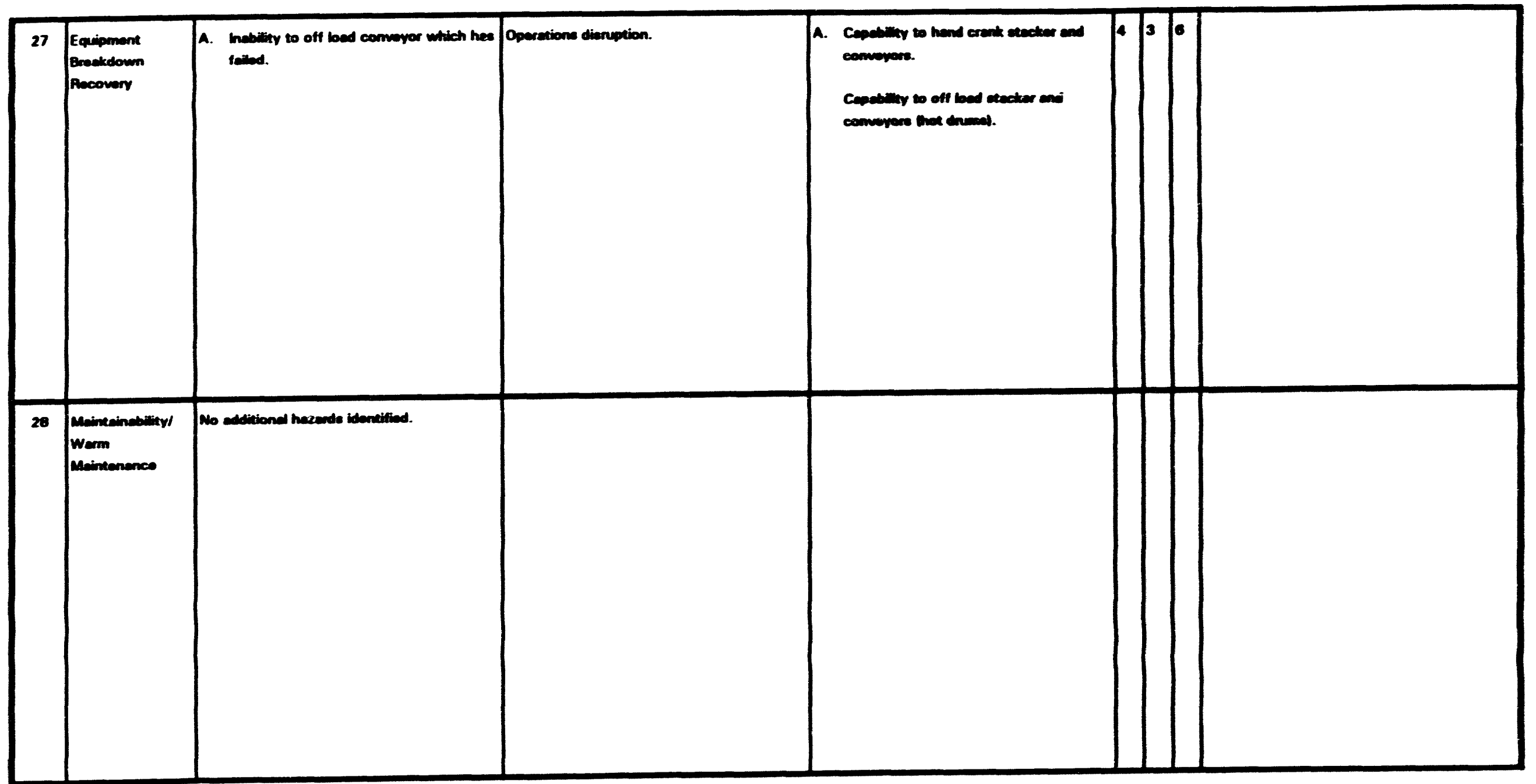




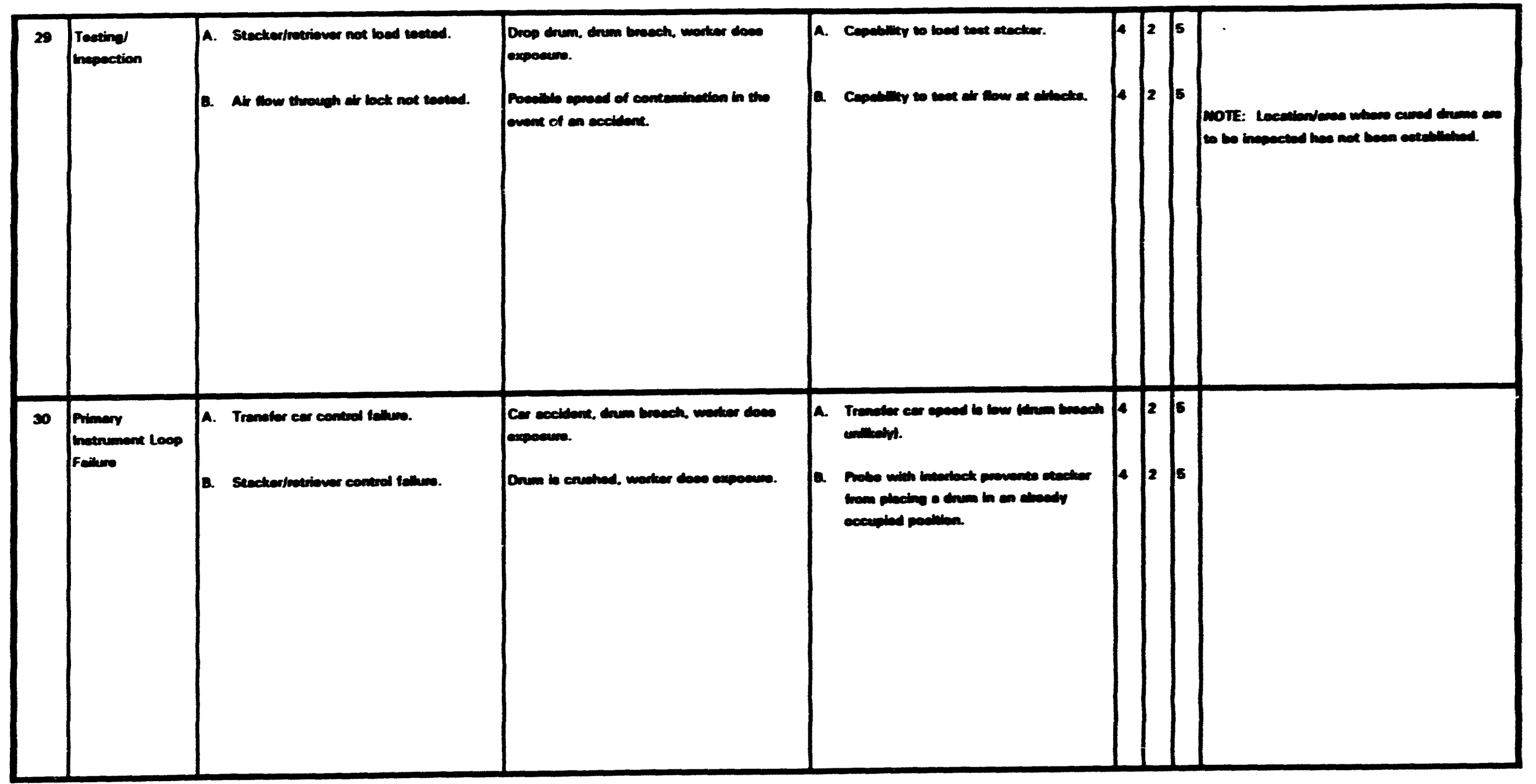




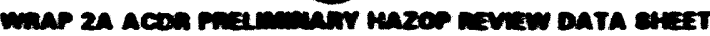

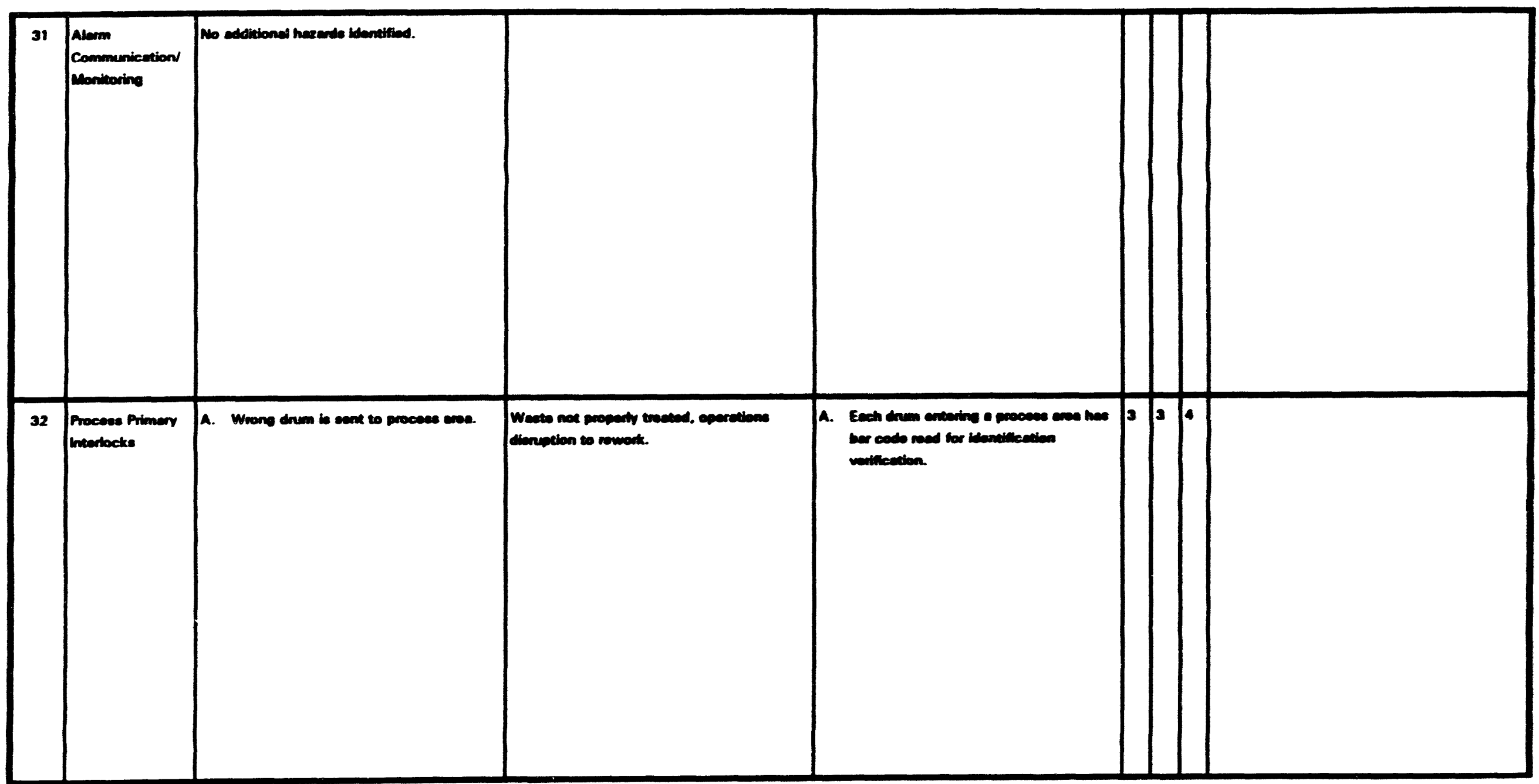





\section{WRAP FACILI IOE-RL \\ DE-AC06-91F

\begin{tabular}{|l|l|l|l|l|l|l|l|}
\hline 35 & Sample Takine & N/A & & & & & \\
& & & & & & & \\
\hline
\end{tabular}


Rovision: 0

Submitted to:

UNITED 8TATES

DEPARTMENT OF ENEAOY

Richland, Washington

Prepared by:

UNTED ENGINEEAS

a consthuctons

A Raythion Company

Wrovem Osprelone 


\section{TABLE OF CONTENTS}

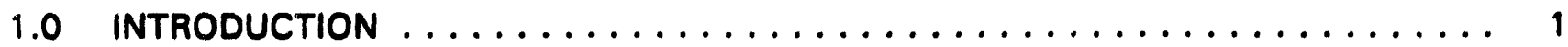

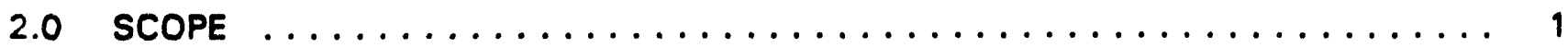

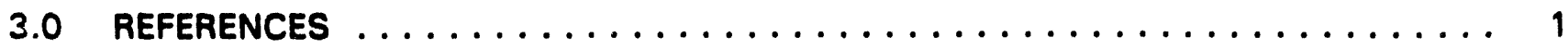

4.0 DESCRIPTION OF LIQUID EFFLUENT COLLECTION SYSTEM $\ldots \ldots \ldots \ldots \ldots \ldots \ldots$

4.1 Design Basis Summary . . . . . . . . . . . . . . . . . . . . 1

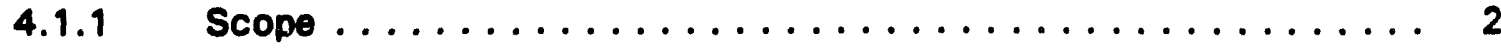

4.1 .2 Design Goals ......................... 2

4.1.3 Functional Requirements ................... 2

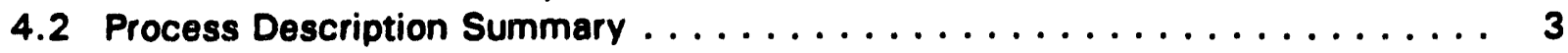

4.2.1 Introduction ........................ 3

4.2.2 Feeds and Throughput $\ldots \ldots \ldots \ldots \ldots \ldots \ldots \ldots \ldots \ldots \ldots$

4.2 .3 Design Requirements .................... 4

4.2 .4 Process Selection ....................... 4

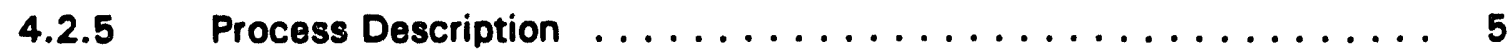

5.0 STUDY CRITERIA AND METHODOLOGY $\ldots \ldots \ldots \ldots \ldots \ldots \ldots$

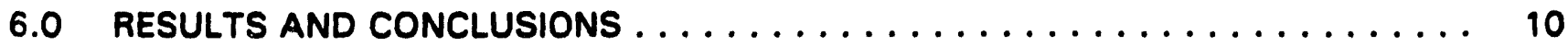




\section{WRAP 2A}

\section{LIOUID EFFLUENT COLLECTION}

\section{HAZOP STUDYREPORT}

\subsection{INTRODUCTION}

A HAZOP study was performed on the advanced conceptual design of the Liquid Effluent System. The HAZOPS team met on 21 September 93, and consisted of the following members:

Name

Larry Walker

Tim Sayers

Doug Chapin

William Cepede

Valerie Walker

\section{Company}

UE\&C

UE\&C

UE\&C

UE\&C

BNFL

\section{Role/Expertise}

Leader, Scribe, Safety

Process

Process

Instrumentation and Controls

Radiological

The purpose of the HAZOPS is to identify major safety and operability problems which can best be resolved during completion of the advanced conceptual design.

\subsection{SCOPE}

This HAZOPS encompassed the active and non-active plant drains and liquid waste systems, as shown on Process Flow Diagrams H-2-140658 and 140659

\subsection{REFERENCES}

1. WHC-SD-W100-FDC-001 Rev. 2A, Functional Design Criteria Waste Receiving And Processing Facility Module $2 \mathrm{~A}$.

2. WHC-SD-W100-SDRD-001 Rev. A, Waste Receiving and Processing Facility Module 2A Supplemental Design Requirements Document.

\subsection{DESCRIPTION OF LIQUID EFFLUENT COLLECTION SYSTEM}

\subsection{Design Basis Summary}




\subsubsection{Scope}

1. Workscope includes handling and treatment of contaminated and non-contaminated liquid waste (not sanitary wastes) generated during normal process operations such as decontamination, equipment flushing, HVAC condensation, chemical make-up, and other processes.

2. Overall Water Balance for the plant.

\subsubsection{Design Goals}

1. No liquid effluent will be discharged to the environment.

2. Develop overall water balance to define water treating capacity and water recycle requirements to the grout stabilization area.

3. Develop wet waste/spent decon collection and pretreatment systems based on proven technology.

4. Develop waste water collection and treatment systems for radioactively contaminated and non-contaminated waste water supply.

5. Minimize generation of secondary waste.

6. Untreated liquid waste cannot be stored beyond 90 days per Washington State requirements.

7. Incorporate the principals of human factors and ALARA into the design process.

\subsubsection{Functional Requirements}

1. Collect, characterize and pretreat wet waste and spent decon.

2. Collect and treat radioactively contaminated and non-contaminated waste water separately (physical separation is required).

3. Non-radioactively contaminated waste water shall be collected, characterized, and packaged for disposal. Alternatively, it can be used within the facility as make-up water for immobilization.

4. Radioactively contaminated waste water shall be used within the facility as makeup water for immobilization or transported to the C018 LETF treatment facility based upon the plant water balance.

5. Liquid waste determined to be hazardous but non-radioactive shall be packaged for disposal in $\mathbf{5 5}$ gallon drums with provision for 2 weeks of lag storage available. 
6. Radioactively contaminated liquid waste treating system for recycle to grouting or feed to C018 LETF will include neutralization, solids removal, and organic removal. A double tank collection system shall be used to provide 2 months storage with each sized at 7000 gallons minimum. Treated waste shall have surge storage capability for 3 months with a minimum capacity of 7000 gallons.

7. All outside tanks shall have freeze protection and spill prevention, collection, and control provisions.

8. Enclosed and vented tanks will be connected to the off-gas treatment system.

9. All tanks and ancillary equipment used to store or treat hazardous waste shall have double containment and leak detection systems per WAC 173.303 and DOE 6430.1A, Division 1323.

10. Leak detection devices and electrical interlocks are required to protect against overfilling of collection devices or release of liquid waste.

\subsection{Process Description Summary}

\subsubsection{Introduction}

1. Radioactive and non-radioactive liquid wastes will be generated at WRAP 2A during normal operations such as decontamination, aqueous solution make-up, building HVAC condensate, and other miscellaneous sources. Sanitary wastes are segregated from the radioactive and non radioactive wastes streams to prevent cross contamination. The sanitary wastes are collected, treated, and disposed of in a separate treatment system. Radioactive and non-radioactive liquid waste treatment systems are provided to collect, sample, treat, and recycle the water within the WRAP 2A facility. The treatment for nonradioactive waste is limited to $\mathrm{pH}$ adjustment while the treatment for the radioactive waste consists of pH adjustment, filtration, and carbon adsorption. A backup capability to dispose of radioactive liquid waste to the C018 LETF is provided. In addition, capability of drumming non-radioactive hazardous waste and shipping it to an approved hazardous waste treatment, storage and disposal facility is also provided.

\subsubsection{Feeds and Throughput}

1. The secondary waste treatment systems are not used to directly treat any of the incoming waste streams. Rather, they are used to collect, sample and treat all liquid wastes which are generated in the WRAP 2A facility during the processing of the incoming waste streams.

2. The radioactive liquid waste system is designed to handle an average of 567 gallons per day while the non-radioactive waste system is expected to handle an average of five gallons per day. The secondary waste treatment systems will be utilized throughout the entire life of the WRAP 2A facility. 


\subsubsection{Design Requirements}

1. No liquid effluent will be discharged to the environment.

2. Provide segregated systems for radioactive and non-radioactive liquid waste.

3. Minimize generation of secondary waste.

4. Incorporate the principals of human factors and ALARA into the process design.

5. All necessary tanks, piping, pumps, monitoring and control instrumentation and chemical injection shall be provided.

6. All liquid waste handling systems have adequate spill prevention, secondary containment and leak detection.

7. All system components in contact with waste designed and constructed to be resistant to any expected or known corrosive environments.

8. Capabilities for extracting samples required to support characterization, processing and process verification of the waste.

9. All system operable locally and from the control area.

10. All tanks provided with process water service.

11. The capability to package hazardous liquid waste for transport and disposal in 55gallon drums as per WHC-EP-0063 and environmental regulations.

12. A radioactive liquid waste collection system consisting of one tank sized to provide two months storage plus a $\mathbf{5 0}$ percent safety factor and a 25 percent "heel".

13. A system to receive and treat radioactive liquid waste from the collection tank shall be provided. Treatment shall condition the waste as needed to permit use as make-up water for immobilization agents or, in situations when this is not possible, make compatible for treatment in the $\mathrm{C}-\mathrm{O} 18 \mathrm{H}$ facility.

\subsubsection{Process Selection}

1. The radioactive and non-radioactive waste collection systems are dictated by the FDC.

2. The treatment provided for the radioactive liquid waste treats the waste to make it suitable for reuse as make-up water in the agitated grout system. The agitated grout process requires water with a neutral to slightly alkaline $\mathrm{pH}$ and is free of organic material. Therefore, $\mathrm{pH}$ adjustment and carbon absorption were selected as part of the treatment process. Filtration of the liquid waste is also provided to prevent residual solids from settling out or fouling piping or equipment downstream of the active waste treatment system. 
3. The treatment provided for the nonactive liquid waste treats the waste to make it suitable for reuse as make-up water in the vibro grout system. The vibro grout requires water with a neutral to slightly alkaline $\mathrm{pH}$ and is non-hazardous; $\mathrm{pH}$ adjustment is the only treatment provided for the nonactive liquid waste. If the waste is determined to be hazardous for reasons other than $\mathrm{pH}$, the waste will be drummed and sent to an approved hazardous waste treatment, storage and disposal facility.

\subsubsection{Process Description}

1. The process scheme for Secondary Waste Treatment is shown on the attached Process Flow Diagrams H-2-140658 and H-2-140659. 


\subsubsection{Nonactive Waste Treatment}

1. Nonactive liquid wastes are collected at an average rate of five gallons per day in the nonactive waste drain header and conveyed to one of the $\mathbf{5 0 0}$ gallon Nonactive Waste Collection Tanks (T-07-101 A,B). The waste is collected in one tank at a time. High level indication in one tank automatically diverts the waste to the empty tank. The waste is then sampled and analyzed for hazardous constituents. Based on the results of the analysis, the waste is disposed of in one of two disposal methods. First, if the waste is identified as being a hazardous waste, the waste is pumped utilizing the Nonactive Waste Pumps (P-07. $101 A, B)$ to a drum fill station. The waste is loaded into drums and shipped to an approved hazardous waste treatment, storage and disposal facility. If the waste is characterized as being both non-active and non-hazardous, then the waste is pumped utilizing the Nonactive Waste Pumps (P-07-101 A,B) to the vibro grout system where it is used for grout makeup water. The treatment of nonactive waste is limited to $\mathrm{pH}$ adjustment. The waste is neutralized to a pH of 7 prior to reuse or drumming. The pH adjustment is accomplished utilizing dilute sulfuric acid and dilute sodium hydroxide supplied from the aqueous solution makeup area. A pH controller located in each tank controls the acid and caustic addition by adjusting the feed rate of the acid and caustic metering pumps. The Nonactive Waste Tank Mixers (M-07-101 A,B) provide the blending for the pH adjustment. The nonactive waste collection tanks are ventilated to the Off-gas Treatment System. The nonactive waste collection tanks are located in an area which provides secondary confinement in the event of spills. A sump is provided within the confinement to collect any spills or leaks. Water collected in the sump is pumped back to one of the nonactive waste collection tanks by the Nonactive Waste Sump Pump (P-07-102). A p "ass water connection is provided on each of the nonactive waste collection tanks to periodically flush the tanks between fill cycles. 


\subsubsection{Active Waste Treatment System}

1. Active liquid wastes are collected at an average rate of $\mathbf{5 6 7}$ gallons per day in the active waste drain header and conveyed to the Active Waste Collection Tank (T-07-201). If the collected wastes have a high solids content, the solids are slurried and pumped to a drum fill station where the solids are drummed. When the solids loading is low, the waste is periodically pumped utilizing the Active Waste Pump (P-07-201) through the Active Waste Filter (F-07-201) and the Active Waste Carbon Filter (F-07-202) to the 3,000-gallon Treated Active Waste Tank (T-07-202). The active waste filter removes particles larger than 25 microns from the waste while the carbon filter removes trace organics and mercury from the waste. The waste is neutralized to a $\mathrm{pH}$ of 7 in the treated active waste tank. The pH adjustment is accomplished utilizing dilute sulfuric acid and dilute sodium hydroxide from the Aqueous Makeup area. The acid and caustic addition is controlled by a pH controller located in treated active waste tank. The treated Active Waste Tank Mixer (M07-201) provides the blending for the pH adjustment. The waste is then sampled and characterized to verify that the waste is acceptable for reuse in the agitated grout system. The waste is then pumped via the Treated Active Waste Pump (P-07-203) to the agitated grout system for reuse within the process. In an event where excessive water is generated. such as fire conditions, the option exists to pump the liquid waste to a truck fill station. The liquid waste would be loaded into tanker trucks for transfer to the CO18 Liquid Effluent Treatment Facility for final disposal. The active waste collection tank and the treated active waste tank are ventilated to the off-gas treatment system. The active waste collection tank, the active waste filter, the active waste carbon filter and the treated active waste tank are loceted in an area which provides secondary confinement in the event of spills. A sump is provided within the confinement to collect any spills or leaks. Water collected in the sump is pumped back to either the active waste collection tank or the treated active waste tank by the Active Waste Sump Pump (P-07-202). A process water connection is provided on the active waste collection tank and the treated active waste tank to periodically flush the tanks between fill cycles.

\subsection{STUDY CRITERIA AND METHODOLOGY}

This HAZOPS has utilized a predetermined set of process deviations/upset conditions to be analyzed by the HAZOPS team for each process deviation, possible courses were postulated and worst case consequences (without benefit of any safeguards were determined. Existing safeguards (design and procedural) were then identified. Those safeguards which could be reasonably expected to be present in the final design were assumed to be existing and were so documented in the HAZOPS. For each cause and effect, hazard severity and probability were qualitatively assessed (taking credit for existing safeguards which reduce hazard probability) using the criteria shown in Table 1. The overall risk rating for each hazard was then determined using the risk ranking matrix shown on Table 2. Recommendations were proposed by the HAZOPS team in instances required by the implementation criteria shown in Table 2. 
TABLE 1

HAZARD SEVERITY AND PROBABILITY CLASSIFICATION CRITERIA

\begin{tabular}{|l|l|l|l|l|}
\hline \multirow{2}{*}{ Target Hazard } & \multicolumn{1}{|c|}{ Catastrophic (1) } & \multicolumn{1}{|c|}{ Extensive (2) } & \multicolumn{1}{c|}{ Moderate (3) } & Operational (4) \\
\cline { 2 - 5 } & $\begin{array}{l}\text { Multiple irreversible } \\
\text { injuries; may include a } \\
\text { fatality }\end{array}$ & $\begin{array}{l}\text { Single irreversible or } \\
\text { several reversible injuries } \\
\text { (no fatalities) } \\
\text { OR }\end{array}$ & Several reversible injuries & \\
\hline Workers & $\begin{array}{l}\text { Fatalities or irreversible } \\
\text { injuries }\end{array}$ & Several injuries & OR & Single injury \\
\hline Oacility & $\begin{array}{l}\text { Partial or full demolition of } \\
\text { facility }\end{array}$ & $\begin{array}{l}\text { Rupture or similar loss of } \\
\text { containment }\end{array}$ & $\begin{array}{l}\text { Major equipment damage } \\
\text { leading to one month or } \\
\text { more facility downtime }\end{array}$ & $\begin{array}{l}\text { Equipment damage } \\
\text { leading to several days of } \\
\text { facility downtime or other } \\
\text { operational penalty }\end{array}$ \\
\hline Onvironment & $\begin{array}{l}\text { Major environmental } \\
\text { impact with significant } \\
\text { cleanup/iability costs }\end{array}$ & $\begin{array}{l}\text { Groundwater, soil, or } \\
\text { public sewer } \\
\text { Contamination }\end{array}$ & $\begin{array}{l}\text { Minor spill or release } \\
\text { resulting in permit violation }\end{array}$ & OR \\
\hline
\end{tabular}

\section{LIKELIHOOD CLASSIFICATION}

\begin{tabular}{|l|l|}
\hline Highly Likely (1) & $\begin{array}{l}\text { Event has occurred at this facility - or - other facility - or - is expected to occur several times during the } \\
\text { next } 10 \text { years. }\end{array}$ \\
\hline Likely (2) & $\begin{array}{l}\text { Event has occurred at this facility - or - is possible to occur at this facility several times during the next } \\
30 \text { years. }\end{array}$ \\
\hline Unlikely (3) & $\begin{array}{l}\text { Event may have occurred at another facility - or - is possible to occur at this facility at least once in the } \\
\text { next } 50 \text { years. }\end{array}$ \\
\hline Extremely Unlikely (4) & $\begin{array}{l}\text { Event is not likely to ever occur in this facility, given a continuation of the current levels of training, } \\
\text { procedures, maintenance, inspection, testing, and other applicable process safety management system } \\
\text { support. }\end{array}$ \\
\hline
\end{tabular}


TABLE 2

RISK RANKING MATRIX AND IMPLEMENTATION CRITERIA

\begin{tabular}{|c|c|c|c|c|}
\hline Likelihood & & & & \\
\hline Highly Likely (1) & 4 & 2 & 1 & 1 \\
\hline Likely (2) & 5 & 3 & 2 & 1 \\
\hline Unlikely (3) & 6 & 4 & 3 & 2 \\
\hline Extremely Unlikely (4) & 7 & 6 & 5 & 4 \\
\hline & Operational (4) & Moderate (3) & Extensive (2) & Catastrophic (1) \\
\hline
\end{tabular}

\section{RISK RANKING IMPLEMENTATION}

\begin{tabular}{|c|l|}
\hline Risk Ranking & \multicolumn{1}{c|}{ Implication } \\
\hline 1 & $\begin{array}{l}\text { Risk level - Very significant } \\
\text { Recommendation = Required from the HAZOPS team } \\
\text { Implementation - Begins immediately }\end{array}$ \\
\hline 2 & $\begin{array}{l}\text { Risk level - Significant } \\
\text { Recommendation = Required from the HAZOPS team } \\
\text { Implementation - Begins within three months }\end{array}$ \\
\hline 3 & $\begin{array}{l}\text { Risk level - Not very significant } \\
\text { Recommendation = Required from the HAZOPS team } \\
\text { Implementation - Begins within one year }\end{array}$ \\
\hline 4 & $\begin{array}{l}\text { Risk level - Not significant, but may be an operational problem } \\
\text { Recommendation = At the discretion of the HAZOPS team } \\
\text { Implementation - As soon as practical, not later than the next major plant turnaround }\end{array}$ \\
\hline 5,6, or 7 & $\begin{array}{l}\text { Risk level - Negligible, but may be an operational problem } \\
\text { Recommendation = At the discretion of the HAZOPS team } \\
\text { Implementation - To be evaluated by management }\end{array}$ \\
\hline
\end{tabular}




\subsection{RESULTS AND CONCLUSIONS}

Because this HAZOPS is performed relatively early in the design phase, existing safeguards have not been fully documented on the process flow diagrams lthese would mostly be shown on the P\&ID's developed during Title Design). However, the HAZOPS team assumed specific safeguards would be present in the final design if it appear reasonable to expect this. These assumed safeguards are documented on the HAZOPS worksheets and credit was taken for these presumed safeguards when assessing risk. During Title Design, the presence of these safeguards need to be verified to validate the conclusions of this HAZOPS.

Eighteen potential safety and operability problems were identified and ovaluated in this HAZOPS. Of these, thirteen were assessed to have a negligible risk level. The remaining five involves a potential safoty and operational problem having a risk ranking classified as being not very significant. For this potential problem, the HAZOPS team has recommended that an additional safeguard be incorporated into the WAAP $2 A$ design.

Table 3 presents a summary of changes to be made in the process flow diagram, assumed design safeguards, and additional safeguards to be evaluated for incorporation into the design of the Liquid Effluent Collection System.

In several instances, the need for human factors analyses and reliability/availability/maintainability analyses during Title Design was highlighted by the HAZOPS team to achieve negligible risk levels. The HAZOPS assumed that such analyses would be performed and that the necessary design requirements/modifications are incorporated. The performance of these desion analyses are considered to be open issues to be resolved during Title Design. Similarly, the HAZOPS team identified the need for a maintainability analysis to develop requirements for warm maintenance at the WRAP $2 A$ Facility.

The HAZOPS is documented in the attached HAZOPS worksheets. 


\section{TARLE3}

LIQUID EFFLUENT COLLECTION HAZOPS SUMMARY

\section{PROCFSS FLOW DIAGRAM CHANGES}

1. Denote containment for active waste filters, active solids drum loadout, $\mathrm{pH}$ probe and sampling of active waste tanks (containment methods/techniques to be identified in Title ( design).

2. Add active water streams from box breakdown (sawing) and emergency showers.

\section{ASSUMED DESIGN SAFEGUARDS}

1. All design basis requirements (e.9., personnel egress routes in accordance with life safety code).

\section{EVALUATEANCORPORATE INTO DESIGN}

1. Route active water lines to minimize personnel exposure from leak lalso applies to acid/caustic lines).

2. Evaluate need for hazardous material containment at nonactive water drum loadout station.

3. Active waste tanks (dumps) operational flexibility/redundancy based on results of RAM analysis.

4. Define level control mechanism for active waste drum loadout.

5. Consider combining the nonactive waste stream into the active waste system (FDC needs to be changed) as a capital cost reduction.

6. Evaluate active waste batching time requirements to avoid supply disruption to grouting operations. 
WRAP 2A ACDR PRELIMINARY HAZOP REVIEW DATA SHEET

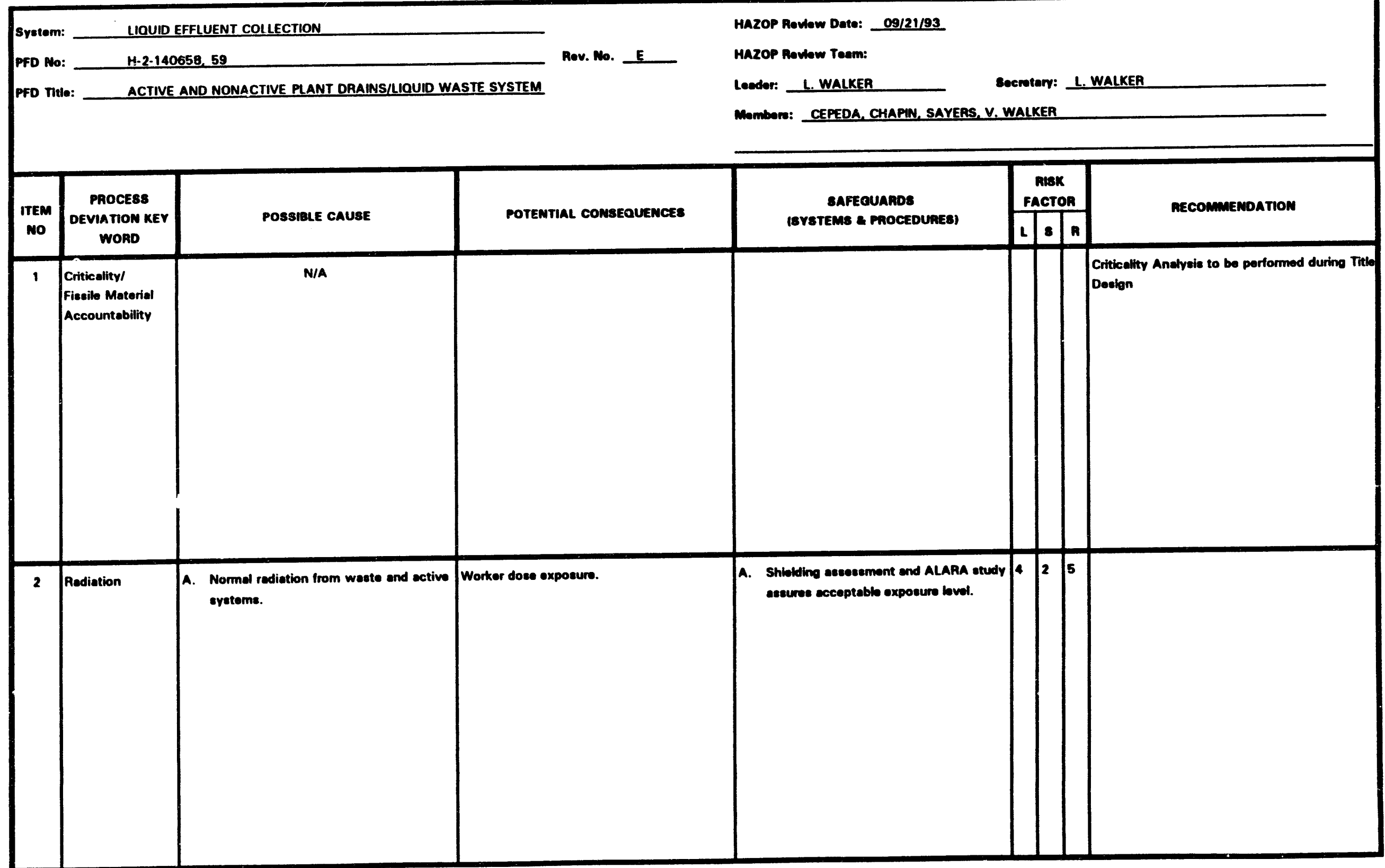


WRAP 2A ACDR PRELIMINARY HAZOP REVIEW DATA SHEET

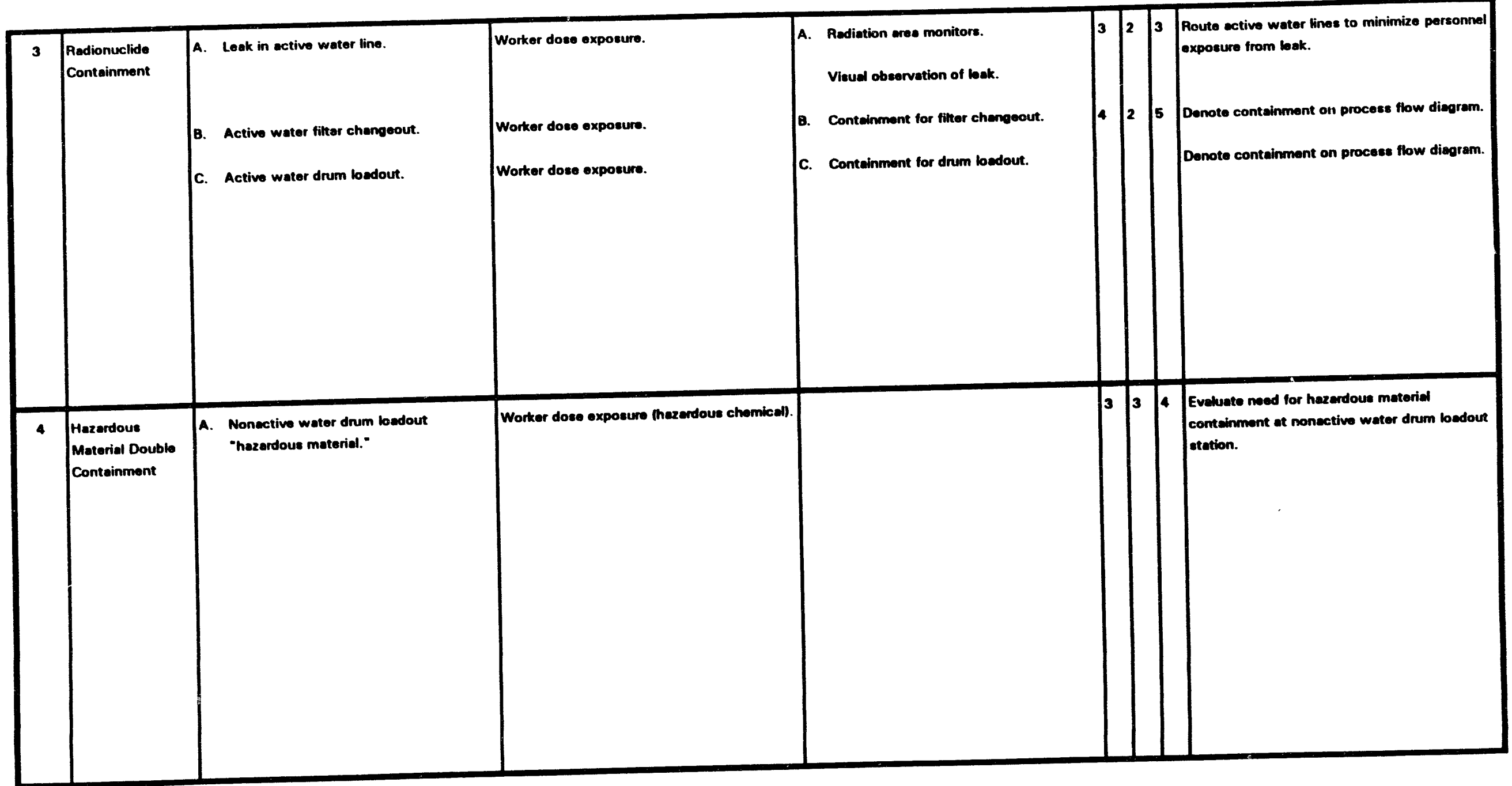


WRAP 2A ACDR PRELIMINARY HAZOP REVIEW DATA SHEET

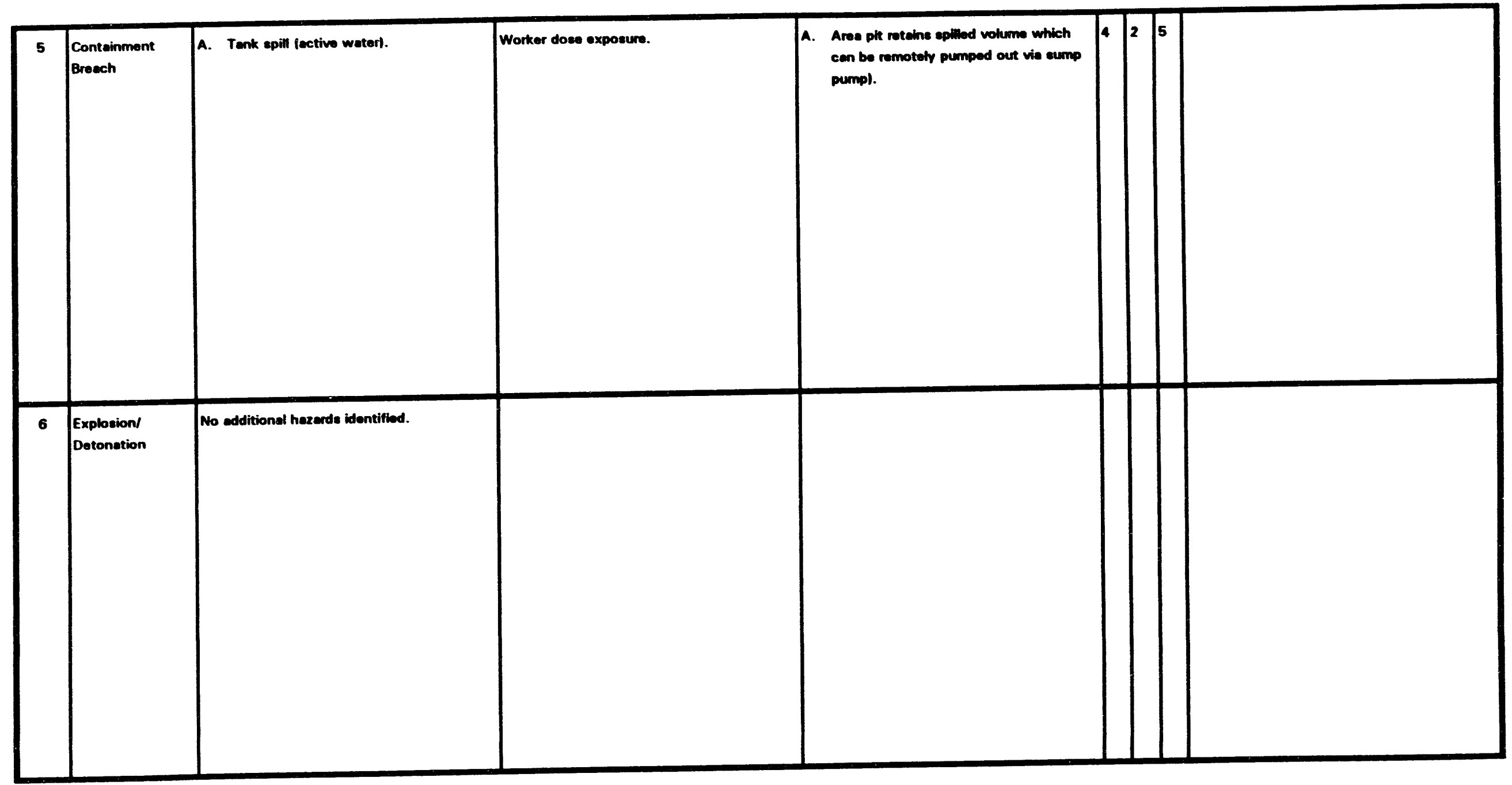




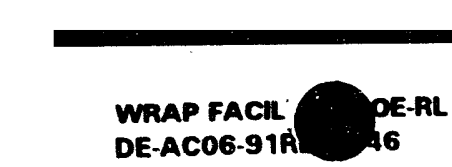

WRAP 2A ACDR PRELIMINARY HAZOP REVIEW DATA SHEET

\begin{tabular}{|c|c|c|c|c|c|c|}
\hline 7 & Fire & $\begin{array}{l}\text { A. Incompatible materials mix in line to } \\
\text { colloction tonk. }\end{array}$ & Exothermal resction. & $\begin{array}{l}\text { A. No incompatiblo materials idontified. } \\
\text { Dilute concontrations in water. }\end{array}$ & \begin{tabular}{l|l|l}
4 & 2 & 5
\end{tabular} & 5 \\
\hline 8 & $\begin{array}{l}\text { Flammable } \\
\text { Moterialal } \\
\text { Combustible } \\
\text { Atmosphore }\end{array}$ & No edditioned hazorde identified. & & & & \\
\hline
\end{tabular}


है
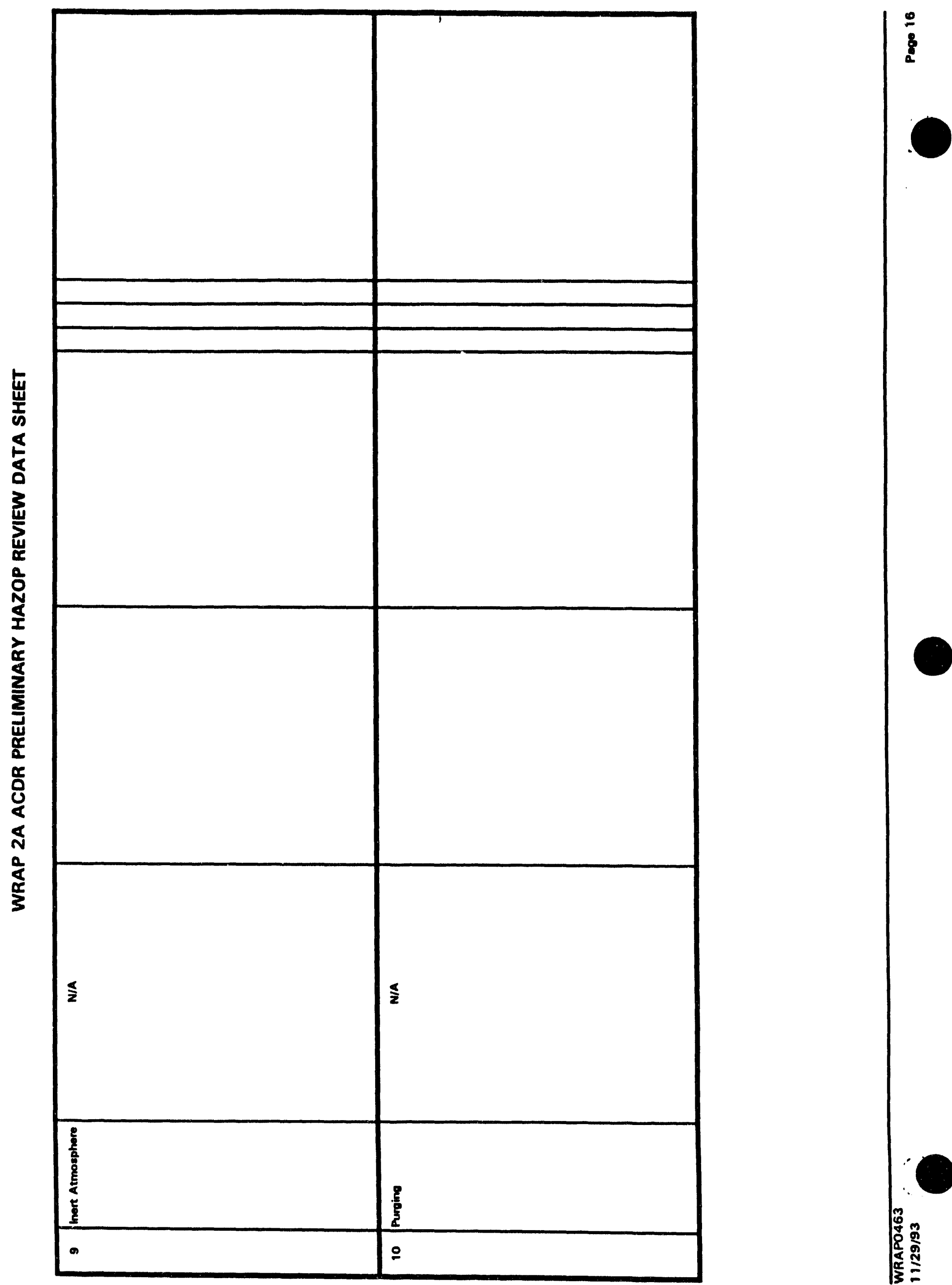

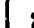

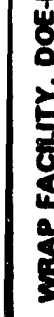




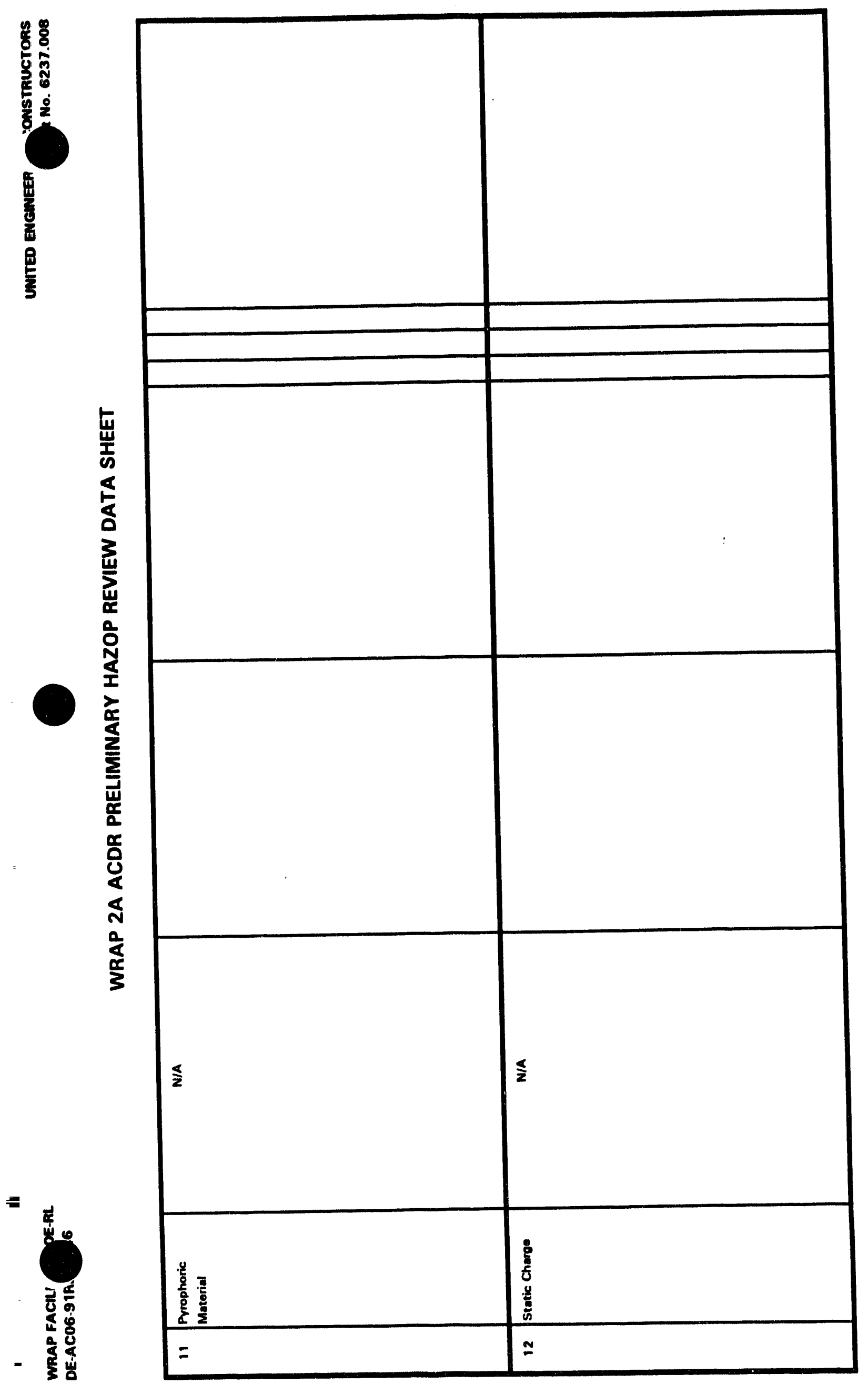


WRAP 2A ACDR PRELIMINARY HAZOP REVIEW DATA SHEET

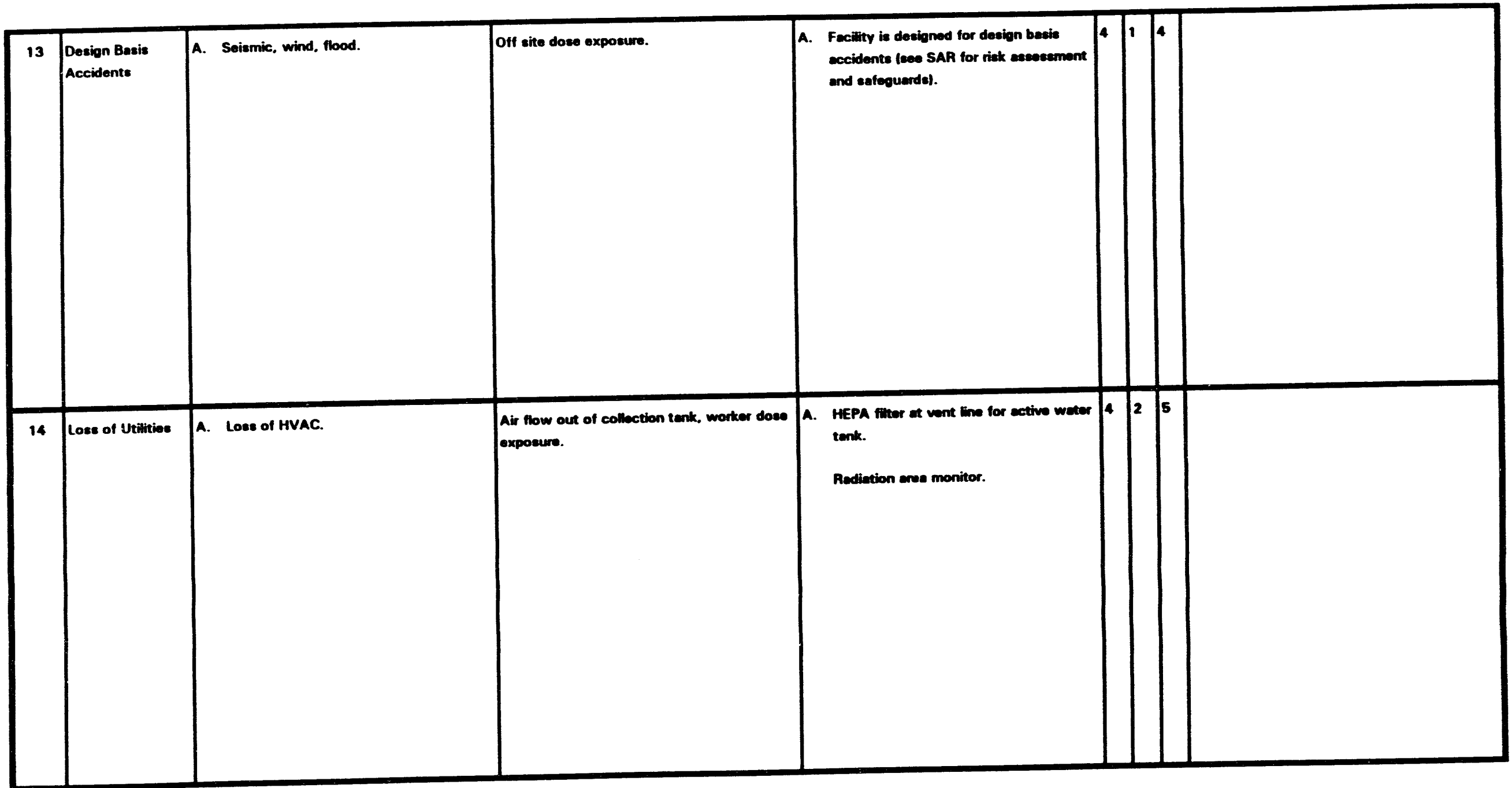




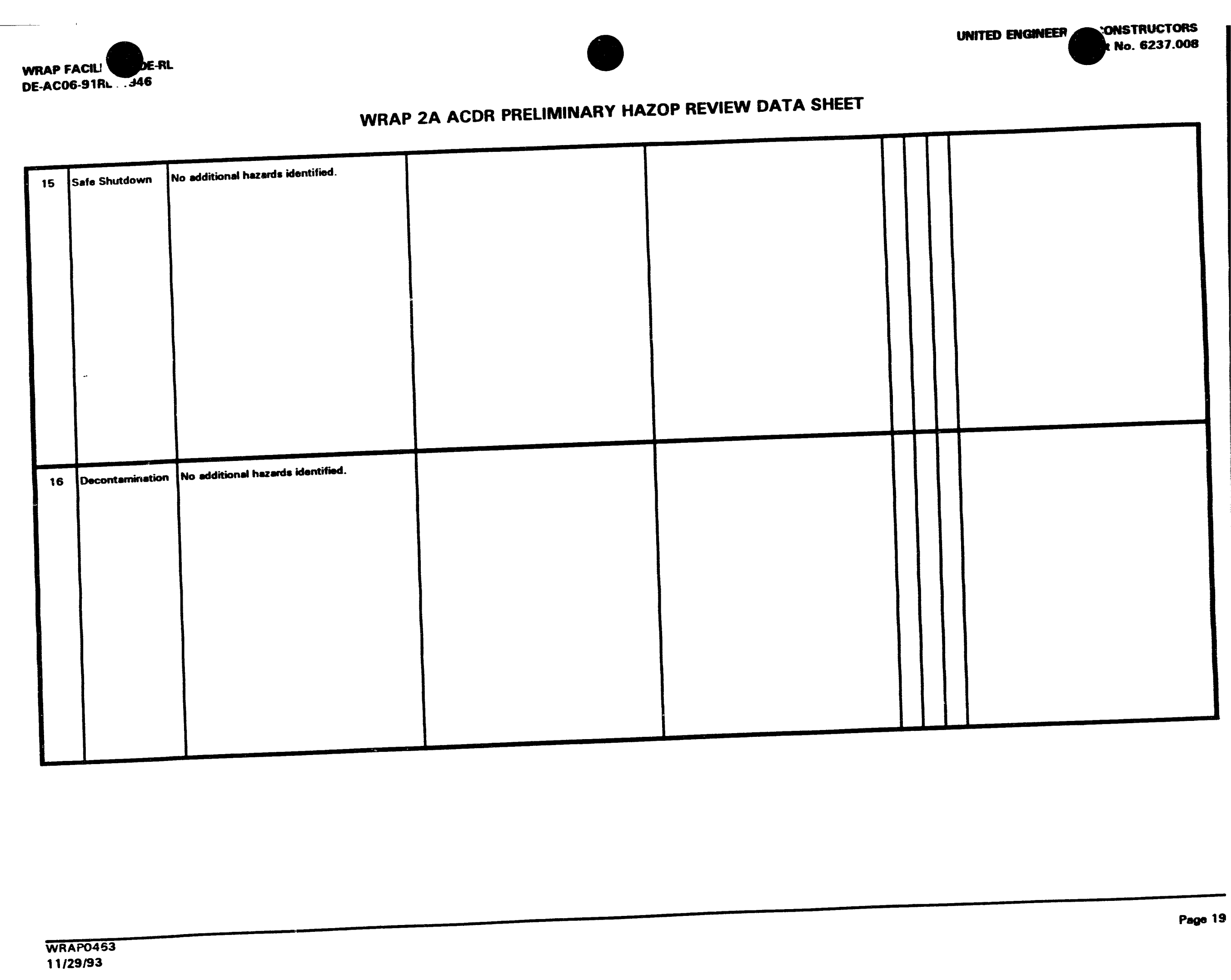


WRAP 2A ACDR PRELIMINARY HAZOP REVIEW DATA SHEET

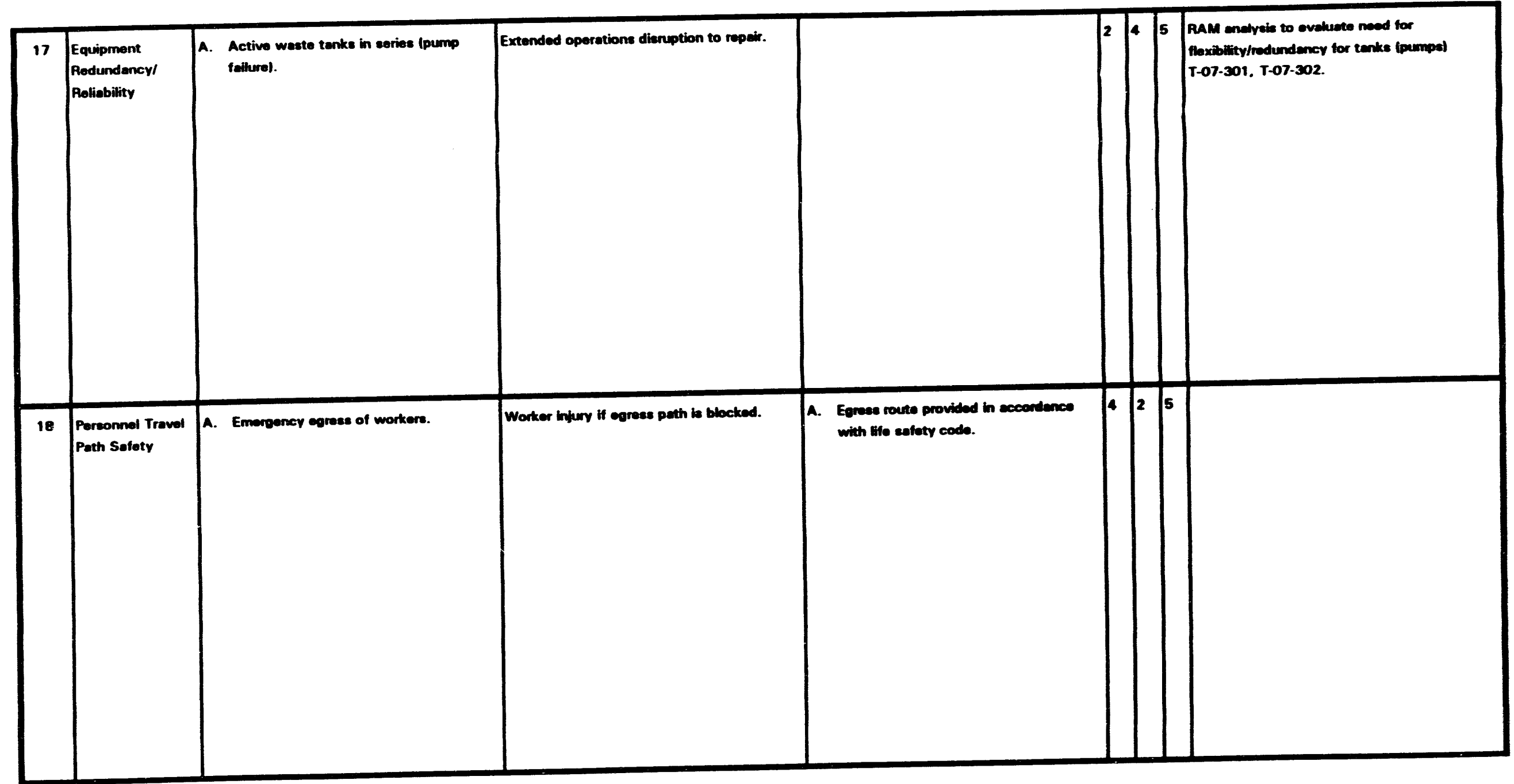


WRAP 2A ACDR PRELIMINARY HAZOP REVIEW DATA SHEET

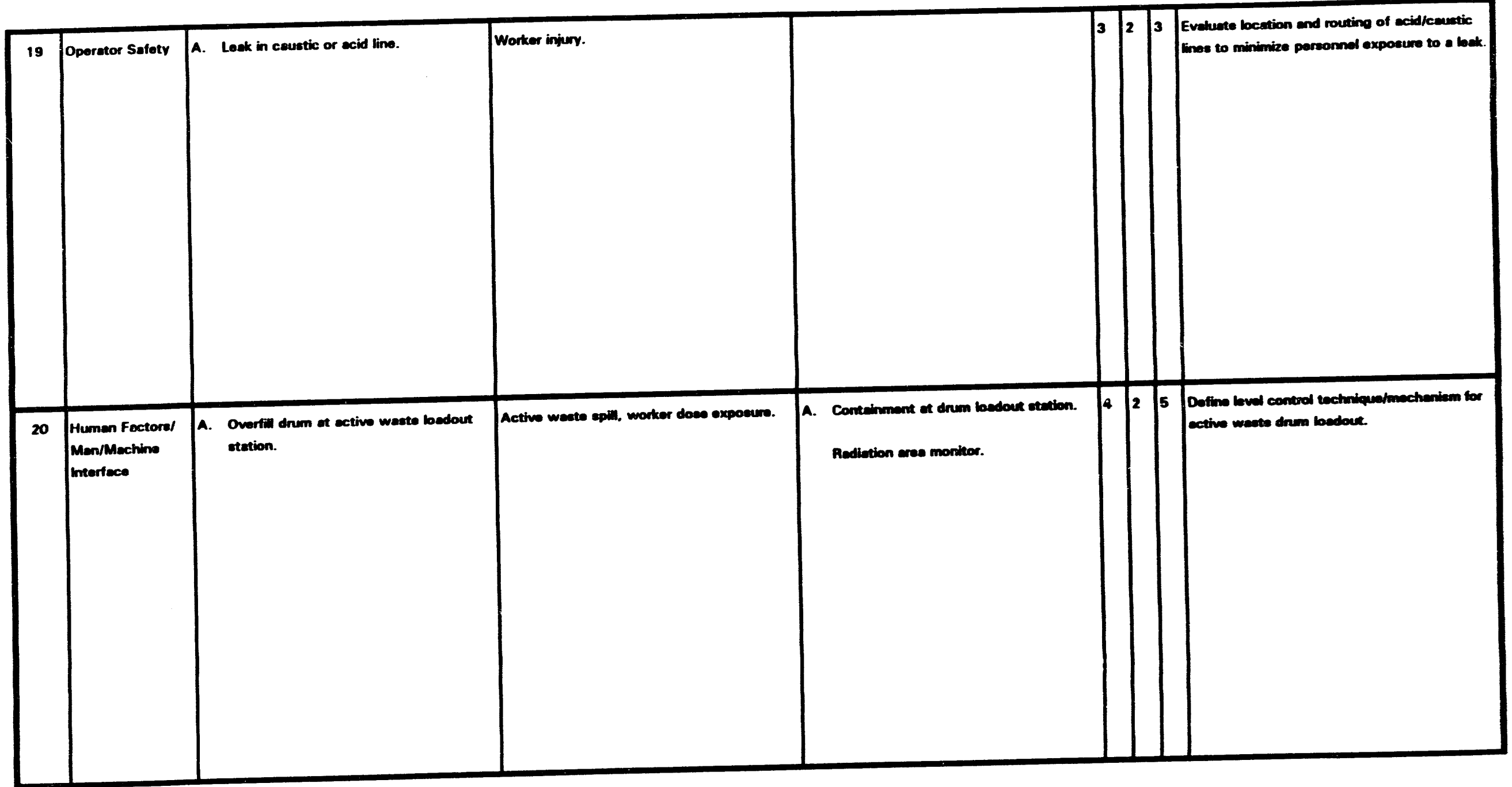





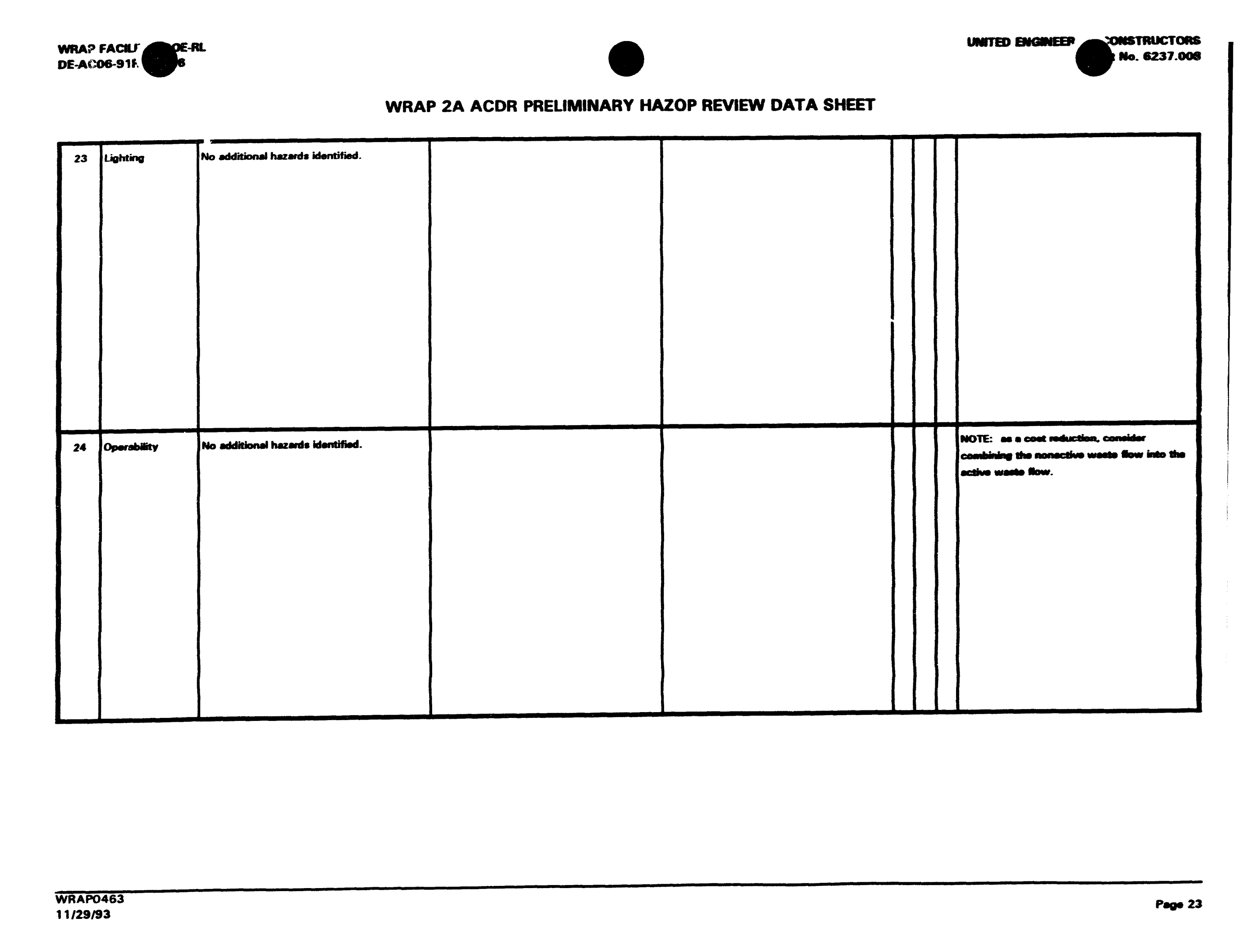



WRAP 2A ACDR PRELMMNARY HAZOP REVIEW DATA SHEET

\begin{tabular}{|c|c|c|c|c|c|}
\hline 27 & $\begin{array}{l}\text { Equipmont } \\
\text { Breskdown } \\
\text { Recovery }\end{array}$ & No edditional hazards identifiod. & & & \\
\hline 28 & $\begin{array}{l}\text { Meinteinebilityl } \\
\text { Werm } \\
\text { Maintenence }\end{array}$ & A. Active wasto permo frailume. & 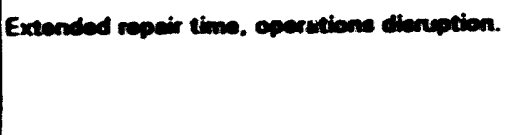 & 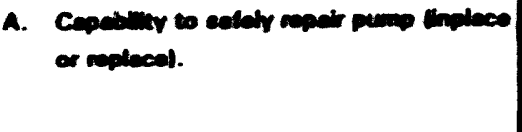 & 25 \\
\hline
\end{tabular}



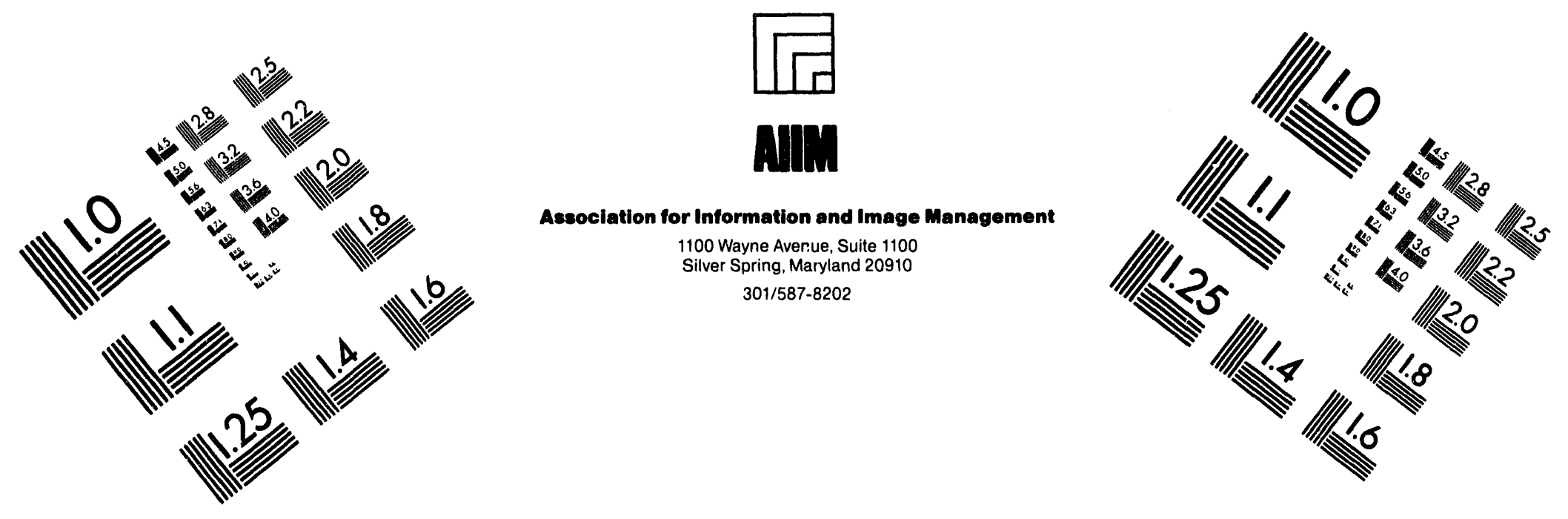

\section{Centimeter}

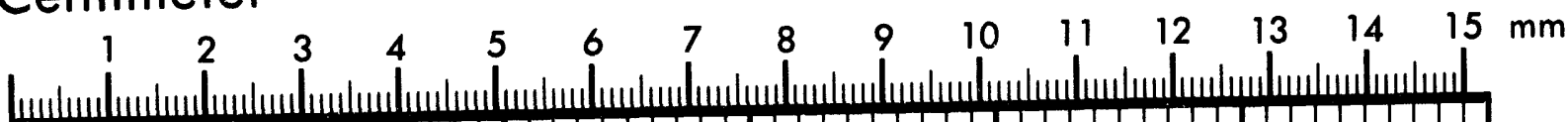

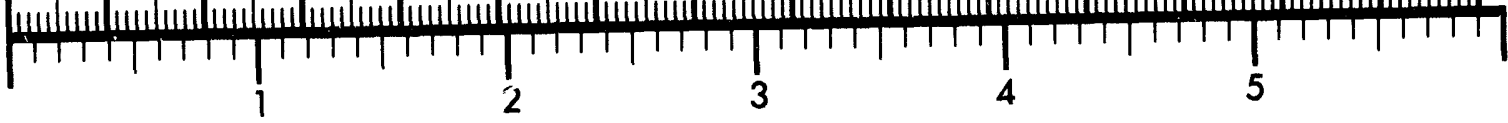
Inches
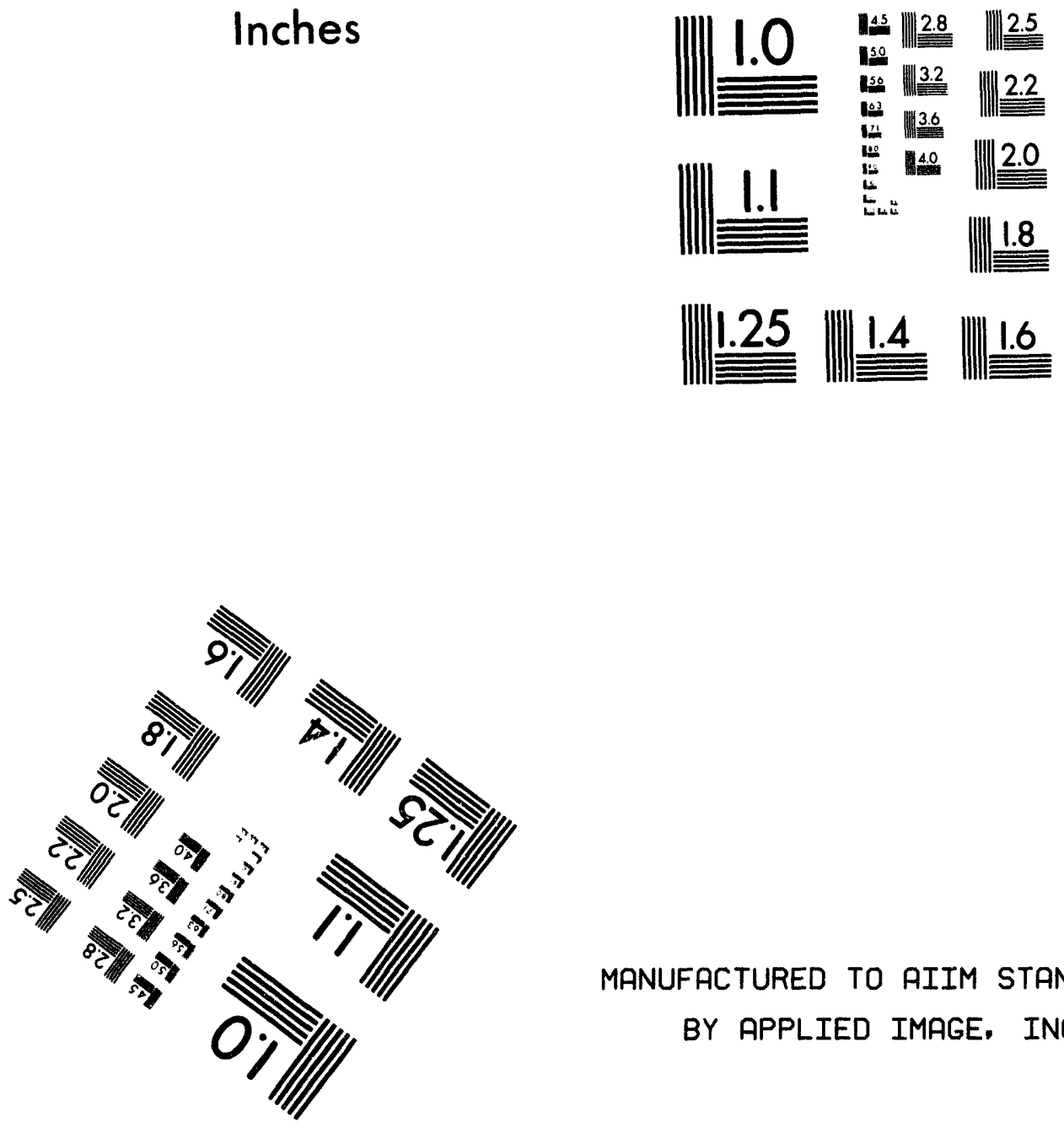

MANUFACTURED TO AIIM STANDARDS

BY APPLIED IMAGE. INC.

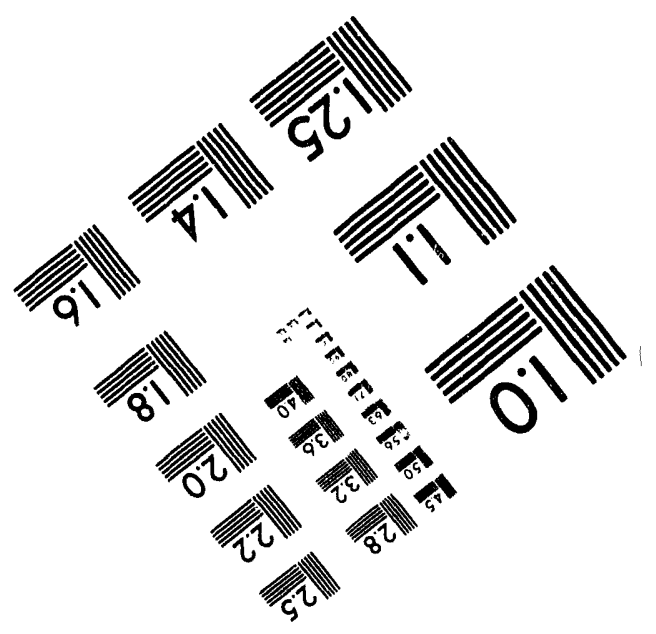



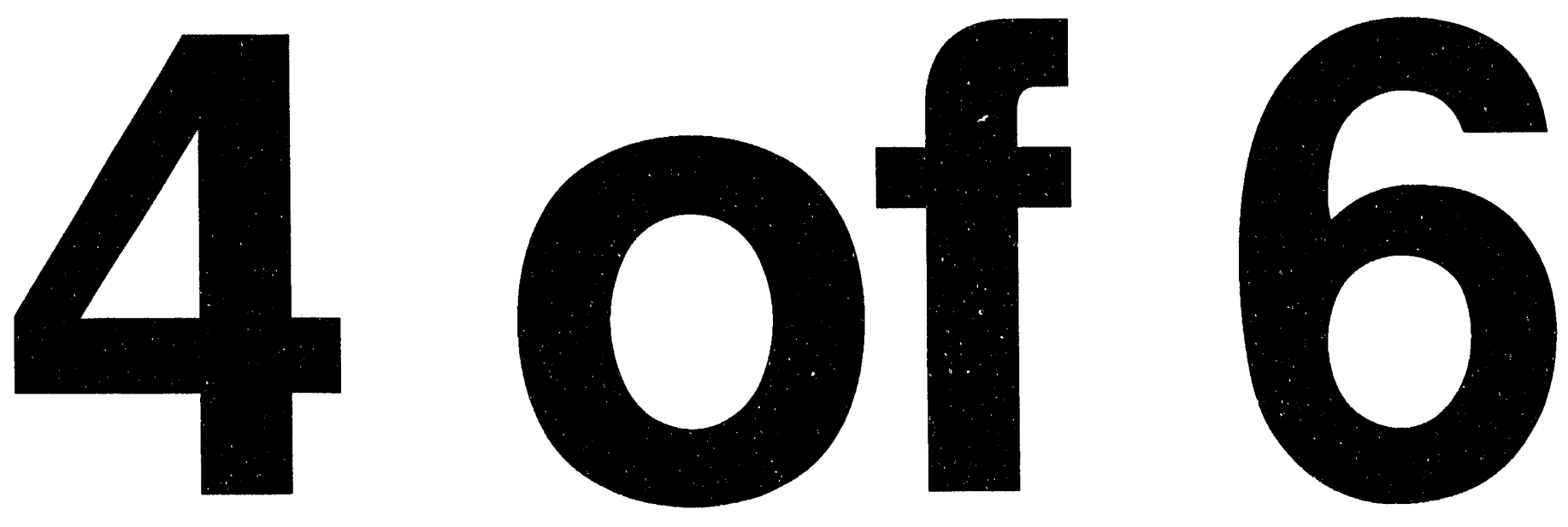
WRAP 2A ACDR PRELIMINARY HAZOP REVIEW DATA SHEET

\begin{tabular}{|c|c|c|c|c|c|c|c|c|}
\hline 29 & $\mid \begin{array}{l}\text { Tosting/ } \\
\text { Inspection }\end{array}$ & $\begin{array}{l}\text { A. Calibration of pH eloment for active } \\
\text { waste tank. }\end{array}$ & Worker dose exposure. & A. Containment for pH probe calibration. & 4 & 2 & 5 & $\begin{array}{l}\text { Evaluate containment for use when calibrating } \\
\text { PH probe Idenote on PFDI. }\end{array}$ \\
\hline 30 & $\begin{array}{l}\text { Primary } \\
\text { instrument Loop } \\
\text { Failure }\end{array}$ & $\begin{array}{l}\text { A. pH control failure. } \\
\text { B. Leval control failuro at troatod ective } \\
\text { wasto tenk. }\end{array}$ & $\begin{array}{l}\text { Weste not propertiy treoted, operetionse } \\
\text { disruption for waete rowort. } \\
\text { Overtlow into room or beckup in procese } \\
\text { sumpe ldowntimo to cleanupl. }\end{array}$ & $\begin{array}{l}\text { B. Indopondent tenk lovel delorm. } \\
\text { Indepondent sump lovel alerm. }\end{array}$ & 3 & 4 & 6 & \\
\hline
\end{tabular}




$$
7
$$


WRAP FACILITY, DOE-RL

DE-AC06-91RL11946
UNITED ENGINEERS \& CONSTRUCTORS

Project No. 6237.008

WRAP LA ACDR PRELIMINARY HAZOP REVIEW DATA SHEET

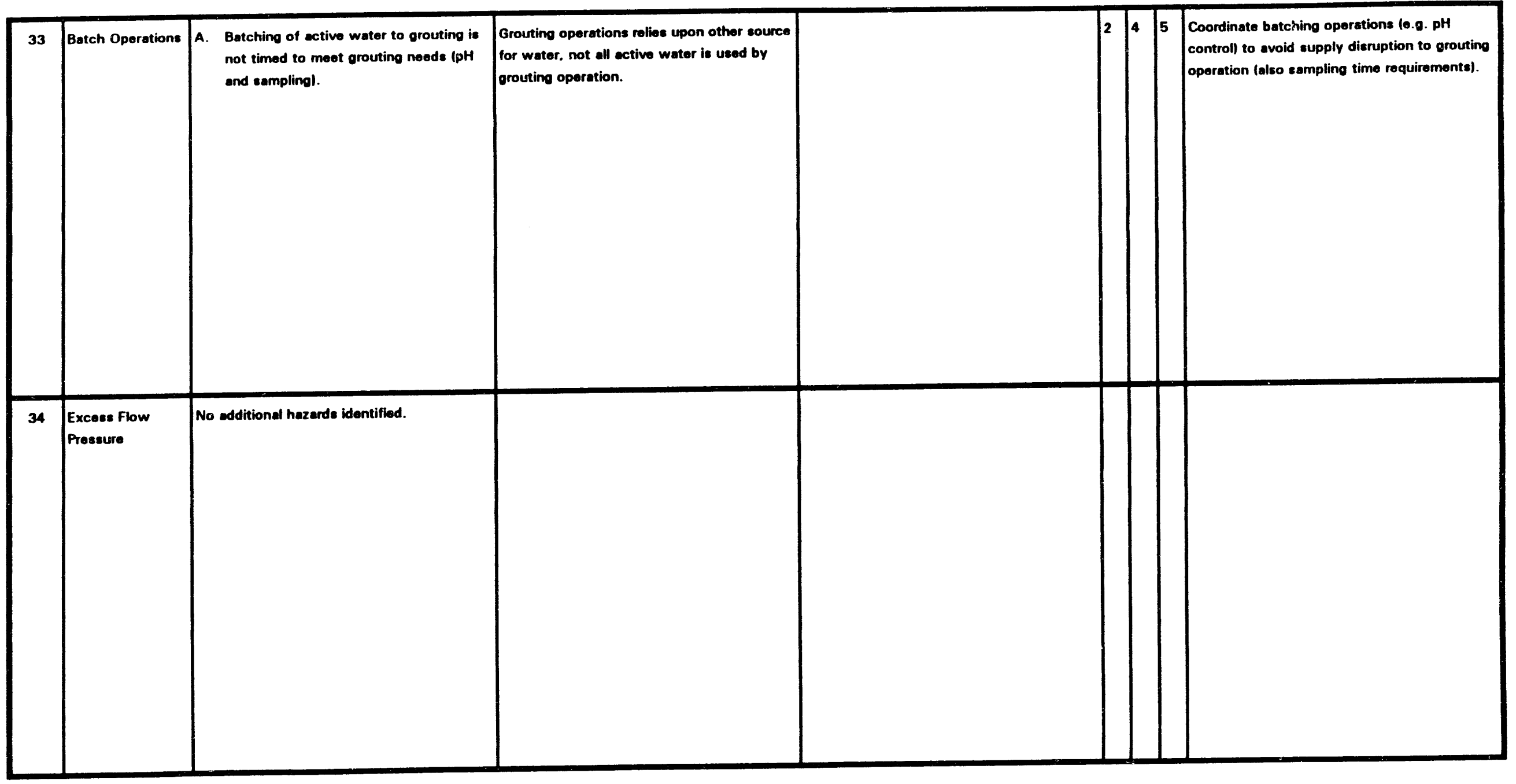

WRAP 463

0

Page 28

$11 / 29 / 93$ 
WRAP 2A ACDR PRELIMINARY HAZOP REVIEW DATA SHEET

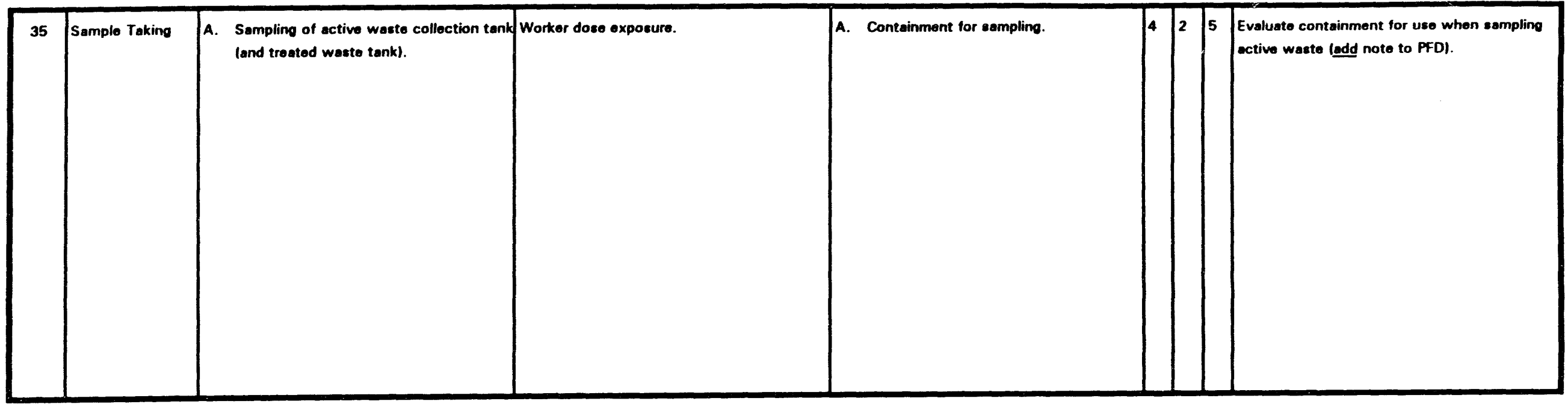


WASTE

RECEIVING

AND

PROCESSING FACILITY

\section{TITLE: WRAP 2A POLYMER ENCAPSULATION/GROUTING SYSTEM HAZOP STUDY REPORT}

Revision: 0

Submitted to:

UNITED STATES

DEPARTMENT OF ENEROY

Richland, Washington

Prepared by:

UNITED ENOINEERS

\& CONSTRUCTORS

A Raythoon Company

Wectem Operntions 


\section{TABLE OF CONTENTS}

\section{Page}

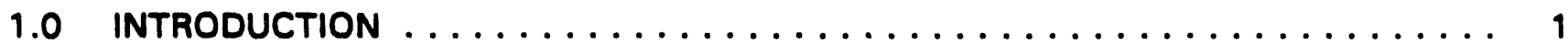

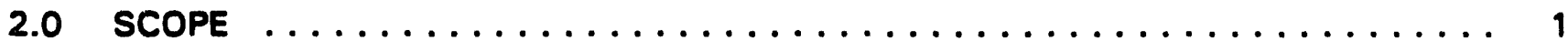

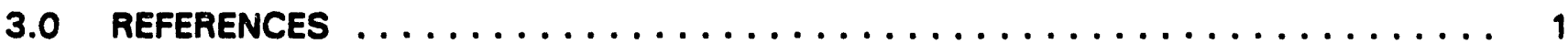

4.0 DESCRIPTION OF POLYMER ENCAPSULATION/GROUTING SYSTEM $\ldots \ldots \ldots \ldots$

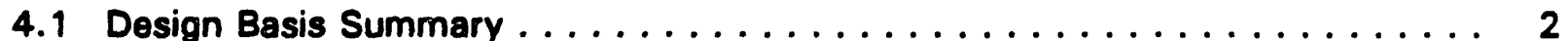

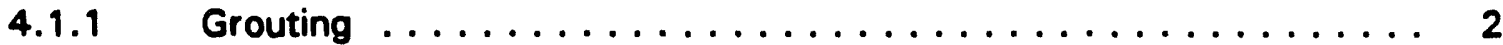

4.1.2 VES Encapsulation ...................... 3

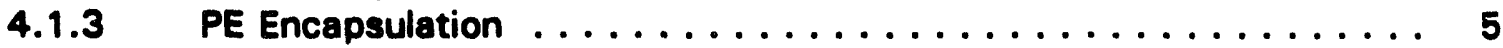

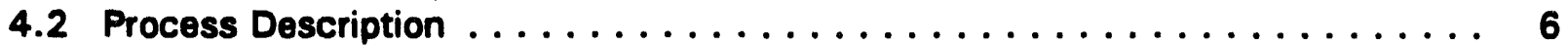

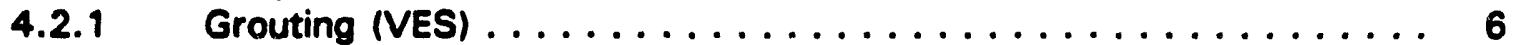

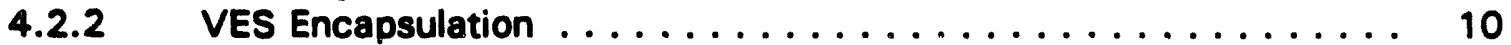

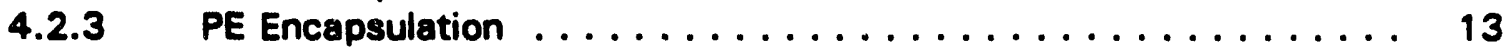

5.0 STUDY CRITERIA AND METHODOLOGY $\ldots \ldots \ldots \ldots \ldots \ldots \ldots \ldots \ldots$

6.0 RESULTS AND CONCLUSIONS $\ldots \ldots \ldots \ldots \ldots \ldots \ldots \ldots \ldots \ldots \ldots \ldots$ 
WRAP 2A

POLYMER ENCAPSULATION/GROUTING SYSTEM

HAZOP STUDY REPORT

\subsection{INTRODUCTION}

A preliminary HAZOP study was performed on the advanced conceptual design of the Polymer Encapsulation/Grouting System. The HAZOPS team met on August 24, 25 and 26, 1993 and consisted of the following members:

\begin{tabular}{|c|c|c|}
\hline Name & Company & Role/Expertise \\
\hline $\begin{array}{l}\text { Larry Walker } \\
\text { Robert Voke } \\
\text { Rich Henkel } \\
\text { Doug Chapin } \\
\text { Bill Cepeda } \\
\text { Valerie Walker } \\
\text { Tom Yount }\end{array}$ & $\begin{array}{l}\text { UE\&C } \\
\text { BNFL } \\
\text { UE\&C } \\
\text { UE\&C } \\
\text { UE\&C } \\
\text { BNFL } \\
\text { WHC }\end{array}$ & $\begin{array}{l}\text { Leader, Scribe, Safety } \\
\text { Process (Grouting) } \\
\text { Process (Encapsulation) } \\
\text { Process } \\
\text { Instrumentation and Control } \\
\text { Radiological } \\
\text { Project }\end{array}$ \\
\hline $\begin{array}{l}\text { Kent Weingardt } \\
\text { John Meyers } \\
\text { Tom Pauly } \\
\text { Owen Kruger } \\
\text { Walt Swita }\end{array}$ & $\begin{array}{l}\text { WHC } \\
\text { WHC } \\
\text { WHC } \\
\text { WHC } \\
\text { WHC }\end{array}$ & $\begin{array}{l}\quad \text { Process } \\
\text { Maintainability } \\
\text { Process } \\
\text { Operations } \\
\text { Project }\end{array}$ \\
\hline
\end{tabular}

The purpose of the HAZOPS is to identify major safety and operability problems which can best be resolved during completion of the advanced conceptual design.

\subsection{SCOPE}

This HAZOPS encompassed the Polymer Encapsulation/Grouting System as shown on the Process Flow Diagrams:

$\begin{array}{lll}\text { System } & \text { Drawing } & \text { Rev } \\ \text { Grouting (VES) } & \text { H-2-140607, 08, 09 } & \text { E } \\ \text { Grouting (PE) } & \text { H-2-140636, 37, 38 } & \text { A } \\ \text { VES Encapsulation } & \text { H-2-140620, 21 } & \text { E } \\ \text { PE Encapsulation } & \text { H-2-140640, 41 } & \text { A }\end{array}$

\subsection{REFERENCES}

1. WHC-SD-W100-FDC-001 Rev. 2A, Functional Design Criteria Waste Receiving And Processing Facility Module $2 \mathrm{~A}$. 
2. WHC-SD-W100-SDRD-001 Rev. A, Waste Receiving and Processing Facility Module 2A Supplemental Design Requirements Document.

\subsection{DESCRIPTION OF POLYMER ENCAPSULATION/GROUTING SYSTEM}

\subsection{Design Basis Summary}

\subsubsection{Grouting}

NOTE: This section applies to both the VES and PE versions of the Grouting System.

\section{Scope}

1. CWBS 1615 workscope includes waste entry into process area, encapsulation or cementation to immobilize waste and associated conveying, handling and monitoring systems.

2. This section will address the cement grout process.

3. Waste will be received in 55-gallon drums in a slurry or shredded solid form that is suitable for cementation to provide the final waste form for disposal.

\section{Desion Goals}

1. Where possible, proven processes and technology will be used in the design. Proof of principle shall be accomplished by actual successful production experience or by laboratory/prototype demonstration supplemented with full scale simulation and engineering analysis.

2. The system shall be designed to ensure that grouting operations are carried out in suitabie high integrity enclosures.

3. Grout and waste mixing will take place in the waste container to keep the entire grouting train contamination free.

4. The system shall utilize an integrated design approach to ensure a compatible interface between the other process areas of the WRAP 2A facility.

5. The system shall be designed to maximize location of components outside of confinement without compromising the confinement criteria or process efficiency.

6. The system design will maintain consideration for human factors, the principles of ALARA and eventual decontamination and decommissioning.

7. The system shall be designed to minimize generation of secondary waste and the lifetime occupational radiation exposure to personnel working on the equipment.

8. Design life of 30 years on a triple shift basis, 5 days per week, and a 70 percent facility availability. (NOTE: A throughput of $29,000 \mathrm{cu}$. t./year will have to be achievable on a single shift basis.) 


\section{Eunotional Requirements}

1. Receipt and handling of groutable waste in 55-gallun drums.

2. Receipt and handling of all raw materials necessary to produce cement grout.

3. Transport, mixing and process for grout production.
a) Sampling of final waste form.
b) Transfer of final waste form to cure/storage area.

4. Lag storage for processed and unprocessed drums. (Unprocessed--support 2 days of verification sampling and treatment operations. Processed--support 3 days of curing treated waste.)

\section{Waste/Product Throughout Requirements:}

\begin{tabular}{|c|c|c|c|c|}
\hline eedstream & Description & $\begin{array}{l}\text { Waste } \\
\text { Receipt } \\
\mathrm{ft}^{3} / \mathrm{day}\end{array}$ & $\begin{array}{c}\text { Waste } \\
\text { Loading } \\
\text { Wt\% }\end{array}$ & $\begin{array}{l}\text { Waste } \\
\text { Product } \\
\mathrm{ft}^{3} / \mathrm{day}\end{array}$ \\
\hline $\begin{array}{l}101 \\
1 D 2 \\
2 C \\
7 \\
9 A \\
9 B\end{array}$ & $\begin{array}{l}\text { 183-H Grit } \\
\text { 183-H Misc Waste } \\
\text { Ferric Hydroxide Sludge } \\
\text { Thermal Treatment Ash } \\
\text { Particulate/Sludge } \\
\text { Heterogeneous Solids/Debris }\end{array}$ & $\begin{array}{r}0.20 \\
0.23 \\
20.18 \\
10.49 \\
19.23 \\
58.90\end{array}$ & $\begin{array}{l}40 \\
40 \\
25 \\
30 \\
25 \\
51\end{array}$ & $\begin{array}{r}0.44 \\
0.23 \\
93.25 \\
45.69 \\
57.19 \\
46.39\end{array}$ \\
\hline
\end{tabular}

- Non-campaigned waste assuming $29,000 \mathrm{cu}$. ft./year total throughput.

\subsubsection{VES Encapsulation}

\section{Scope}

1. Total CWBS 1615 workscope includes waste entry into process area, encapsulation or cementation to immobilize waste and associated conveying, handling and monitoring systems.

2. This section will address the encapsulation process.

3. Waste will be received in 55-gallon drums in a slurry or shredded solid form that is suitable for encapsulation in a polymer to provide the final waste form for disposal.

\section{Desion Goals}

1. Where possible, proven processes and technology will be used in the design. Proof of principle shall be accomplished by actual successful production experience or by laboratory/prototype demonstration supplemented with full scale simulation and engineering analysis. 
2. The system shall be designed to ensure that power operations are carried out in suitable high integrity enclosures.

3. The system shall utilize an integrated design approach to ensure a compatible interface between the other process areas of the WRAP $2 A$ facility.

4. The system shall be designed to maximize location of components outside of confinement without compromising the confinement criteria or process efficiency.

5. The system design will maintain consideration for human factors, the principles of ALARA and eventual decontamination and decommissioning.

6. The system shall be designed to minimize generation of secondary waste and the lifetime occupational radiation exposure to personnel working on the equipment.

7. Design life of $\mathbf{3 0}$ years on a triple shift basis, 5 days per weok, and a 70 percent facility availability. (Throughput of $29,000 \mathrm{ft}^{3} / \mathrm{yr}$ of waste assumed for single shift basis.)

8. Review for process/equipment commonalities between "cement grout" and "polymer encapsulation", and optimize economics where possible.

\section{Eunctional Rearirements}

1. Receipt and handling of waste for encapsulation in 55-gallon drums.

2. Receipt and handling of raw materials necessary to produce polymer waste form.

3. Transport, mixing and process for polymer encapsulation.

a) Sampling of final waste form.

b) Transfer of waste form to cure/storage area.

4. Lag storage for processed and unprocessed drums. (Unprocessed--support 2 days of verification sampling and treatment operations. Processed--support 3 days of curing treated waste.)

5. Material Balance Design Basis

\begin{tabular}{|c|c|c|c|}
\hline Feedstream & $\begin{array}{c}\text { Feed } \\
\text { Throughput } \\
\mathrm{ft}^{3 /} / \mathrm{day} \\
\end{array}$ & $\begin{array}{l}\text { Waste } \\
\text { Loading } \\
w t \% \\
\end{array}$ & $\begin{array}{c}\text { Treated Waste } \\
\text { Output } \\
\mathrm{ft}^{3} / \mathrm{day} \\
\end{array}$ \\
\hline $\begin{array}{l}1 A \\
1 B \\
1 C \\
2 A \\
2 B \\
\text { Total }\end{array}$ & $\begin{array}{r}1.95 \\
3.39 \\
4.99 \\
32.99 \\
2.07 \\
46.39\end{array}$ & $\begin{array}{l}25 \\
25 \\
25 \\
25 \\
60 \\
\end{array}$ & $\begin{array}{r}15.88 \\
26.53 \\
28.02 \\
112.83 \\
2.60 \\
185.86\end{array}$ \\
\hline
\end{tabular}




\subsubsection{PE Encapsulation}

\section{Scope}

1. Workscope includes waste entry into process area, encapsulation or cementation to immobilize waste and associated conveying, handling and monitoring systems.

2. This section will address the encapsulation process.

3. Waste will be received in 55-gallon drums in slurry or shredded solid form that is suitable for encapsulation in a polymer to provide the final waste fcrm for disposal.

\section{Desion Goals}

1. Where possible, proven processes and technology will be used in the design. Proof of principle shall be accomplished by actual successful production experience or by laboratory/prototype demonstration supplemented with full scale simulation and engineering analysis.

2. The system shall be designed to ensure that power operations are carried out in suitable high integrity enclosures.

3. The system shall utilize an integrated design approach to ensure a compatible interface between the other process areas of the WRAP $2 A$ facility.

4 . The system shall be designed to maximize location of components outside of confinement without compromising the confinement criteria or process efficiency.

5. The system design will maintain consideration for human factors, the principles of ALARA and eventual decontamination and decommissioning.

6. The system shall be designed to minimize generkition of secondary waste and the lifetime occupational radiation exposure to personnel working on the equipment.

7. Design life of $\mathbf{3 0}$ years on a triple shift basis, $\mathbf{5}$ days per week, and a $\mathbf{7 0}$ percent facility availability. (Throughput of $29,000 \mathrm{ft}^{3} / \mathrm{yr}$ of waste assumed for single shift basis.)

8. Review for process/equipment commonalities between "cement grout" and "polymer encapsulation", and optimize economics where possible.

\section{Functional Requirements}

1. Receipt and handling of waste for encapsulation in 55-gallon drums.

2. Receipt and handling of raw materials necessary to produce polymer waste form.

3. Transport, mixing and process for polymer encapsulation.

a) Sampling of final waste form. 
b) Transfer of waste form to cure/storage area.

4. Lag storage for processes and unprocessed drums. (Unprocessed--support 2 days of verification sampling and treatment operations. Processed-support 2 days of curing treated waste.)

5. Material Balance Design Basis

\begin{tabular}{|c|c|c|c|}
\hline Feedstream & $\begin{array}{c}\text { Foed } \\
\text { Throughput } \\
\mathrm{ft}^{31} / \mathrm{day} \\
\end{array}$ & $\begin{array}{c}\text { Waste } \\
\text { Loading } \\
\text { wa\% } \\
\end{array}$ & $\begin{array}{c}\text { Treated Waste } \\
\text { Output } \\
\mathrm{ft}^{3} / \text { day } \\
\end{array}$ \\
\hline $\begin{array}{l}1 B \\
1 C \\
101 \\
2 A \\
2 B \\
2 C \\
7 \\
9 A \\
\text { Total }\end{array}$ & $\begin{array}{r}3.39 \\
4.99 \\
0.20 \\
32.99 \\
2.07 \\
20.18 \\
3.42 \\
21.37 \\
88.61\end{array}$ & $\begin{array}{l}40 \\
40 \\
60 \\
60 \\
60 \\
40 \\
60 \\
40\end{array}$ & $\begin{array}{r}16.65 \\
18.12 \\
0.42 \\
42.35 \\
2.76 \\
94.53 \\
31.96 \\
59.61 \\
266.40\end{array}$ \\
\hline
\end{tabular}

\subsection{Process Description}

\subsubsection{Grouting (VES)}

NOTE: The PE version of the Grouting System is essentially the same as the VES version described below.

\section{Brlk Pouder Storage and Distribution}

1. Provision is made to store bulk quantities of dry solids in silos external to the facility.

- Ordinary Portland Cement (OPC)

- Blast Furnace Slag (BFS)

- Pulverized Fly Ash (PFA)

- Grout Additive (such as grpsum)

2. Bulk powder is supplied by road tanker. Each of the four powders will be transferred from the tanker into the appropriate silo by means of compressed air.

- Grout additive will be received in silo T-05-101

- PFA will be received in silo T-05-102

- BFS will be received in silo T-05-103

- OPC will be received in silo T-05-104

3. Each silo is served by an automatic dust bag filter which will minimize dust vented during powder transfer. 
4. Powder will be transferred from outside storage to internal day-silos by means of a dense phase pneumatic pump (P-05-102). This pump will serve the transfer for all powder requirements. Powder will be delivered in 12.5 cubic feet batches to all six day silos on demand.

5. Provision is made for a liquid polymer grout additive to be pumped (P-05-101) into the grout mix fram the drum storage area. For the vibro-grout process the polymer, if required, will be metered into the wet grout mixing tank (T-05-212). For the agitated grout process the polymer, if required, will be pumped directly into the drum being filled.

\section{Equipment Deston Basis}

1. Large outside silos were sized for one month of full production in the grout facility.

2. An additional silo was provided to accommodate an alternative pozzolanic material or solidification binder.

3. The internal silos were sized for a daily production of 10 drums of grouted waste per mix station.

\section{Vibrosarout Syrtem}

1. 55-gallon drums containing weighed shredded waste will be transferred from lag storage to the grout facility. The drum will be placed on a powered roller conveyor (CV-05-212A) awaiting cell entry. When required for grouting the drum will be automatically brought through an airlock (AL-05-203) into the facility.

2. In preparation for filling, the lid fastener is removed from the drum remotely and retained. The drum then proceeds to a lift table. The drum is positioned exactly and lifted through the conveyor by a device which clamps and lifts the drum to the mouth of an inner enclosure. A loose seal is achieved around the drum top and its lid is removed by the simple-double-lid device which exposes the entire drum top for filling.

3. A differential pressure between cell and inner enclosure is continuously maintained to ensure a constant inward air flow. This in-flow of air ensures against outward diffusion of radioactive particles during the lid off period. The door mechanism will be designed to ensure guaranteed air flow from less to more contaminated enclosures.

4. The drum gripping mechanism is attached to a vertical vibrating device (M-05-201) which is used during wet grout addition to achieve a homogeneous product.

5. A known volume of process water is measured into the wet grout mixing tank (T-05212) and is circulated back to this tank using the pump/mixer (P-05-201 A/B). During recirculation, measured quantities of the selected grout powders are transferred to T-05212 from weigh hoppers.

- OPC is measured in via weigh hopper T-05-202

- BFS is measured in via weigh hopper T-05-204

- PFA is measured in via weigh hopper T-05-211 
The grout formulation for the vibro-grout system is unlikely to vary and a standard mix of BFS/OPC or PFA/OPC is anticipated for all shredded waste.

6. Accurate deliveries are achieved by first weighing the appropriate material in the weigh hopper and then delivering it to the mixing tank by screw conveyor.

7. Batches of powder are metered into weigh hoppers by rotary feeders below each day silo.

a. OPC is metered from day silo T-05-201 into weigh hopper T-05-202 by rotary feeder Y-05-201.

b. BFS is metered from day silo T-05-203 into weigh hopper T-05-204 by rotary feeder T-05-203.

c. PFA is metered from day silo T-05-210 into weigh hopper T-05-211 by rotary feeder $Y-05-210$.

8. Batches made up in the wet grout mixing tank will be calculated to provide the waste drum with exactly the amount of grout to fill each drum to 90 percent by volume.

9. If polymer additive is required to improve the quality of the grout, it will be metered into the mixing tank, T-05-212, directly from drum storage via pump, P-05-101.

10. With the waste drum in position and its lid opened the drum filling can begin. A three way valve on the grout recirculation line is actuated allowing the grout to begin filling the drum. The rate of filling will be carefully monitored by the operator who will start the drum vibrator (M-05-201) soon after the grout addition starts. A camera and an ultrasonic level detection system will enable him to control the grout addition and avoid overfilling.

11. When the grout addition is complete the mixing tank will be empty. The vibrator will be stopped and the line from the mixing tank will be cleared using a pneumatic pig.

12. The three way valve is returned to its recirculation position and the next charge of process water will be added to the mixing tank to clean the vessel and await the next grout mix.

13. The full drum of grout is now re-lidded and set down again on the roller convevor for transfer to the cure area.

\section{Anitated Grout System}

1. 55-gallon drums containing weighed repacked waste, and a built in agitator will be transported from lag interim storage to the grout facility. The drum will be placed on a powered roller conveyor (CV-05-212B) awaiting cell entry. When required for grouting the drum will be automatically brought through an airlock (AL-05-201) into the facility. (NOTE: The layout of WRAP $2 A$ may be changed to allow waste to be added to the drum at the mix station. This would remove the need to move a drum of ungrouted waste into the area and, hence, remove the need to have a clamp band on the incoming drum.) 
2. In preparation for filling, the lid fastener is removed from the drum which then proceeds to a lift table. The drum is positioned exactly and lifted through the conveyor by a device which clamps and lifts the drum to the mouth of an inner enclosure. A loose seal is achieved around the drum top and its lid is removed by the simple-double-lid device which exposes the entire drum top for filling.

3. A differential pressure between cell and inner enclosure is continuously maintained to ensure a constant inward air flow. This in-flow of air ensures against outward diffusion of radioactive particles during the lid off period. The door mechanism will be designed to ensure guaranteed air flow from less to more contaminated enclosures.

4. When the drum is in position the agitator will be automatically coupled to the agitator drive assembly.

5. As with the vibro-grout system the process is designed to blend and deliver the required mix and volume of grout to enable the filling of only one drum at a time. For the agitated system however a dry grout is added to the drum. Each drum will be filled to 90 percent level.

6. The grout formulation for the agitated grout system is likely to vary and acceptable formulation 'envelopes' will be established which will be applicable to each campaign lot.

7. Weighed fractions of OPC, BFS, and PFA lor other additives are conveyed from weigh hoppers (T-05- . T-05- and T-05- ) by screw conveyors (CV-05-209, CV-05-205 and CV-05-206) into a blender/hopper (T-05-207).

8. When the powders have been adequately mixed they are measured into a final weigh hopper (T-05-208) which, in turn, delivers the dry grout to the waiting drum. This addition takes place only when the operator is satisfied that the contents of the drum have been mixed adequately.

9. Batches of powder are metered into weigh hoppers by rotary feeders below each day silo.

a. OPC is metered from day silo T-05-209 into weigh hopper T-05by rotary feeder Y-05-209.

b. BFS is metered from day silo T-05-205 into weigh hopper T-05by rotary feeder Y-05-205.

C. PFA is metered from day silo T-05-206 into weigh hopper T-05 by rotary feeder Y-05-206

10. In order to prepare the drum for grouting the following sequence is completed. With the drum in position and the agitator coupled to the drive, the agitator is started and the water and waste is blended together. When the waste and water have been sufficiently mixed the dry blended powder is added slowly to the drum while the agitator is still running. The addition of powder will continue until the drum is full. A TV camera and level detection equipment will allow the operator to control the drum filling. 
11. If a polymer additive is required to improve grout quality, it will be metered into the drum during the fill stage.

12. The full drum of grout is now re-lidded and set down again on the roller conveyor for transfer to the cure area.

\subsubsection{VES Encapalation}

\section{Polvmer Reein and Chemionl Stornan}

1. Vinyl Ester Styrene (VES) resin is received from tank trucks approximately once per week into one of thires VES resin Storage Tanks (T-05-305 A,B,C). Each tank, located under a sun shielded roof outdoors, is sized at 5,900 gallons which is sufficient to receive a full tank truck load. Receipt will be alternated between each tank to minimize the inventory time period.

2. Extender, catalyst, and promoter will be received from 55-gallon drums via drum pumps into Extender Storage Tank T-05-302, Catalyst Storage Tank T-05-303, and Promoter Storage Tank T-05-304, respectively. The 750-gallon extender storage tank, 190-gallon promoter, and catalyst tanks are located outdoors under a sun shielding roof.

3. Solvent will be received and stored in an underground vault to minimize liquid surface area exposure in the event of a tank rupture. This will also allow a more evenly controlled temperature environment to minimize excessive vaporization. Solvent will be received by tank truck into two solvent storage tanks $(T-05-301$ A,B). The entire solvent storage volume will be contained in the vault except during flushing of miscellaneous storage tanks when up to 200 gallons may be contained above ground. Spent solvent will be collected in the hydrocarbon waste tank (T-05-402) also located in the underground vault. Spent solvent and/or waste hydrocarbon will be transferred from the waste tank to tank trucks or drums via hydrocarbon waste transfer pump (P-05-404) for disposal as hazardous waste.

4. The underground storage vault for solvent and hydrocarborı waste will be mechanically ventilated on a continuous basis to prevent build up of explosive and flammable vapor. Ventilation air will be swept through the vault at a design rate of $700 \mathrm{cfm}$ per fire code guidelines. Exhaust air will flow through carbon adsorber prefilters (F-05-301 A or B) and into vault exhaust carbon absorbers (V-05-301 A,B or C) for removal of hydrocarbon vapors. Normally one prefilter and two carbon adsorbers will be in service at a time. Air will then pass through one of the two vault exhaust filters (F-05-302 A or B) for carbon particulate removal prior to discharge through vault exhaust blowers (C-05-301 $A$ or $B$ ) to atmosphere. One blower will normally operate with the second on standby in the event of failure.

5. All tanks are nitrogen blanketed and vented to atmosphere through pressure safety valves. The VES resin storage tanks and solvent storage tanks can also be vented to the tank delivery trucks through flame arrestors during bulk filling. Those tanks containing hydrocarbons will have capability for pump out to the Hydrocarbon Waste Tank, T-05-402. Solvent can be pumped via Solvent Transfer Pumps, P-05-301 A,B, to all tanks for flushing purposes, except for the catalyst storage tank which will be flushed with water. The bulk storage tanks located outdoors will have a curbed area draining to a sump serviced by Bulk 
Storage Sump Pump, P-05-306 which discharges to the hydrocarbon waste tank. The catalyst storage tank will be in a curbed area which drains to a sump serviced by the Catalyst Sump Pump, P-05-307. This pump is capable of pumping aqueous waste to the nonactive waste water collection system. The promoter storage tank is in a curbed area which also services the Polymer Mix Tank, T-05-401.

6. Tanks containing styrene or vinyl ester styrene will have the capability to be cooled with chilled water during high outside ambient temperatures. Liquid contents will be maintained at $70^{\circ} \mathrm{F}$ or less by circulating extender or VES resin through Extender Cooler, E-05-301 or VES Resin Coolers, E-05-305 A,B, respectively. Each tank will be insulated to minimize heat gain.

7. VES resin will be transferred to the polymer mixing tank via VES resin Transfer Pumps, P-05-305A,B once per day at $30 \mathrm{gpm}$. Promoter and extender (if required) will be transferred once per day via Metering Pumps P-05-304 and P-05-302, respectively, to the polymer mixing tank. Catalyst will be transferred continuously to the polymer encapsulation process and combined with the resin premix via in-line static mixers. Catalyst will be forwarded to the mixers by Catalyst Metering Pumps P-05-303 A or B. Any excess catalyst not required, on demand will be returned to the Catalyst Storage Tank, T-05-303.

\section{Polymar Mixing}

1. Vinyl Ester Styrene (VES) resin, promoter, and extender are premixed in the Polymer Mixing Tank, T-05-401. This tank is of sufficient capacity, 1,500 gallon, to allow mixing once per day. The tank will be monitored remotely for liquid level. However, prior to preparation of a batch each day, the tank will be visually inspected by use of a sight glass to ensure it is empty and that any resin inventory has not solidified. The VES resin is then transferred to the mixing tank and metered via a flow totalizer. Promoter and extender, if required, are then metered into the tank by manual activation of the metering pumps which are automatically shut-down subsequently by respective flow totalizers.

2. Promoter is an organic compound such as dimethylanaline or cobalt naphthenate which accelerates the setting of the polymer. Extender and styrene is added as a viscosity control agent to minimize segregation of the mixed waste and resin and to control mixing energy input requirements. The catalyst is an organic (based benzoyl peroxide) or waterbased (hydrogen peroxide) compound which is added during the final in-drum mixing operation. The catalyst is the last ingredient to allow the cross-linking of the thermoset polymer.

3. The contents of the mixing tank are blended by Polymer Mixing Agitator, M-05-401 and by recirculation of the tank contents via Mixed Polymer Pumps, P-05-401 A or B. The Mixed Polymer Cooler, E-05-401, located in the recirculation loop allows cooling of the polymer mix with chilled water during high ambient temperatures. The polymer mixing tank is located in a shed adjacent to the process building. The area containing the mixing tank and promoter storage tank is curbed and drains to a sump serviced by Day Tank Sump Pump, P-05-405. This pump discharges to the hydrocarbon waste tank. During cleanout of the mixing tank with solvent, the contents can be transferred to the waste tank, as well, via the mixed polymer pumps. 


\section{Polymar Encapaulation}

1. Redrummed waste enters the polymer encapsulation area repacked in new drums in premeasured quantities that will allow direct, in-drum, encapsulation with polymer. Repacked drums are delivered via AGV to one of 4 polymer fill stations in Polymer Encapsulation Enclosure, GB-05-401. All 4 stations have the capability for stirred or vibrated in-drum mixing. One of the 4 stations is also capable of vacuum dewatering for removal of any free water formed during initial polymer curing.

\section{a. Stirred Mixing}

1) Waste which is a dry or wet small particulate such as crystals or sludge is mixed with polymer via the stirred technique. The drums containing premeasured waste and an agitator shaft with prop are delivered to Lift Tables, LT-05-401, 402, 403, or 404. The lift table positions the drum under the port and hydraulically raises the drum into position. A simple double lid is opened hydraulically and the agitator shaft is coupled to the motor drive for In-Drum Mixers, M-05-402, 408, 409, or 410. Premixed polymer is then injected into the drum and filling is monitored by television cameras and ultrasonic level detectors in the enclosure. Polymer is automatically metered into the drums based upon predetermined waste loadings and controlled by load cells on the lift tables.

2) The mixed polymer is pumped to the encapsulation enclosure via Mixed Polymer Pumps, P-05-401 A or B. Catalyst is mixed with the polymer resin in In-Line Mixers, M-05-404, 405, 406, or 407. The flow of catalyst is controlled proportional to that of resin by proportional flow controllers. Preset catalyst and polymer quantities are metered upstream of the in-line mixer. After each batch, compressed air is used to clear the in-line mixers and any piping where catalyst and resin have been premixed. Periodically, the mixers and piping will be disassembled, removed from the process building, and cleaned in solvent.

3) During injection of the premixed polymer into the drums, the waste and polymer are mixed via the in-drum mixers. After polymer injection, the mixing will continue until a homogeneous mix is obtained as determined by mixer amperage and visual observation.

4) After mixing, the agitator prop is detached and the mixed polymer and waste is allowed to sit until a gel is formed. Verification of gel formation can be confirmed by visual inspection using television cameras mounted in the enclosure. This may be aided by using the vibratory mixers to produce standing waves apparent on the surface prior to polymer setup. The simple double lid is then closed and the drum is lowered. An AGV then retrieves the capped drum and transports it to the polymer curing and storage area. One percent of the cured product will be transported to the sample management area for core sampling.

\section{b. Vibrated Mixing}

1) Waste forms which are large, irregular, or non-mixable by stirred techniques are mixed by vibrated techniques. This process uses Vibratory Mixer, M-05-403, 411, 412, or 413 which are positioned on the lift tables. The vibratory mixers provide mixing during and after introduction of polymer into the 
drum. The action of the vibratory mixers is to remove air pockets for macroencapsulated waste such as lead bricks or mix shredded or irregular waste. All other operations are identical to the stirred mixing process.

\section{Free Water Removal}

1. The vacuum dewatering system is capable of removing free water which may form in curing drums resulting from waste encapsulated by stirred or vibrated mixing techniques. CCTV in the polymer encapsulation enclosure will allow visual inspection of drum contents during the initial curing phase. If free water generation is evident, the drum will be retained at the enclosure and free water removed via vacuum dewatering. This operation is expected to occur very infrequently, if ever, assuming proper control of all polymer mixing and encapsulation parameters.

2. A vacuum will be drawn on a disposable suction tube inserted into the drum using the Vacuum Dewater Pump, P-05-403. Water will be drawn from the 55 gallon drum into a Liquid Catch Drum, V-05-401. Waste water collected in the Liquid Catch Drum will be transferred to the active waste water collection system via Waste Water Transfer Pump, P-05-402.

\section{Cure Storane}

1. After completion of the polymer encapsulation treatment process, drums of treated waste will be transferred to a polymer cure storage area for final curing. This transfer will be done after the polymer has gelled to form a stable mass that will not shift or spill during transit. The drums will be relocated to the polymer cure storage area prior to initiation of the temperature exotherm. Each drum will be retained in this area for up to 72 hours (per waste form qualification treatability study) to allow heat removal during curing. This will necessitate a polymer cure storage capacity of 84 drums, equivalent to two days of polymer treated waste production. An air ventilation system will maintain the room air temperature at $95^{\circ} \mathrm{F}$ or less. Room air will be exhausted through the active HVAC system HEPA filters and stack. Drum temperature will be monitored by use of infrared pyrometers throughout the exotherm and cooling period.

\subsubsection{PE Encapsulation}

The polyethylene bulk storage and pneumatic transport system is shown on PFD H-2140640. The polymer encapsulation system is shown on PFD H-2-140641.

\section{Polvethulene Bulk Storane}

1. Polyethylene pellets are received in bulk from trucks equipped with independent compressed air pneumatic transport systems. The shipments are received once every 20 days into T-05-302, bulk polyethylene silo. Transport air is exhausted through 5-05-302, polyethylene silo dust collector, and S-05-301, additive silo dust collector, using C-05-302 and 303, silo fans, respectively. bulk additive and polyethylene are conveyed by gravity flow through $Y-05-301$ and $Y-05-302$, bulk rotary feeders, and CV-05-301 and CV-05-302, bulk air slides, to P-05-302, dense phase pump. Solids are conveyed in $12.5 \mathrm{ft}_{3}$ batch sizes using air supplied by C-05-301, air compressor package. The air supply system is composed of a centrifugal air compressor, dual dryers, filter and receiver. Solids are conveyed to the day silos at rates ranging from 50 to $150 \mathrm{ft}_{3} / \mathrm{hr}$. 


\section{Polyethuden Encapsulation-Fxtmuder Mixing}

1. Polyethylene pellets and additive are received by batch pneumatic transport from bulk storage in T-05-404 and T-05-403, polyethylene and additive silos, respectively. Air is exhausted via S-05-404 and S-05-403, silo dust collectors, to the off-gas system.

2. Particulate waste is received by gravity flow from the sludge conditioning area into T05-405, waste hopper. Particulate waste is fed to X-05-402, polyethylene/waste extruder, using Y-05-405, waste rotary feeder and CV-05-405, waste screw conveyor. Additive and polyethylene are fed to the extruder using $Y-05-403$ and 404, rotary feeders, and CV-05403 and 404, screw conveyors, respectively. The speeds of the rotary feeders and conveyors are set proportionally to obtain the proper mix of additive, polyethylene, and waste. The extruder speed is interlocked with the feeding equipment to provide shutdown of the feeders in the event of emergency extruder shutdown.

3. Waste, polyethylene, and additives (if required) are mixed and heated within the twin screw extruder. The extruder uses multiple electrically heated zones to allow melting of the polyethylene and flashing of the moisture in the waste. Moisture, which flashes off as superheated stream under partial vacuum, is collected in dome chambers and directed to the vent treatment system. The dry molten mixed waste and polyethylene is extruded at approximately $300^{\circ} \mathrm{F}$ into 55-gallon drums.

4. Empty drums are transported into GB-05-401, polymer encapsulation enclosure, through airlock AL-05-402 using roller conveyors, CV-06-401B, 402B and 405. The empty drums are indexed onto $X-05-404$, turntable conveyor assembly. The turntable has a capacity of 6 drums and is capable of rotating to index a new empty drum under the extruder discharge. The turntable also allows incremental partial filling of each drum if shrinkage during cooling of the monolith is encountered. Full drums are then conveyed onto roller conveyor, CV-05-406, where the drum lid is added using RT-05-402, lid clasp placement mechanism. Drums are then conveyed through airlock AL-05-403 from the enclosure using roller conveyors, CV-05-407 and 408. The full drums are transported by AGV to the cure/storage area where final cooling and solidification occurs. The cure storage area will be capable of holding 80 drums which is $\mathbf{4 8}$ hours of equivalent production capacity.

5. The extruder vent system is composed of E-05-401, extruder vent condenser, where vented moisture condenses and is collected in V-05-401, condensate receiver. The condenser is cooled using chilled water at flow rates controlled by the condenser outlet temperature. Condensate collected in the receiver is transferred twice per day to the active water collection system using P-05-402, condensate pump. Vacuum at $2^{n} \mathrm{Hg}$ absolute is maintained on the extruder vent system using P-05-403, vent vacuum pump. The noncondensible vapors are vented to the offgas system for treatment.

\section{Polyethylene Fncapaviation-Cravity Infill}

1. Oversize waste such as lead bricks packed in 55-gallon drums are received from interim drum storage into the enclosure via entry airlock, AL-05-402. The preloaded drums are conveyed to the turntable conveyor assembly, X-05-404. Hot molten polyethylene, heated to a maximum of $450^{\circ} \mathrm{F}$ is added to the drums incrementally by indexing the drums under the extruder discharge. Full drums are discharged from the enclosure using the same path as previously described. 
2. Gravity-infilling of waste with polyethylene is possible for only certain oversize waste forms without preheating the waste and drum. These include wastes, such as lead bricks or sized lead, which have low specific heats per unit mass. Other oversize waste forms must be vibro-infilled with grout.

\subsection{STUDY CRITERIA AND METHODOLOQY}

This HAZOPS utilized a predetermined set of process deviations/upset conditions to be analyzed by the HAZOPS team. For each process deviation, possible causes were postulated and worst case consequences (without benefit of any safeguards) were determined. Existing safeguards (design and procedural) were then identified. Those safeguards which could be reasonable expected to be present in the first design were assumed to be existing and were so documented in the HAZOPS. For each cause and effect, hazard severity and probability were qualitatively assessed (taking credit for existing safeguards which reduce hazard probability) using the criteria shown in Table 1. The overall risk rating for each hazard was the determined using the risk ranking matrix shown in Table 2. Recommendations were proposed by the HAZOPS team in instances required by the implementation criteria shown in Table 2. 
TABLE 1

HAZARD SEVERITY AND PROBABILITY CLASSIFICATION CRITERIA

SEVERITY CLASSIFICATION

\begin{tabular}{|c|c|c|c|c|}
\hline \multirow{2}{*}{ Target Hazard } & \multicolumn{4}{|c|}{ Soverity Class (Worst-case Scenario) } \\
\hline & Catastrophic (1) & Extensive (2) & Moderate (3) & Operational (4) \\
\hline Community & $\begin{array}{l}\text { Multiple irreversible } \\
\text { injuries; may include a } \\
\text { fatality } \\
\text { OR }\end{array}$ & $\begin{array}{l}\text { Single irreversible or } \\
\text { several reversible injuries } \\
\text { (no fatalities) } \\
\text { OR }\end{array}$ & $\begin{array}{l}\text { Several reversible injuries } \\
\text { OR }\end{array}$ & \\
\hline Workers & $\begin{array}{l}\text { Fatalities or irreversible } \\
\text { injuries } \\
\text { OR } \\
\end{array}$ & $\begin{array}{l}\text { Several injuries } \\
\text { OR }\end{array}$ & $\begin{array}{l}\text { Single injury } \\
\text { OR } \\
\end{array}$ & \\
\hline Facility & $\begin{array}{l}\text { Partial or full demolition of } \\
\text { facility } \\
\text { OR }\end{array}$ & $\begin{array}{l}\text { Rupture or similar loss of } \\
\text { containment } \\
\text { OR }\end{array}$ & $\begin{array}{l}\text { Major equipment damage } \\
\text { leading to one month or } \\
\text { more facility downtime } \\
\text { OR }\end{array}$ & $\begin{array}{l}\text { Equipment damage } \\
\text { leading to several days of } \\
\text { facility downtime or other } \\
\text { operational penalty } \\
\text { OR }\end{array}$ \\
\hline Environment & $\begin{array}{l}\text { Major environmental } \\
\text { impact with significant } \\
\text { cleanup/iability costs }\end{array}$ & $\begin{array}{l}\text { Groundwater, soil, or } \\
\text { public sewer } \\
\text { contamination }\end{array}$ & $\begin{array}{l}\text { Minor spill or release } \\
\text { resulting in permit violation }\end{array}$ & \\
\hline
\end{tabular}

\section{LIKELIHOOD CLASSIFICATION}

\begin{tabular}{|l|l|}
\hline Highly Likely (1) & $\begin{array}{l}\text { Event has occurred at this facility - or - other facility - or - is expected to occur several times during the } \\
\text { rext } 10 \text { years. }\end{array}$ \\
\hline Likely (2) & $\begin{array}{l}\text { Event has occurred at this facility - or - is possible to occur at this facility several times during the next } \\
30 \text { years. }\end{array}$ \\
\hline Unlikely (3) & $\begin{array}{l}\text { Event may have occurred at another facility - or - is possible to occur at this facility at least once in the } \\
\text { next } 50 \text { years. }\end{array}$ \\
\hline Extremely Unlikely (4) & $\begin{array}{l}\text { Event is not likely to ever occur in this facility, given a continuation of the current levels of training, } \\
\text { procedures, maintenance, inspection, testing, and other applicable process safety management system } \\
\text { support. }\end{array}$ \\
\hline
\end{tabular}


TABLE 2

RISK RANKING MATRIX AND IMPLEMENTATION CRITERIA

RISK RANKING MATRIX

\begin{tabular}{|c|c|c|c|c|}
\hline Likelihood & & & \\
\hline Highly Likely (1) & 4 & 2 & 1 & 1 \\
\hline Likely (2) & 5 & 3 & 2 & 1 \\
\hline Unlikely (3) & 6 & 4 & 3 & 2 \\
\hline Extremely Unlikely (4) & 7 & 6 & 5 & 4 \\
\hline & Operational (4) & Moderate (3) & Extensive (2) & Catastrophic (1) \\
\hline
\end{tabular}

\section{RISK RANKING IMPLEMENTATION}

\begin{tabular}{|c|l|}
\hline Risk Ranking & \multicolumn{1}{c|}{ Implication } \\
\hline 1 & $\begin{array}{l}\text { Risk level - Very significant } \\
\text { Recommendation = Required from the HAZOPS team }\end{array}$ \\
\hline 2 & $\begin{array}{l}\text { Risk level - Significant } \\
\text { Recommendation = Required from the HAZOPS team }\end{array}$ \\
\hline 3 & $\begin{array}{l}\text { Risk level - Not very significant } \\
\text { Recommendation = Required from the HAZOPS team }\end{array}$ \\
\hline 4 & $\begin{array}{l}\text { Risk level - Not significant, but may be an operational problem } \\
\text { Recommendation = At the discretion of the HAZOPS team }\end{array}$ \\
\hline 5,6, or 7 & $\begin{array}{l}\text { Risk level - Negligible, but may be an operational problem } \\
\text { Recommendation = At the discretion of the HAZOPS team }\end{array}$ \\
\hline
\end{tabular}




\subsection{RESULTS AND CONCLUSIONS}

Because this HAZOPS is performed relatively early in the design phase, existing safeguards have not been fully documented on the process flow diagrams (these would mostly be shown on the P\&IDs developed during Title Design). However, the HAZOPS team assumed specific safeguards would be present in the final design if it appear reasonable to expect this. These assumed safeguards are documented on the HAZOPS worksheets and credit was taken for these presumed safeguards when assessing risk. During Title Design, the presence of these safeguards need to be verified to validate the conclusions of this HAZOPS.

For the grouting system, forty-five potential safety and operability problems were identified and evaluated in this HAZOPS. of these, thirty-three were assessed to have a negligible risk level. The remaining twelve involve potential safety and operational problems having a risk ranking classified between significant and not significant. For these potential safety and operational problems, the HAZOPS team has recommended that additional safeguards be evaluated and incorporated into the WRAP 2A Design. Table 3 presents a summary of changes to be made in the process flow diagrams, assumed design safeguards and additional safeguards to be evaluated for incorporation into the design.

For the VES encapsulation system, twenty potential safety and operational problems were determined to have a risk ranking classified as between very significant and not significant. For these potential problems, additional safeguards have been recommended for evaluation and incorporation as summarized in Table 4.

For the PE encapsulation system, six potential safety and operability problems were determined to have a risk ranking classified as between not very significant and not significant. For these potential problems, additional safeguards have been recommended as summarized in Table 5.

In several instances, the need for human factors analyses and reliability availability/maintainability analyses during Title Design was highlighted by the HAZOPS team to achieve negligible risk levels. The HAZOPS assumed that such analyses would be performed and that the necessary design requirements/modifications are incorporated. The performance of these design analyses are considered to be open issues to be resolved during Title Design. Similarly the HAZOPS team identified the need for a maintainability analysis to develop requirements for warm maintenance at the WRAP 2A facility.

The HAZOPS is documented in the attached HAZOPS worksheets. 


\section{TABLE3 \\ GROUTINO HAZOPS SUMMARY}

NOTE: Items listed in this table apply equally to the PE and VES versions of the Grouting System, unless noted otherwise.

\section{PROCESS FLOW DIAGRAM CHANGES}

1. Show control loops (woight, flow, level)

2. Add flush line from wet grout mixing tank

3. Add miscellaneous feed hopper to supply wet grout mixing tank (PE/grout system only)

\section{ASSUMED DESIGN SAFEGUARDS}

1. General design basis requirements are other safeguards listed in previous HAZOPS (e.g., radiation shielding).

2. Slow starting/stopping of drum containing uncured grout.

3. Mechanism to keep anclosed portion of drum clean when grout filling/vibrating.

4. Alarm/interlock for door position at drum port.

5. In-line wet grout fill valve fails closed (no flow to drum).

6. Capability to automatically drain wet grout mixing tank upon loss of power (provide same delay).

7. Noise protection as required.

8. Capability to easing cleanout caked lines (e.9., couplings).

9. Mechanism to prevent bridging in silo's and static charge buildup inside grouting enclosure.

10. Capability to cleanup grouting hood/enclosure (dry or wet grout spill/dust).

11. Oil-free air compressor.

12. Periodic sampling of wet grout (procedural safeguard).

13. Redundant water flow measurement for in-drum grout mixing.

14. Capability to maintain equipment inside enclosure.

15. Capability to remove loaded drum from lift table in the event of lift failure.

16. Appropriate materials of construction (corrosion).

17. Capability to calibrate instruments.

18. Capability to compared individual and combined weight measurements to detect instrumentation/control failure.

19. Sump for cleanup of grouting enclosure. 
20. Conveyor section of drum filling station is protected from grout spill and/or is deigned for easy replacement.

21. Capability to sample incoming material from truck.

22. Level detection of grout in drum to prevent overfilling.

23. Capability to easily replace grout fill line to drum.

\section{EVALUATEANCORPORATEINTO TITLEI DESIGN}

1. Air-tight containment at drum filling port.

2. Mechanism to prevent splashing at drum during grout mixing/vibration.

3. Verify drum vent is large enough to avoid pressure build up during grout curing.

4. Interlock to provent wrong drum entering grouting enclosure (mix up in drum lots).

5. Evaluate effect of incompatible waste (unremoved) accidentally mixing with grout.

6. Day tank for process water (loss of water supply).

7. Drum lid sticking (on/off)-prior to grout filling

(Drum Deformation) -after grout filling

-after grout curing

8. Perform enclosure configuration study to eliminate need for relidding/delidding drums.

9. Verify that acceptable weighing sensitivity/tolerances can be achieved.

10. Define acceptable formulation ranges.

11. Perform ram analysis to identify redundant equipment requirements.

12. Closed circuit TV yersus direct observation at grouting enclosure.

13. Perform human factors evaluation to assure effective man/machine interface.

14. Separate transfer equipment from silo's (inadvertent routing to wrong feed bins).

15. Coupling/alignment of clamp for drum lid (remote operation versus operator task).

17. Toxicity/flammability of polymer additive (TBD).

18. Growth inhibition additives for active recycled water (not part of this system). 


\section{VES ENCAPSULATION HAZOPS SUMMARY}

\section{CHANGES TO PROCESS FLOW DIAGRAMS}

1. Provide containment for drum delidding/relidding (for consistency with grouting design).

2. Add note that in-line static mixer is not used when in-drum rotating mixer is used.

3. Provide capability to sample hydrocarbon waste tank.

\section{ASSUMFD DESICN SAFEGUARDS}

1. General design basis requirements and other safeguards listed in previous HAZOPS (e.g., air tight containment at drum port).

2. Enclosure materials of construction are resistant to chemical vapors.

3. Separate king of promoter and catalyst.

4. Mechanism to prevent accidentally filling wrong tank (e.g.. getting promoter into catalyst tank).

5. Equipment inside enclosure is designed for hazardous area (non-sparking, grounded).

6. Capability to remove drum from failed lift table before exotherm begins.

7. Mechanism to prevent accidental flow of catalyst into other lines.

8. Nitrogen purge is sized to accommodate maximum tank flow (with nitrogen supply failure alarm).

9. Tanks and lines are grounded in accordance with NEC77.

10. Capability to flush VES lines (without flushing VES storage tanks).

11. Capability to easily seplace VES lines solidified with polymer.

12. Capability to safely remove in-line mixer and clean-in solvent (e.g., hood?).

13. Capability for remote transport of hot drums during exotherm period.

14. Capability to change out carbon absorbers safely.

15. Capability to cleanup chemical spill inside building (e.g., line/valve leak).

16. Spill containment at truck unloading station.

17. Capability to sample material from truck prior to off loading.

\section{EVALUATE/INCORPORATE INTO TITLE IDESIGN}

1. Capability for personnel entry into vault.

2. Evaluate need to empty storage tanks prior to manned entry into vault (solvent tank, hydrocarbon waste tank).

3. Evaluate need to vent storage tanks in vault through carbon absorbers for manned entry safety. 
4. Evaluate NEC area classification (e.g., in vault).

5. Evaluate installation of sump pump in vault with leak detection (avoid manned entry for inspection).

6. Evaluate need to vent outside storage tanks through carbon absorbers or flame arrestor.

7. Evaluate effect of syrene loss of cooling.

8. Evaluate time limit for VES sotting up in transfer lines and provide capability to drain line.

9. Evaluate effect of vapor release from enclosure upon loss of HVAC.

10. Evaluate need for spill cleanup/personnel protection at outside chemical transfer area.

11. Evaluate cleaning requirements for polymer mixing tank (remove polymer first, followed by solvent flush ?) and provide equipment with this capability.

12. Reevaluate plant air blowdown into drum to avoid spraying polymer in enclosure.

13. Evaluate drum lid sticking after exotherm.

14. Evaluate disposal of drum while fails to gel (drum recycle is an FDC requirement).

15. Evaluate possibility of polymer solidification inside hydrocarbon waste tank (e.g., transfer pump failure).

1'j. Evaluate workability of vacuum dewatering system (how to remove thin layer of liquid?).

17. Evaluate acceptability o sending VES-contaminated water to waste water treatment (may need a contaminated waste tank or relocate the dewatering station to cure storage area).

18. Verify capability to accurately meter the catalyst flow $(.01 \mathrm{gal} / \mathrm{min})$. Consider alternative addition mechanism (e.g., solid addition).

19. Evaluate lab support requirements for chemical sample testing (e.g., at truck unloading of VES).

20. Verify that vault keeps solvent tank temperature at acceptably low lovel.

21. Provide flexibility between VES transfer pumps and coolers. 


\section{TABLE 8}

\section{POLYETHYLENE ENCAPSULATION HAZOPS SUMMARY}

\section{CHANGES TO PROCESS FLOW DIAGRAMS}

1. Show water cooling of extruder.

2. Show control loops (e.9., level control for drum filling).

3. Denote sampling point at extruder discharge.

\section{ASSUMED DESIGN SAFEGUARDS}

1. Catch pan for drips from extruder.

2. Mechanism to control dust inside enclosure at waste/feed bins. Waste tin is enclosed (with vent to pug mill).

3. Design precludes accidental contamination of cooling water.

4. Extruder high temperature alarm/shutdown or limit power input.

5. Mechanism to prevent bridging in silos.

6. Grounding of lines/equipment to prevent static charge buildup.

7. Inherent design of extruder precludes damage upon loss of cooling.

8. HEPA filter at offgas treatment is not damaged by high temperature vapors (loss of vapor cooling).

9. High temperature alarm for condenser vapors.

10. Inherent design of extruder precludes damage from reheating cold (filled) extruder -loss of power.

11. Remote handling of hot drums.

12. Design controls/minimizes dust release during PE/additive transfer.

13. Provide waste size reduction in accordance with extruder clearance tolerances.

14. Capability to remove drums when turntable has failed.

15. Maintainability access for equipment in enclosure.

16. Capability to adjust/calibrate speed of waste feed conveyor to extruder.

17. Control system tracks filling status of drums on turntable (number of times a drum has gone around to the fill position).

18. Level alarm/indication as a backup to drum filling level control (e.g., cooled circuit TV).

19. Interlock prevents filling from extruder if drum is not in position.

20. Level alarm at feed bins.

21. Level alarm at condenser recoiver.

22. High pressure alarm/shutdown for extruder. 
23. High pressure relief at extruder vent (vapor surge).

24. Capability to sample PE, additive at truck unloading.

25. Capability to sample condenser water.

26. Drum turntable designed for easy cleanup of PE spill.

\section{EVALUATE/INCORPORATE INTO TITLE IDESIGN}

1. Evaluate method to survey hot $\left(300^{\circ} \mathrm{F}\right)$ drums upon exiting enclosure-also deconning drums.

2. Provide two bins for wet/dry waste feed with appropriate feed mechanisms.

3. Consider locating PE and additive conveyors outside enclosure.

4. Evaluate possibility of +Dp in enclosure due to heat sources (extruder/drums) when HVAC fails.

5. Sump in enclosure for water spilis/cleanup.

6. Verify that drum vent can adequately allow air inflow during drum cooling.

7. Evaluate explosive properties of PE dust.

8. Evaluate amount/concentration of organic vapors released from extruder upon loss of vacuum (and provide redundant vacuum pump as necessary to reduce explosion possibility).

9. Evaluate volume of free flow from extruder upon loss of power (drum overflow/spill).

10. Consider locating vacuum pump and condensed outside enclosure.

11. Evaluate increasing extruder clearance/tolerances so that larger particle size waste can be used.

12. Define operator tasks and control system interrelationship (provide interlocks that counter human error).

13. Provide capability for additive addition at pug mill.

14. Evaluate using pug mill to control quality/consistency of waste feed to extruder.

15. Evaluate locating extruder outside enclosure.

16. Evaluate drum rework (FDC requirement).

17. Consider feasibility of continuous shift operation (extruder).

18. Evaluate separating material transfer lines from silo's/inadvertent routing to wrong feed bins. 
WRAP 2A ACDR PRLIMINARY HAZOP REVIEW DATA SHEET

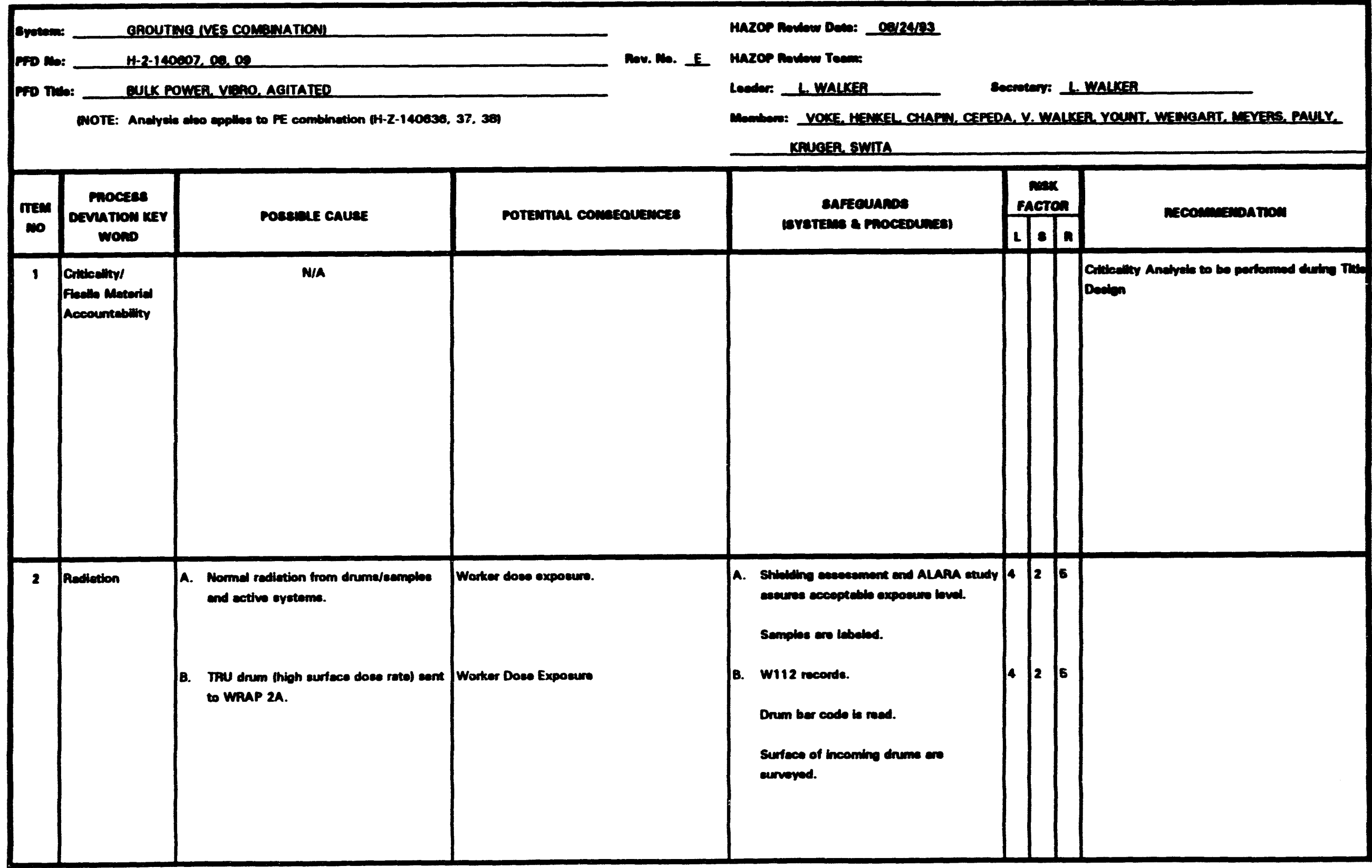




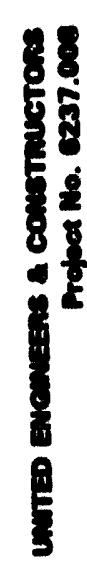

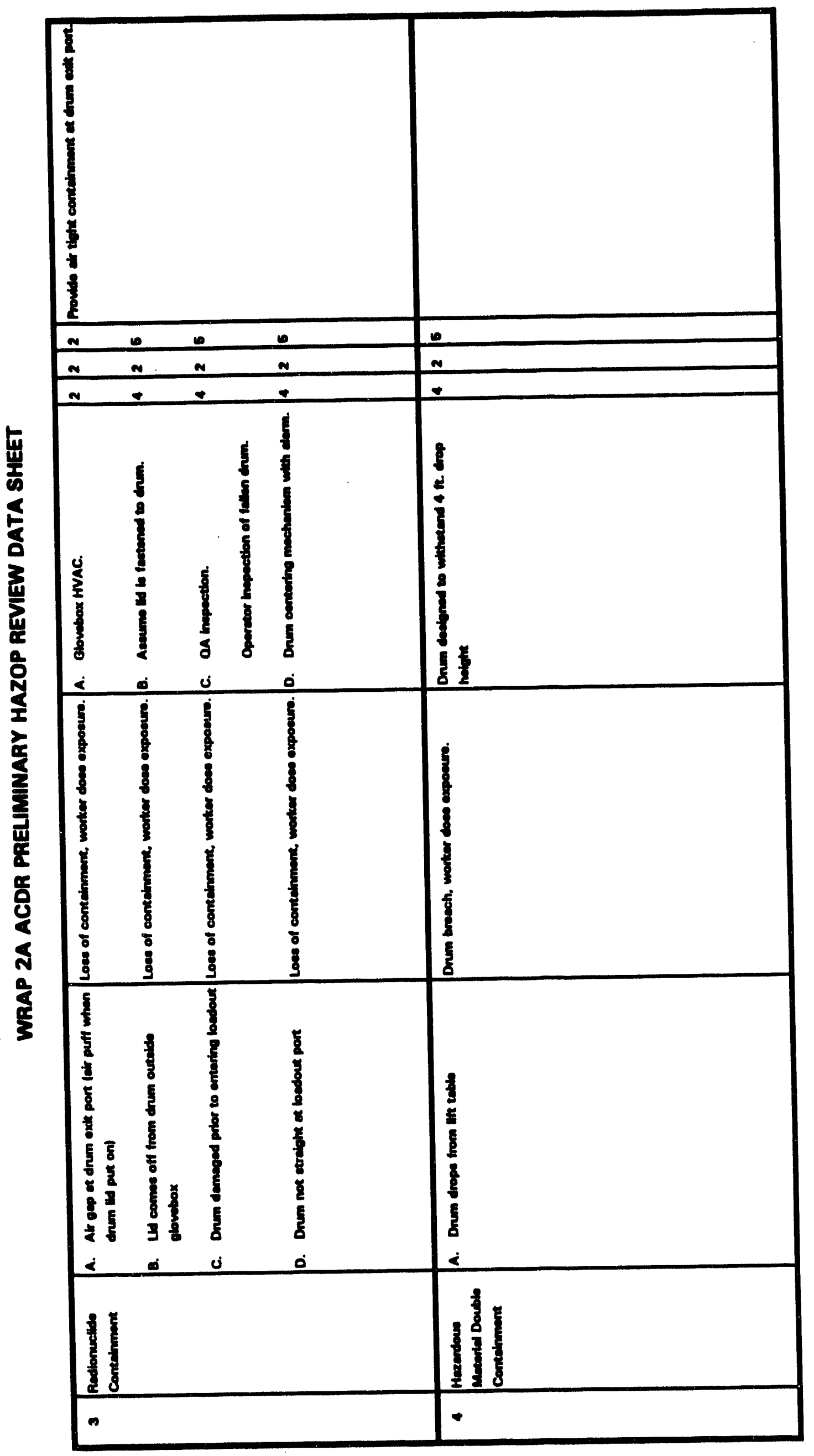


WRAP 2A ACDR PRELIMINARY HAZOP REVIEW DATA SHEET

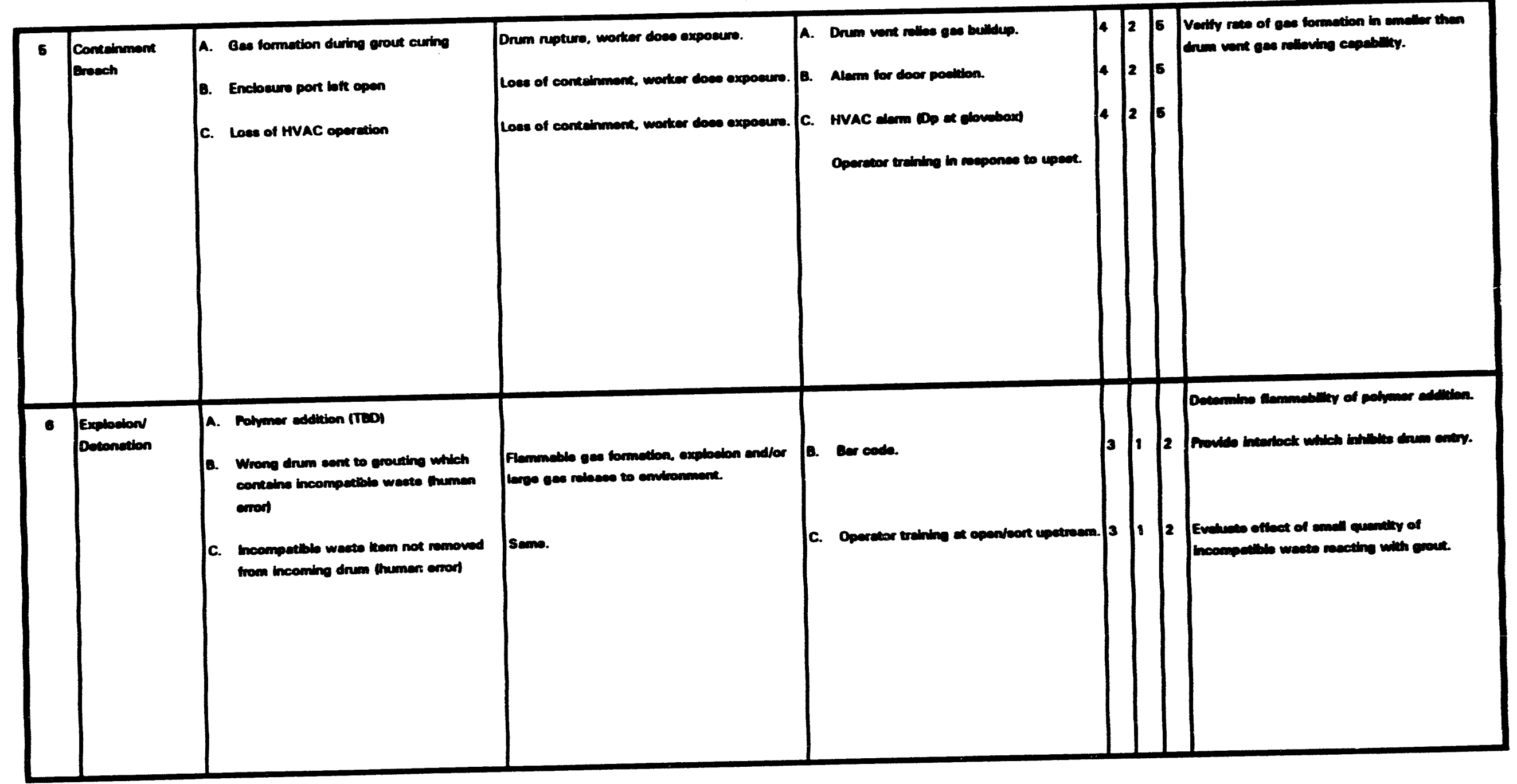




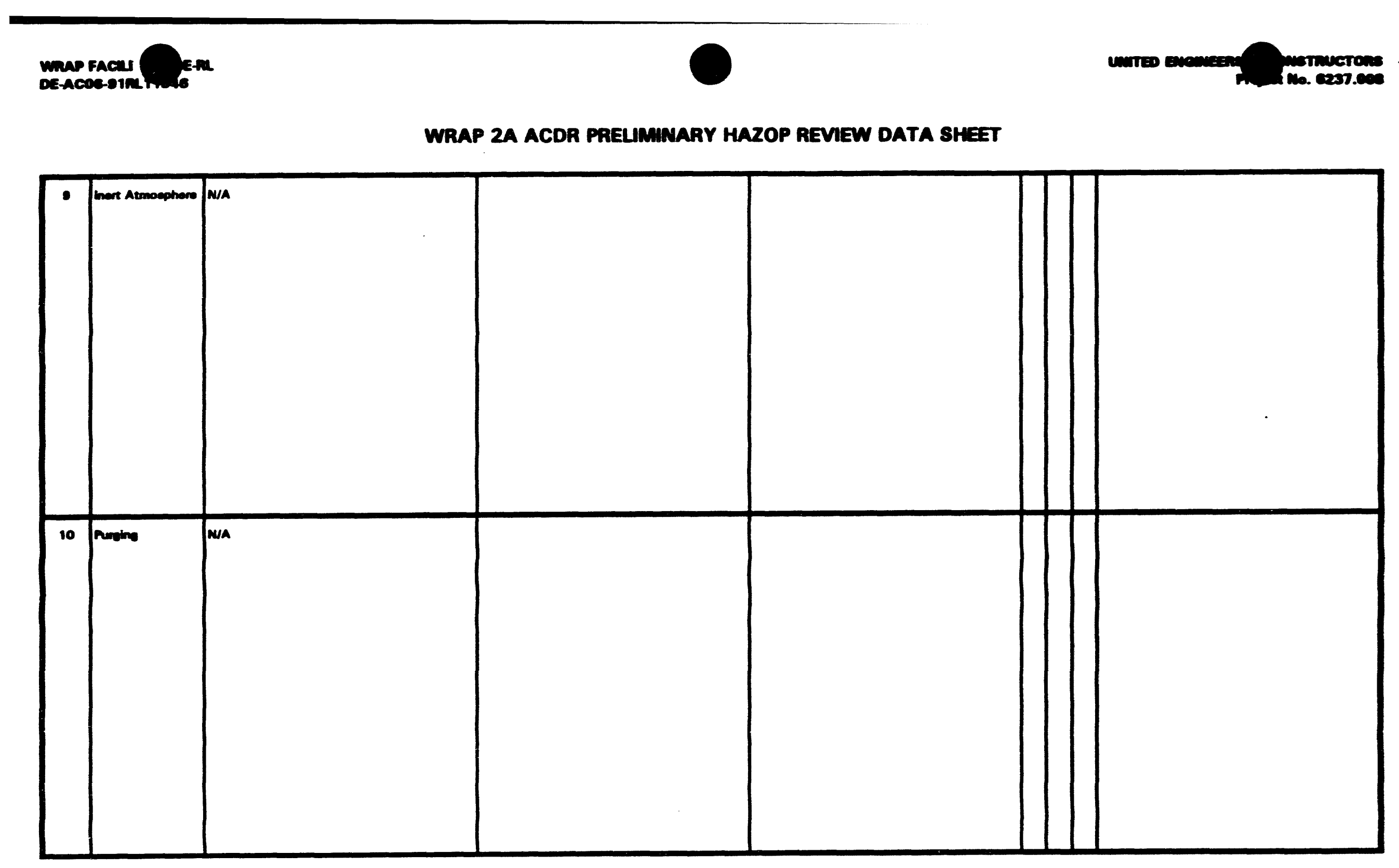




\section{WRAP 2A ACDR PRELIMMNARY HAZOP REVIEW DATA SHEET}

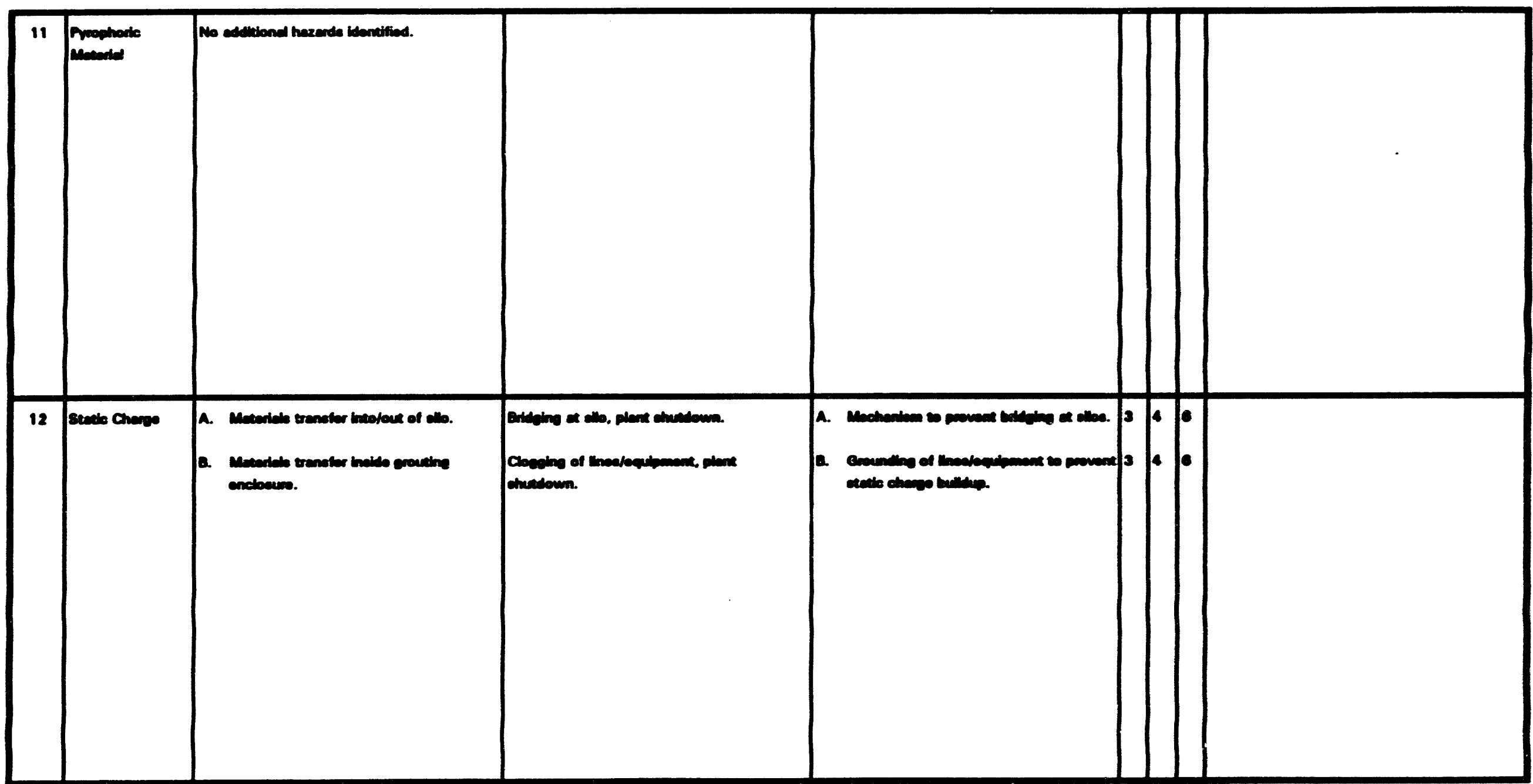




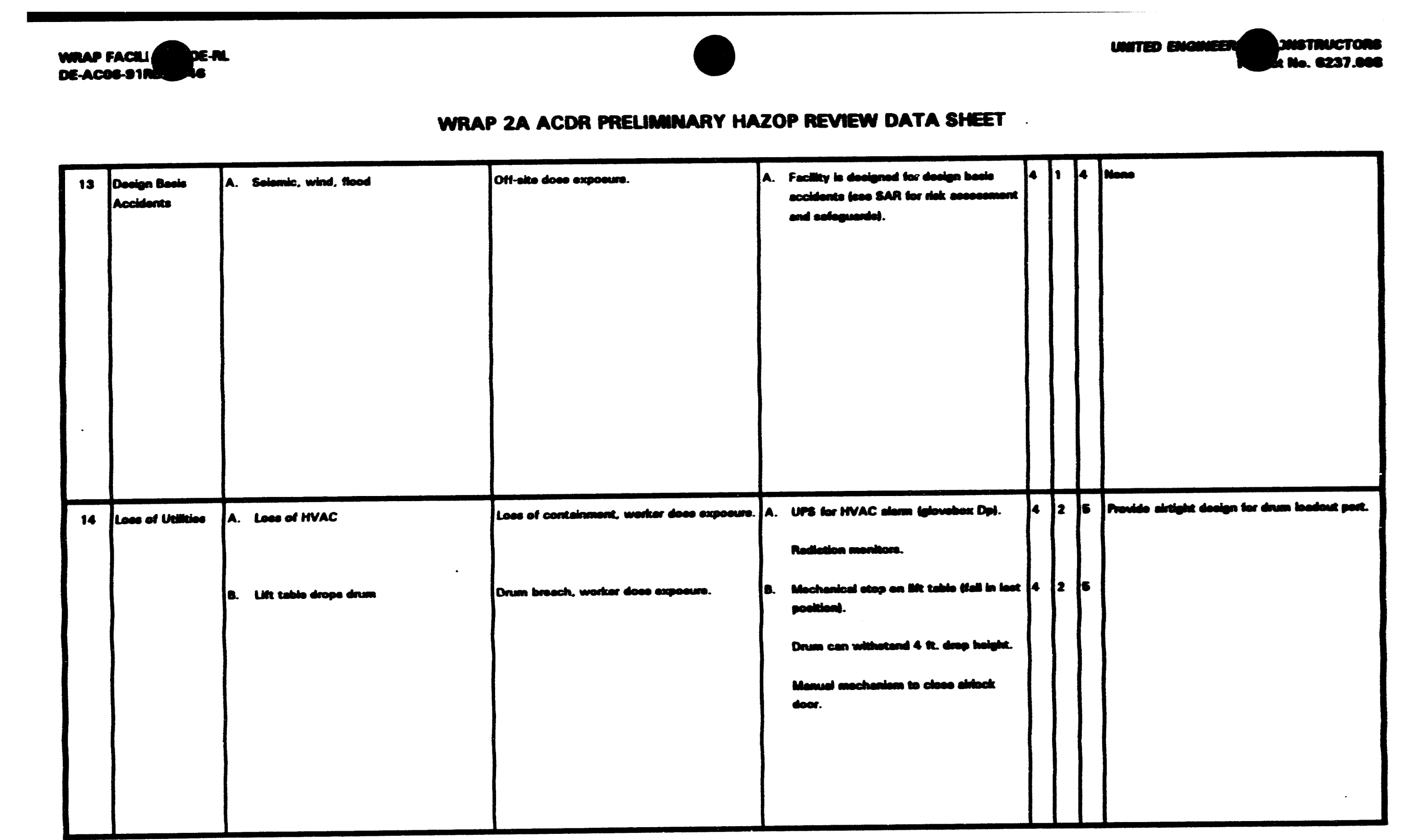



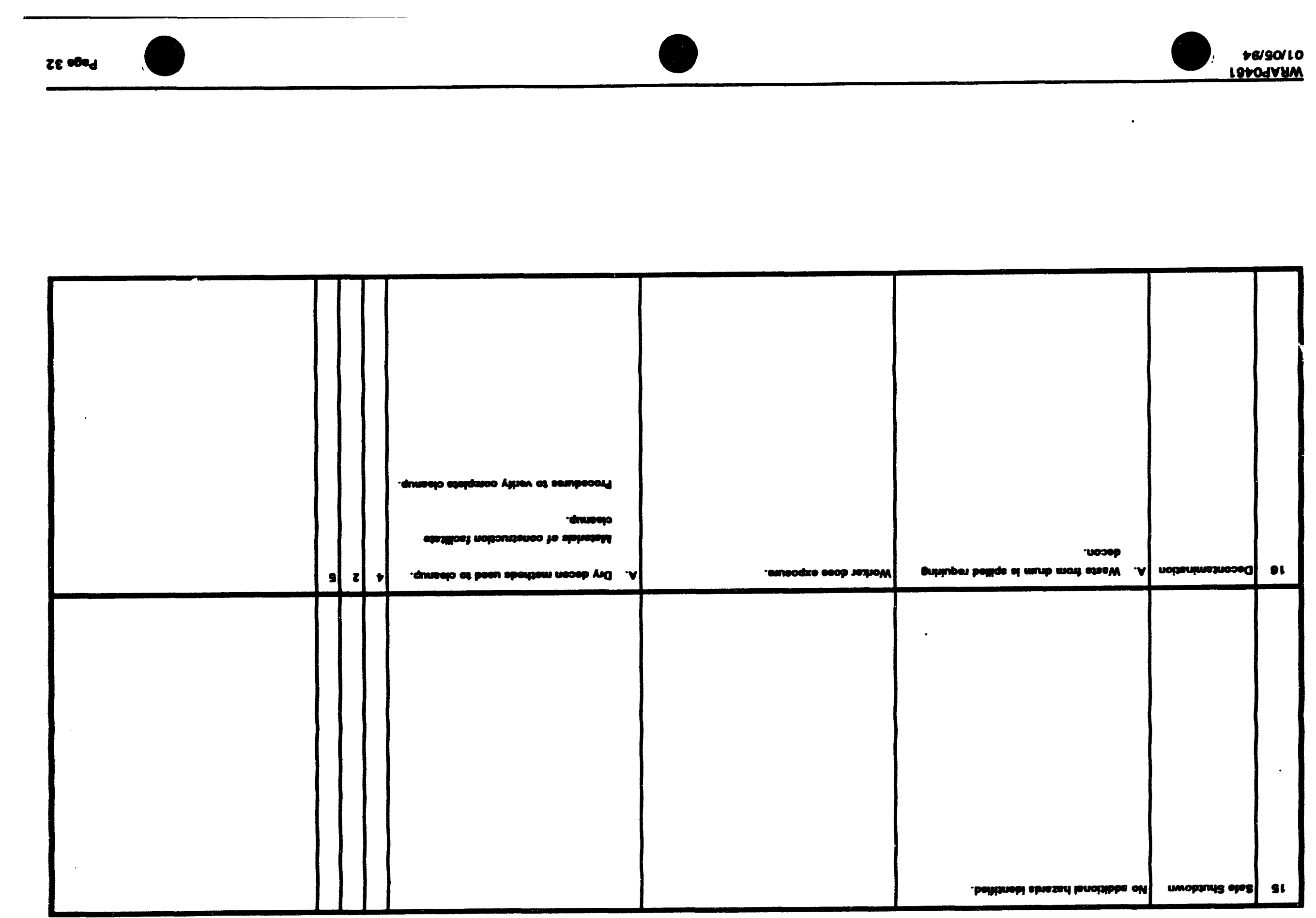

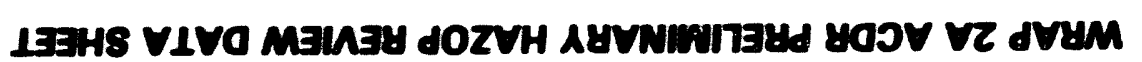




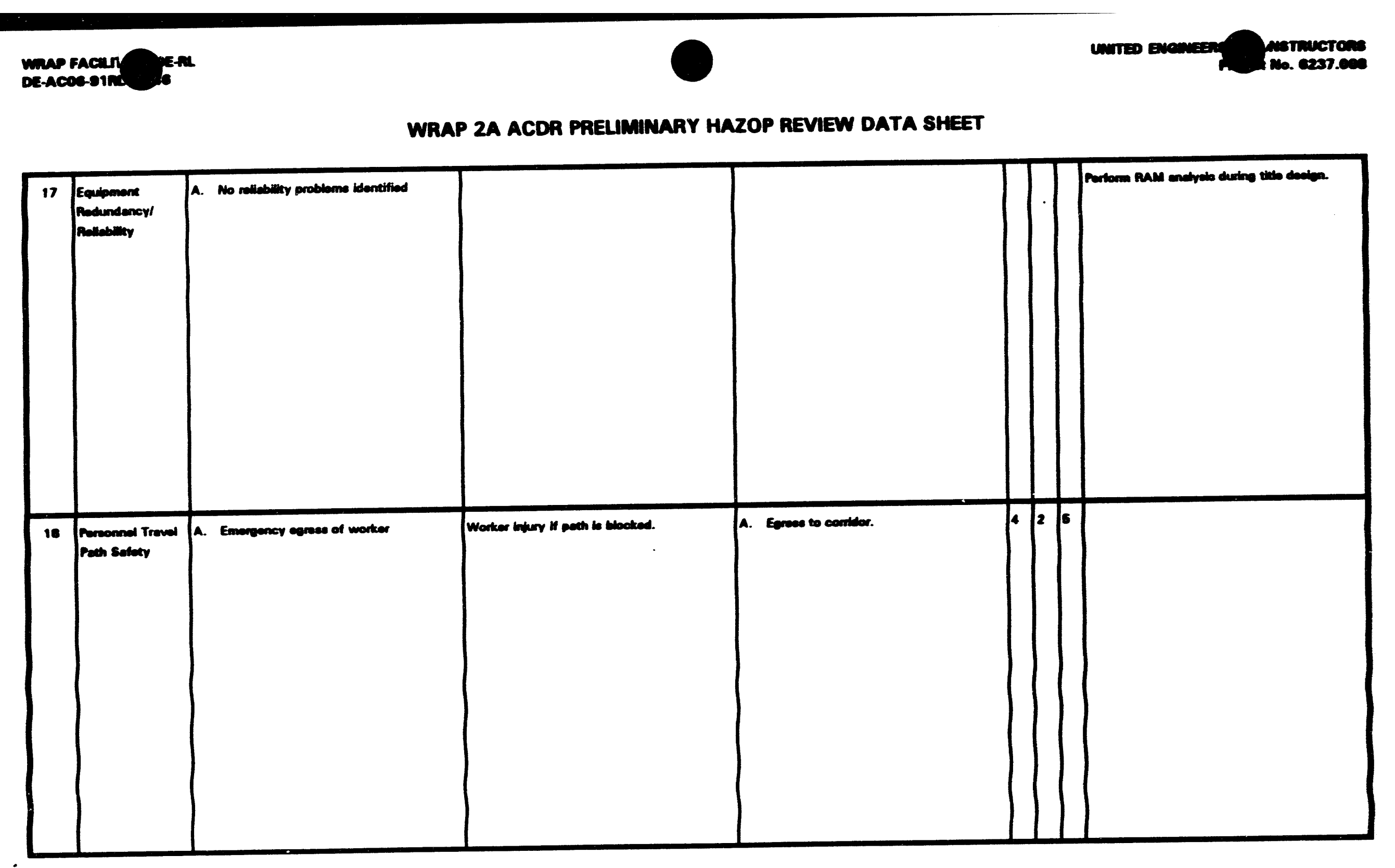

$$
=
$$


WRAP 2A ACDR PRELIMINARY HAZOP REVIEW DATA SHEET

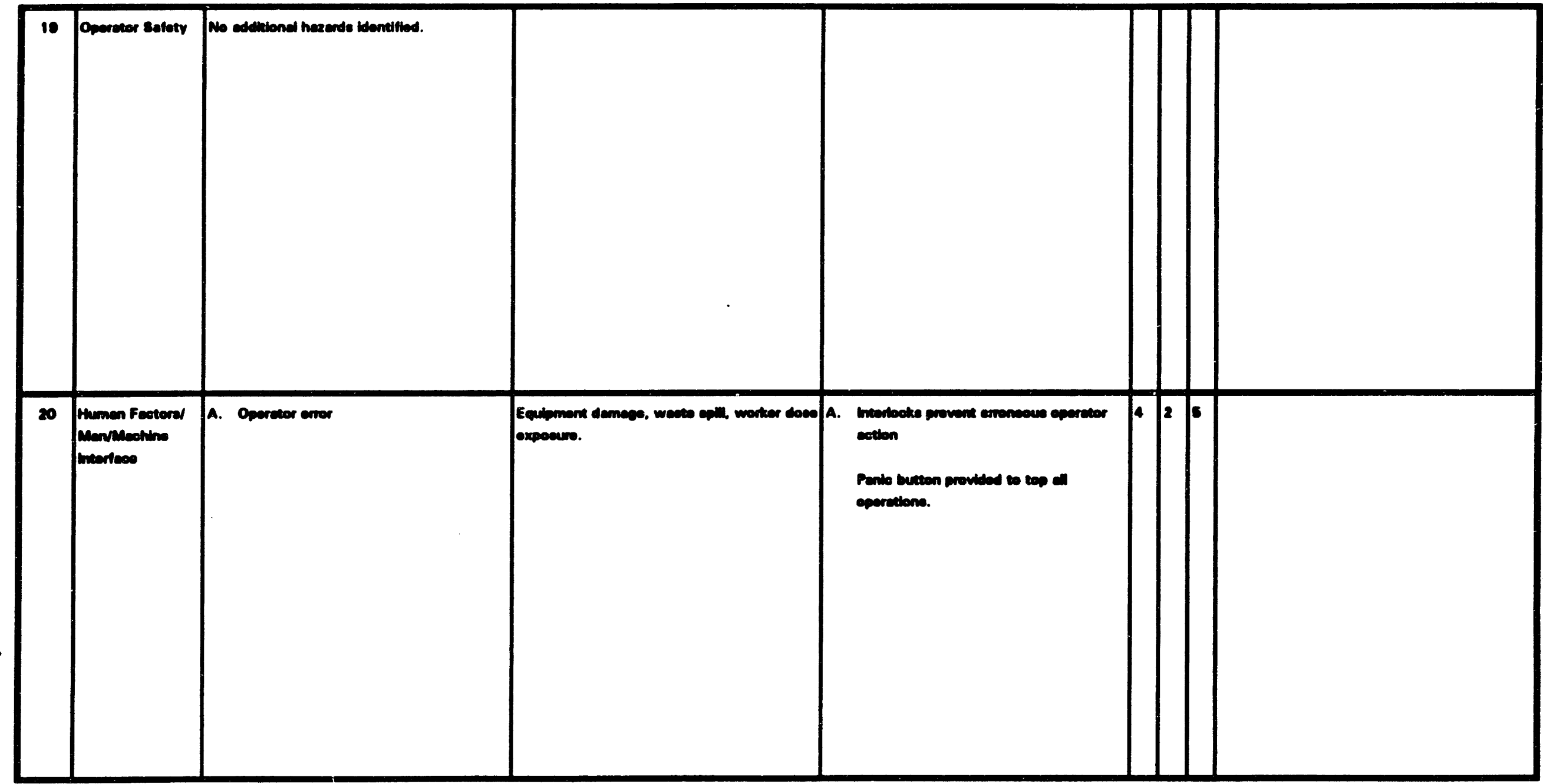


WRAP 2A ACDR PRELIMINARY HAZOP REVIEW DATA SHEET

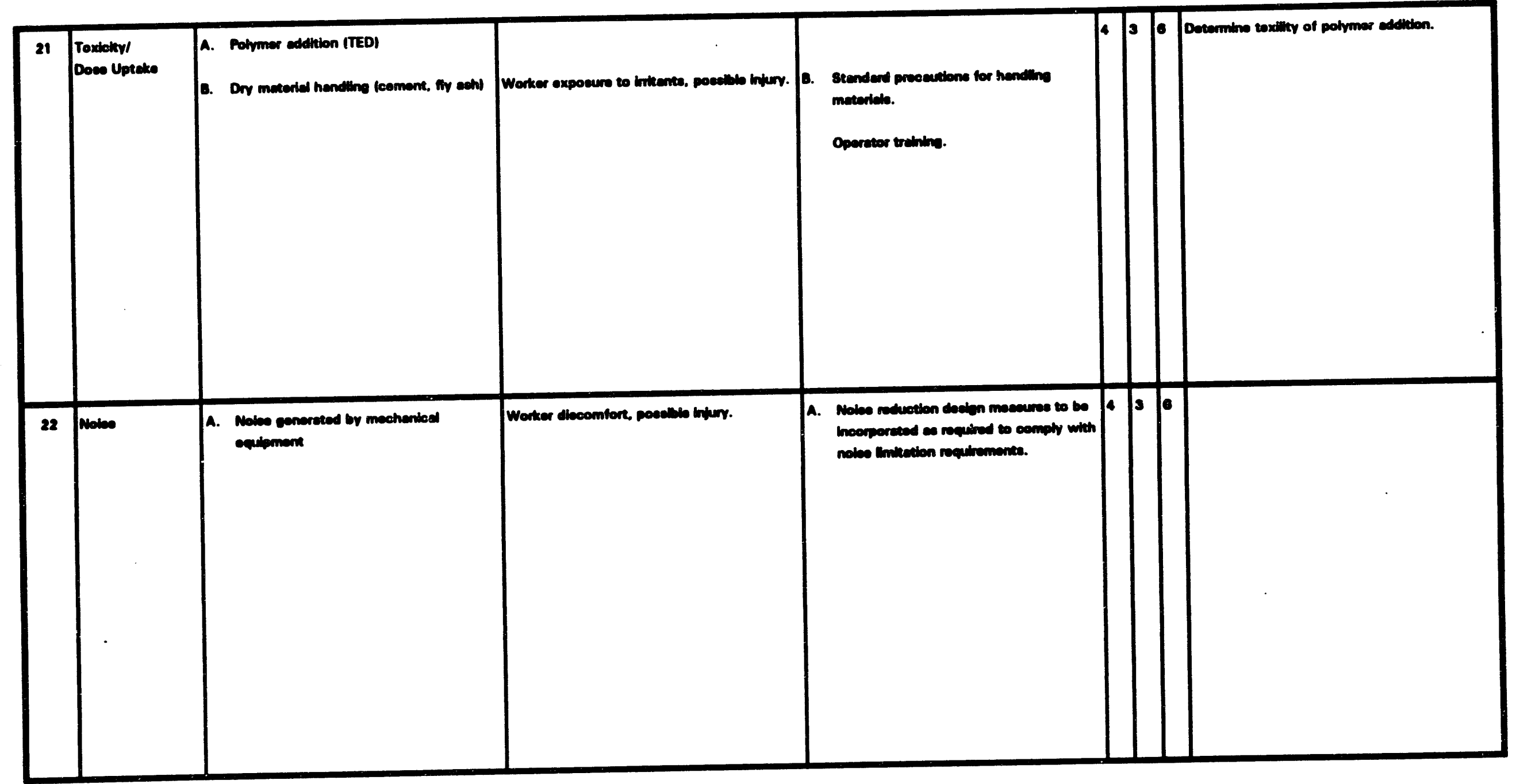




\section{WRAP 2A ACDR PRELIMINARY HAZOP REVIEW DATA SHEET}

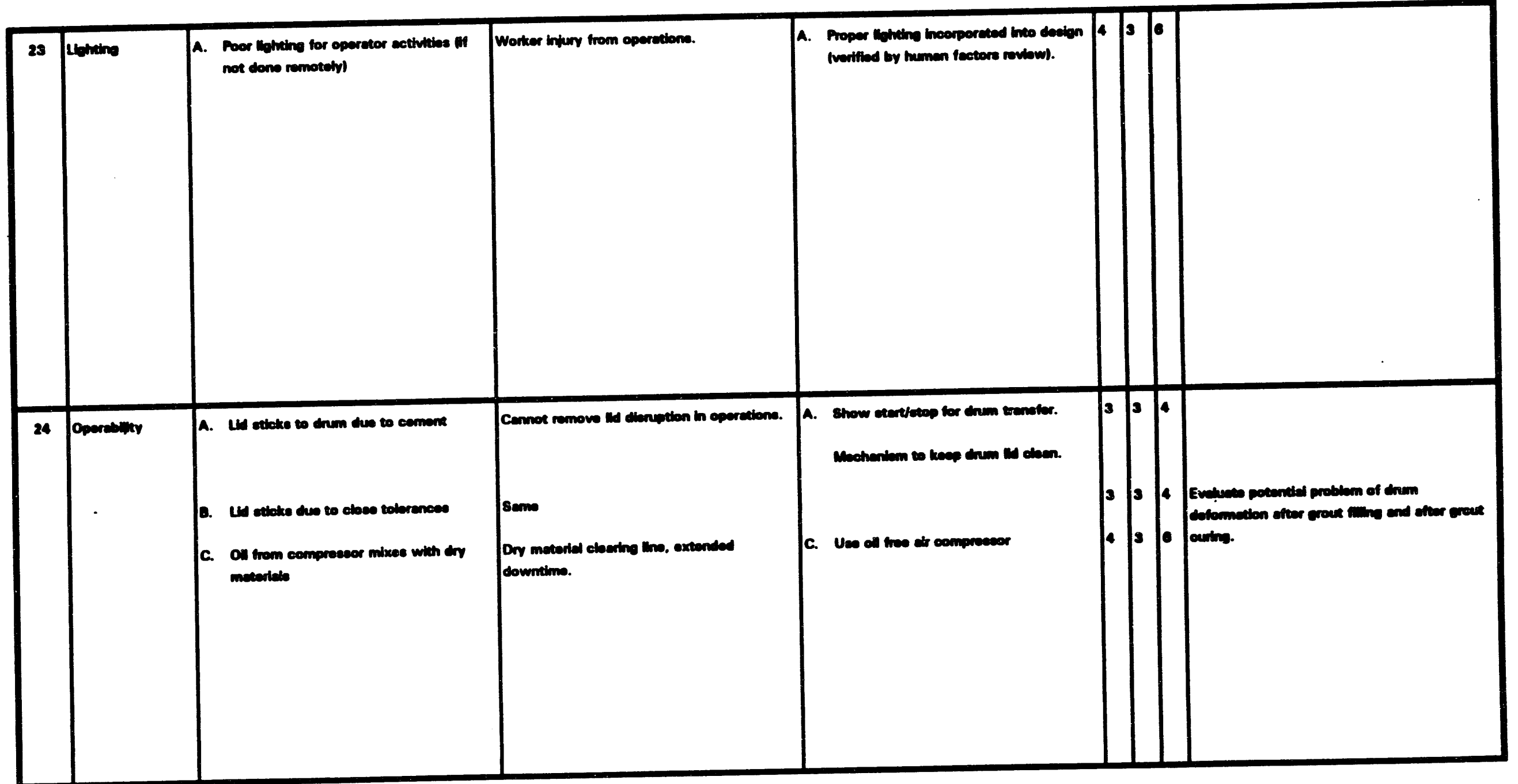




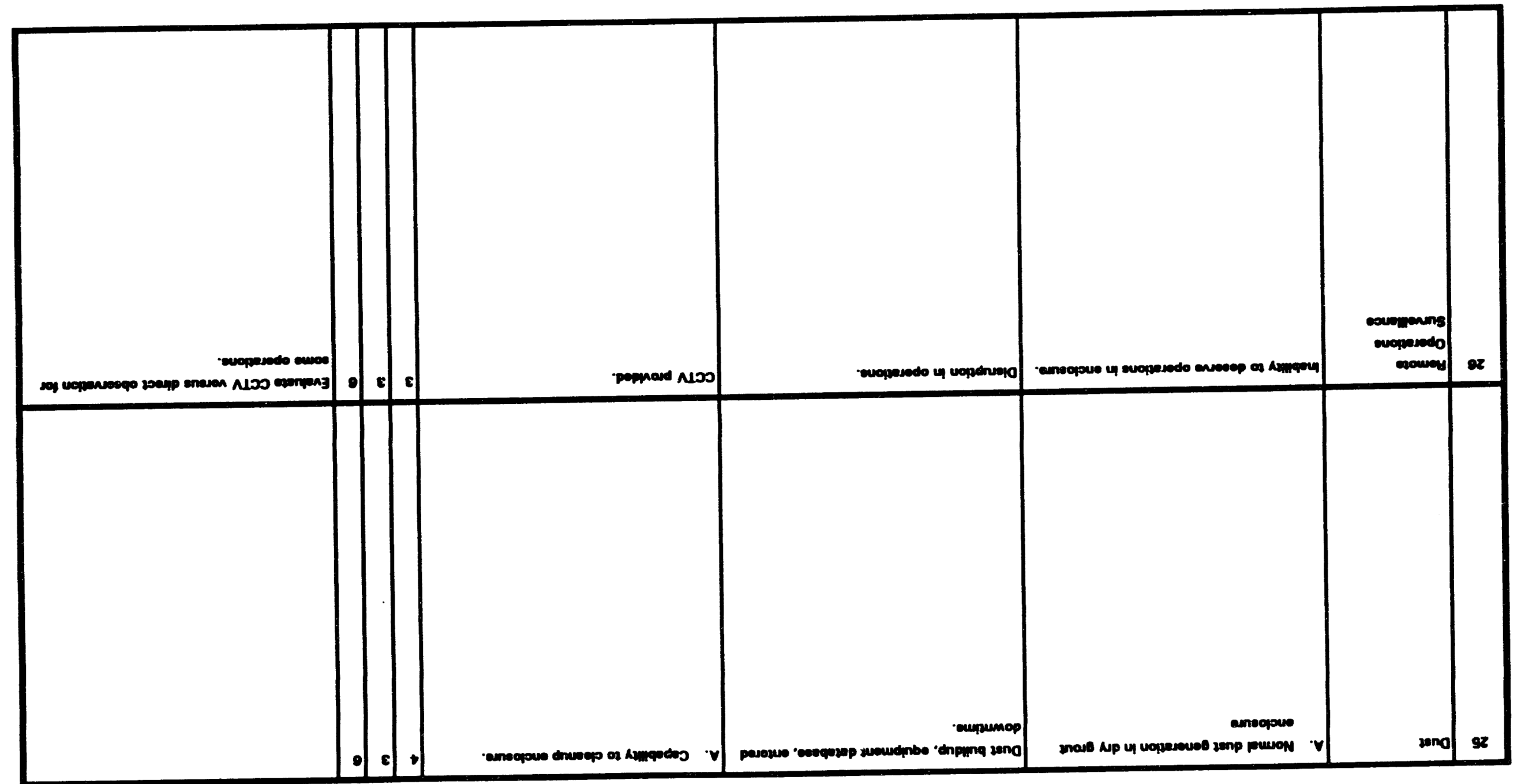

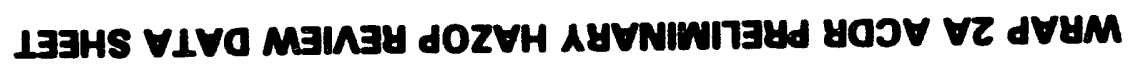

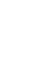

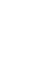


WRAP 2A ACDR PRELIMINARY HAZOP REVEW DATA BHEET

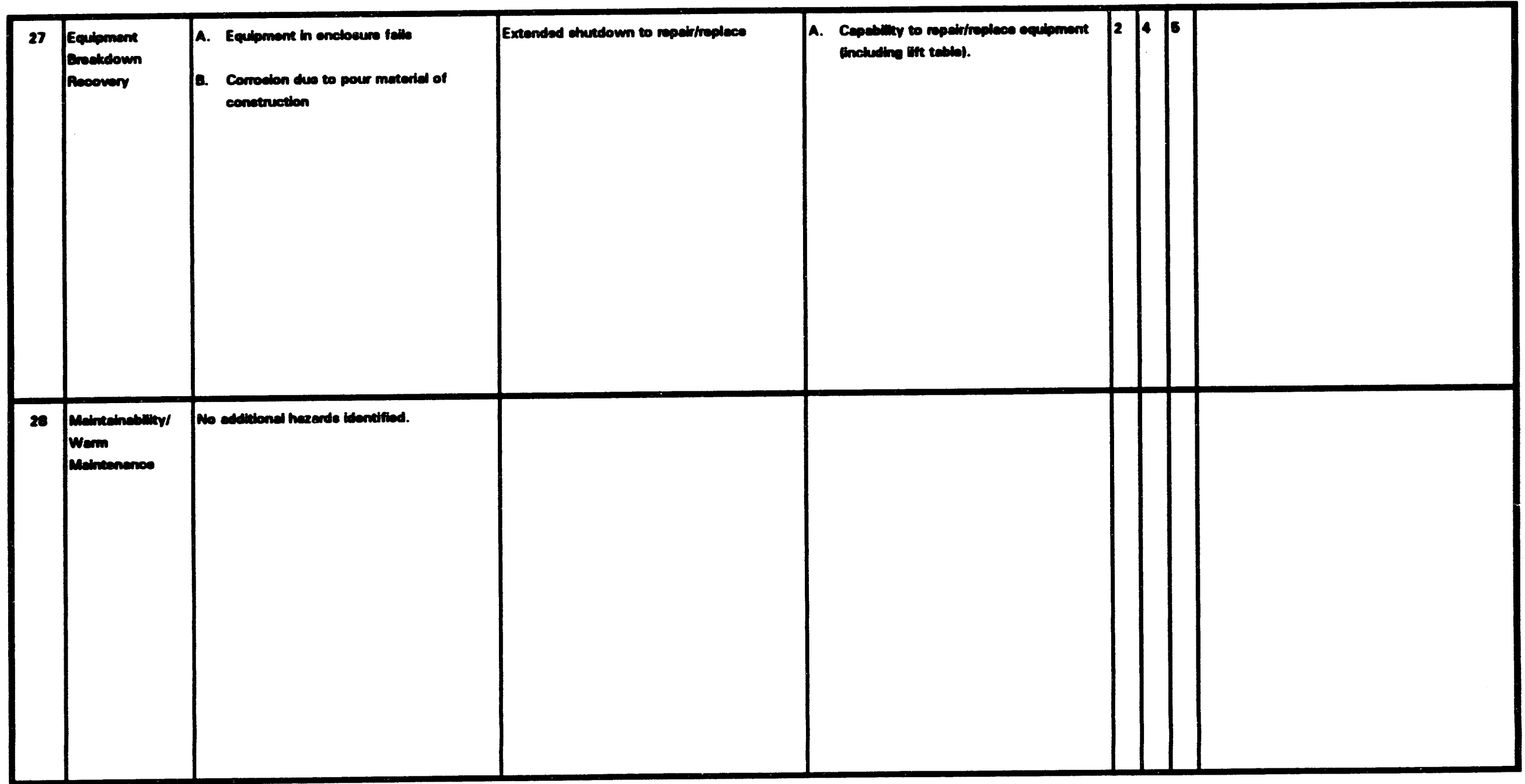


WRAP 2A ACDR PRELIMINARY HAZOP REVIEW DATA SHEET

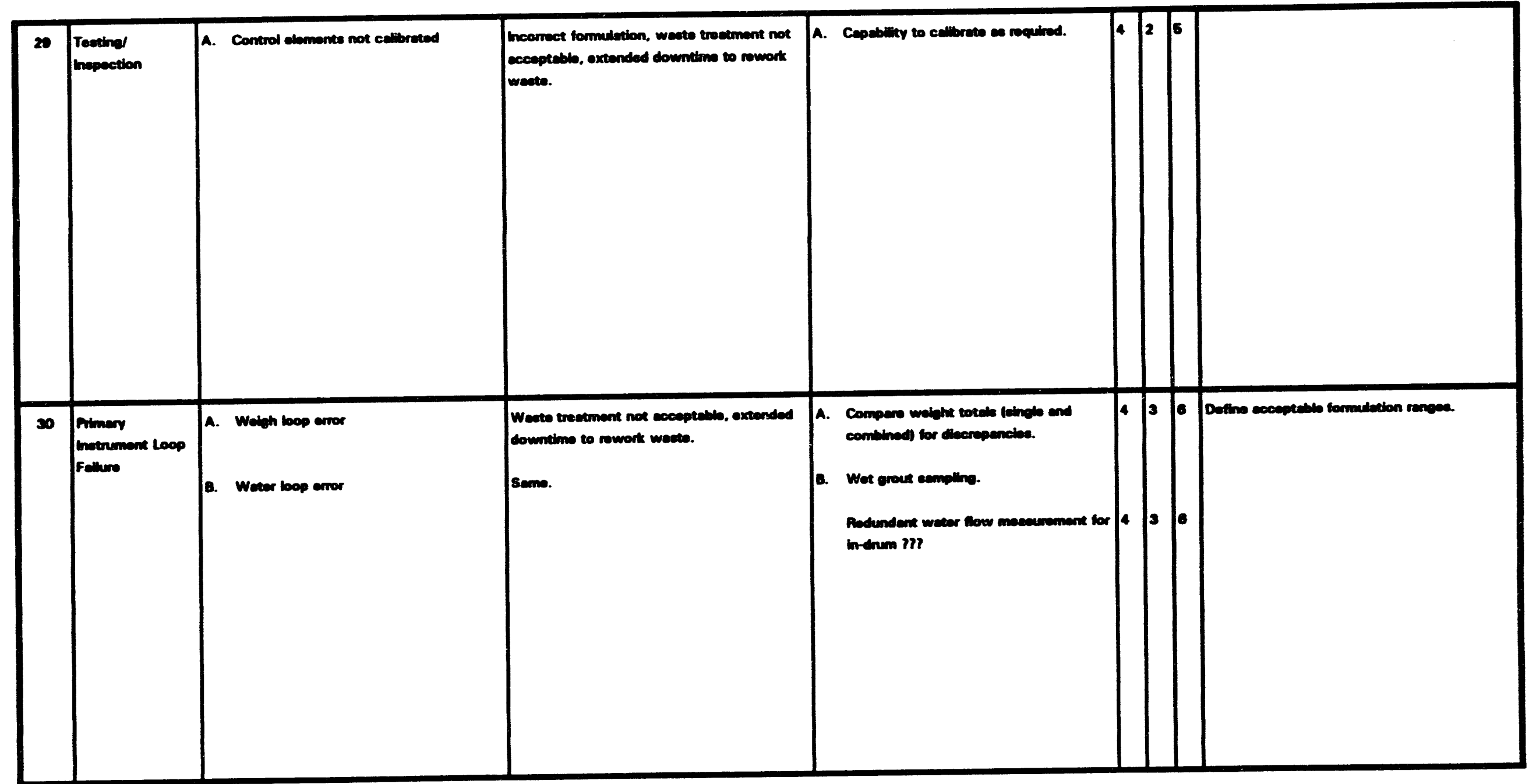


WRAP $2 A$ ACDR PRELIMMMARY HAZOP REVIEW DATA SHEET

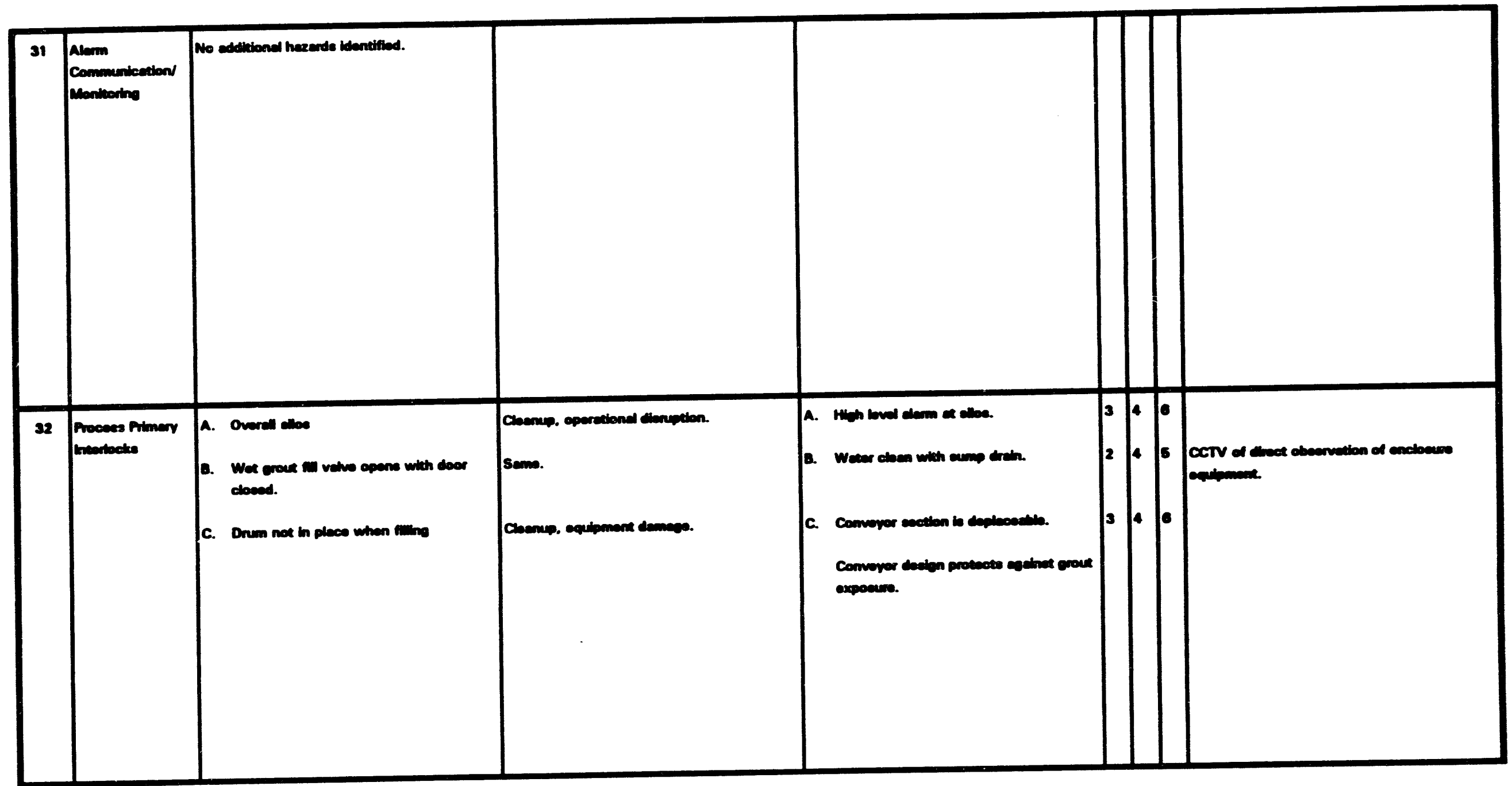


WRAP 2A ACDR PRELIMINARY HAZOP REVIEW DATA SHEET

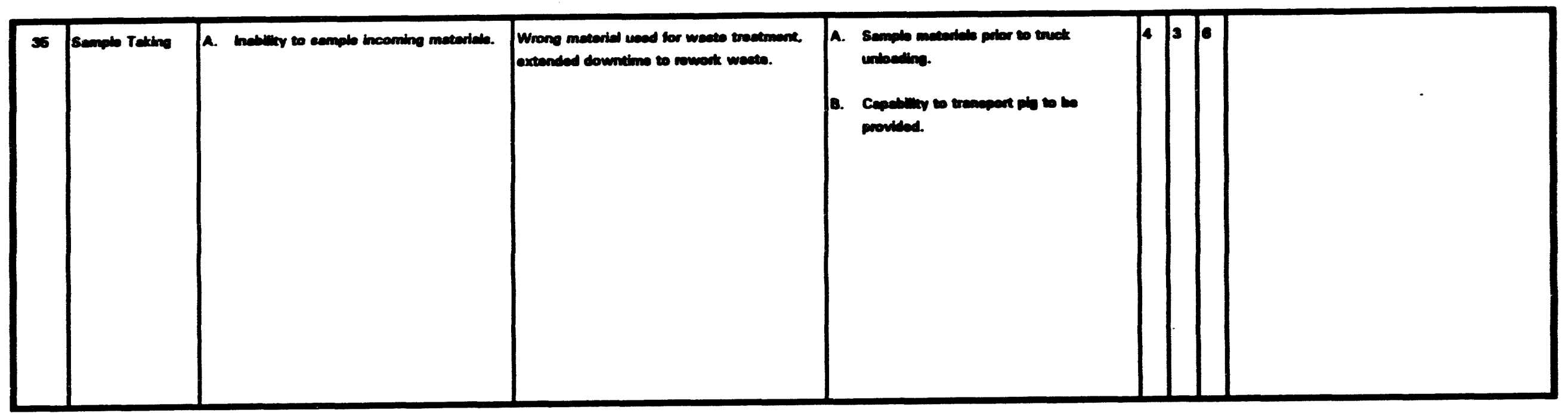




\section{WRAP 2A ACDR PRELUMUAAY HAZOP REVEW DATA SHEET}

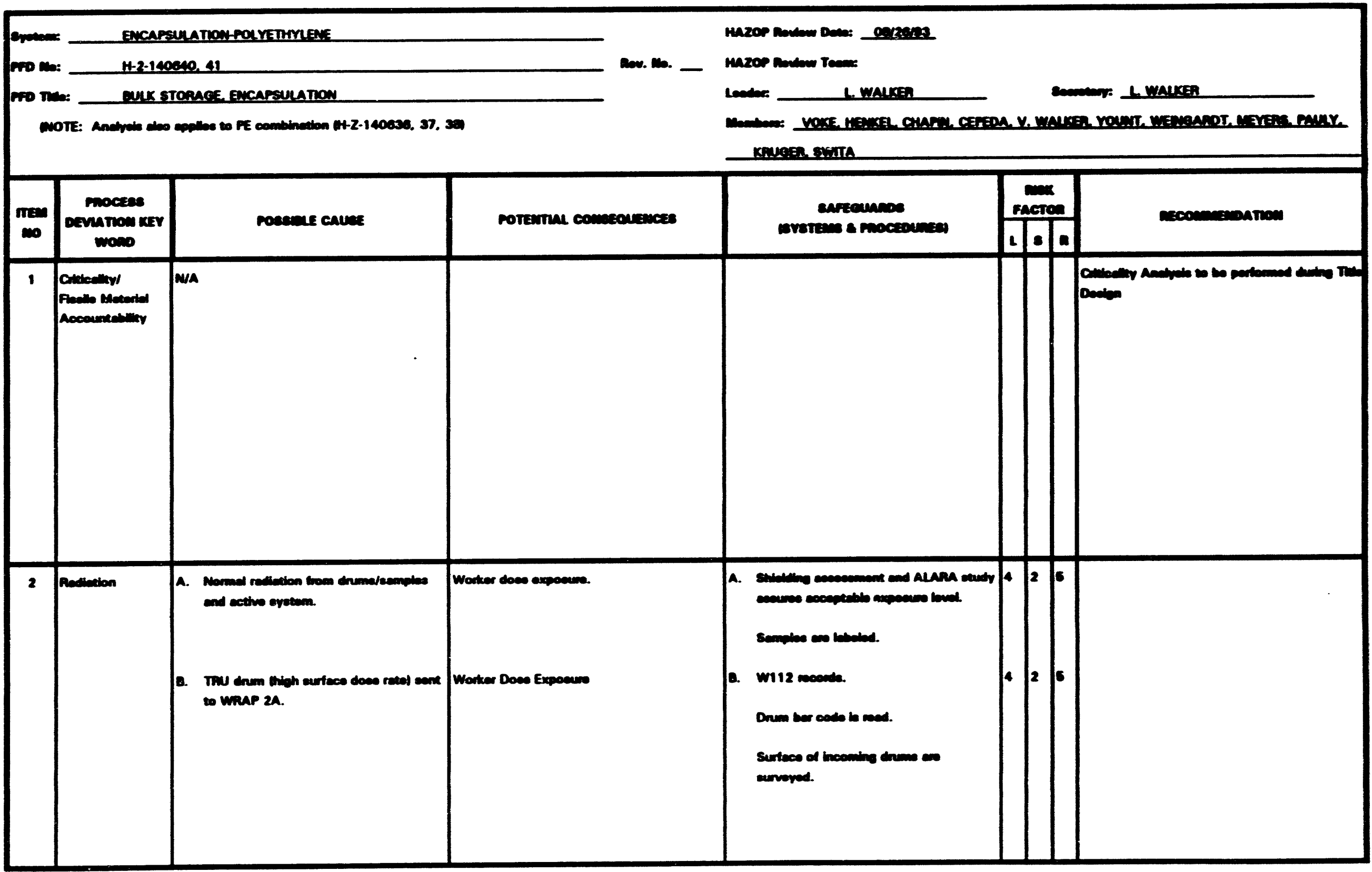


WRAP 2A ACDR PRELMUMARY HAZOP REVIEW DATA SHEET

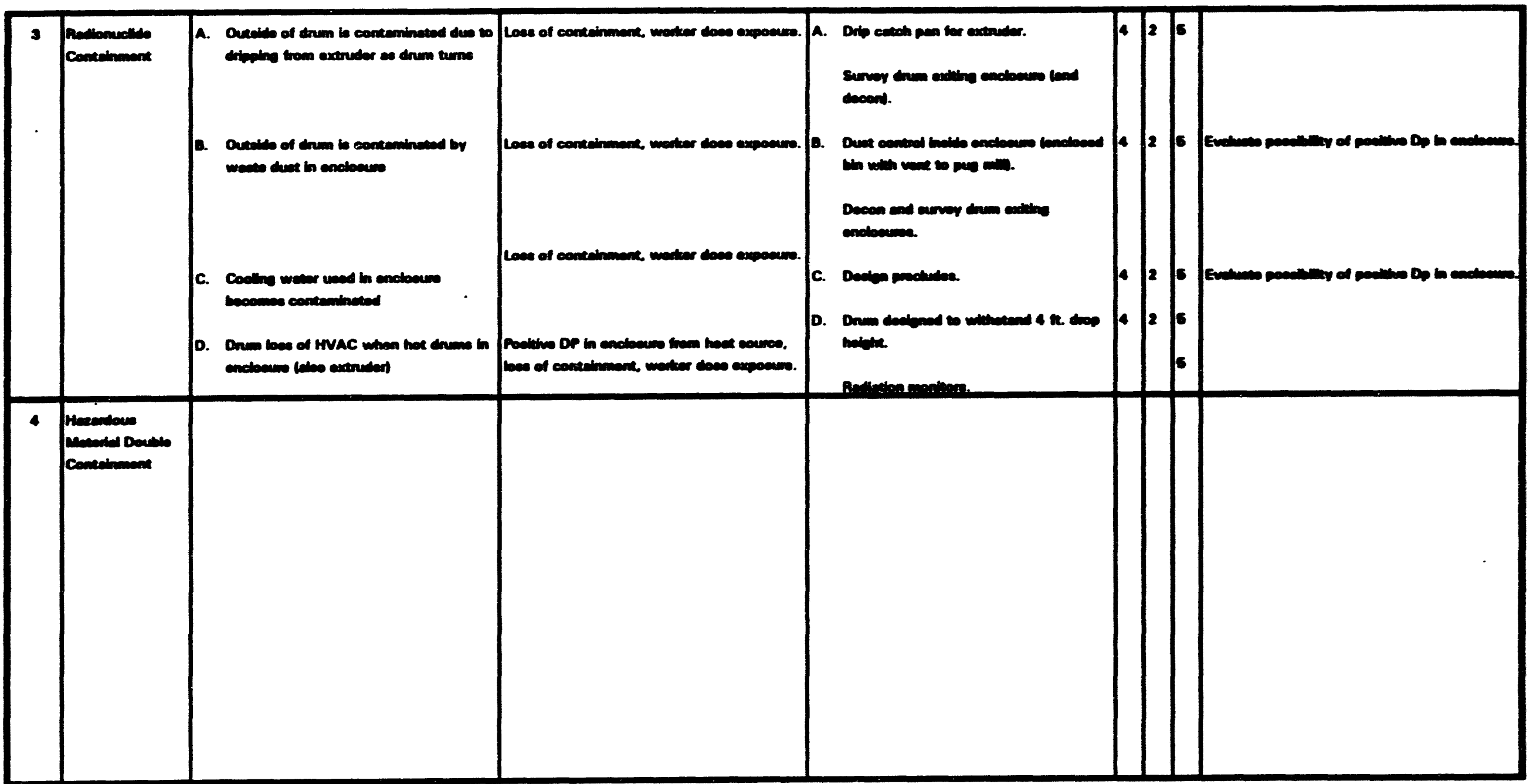


WRAP 2A ACDR PRELMMMARY HAZOP REVIG DATA 8HET

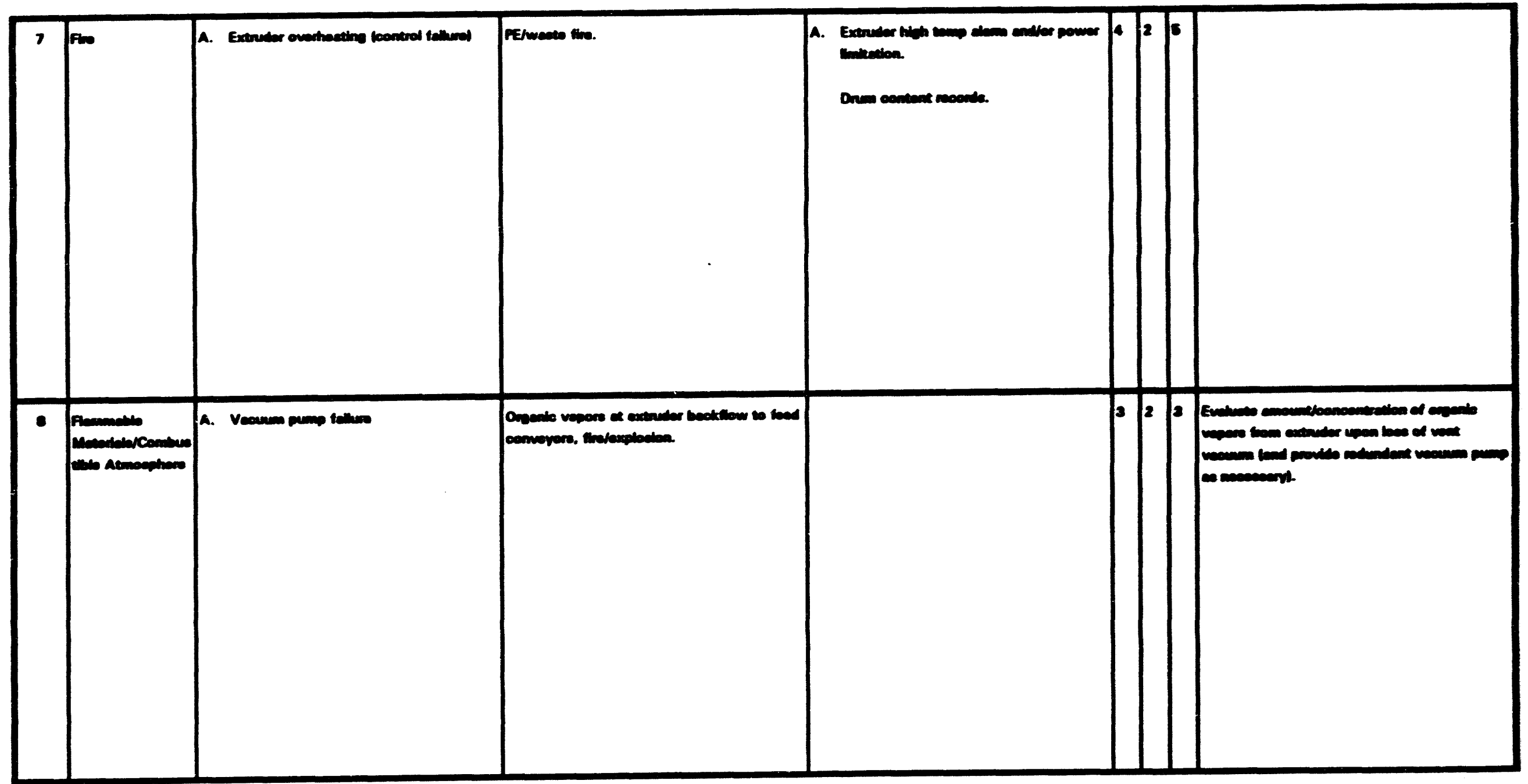



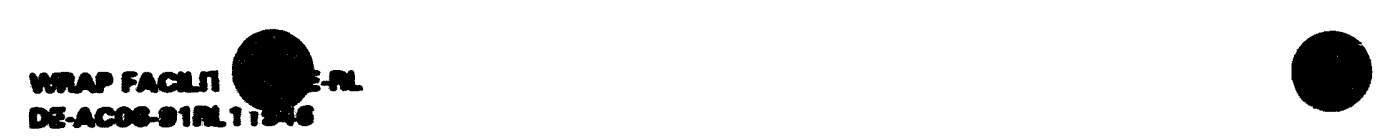

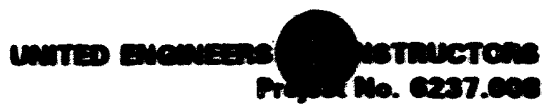

WRAP $2 A$ ACDR PRELMMMARY HAZOP REVIEW DATA SHEET

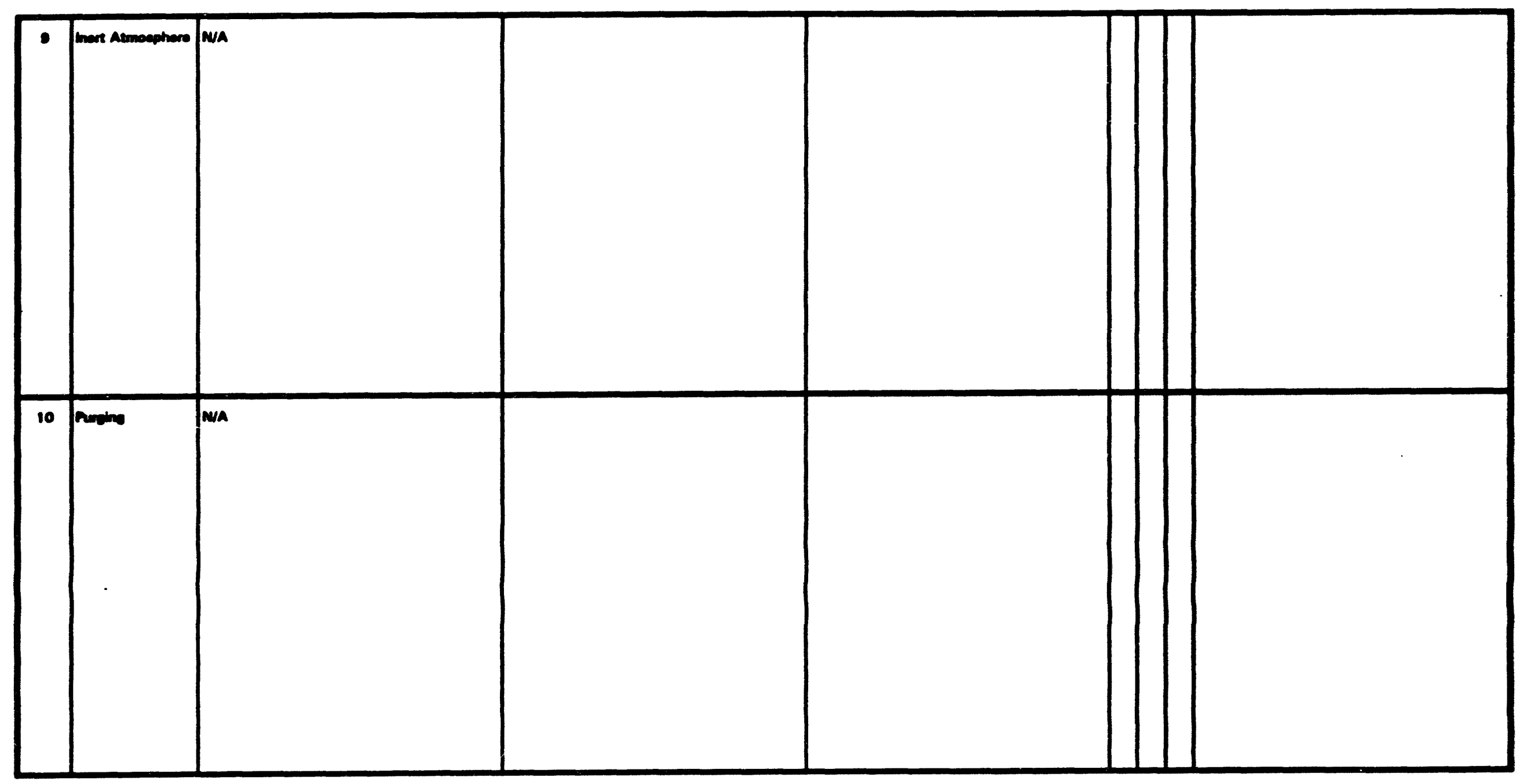


WRAP 2A ACDR PRELIMINARY HAZOP REVEW DATA 8HEET

\begin{tabular}{|c|c|c|c|c|c|c|}
\hline 11 & $\begin{array}{l}\text { Prophorte } \\
\text { moctertal }\end{array}$ & N/A & & & & \\
\hline 12 & steted Chanse & 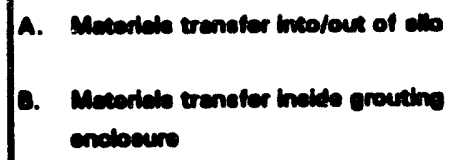 & 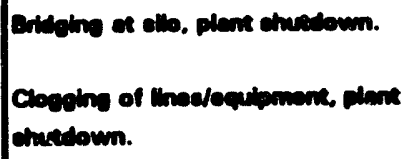 & 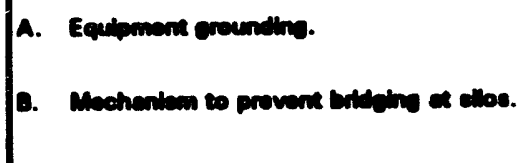 & $3 \mid 4$ & 6 \\
\hline
\end{tabular}




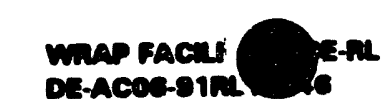

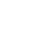

WRAP 2A ACDR PRELIMINARY HAZOP REVIEW DATA SHEET

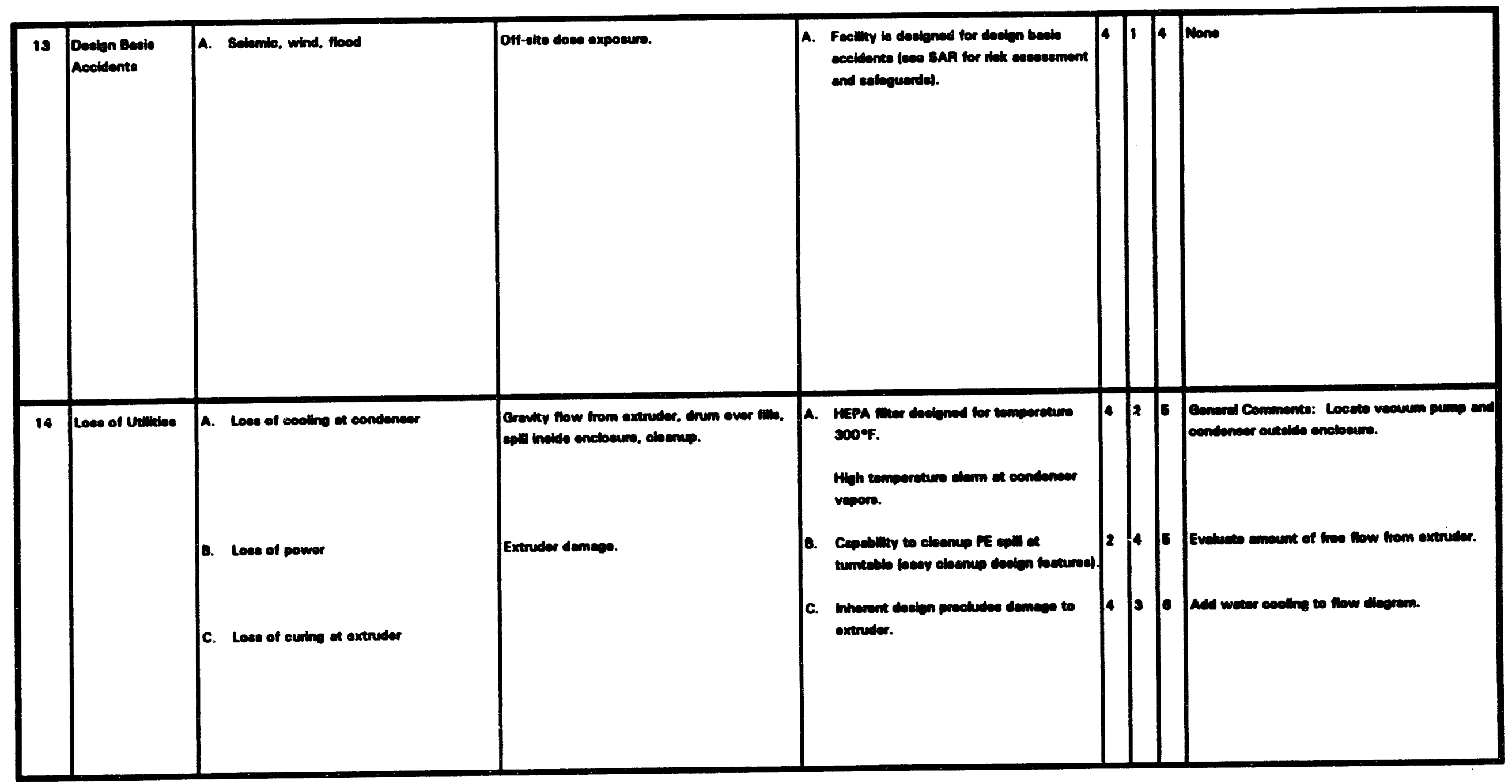


WRAP 2A ACDR PRELIMUNARY HAZOP REVEW DATA 8HEET

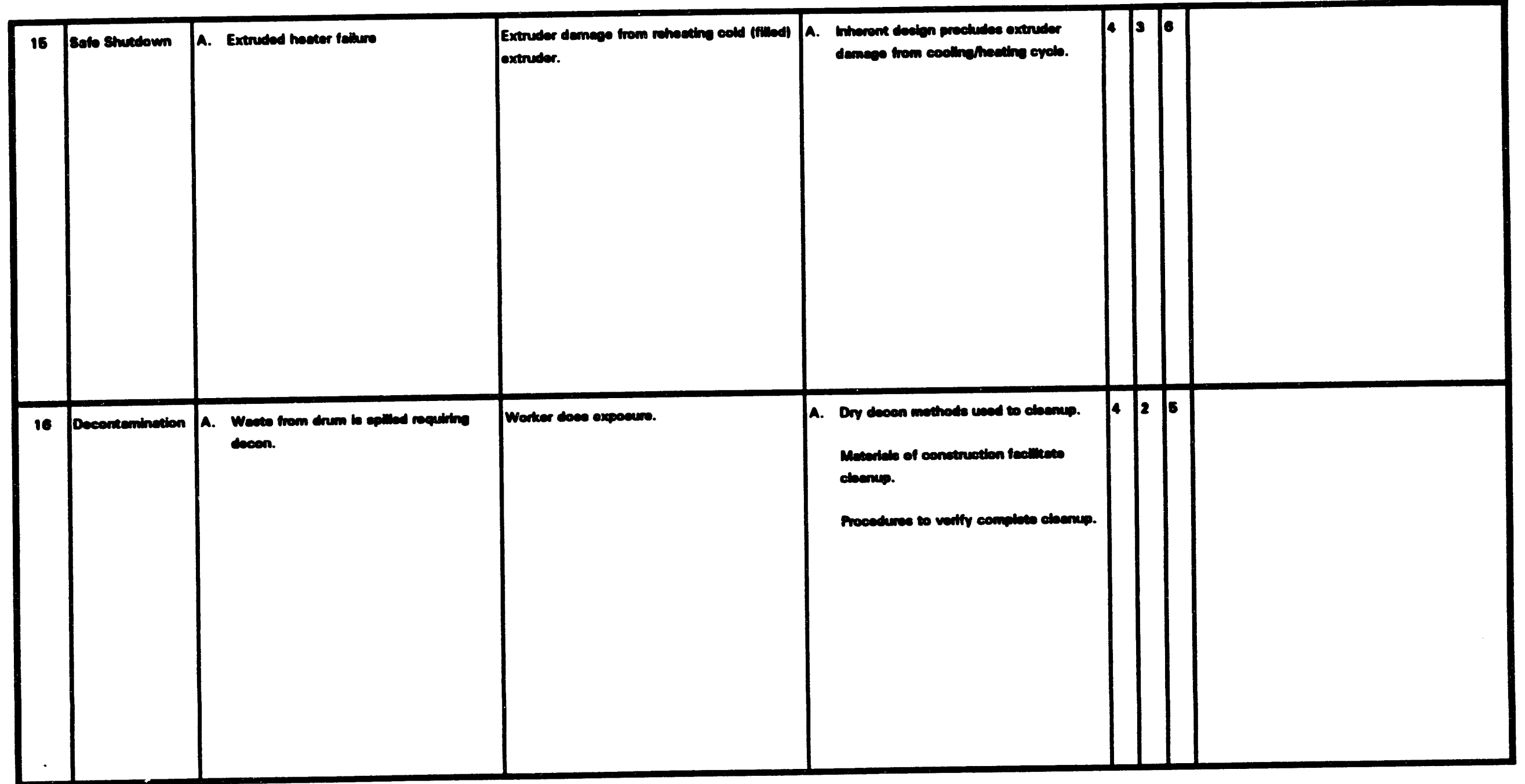


88
8
8
8
5
5

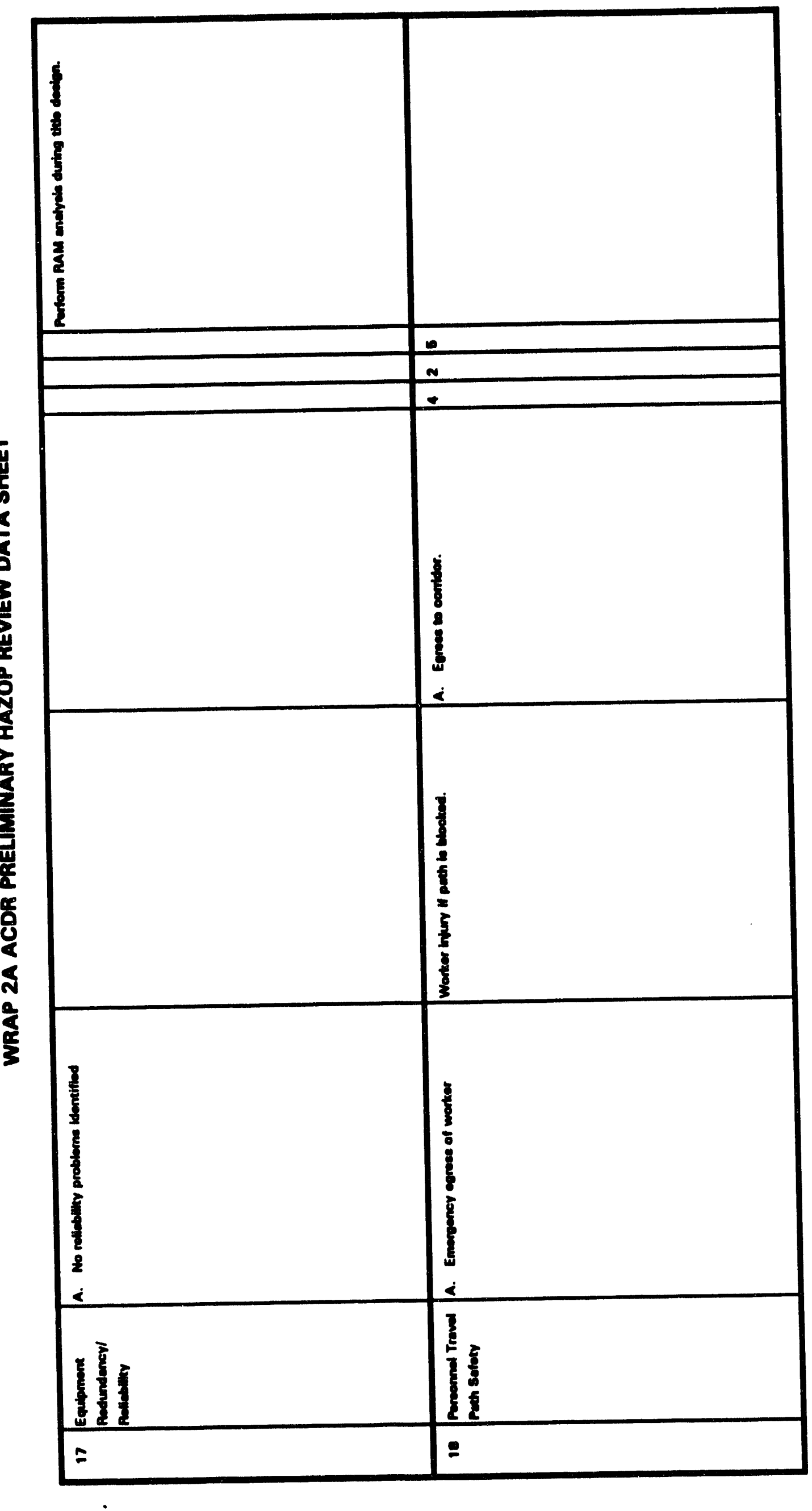


WRAP 2A ACDR PRELIMINARY HAZOP REVIEW DATA SHEET

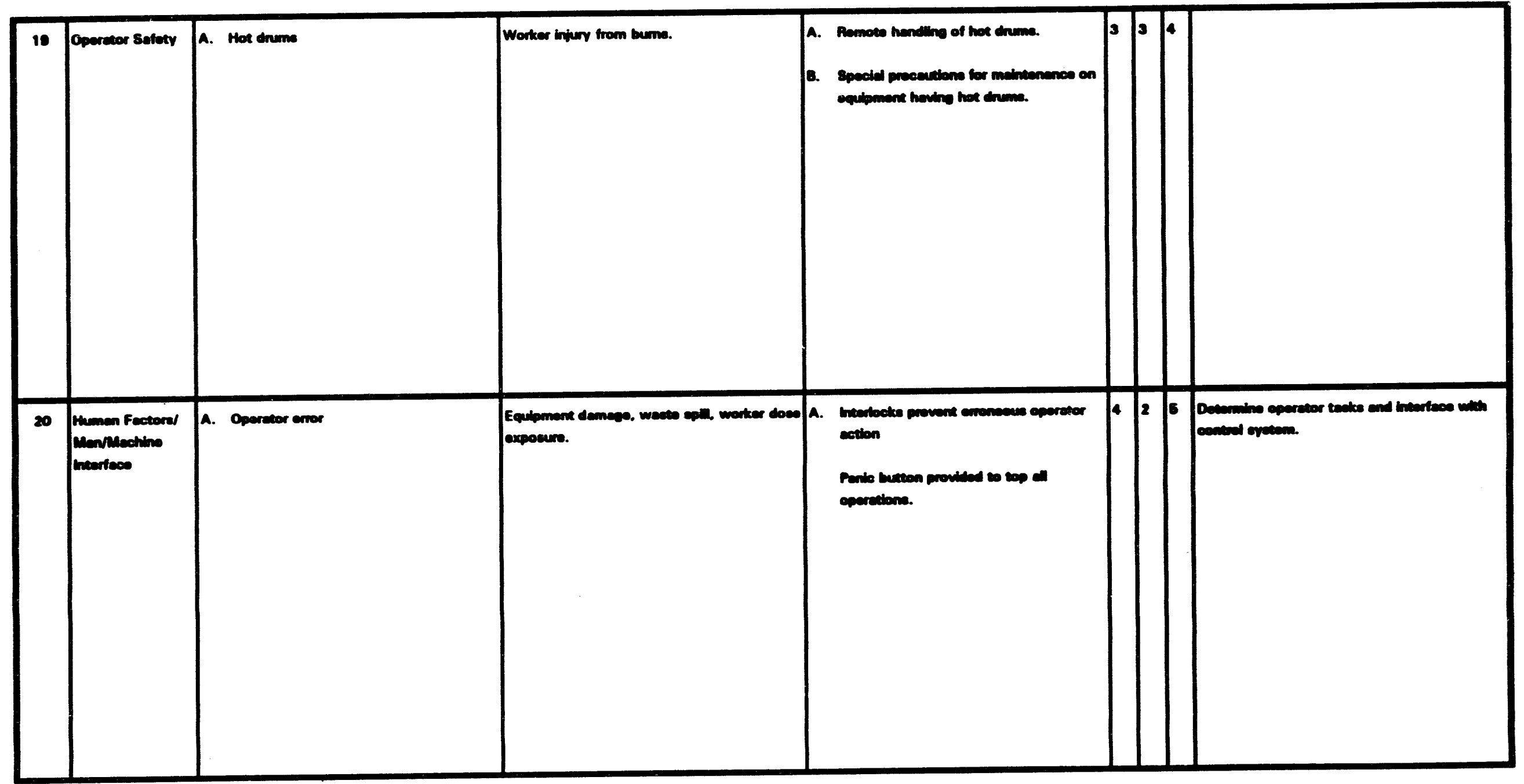


WRAP 2A ACDR PRELIMINARY HAZOP REVIEW DATA SHEET

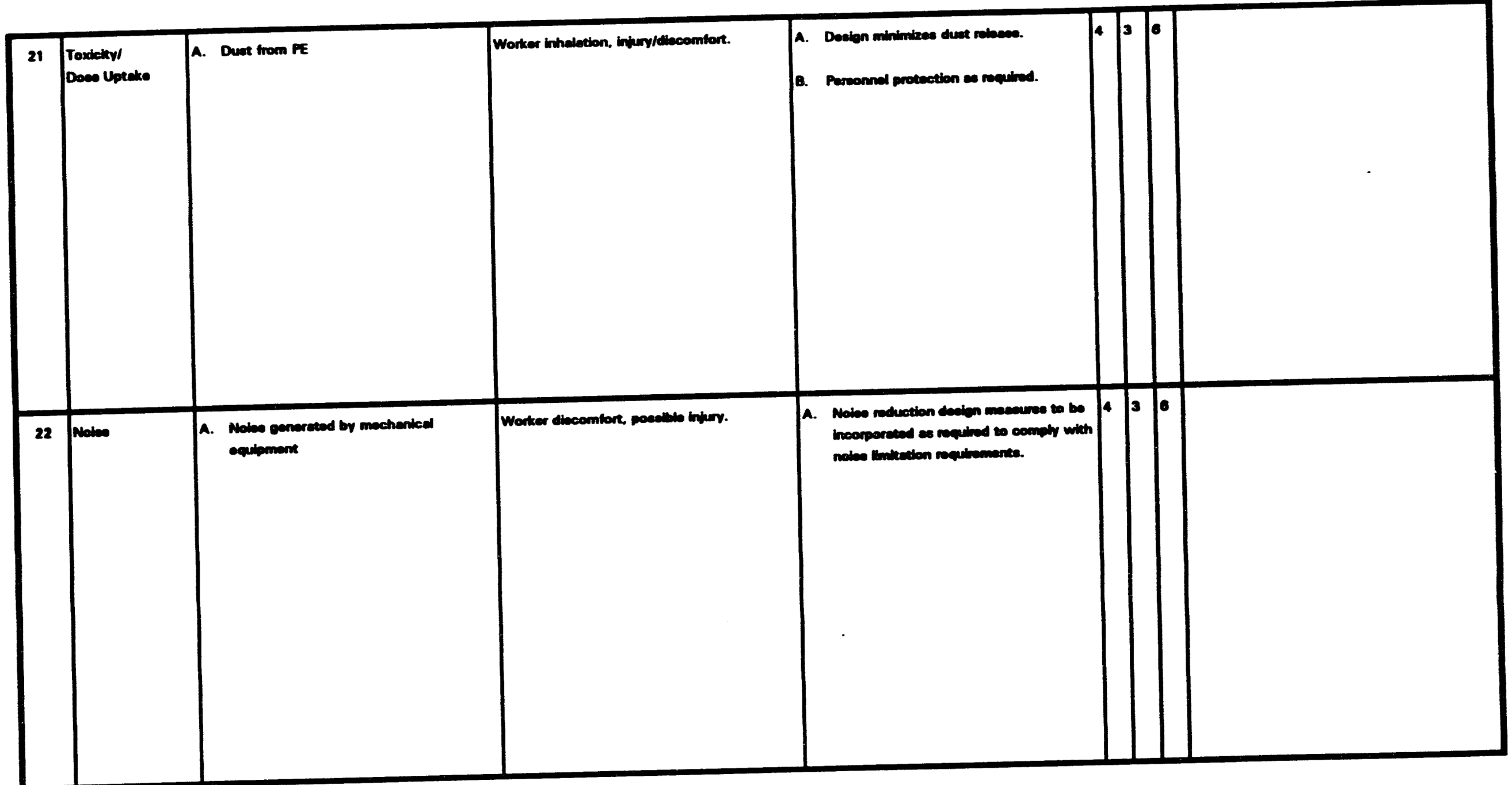




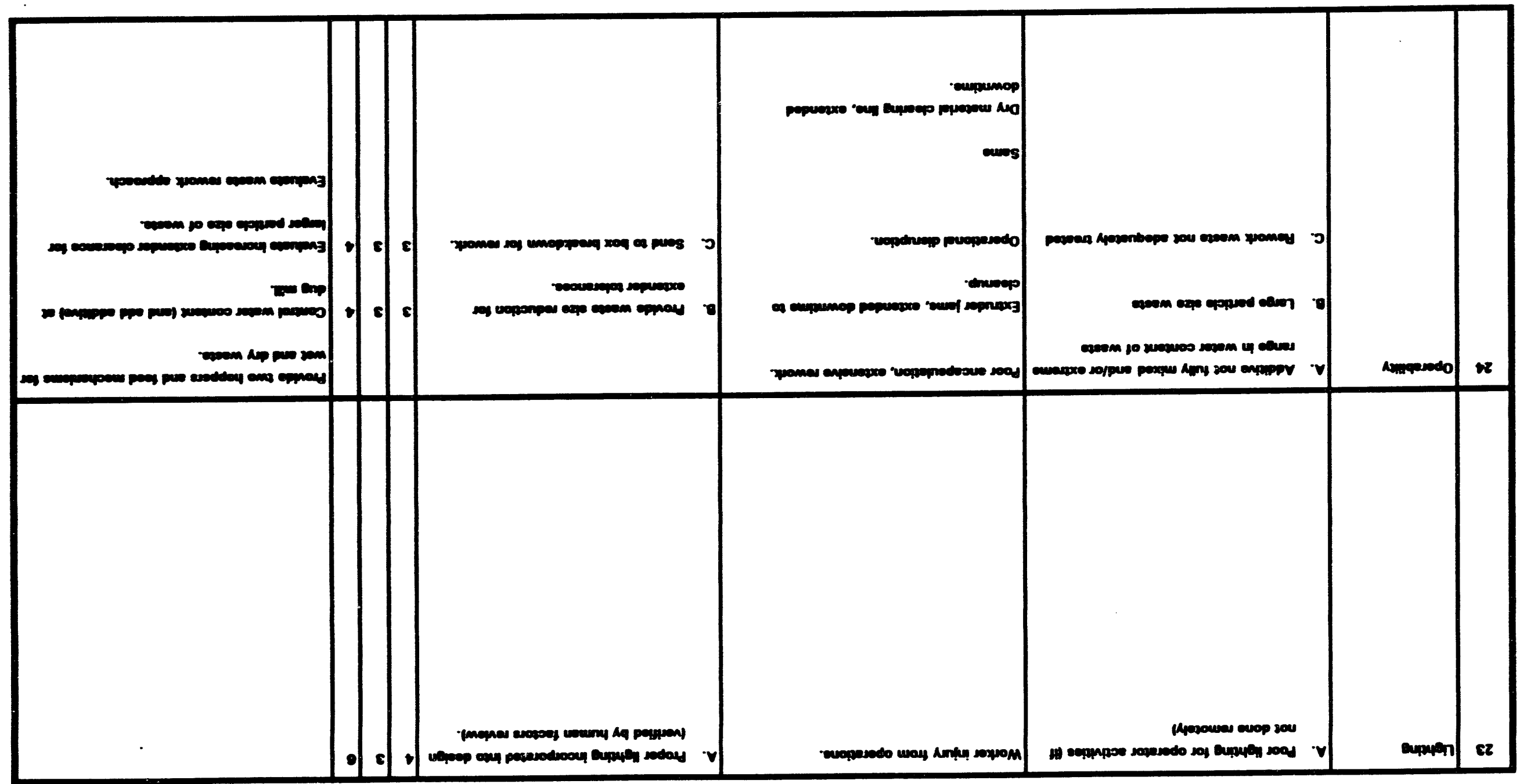

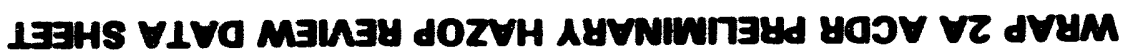


WRAP 2A ACDR PRELUMINARY HAZOP REMEW DATA SHEET

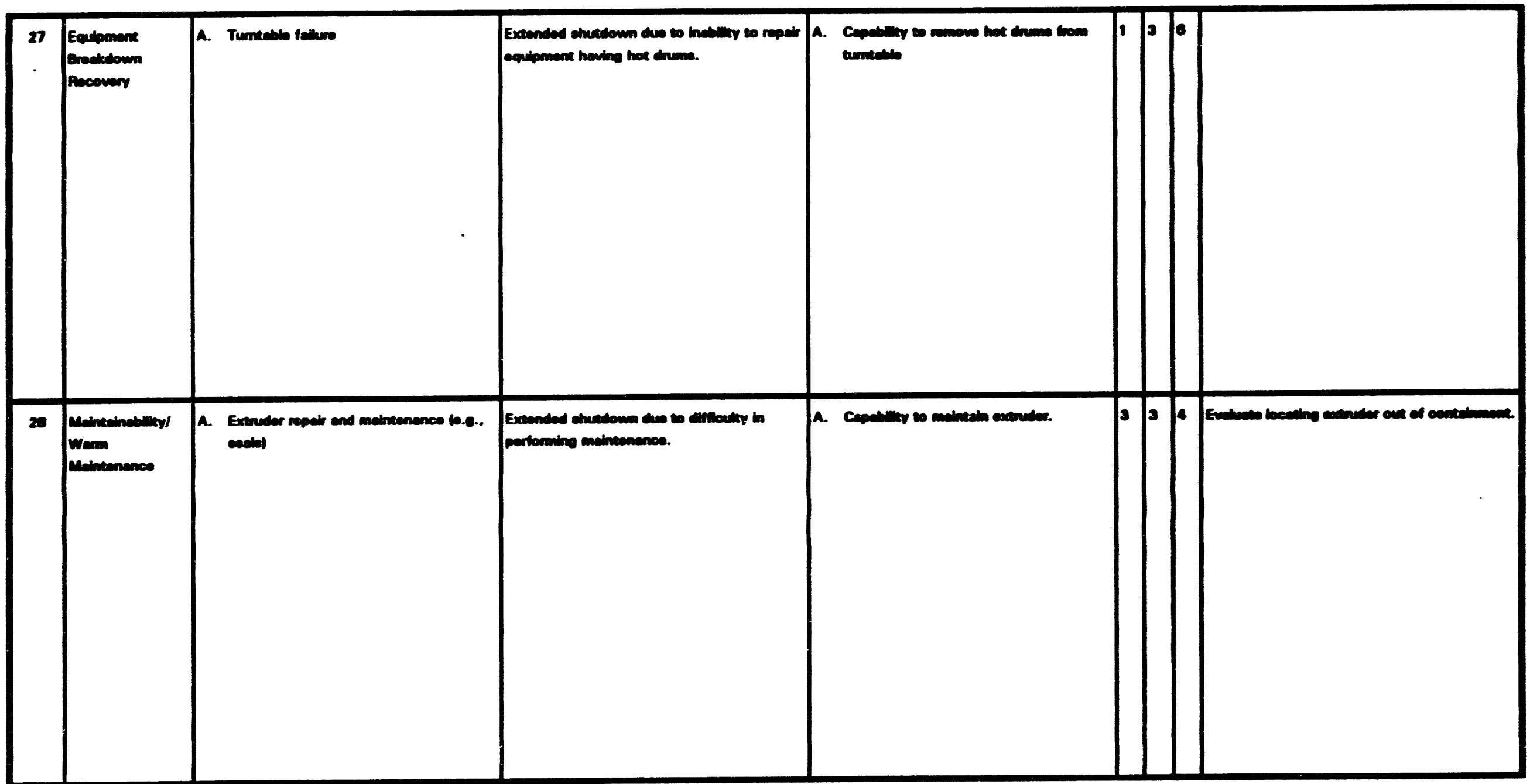


WRAP 2A ACDR PRELMMNARY HAZOP REVEW DATA SHEET

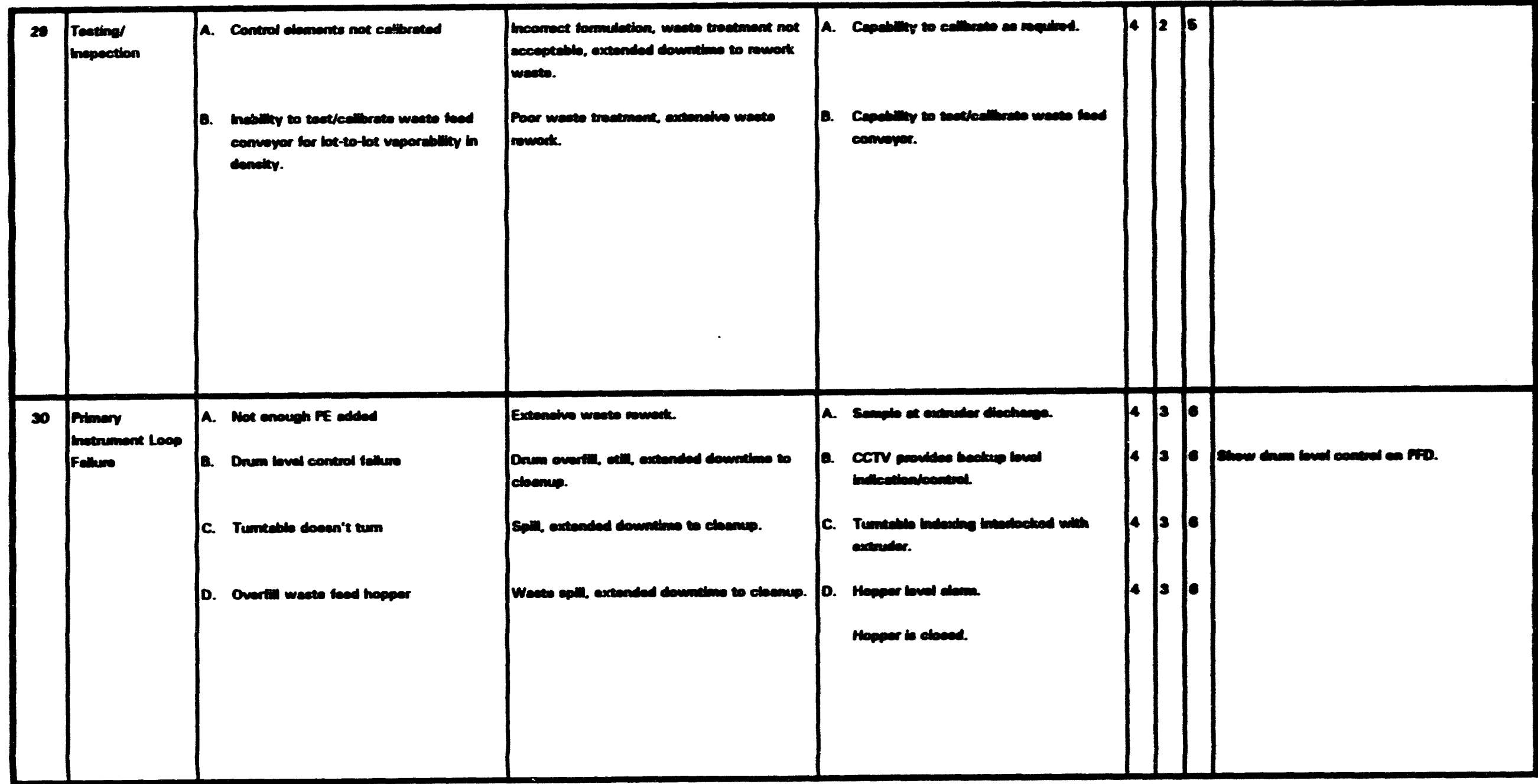




\section{mes racerry. Doten}

De-aceserimitises

WRAP $2 A$ ACDR PRELMMLARY HAZOP REVEW DATA SHETT

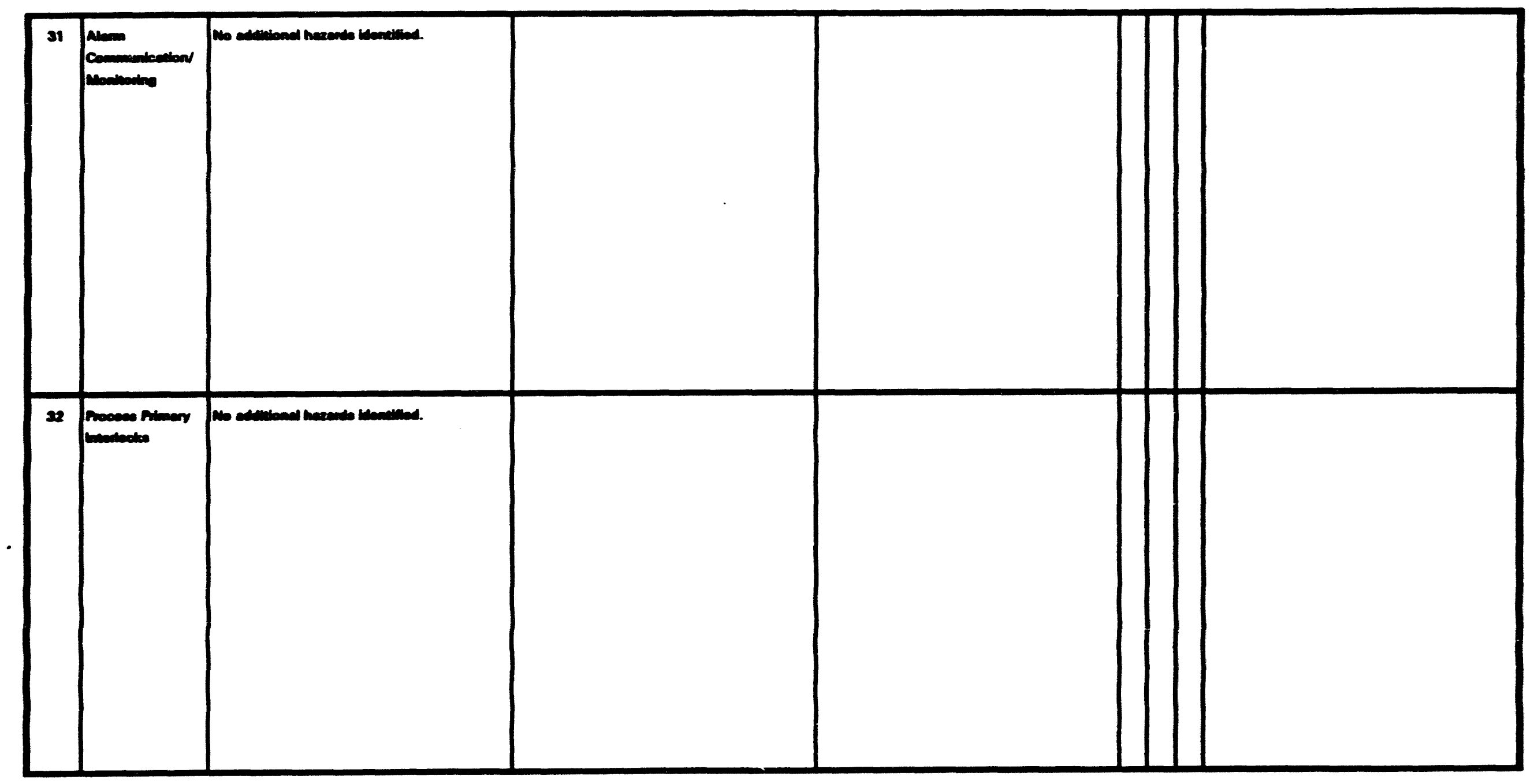




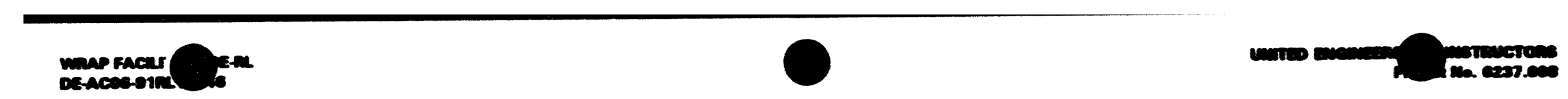

WRAP 2A ACDA PRELAMUAR HAZOP REMEW DATA SHEET

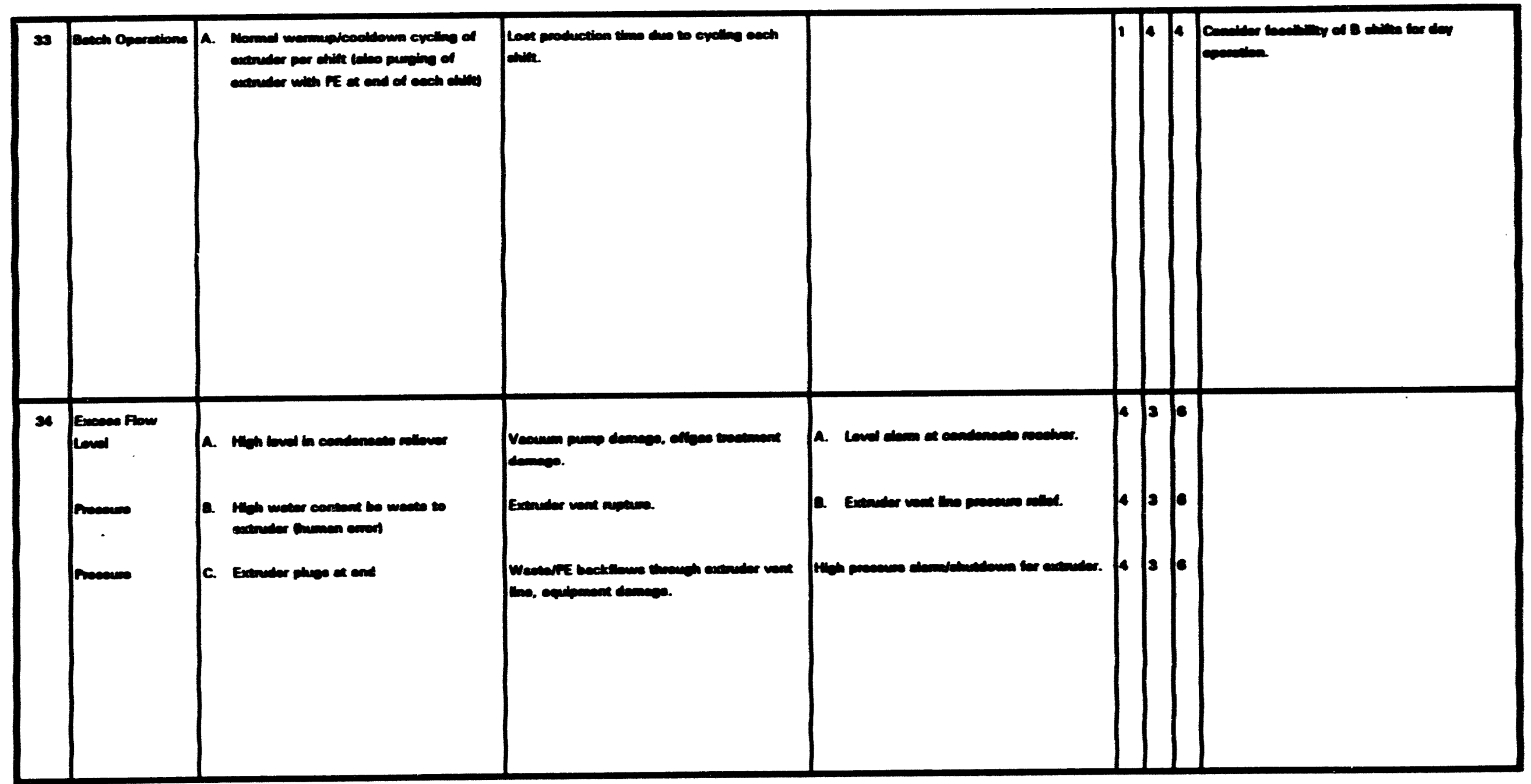




\section{WRAP $2 A$ ACDR PRELUMULARY HAZOP REVIEW DATA EHEET}

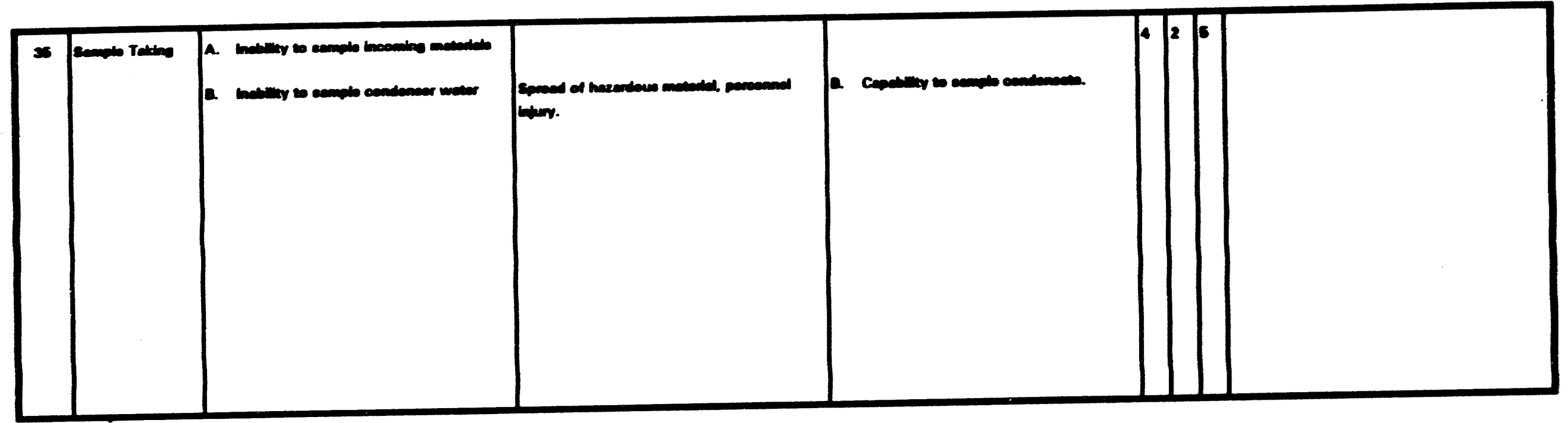


WRAP 2A ACDA PRELUMMARY HAZOP REMEW DATA SHEET

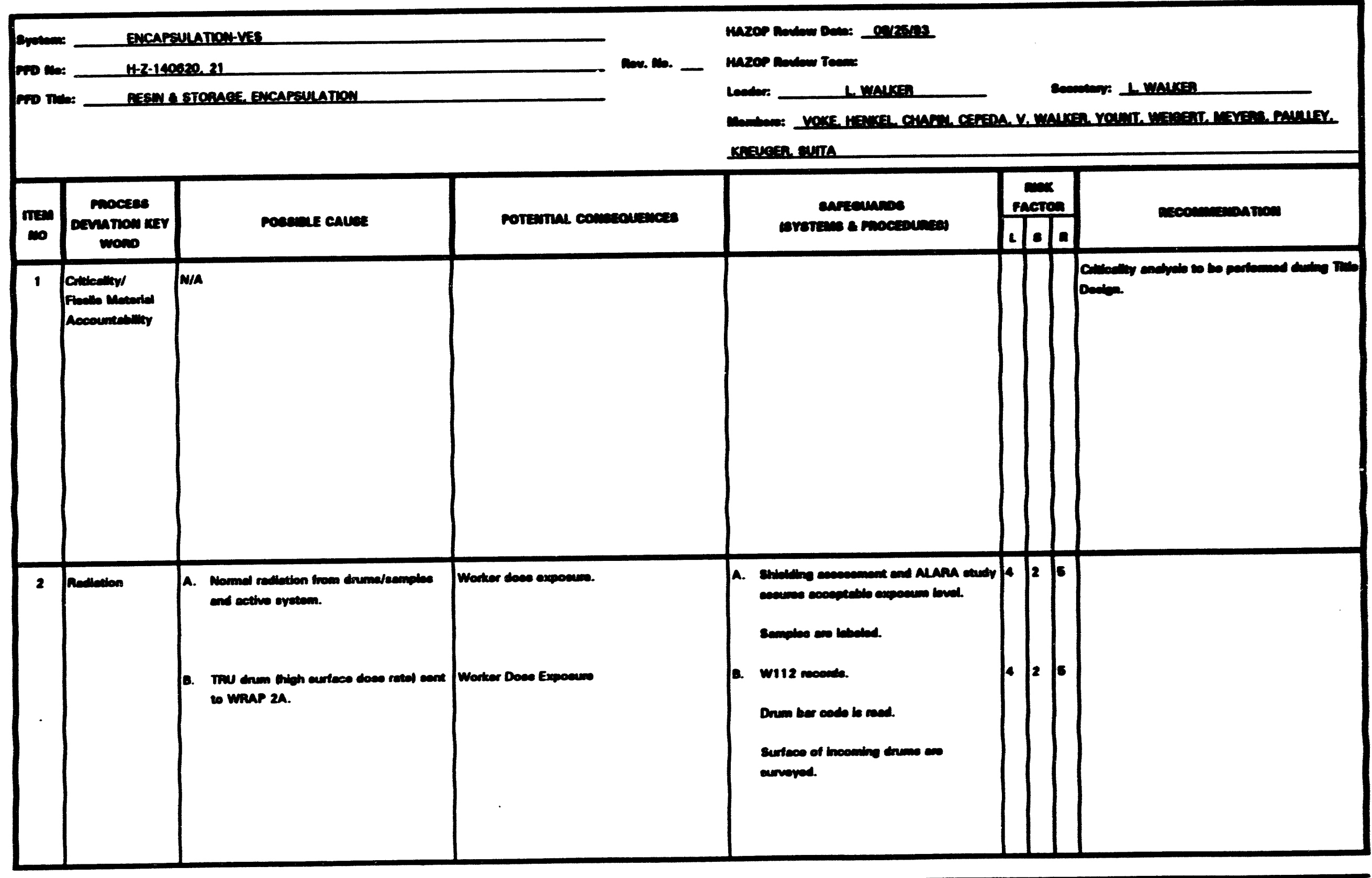


WRAP 2A ACDR PRELIMINARY HAZOP REVIEW DATA SHEET

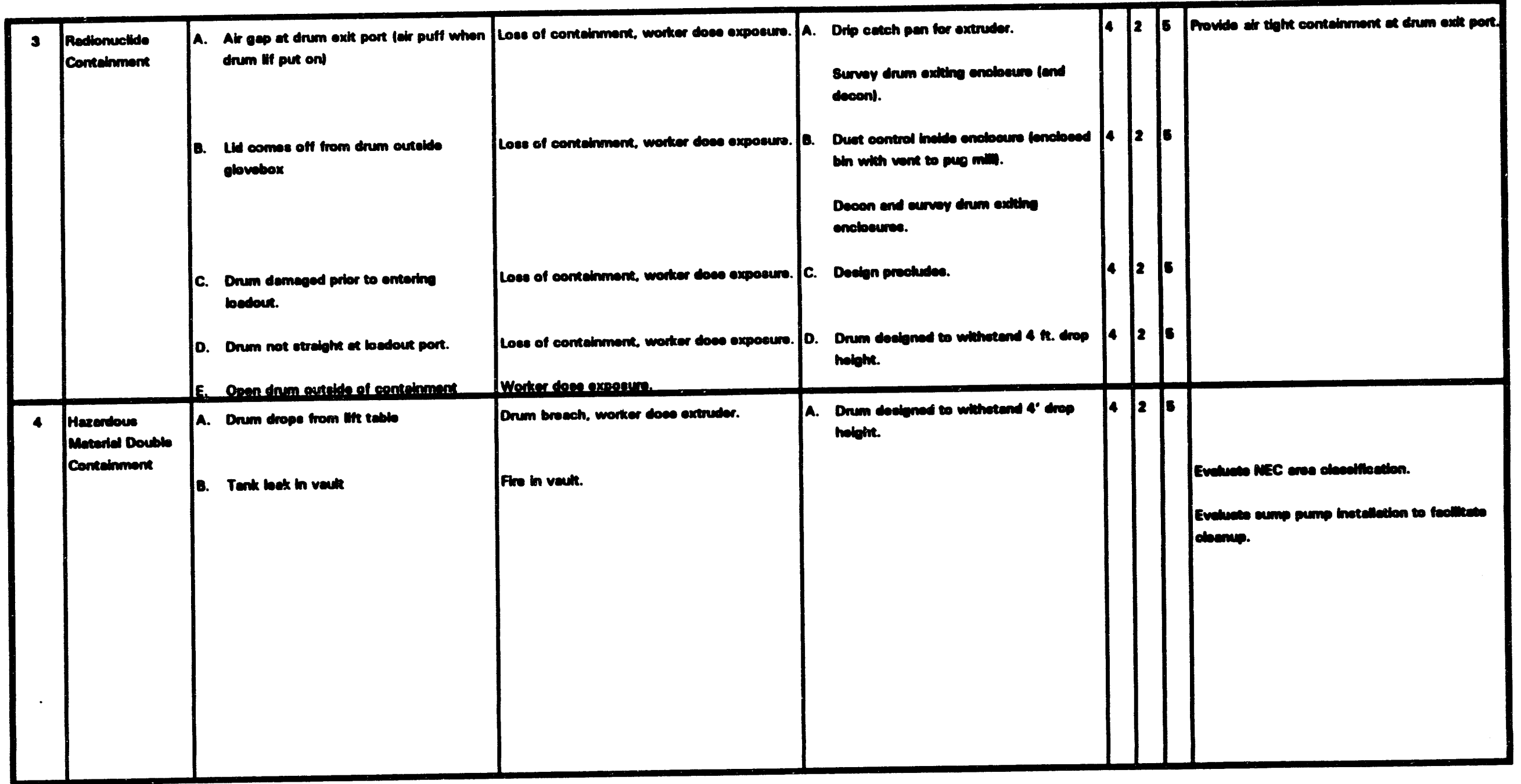


WRAP 2A ACDR PRELIMINARY HAZOP REVIEW DATA SHEET

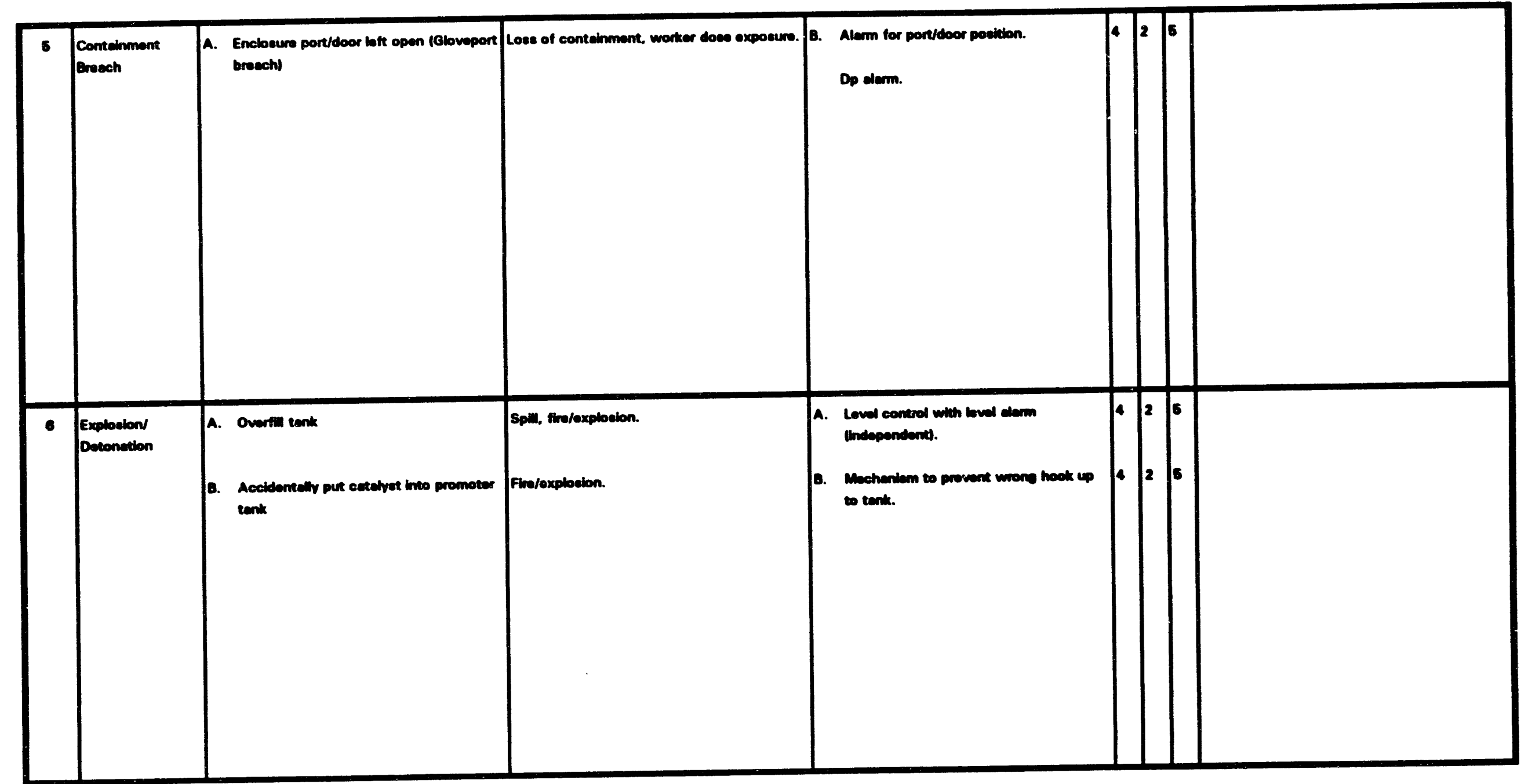


WRAP 2A ACDR PRELIMINARY HAZOP REVIEW DATA SHEET

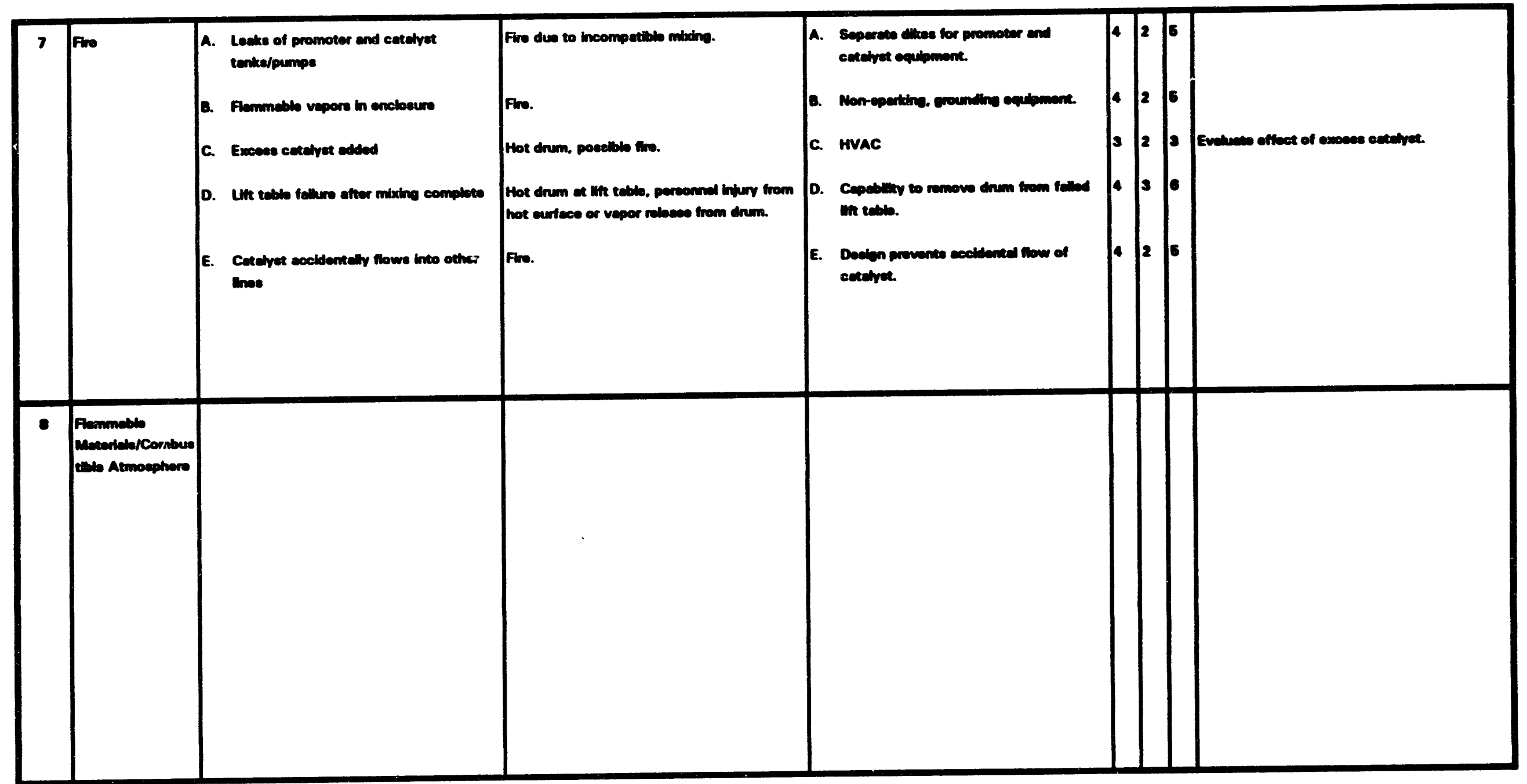


WRAP 2A ACDR PRELIMINARY HATOP REVIEW DATA SHEET

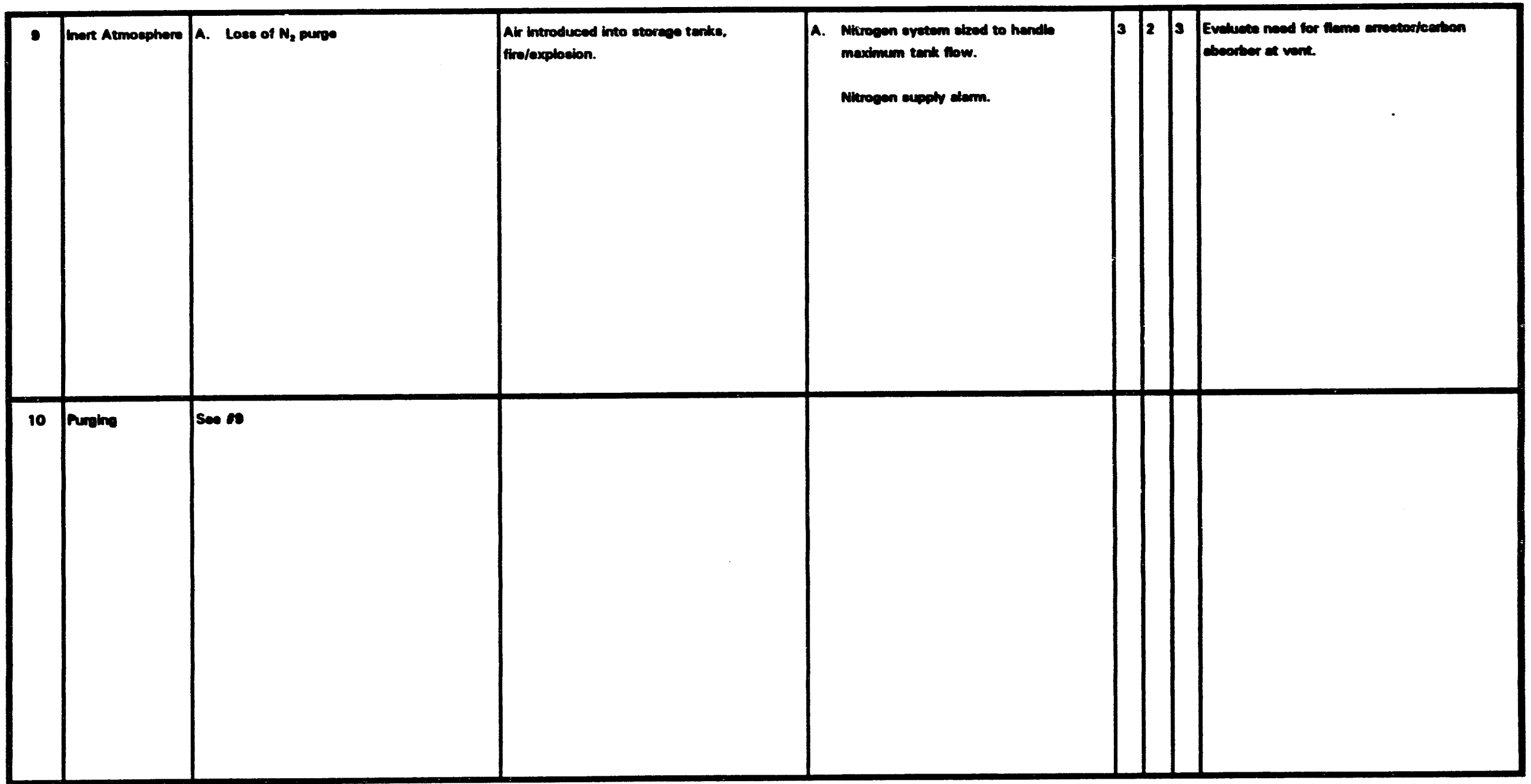


WRAP 2A ACDR PRELIMINARY HAZOP REVIEW DATA SHEET

\begin{tabular}{|c|c|c|c|c|c|c|}
\hline 11 & $\begin{array}{l}\text { Prophorite } \\
\text { Mocterilat }\end{array}$ & w/A & & & & \\
\hline 12 & Stente Cherese & 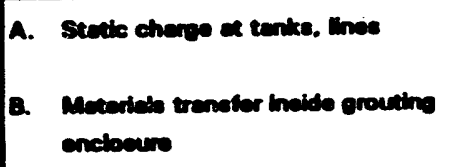 & 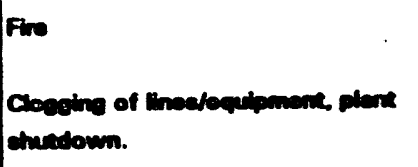 & 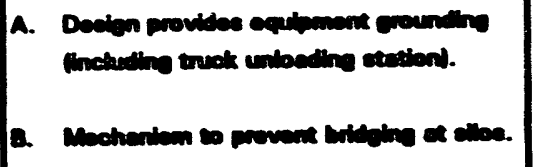 & 25 & \\
\hline
\end{tabular}


WRAP 2A ACDR PRELIMINARY HAZOP REVIEW DATA SHEET

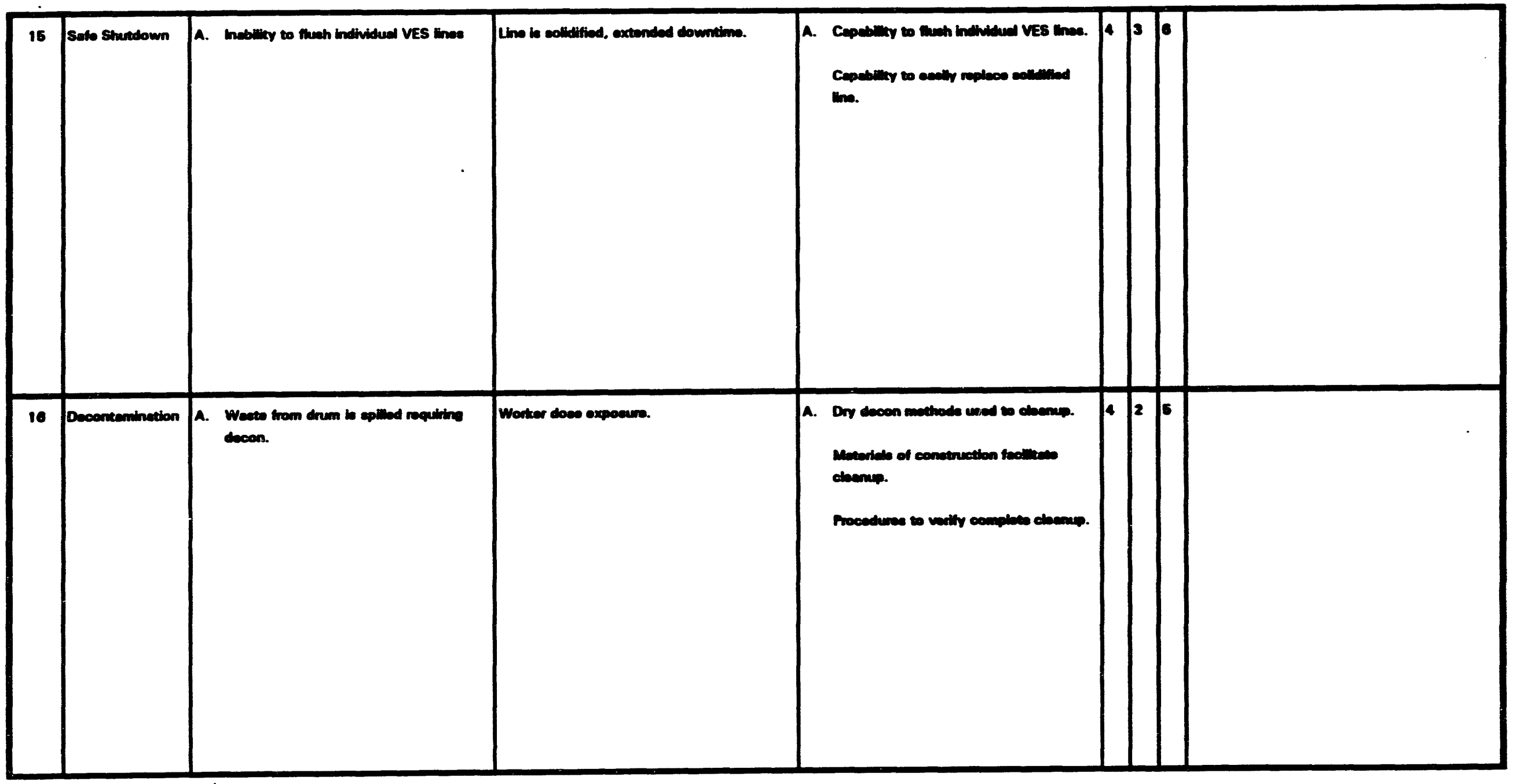




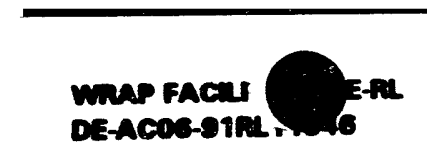

WRAP 2A ACDR PRELIMINARY HAZOP REVIEW DATA SHEET

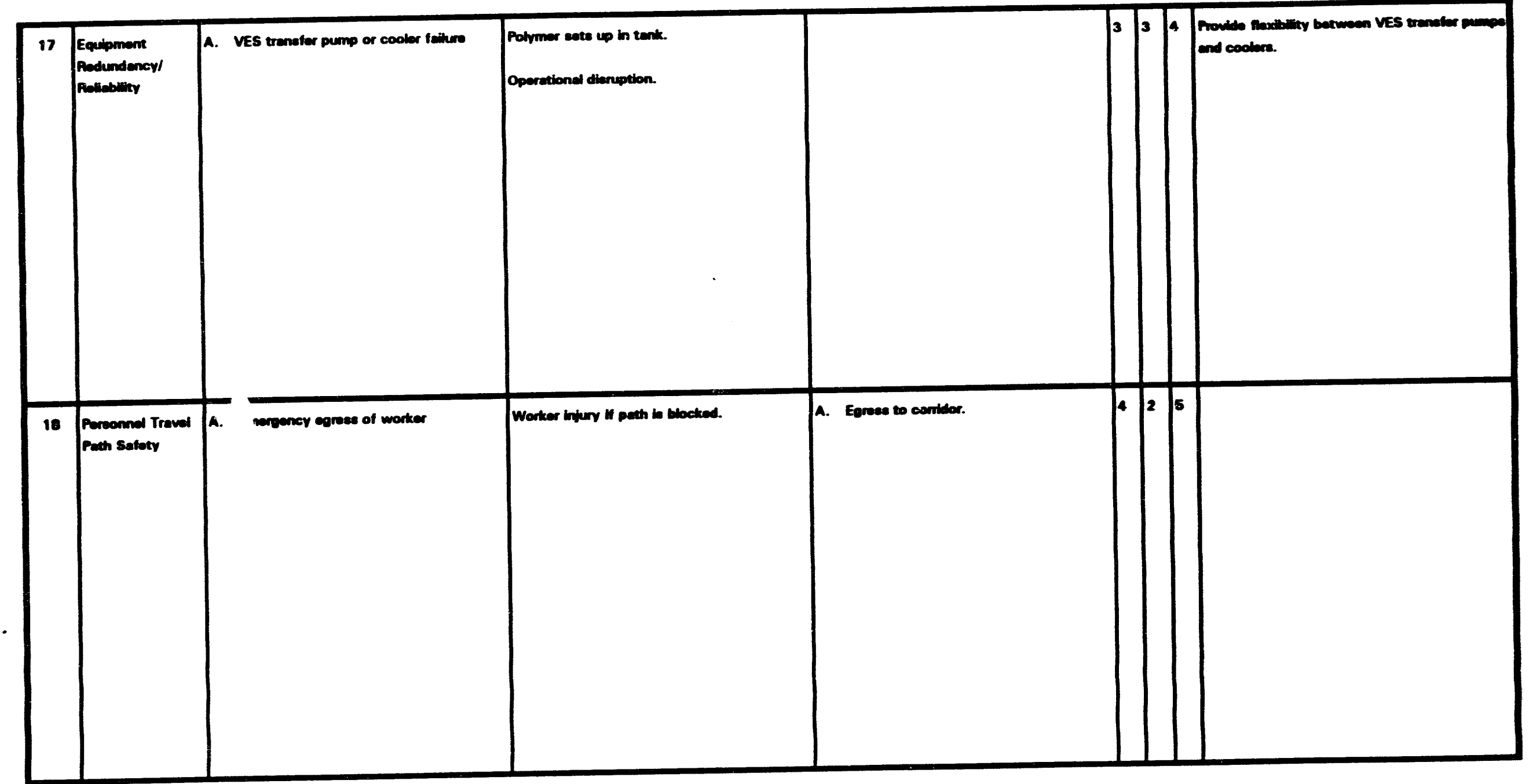


WRAP 2A ACDR PRELIMINARY HAZOP REVEW DATA SHEET

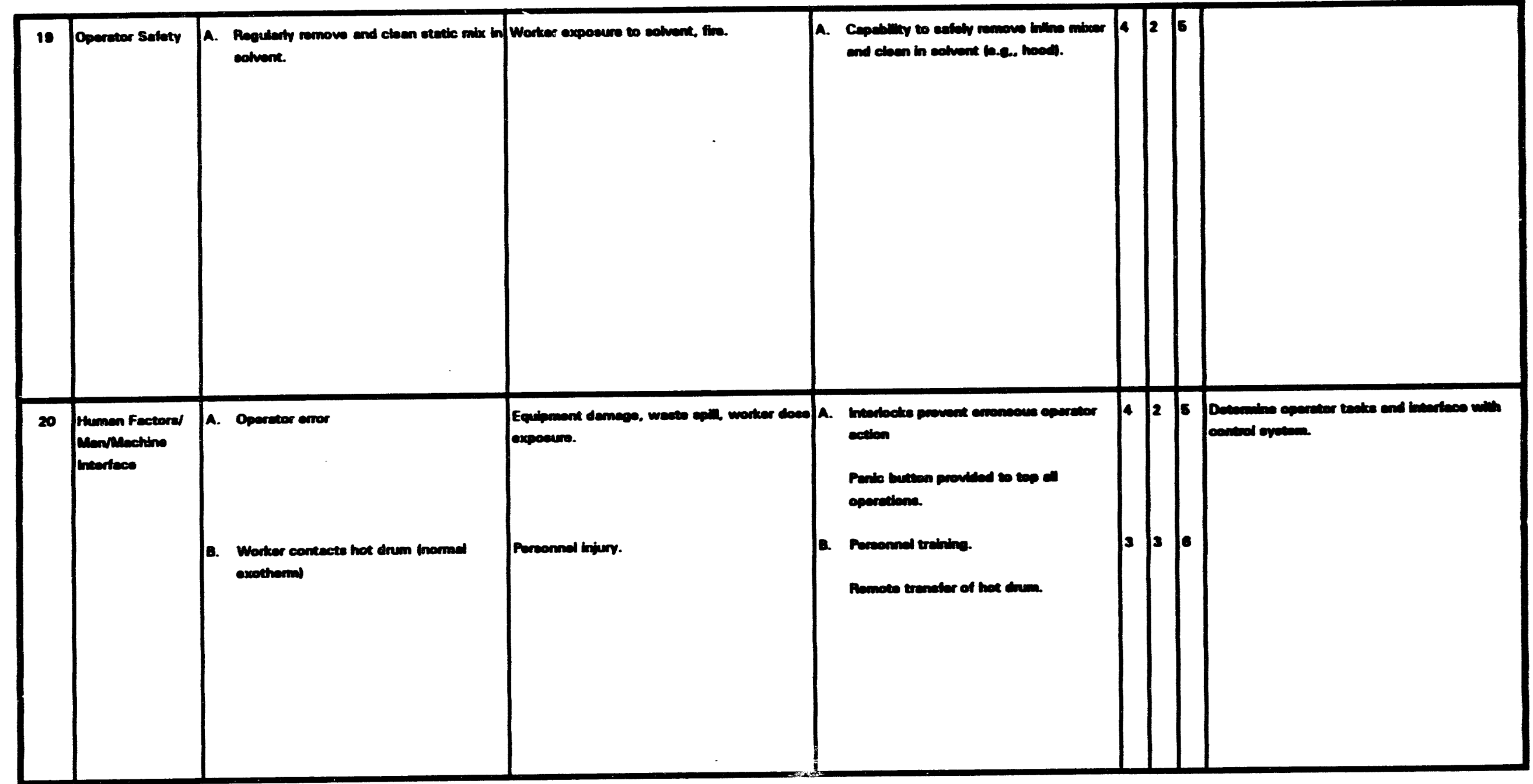




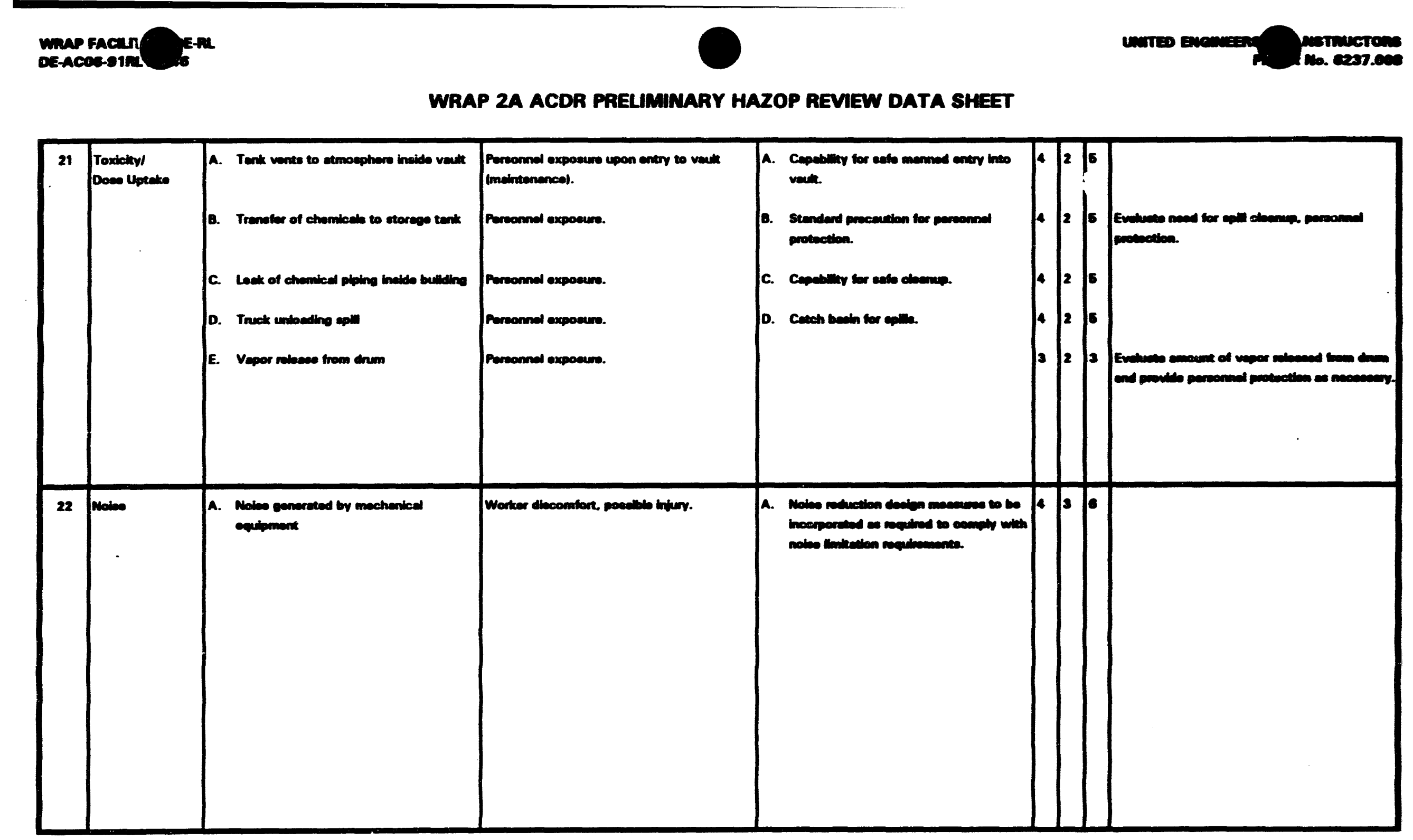


WRAP 2A ACDR PRELUMMARY HAZOP REVIEW DATA SHEET

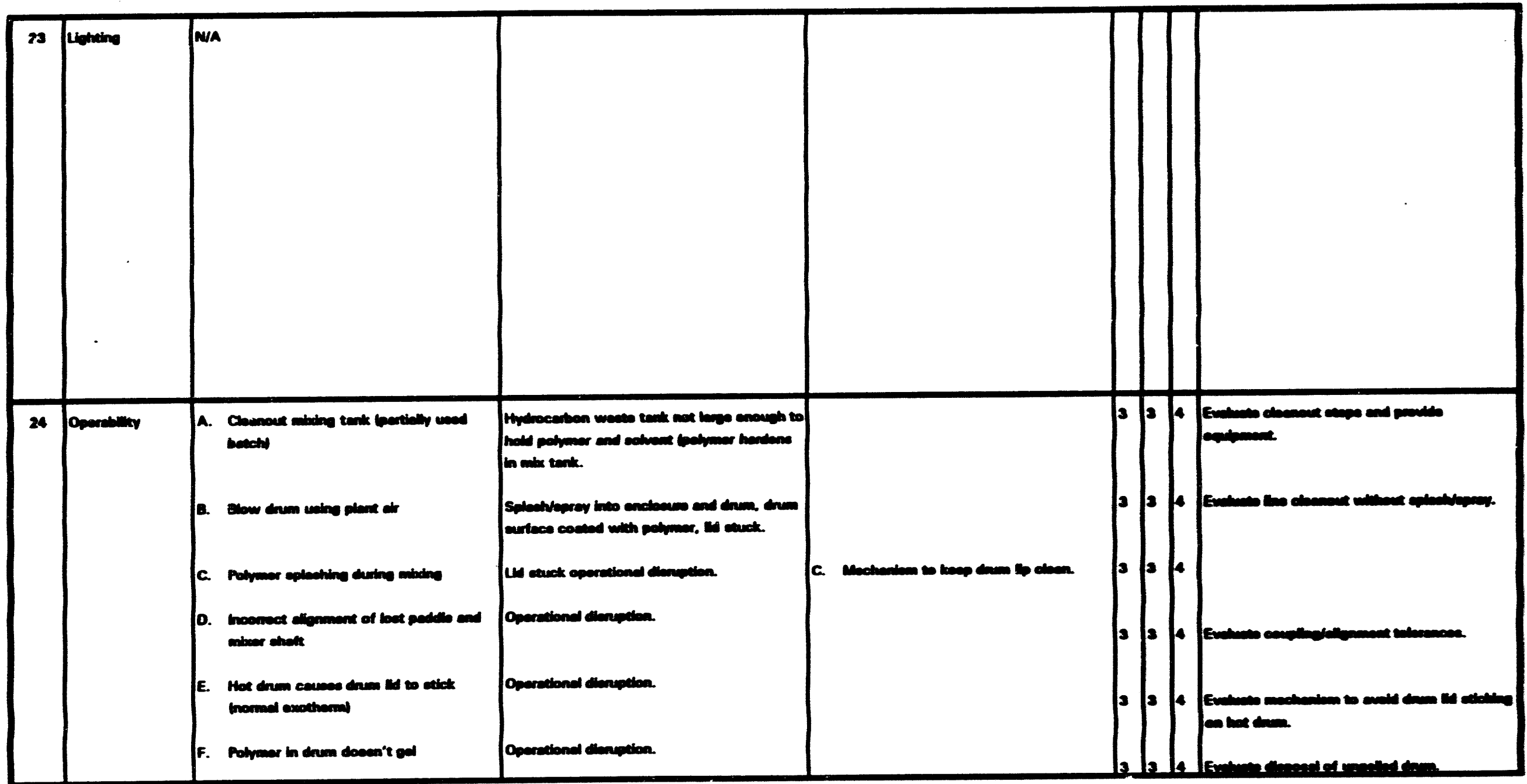


WRAP $2 A$ ACDR PRELUMARY HAZOP REVIW DATA sHET

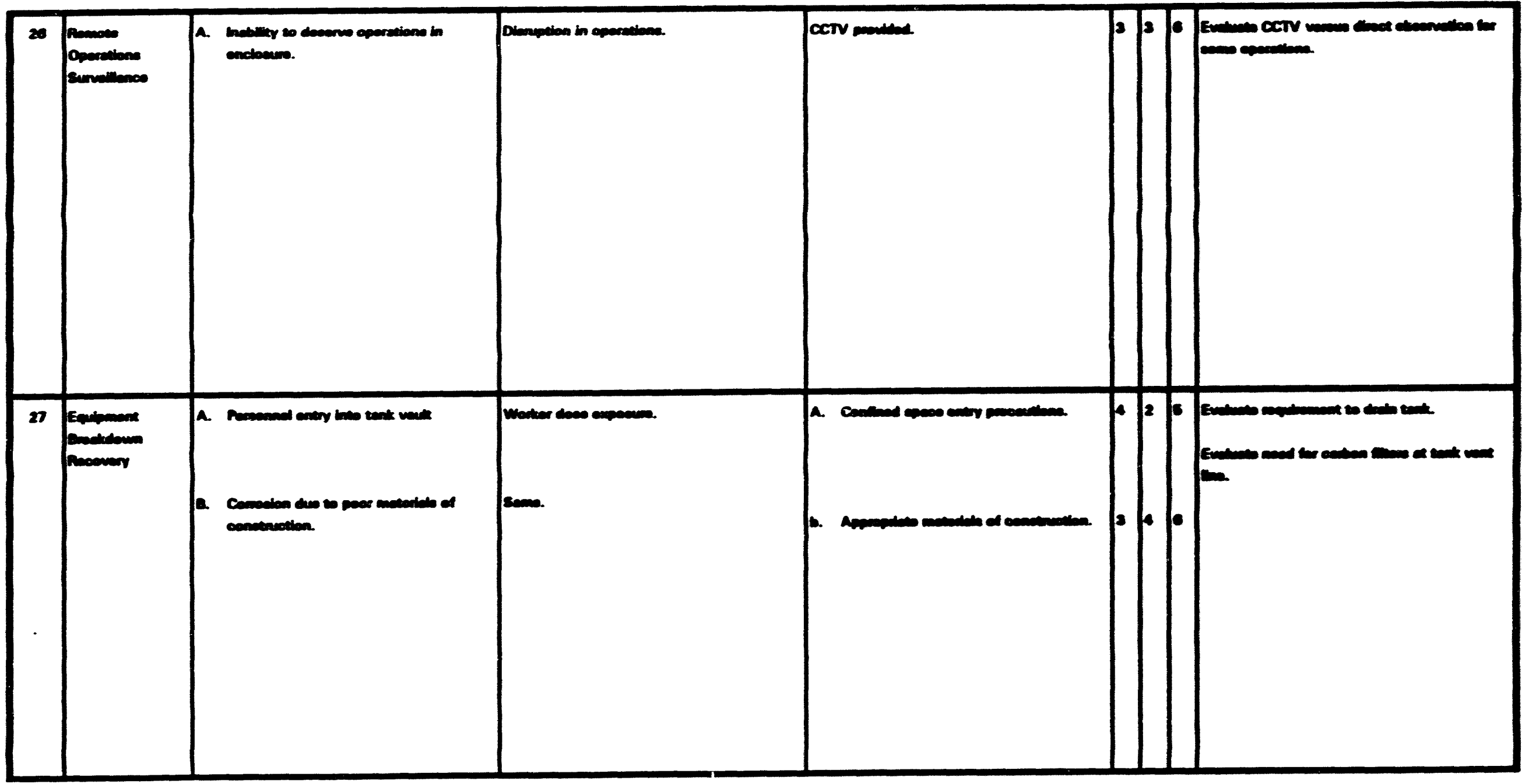




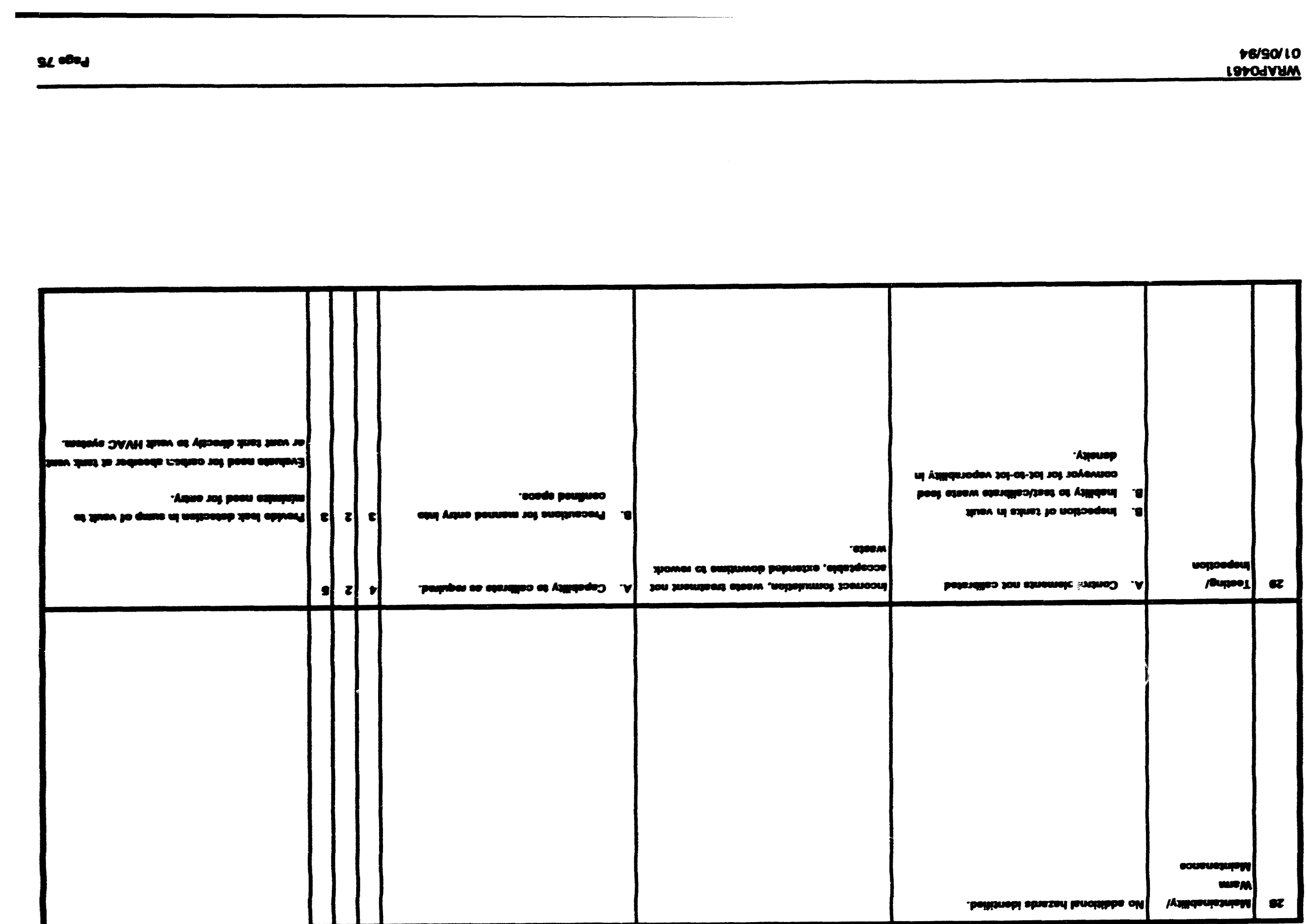

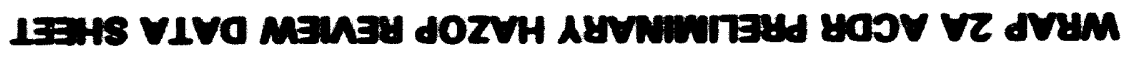


WRAP 2A ACDR PRELIMINARY HAZOP REVIEW DATA SHEET

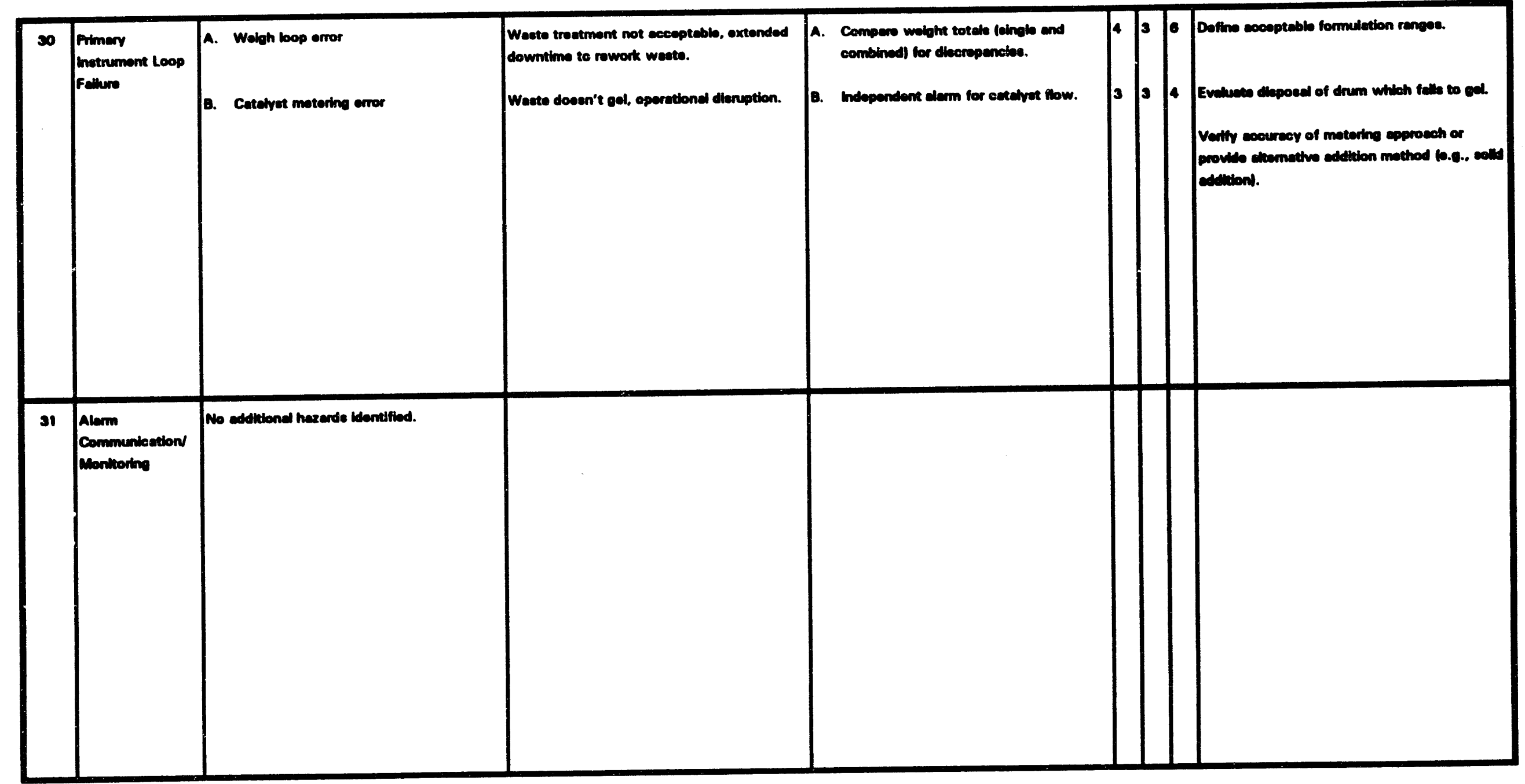


WRAP 2A ACDR PRELIMINARY HAZOP REVIEW DATA SHEET

\begin{tabular}{|c|c|c|c|c|c|c|c|c|}
\hline 32 & $\begin{array}{l}\text { Procese Primany } \\
\text { Interlocke }\end{array}$ & 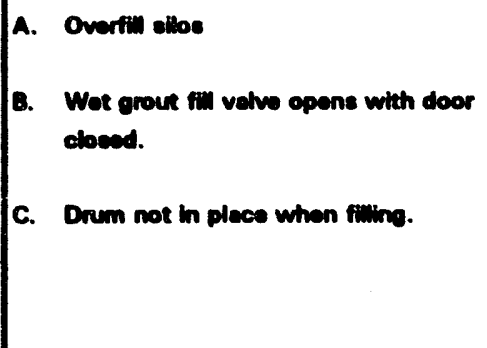 & 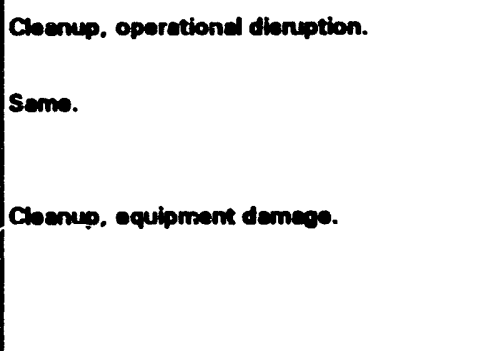 & 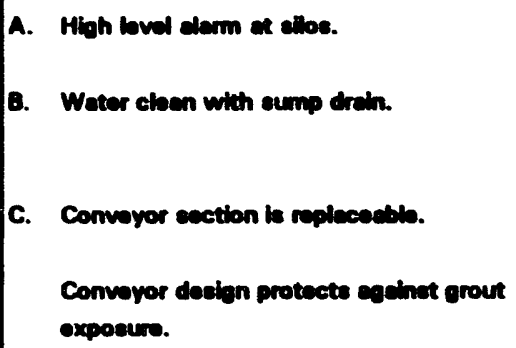 & 3 & 4 & $\begin{array}{l}6 \\
5\end{array}$ & 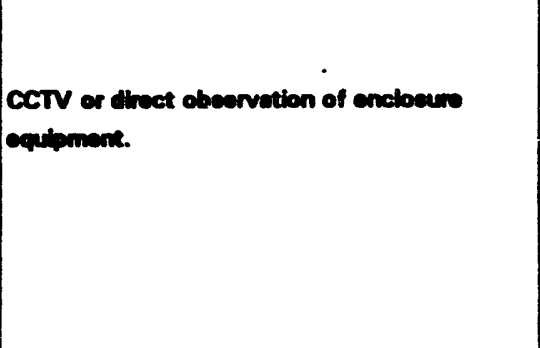 \\
\hline $\mathbf{3 3}$ & Betch Operetions & A. Wrone chomicel rocelved in truck. & Weate doesn't gel, operetiond dlereption. & $\begin{array}{l}\text { A. Semple truck contente petior to off } \\
\text { loceline. }\end{array}$ & 4 & 3 & e & $\begin{array}{l}\text { Evelueco leb eupport requiremente for chemiced } \\
\text { exnpling. }\end{array}$ \\
\hline
\end{tabular}




\section{unAP FAcurr, Dosefh

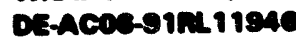

WRAP 2A ACDR PRELIMINARY HAZOP REVIEW DATA SHEET

\begin{tabular}{|c|c|c|c|c|c|c|c|}
\hline 34 & $\begin{array}{l}\text { Excosec flow } \\
\text { Lovel } \\
\text { Tompereture }\end{array}$ & 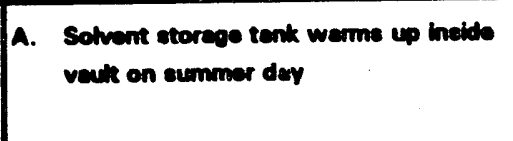 & 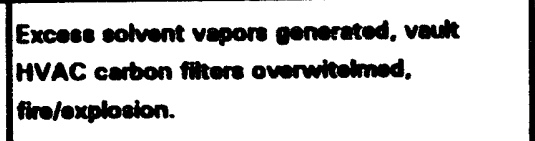 & 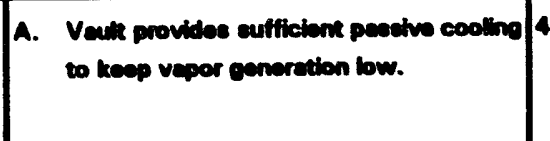 & 2 & 5 & 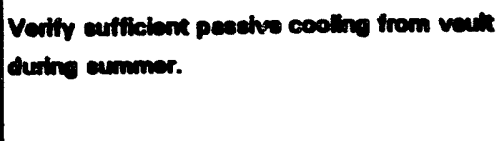 \\
\hline 36 & Somplo Tokino & 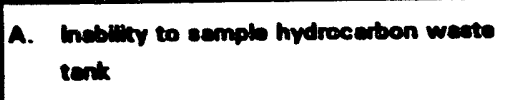 & 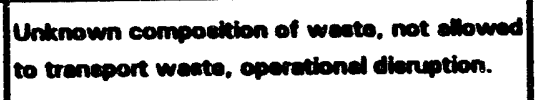 & 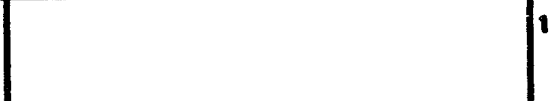 & 3 & 2 & 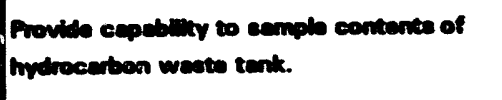 \\
\hline
\end{tabular}


1.0 INTRODUCTION $\ldots \ldots \ldots \ldots \ldots \ldots \ldots \ldots \ldots \ldots \ldots \ldots \ldots \ldots \ldots$

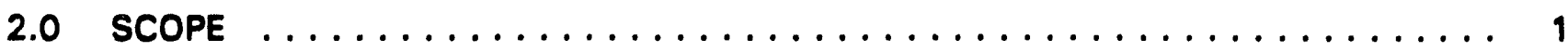

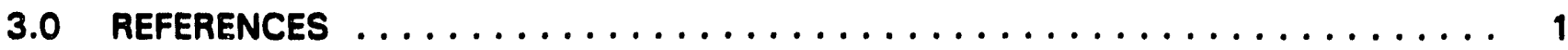

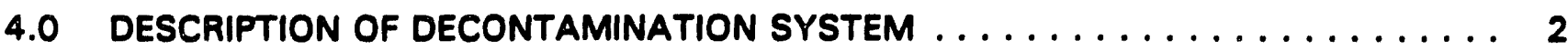

4.1 Design Basis Summary . . . . . . . . . . . . . . . . . . . 2

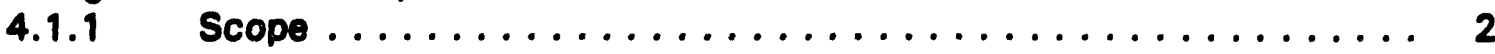

4.1 .2 Design Goals ........................ 2

4.1.3 Functional Requirements ................... 3

4.2 Process Description Summary . . . . . . . . . . . . . . . . . . . 3

4.2.1 Decontamination Water Supply System $\ldots \ldots \ldots \ldots \ldots \ldots \ldots$

4.2.2 Box Breakdown Area ..................... 3

4.2.3 Size Reduce and Repackage Enclosures ............... 3

4.2.4 Sample Management Enclosure ................... 4

4.2.5 Specialty Waste Process Enclosures . . . . . . . . . . . . . . 4

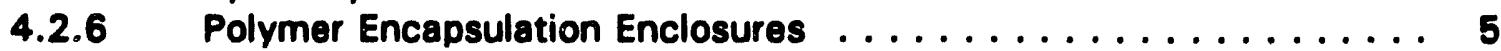

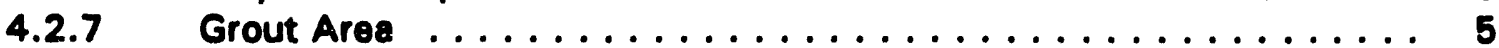

$4.2 .8 \quad$ Cure Storage Area $\ldots \ldots \ldots \ldots \ldots \ldots \ldots \ldots \ldots \ldots \ldots$

5.0 STUDY CRITERIA AND METHODOLOGY $\ldots \ldots \ldots \ldots \ldots \ldots \ldots \ldots$

6.0 RESULTS AND CONCLUSIONS $\ldots \ldots \ldots \ldots \ldots \ldots \ldots \ldots$ 
WRAP 2A

\section{DECONTAMINATION SYSTEM}

\section{HAZOP STUDY REPORT}

\subsection{INTRODUCTION}

A preliminary HAZOP study was performed on the advanced conceptual design of the Decontamination System. The HAZOP team met on 8 September 93, and consisted of the following members:

\begin{tabular}{lll} 
Name & Company & Role/Expertise \\
\hline Larry Walker & RE\&C & Leader, Scribe, Safety \\
Mike Dailor & RE\&C & Process \\
Doug Chapin & RE\&C & Process \\
William Cepeda & RE\&C & Instrumentation and Controls \\
Valerie Walker & BNFL & Radiological \\
Andrew Sharpe & BNFL & Mechanical/Operations \\
Milt Hayward & WHC & --interface, material handling \\
Ron Kolodzej & WHC & Nuclear Safety \\
Dave Mertz & WHC & Mechanical/Process \\
Bob Horges & WHC & Mechanical
\end{tabular}

The purpose of the HAZOP is to identify major safety and operability problems which can best be resolved during completion of the advanced conceptual design.

\subsection{SCOPE}

This HAZOP encompassed the Decontamination System, as shown on Process Flow Diagram H-2-140602, Rev. E.

\subsection{REFERENCES}

1. WHC-SD-W100-FDC-001 Rev. 2A, Functional Design Criteria Waste Receiving And Processing Facility Module $2 \mathrm{~A}$.

2. WHC-SD-W100-SDRD-001 Rev. A, Waste Receiving and Processing Facility Module $2 A$ Supplemental Design Requirements Document. 


\subsection{DESCRIPTION OF DECONTAMINATION}

\subsection{Decign Basis Summary}

\subsubsection{Scope}

1. This section includes decontamination of process enclosures including equipment within the process enclosures, and exterior of treated waste containers.

\subsubsection{Decign Coals}

1. Minimize generation of secondary waste and aid decommissioning.

2. Maximize use of a dry system, e.g., manual wiping with scrub pad and cleaning solution.

3. If necessary, provide decontamination system (permanent or portable) that is capable of providing intermittent washdown of process enclosures or contaminated treated waste containers prior to removal from cell.

4. Design and/or prepare all potential surfaces (polish/coat/strip etc.) for ease of decontamination.

5. Components not exposed to contamination that can be located outside of confinement without compromising the confinement criteria (Section 1324-6 of DOE 6430.1A) shall be so located.

6. Incorporate principals of human factors and AARA into the design process.

\subsubsection{Functional Requirements}

1. Decontaminate process enclosures/equipment.

2. Decontaminate treated waste containers.

\subsection{Process Description Summary}




\subsubsection{Decontamination Water Supply System}

1. All process areas of the WRAP 2A facility will be supplied with a water header for decontamination of equipment and enclosures except for the Box Breakdown area. Process water will be supplied from the process water distribution system as shown on $\mathrm{H}-2$ 140690. Water supply pressure will range from between 40 and 60 psi. The decontamination system can use water at this pressure by-passing the decontamination booster pump P-04-201. However, for most applications supply water pressure will be boosted to approximately 150 psi to provide a more physically aggressive spray to remove loosely held contamination. Water decontamination effectiveness can be further improved by detergent dosing as follows. The proportional flow control instrument on the discharge side of P-04-201 is activated and sends a signal to the decontamination solution metering pump (P-12-107, H-2-140687) situated in the AMU area. The metering pump is triggered to pump detergent at a controlled rate to the mixing tee downstream of P-04-201 to yield a detergent dosed water solution.

\subsubsection{Box Breakdown Area}

1. The Box Breakdown ar is part of the overall open, sort, size reduce and repack process flow diagram (H-2-140628). The area will have remotely operated heavy equipment to size reduce and repackage waste received in large boxes, into drums.

2. Strippable coating has been selected to decontaminate general building areas and equipment in the box breakdown on an infrequent periodic basis. The method will involve spraying a protective strippable coating film on areas and items to be decontaminated. After a number of operations have been carried out in the Box Breakdown area, a second spraying will be carried out to trap the contamination that has been generated by these operations. Manual access to the Box Breakdown area will then be permitted for the removal of strippable coating with sandwiched radioactive waste.

3. The Box Breakdown aros will also be used to destructively examine $1 \%$ of the product drums from WRAP 2A. This operation will be carried out using mechanical cutting methods (i.e., saws). The Box Breakdown area may also be used to carry out ad hoc or maintenance operations on an infrequent basis.

\subsubsection{Size Reduce and Repackage Enclosures}

1. The two size reduce and repackage enclosures receive, physically condition and weigh out waste for either polymer or grout encapsulation processes. 
2. The larger enclosure contains the following major solid waste processing equipment: a drum elevator/tipper, two sort tables, two manipulators, a shredder unit, a vibrating table and weigh hopper. These items will become contaminated and will require periodic decontamination. The decontamination proposal is to use strategically positioned hydrolasers (X-04-210A, B, C and D) located close to equipment. Hydrolasers will have a selection of nozzles and extensions available for fitting within the enclosure. These auxiliary features enhance the versatility of the gloveported hydro laser decontamination operation. Liquid effluent resulting from decontamination will be drained to the enclosure sump. The sump will bo emptied by the sump pump (P-04-210A) which operates on level control to discharge effluent into the active drain for subsequent collection in the secondary waste treatment area. Hydrolasers will operate at the higher water pressure of approximately 150 psi. Detergent may also be added to increase decontamination.

3. The smaller enclosure is similar to the larger enclosure and contains a drum tipper/elevator, a sort table, a manipulator and a pug mill for processing sludge and particulate wastes. The decontamination proposal is to use strategically placed hydrolasers (X-04-210 E\&F) in the same manner as described above for the larger enclosure. The pug mill will be used to homogenize, deagglomerate and control the particle size of the sludge/particulate waste and will hence become heavily contaminated. As a result of this, the pug mill will require a high pressure fixed spray system (C-04-211) at 1500 psi for decontaminating the inside of the equipment. A positive displacement pump P-04-211 increases the water from the small enclosure's header from 150 to 1500 psi. This system will be used prior to decommissioning and periodically as required. Liquid effluent will drain to the enclosure sump and be pumped into the active drain by sump pump (P-04-210B).

\subsubsection{Sample Management Enclosure}

1. The sample management enclosures consist of an enclosure containing remotely operated equipment for drummed waste lot verification and product certification sampling, and a series of fume hoods for rudimentary sample tests and sample repackaging.

2. The drum sampling enclosure will be routinely decontaminated by manual techniques through gloveports. Manual decontamination will involve the use of brushes and wipes. Small amounts of water and/or hand cleaners may also be used to facilitate contamination removal.

3. The drum sampling enclosure is also fitted with a fixed spray ring (X-04-220) for decontaminating walls during decommissioning. Liquid effluent produced will drain to the enclosure sump and be pumped into the active drain by sump pump (P-04-220).

4. Fume hood enclosures (GB-05-601A,B,C\&D) will be decontaminated by manual means through the aperture located at the front of each fume hood. The method will involve gloved operators wiping down the fume hood internals through the access aperture. 


\subsubsection{Specialty Waste Process Enclosures}

1. The special waste process enclosure comprises a main enclosure and a sub-enclosure for pre-treating and re-drumming lead, mercury and resctive metals during phased campaigns. Initially, lead and mercury will be campaigned followed by enclosure equipment change out to campaign reactive metals. The initial major equipment will comprise: a drumhandler/elevator, a manipulator, a sort table, a shredder and other equipment similar to the size reduce and repackage enclosures. Consequently the decontamination methods selected will be to use strategically positioned hydrolesers (X-05-231A,B\&C) in close proximity to equipment needing decontamination. Hydrolasers will operate at the higher available water pressure of approximately 150 psi, detergent may also be added to increase decontamination factors. Liquid effluent resulting from the decontamination process will drain to the enclosure sump. Pump (P-04-230) operates on sump level control to automatically discharge effluent from the enclosure sump. The enclosure is also fitted with a fixed spray ring $(X-04-230)$ for decontaminating walls and general areas.

2. The sub-enclosure is used for mercury amalgamation and will be conveniently decontaminated by manual wiping techniques through gloveports.

\subsubsection{Polymer Encapsulation Enclosures}

1. The polymer encapsulation enclosure contains the polyethylene extruder/condenser and the extrusion mixing line. Polymer and waste are mixed in the extruder with the output filling the empty drums on the extrusion mixing line. There is a potential for drums to become contaminated during filling which is undertaken inside containment.

2. Normal enclosure decontamination will be completed by manually wiping the inside of the enclosure with swabs wetted by organic solvent. After the solvent cleaning a water based swab will be used to remove solvent residue. Additional decontamination is provided in the form of spray ring $X-04-240$ which sprays the enclosure walls.

3. In the drum decontamination area, product drums from the mixing line will be swabbed and the swab monitored for contamination. If in the unlikely event the drums are found to be contaminated, decontamination will be carried out by manually wiping the outside of the drum with organic solvent applied to swabs. The drum will be re-monitored for activity to ensure that is acceptable to be transferred to storage.

4. Liquid waste will be pumped from the enclosure sump to the active drain using P-04240. This system will definitely be used prior to enclosure decommissioning and periodically as required.

\subsubsection{Grout Area}

1. Grout waste product drums will be produced in the grout area. There is a potential for drums to become contaminated during grout encapsulation which is undertaken inside containment. In the drum decontamination area, swab wipe monitoring technique will be used at the drum monitoring station. At the station, the operator swabs the drum and deposits the swab in a shielded gamma monitor within the enclosure. The gamma monitor count will determine the degree of external drum contamination. 
2. If monitoring indicates that decontamination is required then decontamination will be carried out by manually wiping the outside of the drum with solvent applied to awabs. The monitoring procedure will be repeated to determine if the drum is suitable for export or if further decontamination is required.

3. Decontamination in and around the drum decontamination area can be augmented by using strategically placed hydrolaser X-04-251 through gloveports.

4. Fixed spray rings, X-04-250A\&B, will be provided to decontaminate walls and general areas. Liquid effluent from water spray operation will drain to the enclosure sump for discharge to the active drain via sump pump (P-04-251).

\subsubsection{Cure Storage Area}

1. In the cure Storage area, product drums will be allowed to cure. After the curing period the drum lids will be opened and the product surface will be inspected for the presence of cure bleed water. Dewatering will take place if required.

2. When removing/replacing the lid there is the possibility of moisture running onto the side of the drum. After relidding, the drum will be swab monitored and in the vent that the drum does need decontaminating, the drum will be sent to the drum decontamination booth for a high pressure spray at 1500 psi using drum spray X-04-262 and positive displacement pump P-04-260. Spraying works on a recirculation system to minimize water consumption. The system will operate in the following manner: pump P-04-260 draws water through a filter from the sump and delivers through spray nozzles situated adjacent to the slowly rotating drum. Spent water will be drained to the sump for re-use. Sump level controls ensure that suitable operating levels are maintained. The sump water will be monitored remotely for gamma activity. When the activity of the water reaches a pre-determined level, a signal will be sent to switch off P-04-260 and the active water will be discharged via sump pump P-04-261. The sump will then be refilled with process water to permit the drum decontamination cycle to continue. The drum will be re-monitored ( as previously described) before the drum is released.

3. A fixed spray ring $(X-04-260)$ is provided to decontaminate walls and general areas. Liquid effluent from the water spray operation will drain to the enclosure sump for discharge to the active drain via sump pump (P-04-261).

\subsection{STUDY CRITERIA AND METHODOLOGY}

This HAZOP utilized a predetermined set of process deviations/upset conditions to be analyzed by the HAZOP terms for each process deviation, possible causes were postulated and worst case consequences (without benefit of any safeguards) were determined. Existing safeguards (design and procedural) were then identified. Those safeguards which could be reasonably expected to be present in the final design were assumed to be existing and were so documented in the HAZOP. For each cause and effect, hazard severity and probability were qualitatively assessed (taking credit for existing safeguards which reduce hazard probability) using the criteria shown in Table 1. The overall risk rating for each hazard was then determined using the risk ranking matrix shown on table 2. recommendations were proposed by the HAZOP team in instances required by the implementation criteria shown in Table 2. 
TABLE 1

HAZARD SEVERITY AND PROBABILITY CLASSIFICATION CRITERIA

\begin{tabular}{|c|c|c|c|c|}
\hline \multirow{2}{*}{ Target Hazard } & \multicolumn{4}{|c|}{ Severity Class (Worst-case Scenario) } \\
\hline & Catastrophic (1) & Extensive (2) & Moderate (3) & Operational (4) \\
\hline Community & $\begin{array}{l}\text { Multiple irreversible } \\
\text { injuries; may include a } \\
\text { fatality } \\
\text { OR }\end{array}$ & $\begin{array}{l}\text { Single irreversible or } \\
\text { several reversible injuries } \\
\text { (no fatalities) } \\
\text { OR }\end{array}$ & Several reversible injuries & \\
\hline Workers & $\begin{array}{l}\text { Fatalities or irreversible } \\
\text { injuries } \\
\text { OR }\end{array}$ & $\begin{array}{l}\text { Several injuries } \\
\text { OR }\end{array}$ & $\begin{array}{l}\text { Single injury } \\
\text { OR }\end{array}$ & \\
\hline Facility & $\begin{array}{l}\text { Partial or full demolition of } \\
\text { facility } \\
\text { OR }\end{array}$ & $\begin{array}{l}\text { Rupture or similar loss of } \\
\text { containment } \\
\text { OR }\end{array}$ & $\begin{array}{l}\text { Major equipment ciamage } \\
\text { leading to one month or } \\
\text { more facility downtime } \\
\text { OR }\end{array}$ & $\begin{array}{l}\text { Equipment damage } \\
\text { leading to several days of } \\
\text { facility downtime or other } \\
\text { operational penalty } \\
\text { OR }\end{array}$ \\
\hline Environment & $\begin{array}{l}\text { Major environmental } \\
\text { impact with significant } \\
\text { cleanup/iability costs }\end{array}$ & $\begin{array}{l}\text { Groundwater, soil, or } \\
\text { public sewer } \\
\text { contamination }\end{array}$ & $\begin{array}{l}\text { Minor spill or release } \\
\text { resulting in permit violation }\end{array}$ & \\
\hline
\end{tabular}

\section{LIKELIHOOD CLASSIFICATION}

\begin{tabular}{|l|l|}
\hline Highly Likely (1) & $\begin{array}{l}\text { Event has occurred at this facility - or - other facility - or - is expected to occur several times during the } \\
\text { next } 10 \text { years. }\end{array}$ \\
\hline Likely (2) & $\begin{array}{l}\text { Event has occurred at this facility - or - is possible to occur at this facility several times during the next } \\
30 \text { years. }\end{array}$ \\
\hline Unlikely (3) & $\begin{array}{l}\text { Event may have occurred at another facility - or - is possible to occur at this facility at least once in the } \\
\text { next } 50 \text { years. }\end{array}$ \\
\hline Extremely Unlikely (4) & $\begin{array}{l}\text { Event is not likely to ever occur in this facility, given a continuation of the current levels of training. } \\
\text { procedures, maintenance, inspection, testing, and other applicable process safety managernent system } \\
\text { support. }\end{array}$ \\
\hline
\end{tabular}


TABLE 2

RISK RANKING MATPXX AND MMPLEMETATION CaTEAA

\begin{tabular}{|c|c|c|c|c|}
\hline Likelihood & & & & \\
\hline Highly Likely (1) & 4 & 2 & 1 & 1 \\
\hline Likely (2) & 5 & 3 & 2 & 1 \\
\hline Unlikely (3) & 6 & 4 & 3 & 4 \\
\hline Extremely Unlikely (4) & 7 & 6 & 5 & Catastrophic (1) \\
\hline
\end{tabular}

RISK RANKING IMPLEMENTATION

\begin{tabular}{|c|l|}
\hline Risk Ranking & \multicolumn{1}{|c|}{ Implication } \\
\hline 1 & $\begin{array}{l}\text { Risk level - Very significant } \\
\text { Recommendation = Required from the HAZOP team } \\
\text { Implementation - Begins immediately }\end{array}$ \\
\hline 2 & $\begin{array}{l}\text { Risk level - Significant } \\
\text { Recommendation = Required from the HAZOP team } \\
\text { Implementation - Begins within three months }\end{array}$ \\
\hline 3 & $\begin{array}{l}\text { Risk level - Not very significant } \\
\text { Recommendation = Required from the HAZOP team } \\
\text { Implementation - Begins within one year }\end{array}$ \\
\hline 4 & $\begin{array}{l}\text { Risk level - Not significant, but may be an operational problem } \\
\text { Recommendation = At the discretion of the HAZOP team } \\
\text { Implementation - As soon as practical, not later than the next major plant turnaround }\end{array}$ \\
\hline 5,6, or 7 & $\begin{array}{l}\text { Risk level - Negligible, but may be an operational problem } \\
\text { Recommendation = At the discretion of the HAZOP team } \\
\text { Implementation - To be evaluated by management }\end{array}$ \\
\hline
\end{tabular}




\subsection{RESULTS AND CONCLUBIONS}

Because this HAZOP is performed relatively early in the design phase, existing safeguards have not been fully documented on the process flow diagrams (these would mostly be shown on the F $11 D^{\prime}$ 's developed during Title Design). However, the HAZOP team assumed specific safeguards would be present in the final design if it appear reasonable to expect this. These assume' 'safeguards are documented on the HAZOP worksheets and credit was taken for these presumed safeguards when assessing risk. During Title Design, the presence of these safeguards need to be verified to validate the conclusions of this HAZOP.

Ninoteen potential safoty and operability problems wore identified and evaluated on the HAZOP. Of these, fifteen were assessed to have a negligible risk level. The remaining four involved operational problems having risk rankings clessified as ranging between significant and not significant. For these potential problems, the HAZOP team has recommended that additional safoguards be evaluated and incorporated into the WRAP 2A design. Table 3 presents a summary of changes to be made in the process flow diagram, assumed design safeguards, and additional safeguards to be evaluated for incorporation into the design.

In several instances, the nead for human factors analyses and reliability/availability/maintainability analyses during Title Design was highlighted by the HAZOP team to achieve negligible risk levels. The HAZOP assumed that such analyses would be performed and that the necessary design requirements/modifications are incorporated. The performance of these design analyses are considered to be open issues to be resolved during Title Design. Similarly, the HAZOP team identified the need for a maintainability analysis to develop requirements for warm maintenance at the WRAP $2 A$ Facility.

The HAZOP is documented in the attached HAZOP worksheets. 

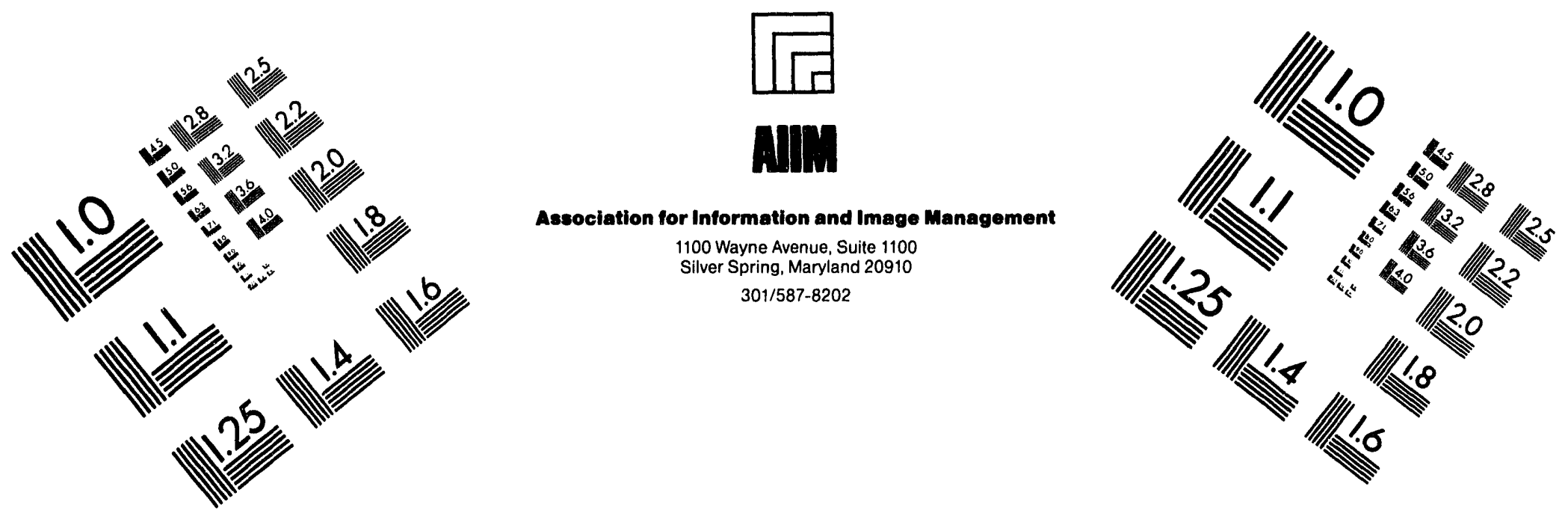

\section{Centimeter}

$\begin{array}{llllllllllllllll}1 & 2 & 3 & 4 & 5 & 6 & 7 & 8 & 9 & 10 & 11 & 12 & 13 & 14 & 15 & \mathrm{~mm}\end{array}$

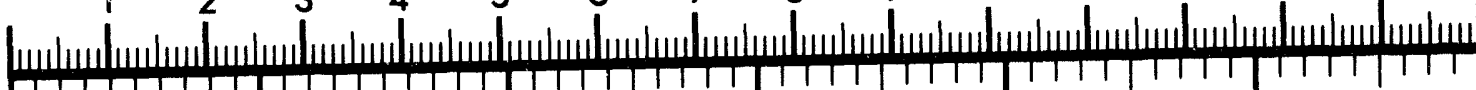

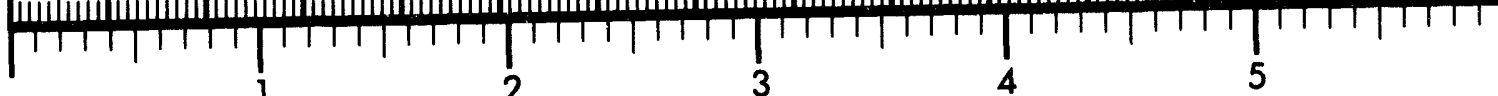
Inches
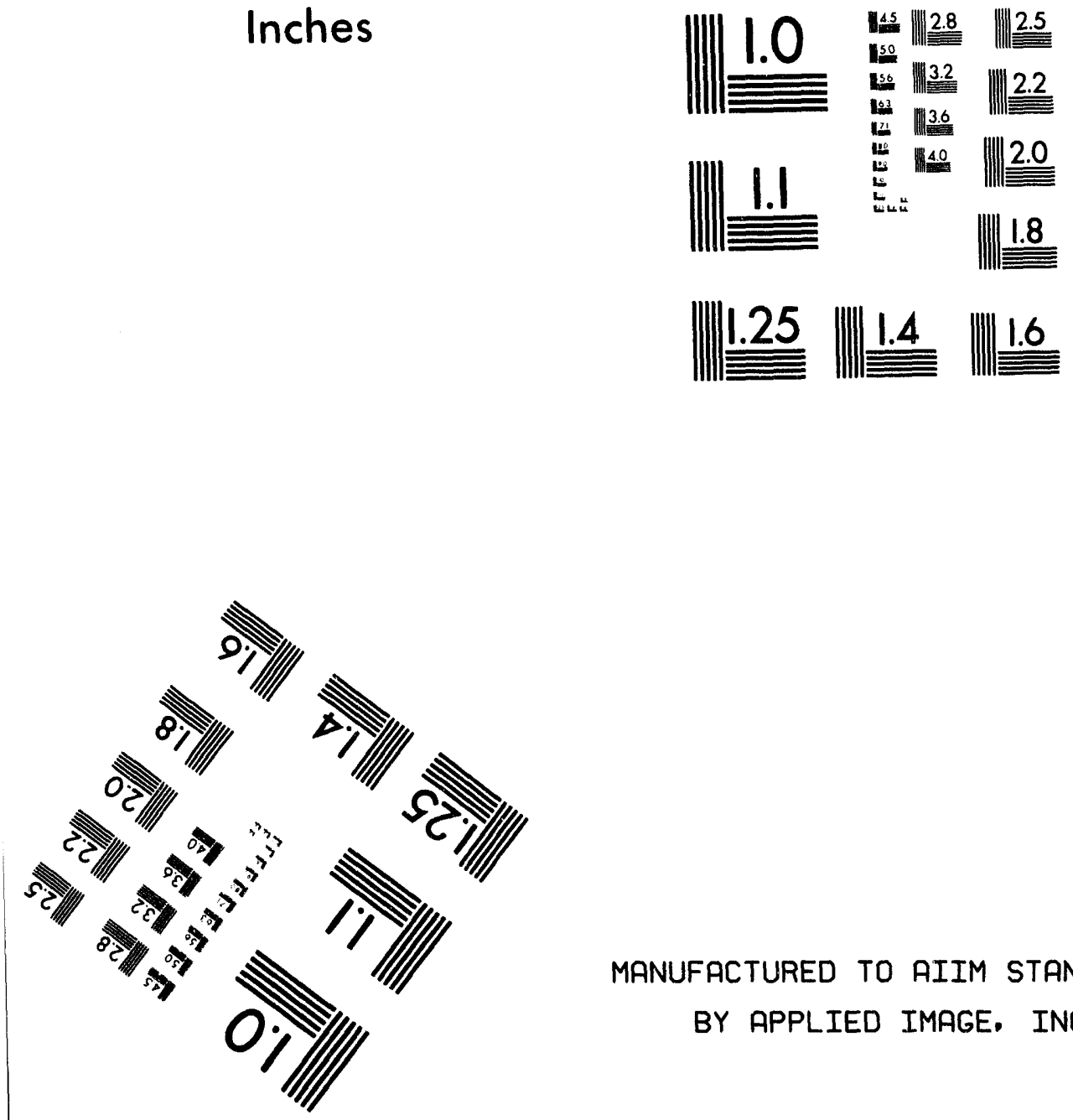

MANUFACTURED TO AIIM STANDARDS BY APPLIED IMAGE, INC.

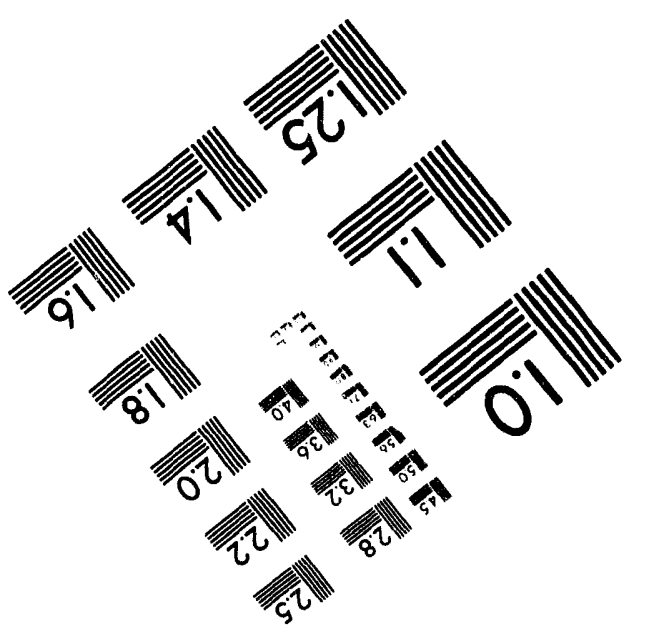



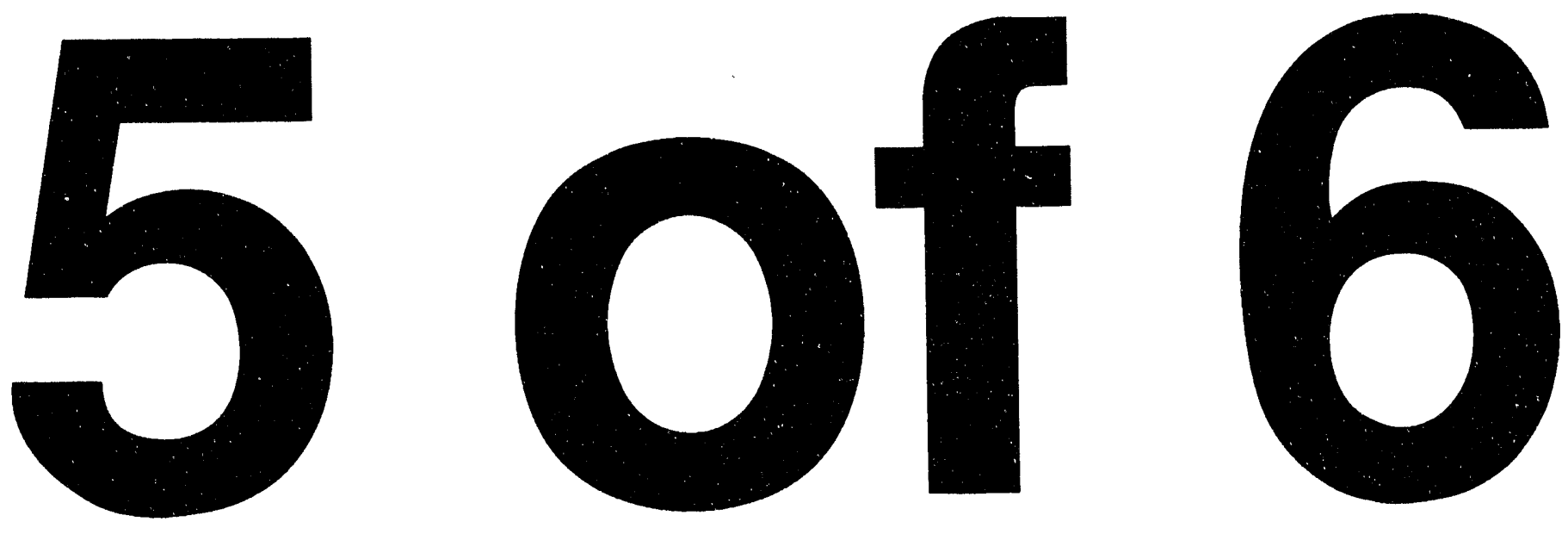


\section{TABLE 3 \\ DECONTAMINATION HAZOP SUMMARY}

\section{CHANGES TO PROCESS FLOW DIAGRAM}

1. Eliminate recycling at cure storage area and show water flow directly to pum P-04-260 (with check valves - or relocate check valves to flow steam \#1)

2. Provide vacuum system for cleanup of drum waste prior to wet decon cleanup.

3. Show drum turner at cure storage area.

\section{ASSUMED DESIGN SAFEGUARDS}

1. General design basis requirements (e.g., shielding as required for sups/discharge lines).

2. Design minimizes possibility of leaks in sump discharge lines (outside enclosures).

3. Capability for personnel in bubble suits to safely enter box breakdown enclosure to remove/apply strippable coating.

4. Sump pumps in enclosures are accessible for maintenance and testing/inspection.

5. Over pressure protection for decon/water lines.

6. Low level alarm/shutdown of sump pumps.

7. High level alarm at sumps initiates decon/water supply shutdown.

8. Booster pump shutdown initiates shutdown.

\section{EVALUATE/INCORPORATE INTO TITLE I DESIGN}

1. Eliminate high pressure decon/water supply (to less than 150 psi) - is booster pump needed?

2. Evaluate possibility of enclosure damage from high pressure decon/water spray.

3. Evaluate flammability/toxicity of decon solvent (also its compatibility with waste).

4. Size sumps to contain free flow of decon/water (loss of power) or provide fail closed valves.

5. Evaluate effect of decon/water vapors entering HVAC exhaust system (off-gas treatment).

6. Evaluate need for permanent versus temporary decon system for enclosures based on purpose for decon.

7. Evaluate use of a strippable drum coating for decon of outgoing drums.

8. Evaluate mechanism to survey hot drums leaving enclosure.

9. Evaluate alternate method to decon box breakdown enclosure.

10. Evaluate collection tank from sump discharge header.

11. Evaluate need for sampling of sump discharge header. 
12. Evaluate compatibility of decon solvent/solution with waste.

13. Evaluate need for fitler in sump discharge lines(s).

14. Replace gamma monitor with alpha monitor at cure storage area. 
WRAP 2A ACDR PRELIMINARY HAZOP REVIEW DATA SHEET

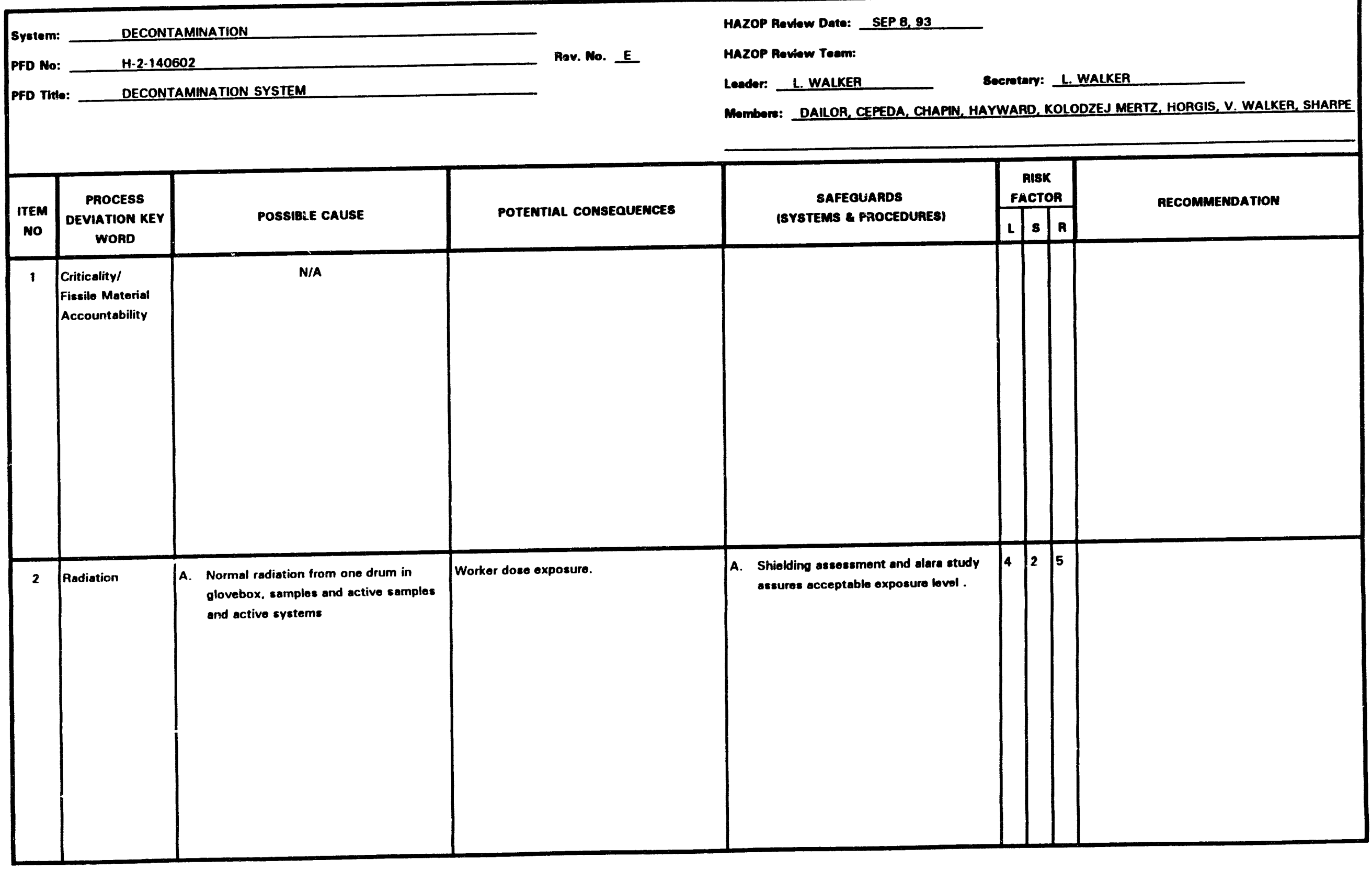


WRAP 2A ACDR PRELIMINARY HAZOP REVIEW DATA SHEET

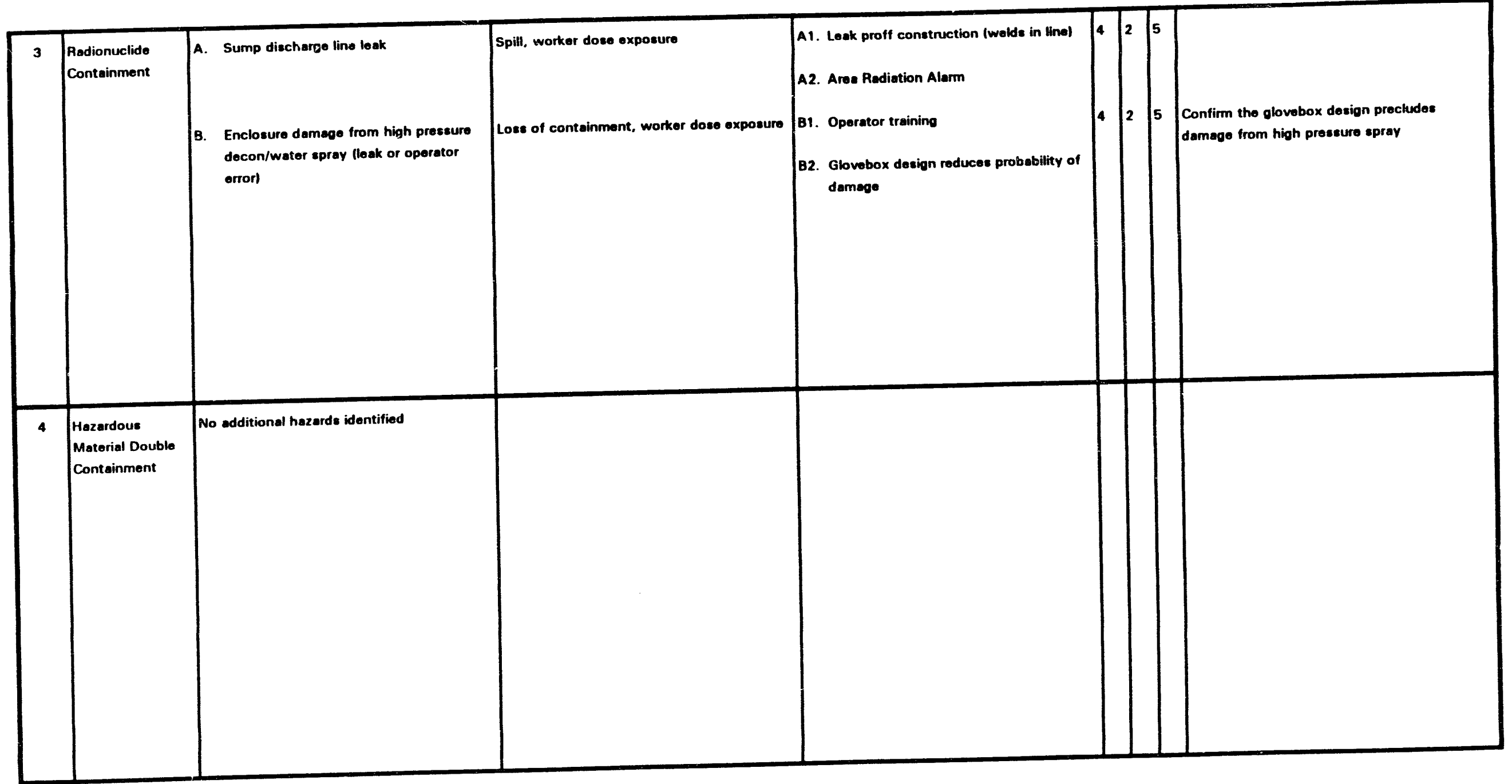


WRAP 2A ACDR PRELIMINARY HAZOP REVIEW DATA SHEET

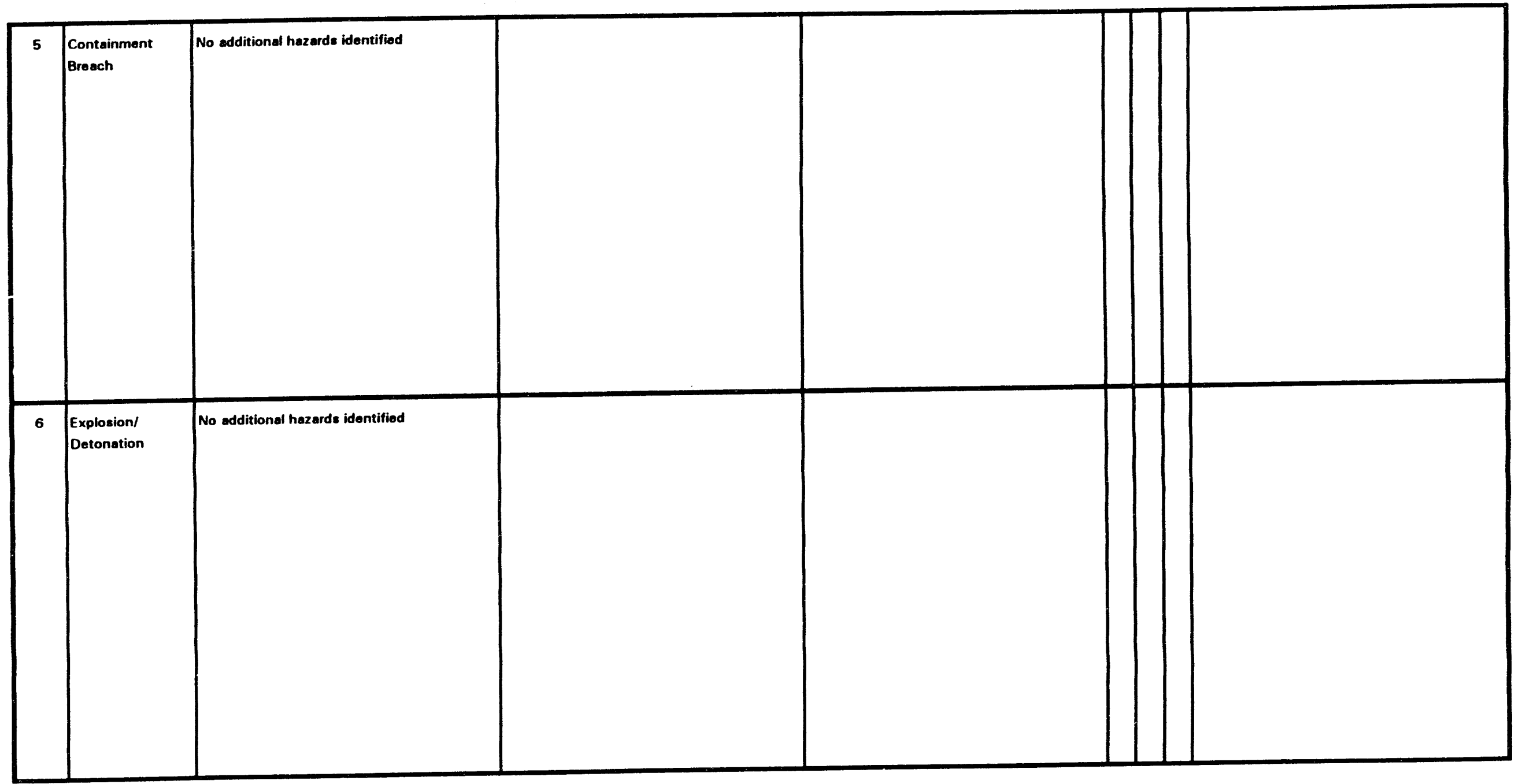


WRAP 2A ACDR PRELIMINARY HAZOP REVIEW DATA SHEET

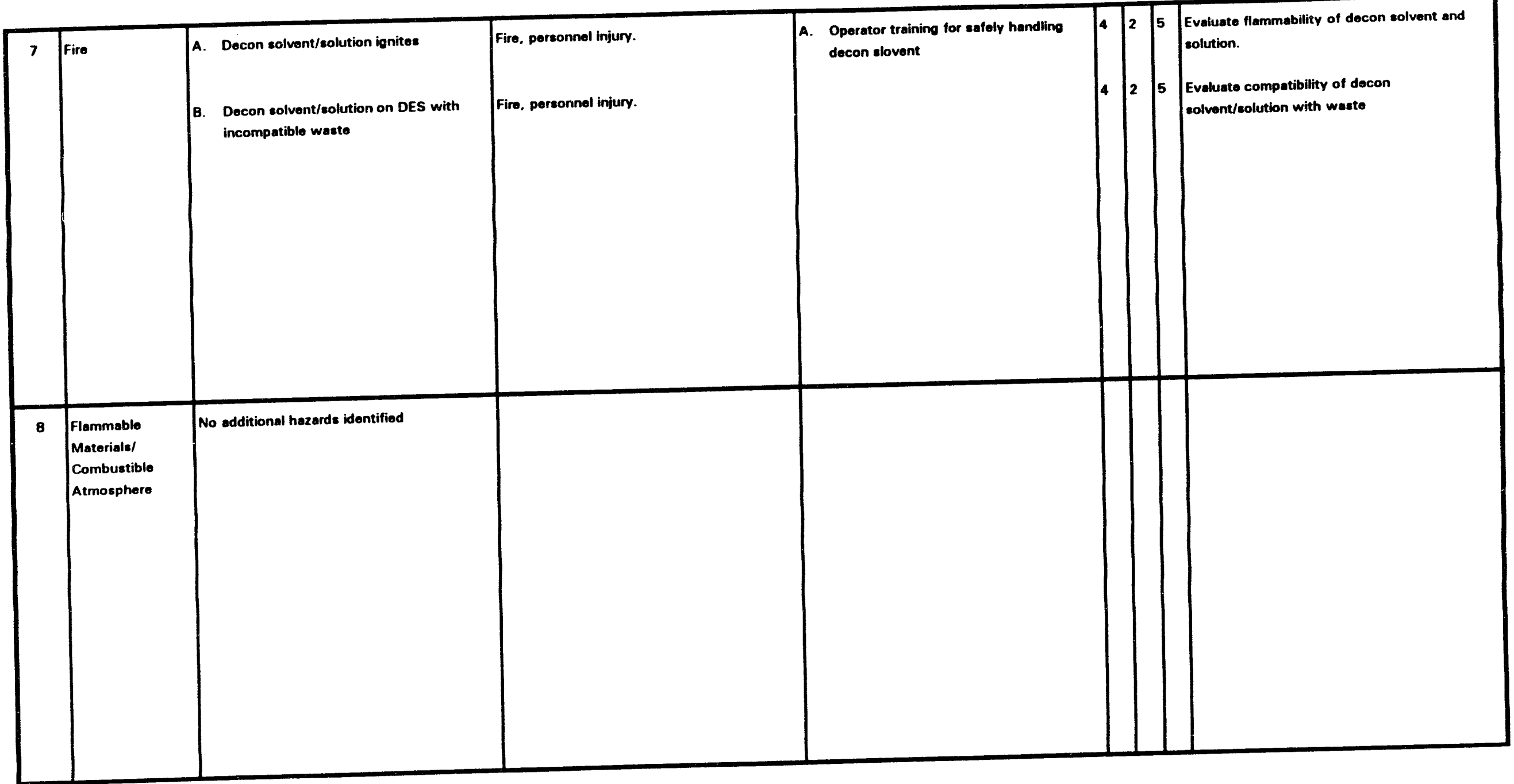




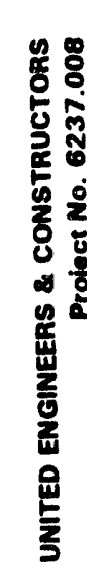

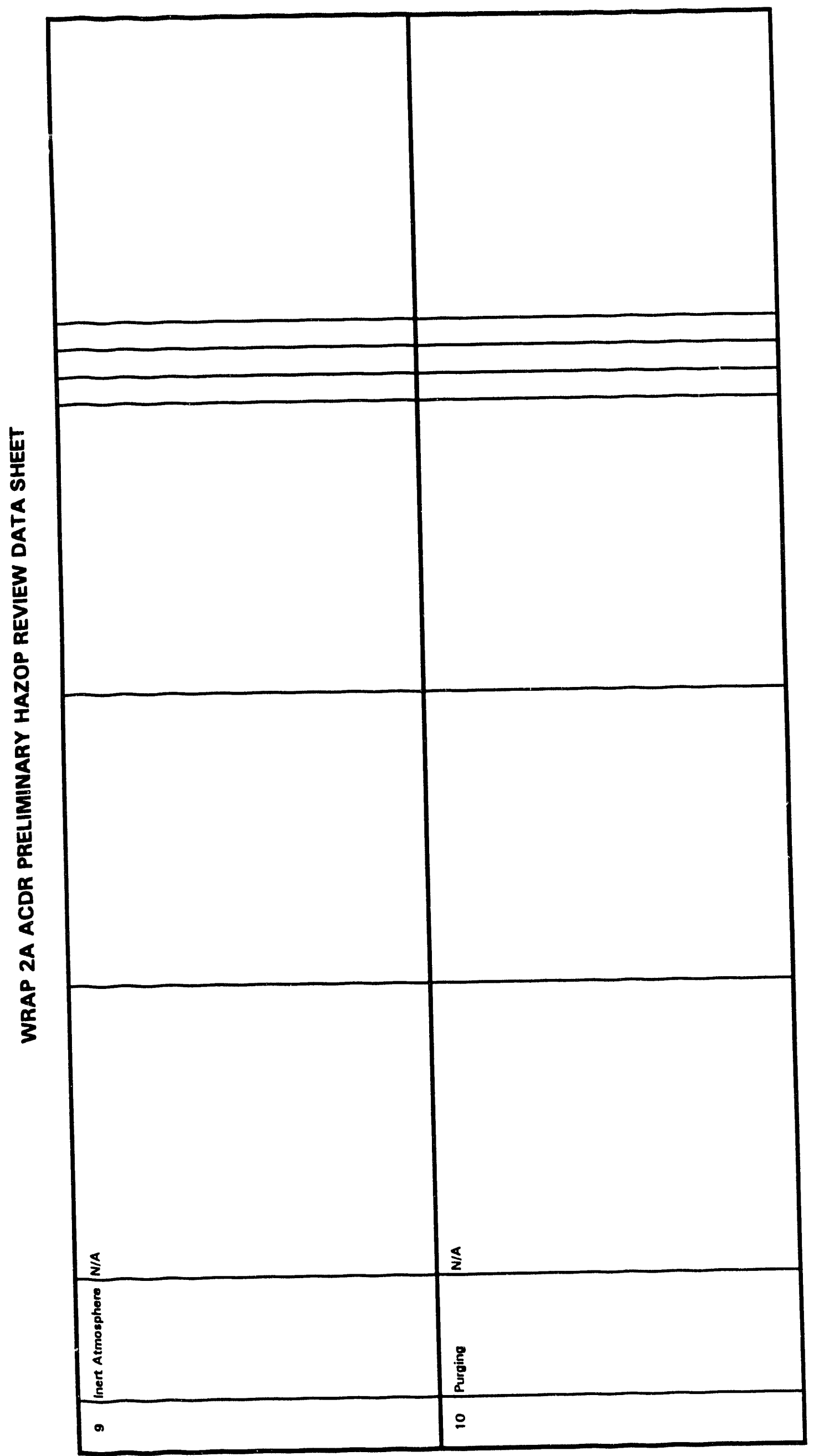


范

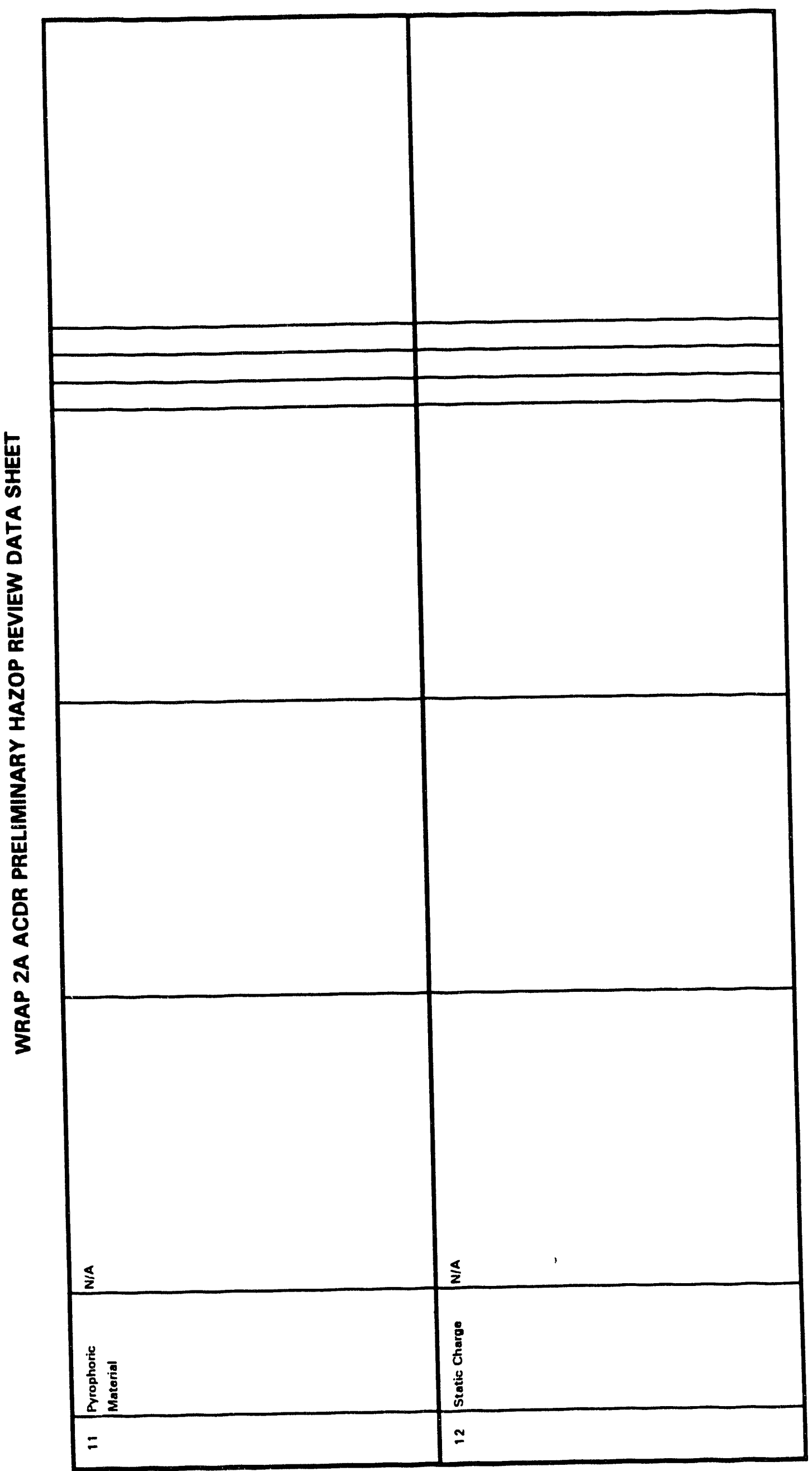


WRAP 2A ACDR PRELIMINARY HAZOP REVIEW DATA SHEET

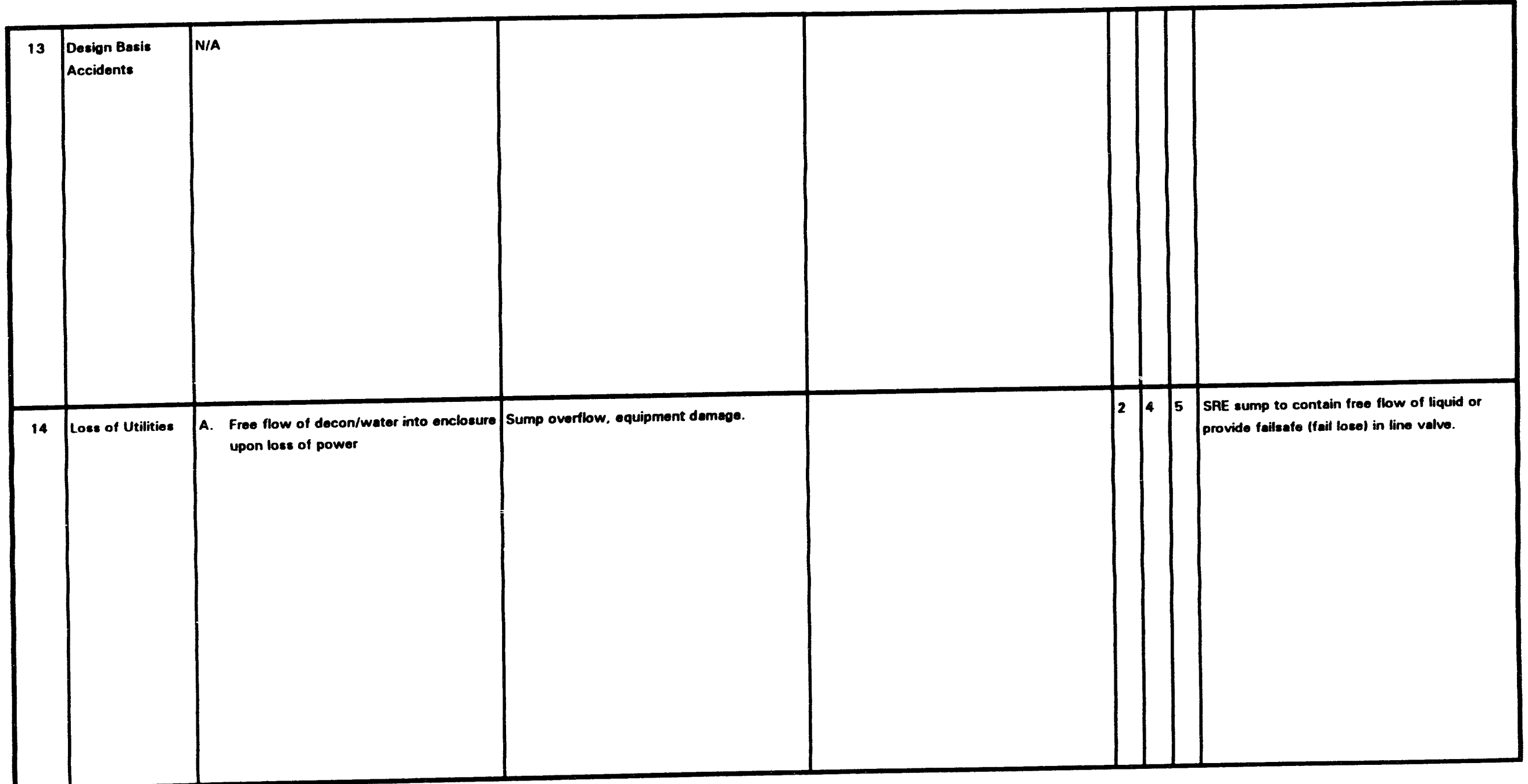


WRAP 2A ACDR PRELIMINARY HAZOP REVIEW DATA SHEET

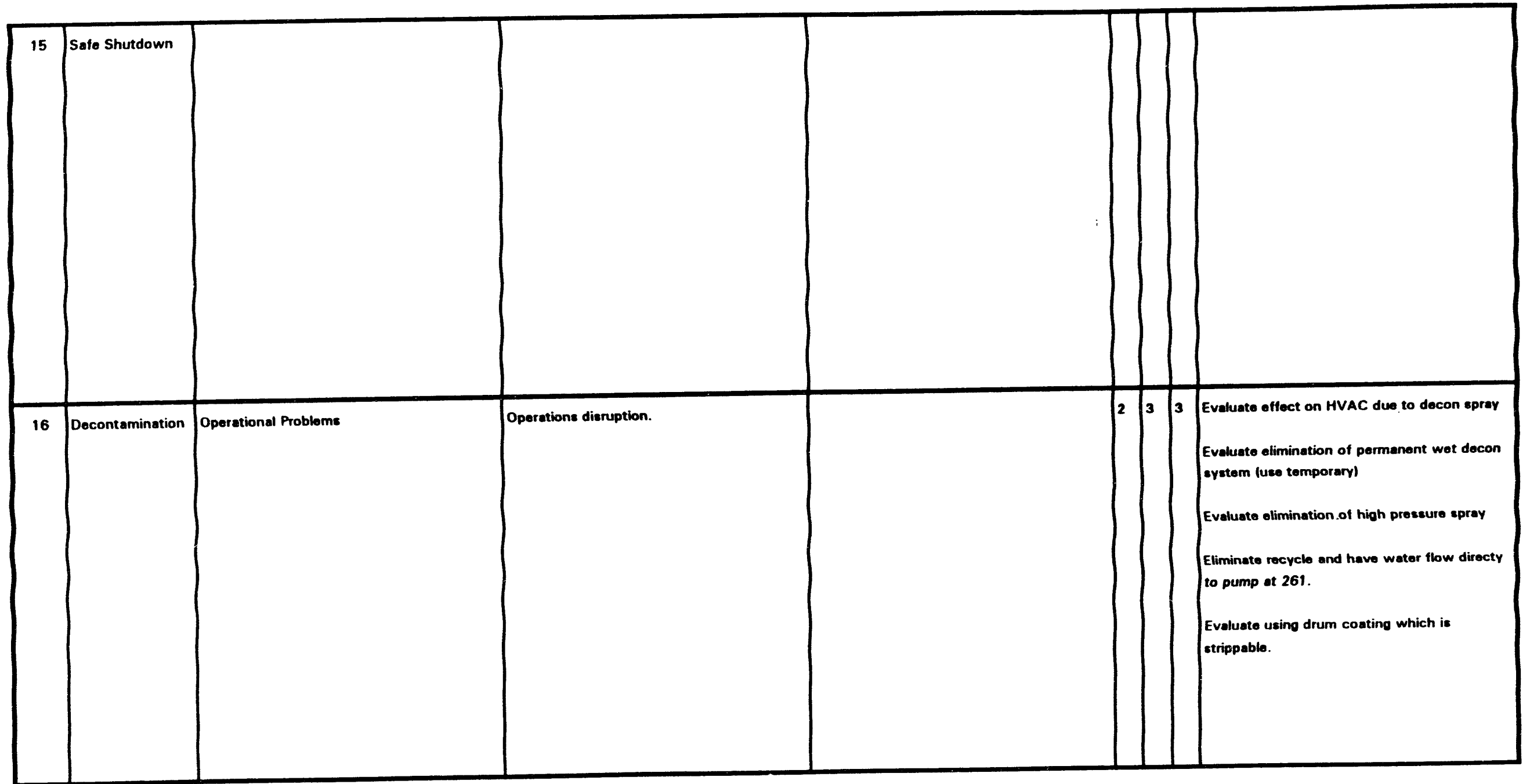


WRAP 2A ACDR PRELIMINARY HAZOP REVIEW DATA SHEET

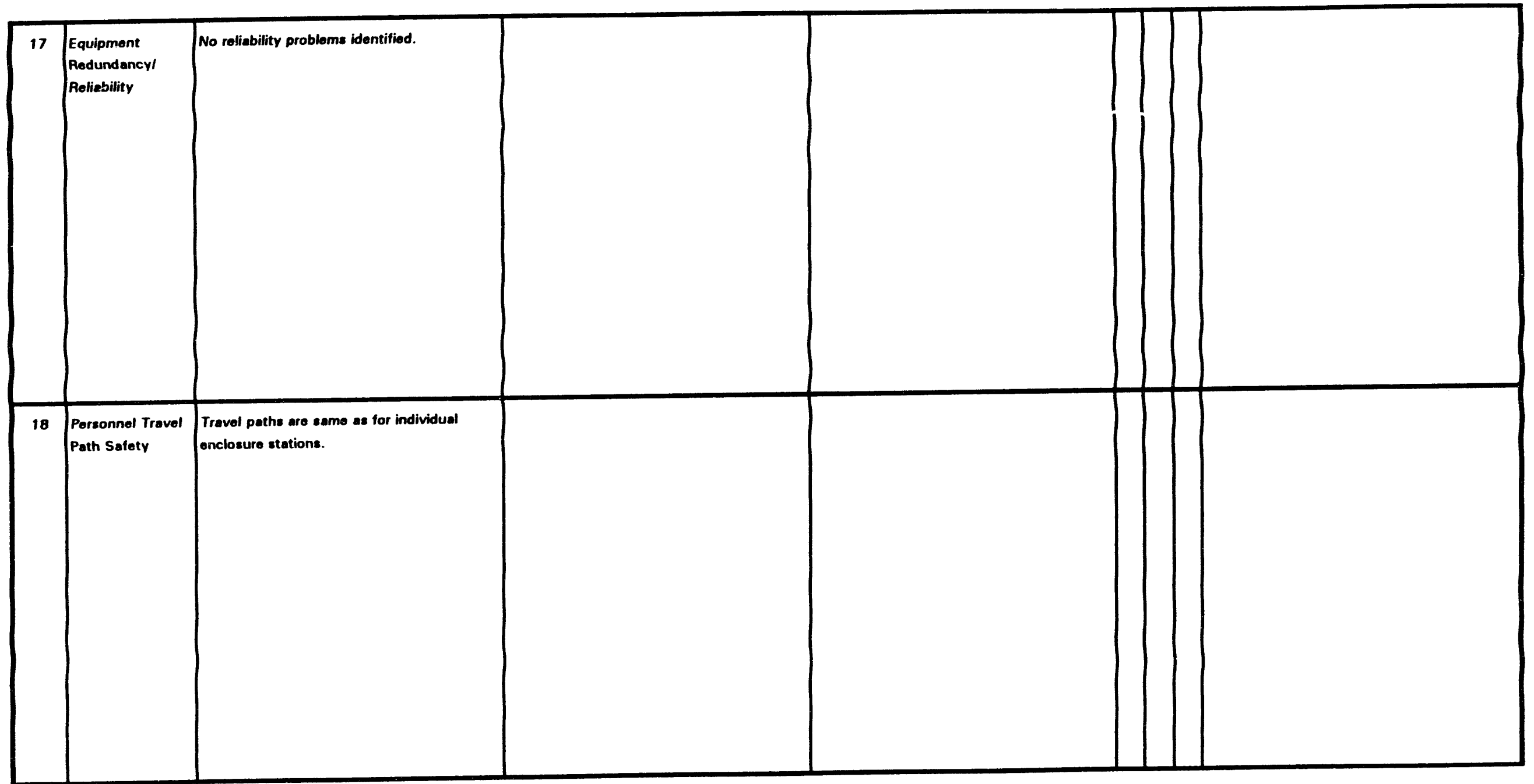


WRAP 2A ACDR PRELIMINARY HAZOP REVIEW DATA SHEET

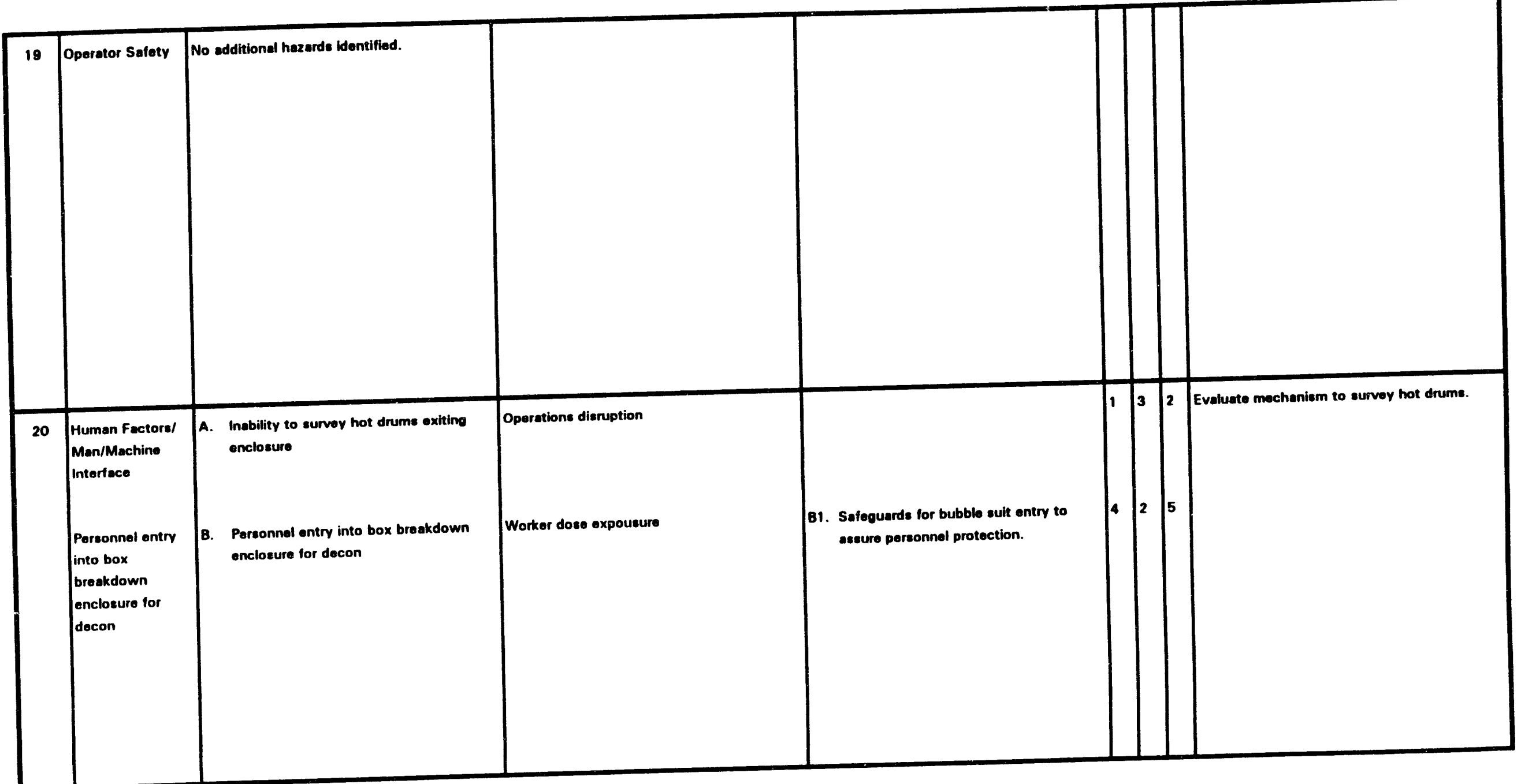


WRAP 2A ACDR PRELIMINARY HAZOP REVIEW DATA SHEET

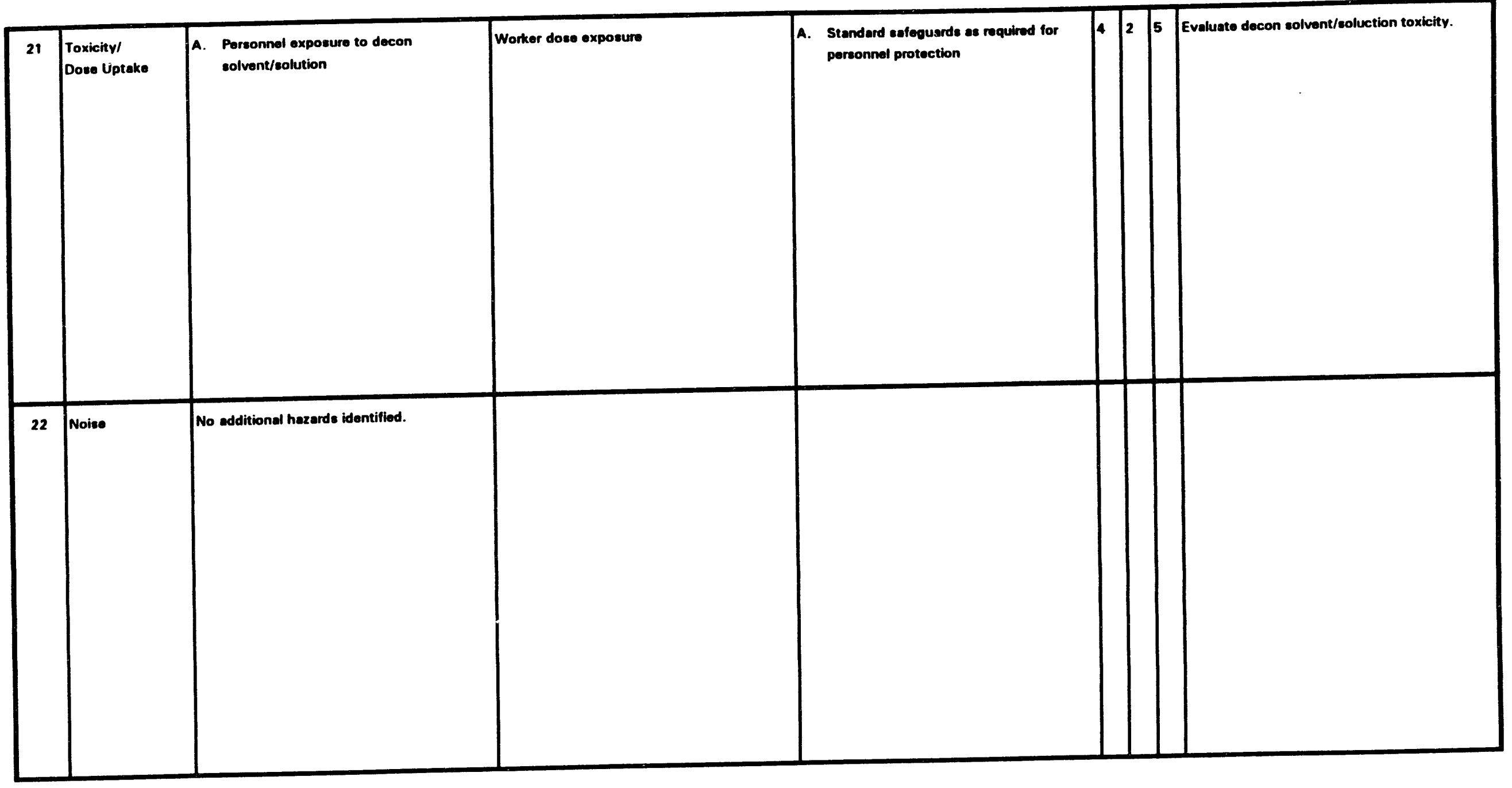


WRAP 2A ACDR PRELIMINARY HAZOP REVIEW DATA SHEET

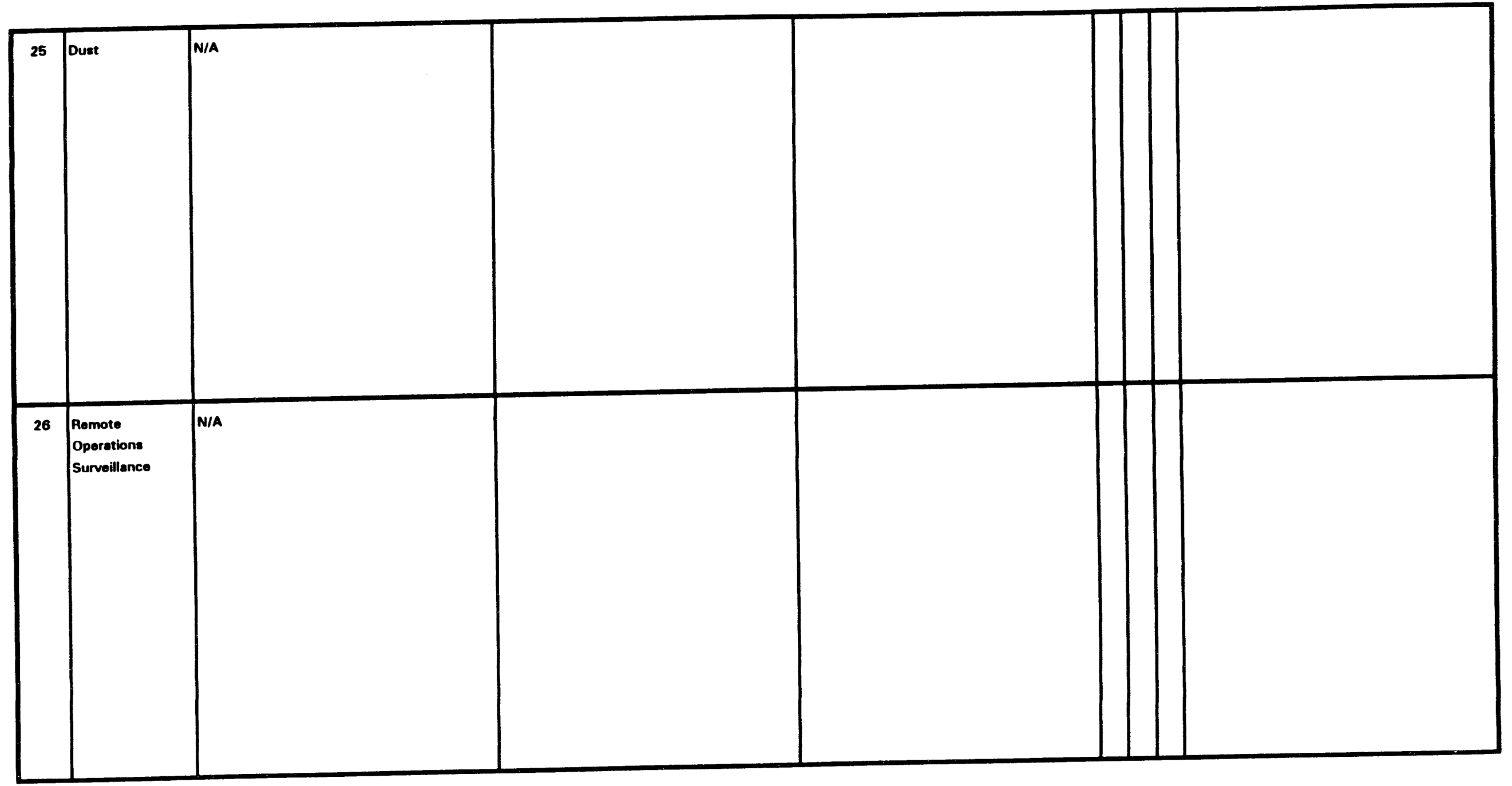


WRAP 2A ACDR PRELIMINARY HAZOP REVIEW DATA SHEET

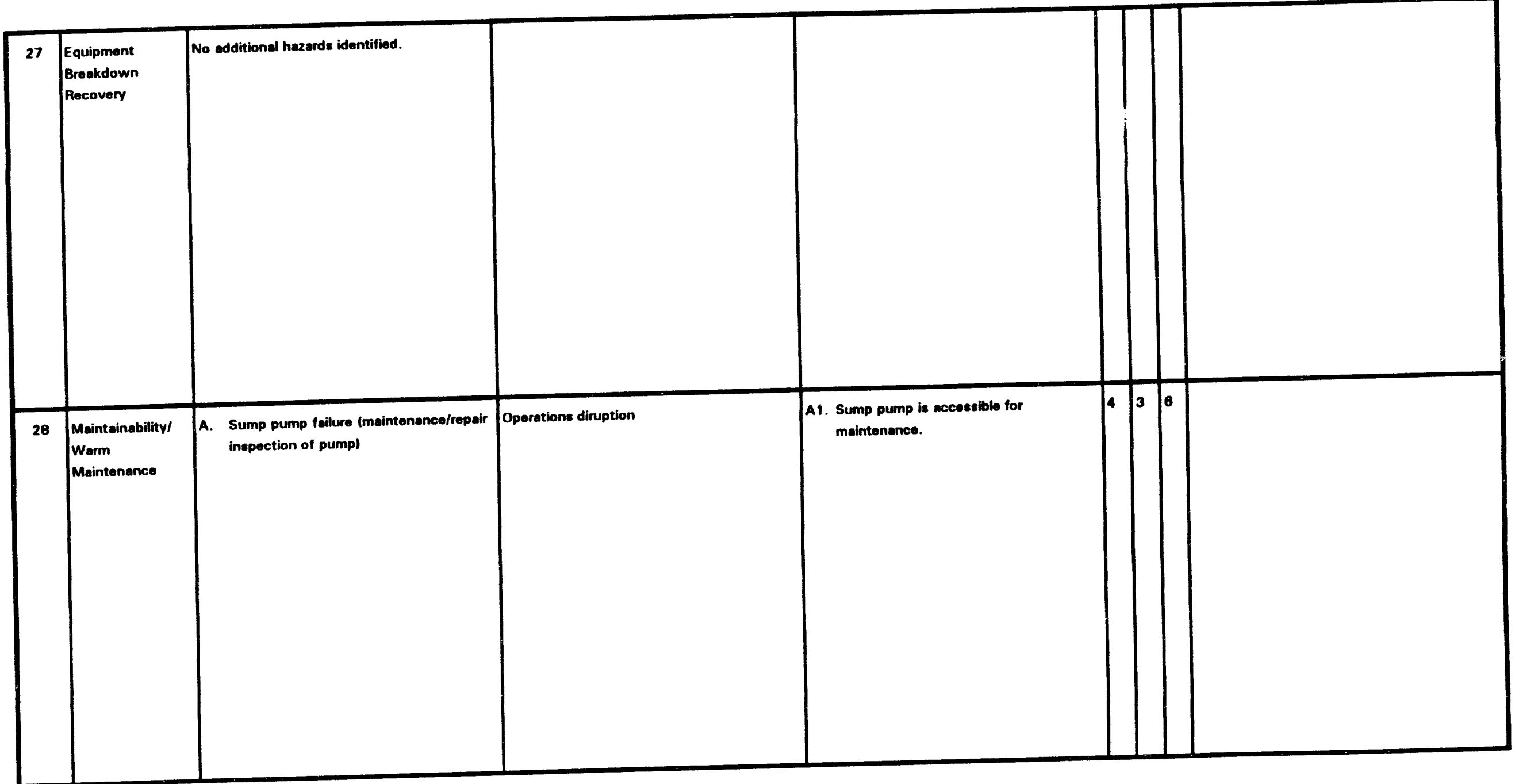


WRAP 2A ACDR PRELIMINARY HAZOP REVIEW DATA SHEET

\begin{tabular}{|c|c|c|c|c|c|c|c|}
\hline 29 & \begin{tabular}{|l} 
Testing/ \\
Inspection
\end{tabular} & A. Flow element no calibrated & $\begin{array}{l}\text { diliute/concontrated docon/woter solution, } \\
\text { operetions disuption. }\end{array}$ & $\begin{array}{l}\text { A1. Capsbility to calibrate flow oloment. } \\
\text { Procodural roquirement to limint tost } \\
\text { holist. } \\
\text { Enclosure containment. }\end{array}$ & $4{ }^{4}$ & 8 & \\
\hline 30 & \begin{tabular}{|l|} 
Primary \\
Instrument Loop \\
Failure
\end{tabular} & $\begin{array}{l}\text { A. Sump lovel control tailure. } \\
\text { B. Booster pump tailure. }\end{array}$ & 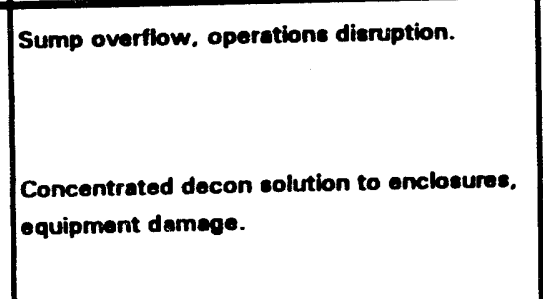 & $\begin{array}{l}\text { A1. Sump hloh lovel alorm ethutedown } \\
\text { booster pump } \\
\text { B1. Alom/linterlock shutedown docon } \\
\text { solvont pump whon booster pump } \\
\text { stops. }\end{array}$ & $\left.\int_{4}^{4}\right|^{3}$ & 6 & \\
\hline
\end{tabular}




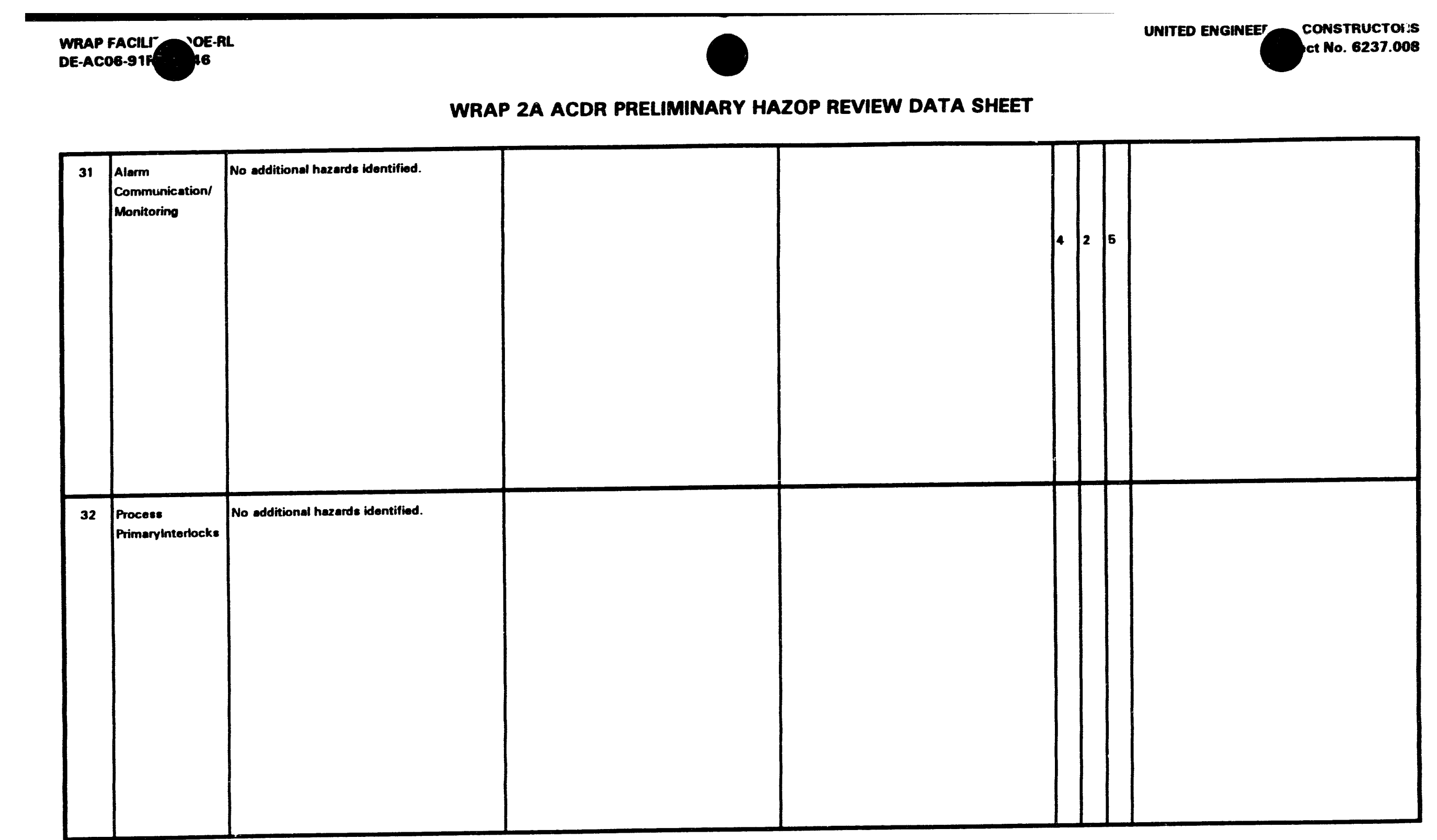


WRAP 2A ACDR PRELIMINARY HAZOP REVIEW DATA SHEET

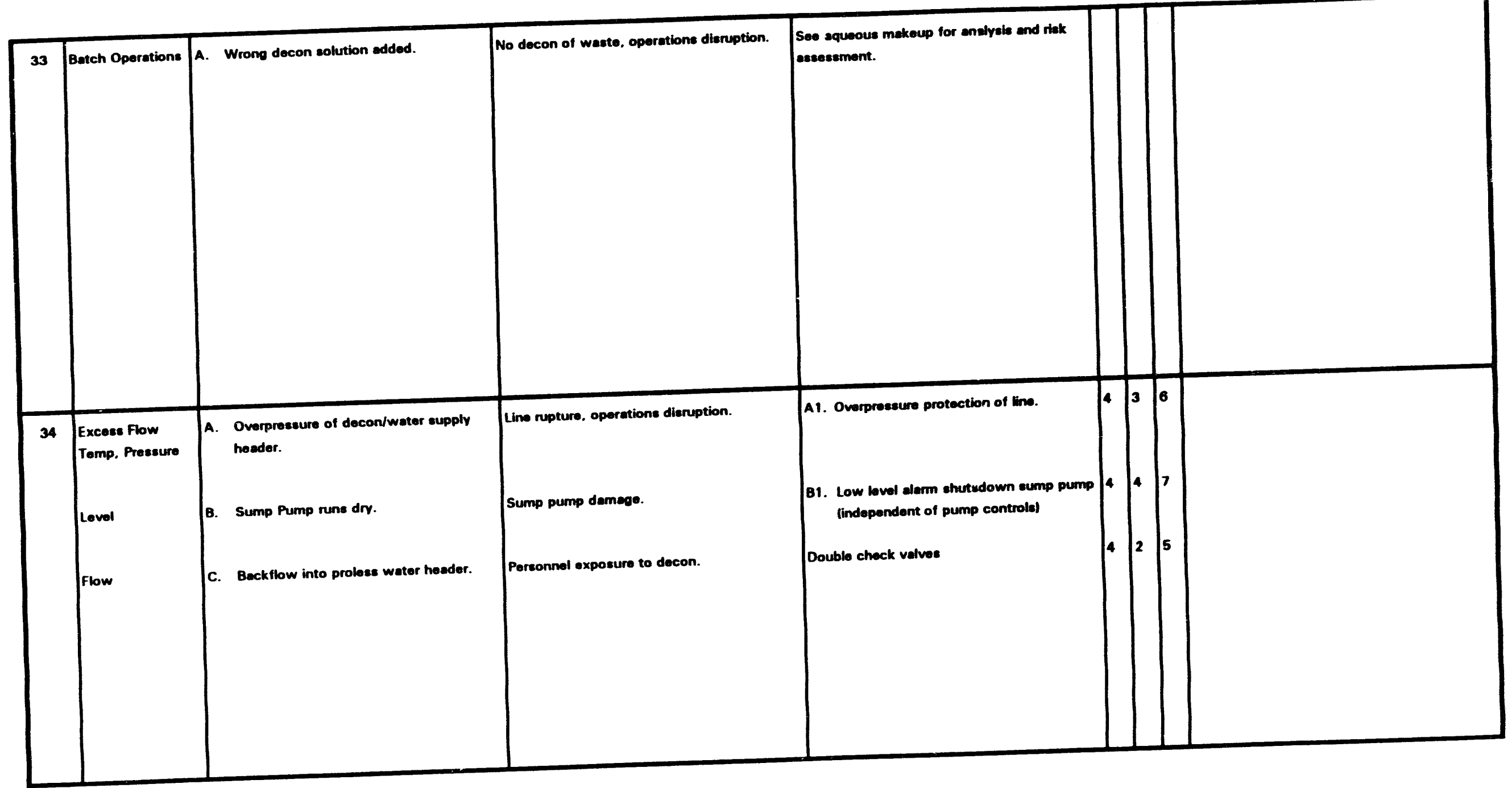




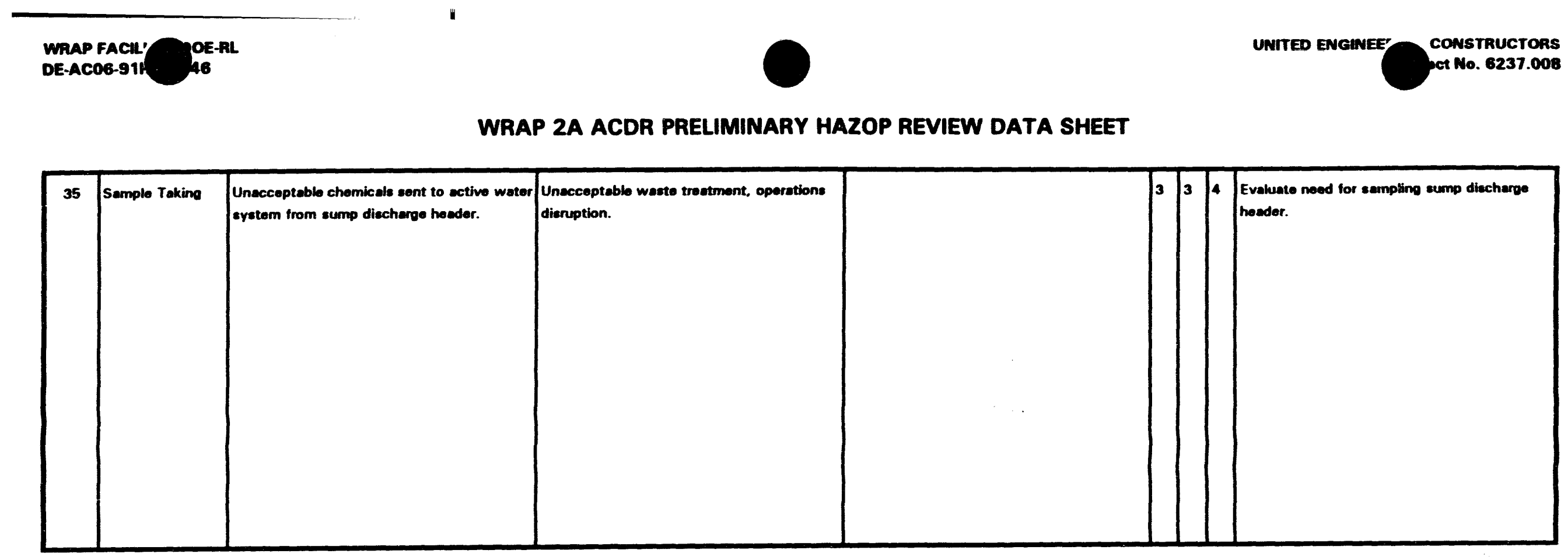


TITE: WRAP 2A AQUEOUS SOLUTION MAKEUP

HAZOP STUDY REPORT

Rovision: 0

Submitted to:

\section{UNTTED STATES \\ DEPARTMENT OF ENEROY \\ Aichland, Wochington}

Propared by:

UNTrep avelmesns

a constauctons

A Roythoon compony

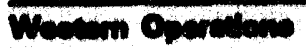


WRAP 2A

\section{AQUEOUS SOLUTION MAKEUP}

\section{HAZOP STUDY REPORT}

\subsection{INTRODUCTION}

A HAZOP study was performed on the advanced conceptual design of the Aqueous Chemical Makeup System. The HAZOPS team met on 21 September 93, and consisted of the following members:

Name

Larry Walker

Tim Sayers

Doug Chapin

William Cepeda

Valerie Walker
Company

UE\&C

UE\&C

UE\&C

UE\&C

BNFL
Role/Expertise

Leader, Scribe, Safety

Process

Process

Instrumentation and Controls

Radiological

The purpose of the HAZOPS is to identify major safety and operability problems which can best be resolved during completion of the advanced conceptual design.

\subsection{SCOPE}

This HAZOPS encompassed the Aqueous Solution Makeup System, as shown on Process Flow Diagram H-2-140687 (Rev. E).

\subsection{REFERENCES}

1. WHC-SD-W100-FDC-001 Rev. 2A, Functional Design Criteria Waste Receiving And Processing Facility Module $2 \mathrm{~A}$.

\subsection{DESCRIPTION OF AQUEOUS SOLUTION MAKEUP SYSTEM}

\subsection{Design Basis Summary}

\subsubsection{Scope}

(later)

\subsubsection{Design Goals}

(later) 


\subsubsection{Functional Requirements}

1. Storage in bulk, drums, and pallets of raw chemicals will be provided for two weeks of operation.

2. Bulk storage tanks shall be ventilated to operate under vacuum relative to ambient room pressure.

3. Segregated storage space shall be provicied for incompatible solid and liquid regents (e.g. acid and alkaline chemicals).

4. Two single-tank chemical makeup/feed trains with delivery systems shall be provided to support the specialty processing area.

5. Floor space and services to permit the installation of one additional makeup/feed train shall be provided.

6. The makeup/feed systems shall be targeted to be sized to require chemical makeup once per week, however several times per week is acceptable if economically justified.

7. Instrumentation for local and remote detection and alarms for liquid level, leaks, temperature and pressure shall be provided.

8. Appropriate sample ports shall be provided on the makeup/feed systems.

9. The makeup/feed systems shall be ventilated to operate the rom.

10. The makeup/feed system tanks shall be sized for $125 \%$ of maximum expected capacity.

11. Mixing capability shall be provided on all makeup/feed systems tanks.

12. Spill collection shall be provided for all reagents.

\subsection{Process Description Summary}

\subsubsection{Introduction}

1. The aqueous solution make-up area is utilized for receipt, storage, mixing and delivery of aqueous reagents used for $\mathrm{pH}$ adjustment and decontamination. Segregated storage space with leak detection and spill collection capabilities are provided for incompatible chemicals. Concentrated reagents are diluted in a chemical feed tank and pumped to users on demand. 


\subsubsection{Feeds and Throughput}

1. The aqueous solution make-up area, being an utility area, does not directly process any of the incoming wastes.

2. The aqueous solution make-up systems will be utilized throughout the entire life of the WRAP 2A facility.

\subsubsection{Design Requirements}

1. Storage in bulk, drums, and pallets of raw chemicals will be provided for two weeks of operation.

2. Bulk storage tanks shall be ventilated to operate under vacuum relative to ambient room pressure.

3. Segregated storage space shall be provided for incompatible solid and liquid reagents (e.g., acid and alkaline chemicals).

4. Floor space and services to permit the installation of one additional make-up/feed train shall be provided.

5. The make-up/feed systems shall be targeted to be sized to require chemical make-up once per week, however several times per week is acceptable if economically justified.

6. Instrumentation for local and remote detection and alarms for liquid lovel, leaks, temperature and pressure shall be provided as required.

7. Appropriate sample ports shall be provided on the make-up/feed systems.

8. The make-up/feed systems shall be ventilated to operate under a vacuum relative to ambient room pressure.

9. Mixing capability shall be provided on all make-up/feed systems tanks.

10. Spill collection shall be provided for all reagents.

\subsubsection{Process Selection}

1. Aqueous solution make-up systems are provided in accordance with the FDC and the process requirements of the secondary waste treatment area, the decontamination area, and the special waste area.

\subsubsection{Process Description}

1. The process scheme for the Aqueous Solution Makeup area is shown on the attached Process Flow Diagram H-2-140687. 


\subsubsection{Acid Feed System}

1. Dilute sulfuric acid is prepared in the Aqueous Solution Makeup area for use in the Secondary Waste Treatment area. Sulfuric acid is made up in 1 percent to 5 percent solutions by weight by filling the Acid Feed Tank (T-12-101) with process water to a predetermined level. A level controller automatically shuts off the process water supply to the acid feed tank upon high level indication to prevent overfilling the tank. Then the appropriate amount of concentrated sulfuric acid ( 93 percent acid by weight) is pumped from a 55-gallon drum using the Acid Drum Pump (P-12-101) to the Acid Feed Pot (T-12104). The concentrated sulfuric acid is then slowly drained into the acid feed tank while the Acid Tank Mixer (M-12-101) blends the two miscible liquids into a homogenous mixture. The dilute sulfuric acid is pumped on demand to the Secondary Waste Treatment area by the Acid Metering Pump (P-12-102). The flow rate of the pump is controlled from a pH control signal received from the Secondary Waste Treatment area. A sample connection is provided on the acid feed tank to draw a sample of dilute acid for verification of acid strength. Off-gas from the acid feed tank is directed to the Off-gas Treatment system. The acid feed tank may periodically be flushed between make-up cycles with all generated wastes being directed to the Nonactive Waste Drain Header. The acid feed tank has a 75 gallon capacity. In the event that dilute acid can be directly purchased from a chemical supplier, the acid feed tank has the capacity to hold the entire contents of a 55gallon drum.

\subsubsection{Caustic Feed System}

1. Dilute sodium hydroxide is prepared in the Aqueous Solution Make-up area for use in the Secondary Waste Treatment area and the Special Waste Treatment area. Sodium hydroxide is made up in 1 percent to 5 percent solutions by weight by filling the Caustic Feed Tank (T-12-102) with process water to a predetermined level. A level controller automatically shuts off the process water supply to the caustic feed tank upon a high level indication to prevent overfilling of the tank. Then the appropriate amount of concentrated sodium hydroxide (50 percent by weight) is pumped from a 55-gallon drum using the Caustic Drum Pump (P-12-103) to the Caustic Feed Pot (T-12-105). The concentrated sodium hydroxide is then slowly drained into the caustic feed tank while the Caustic Tank Mixer (M-12-102) blends the two miscible liquids into a homogenous mixture. The dilute sodium hydroxide is pumped on demand to the Secondary Waste Treatment area by the Secondary Waste Treatment Caustic Pump (P-12-104). The flow rate of the pump is controlled from a pH control signal received from the Secondary Waste Treatment area. Likewise, dilute sodium hydroxide is also pumped on demand to the chemical scrubber located in the Special Waste Treatment area by the Chemical Scrubber Feed Pump (P-12105). The flow rate of the pump is controlled from a pH control signal received from the chemical scrubber. A sample connection is provided on the caustic feed tank to draw a sample of dilute caustic for verification of caustic strength. Off-gas from the caustic feed tank is directed to the off-gas treatment system. The caustic feed tank may periodically be flushed between make-up cycles with all generated wastes being directed to the nonactive waste drain header. The caustic feed Tank has a 75 gallon capacity. In the event that dilute caustic can be directly purchased from a chemical supplier, the acid feed tank has the capacity to hold the entire contents of a 55-gallon drum. 


\subsubsection{Decontamination Solution System}

1. A generic chemical feed system is provided for make-up of decontamination solutions to allow flexibility in feeding a variety of chemicals. Under normal operating conditions, concentrated decontamination solutions, such as surfactants, are received in 55-gallon drums from the chemical supplier. The decontamination solution is pumped from a 55gallon drum using the Decon Solution Drum Pump (P-12-106) to the Decon Solution Feed Tank (T-12-103). The decontamination solution is pumped by the Decon Solution Metering Pump (P-12-107) on demand to an inline mixing tee located downstream of the discharge of the deconwater booster pump. The flow rate of the pump is controlled in proportion to the decontamination fluid flow rate from a flow control signal received from the decontamination area. In addition, the capability of using dilute decontamination solutions is provided. To make-up a dilute decontamination solution, the Decon Solution Feed Tank (T-12-103) is filled with process water to a predetermined level. A level controller automatically shuts off the process water supply to the Decon Feed Tank upon high level indication to prevent overfilling the tank. Then the appropriate amount of concentrated decontamination solution is pumped from a 55-gallon drum using the Decon Solution Drum Pump (P-12-106) to the Decon Solution Feed Pot (T-12-106). The concentrated decontamination solution is then slowly drained into the Decon Solution Feed Tank while the Decon Solution Tank Mixer (M-12-103) blends the two miscible liquids into a homogenous mixture. A sample connection is provided to draw a sample of decontamination solution. Off-gas from the Decon Solution Feed Tank is directed to the Off-gas Treatment system. The decon solution feed tank may periodically be flushed between make-up cycles with all generated wastes being directed to the nonactive waste drain header. The Decon Solution Feed Tank has a 150 gallon capacity to hold the entire contents of two 55-gallon drums. This tank is for concentrated decon solution and will be mixed with water to provide the required decon volume.

\subsubsection{Chemical Bulk Storage}

1. Segregated bulk storage areas are provided for acids, caustics, oxidizers and organics. Each storage area is sized to accommodate storage of two weeks of required chemicals. 


\subsection{STUDY CRITERIA AND METHODOLOGY}

This HAZOPS has utilized a predetermined set of process deviations/upset conditions to be analyzed by the HAZOPS team for each process deviation, possible courses were postulated and worst case consequences (without benefit of any safeguards were determined. Existing safeguards (design and procedural) were then identified. Those safeguards which could be reasonably expected to be present in the final design were assumed to be existing and were so documented in the HAZOPS. For each cause and effect, hazard severity and probability were qualitatively assessed (taking credit for existing safeguards which reduce hazard probability) using the criteria shown in Table 1. The overall risk rating for each hazard was then determined using the risk ranking matrix shown on Table 2 . Recommendations were proposed by the HAZOPS team in instances required by the implementation criteria shown in Table 2. 
TABLE 1

HAZARD SEVERITY AND PROBABILITY CLASSIFICATION CRITERIA

\begin{tabular}{|l|l|l|l|l|}
\hline \multirow{2}{*}{ Target Hazard } & \multicolumn{1}{|c|}{ Catastrophic (1) } & \multicolumn{1}{|c|}{ Extensive (2) } & \multicolumn{1}{c|}{ Moderate (3) } & Operational (4) \\
\cline { 2 - 5 } & $\begin{array}{l}\text { Multiple irreversible } \\
\text { injuries; may include a } \\
\text { fatality }\end{array}$ & $\begin{array}{l}\text { Single irreversible or } \\
\text { several reversible injuries } \\
\text { (no fatalities) } \\
\text { OR }\end{array}$ & Several reversible injuries & OR \\
\hline OR & $\begin{array}{l}\text { Fatalities or irreversible } \\
\text { injuries } \\
\text { OR }\end{array}$ & Several injuries & Single injury & OR \\
\hline Facility & $\begin{array}{l}\text { Partial or full demolition of } \\
\text { facility }\end{array}$ & $\begin{array}{l}\text { Rupture or similar loss of } \\
\text { containment }\end{array}$ & $\begin{array}{l}\text { Major equipment damage } \\
\text { leading to one month or } \\
\text { more facility downtime }\end{array}$ & $\begin{array}{l}\text { Equipment damage } \\
\text { leading to several days of } \\
\text { facility downtime or other } \\
\text { Operational penalty }\end{array}$ \\
\hline Environment & $\begin{array}{l}\text { Major environmental } \\
\text { impact with significant } \\
\text { cleanup/lability costs }\end{array}$ & $\begin{array}{l}\text { Groundwater, soil, or } \\
\text { public sewer } \\
\text { contamination }\end{array}$ & $\begin{array}{l}\text { Minor spill or release } \\
\text { resulting in permit violation }\end{array}$ & OR \\
\hline
\end{tabular}

\section{LIKELIHOOD CLASSIFICATION}

\begin{tabular}{||l|l|}
\hline Highly Likely (1) & $\begin{array}{l}\text { Event has occurred at this facility - or - other facility - or - is expected to occur several times during the } \\
\text { next } 10 \text { years. }\end{array}$ \\
\hline Likely (2) & $\begin{array}{l}\text { Event has occurred at this facility - or - is possible to occur at this facility several times during the next } \\
30 \text { years. }\end{array}$ \\
\hline Unlikely (3) & $\begin{array}{l}\text { Event may have occurred at another facility - or - is possible to occur at this facility at least once in the } \\
\text { next } 50 \text { years. }\end{array}$ \\
\hline Extremely Unlikely (4) & $\begin{array}{l}\text { Event is not likely to ever occur in this facility, given a continuation of the current levels of training, } \\
\text { procedures, maintenance, inspection, testing, and other applicable process safety management system } \\
\text { support. }\end{array}$ \\
\hline
\end{tabular}

\section{TABLE 2}

RISK RANKING MATRIX AND IMPLEMENTATION CRITERIA 


\begin{tabular}{|c|c|c|c|}
\hline Likelihood & & & \\
\hline Highly Likely (1) & 4 & 2 & 1 \\
\hline Likely (2) & 5 & 3 & 2 \\
\hline Unlikely (3) & 6 & 4 & 3 \\
\hline Extremely Unlikely (4) & 7 & 6 & 5 \\
\hline
\end{tabular}

RISK RANKING IMPLEMENTATION

\begin{tabular}{|c|l|}
\hline Risk Ranking & \multicolumn{1}{|c|}{ Implication } \\
\hline 1 & $\begin{array}{l}\text { Risk level - Very significant } \\
\text { Recommendation = Required from the HAZOPS team } \\
\text { Implementation - Begins immediately }\end{array}$ \\
\hline 2 & $\begin{array}{l}\text { Risk level - Significant } \\
\text { Recommendation = Required from the HAZOPS team } \\
\text { Implementation - Begins within three months }\end{array}$ \\
\hline 3 & $\begin{array}{l}\text { Risk level - Not very significant } \\
\text { Recommendation = Required from the HAZOPS team } \\
\text { Implementation - Begins within one year }\end{array}$ \\
\hline 4 & $\begin{array}{l}\text { Risk level - Not significant, but may be an operational problem } \\
\text { Recommendation = At the discretion of the HAZOPS team } \\
\text { Implementation - As soon as practical, not later than the next major plant turnaround }\end{array}$ \\
\hline 5,6, or 7 & $\begin{array}{l}\text { Risk level - Negligible, but may be an operational problem } \\
\text { Recommendation = At the discretion of the HAZOPS team } \\
\text { Implementation - To be evaluated by management }\end{array}$ \\
\hline
\end{tabular}




\subsection{RESULTS AND CONCLUSIONS}

Because this HAZOPS is performed relatively early in the design phase, existing safeguards have not been fully documented on the process flow diagrams (these would mostly be shown on the P\&ID's developed during Title Design). However, the HAZOPS team assumed specific safeguards would be present in the final design if it appear reasonable to expect this. These assumed safeguards are documented on the HAZOPS worksheets and credit was taken for these presumed safeguards when assessing risk. During Title Design, the presence of these safeguards need to be verified to validate the conclusions of this HAZOPS.

Eight potential safety and operability problems were identified and evaluated in this HAZOPS. Of these, seven were assessed to have a negligible risk level. The remaining one involves a potential safety and operational problem having a risk ranking classified as being not very significant. For this potential problem, the HAZOPS team has recommended that an additional safeguard be incorporated into the WRAP $2 A$ design.

Table 3 presents a summary of changes to be made in the process flow diagram, assumed design safeguards, and additional safeguards to be evaluated for incorporation into the design.

The HAZOPS is documented in the attached HAZOPS worksheets. 


\section{TABLE 3}

\section{AQUEOUS SOLUTION MAKEUP HAZOPS SUMMARY}

\section{PROCESS FLOW DIAGRAM CHANGES}

1. Denote separation/containment of bulk storage drums and feed tanks lincompatible materials).

2. Add vent line for each feed pot.

3. Denote that tank vent lines discharge "to safe location."

\section{ASSUMED DESIGN SAFEGUARDS}

1. All design basis requirements (e.g., personal protection equipment, safety showers for acid/caustic materials).

\section{EVALUATEIINCORPORATE INTO TITLE I DESIGN}

1. Specific bulk chemicals for use in process (PE encapsulation instead of VES). 
WRAP 2A ACDR PRELIMINARY HAZOP REVIEW DATA SHEET

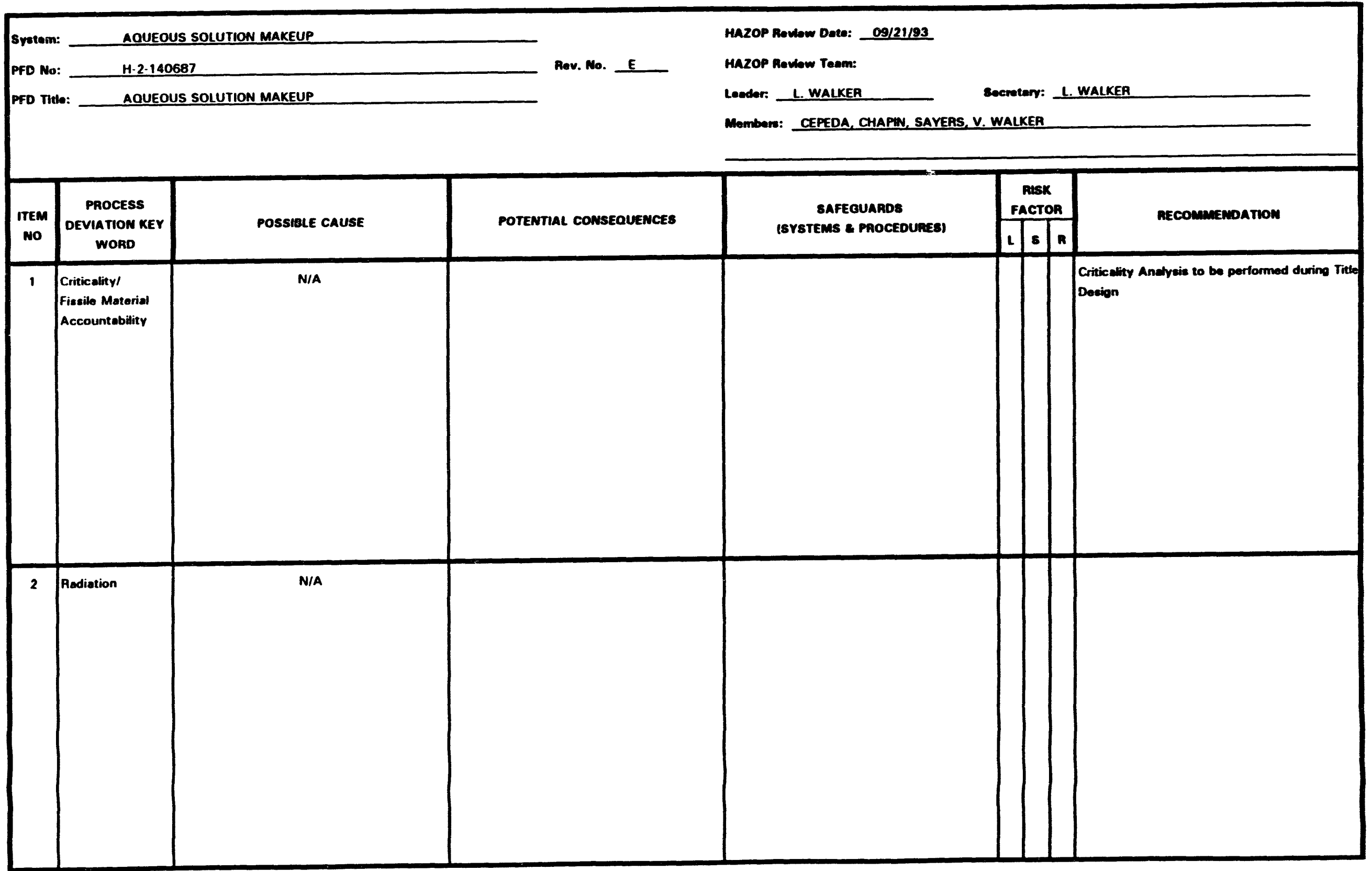



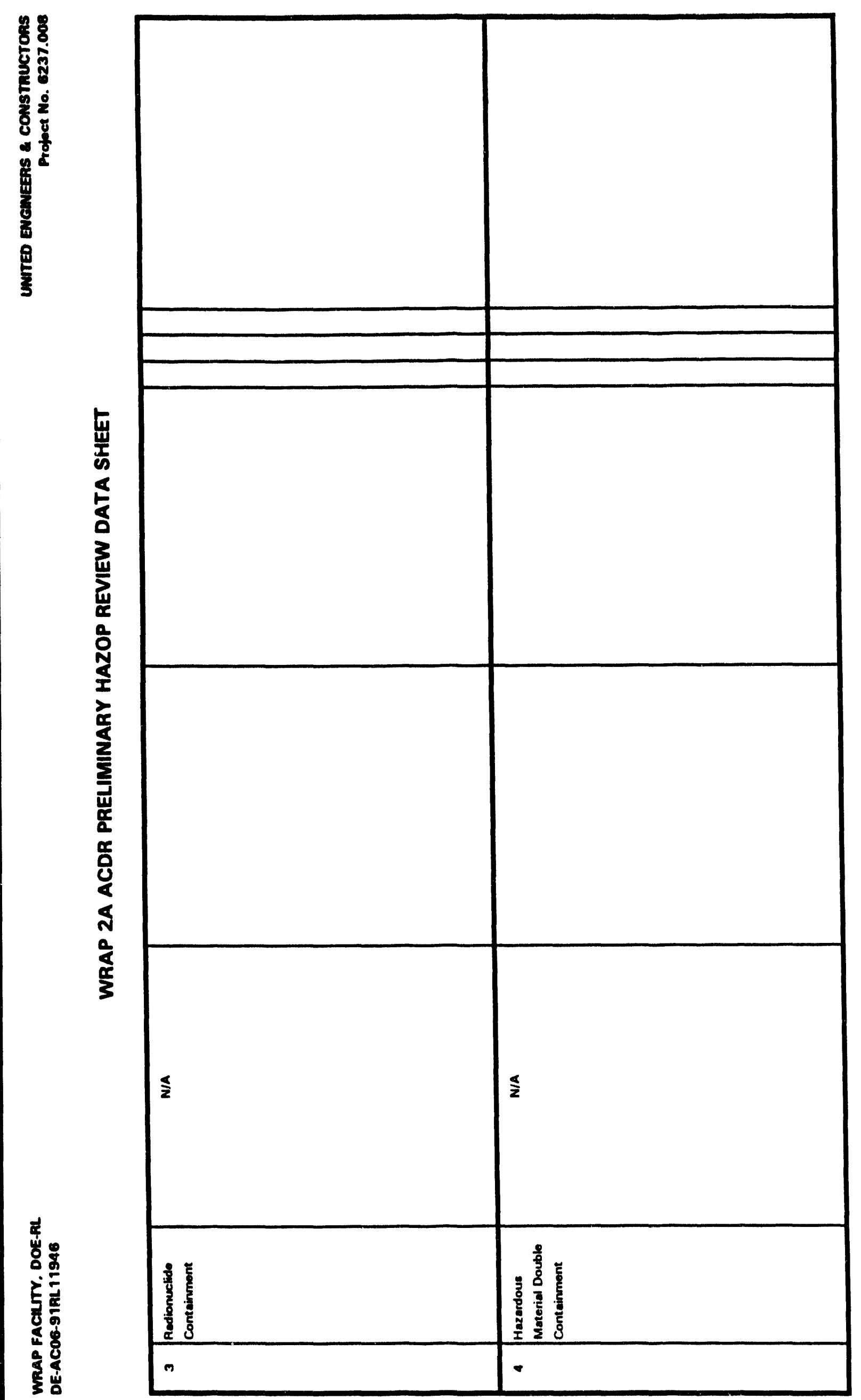
WRAP 2A ACDR PRELIMINARY HAZOP REVIEW DATA SHEET

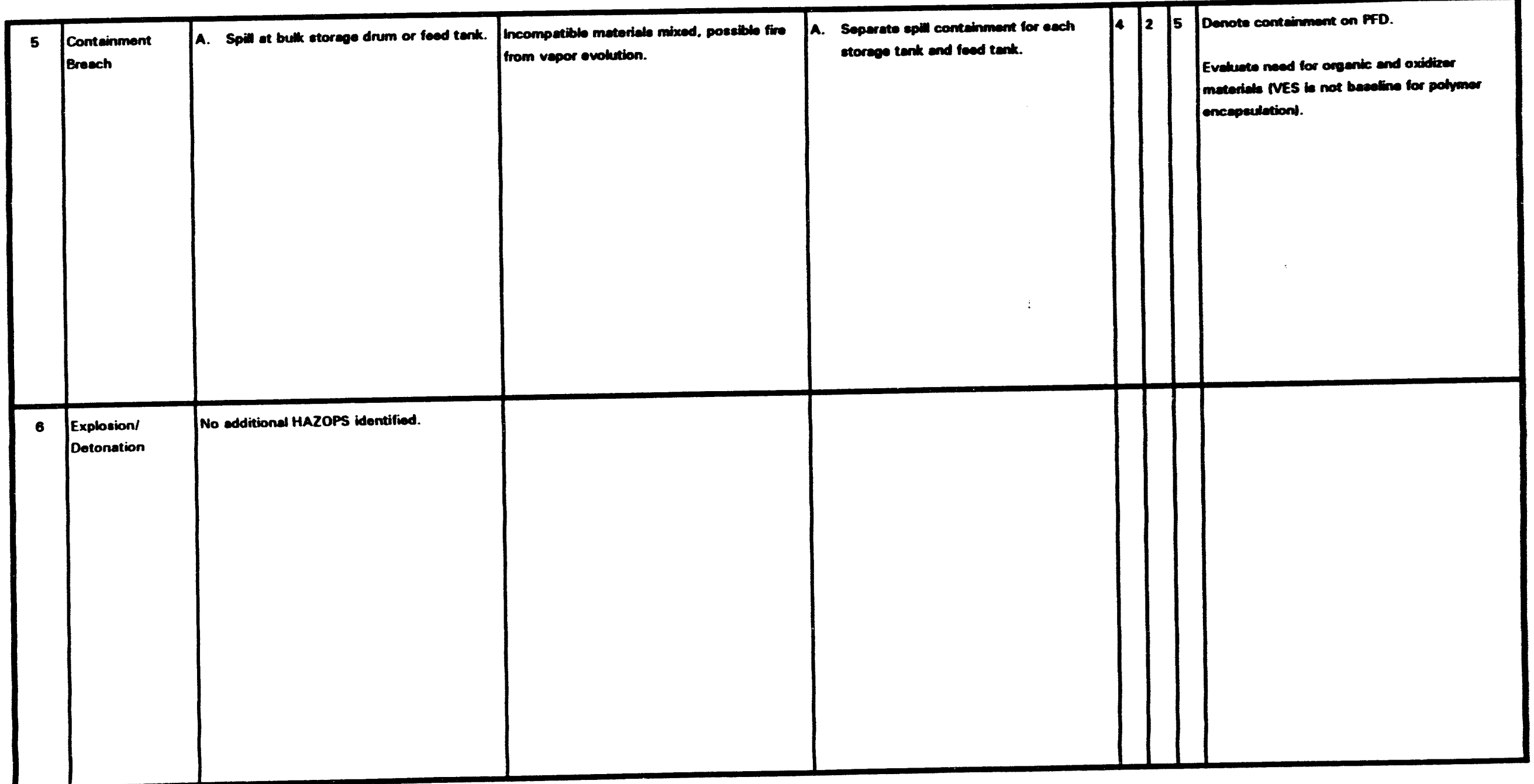




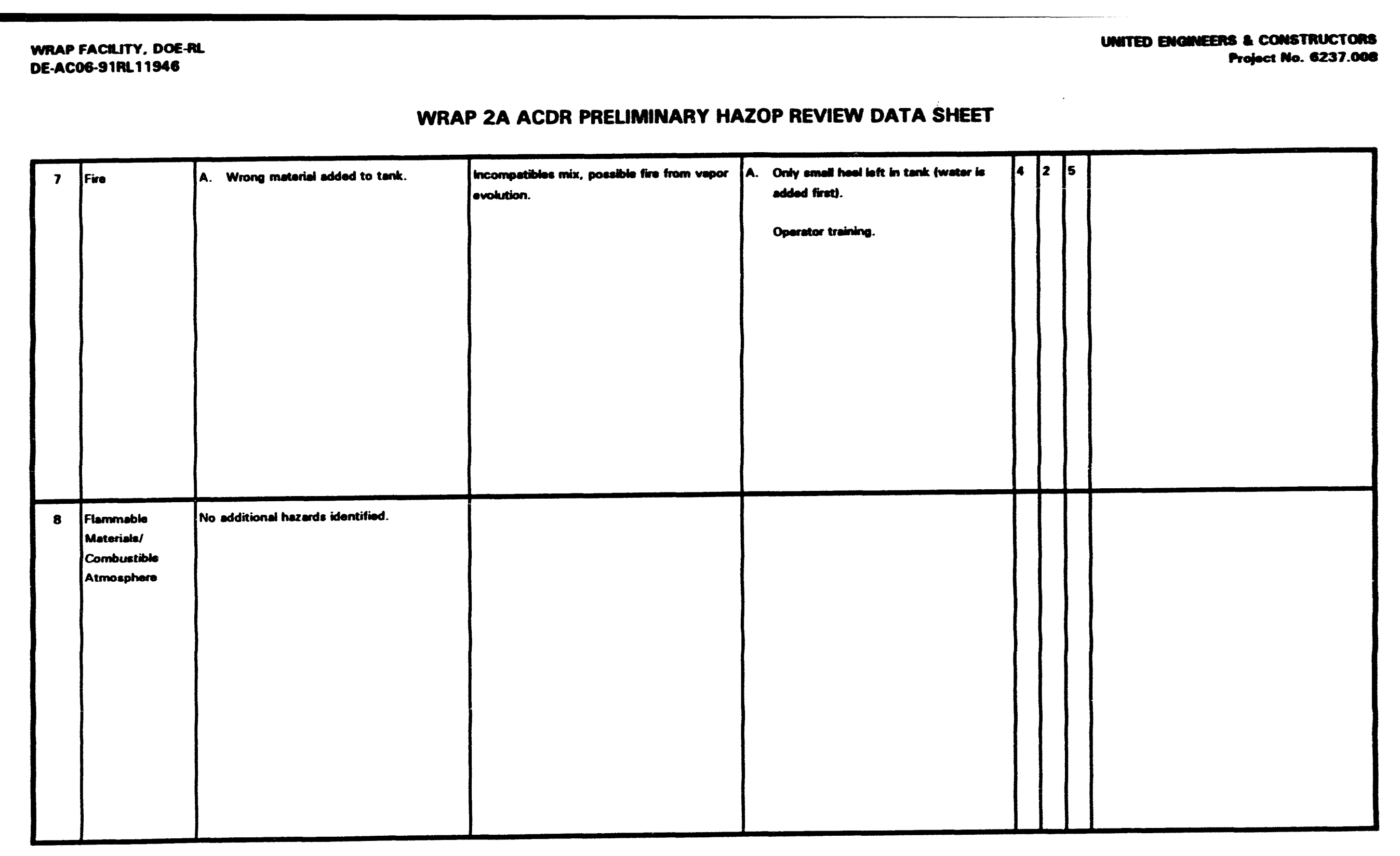


WRAP 2A ACDR PRELIMINARY HAZOP REVEW DATA SHEET

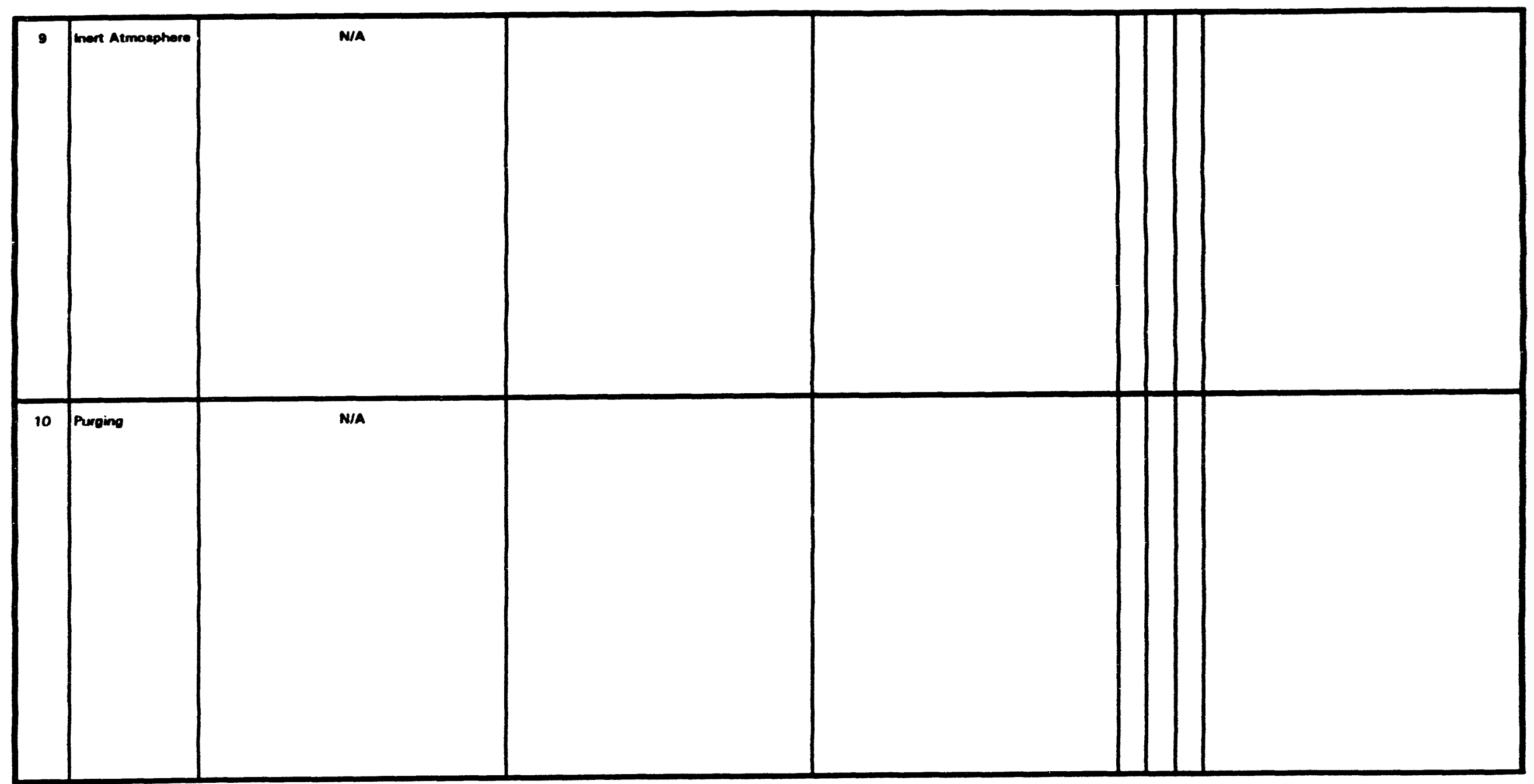




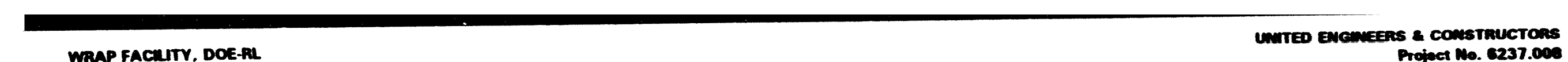

DE-ACO6-91AL 11946

WRAP 2A ACDR PRELIMINARY HAZOP REVIEW DATA SHEET

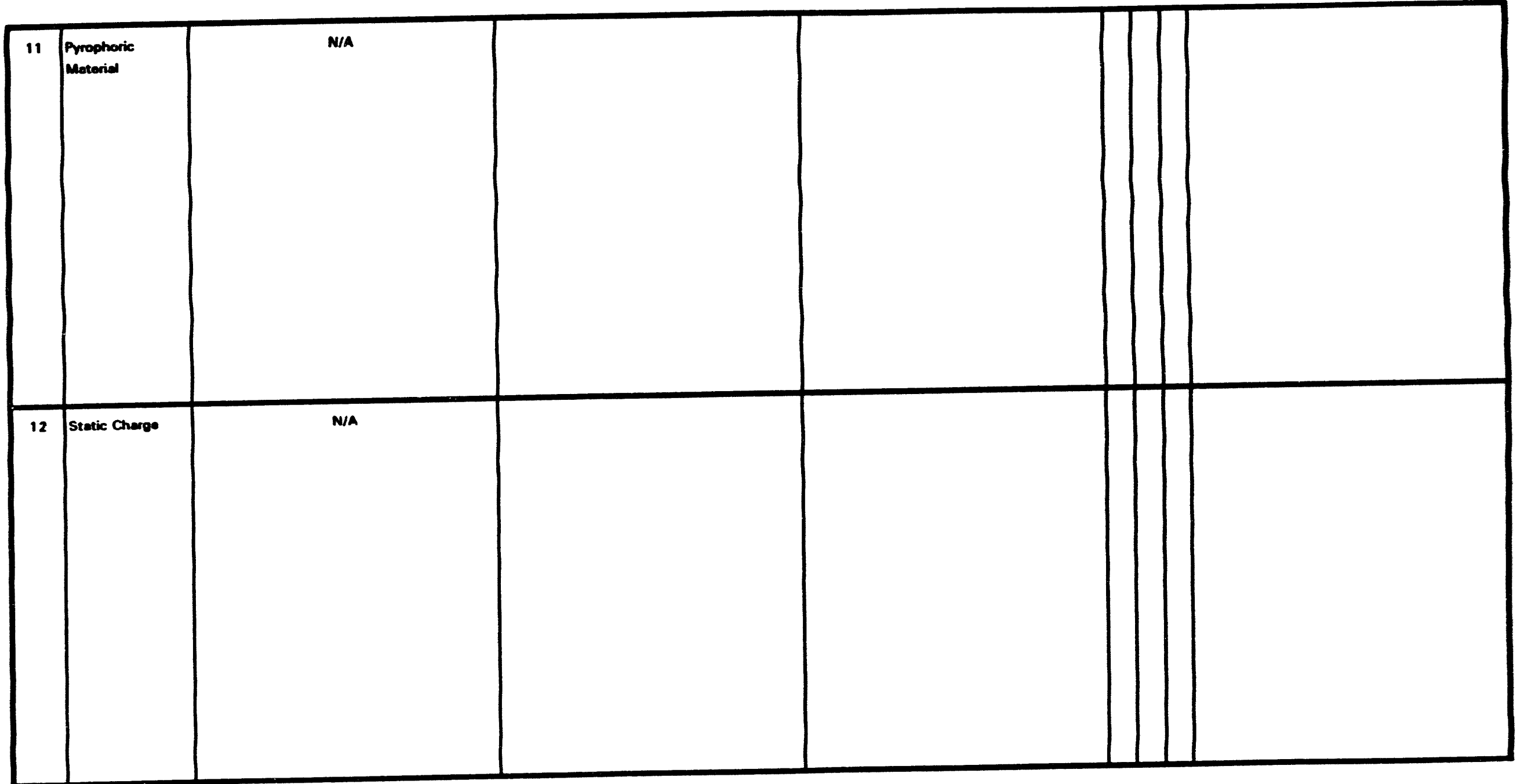




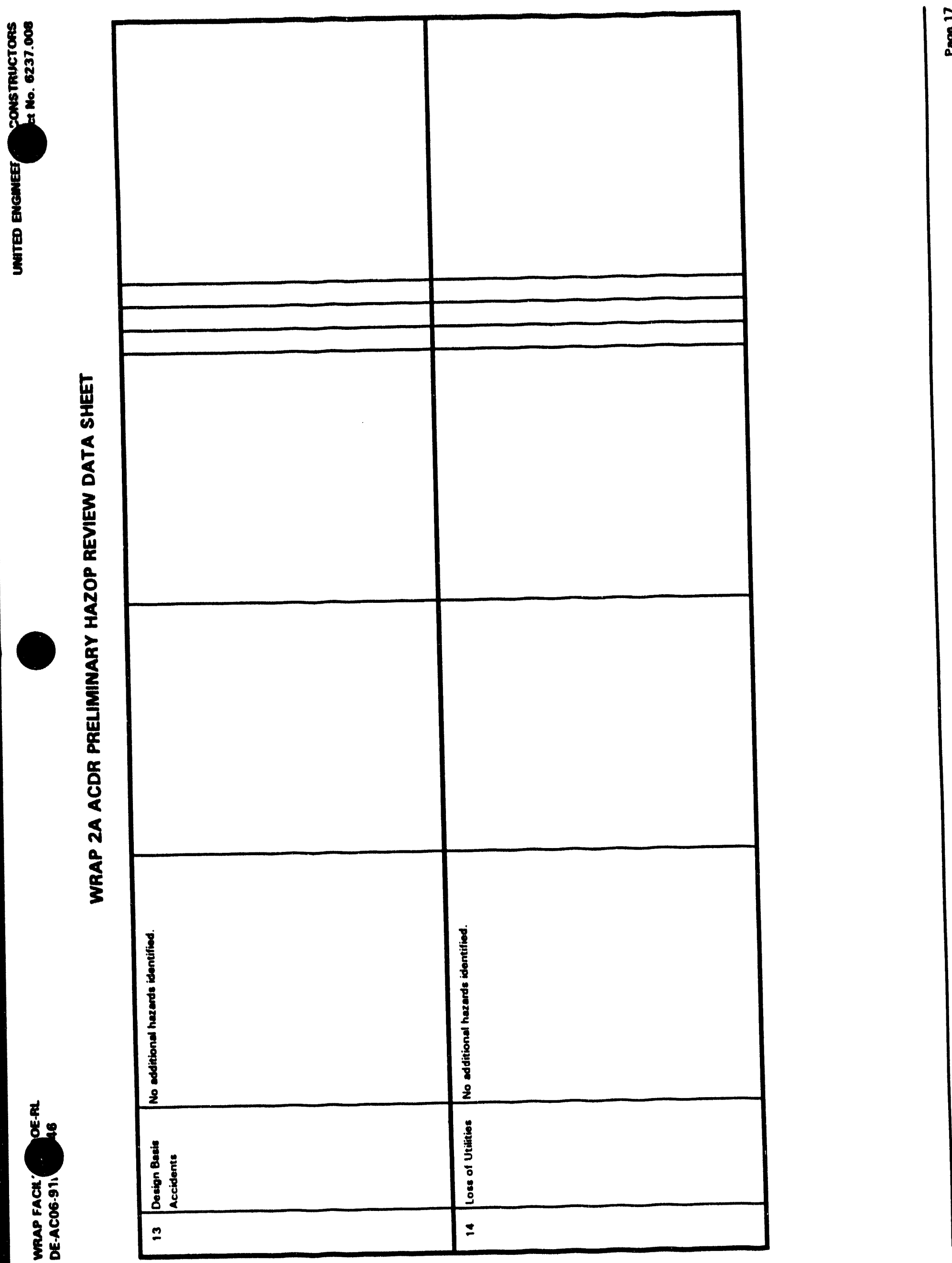

倍 


$$
81
$$


WRAP 2A ACDR PRELIMINARY HAZOP REVIEW DATA SHEET

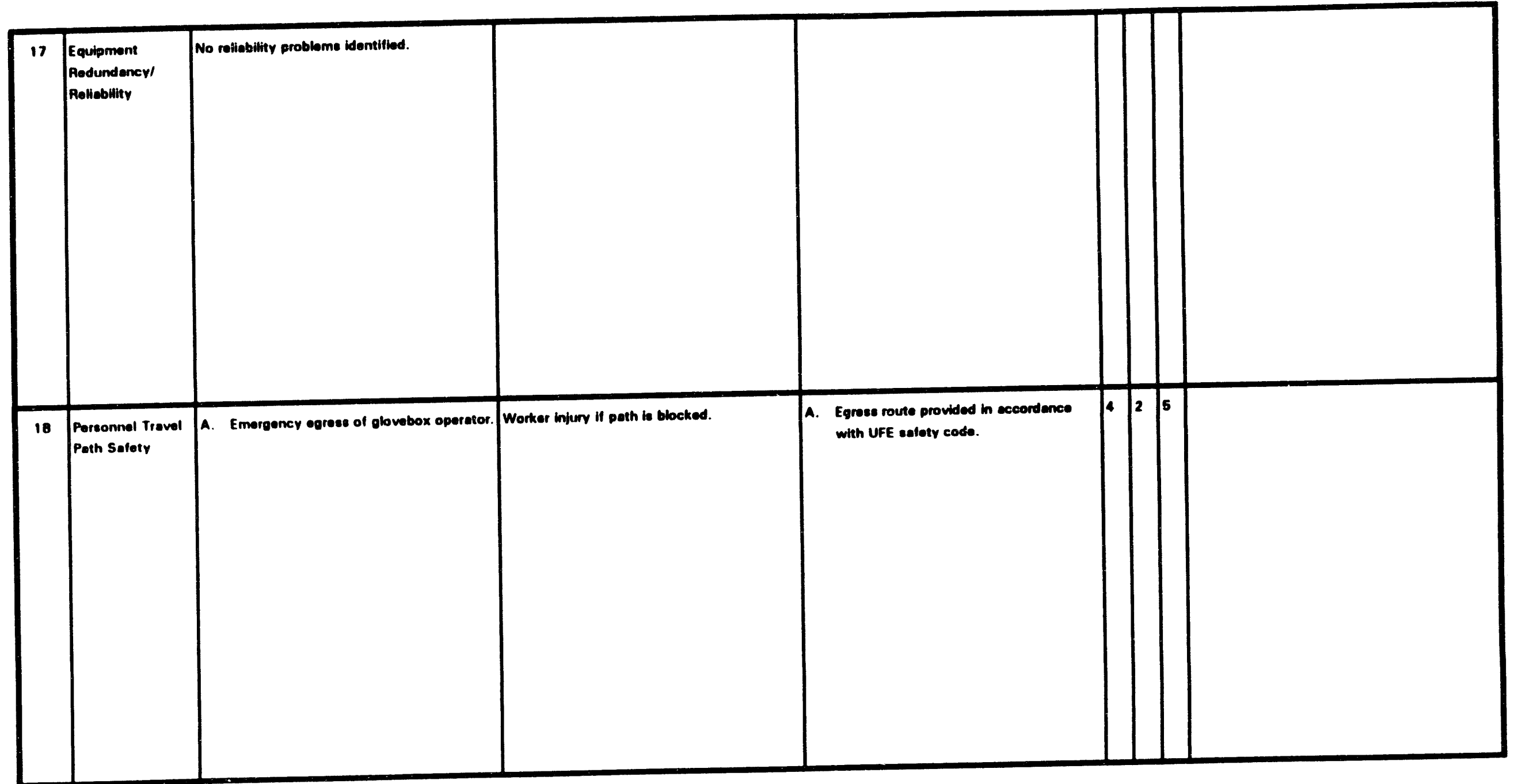


WRAP 2A ACDR PRELIMINARY HAZOP REVIEW DATA SHEET

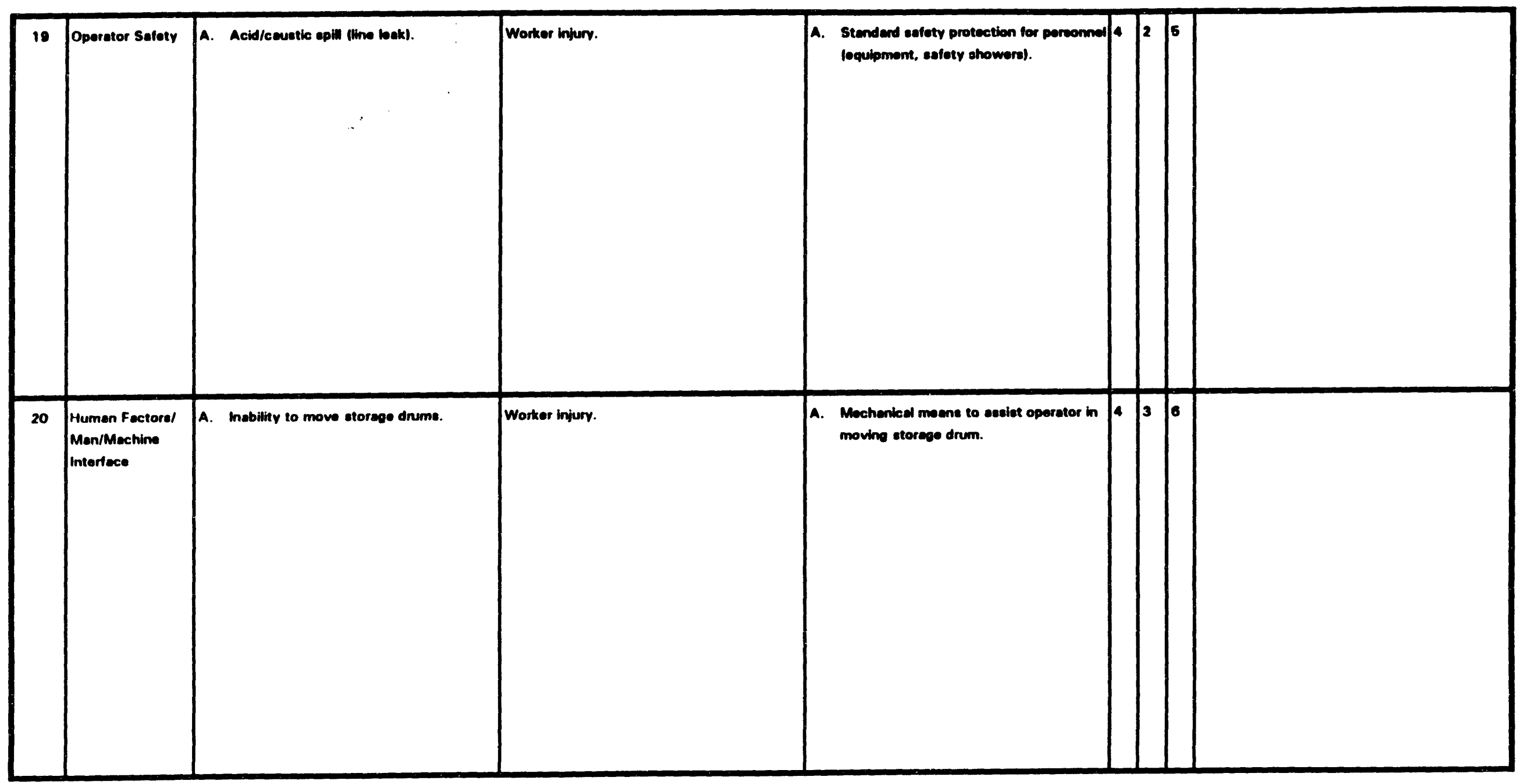


WRAP 2A ACDR PRELIMINARY HAZOP REVIEW DATA SHEET

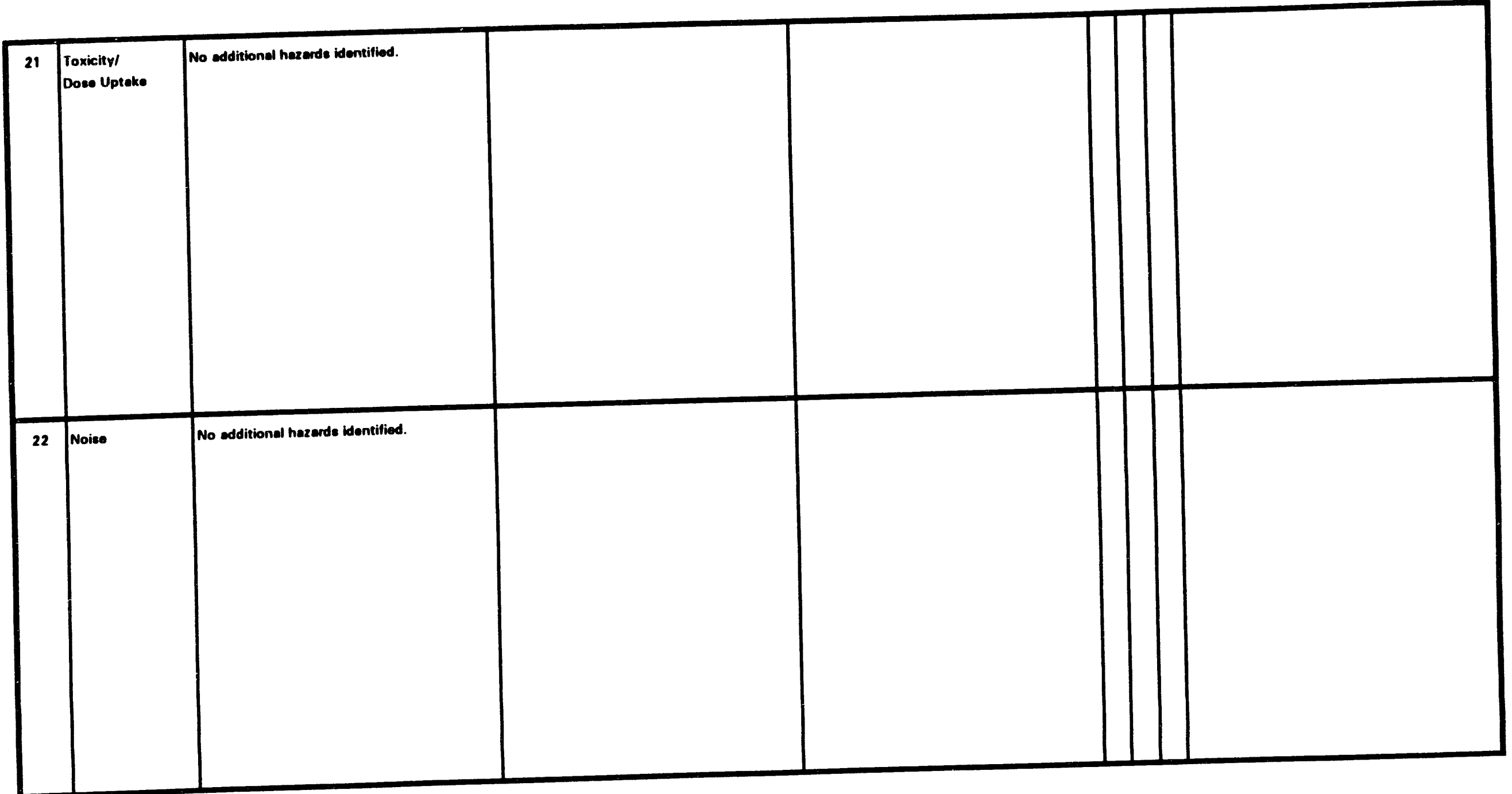



WRAP 2A ACDR PRELIMINARY HAZOP REVIEW DATA SHEET

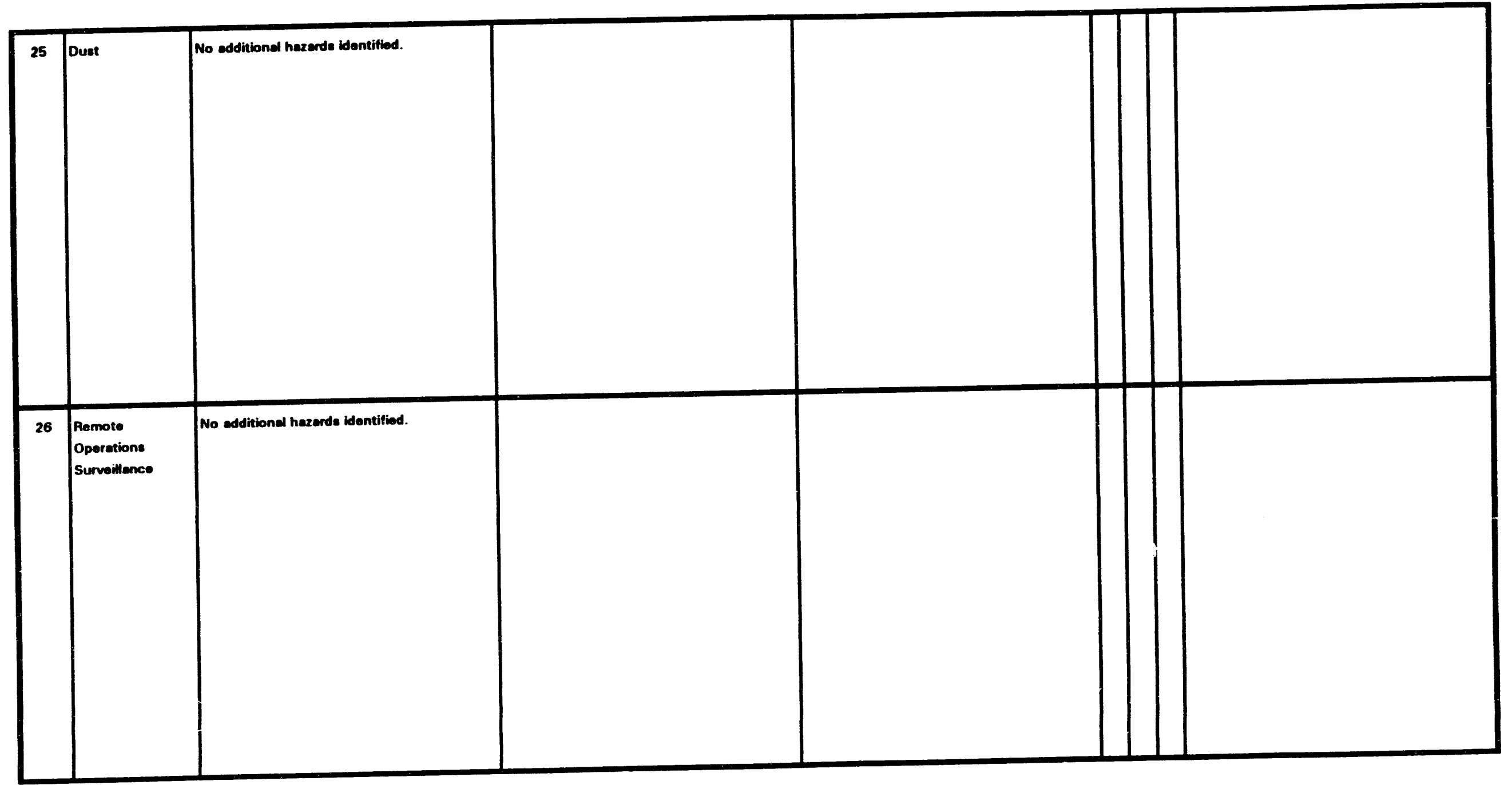


WRAP 2A ACDR PRELIMINARY HAZOP REVIEW DATA SHEET

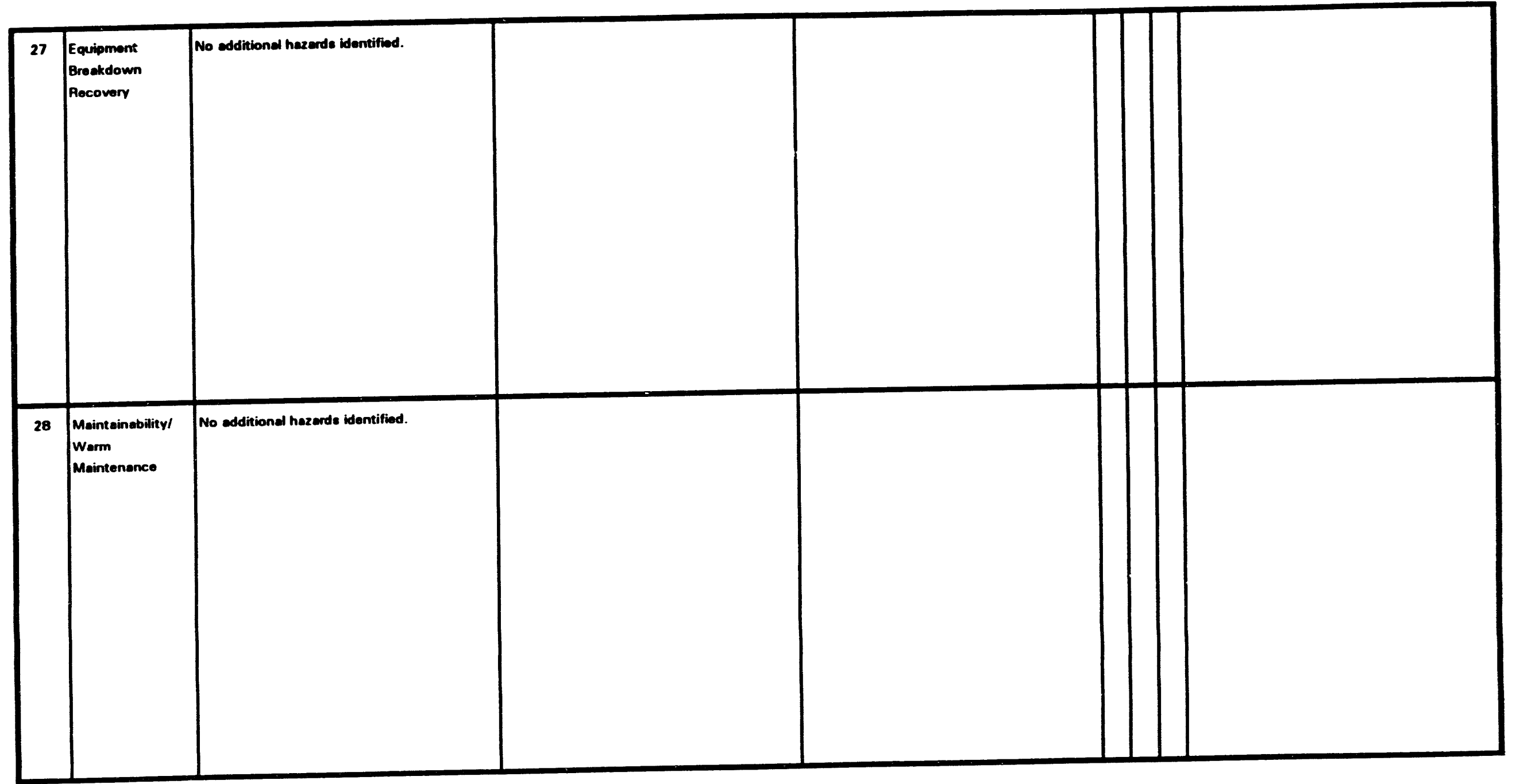


WRAP 2A ACDR PRELIMINARY HAZOP REVIEW DATA SHEET

\begin{tabular}{|c|c|c|c|c|c|c|}
\hline 29 & \begin{tabular}{|l} 
Tosting/ \\
inspoction
\end{tabular} & No eddhiones hazerde identified. & & & & \\
\hline 30 & \begin{tabular}{|l|} 
Primary \\
instrument Loop \\
Fosilure
\end{tabular} & 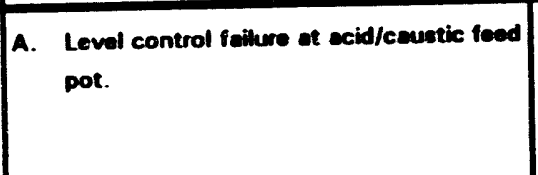 & 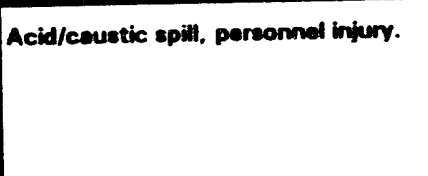 & 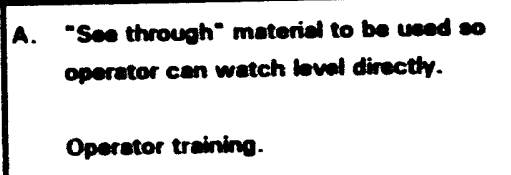 & $\left.4\right|^{5}$ & \\
\hline
\end{tabular}





$$
\pi
$$


WRAP 2A ACDR PRELIMINARY HAZOP REVIEW DATA SHEET

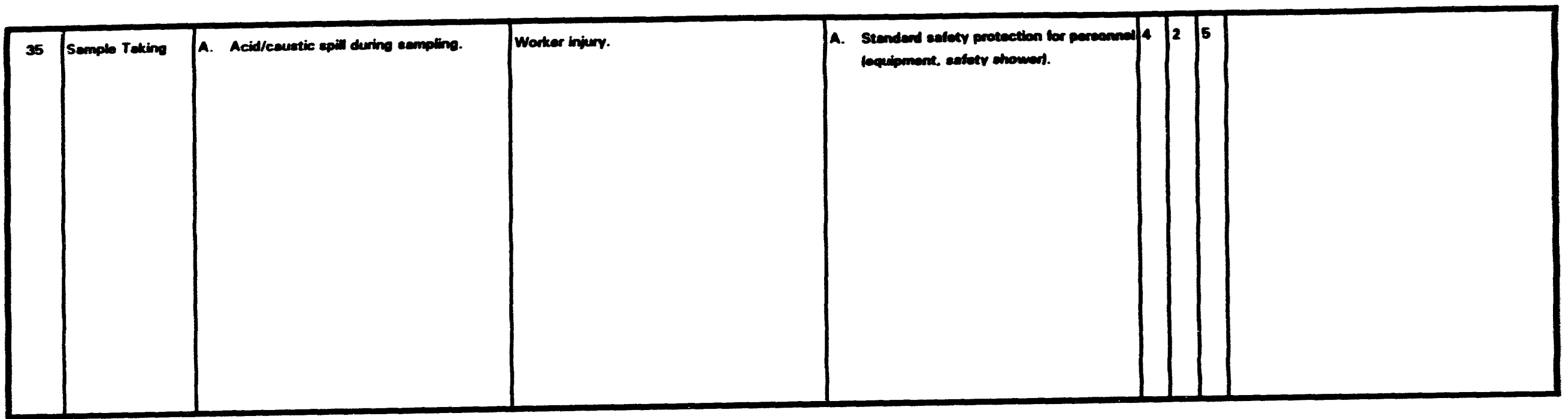




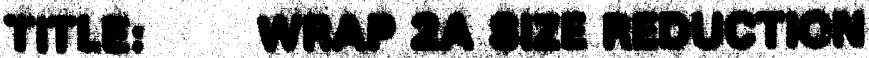

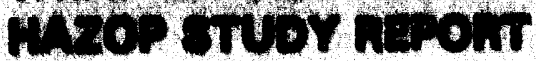

Rovialon: 0

Submitud to:

\section{UMTe staT: \\ Dovinimat os ammor \\ Nokliond, Wechington}

Prepened by:

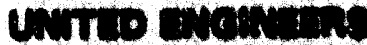
a cowitnugtons
A flevthenen Compeny

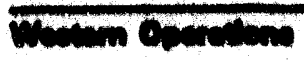


IABLE OF CONTENTS

Page

1.0 INTRODUCTION $\ldots \ldots \ldots \ldots \ldots \ldots \ldots \ldots \ldots \ldots \ldots \ldots \ldots \ldots \ldots \ldots$

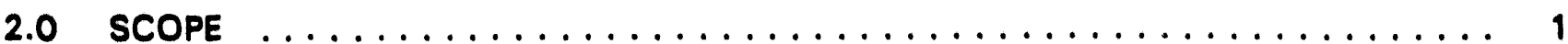

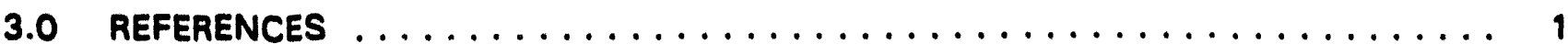

4.0 DESCRIPTION OF SAMPLE MANAGEMENT SYSTEM $\ldots \ldots \ldots \ldots \ldots \ldots \ldots$

4.1 Design Basis Surnmary . . . . . . . . . . . . . . . . . . . 2

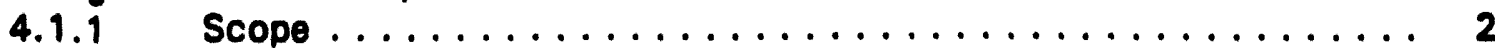

4.1 .2 Design Goals . . . . . . . . . . . . . . . . . . 2

4.1.3 Functional Requirements ................... 3

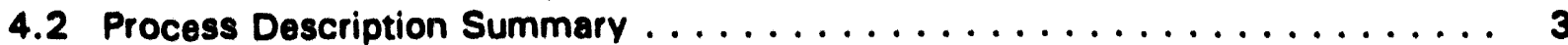

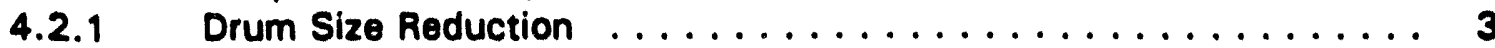

4.2.2 Box Breakdown ...................... 9

5.0 STUDY CRITERIA AND METHODOLOGY $\ldots \ldots \ldots \ldots \ldots \ldots \ldots \ldots$

6.0 RESULTS AND CONCLUSIONS $\ldots \ldots \ldots \ldots \ldots \ldots \ldots \ldots \ldots \ldots$ 


\section{WRAP 2A}

\section{SIZFERDUCTION}

\section{HAZOP STUDY REPORT}

\subsection{INTRODUCTION}

A preliminary HAZOP study was performed on the advanced conceptual design of the Size Reduction System (Box and Drum). The HAZOP team met on 3 August 93, and consisted of the following members:

\section{Name}

Larry Walker

Les Dutton

Andrew Sharpe

William Capoda

William Schrader

Gary Booth

Bob Horges

Owen Kruger

John Moyers

Tom Pauly

\section{Comn:ny}

UE\&C

BNFL

BNFL

UE\&C

UE\&C

WHC

WHC

WHC

WHC

WHC

\section{Bola/Expentise}

Leader, Scribe, Safety

Mechanical/Operations

Process/Mechanical

Instrumentation and Controls

Radiological

Radiological

Mochanical

Operations

Maintainability

Process

The purpose of the HAZOP is to identify major safety and operability problems which can best be resolved during completion of the advanced conceptual design.

\subsection{SCOPE}

This HAZOP encompassed the Size Reduction System (Box and Drum), as shown on Process Flow Diagram H-2-140628, Sheets 1 through 3 (Rev. E, E, and A, respectively).

\subsection{REFERENCES}

1. WHC-SD-W100-FDC-001 Rev. 2A, Functional Design Criteria Waste Receiving And Processing Facility Module $2 A$.

2. WHC-SD-W100-SDRD-001 Rev. A, Waste Receiving and Processing Facility Module $2 A$ Supplemental Design Requirements Document. 


\subsection{DESCRIPTION OF SIZE REDUCTION 8YSTEM}

\subsection{Docign Basis summary}

\subsubsection{8cope}

1. This section will address size reduction of oversized solid waste, direct repack of wastes and homogenization/deagglomeration of sludges and particulates. This section will also address waste entry/exit to the processing area, confinement enclosures, and conveying equipment in and out of the enclosures.

2. It is expected that size reduction, direct repack and homogenization of drummed waste will take place within enclosures. Boxed waste is expected to be size reduced by remote manipulators in a dedicated cell.

3. All wastes entering WRAP 2A will require some pretreatment prior to immobilization. The size reduction area will process all waste entering the facility with the exception of those classified as apecial or campaigned waste. Special waste entering WRAP 2A in boxes will, however, be size reduced prior to macro encapsulation or treatment in the special waste enclosure.

\subsubsection{Decign Coals}

1. The principle design goal is to provide cost effective and safe designs to size reduce, direct repack and homogenize waste items in WRAP $2 A$.

2. The system shall be designed to ensure that operations are carried out in suitable high integrity enclosures to prevent the egress of radioactive and hazardous particulates.

3. The system shall utilize an integrated design approach to ensure a compatible interface between the other process areas of the WRAP 2A facility.

4. The equipment shall be designed to minimize maintenance and decommissioning requirements.

5. The system shall be designed to minimize generation of secondary waste and the lifetime occupational radiation exposure to personnel working on the equipment.

6. Mechanical drives and other components will be located outside of the product confinement ared as much as possible to limit contamination of equipment and maintain worker exposure to radioactive and hazardous waste ALARA.

7. Incorporate the principles of human factors, ALARA principals and decontamination and decommissioning throughout all design phases. 


\subsubsection{Functional Requirements}

\section{Size Reduction}

1. Various size reduction and homogenization operations and methods will be considered and optimized during the conceptual design and advenced conceptual design phase of the project. Equipment selected will be appropriate to waste form and handling operations.

2. Equipment shall be provided, if necessary, to ensure waste items are adequately stabilized when size reduction operations are being carried out.

3. Use of glovebox containment enclosures shall be considered when assessing the alpha confinement requirements.

\section{Transfers in Containment}

1. The use of floor mounted transfer cars and overhead hoists shall be considered when moving RMW into containment.

2. RMW shall be posted into and out of containment using suitable bagless transfer or airlock systems.

\subsection{Process Description Summary}

\subsubsection{Drum Size Reduction}

1. The process description for drum size reduction, direct repack and sludge repacking is described in three sections as follows:
a. Size Reduction and Repack Cell
b. Shredding and Repack Enclosure
c. Sludge Repacking Enclosure

2. Each of these processes are illustrated on the Process Flow Diagram (H-2-140628 Sheet 1 and 3). Reference should be made to these drawings when reading the following process descriptions.

\section{Size Reduction and Repack Cell}

3. 55 to $\mathbf{8 5}$ gallon drums are transported form the receipt and shipping area into the size reduction and repack cell through double airlock door (AL-05-501) on roller conveyor (CV05-501). This allows drums to be transferred form the Zone 3 receipt area into the Zone 2 size reduction cell. 
4. Drums are then transported from conveyor (CV-05-501) onto a conveyor mounted transfer car (TC-05-501) using a further roller conveyor (CV-05-502). The transfer car has the ability to transfer drums to any one of the three process enclosures shredding and repack, sludge repacking or special waste. The transfer car also has the capability of transferring redrummed waste from the Box Breakdown area (H-2-140628 Sheet 2) via simple Double Lid Door (DO-05-562) and the hydraulic lift table (LT-05-561).

Shredding and Repack Enclosure

\section{Drum Entry}

5. Drums which are to be processed in the shredding and repack enclosure (GB-05-521) are transported on the transfer car (TC-05-501) to be in line with the hydraulic lift table (LT05-521) located at the entry position of the enclosure. The drum is then transferred from the car onto the lift table and elevated to interface with the simple double lid entry port (DO-05-521). Entry of a 55 gallon drum from within an overpack is achieved by using the simple double lid mechanism to remove the lid off the overpack to allow removal of the 55 gallon drum from the overpack. The drum lifter (DH-05-521) is lowered between the two drums to clamp onto the $\mathbf{5 5}$ gallon drum which is raised into the process enclosure by the drum hoist (CR-05-521). Closing of the double lid door after entry of the 55 gallon drum replaces the lid onto the overpack which is then lowered from the entry port. Drums for processing which are not within overpacks, follow the same procedure but the lid removal mechanism is disabled.

6. The simple double lid allows the drum to be transferred from the Zone 2 size reduction cell into the Zone 1 process enclosure. Once inside the entry enclosure the drum is transferred to be above sliding hatch (DO-05-522), the hatch door is opened and the drum lowered into the lid removal area. The sliding hatch is then closed.

\section{Lid Removal}

7. Having transferred through the sliding hatch the drum rests on the supporting conveyors of the drum pusher unit (CY-05-521). The drum pusher then transfers the drum to be positioned adjacent to the drum handler/tipper (DH-05-522), the band saw (RT-05-521) and the drum lid remover (RT-05-522). With the drum in position, the grabber on the handler/tipper clamps the drum around its rolling rings, the band saw then cuts through restraining clamp band thus exposing the drum lid which is then be removed by the lid remover. Lids and clamp bands will be stored in the enclosure adjacent to the removal equipment for subsequent loading into an empty drum for disposal. At this point in the process the drum is lifted by the drum handler/tipper to either the Repack line or the Shredder line depending on the type of waste contained in the drum. 


\section{Repack}

8. The following categories of drummed waste will be lifted by the drum handler to be processed in the repack line:

\begin{tabular}{|c|l|c|}
\hline Feedstream & \multicolumn{1}{|c|}{ Description } & $\begin{array}{c}\text { Drums per day } \\
\text { (averaged over the } \\
\text { lifetime of the plant) }\end{array}$ \\
\hline 1D2 & 183H Misc Waste & 0.02 \\
9B & Heterogeneous Solids/Debris & 4.29 \\
\hline Total & & 4.31 \\
\hline
\end{tabular}

9. When the drum is lifted to the repack line, the waste sorting table (ST-05-521B) traverses horizontally to position itself underneath the drum handler/tipper. The drum grabber, on the handler tipper, then rotates to empty the drum contents onto the sorting table. When all the waste has been tipped from the drum, the sort table traverses back to position itself adjacent to an operating face in the process enclosure. In this position the waste is visually inspected on the sort table and any items which are not considered suitable for direct repacking are removed using manipulators (EM-05-521B) and loaded back into the empty drum held in the handler tipper, this waste together with the empty drum itself is subsequently lifted to the shredding line for processing.

10. Once the waste held on the sorting table is judged, after visual inspection, suitable for direct repacking, the sort table tips the waste onto vibrating conveyor (CV-05-521). The purpose of the vibrating conveyor is to feed both direct repack waste and shredded waste to either the direct repack load out port (DO-05-5248), for direct repack items or the feed hopper (T-05-521A) for shredded wastes. Direct repack items are loaded directly into the new drums using the large item hoist (CR-05-527) via the simple double lid (DO-05-524B). Once the drum is full the simple double lid is closed and the drum lowered from the enclosure using the lift table (LT-05-523B). The drum is then transferred onto the AGV and transported to further process areas within the plant.

\section{Shredding}

11. The following categories of drummed waste will be lifted by the drum handler to be processed in the shredding line:

\begin{tabular}{|c|l|c|}
\hline Feedstream & \multicolumn{1}{|c|}{ Description } & $\begin{array}{c}\text { Drums per day } \\
\text { (averaged over the } \\
\text { lifetime of the plant) }\end{array}$ \\
\hline 1A & 183 H Solidified Liquid & 0.39 \\
ID2 & 183 H Misc. Waste & 0.02 \\
\hline Total & Heterogeneous Solids/Debris & 4.29 \\
\hline
\end{tabular}


12. When the drum is lifted to the shredding line, the waste sort table (ST-05-521A) traverses horizontally to position itself underneath the drum handler/tipper. The drum grabber, on the handler/tipper, then rotates to empty the drum contents onto the sorting table. When all the waste has been tipped from the drum, the sort table traverses back to position itself adjacent to an operating face in the process enclosure. Where waste can not be displaced from the drum, the drum and its contents are loaded onto the sorting table as a single item awaiting shredding. With the sort table adjacent to the operating face the waste is visually inspected and any items which are not considered suitable for shredding are removed using manipulators (EM-05-521A) and loaded out of the shredding and repack enclosure using the glovebox Hoist (CR-05-522), the waste transfer tray (X-05-521), the simple double lid (DO-05-523) and the lift table (LT-05-522). These drums containing non shreddable items are then transported on the hand pallet truck (FT-05-501) to conveyor (CV-05-501) for removal of the drum from WRAP 2A via the receipt area. It is possible that feedstream 1 A could contain liquors. If liquids are detected by visual inspection while on the sort table, they are absorbed by absorbent discharged from weigh hopper (T-05-522).

13. Once the waste which is held on the sorting table is certified as suitable for shredding, the sort table tips the waste into the coarse shredder (SH-05-521) which subsequently allows the coarse shredded waste to feed by gravity into the fine shredder for further shredding, in order to achieve greater packing efficiency of waste in the product drums.

14. The vibrating table feeds shredded waste into the weigh hopper until the required mass of waste is recorded on the load cells of the weigh hopper. When this desired mass is achieved, the weigh hopper sends a feedback signal to stop the drive to the vibrating conveyor thus preventing further depositing of waste into the weigh hopper, within a given tolerance. At this point the simple double lid door (DO-05-524A) opens and the waste is deposited from the weigh hopper into a new drum which is correctly positioned on lift table (LT-05-523A) underneath the simple double lid door aperture, any fixtures such as waste antifloatation devices are then fitted to the drum. The simple double lid door is then closed, the drum lid replaced and secured onto the drum. The lift table then descends and the drum is fed onto an AGV using the conveyor on the lift table. The AGV then transports the repacked drum of waste for further processing within the plant.

15. Empty drums from both the shredding and direct repack lines are transferred to the empty drum compactor enclosure (GB-05-581) on the transfer car (TC-05-521) to be compacted using the compactor (CM-05-581). Compacted drums are then loaded into 85 gallon overpacks using the hoist (CR-05-581), compact handler (DH-05-581) and simple double lid (DO-05-581). Once the overpack is full the simple double lid closes, the lift table (LT-05-581) lowers and the overpack is transferred out of WRAP 2A via the receipt area and lag store. 


\section{Sludoe Rerogaking Enclosure}

16. The following categories of drummed waste will be processed in the sludge repacking enclosure:

\begin{tabular}{|c|l|c|}
\hline Feedatream & \multicolumn{1}{|c|}{ Description } & $\begin{array}{c}\text { Drums per Day } \\
\text { (averaged over the } \\
\text { lifotime of the plant) }\end{array}$ \\
\hline IB & Crystalline 183 H Solids & 0.63 \\
IC & 183 H Basin Waste & 0.68 \\
$2 A$ & Sandblast Grit & 0.03 \\
$2 B$ & Ammonium Sulfate Sludge & 4.35 \\
$2 C$ & lon Exchange Resin & 0.27 \\
7 & Ferric Hydroxide Sludge & 2.66 \\
9 & Thermal Treatment Ash & 1.38 \\
\hline Total & Particular/Sludge (Box \& Drums) & 3.18 \\
\hline
\end{tabular}

\section{Drum Entry}

17. Drums which are to be processed in the pug mill enclosure (GB-05-541) are transported on the transfer car (TC-05-501) to be in line with the hydraulic lift table (LT-05$541)$ located at the entry position to the enclosure. The drum is then transferred from the car onto the lift table and elevated to interface with the simple double lid entry port (DO-055411.

18. With the drum in position the simple double lid is activated and the double lid door opened. Drums are then lifted through the double lid door aperture into the process enclosure using the drum lifter (DH-05-541) and the drum hoist (CR-05-541), the simple double lid door is then closed. The simple double lid allows the drum to be transferred from the Zone 2 size reduction cell into the Zone 1 process enclosure. Once inside the entry enclosure the drum is transferred to be above sliding hatch (DO-05-522), the hatch door is opened and the drum is lowered into the lid removal area. The sliding hatch is then closed.

\section{Lid Removal}

19. Having transferred through the sliding hatch the drum rests on the supporting conveyors of the drum pusher unit (CY-05-541). The drum pusher then transfers the drum to be positioned adjacent to the drum handler/tipper (DH-05-542), the Band Saw (RT-05$541)$ and the drum lid remover (RT-05-542). With the drum in position, the grabber on the handler/tipper clamps the drum around its rolling rings, the band saw then cuts through restraining clamp band thus exposing the drum lid which is then be removed by the lid remover. The drum is then lifted by the drum handler tipper to the pug mill process line. 
20. When the drum is lifted to the pug mill line the waste sort table (ST-05-541) traverses horizontally to position itself underneath the drum handler tipper. The drum grabber, on the handler/tipper, then rotates to empty the drum contents onto the sorting table. When all the waste has been tipped from the drum, the sort table traverses back to position itself adjacent to an operating face in the process enclosure. With the sort table adjacent to the operating face the waste is visually inspected on the sort table and any items which are not considered suitable for pug mill processing are removed usir- manipulators (EM-05-542) and loaded out of the pug mill enclosure using the glovebox hoist (CR-05-542), the waste transfer tray (X-05-541), the simple double lid (DO-05-543) and the lift table (LT-05-542). These drums containing non-processable items from the pug mill enclosure are then transported on the hand pallet truck (FT-05-501) to conveyor (CV-05-501) for removal of the drum from WRAP 2A via the receipt area. Once the waste held on the sort table is certified as suitable for processing, the sort table tips the waste into the pug mill (SH-05541). The pug mill homogenizes, delumps, controls the particle size of the waste, and allows any additives to be added to the waste prior to immobilization in polyethylene as shown on drawings H-2-140641.

21. Empty drums are lowered on the drum handler (DH-05-542) and transferred onto a transfer car (TC-05-521) housed in a containment enclosure (GB-05-522), provided for the transfer of empty drums to the empty drum compaction enclosure. Once at the empty drum compaction enclosure the empty drums are compacted and loaded into overpacks as described in para 15.

\section{Process Samoling Within Enclosures}

22. Each of the three main process lines repack, shredding and sludge repacking, will be fitted with a purged port bagless transfer units (DO-05-525B), (DO-05-525A) and (DO-05545) respectively which will allow samples of waste to be transferred from each process line for sample analysis. 


\subsubsection{Box Breakdown}

1. The following process description should be read in conjunction with the Process Flow Diagram for the box breakdown area within WRAP 2A (H-2-140628 Sht. 2). Reference should be made to this drawing when reading the following process description. Waste processed in the Box Breakdown area are as follows:

\begin{tabular}{|c|l|c|}
\hline Feedstream & \multicolumn{1}{|c|}{ Description } & $\begin{array}{c}\text { Drums per Day } \\
\text { (averaged over the } \\
\text { lifotime of tha plant) }\end{array}$ \\
\hline $1 D$ & 0.18 \\
$9 A$ & Sludge Particular & 0.18 \\
$9 B$ & Hoterogeneous Solids/Debris & 0.18 \\
$5 C 1$ & Elemental Lead & 0.62 \\
$5 C 3$ & Lead Contaminated Solids & 0.62 \\
\hline Total & & 1.78 \\
\hline
\end{tabular}

2. Boxes and oversized drums enter the box breakdown cell through airlock (AL-05-501) on conveyors (CV-05-561A,B,C) the airlock allows the waste to be passed froin a Zone 3 to a Zone 1 area.

3. When in the box breakdown cell, the overhead crane (CR-05-561) picks the box off the conveyor (CV-05-561C) and places it on the floor of the cell. The overhead telescopic mounted power manipulator (EM-05-561) then cuts through the restraining clamp which holds the lid on the box. The overhead crane then lifts the lid off the box and places it on the floor of the cell. Both overhead crane and power manipulator have the ability to cover the full envelope volume of the box breakdown cell.

4. The power manipulator then returns to either:

a. Lift small items of waste from the box and place them inside a 55-gallon drum, itself contained within an 85-gallon drum overpack, through the simple lid door (DO-05-561).

b. Size reduce large items of waste, using tools provided at a remote tool change station, and place the size reduced waste into the 55-gallon drum described in $4 a$ above, through door (D0-05-561).

c. Lift HEPA filters from the box, place them in the filter press (C-05-561) and after compression, lift and place the filter into the 55-gallon drum described in $4 a$ above, through door (DO-05-561).

5. Upon complete removal and size reduction of the waste, the power manipulator size reduces and disposes of the box itself, into a 55-gallon drum through door (D0-05-561).

3. If the manipulator encounters waste outside its capability to size reduce and process, a subchange facility is provided through which personnel can enter in protective clothing, to carry out size reduction and processing as required. 
7. Within the box breakdown cell there is the option to decontaminate the box, once the waste contents have been removed, either remotely or manually. The power manipulator will be used for remote decontamination of the boxes. In the event that further local decontamination is required, access into the Box Breakdown area will be made through the subchange room to manually decontaminate as required. Then the box is removed from the box breakdown cell using the overhead crane, conveyors and the airlock. The box can then be reused.

\subsection{STUDY CRITERIA AND METHODOLOQY}

This HAZOP has utilized a predetermined set of process deviations/upset conditions to be analyzed by the HAZOP team for each process deviation, possible courses were postulated and worst case consequences (without benefit of any safeguards wore dotermined. Existing safeguards (design and procedural) were then identified. Those safeguards which could be reasonably expected to be present in the final design were assumed to be existing and were so documented in the HAZOP. For each cause and effect, hazard severity and probability were qualitatively assessed (taking credit for existing safeguards which reduce hazard probability) using the criteria shown in Table 1. The overall risk rating for each hazard was then determined using the risk ranking matrix shown on Table 2. Recommendations were proposed by the HAZOP team in instances required by the implementation criteria shown in Table 2. 
TABLE 1

HAZARD SEVERITY AND PROBABILITY CLASSIFICATION CRITERIA

\begin{tabular}{|c|c|c|c|c|}
\hline \multirow{2}{*}{ Target Hazard } & \multicolumn{4}{|c|}{ Severity Class (Worst-case Scenariol } \\
\hline & Catastrophic (1) & Extensive (2) & Moderate (3) & Operational (4) \\
\hline Community & $\begin{array}{l}\text { Multiple irreversible } \\
\text { injuries; may include a } \\
\text { fatality } \\
\text { OR }\end{array}$ & $\begin{array}{l}\text { Single irreversible or } \\
\text { several reversible injuries } \\
\text { (no fatalities) } \\
\text { OR }\end{array}$ & $\begin{array}{l}\text { Several reversible injuries } \\
\text { OR }\end{array}$ & \\
\hline Workers & $\begin{array}{l}\text { Fatalities or irreversible } \\
\text { injuries } \\
\text { OR }\end{array}$ & $\begin{array}{l}\text { Several injuries } \\
\text { OR }\end{array}$ & $\begin{array}{l}\text { Single injury } \\
\text { OR }\end{array}$ & \\
\hline Facility & $\begin{array}{l}\text { Partial or full demolition of } \\
\text { facility } \\
\text { OR }\end{array}$ & $\begin{array}{l}\text { Rupture or similar loss of } \\
\text { containment } \\
\text { OR }\end{array}$ & $\begin{array}{l}\text { Major equipment damage } \\
\text { leading to one month or } \\
\text { more facility downtime } \\
\text { OR }\end{array}$ & $\begin{array}{l}\text { Equipment damage } \\
\text { leading to several days of } \\
\text { fecility downtime or other } \\
\text { operational penalty } \\
\text { OR }\end{array}$ \\
\hline Environment & $\begin{array}{l}\text { Major environmental } \\
\text { impact with significant } \\
\text { cleanup/liability costs }\end{array}$ & $\begin{array}{l}\text { Groundwater, soil, or } \\
\text { public sewer } \\
\text { contamination }\end{array}$ & $\begin{array}{l}\text { Minor spill or release } \\
\text { resulting in permit violation }\end{array}$ & \\
\hline
\end{tabular}

\section{LIKELIHOOD CLASSIFICATION}

\begin{tabular}{|l|l|}
\hline Highly Likely (1) & $\begin{array}{l}\text { Event has occurred at this facility - or - other facility - or - is expected to occur several times during the } \\
\text { next } 10 \text { years. }\end{array}$ \\
\hline Likely (2) & $\begin{array}{l}\text { Event has occurred at this facility - or - is possible to occur at this facility several times during the next } \\
30 \text { years. }\end{array}$ \\
\hline Unlikely (3) & $\begin{array}{l}\text { Event may have occurred at another facility - or - is possible to occur at this facility at least once in the } \\
\text { next } 50 \text { years. }\end{array}$ \\
\hline Extremely Unlikely (4) & $\begin{array}{l}\text { Event is not likely to ever occur in this facility, given a continuation of the current levels of training. } \\
\text { procedures, maintenance, inspection, testing, and other applicable process safety management system } \\
\text { support. }\end{array}$ \\
\hline
\end{tabular}




\section{TABLE?}

RISK RANKING MATRIX AND IMPLEMENTATION CRITEMA

\begin{tabular}{|c|c|c|c|c|}
\hline Likelihood & & & & \\
\hline Highly Likely (1) & 4 & 2 & 1 & 1 \\
\hline Likely (2) & 5 & 3 & 2 & 1 \\
\hline Unlikely (3) & 6 & 4 & 3 & 2 \\
\hline Extremely Unlikely (4) & 7 & 6 & 5 & 4 \\
\hline
\end{tabular}

\section{RISK RANKING MMPLEMENTATION}

\begin{tabular}{|c|c|}
\hline Risk Ranking & Implicention \\
\hline 1 & $\begin{array}{l}\text { Risk level - Very significant } \\
\text { Recommendation = Required from the HAZOP team } \\
\text { Implementation - Begins immediately }\end{array}$ \\
\hline 2 & $\begin{array}{l}\text { Risk level - Significant } \\
\text { Recommendation = Required from the HAZOP team } \\
\text { Implementation - Begins within three months }\end{array}$ \\
\hline 3 & $\begin{array}{l}\text { Risk level - Not very significant. } \\
\text { Recommendation = Required from the HAZOP team } \\
\text { Implementation - Begins within one yoar }\end{array}$ \\
\hline 4 & $\begin{array}{l}\text { Risk level - Not significant, but may be an operational problem } \\
\text { Recommendation = At the discretion of the HAZOP team } \\
\text { Implementation - As scon as prectical, not later than the naxt major plam tumaround }\end{array}$ \\
\hline 5,6, or 7 & $\begin{array}{l}\text { Risk level - Negligible, but may be an operational problem } \\
\text { Recommendation = At the discretion of the HAZOP team } \\
\text { Implementation - To be evaluated by management }\end{array}$ \\
\hline
\end{tabular}




\subsection{RESULTS AND CONCLUSIONS}

Because this HAZOP is performed relatively early in the design phase, existing safoguards have not been fully documented on the process flow diagrams (these would mostly be shown on the P\&ID's developed during Title Design). However, the HAZOP team assumed specific safoguards would be present in the final design if it appear reasonable to expect this. These assumed safeguards are documented on the HAZOP worksheets and credit was taken for these presumed safeguards when assessing riak. During Title Design, the presence of these safeguerds need to be verified to validate the conclusions of this HAZOP.

Thirty-three potential safoty and operability problems wore identified and evaluated on the HAZOP. Of these, 27 wore asseased to have a negligible risk level. The remaining 6 involved potential hazards having a riak ranking of between significant and not significant. For these potential hazards, the HAZOP team has recommended that additional safeguards be evaluatud and incorporated into the WRAP $2 A$ design. Table 3 presents a summary of changes to be made in the process flow diagram, assumed design safoguards, and additional safoguards to be evaluated for incorporation into the design.

In several instances, the need for human factors analyses and reliability/availability/maintainability analyses during Titlo Design was highlighted by the HAZOP team to achieve negligible riak levels. The HAZOP assumed that such analyses would be performed and that the necessary design requirements/modifications are incorporated. The performance of these design analyses are considered to be open issues to be resolved during Title Design. Similarly. the HAZOP team identified the need for a maintainability analyais to develop requirements for warm maintenance at the WRAP $2 A$ Facility.

The HAZOP is documented in the atteched HAZOP worksheots. 


\section{TARE3}

SIZE REDUCTION HAZOP SUMMARY

\section{PROCESS FLOW DIAGRAM CHANGES}

1. Add note that the drum lid is to be fastened to waste drum upon exit from glovebox (to withatand drum drop).

\section{ASSUMED DFSICN SAFECUARDS}

1. All desion bacis requirements.

2. Standard alarms for control loops.

3. Caps on glovbbox ports when not in use.

4. Mochanical stops for equipment (loft tables, drum lifts) and minimize use of unit switches.

5. UPS for monitor/alarms (HVAC failure).

6. Panic button for emergency shutdown of glovebox equipment.

7. If used, shredder hydraulics located outside of glovebox and no continuous path of oil through sael into glovebox interior.

\section{EVALUATEANCORPORATE INTO TITLELDESICN}

1. NEC area classification evaluation; non-sparking/grounded equipment.

2. Purging at Shredders.

3. Glovebox fire protection/suppreasion (e.g., at shredder discharge and conveyor).

4. Cooling mochaniem for box breakdown tools (0.9.. saw).

5. Ensure no excessive gas generation in drum (from shredder discharge conveyor).

6. Drum fillinghoadout port (air tight containment and impact of drum linor).

7. Grate at pug mill entry.

8. Dust generation/control at pug mill for certain waste streams.

9. Ease of shredder maintenance (e.9., hoist outside glovebox).

10. Hot maintenance requirements with decontamination.

11. Capability to test hoist inside glovebox (or replace hoist).

12. Limit discharge hopper size with level/weight indication (e.9., $1 / 2$ volume of drum volume).

13. Capability to test hoist inside glovebox (or replace hoist).

14. Sample dig handling external to glovebox.

15. Human factors engineering.

16. CCTV for glovebox operations. 
WRAP 2A ACDR PRELMMNARY HAZOP REVEW DATA SHEET

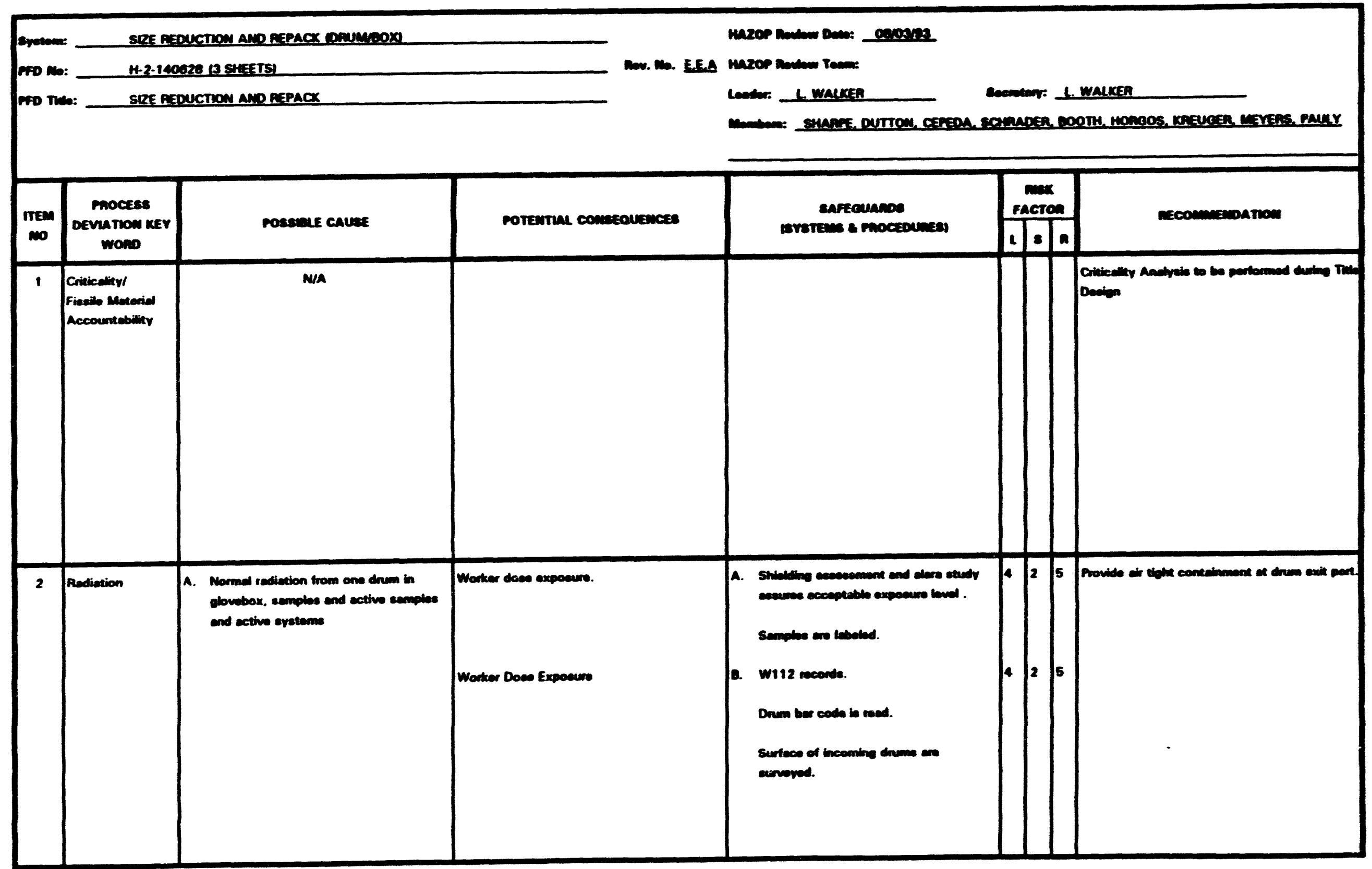


WRAP 2A ACDR PRELIMUMARY HAZOP REVEW DATA SHEET

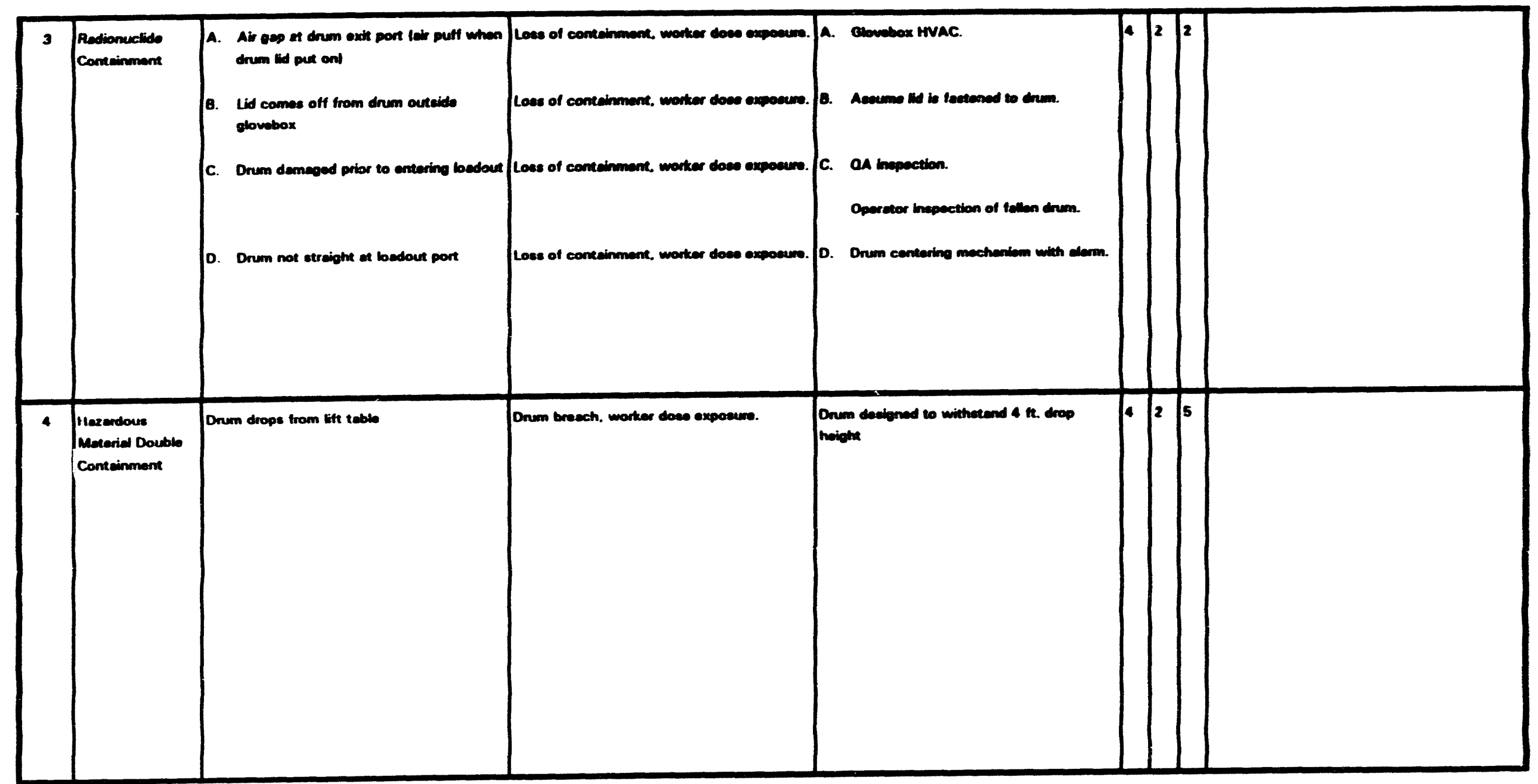




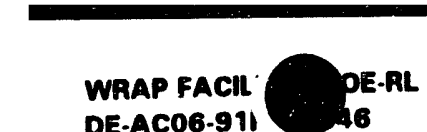

WRAP 2A ACDR PRELIMINARY HAZOP REVIEW DATA SHEET

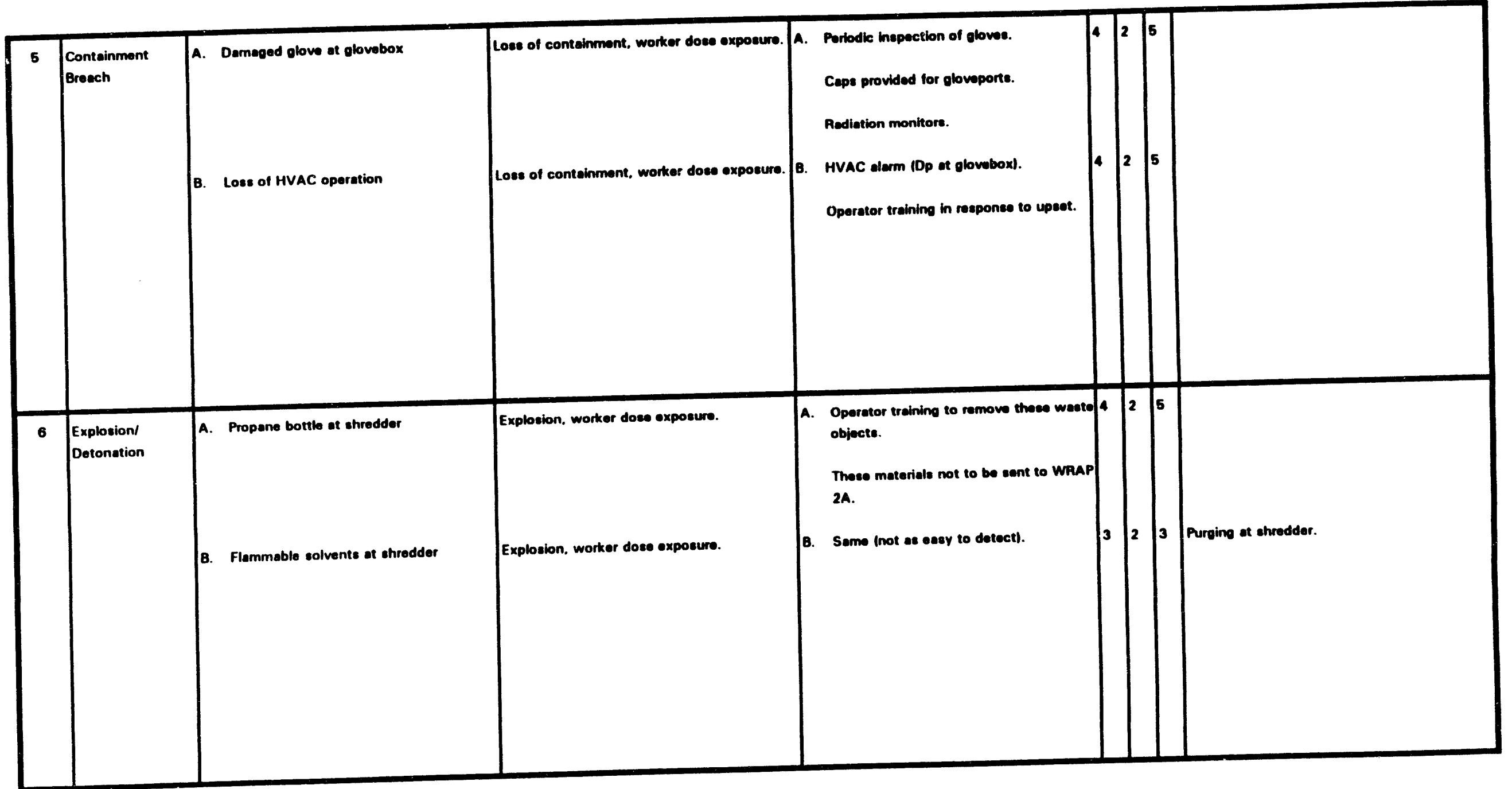


WRAP 2A ACDR PRELIMINARY HAZOP REVIEW DATA SHEET

\begin{tabular}{|c|c|c|c|c|c|c|c|c|}
\hline 7 & Fire & $\begin{array}{l}\text { A. NOCs at sort table } \\
\text { B. Hot tools at box breakdown }\end{array}$ & $\begin{array}{l}\text { Fire/oxplosion. loses of conteinment. worker } \\
\text { dose exposure. } \\
\text { Fire. loss of contsinmont workers dose } \\
\text { exposure. }\end{array}$ & 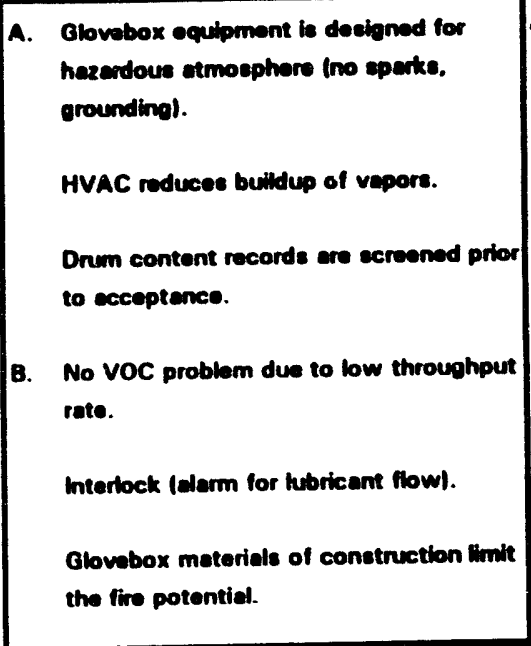 & 4 & 2 & 5 & Cooling mechanism for box breakdown tooks. \\
\hline 8 & $\begin{array}{l}\text { Flammable } \\
\text { Matoriatel } \\
\text { Combustible } \\
\text { Atmosphere }\end{array}$ & $\begin{array}{l}\text { A. Gas formation at shredded discharge } \\
\text { conveyor }\end{array}$ & $\begin{array}{l}\text { Fire in glovebox. worker dose exposure. } \\
\text { Bulging drum from ges formetion maide } \\
\text { drum. drum breschment, worker doee } \\
\text { exposure. }\end{array}$ & $\begin{array}{l}\text { A. Fire protoction evstem in glowebox. } \\
\text { Limnited drum vent size. }\end{array}$ & 3 & 2 & 5 & $\begin{array}{l}\text { Dasion to ensure no exceseive ges formation } \\
\text { when drum being loeded out. }\end{array}$ \\
\hline
\end{tabular}




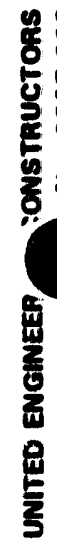

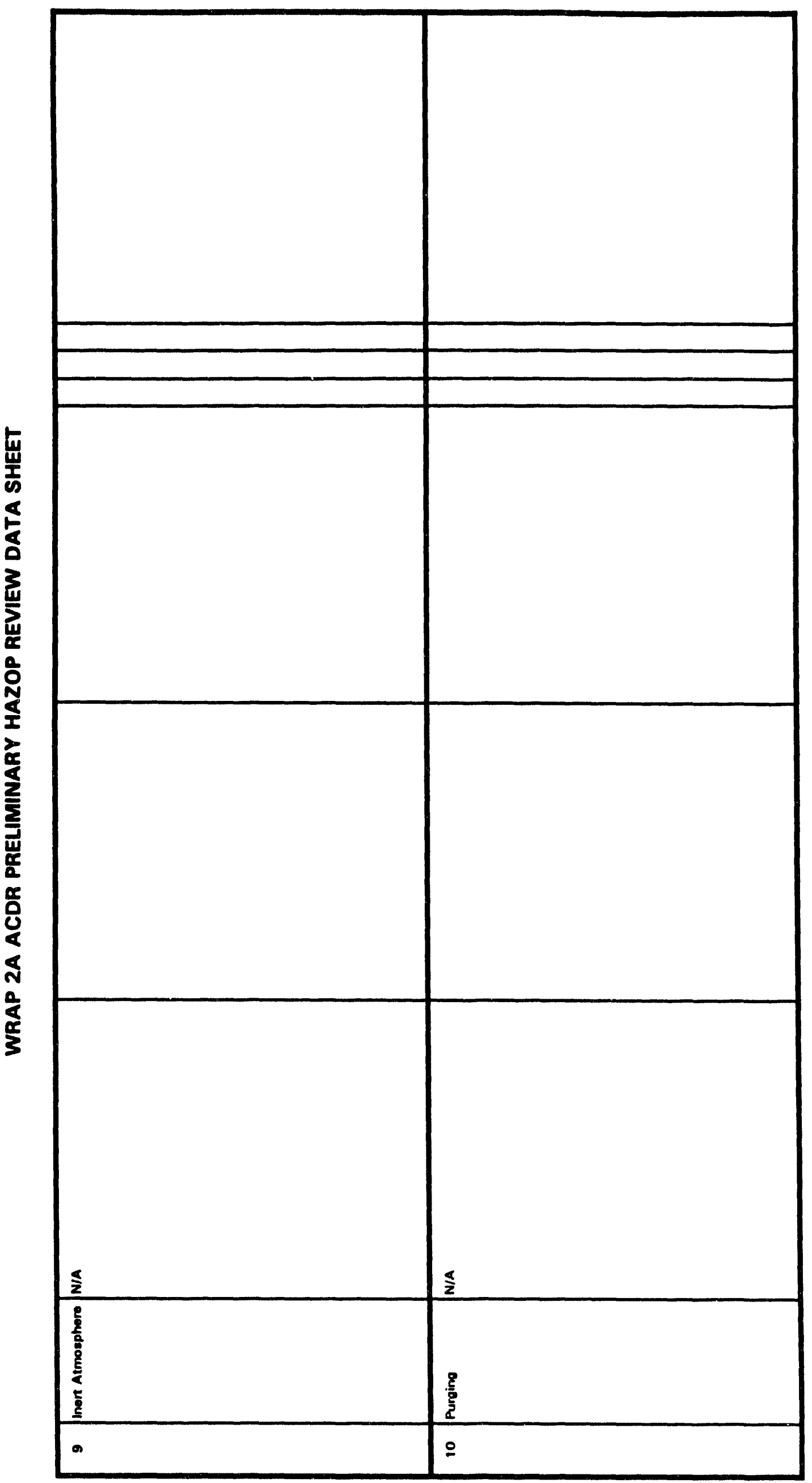


WRAP 2A ACDR PRELIMINARY HAZOP REVIEW DATA SHEET

\begin{tabular}{|c|c|c|c|c|c|c|}
\hline 11 & $\begin{array}{l}\text { Pyrophoric } \\
\text { Moterial }\end{array}$ & $\begin{array}{l}\text { A. Pyrophoric materials inedvertently sont } \\
\text { to WRAP } 2 A \text { (and not romovod by } \\
\text { operator at sort toble) }\end{array}$ & Five in alovobox, worker dose exposure. & 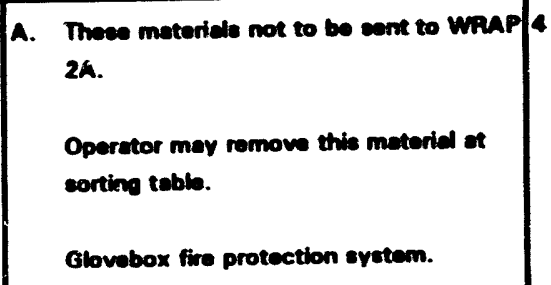 & 25 & \\
\hline 12 & | Static Charge & Soe hem $\$ 7$ & & & & \\
\hline
\end{tabular}


WRAP 2A ACDR PRELIMINARY HAZOP REVIEW DATA SHEET

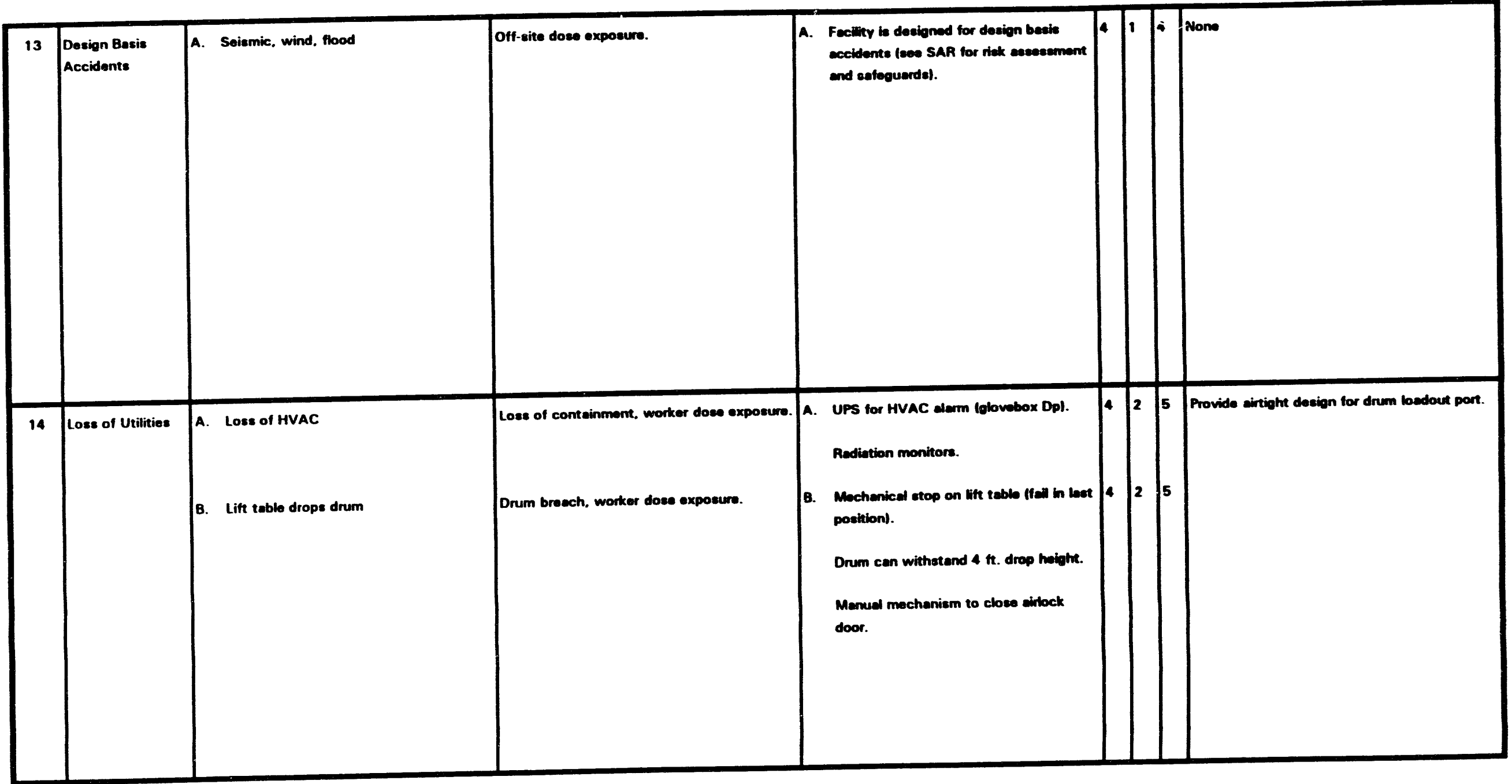


WRAP 2A ACDR PRELIMINARY HAZOP REVIEW DATA SHEET

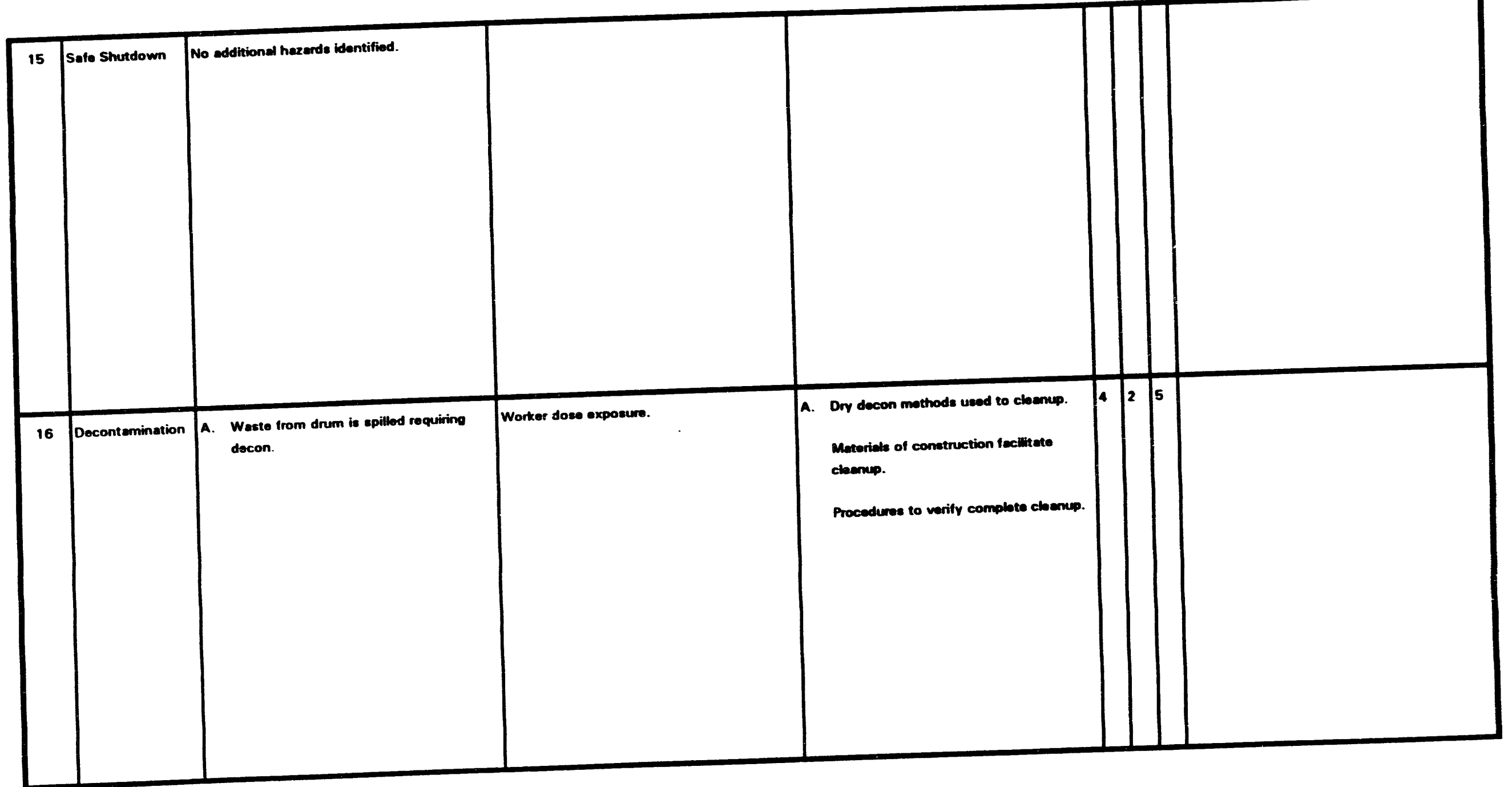


WRAP 2A ACDR PRELIMINARY HAZOP REVIEW DATA SHEET

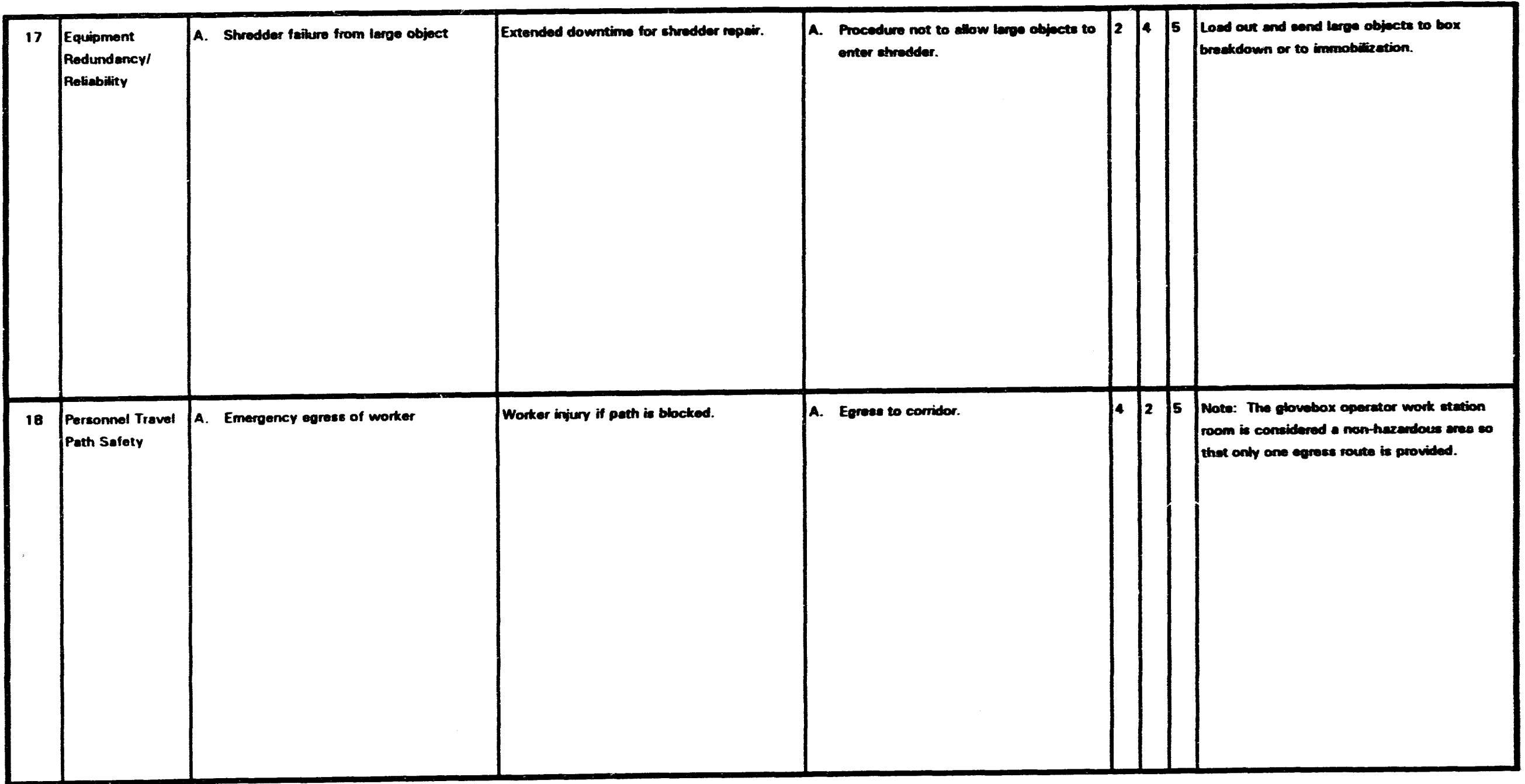


WRAP 2A ACDR PRELIMINARY HAZOP REVIEW DATA SHEET

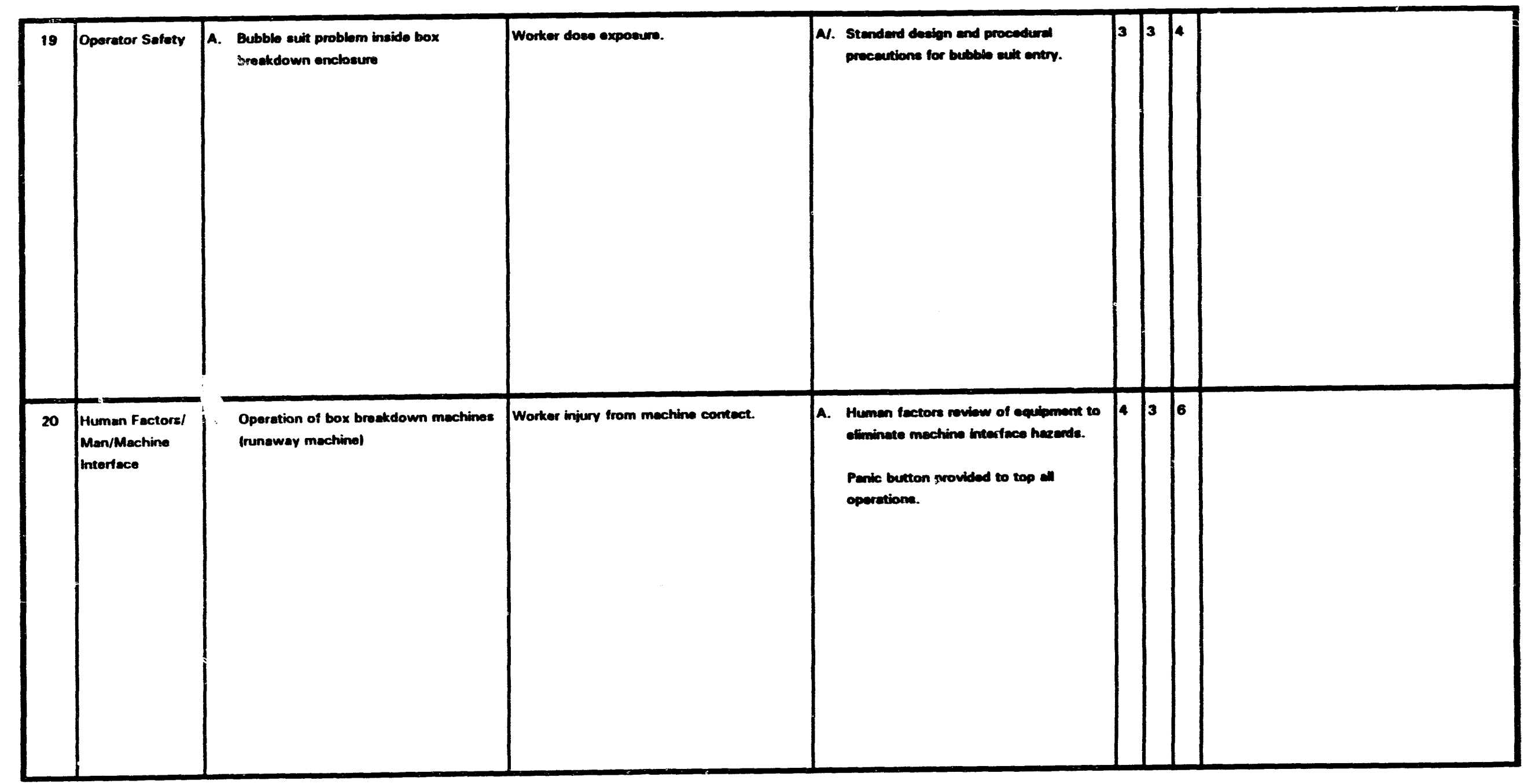


WRAP 2A ACDR PRELIMINARY HAZOP REVIEW DATA SHEET

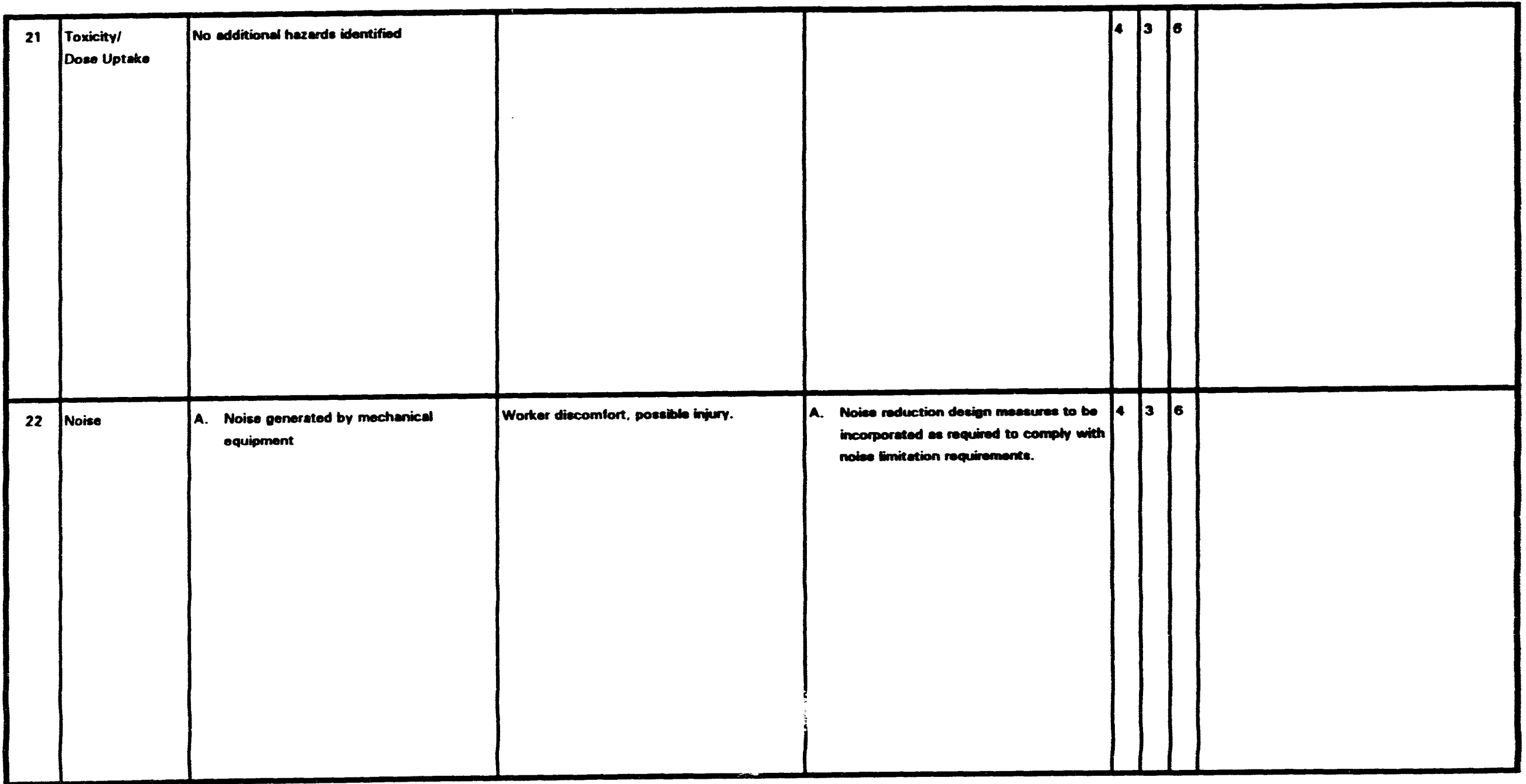



WRAP 2A ACDR PRELIMINARY HAZOP REVIEW DATA SHEET

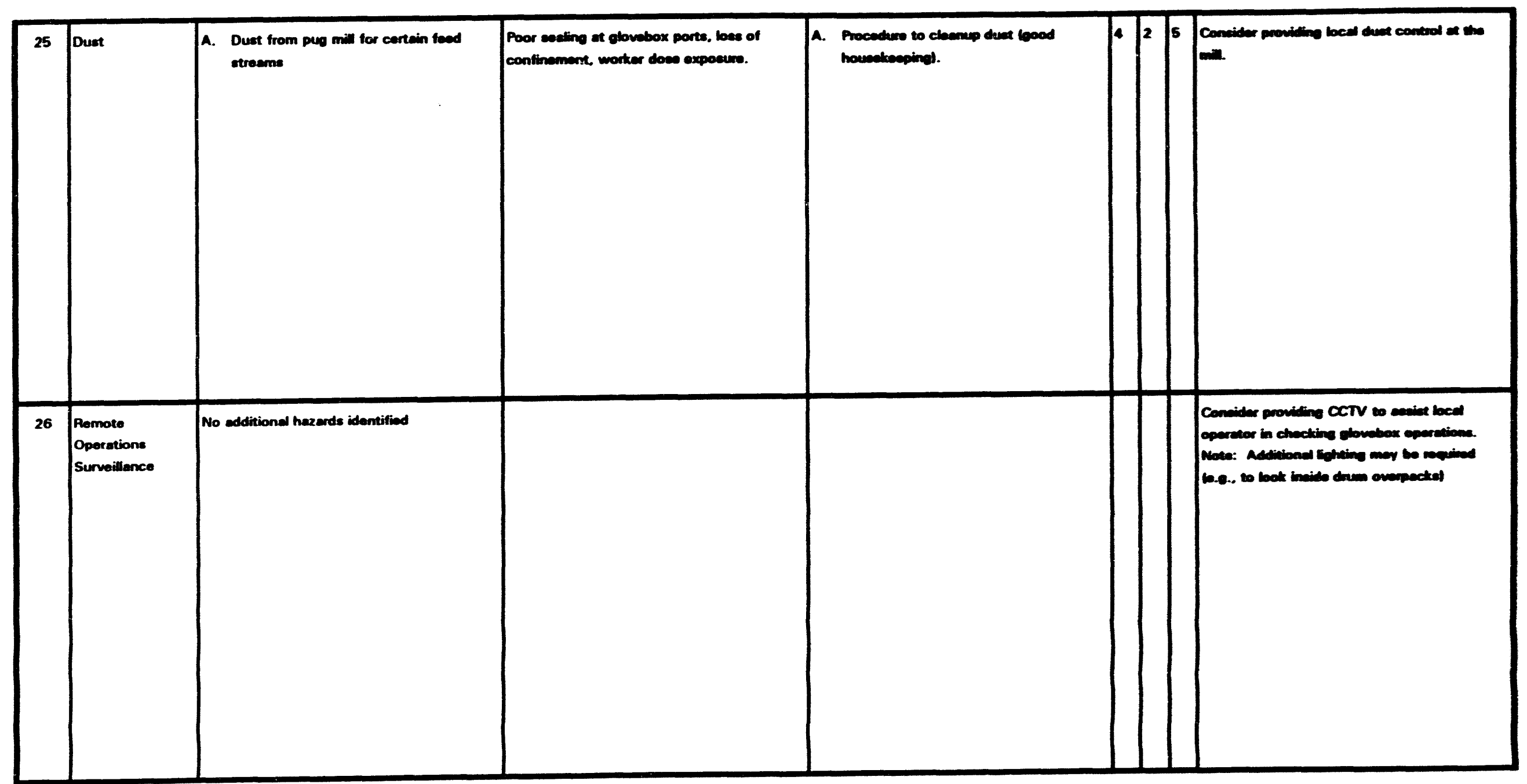


WRAP 2A ACDR PREUMMMARY HAZOP REVEW DATA SHEET

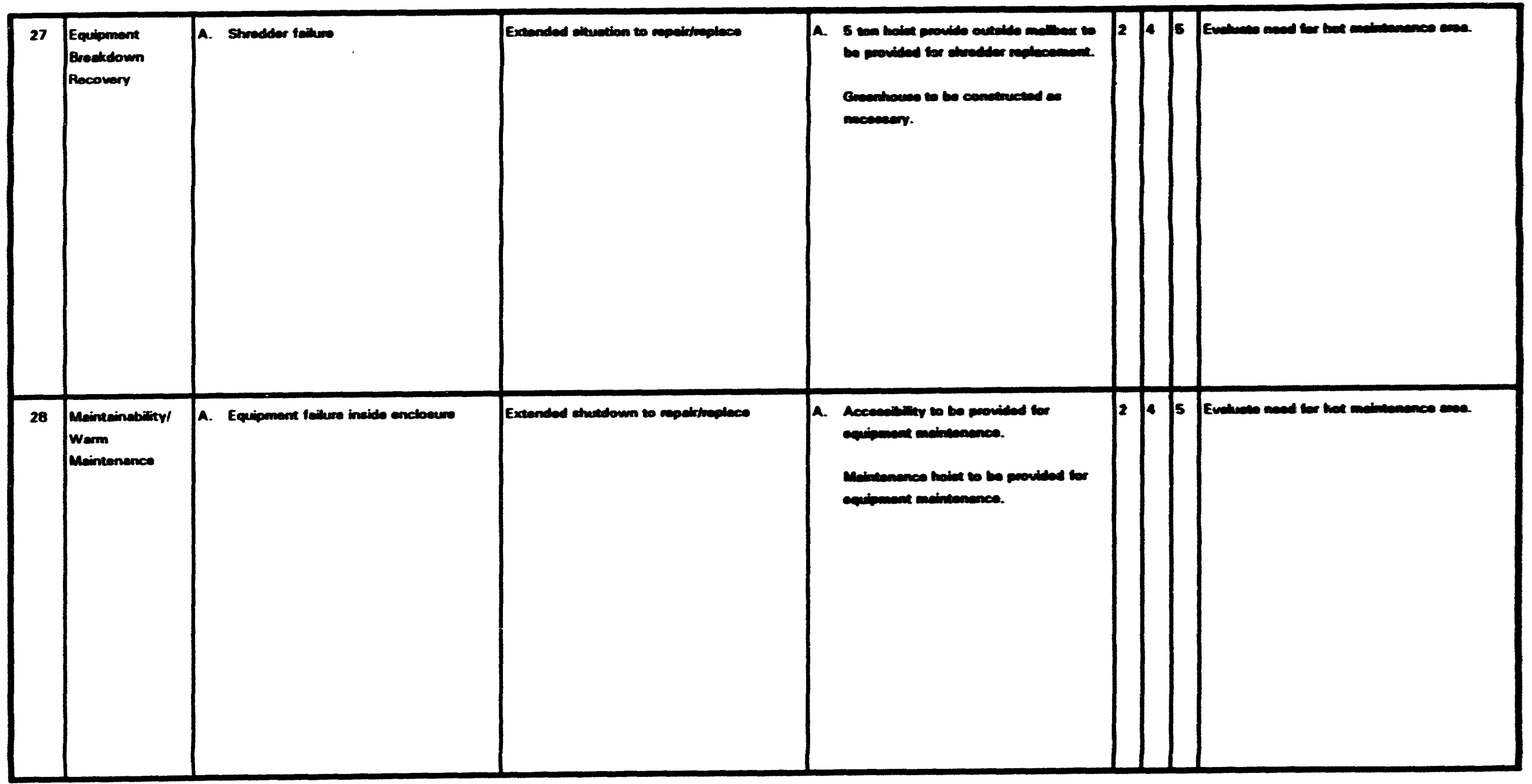


MRAP $2 A$ ACDR PREUMMLAY HAZOP REMEN DATA SHET

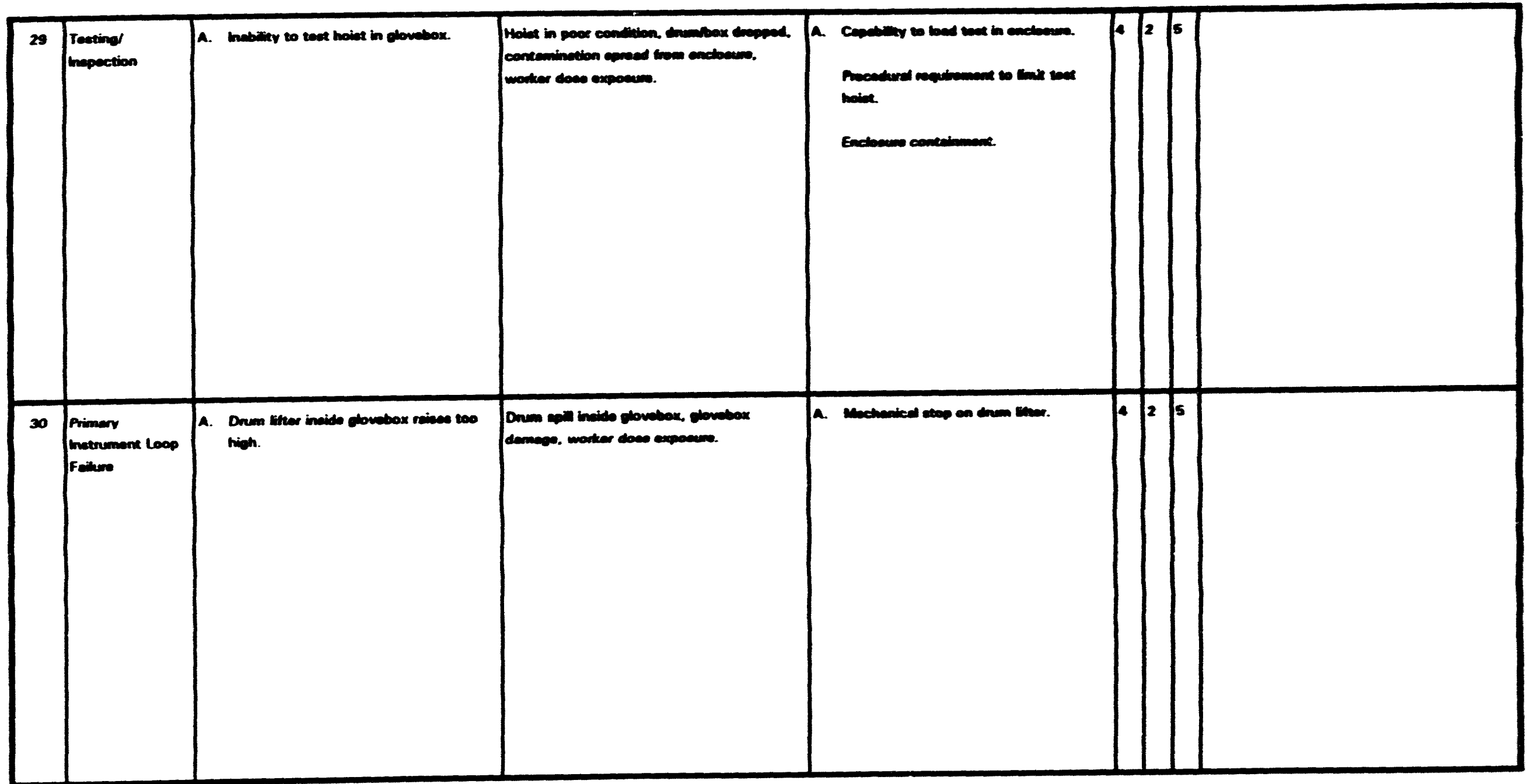


WRAP 2A ACDR PRELIMMARY HAZOP REVIEW DATA SHEET

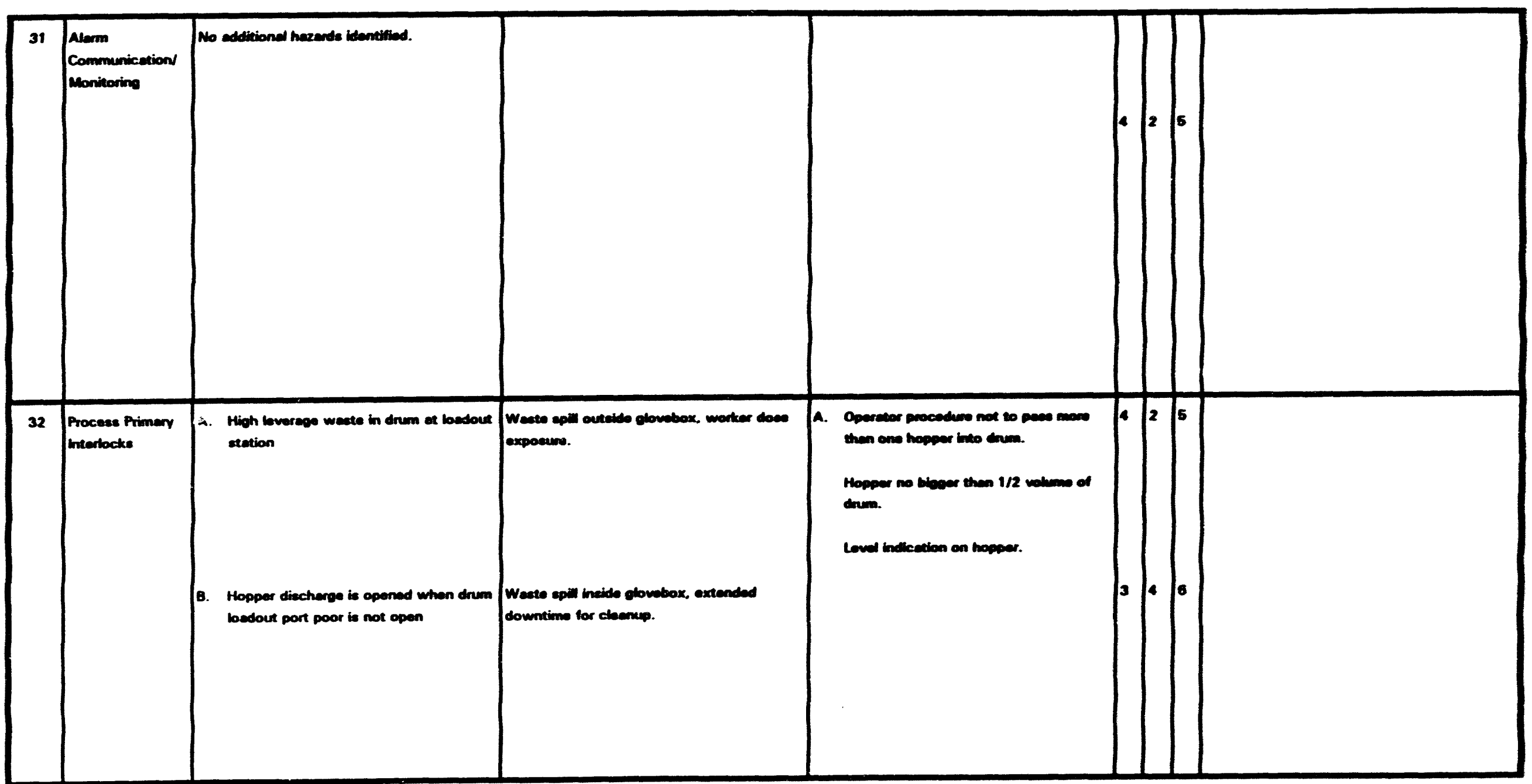


WRAP 2A ACDR PRELIMINARY HAZOP REVIEW DATA SHEET

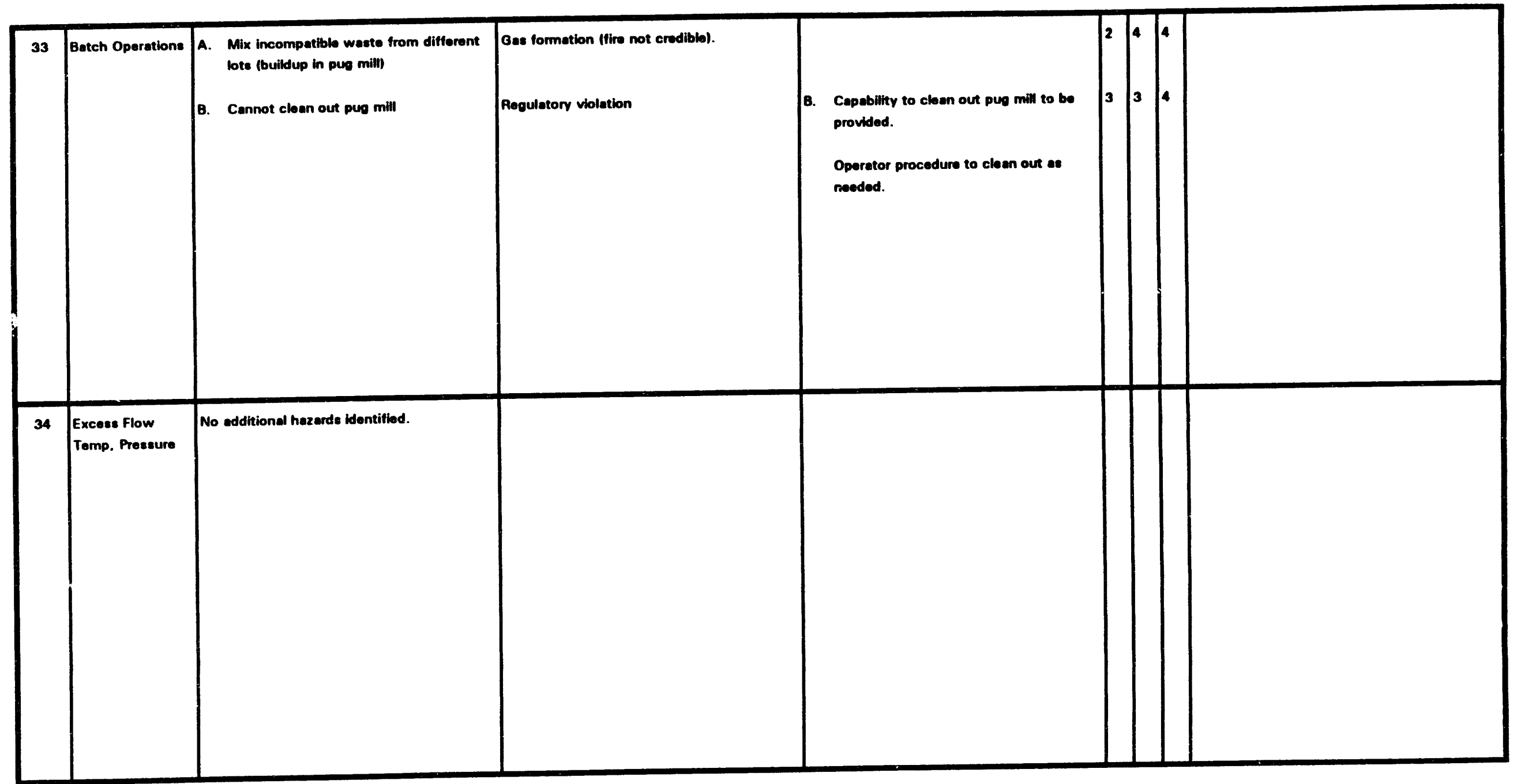


WRAP 2A ACDR PRELIMINARY HAZOP REVIEW DATA SHEET

\begin{tabular}{|c|c|c|c|c|c|c|c|}
\hline 35 & Semple Teking & A. Rediation from semplo & Worker exposure to rediation & A. & $\begin{array}{l}\text { Semple pio to be used. } \\
\text { Capebility to traneport pio to be } \\
\text { providod. }\end{array}$ & 42 & 5 \\
\hline
\end{tabular}


1.0 INTRODUCTION $\ldots \ldots \ldots \ldots \ldots \ldots \ldots \ldots \ldots \ldots \ldots \ldots \ldots \ldots \ldots \ldots$

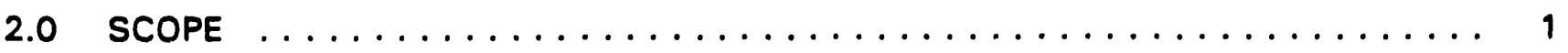

3.0 References $\ldots \ldots \ldots \ldots \ldots \ldots \ldots \ldots \ldots \ldots \ldots \ldots \ldots \ldots \ldots \ldots \ldots \ldots \ldots \ldots$

4.0 DESCRIPTION OF SAMPLE MANAGEMENT SYSTEM $\ldots \ldots \ldots \ldots \ldots \ldots \ldots 2$

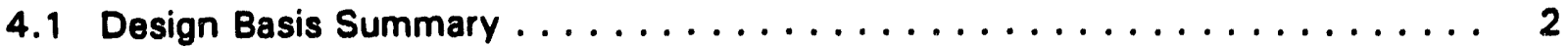

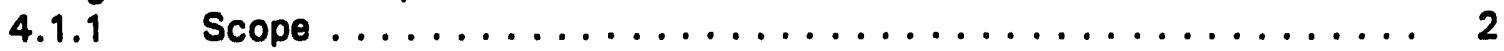

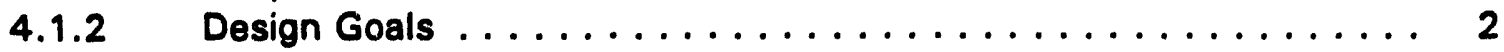

4.1.3 Functional Requirements $\ldots \ldots \ldots \ldots \ldots \ldots \ldots \ldots \ldots, 2$

4.2 Process Description Summary $\ldots \ldots \ldots \ldots \ldots \ldots \ldots \ldots \ldots \ldots \ldots \ldots$

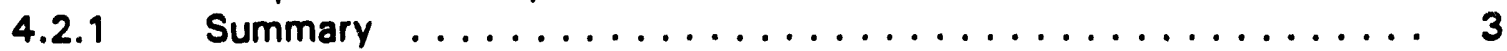

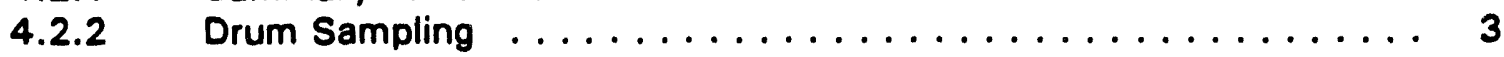

4.2.3 Sample Handling $\ldots \ldots \ldots \ldots \ldots \ldots \ldots \ldots \ldots, \ldots \ldots$

5.0 STUDY CRITERIA AND METHODOLOGY $\ldots \ldots \ldots \ldots \ldots \ldots \ldots \ldots \ldots$

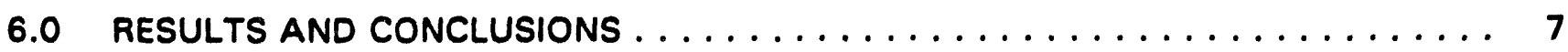


WRAP 2A

SAMPLE MANAGEMENT

HAZOP STUDY REPORT

\subsection{INTRODUCTION}

A HAZOP study was performed on the advanced conceptual design of the Sample Management System. The HAZOPS team met on 28 July 93, and consisted of the following members:

Name Comoany Role/Expertise

Larry Walker UE\&C Leader, Scribe, Saféty

Valerie Walker BNFL Radiological

Robert Voke BNFL Process Design

Andrew Sharpe BNFL Mechanical/Operations

William Cepeda UE\&C Instrumentation and Controls

The purpose of the HAZOPS is to identify major safety and operability problems which can best be resolved during completion of the advanced conceptual design.

\subsection{SCOPE}

This HAZOPS encompassed the Sample Management System, as shown on Process Flow Diagram H-2-140633, Sheets 1 and 2 (Rev. D and A respectively).

\subsection{REFERENCES}

1. WHC-SD-W100-FDC-001 Rev. 2A, Functional Design Criteria Waste Receiving And Processing Facility Module $2 \mathrm{~A}$.

2. WHC-SD-W100-SDRD-001 Rev. A, Waste Receiving and Processing Facility Module $2 A$ Supplemental Design Requirements Document. 


\subsection{DESCRIPTION OF SAMPLE MANAGEMENT SYSTEM}

\subsection{Design Basis Summary}

\subsubsection{Scope}

1. The workscope includes waste/product drum entry/exit into/out of the process area, waste drum sampling, product drum sampling, sample flask receipt/dispatch, limited sample analysis, bar coding of samples, data recording and archiving of samples.

\subsubsection{Design Goals}

1. Where possible, proven processes and technology will be used in the design. Proof of principal shall be accomplished by actual successful production experience or by laboratory/prototype demonstration supplemented with full scale simulation and engineering analysis.

2. The system shall abe designed to ensure that drum sampling operations are carried out in suitable high integrity enclosures.

3. Samples requiring analysis within the SMA or repacking for routing to an external laboratory shall be treated within suitable fume hood enclosures.

4. The system shall be designed to maximize location of components outside of confinement without compromising the confinement criteria.

5. The system design will maintain consideration for human factors, the principals of ALARA and eventual decontamination and decommissioning.

6. The system shall be designed to minimize generation of secondary waste and the lifetime occupation radiation exposure to personnel working in the area.

7. Design life of 30 years on a triple shift basis, 5 days per week, and a $70 \%$ facility availability.

\subsubsection{Functional Requirements}

1. Receipt and handling of raw waste and immobilized product in $\mathbf{5 5}$ gallon drums.

2. Receipt and handling of samples of radioactive mixed wastes.

3. Analytical and test capabilities including $\mathrm{pH}$, bulk specific gravity, conductivity, compressive strength and penetration resistance.

4. Archive storage of samples.

5. Sample shipping to other laboratories.

6. Office space for sample tracking, protocol management and analytical results tracking. 


\subsection{Process Description Summary}

\subsubsection{Summary}

1. The Sample Management Area (SMA) consists principally of a sample enclosure and a laboratory area. The sample enclosure will be equipped to lift a 55 gallon drum into the area, de-lid the drum, take a sample of the waste, re-lid the sampled drum, place the drum into an empty 83 gallon drum and re-lid the 83 gallon drum so that it can be returned to storage. The laboratory area will be where samples are bar coded and logged onto the data record system. The area will also have four sample fume hoods, two for the handling of active samples and two for the handling of inactive samples. The sample fume hoods will be equipped to perform any simple analysis work required or to be used for repacking samples for transfer out of WRAP $2 A$.

\subsubsection{Drum Sampling}

1. The drum to be sampled will be placed on a lift table below the $\mathbf{5 5}$ gallon drum entry port in the sample enclosure. The simple double lid port above the drum is opened and the drum raised partly into the enclosure using the lift table. The drum hoist picks up the drum and places it on the drum band removal, de-lidding and sample extraction station. The enclosure simple double lid entry port is then closed and the drum lid removed. A sphincter port is opened to allow the sample container to be posted into the enclosure. A sample of the waste is extracted and the sample container posted back out of the enclosure for transfer to an external analytical facility. The 55 gallon drum is re-lidded and then an empty 83 gallon drum is placed below the enclosure simple double lid entry port. The $\mathbf{8 3}$ gallon drum is de-lidded and the 55 gallon drum is place dint eh 83 gallon drum using the enclosure hoist. The 83 gallon drum is then re-lidded and the overpacked 55 gallon drum is returned to the external storage facility.

\subsubsection{Sample Handling}

1. Non-radioactive samples will be transported to the SMA in standard sample containers. Radioactive samples taken out of Zone 1 areas will be transported to the SMA in shielded sample pigs. These will be collected in racks and wil' be delivered by manual powered hand cart. Samples which require analysis by external analytical facilities but which do not require repackaging will be bar coded and logged onto the data record system prior to dispatch. Samples which require repackaging or analysis within the SMA will be placed in the designated sample fume hood. The fume hoods will be positioned and labelled so that there is a clear distinction between the active and inactive fume hoods. In addition the inactive fume hoods will not be equipped to handle shielded sample pigs. The SMA will be manned by competent laboratory personnel and therefore further physical methods of preventing samples being treated in the wrong fume hood will not be necessary. 


\subsection{STUDY CRITERIA AND METHODOLOGY}

This HAZOF has utilized a predetermined set of process deviations/upset conditions to be anaiyzed by the HAZOP team for each process deviation, possible courses were postulated and worst case consequences (without benefit of any safeguards were determined. Existing safeguards (design and procedural) were then identified. Those safeguards which could be reasonably expected to be present in the final design were assumed to be existing and were 80 documented in the HAZOP. For each cause and effect, hazard severity and probability were qualitatively assessed (taking credit for existing safeguards which reduce hazard probability) using the criteria shown in Table 1. The overall risk rating for each hazard was then determined using the risk ranking matrix shown on Table 2 . Recommendations were proposed by the HAZOP team in instances required by the implementation criteria shown in Table 2. 
TABLE 1

HAZARD SEVERITY AND PROBABILITY CLASSIFICATION CRITERIA

\begin{tabular}{|c|c|c|c|c|}
\hline \multirow{2}{*}{ Target Hazard } & \multicolumn{4}{|c|}{ Severity Class (Worst-case Scenario) } \\
\hline & Catastrophic (1) & Extensive (2) & Moderate (3) & Operational (4) \\
\hline Community & $\begin{array}{l}\text { Multiple irreversible } \\
\text { injuries; may include a } \\
\text { fatality }\end{array}$ & $\begin{array}{l}\text { Single irreversible or } \\
\text { several reversible injuries } \\
\text { (no fatalities) } \\
\text { OR }\end{array}$ & $\begin{array}{l}\text { Several reversible injuries } \\
\text { OR }\end{array}$ & \\
\hline Workers & \begin{tabular}{|l|}
$\begin{array}{l}\text { Fatalities or irreversible } \\
\text { injuries }\end{array}$ \\
OR \\
\end{tabular} & $\begin{array}{l}\text { Several injuries } \\
\text { OR }\end{array}$ & $\begin{array}{l}\text { Single injury } \\
\text { OR } \\
\end{array}$ & \\
\hline Facility & $\begin{array}{l}\text { Partial or full dernolition of } \\
\text { facility } \\
\text { OR } \\
\end{array}$ & $\begin{array}{l}\text { Rupture or similar loss of } \\
\text { containment } \\
\text { OR } \\
\end{array}$ & $\begin{array}{l}\text { Major equipment damage } \\
\text { leading to one month or } \\
\text { more facility downtime } \\
\text { OR }\end{array}$ & $\begin{array}{l}\text { Equipment damage } \\
\text { leading to several days of } \\
\text { facility downtime or other } \\
\text { operational penalty } \\
\text { OR }\end{array}$ \\
\hline Environment & $\begin{array}{l}\text { Major environmental } \\
\text { impact with significant } \\
\text { cleanup/iability costs }\end{array}$ & $\begin{array}{l}\text { Groundwater, soil, or } \\
\text { public sewer } \\
\text { contamination }\end{array}$ & $\begin{array}{l}\text { Minor spill or release } \\
\text { resulting in permit violation }\end{array}$ & \\
\hline
\end{tabular}

\section{LIKELIHOOD CLASSIFICATION}

\begin{tabular}{|l|l|}
\hline Highly Likely (1) & $\begin{array}{l}\text { Event has occurred at this facility - or - other facility - or - is expected to occur several times during the } \\
\text { next } 10 \text { years. }\end{array}$ \\
\hline Likely (2) & $\begin{array}{l}\text { Event has occurred at this facility - or - is possible to occur at this facility several times during the next } \\
30 \text { years. }\end{array}$ \\
\hline Unlikely (3) & $\begin{array}{l}\text { Event may have occurred at another facility - or - is possible to occur at this facility at least once in the } \\
\text { next } 50 \text { years. }\end{array}$ \\
\hline Extremely Unlikely (4) & $\begin{array}{l}\text { Event is not likely to ever occur in this facility, given a continuation of the current levels of training, } \\
\text { procedures, maintenance, inspection, testing, and other applicable process safety management system } \\
\text { support. }\end{array}$ \\
\hline
\end{tabular}


TABLE 2

RISK RANKING MATRIX AND IMPLEMENTATION CRITERIA

\begin{tabular}{|c|c|c|c|c|}
\hline Likelihood & & & & \\
\hline Highly Likely (1) & 4 & 2 & 1 & 1 \\
\hline Likely (2) & 5 & 3 & 2 & 1 \\
\hline Unlikely (3) & 6 & 4 & 3 & 2 \\
\hline Extremely Unlikely (4) & 7 & 6 & 5 & 4 \\
\hline
\end{tabular}

\section{RISK RANKING IMPLEMENTATION}

\begin{tabular}{|c|l|}
\hline Risk Ranking & \multicolumn{1}{c|}{ Implication } \\
\hline 1 & $\begin{array}{l}\text { Risk level - Very significant } \\
\text { Recommendation = Required from the HAZOP team } \\
\text { Implementation - Begins immediately }\end{array}$ \\
\hline 2 & $\begin{array}{l}\text { Risk level - Significant } \\
\text { Recommendation = Required from the HAZOP team } \\
\text { Implementation - Begins within three months }\end{array}$ \\
\hline 3 & $\begin{array}{l}\text { Risk level - Not very significant } \\
\text { Recommendation = Required from the HAZOP team } \\
\text { Implementation - Begins within one year }\end{array}$ \\
\hline 4 & $\begin{array}{l}\text { Risk level - Not significant, but may be an Operational problem } \\
\text { Recommendation = At the discretion of the HAZOP team } \\
\text { Implementation - As soon as practical, not later than the next major plant turnaround }\end{array}$ \\
\hline 5,6, or 7 & $\begin{array}{l}\text { Risk level - Negligible, but may be an operational problem } \\
\text { Recommendation = At the discretion of the HAZOP team } \\
\text { Implementation - To be evaluated by management }\end{array}$ \\
\hline
\end{tabular}




\subsection{RESULTS AND CONCLUSIONS}

Because this HAZOP is performed relatively early in the design phase, existing safeguards have not been fully documented on the process flow diagrams (these would mostly be shown on the P\&ID's developed during Title Design). However, the HAZOP team assumed specific safeguards would be present in the final design if it appear reasonable to expect this. These assumed safeguards are documented on the HAZOP worksheets and credit was taken for these presumed safeguards when assessing risk. During Title Design, the presence of these safeguards need to be verified to validate the conclusions of this HAZOP.

All of the potential hazards and operability problems evaluated in this HAZOP, with one exception, have risk levels classified as negligible. The one exception involves the possibility of a drum spill outside the sampling glovebox if the receiving overpack drum is not in position (mechenical equipment failure plus drum position sensor failure). The HAZOP team recommends that a redundant drum position switch be provided at the glovebox loadout station, thereby, reducing the risk level to a negligible classification. In an unrelated matter, the HAZOP team has recommended, at its discretion, that a closed in circuit television camera with monitor be mounted at the sampling glovebox. This could be used to assist the local operator in checking criteria glovebox operations (e.g., to look inside the overpack drum repacks during drum entry).

Table 3 presents a summary of changes to be made in the process flow diagram, assumed design safeguards, and additional safeguards to be evaluated for incorporation into the design.

In several instances, the need for human factors analyses and reliability/availability/maintainability analyses during Title Design was highlighted by the HAZOP team to achieve negligible risk levels. The HAZOP assumed that such analyses would be performed and that the necessary design requirements/modifications are incorporated. The performance of these design analyses are considered to be open issues to be resolved during Title Design. Similarly, the HAZOP team identified the need for a maintainability analysis to develop requirements for warm maintenance at the WRAP 2A Facility.

The HAZOP is documented in the attached HAZOP worksheets. 


\section{IAPE3}

\section{SAMPLE MANAOEMENT HAZOP SUMMARY}

\section{PROCFSS FLOW DIACRAM CHANGES}

(none identified)

\section{ASSUMED DESICN SAFECUARDS}

1. All desion basis requirements.

2. Fume hood door position alarm.

3. High flow shutdown for plant air line to glovebox.

4. Equipment in glovebox is designed for hazardous area (non-sparking, grounded).

5. HVAC upset alarm (DP or air flow) for glovebox with hardwired backup alarm.

6. Lubricant cooling for waste core drilling (with interlock/alarm for loss of lubricant flow).

7. Manipulator fluid is non-flammable.

8. Hoist lift is fail safe design (retains load).

9. Airlock doors fail in lost position (with mechanical means to open/close door).

10. Dry decon methods for cleanup.

11. Movement path of manipulator arms does not cross glove positions.

12. Mechanism to independently verify/alarm fume hood air flow.

13. Local HVAC duct at coring station.

14. DP alarm at HEPA filter.

15. Manual means to operate mechanical equipment (conveyor, lift table) for breakdown recovery.

16. Capability to load-test hoist in glovebox.

17. Travel limit switch (mechanism) for manipulator and lift table.

18. AGV status/modification alarm.

19. Fail-safe design of interlocks (operations shutdown upon loss of interlock signal).

\section{EVALUATE/INCORPORATE INTO TITLE I DESIGN}

1. Redundant position sensor/alarm for glovebox drum port to detect that drum is not in position.

2. Consider closed circuit TV to assist glovebox operator (additional lighting may be required to louk inside drums).

3. Determine warm maintenance requirements for repairs of specific equipment. 
WRAP 2A ACDR PRELIMINARY HAZOP REVIEW DATA SHEET

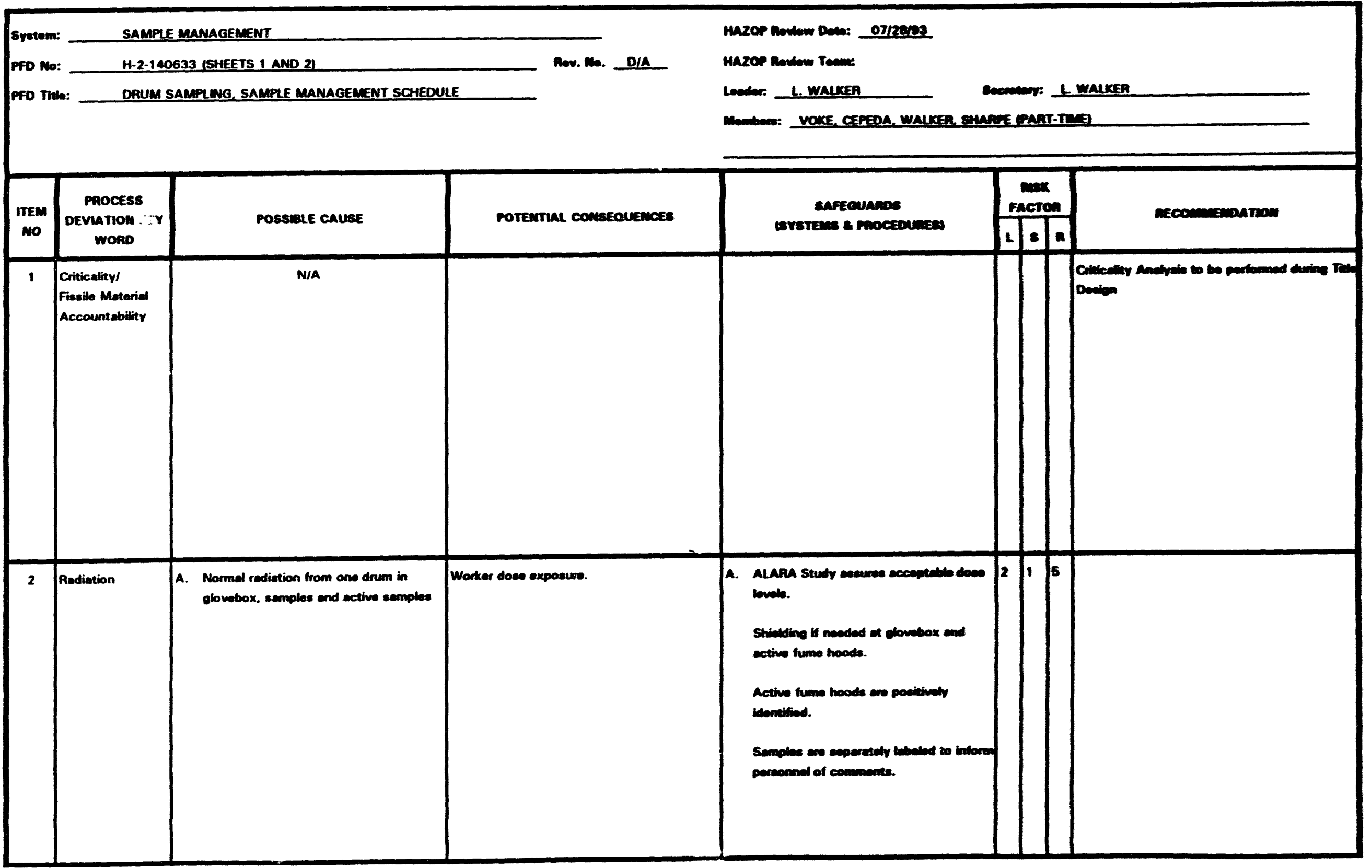




\section{WRAP 2A ACDR PRELIMINARY HAZOP REVIEW DATA SHEET}

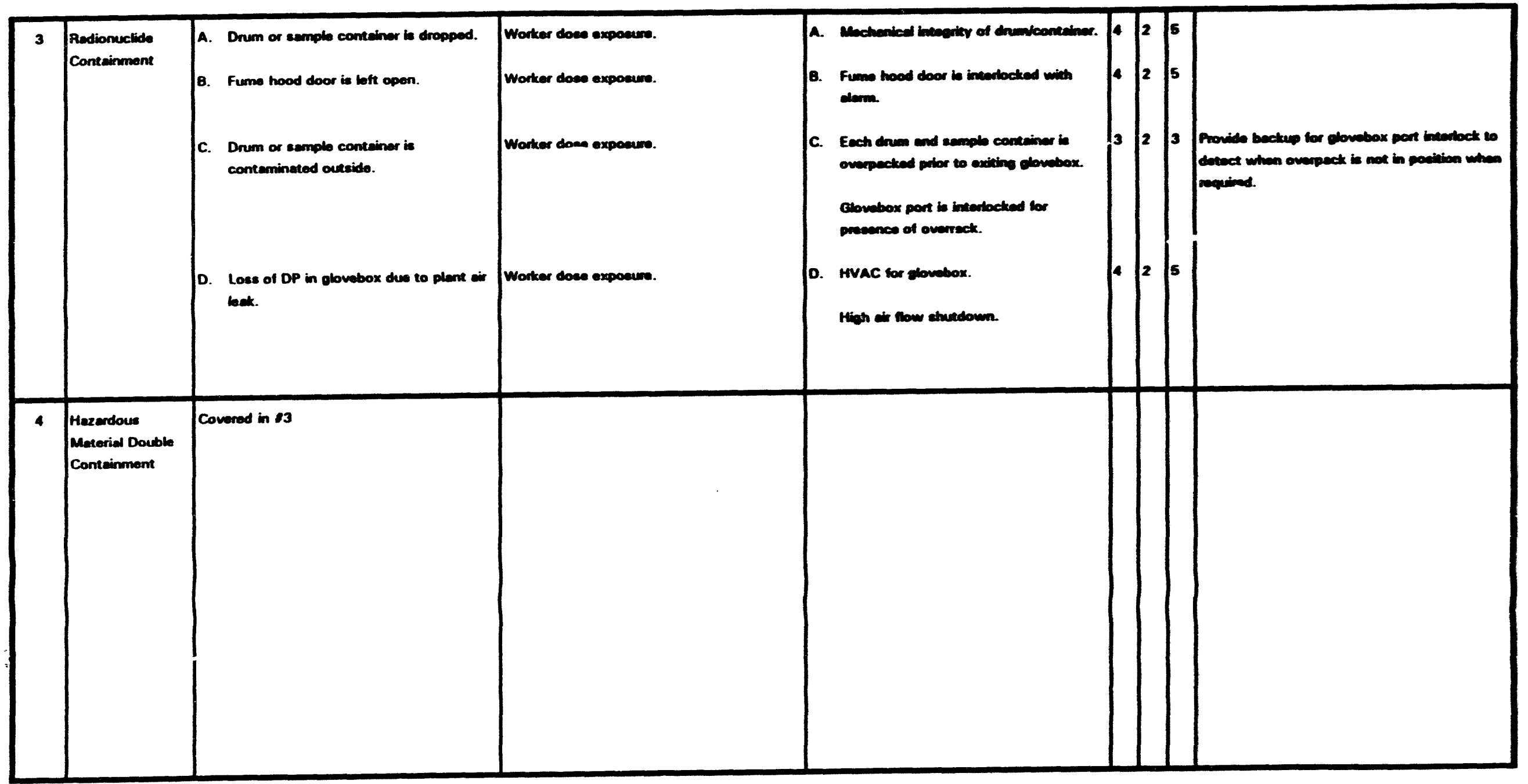



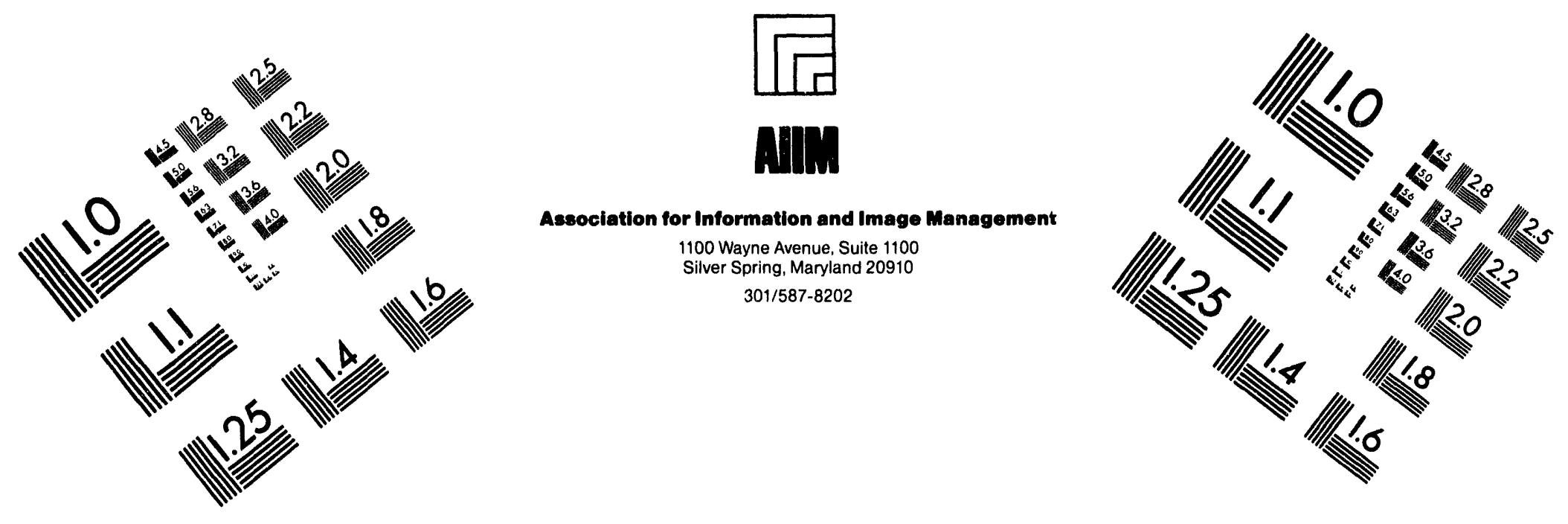

\section{Centimeter}

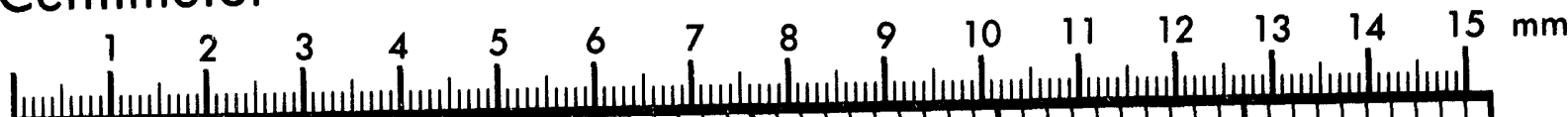

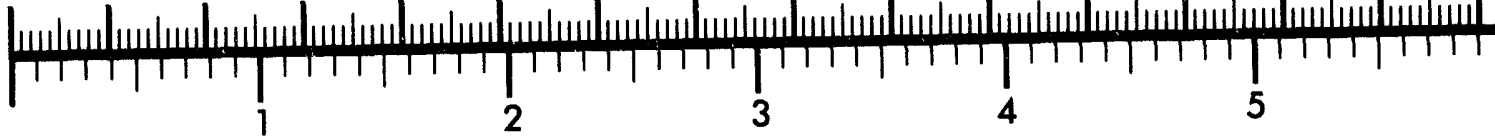
Inches
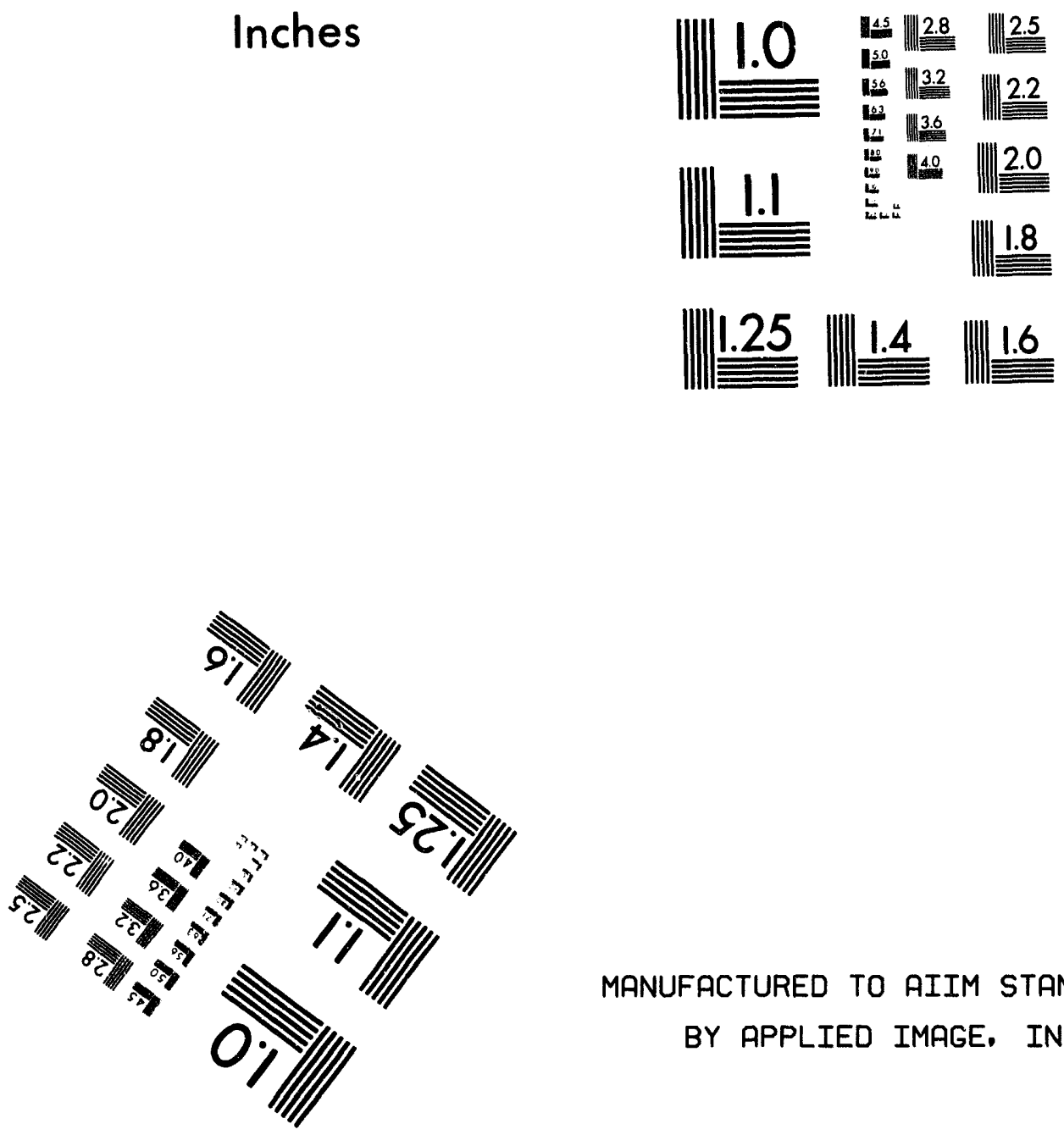

MANUFACTURED TO AIIM STANDARDS BY APPLIED IMAGE. INC.

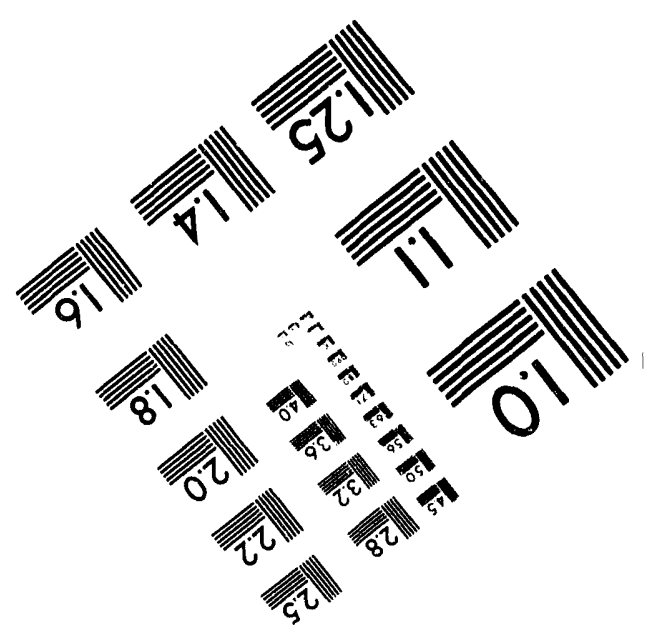



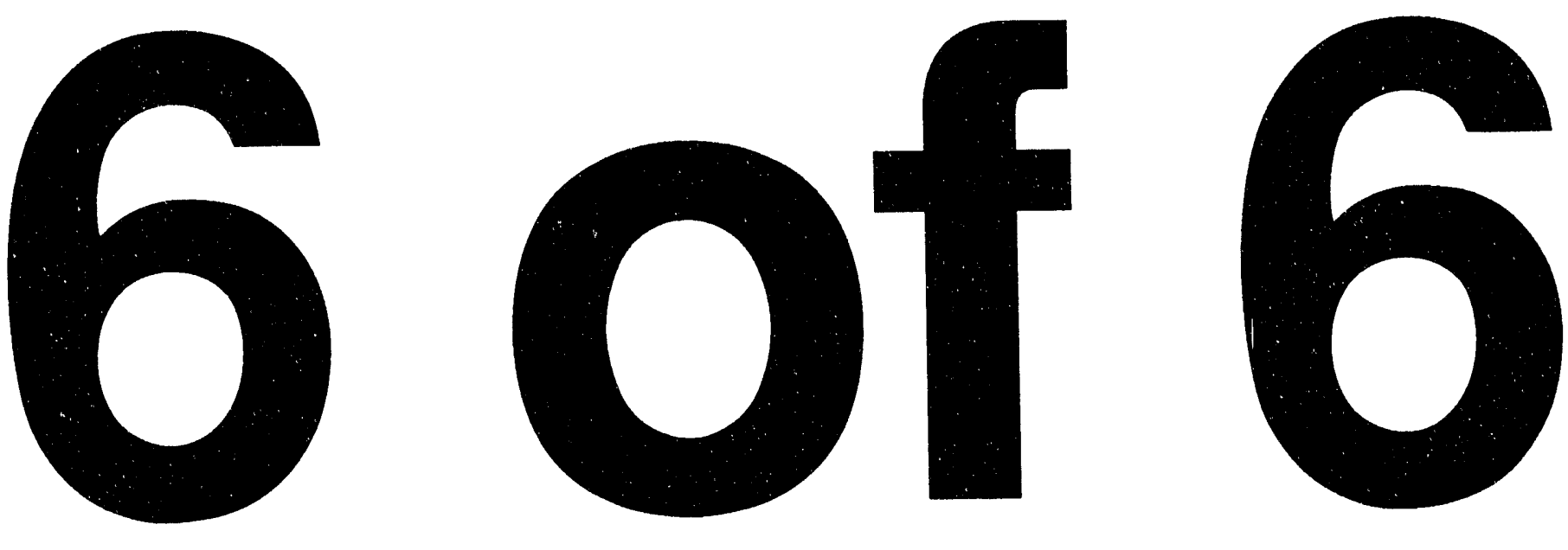
WRAP 2A ACDR PRELIMINARY HAZOP REVIEW DATA SHEET

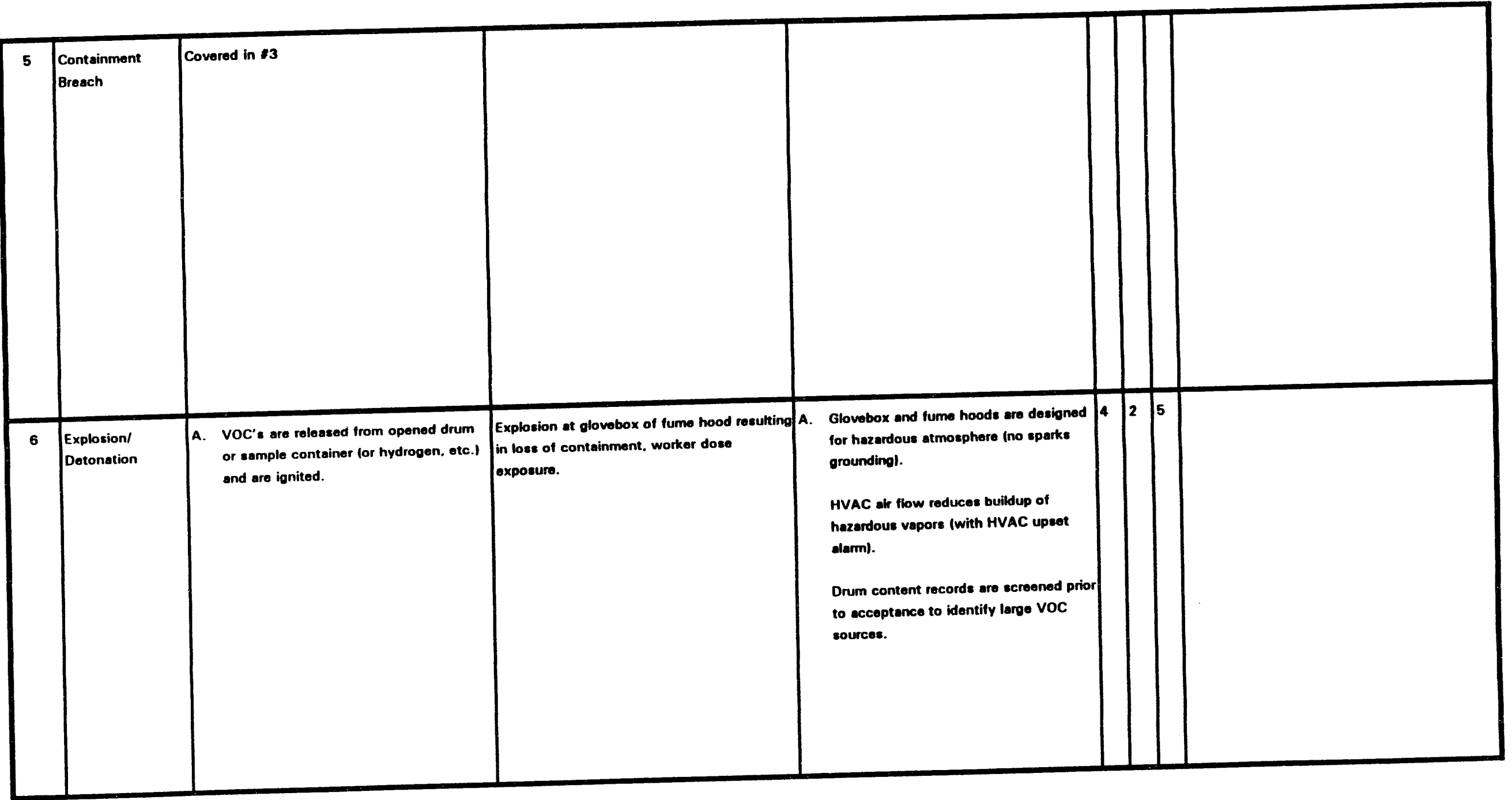


WRAP 2A ACDR PRELIMINARY HAZOP REVIEW DATA SHEET

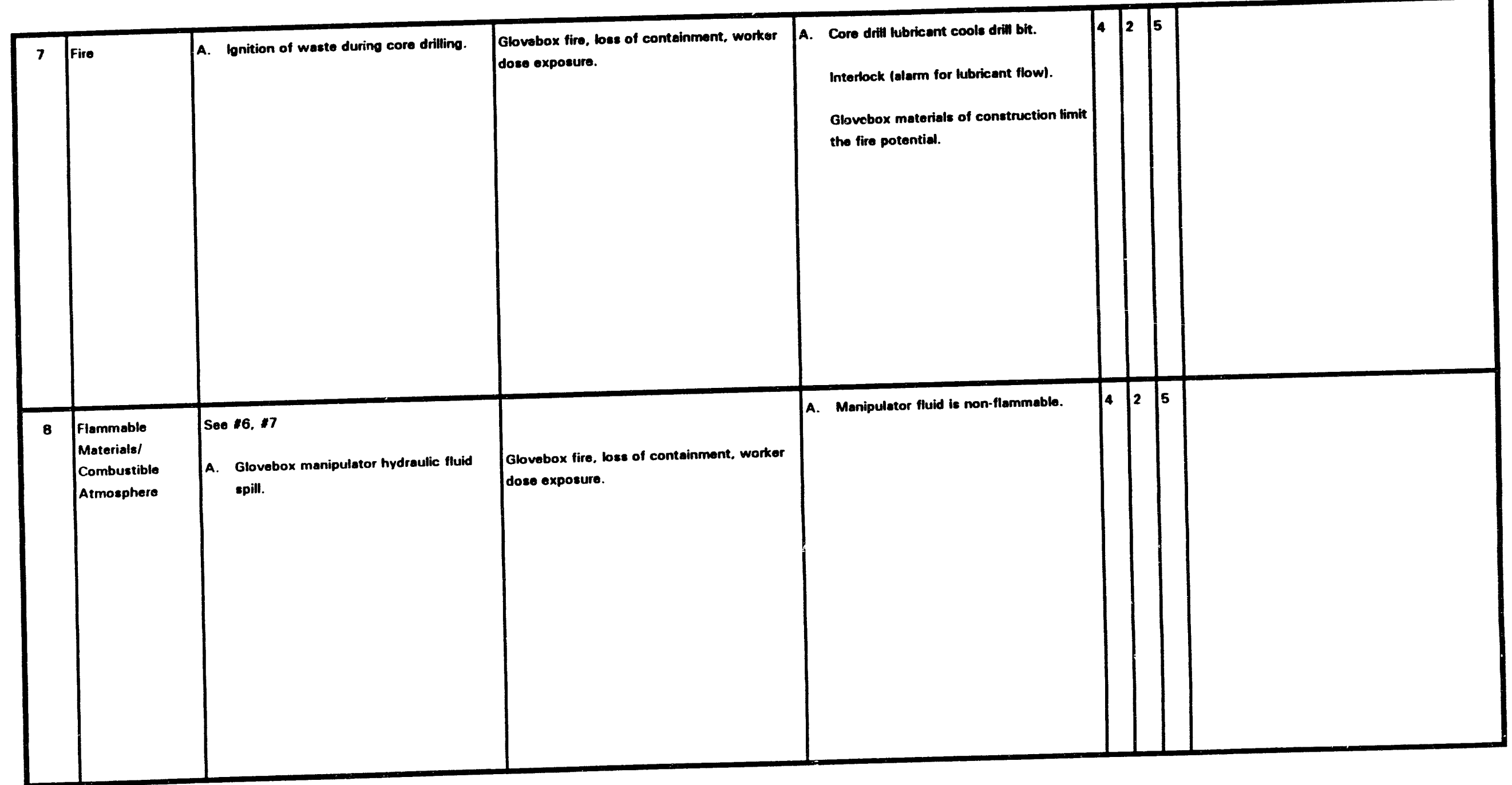




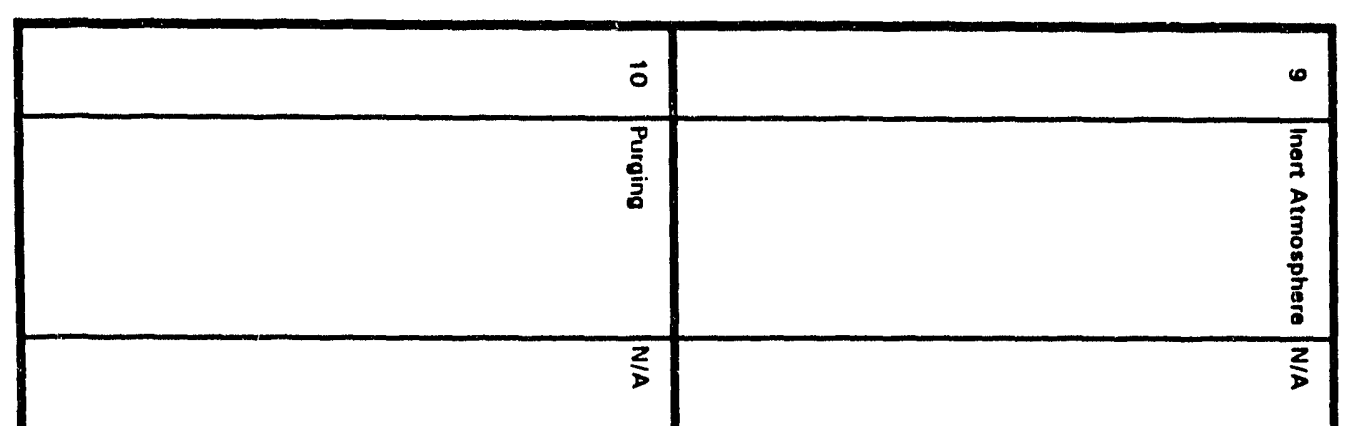

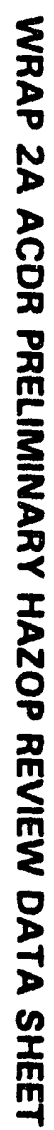



WRAP 2A ACDR PRELIMINARY HAZOP REVIEW DATA SHEET

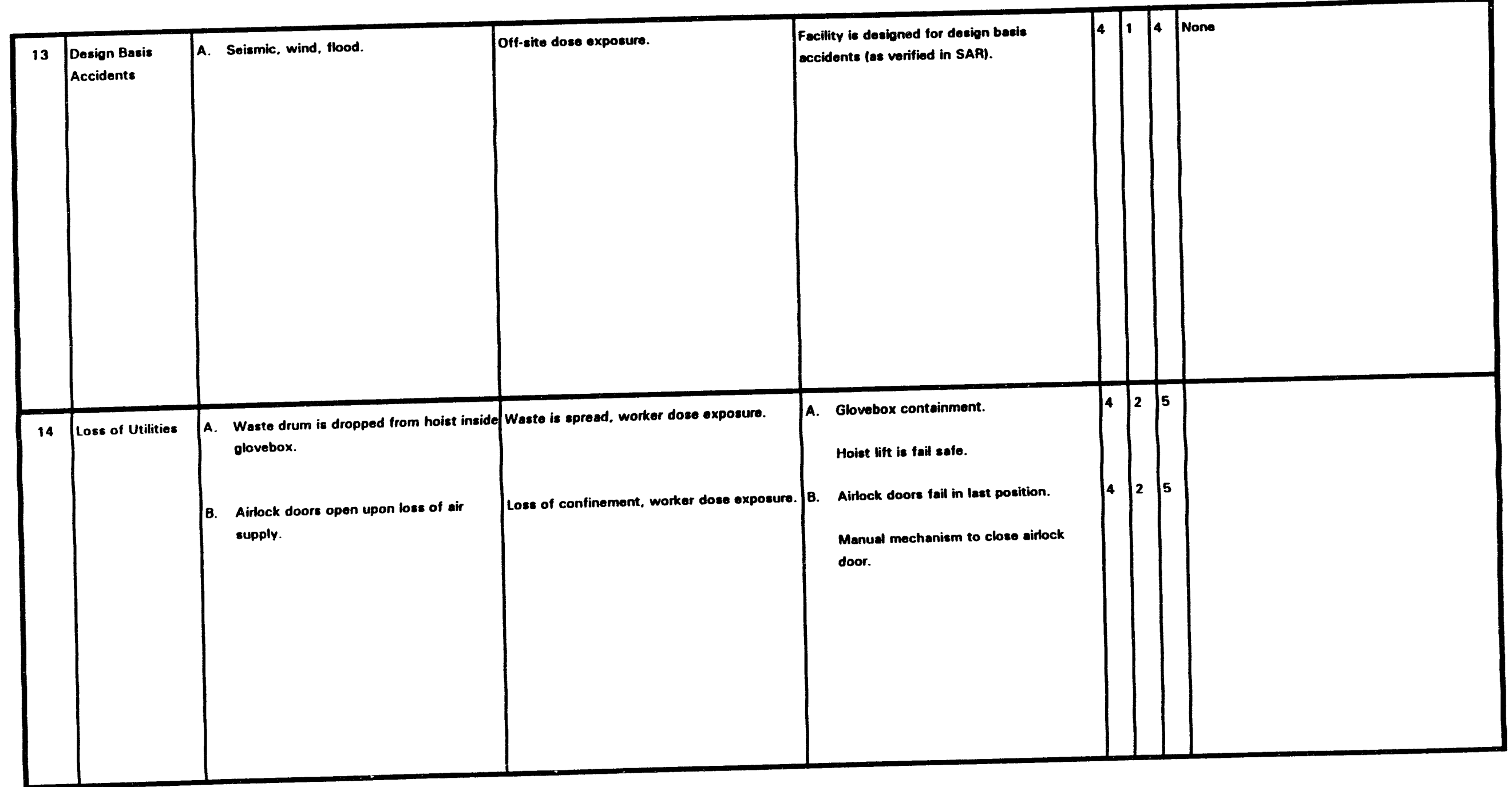


WRAP 2A ACDR PRELIMINARY HAZOP REVIEW DATA SHEET

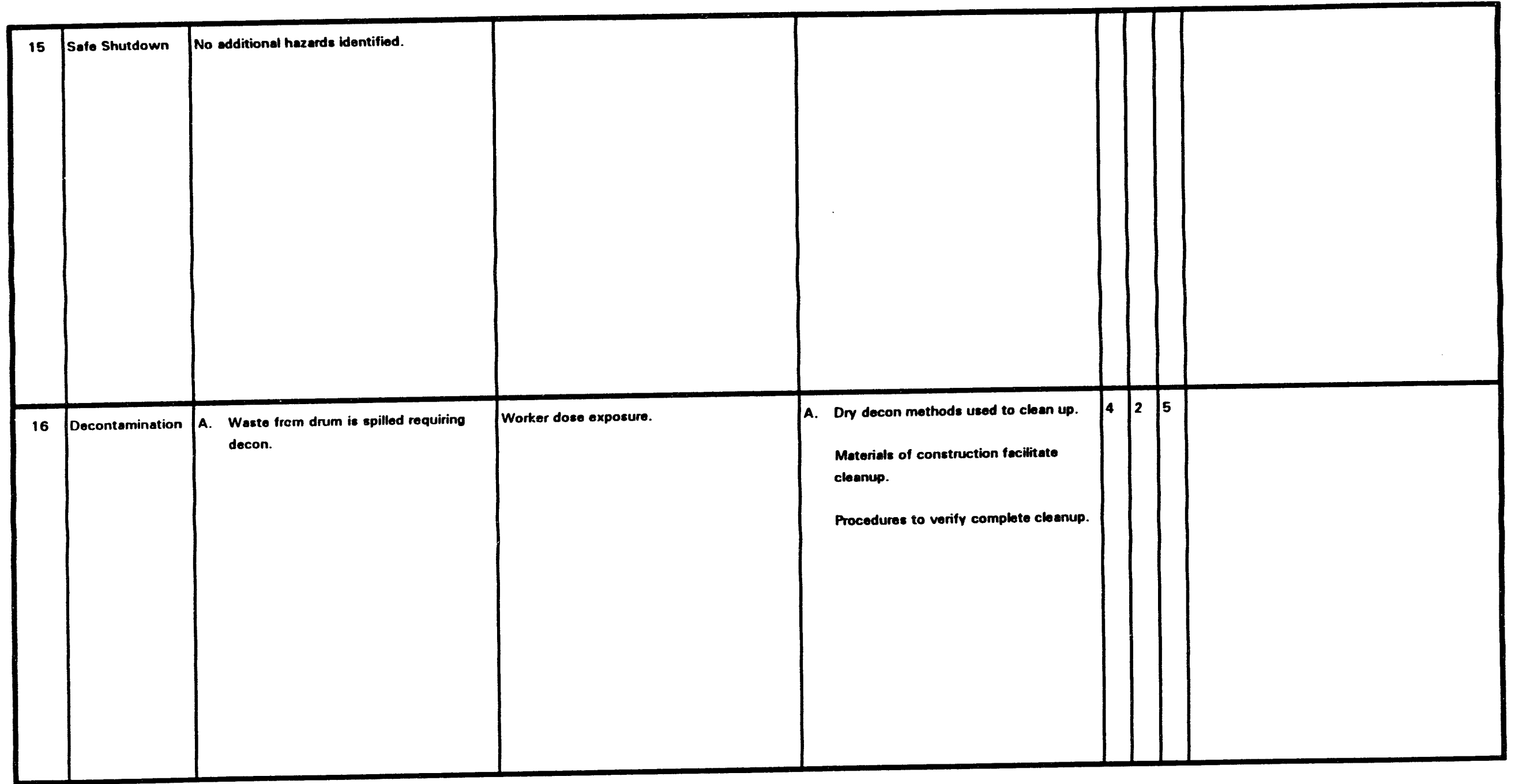




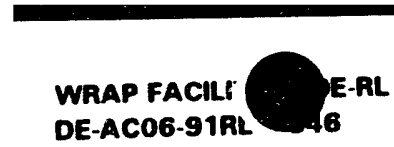

WRAP 2A ACDR PRELIMINARY HAZOP REVIEW DATA SHEET

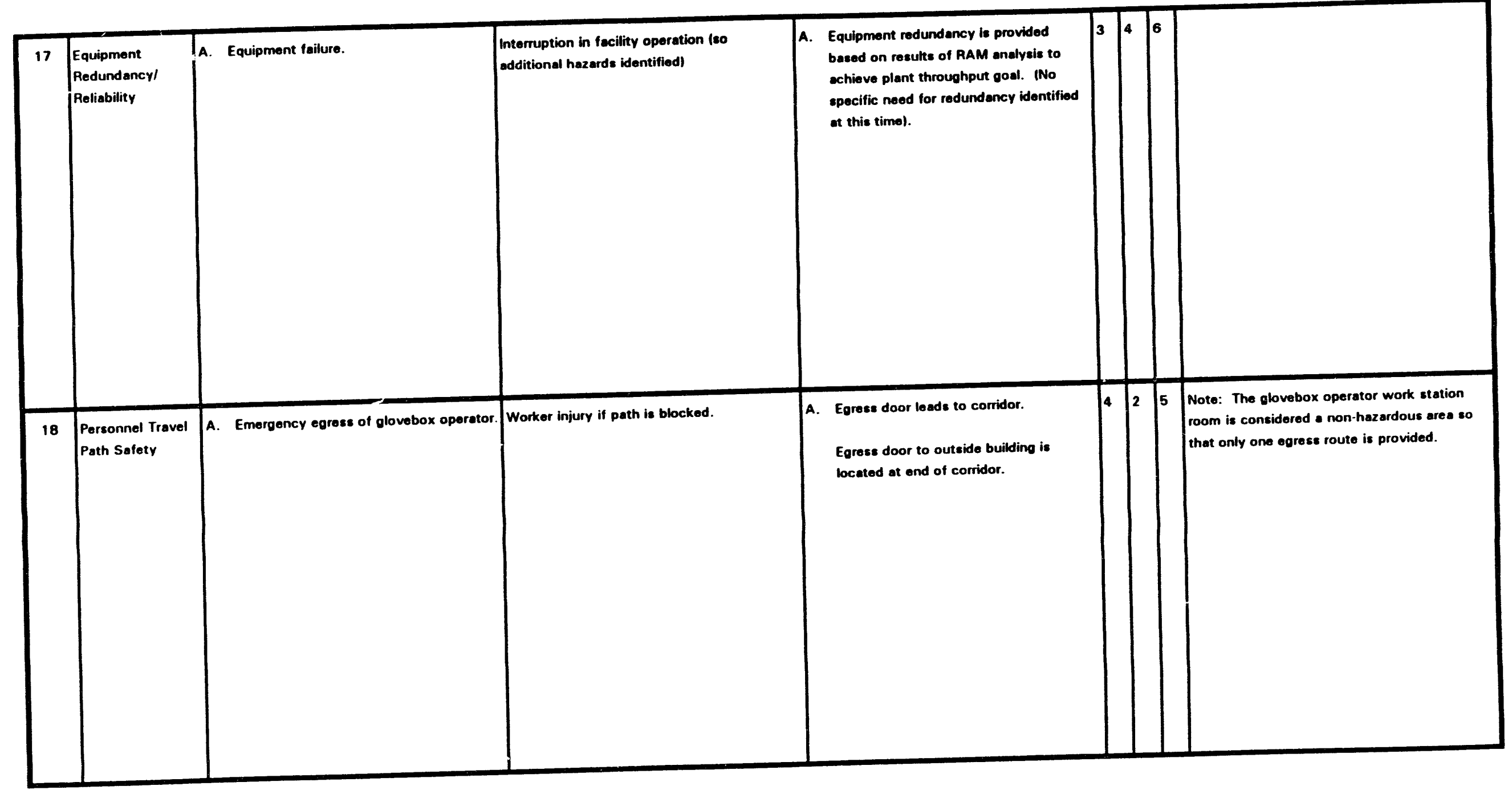


WRAP 2A ACDR PRELIMINARY HAZOP REVIEW DATA SHEET

\begin{tabular}{|c|c|c|c|c|c|c|c|}
\hline 19 & Operator Safoty & No odditional hazards identified. & & & & & \\
\hline 20 & $\begin{array}{l}\text { Human Factors/ } \\
\text { Man/Machine } \\
\text { Interface }\end{array}$ & $\begin{array}{l}\text { A. Operation of core samples or drum lid } \\
\text { saw. }\end{array}$ & Worker injury from machine contact. & $\begin{array}{l}\text { A. Sowing and coring are remote } \\
\text { oporations. } \\
\text { ARC's of manipulator end glove do not } \\
\text { cross. } \\
\text { Humen factore review of equipment } \\
\text { eliminates machine interface hazards. }\end{array}$ & \begin{tabular}{|l|l|}
4 & 3 \\
\end{tabular} & 6 & \\
\hline
\end{tabular}


WRAP 2A ACDR PRELIMINARY HAZOP REVIEW DATA SHEET

\begin{tabular}{|c|c|c|c|c|c|c|c|}
\hline 21 & \begin{tabular}{|l} 
Toxicityl \\
Dose Upteke
\end{tabular} & $\begin{array}{l}\text { A. Loss of glovebox or fume hood HVAC } \\
\text { operation. }\end{array}$ & $\begin{array}{l}\text { Worker dose exposure to toxic wasto } \\
\text { matorials. }\end{array}$ & $\begin{array}{l}\text { A. DP ederm for alovebox which is } \\
\text { independent of DP HVAC controls. } \\
\text { Mochenism to indopendently } \\
\text { vority/alem furmo hood air flow. }\end{array}$ & $43^{3}$ & 6 & 3 \\
\hline 22 & Noise & $\begin{array}{l}\text { A. Noise oenerated by mechanical } \\
\text { equipment (e. o. core drillingl. }\end{array}$ & Worker discomfon, possible injury. & $\begin{array}{l}\text { A. Noise reduction desion measures } \\
\text { incorporated as required to comply with } \\
\text { noise limitetion requirements. }\end{array}$ & $4 \sqrt[3]{3}$ & 6 & \\
\hline
\end{tabular}


WRAP 2A ACDR PRELIMINARY HAZOP REVIEW DATA SHEET

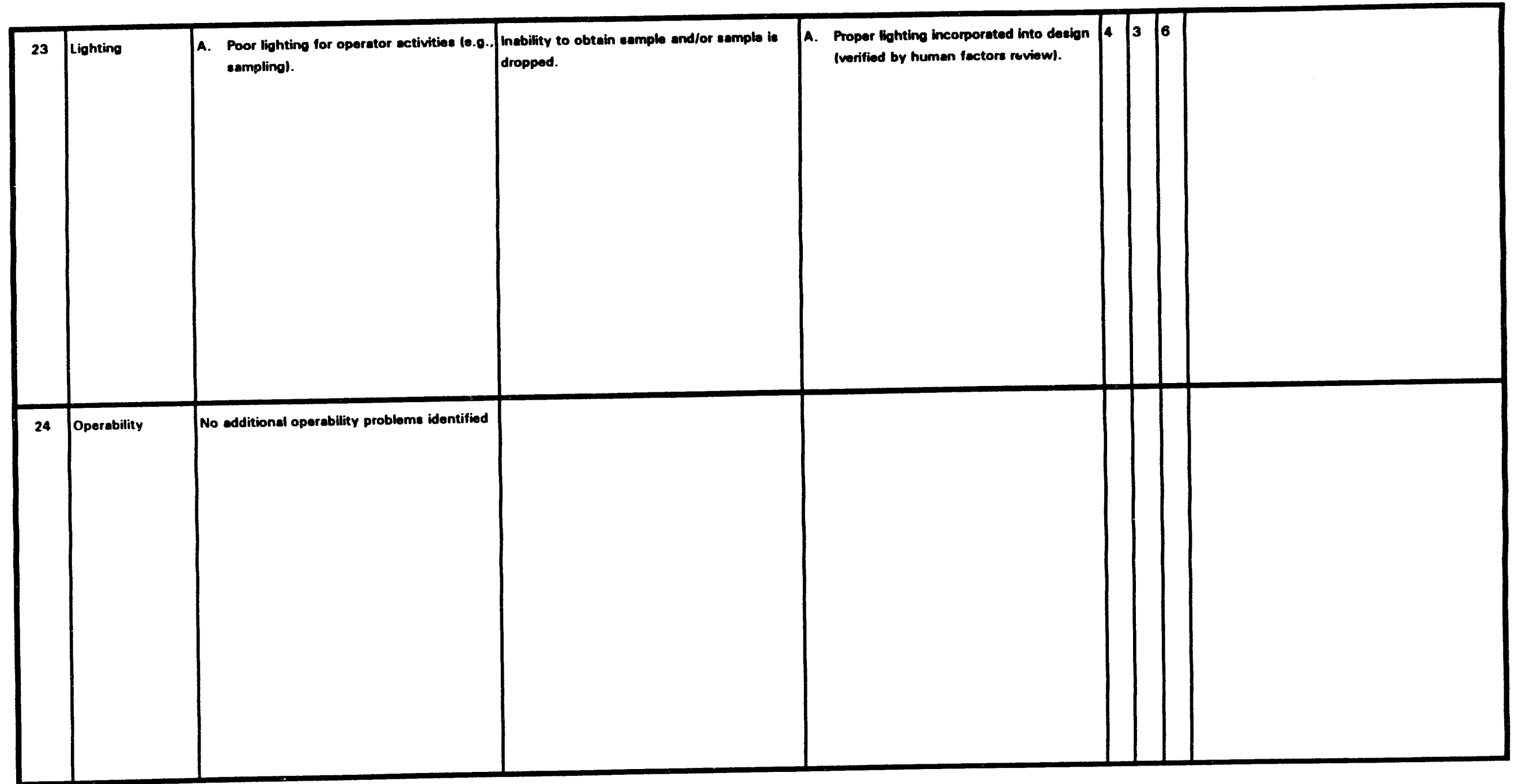


WRAP 2A ACDR PRELIMINARY HAZOP REVIEW DATA SHEET

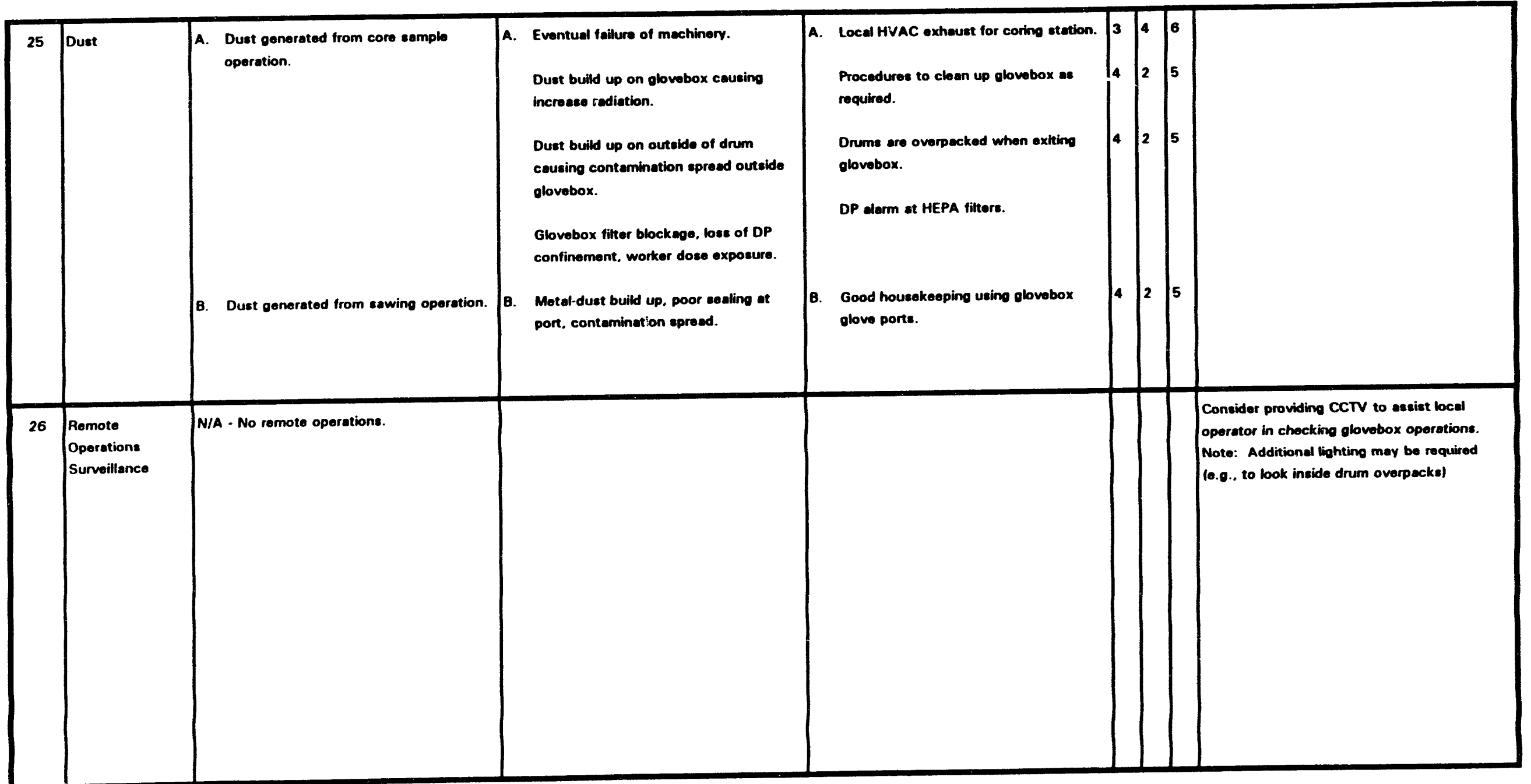




\section{WRAP $2 A$ ACDR PRELIMINARY HAZOP REVIEW DATA SHEET}

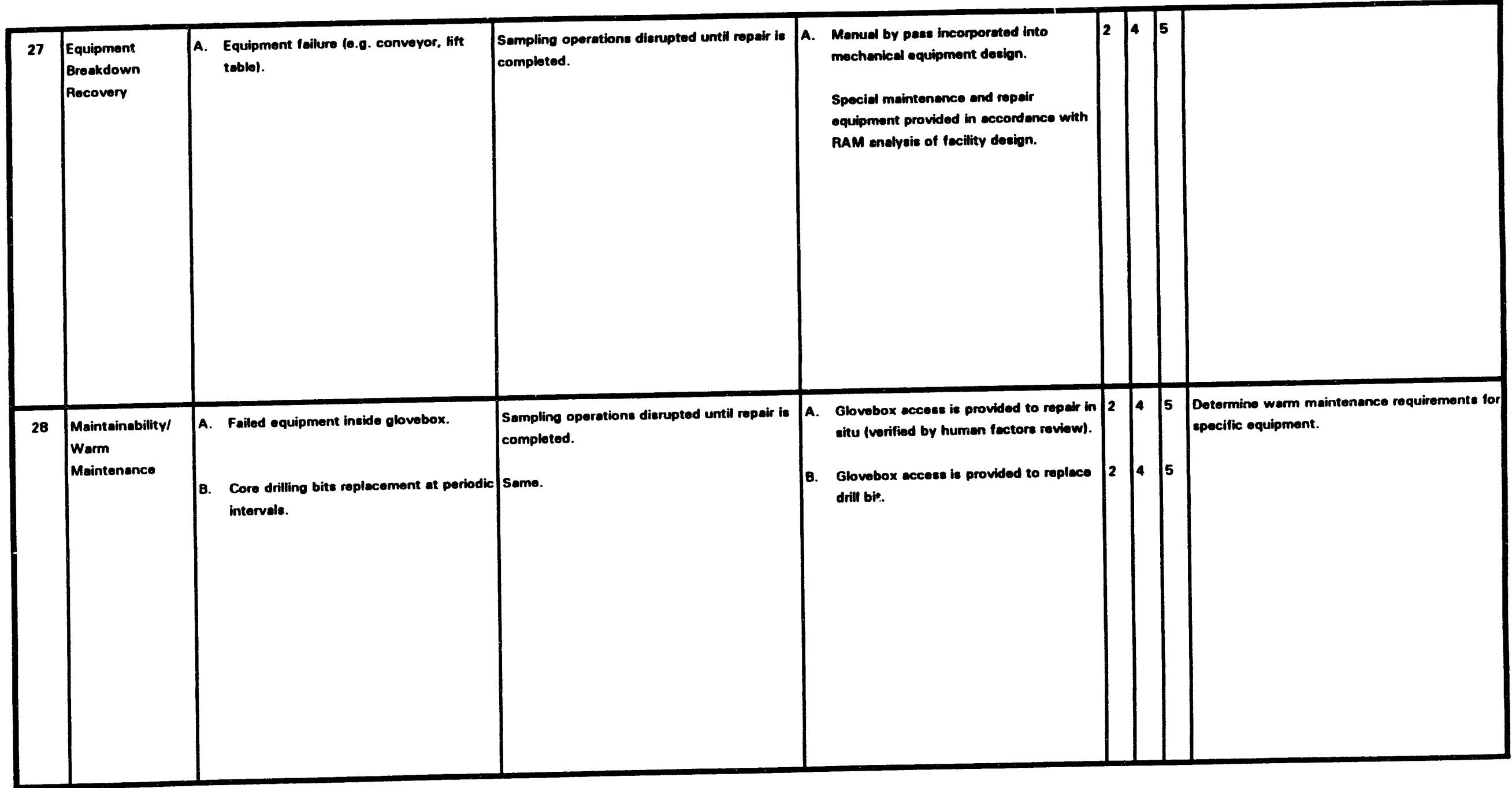




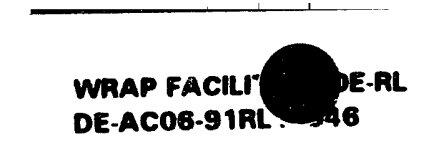

WRAP 2A ACDR PRELIMINARY HAZOP REVIEW DATA SHEET

\begin{tabular}{|c|c|c|c|c|c|c|c|}
\hline 29 & $\begin{array}{l}\text { Testing/ } \\
\text { Inspection }\end{array}$ & $\begin{array}{l}\text { A. Inability to loed test hoist inside } \\
\text { glovebox. }\end{array}$ & $\begin{array}{l}\text { Hoist in poor condition, drum le dropped, } \\
\text { contamination spread from glovebox, worker } \\
\text { dose exposure. }\end{array}$ & $\begin{array}{l}\text { A. Capability to loed tost hoist is provided } \\
\text { in glovebox design. } \\
\text { Procedural requirement to losd tost } \\
\text { hoist. } \\
\text { Glovebox containment if drum drope. }\end{array}$ & \begin{tabular}{|l|l}
4 & 2
\end{tabular} & 5 & \\
\hline 30 & \begin{tabular}{|l|} 
Primary \\
Inetrument Loop \\
Failure
\end{tabular} & $\begin{array}{l}\text { A. Lose of glovebox DP control. } \\
\text { B. Loss of glovebox menipulator control. } \\
\text { C. Loss of lift teble control. } \\
\text { D. Loss of drum sawing control. }\end{array}$ & $\begin{array}{l}\text { Contemination spread, worker dose } \\
\text { exposure. } \\
\text { Glovebox dameged contemination spreed, } \\
\text { worker dose exposure. } \\
\text { Drum is crushed againat glovebox. } \\
\text { contemination spreed, worker dose } \\
\text { exposure. } \\
\text { Drum is demaged and bocornes } \\
\text { conteminated outeide. worker dose } \\
\text { exposure. }\end{array}$ & $\begin{array}{l}\text { A. Glovebox DP alarm is independent of DP } \\
\text { control loop. } \\
\text { B. Limit trovel switch for manipulator. } \\
\text { C. Limit trovel switch for lift table. } \\
\text { D. Limit trevel switch for eaw. } \\
\text { Drum is overpacked prior to exiting } \\
\text { olovebox. }\end{array}$ & $\left.\int_{4}^{4}\right|_{4} ^{4}$ & 5 & \\
\hline
\end{tabular}


WRAP 2A ACDR PRELIMINARY HAZOP REVIEW DATA SHEET

\begin{tabular}{|c|c|c|c|c|c|c|c|}
\hline 31 & $\begin{array}{l}\text { Alarm } \\
\text { Communication/ } \\
\text { Monitoring }\end{array}$ & $\begin{array}{l}\text { A. AGV communication upset. } \\
\text { B. Loss of gbvebox DP alarm. }\end{array}$ & $\begin{array}{l}\text { AGV eccident, drum rupture. contemination } \\
\text { spread, worker dose exposure. } \\
\text { Lose of containment if glovebox DP is aleo } \\
\text { lost (0.0.. control failure), worker dose } \\
\text { exposure. }\end{array}$ & $\begin{array}{l}\text { A. Drum cen withatend AQV eccident. } \\
\text { AGV atatus malfunction alarm. } \\
\text { B. Hardwired backup elarm for glovebox } \\
\text { DP upset. }\end{array}$ & $\int_{4}^{4} \int_{2}^{2}$ & 5 & \\
\hline 32 & $\begin{array}{l}\text { Process Primary } \\
\text { Interlocks }\end{array}$ & A. Control systom malfunction. & $\begin{array}{l}\text { All interlocks lost, upsets occur ae previousin } \\
\text { analyzed, worker dose exposure. }\end{array}$ & $\begin{array}{l}\text { A. Interlocks are fail safle desion } \\
\text { (operations shutdown if intorlocks lost). } \\
\text { NOTE: Adminietrative control of } \\
\text { interlock override is provided. }\end{array}$ & \begin{tabular}{l|l}
4 & 2
\end{tabular} & 5 & \\
\hline
\end{tabular}


WRAP 2A ACDR PRELIMINARY HAZOP REVIEW DATA SHEET

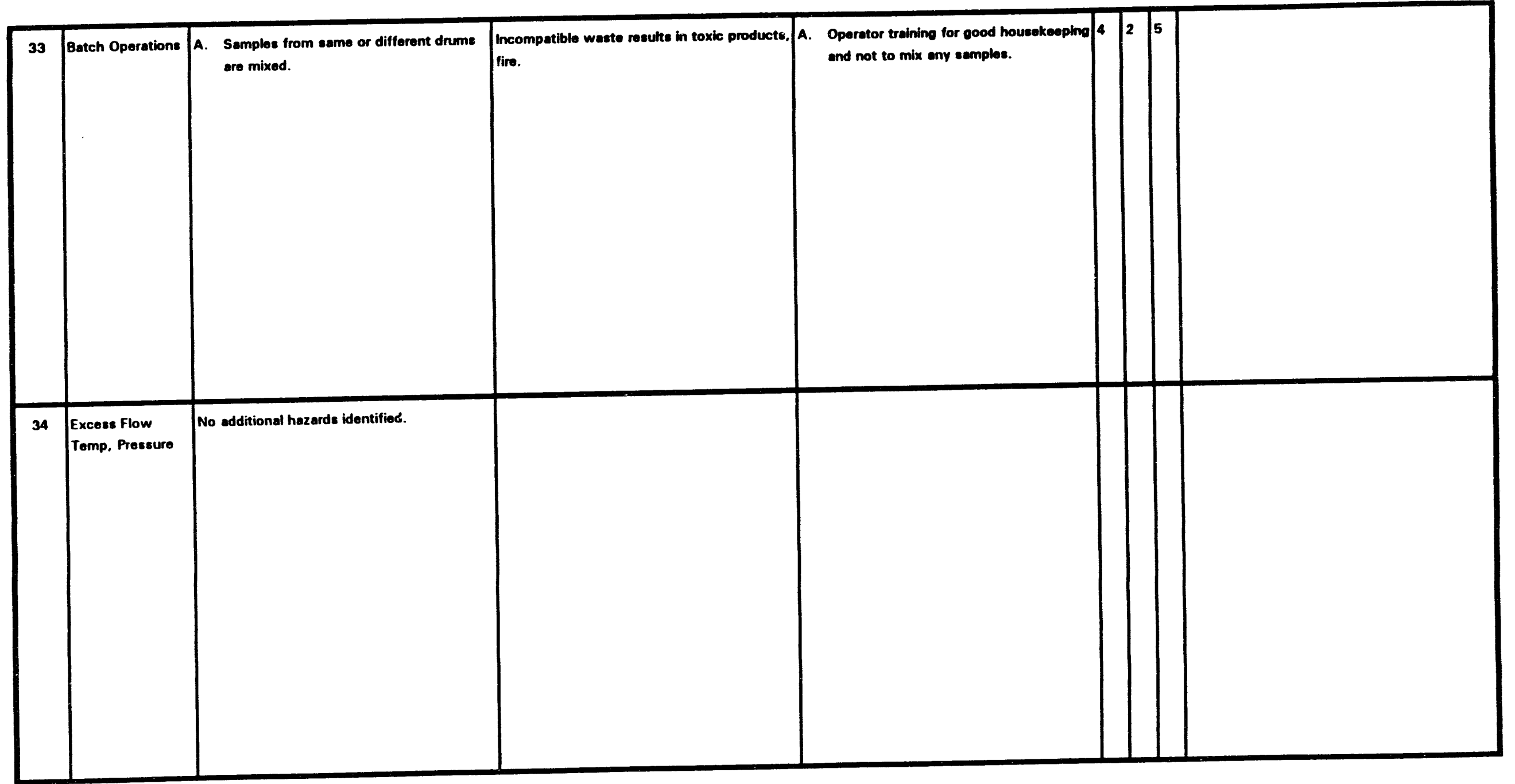


告

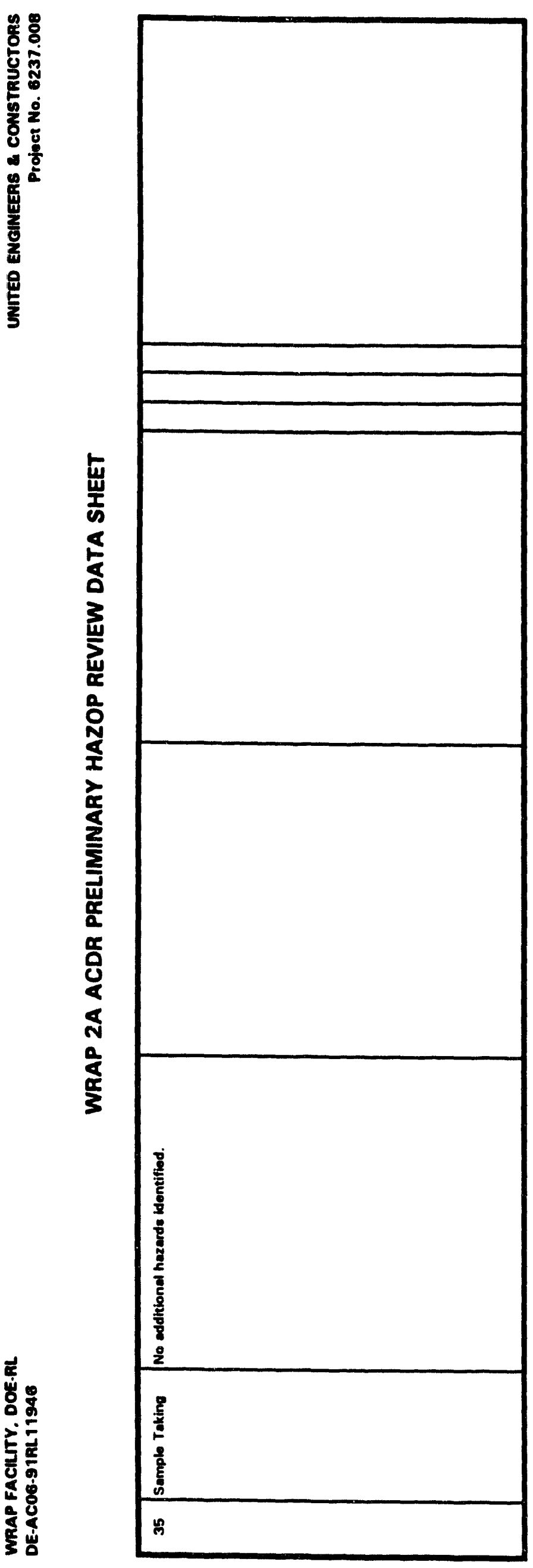


cunpondo unased

Aueduros vesplat $v$

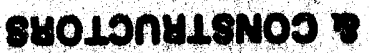

SEEENOUE OELWO

:Aq porodold

volbu!ysem puspypy ADEBNE DO LNBMLENAEO saLV18 oalwn

:01 perpulung

0 :uo!snoy

\section{ALITIOVA ONISSJOOHd ONV ONINIJDEY $\exists \perp S V M$}




\section{TABLE OF CONTENTS}

PAGE

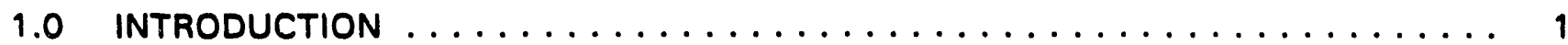

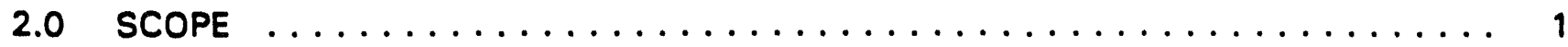

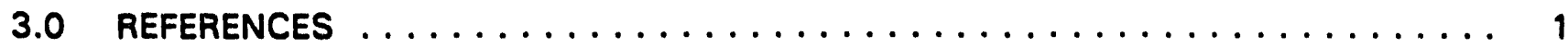

4.0 DESCRIPTION OF OFF-GAS TREATMENT SYSTEM $\ldots \ldots \ldots \ldots \ldots \ldots \ldots \ldots$

4.1 Design Basis Summary . . . . . . . . . . . . . . . . . . . . 1

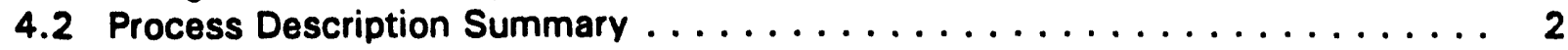

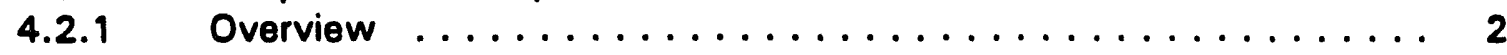

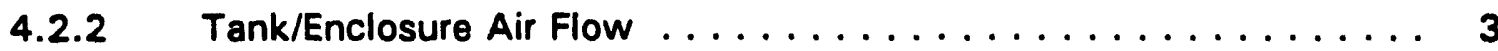

4.2.3 Liquid Waste Collection Tanks Off-Gas . . . . . . . . . . . . 3

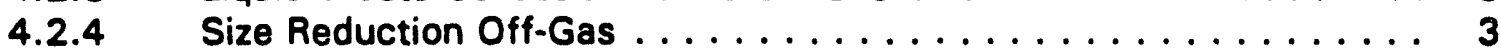

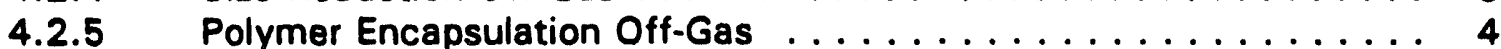

4.2.6 Grout Silo Dusts Collectors Off-Gas . . . . . . . . . . . . . . . 4

4.2.7 Grout Stabilization Off-Gas ................... 4

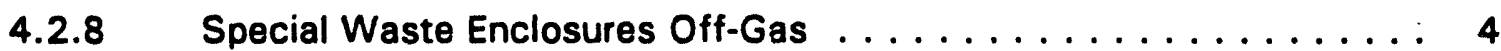

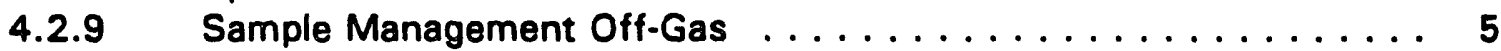

5.0 STUDY CRITERIA AND METHODOLOGY $\ldots \ldots \ldots \ldots \ldots \ldots \ldots \ldots$

6.0 RESULTS AND CONCLUSIONS $\ldots \ldots \ldots \ldots \ldots \ldots \ldots \ldots \ldots \ldots$ 
WRAP 2A

OFF-GAS TREATMENT

\section{HAZOP STUDY REPORT}

\subsection{INTRODUCTION}

A preliminary HAZOP study was performed in the advanced conceptual design of the offgas treatment system. The HAZOP team met on August 27, 1993 and consisted of the following members:

$\begin{array}{lll}\text { Name } & \text { Company } & \text { Role/Expertise } \\ \text { Larry Walker } & \text { RE\&C } & \text { Leader, Scribe, Safety } \\ \text { Tom Nelson } & \text { RE\&C } & \text { Process } \\ \text { Marv Gehret } & \text { RE\&C } & \text { HVAC } \\ \text { Doug Chapin } & \text { RE\&C } & \text { Process } \\ \text { Bill Cepeda } & \text { RE\&C } & \text { Instrumentation and Controls } \\ \text { Valerie Walker } & \text { BNFL } & \text { Radiological }\end{array}$

The purpose of the HAZOP Study is to identify major safety and operability problems which can best be resolved during completion of the advanced conceptual design.

\subsection{SCOPE}

This HAZOP System encompassed the off-gas treatment system as shown on Process Flow Diagram H-2-140600 (Rev. E).

\subsection{REFERENCES}

1. WHC-SD-W100-FDC-001 Rev. 2A, Functional Design Criteria Waste Receiving and Processing Facility Module 2 A.

2. WHC-SD-W100-SDRD-001 Rev. A, Waste Recovery and Processing Facility Module 2A Supplemental Design Requirements Document.

\subsection{DESCRIPTION OF OFF-GAS TREATMENT SYSTEM}

\subsection{Design Basis Summary}

1. A special exhaust ventilation system will be provided to remove radioactive and nonradioactive contaminants from gases and vapors created during processing. The system shall be comprised of inlet air ducts and HEPA filters to tanks and enclosures and exhaust ducts with off-gas treatment equipment and control dampers. Treated off-gas will be discharged to the Zone 1 HVAC exhaust system. The off-gas treatment system in conjunction with the HVAC system shall ensure safe operation and maintain airflow from non-contaminated areas to areas of progressively higher potential contamination. 
2. The off-gas treatment system will operate continuously ( 24 hours per day, 7 days per week).

3. All tanks and process enclosures within the building shall operate under negative pressure $(-0.7$ to -1.0 inches W.C.) relative to ambient room pressure.

4. Tanks are vented at a rate of four air changes per hour, based on empty tanks. Enclosures are vented at a rate of eight to ten air changes per hour and a minimum of one ACFM per square foot of floor area.

5. Provide one stage of HEPA filtration on inlet air ducts to indoor tanks and enclosures vented to the off-gas treatment system.

6. Ducts shall be sized for the transport velocities needed to convey, without setting, all particulate contaminants.

7. Provide moisture separators or heaters to minimize moisture loading on filters.

8. Provide changeable prefilters upstream of first HEPA filters on exhaust ducts.

9. Provide parallel HEPA filter systems so that one may be changed out while the other is operating.

10. Permit in-place testing of HEPA filter installations.

11. Transfer system for all dry materials shall be enclosed and have adequate provisions for the collection of dust and particulate materials.

12. The off-gas and HVAC systems shall be controlled by a central process control system.

\subsection{Process Description Summary}

\subsubsection{Overview}

The off-gas treatment system is designed to prevent the spread of airborne contamination from indoor process enclosures and equipment to the general process area or to the atmosphere. The off-gas system is a closed system which maintains process enclosures, vessels and tanks under a negative pressure and collects and treats off-gas from these confined areas before discharge to the Zone 1-HVAC exhaust system.

Off-gas is primarily exhaust ventilation air which may be contaminated with noxious gases or particulates form tanks and enclosures. Both active and nonactive off-gas are treated in the same system since the volume of nonactive gases is less than two percent of the total off-gas volume and the use of double HEPA filtration on all streams prevents contamination by active off-gases to nonactive area in case of positive system pressures.

The off-gas treatment system includes reheaters, dust collectors, HEPA filters, carbon adsorbers and controls to treat off-gas from the above mentioned tanks and enclosures. This system is designed to operate on a continuous basis. 
The off-gas treatment system is shown on PFD H-2-140600. Large off-gas treatment equipment layout (baghouse, carbon adsorbers, larger filters) is shown on drawing H-2140601. Small equipment, such as canister filters to inlet air and tank vents and tank vent reheaters, are located in ducts near the source of contamination.

\subsubsection{Tank/Enclosure Air Flow}

Inlet air is drawn from Zone 2 room air in the process area through inlet air HEPA filters to tanks and enclosures. Inlet air filters are necessary to protect the process area from contamination in case the tanks or enclosures develop a positive pressure. These filters will be small, circular nontestable HEPA filters designed to be installed in the mist air piping near the tanks and enclosures. Outlet air filters are locoted in the exhaust air piping from enclosures. These filters will be similar to the inlet HEPA filters but will also include a prefilter. Outlet filters are not provided on tanks because the air should not contain particulate, and may be water saturated which would lead to plugging problems.

The pressures in the tanks and enclosures are controlled at a negative pressure of -0.7 to -1.0 inches of water by manual adjustment of inlet air dampers located upstream of the inlet air filters. The air flow rates from the tanks and enclosures are controlled automatically by their controllers and dampers. Tanks are vented at a flow rate criteria of four air changes per hour, assuming the tanks are empty. Enclosures are vented at a flow rate criteria of 8 to 10 air changes per hour, and a minimum of one ACFM per square foot of floor area.

\subsubsection{Liquid Waste Collection Tanks Off-Gas}

Off-gas from the two Nonactive Waste Collection tanks (T-07-101A,B) is continuous and heated $20^{\circ} \mathrm{F}$ in the Nonactive Tanks Off-Gas Reheater (H-04-101) to prevent moisture condensation before passing through downstream filters. This is an electric heater which is shutoff by a low air flow switch to prevent over-temperature. A flow controller maintains the required flow rate through the tanks by controlling a modulating damper.

Off-gas from the Active Waste Collection Tank (T-07-201) and ihe Treated Active Waste Tank (T-07-202) are combined and heated $20^{\circ} \mathrm{F}$ in the Active Tanks Off-Gas Reheater $(H$ 04-102) to prevent moisture condensation before passing through downstream filters. This is an electric heater which is shutoff by a low air flow switch to prevent over-temperature. A flow controller maintains the required flow rate through the tanks by controlling a modulating damper.

Off-ga from the Nonactive and Active Waste Collection Tanks are combined and flow to Waste Tanks Off-Gas Filter (F-04-101A,B). This 1000 ACFM filter contains a prefilter and two stages of HEPA filtration.

\subsubsection{Size Reduction Off-Gas}

Off-gas from the Solid Waste Conditioning Enclosure and Sludge/Particulate Conditioning Enclosure are flow controlled individually and then combined and flow to the Size Reduction Off-Gas Dust Collector (S-04-101A,B). This is a reverse pulse jet baghouse designed to remove the majority of the fugitive dust generated in these enclosures. Compressed air is supplied to the dust collector to reverse the air flow through the filter bags, shaking loose the dust collected on the bags. Dust is collected in a sloped hopper and discharged through a rotary valve to a drum with a dust seal. 
Off-gas from the Box Breakdown Cell and Empty Drum Compactor Enclosure are flow controlled individually and then combined with filtered off-gas from the Dust Collector. The combined off-gas then passes through the Size Reduction Off-Gas Filter (F-04-102A,B). This 6,000 ACFM filter contains size trains, each with a firescreen, prefilter and two HEPA filters.

\subsubsection{Polymer Encapsulation Off-Gas}

Off-gas from the Polymer Encapsulation Enclosure is flow controlled and then filtered in the Polymer Encapsulation Off-Gas Filter(F-04-103A,B). This 1000 ACFM filter includes a firescreen, prefilter, HEPA filter, two carbon adsorbers and a total HEPA filter. The carbon adsorbers will remove any residual organics from the off-gas.

\subsubsection{Grout Silo Dusts Collectors Off-Gas}

Off-gas is generated from pneumatic conveying of grouting powders from the Bulk Powder Storage Silos to the three vibro Grout Silos and the three Agitated Grout Silos. Powder is transferred from one Bulk Silo to one of the six indoor silos at a time by Dense Phase Pump using 100 SCFM of compressed air. A continuous off-gas flow of 100 ACFM will also be drawn from the six grout silos and weigh hoppers to maintain negative pressure in these tanks.

Off-gas from the Vibro Grout Silos and Agitated Grout Silos are flow controlled individually and then combined and flow to the Grout Powder Tanks Off-Gas Filter (F-04-105A,B). This 1000 ACFM filter includes a firescreen, prefilter and two HEPA filters.

\subsubsection{Grout Stabilization Off-Gas}

Off-gas from the Grout Stabilization Enclosure is flow controlled and then filtered through the Grout Enclosure Off-Gas Filter (F-04-106). This 2000 ACFM includes a firescreen, prefilter and two HEPA filters. This filter is not spared, but during a filter changeout, the off-gas flow will be directed to either F-04-102A or 102B, whichever is not in use at the time of the filter changeout.

\subsubsection{Special Waste Enclosures Off-Gas}

Off-gas from the Special Waste Shredder Enclosure. Special Waste Treating Enclosure and Chemical Scrubber are flow controlled individually and then flows to the special Waste Enclosures Off-Gas Filter (F-04-107A,B). This 1500 ACFM filter includes a firescreen, prefilter, HEPA filter, two carbon filters and a HEPA filter. The carbon filters consist of packed beds of sulfur impregnated granular activated carbon capable of removing elemental and organic mercury which may be present in the special waste enclcsures. The carbon filters can also remove trace amounts of organic hydrocarbons which may be present in the off-gas. 


\subsubsection{Sample Management Off-Gas}

Four Sample Management hoods are designed to draw air in at 125 feet per minute through hood openings. While not all hoods will likely be used at the same time, the off-gas ducts are designed for all hoods in operation. Off-gas from the hoods is combined with off-gas from the Drum Sampling Enclosure and flow controlled to the Sample Management Off-Gas Filter (F-04-108). This 1500 ACFM filter includes a firescreen, prefilter, HEPA filter, two carbon filters and a HEPA filter. This filter is not spared, but when a filter changeout is necessary, the off-gas will be diverted to F-04-107A or 107B, whichever filter is not in use.

\subsection{STUDY CRITERIA AND METHODOLOOY}

This HAZOP System utilized a predetermined set of process deviations/upset conditions to be analyzed by the HAZOP System team. For each process deviation, possible causes were postulated and worst case consequences (without benefit of any safeguards) were determined. Existing safeguards (design and procedural) were then identified. These safeguard which could be reasonably expected to be present in the first deign were assumed to be existing and were so documented in the HAZOP System. For each cause and effect, hazard severity and probability were qualitatively assessed (taking credit for existing upgrades which reduce hazard probabilityl using the criteria shown in Table 1. The overall risk rating for each hazard was then determined using the risk ranking matrix shown in Table 2. Recommendations were proposed by the HAZOP System team in instances required by the implementation criteria shown in Table 2. 
TABLE 1

HAZARD SEVERITY AND PROBABILITY CLASSIFICATION CRITERIA

\section{SEVERITY CLASSIFICATION}

\begin{tabular}{|c|c|c|c|c|}
\hline \multirow{2}{*}{ Targot Hazard } & \multicolumn{4}{|c|}{ Severity Class (Worst-case Scenario) } \\
\hline & Catastrophic (1) & Extensive (2) & Moderate (3) & Operational (4) \\
\hline Community & $\begin{array}{l}\text { Multiple irreversible } \\
\text { injuries; may include a } \\
\text { fatality }\end{array}$ & $\begin{array}{l}\text { Single irreversible or } \\
\text { several reversible injuries } \\
\text { (no fatalities) }\end{array}$ & Several reversible injuries & \\
\hline & OR & OR & OR & \\
\hline Workers & $\begin{array}{l}\text { Fatalities or irreversible } \\
\text { injuries } \\
\text { OR }\end{array}$ & $\begin{array}{l}\text { Several injuries } \\
\text { OR }\end{array}$ & $\begin{array}{l}\text { Single injury } \\
\text { OR }\end{array}$ & \\
\hline Facility & $\begin{array}{l}\text { Partial or full demolition of } \\
\text { facility } \\
\text { OR }\end{array}$ & $\begin{array}{l}\text { Rupture or similar loss of } \\
\text { containment } \\
\text { OR } \\
\end{array}$ & $\begin{array}{l}\text { Major equipment damage } \\
\text { leading to one month or } \\
\text { more facility downtime } \\
\text { OR } \\
\end{array}$ & $\begin{array}{l}\text { Equipment damage } \\
\text { leading to several days of } \\
\text { facility downtime or other } \\
\text { operational penalty } \\
\text { OR }\end{array}$ \\
\hline Environment & $\begin{array}{l}\text { Major environmental } \\
\text { impact with significant } \\
\text { cleanup/iability costs }\end{array}$ & $\begin{array}{l}\text { Groundwater, soil, or } \\
\text { public sewer } \\
\text { contamination }\end{array}$ & $\begin{array}{l}\text { Minor spill or release } \\
\text { resulting in permit violation }\end{array}$ & \\
\hline
\end{tabular}

\section{LIKELIHOOD CLASSIFICATION}

\begin{tabular}{|l|l|}
\hline Highly Likely (1) & $\begin{array}{l}\text { Event has occurred at this facility - or - other facility - or - is expected to occur several times during the } \\
\text { next } 10 \text { years. }\end{array}$ \\
\hline Likely (2) & $\begin{array}{l}\text { Event has occurred at this facility - or - is possible to occur at this facility several times during the next } \\
30 \text { years. }\end{array}$ \\
\hline Unlikely (3) & $\begin{array}{l}\text { Event may have occurred at another facility - or - is possible to occur at this facility at least once in the } \\
\text { next } 50 \text { years. }\end{array}$ \\
\hline Extremely Unlikely (4) & $\begin{array}{l}\text { Event is not likely to ever occur in this facility, given a continuation of the current levels of training, } \\
\text { procedures, maintenance, inspection, testing, and other applicable process safety management system } \\
\text { support. }\end{array}$ \\
\hline
\end{tabular}




\section{RISK RANKING MATRIX AND IMPLEMENTATION CRITERIA}

RISK RANKING MATRIX

\begin{tabular}{|c|c|c|c|c|}
\hline Likelihood & & & & \\
\hline Highly Likely (1) & 4 & 2 & 1 & 1 \\
\hline Likely (2) & 5 & 3 & 2 & 1 \\
\hline Unlikely (3) & 6 & 4 & 3 & 2 \\
\hline Extremely Unlikely (4) & 7 & 6 & 5 & 4 \\
\hline & Operational (4) & Moderate (3) & Extensive (2) & Catastrophic (1) \\
\hline
\end{tabular}

\section{RISK RANKING IMPLEMENTATION}

\begin{tabular}{|c|l|}
\hline Risk Ranking & \multicolumn{1}{c|}{ Implication } \\
\hline 1 & $\begin{array}{l}\text { Risk level - Very significant } \\
\text { Recommendation = Required from the HAZOPS team }\end{array}$ \\
\hline 2 & $\begin{array}{l}\text { Risk level - Significant } \\
\text { Recommendation = Required from the HAZOPS team }\end{array}$ \\
\hline 3 & $\begin{array}{l}\text { Risk level - Not very significant } \\
\text { Recommendation = Required from the HAZOPS team }\end{array}$ \\
\hline 4 & $\begin{array}{l}\text { Risk level - Not significant, but may be an Operational problem } \\
\text { Recommendation = At the discretion of the HAZOPS team }\end{array}$ \\
\hline 5,6, or 7 & $\begin{array}{l}\text { Risk level - Negligible, but may be an operational problem } \\
\text { Recommendation = At the discretion of the HAZOPS team }\end{array}$ \\
\hline
\end{tabular}




\subsection{RESULTS AND CONCLUSIONS}

Because this HAZOP System is preformed relatively early in the design phase, existing safeguards have not been fully documented on the process flow diagrams (these would mostly be shown in the P\&lDs developed during Title design). However, the HAZOPS team assumed specific safeguards would be present in the final design if it appear reasonable to expect this. These assumed safeguards are documented on the HAZOPS worksheets and credit was taken for these presumed safeguards when assessing risk. During Title design, the presence of these safeguards need to be verified to validate the conclusions of this HAZOPS.

Twenty-one potential safety and operability problems were identified and evaluated in the HAZOPS. Of these, nineteen were assessed to have a negligible risk level. The remaining two involve potential hazards having a risk ranking classified as not very significant. For these potential hazards, the HAZOPS team has recommended that additional safeguards be ovaluated and incorporated into the WRAP 2A design. TABLE 3 presents a summary of changes to be made in the process flow diagram, assumed design safeguards and additional safeguards to be evaluated for incorporation into the design.

In several instances, the need for human factors analysis and reliability/availability/maintainability analysis during Title design was highlighted by the HAZOPS team to achieve negligible risk levels. The HAZOPS assumed that such analysis would be performed and that the necessary design requirements/modifications are incorporated. The performance of these design analysis are considered to be open issues to be resolved during Title design. Similarly, the HAZOPS team identified the need for a maintainability analysis to develop requirements for warm maintenance at the WRAP $2 A$ Facility.

The HAZOPS is documented in the attached HAZOPS worksheets. 


\section{TABLE 3}

OFF-GAS TREATMENT HAZOPS SUMMARY

\section{PROCESS TO PROCESS FLOW DIAGRAM}

None Identified

\section{ASSUMED DESIGN SAFEGUARDS}

1. Baghouse is designed to minimize dusting during changeout.

2. Baghouse equipment is provided.

3. Fire screen at HEPA filters.

4. Ductwork designed for seismic event based on hazard classification.

5. Dampers left in last position upon loss of power.

6. Dp alarm at HEPA filters.

\section{EVALUATEANCORPORATE INTO TITLE DESIGN}

1. Enclosure containment at baghouse loadout drum and mechanism to loadout dust through enclosure.

2. Need for explosive venting at baghouse.

3. Evaluate possibility of incompatible materials from different sources mixing upstream of carbon filters at cross connects.

4. Evaluate need for fire dampers.

5. Evaluate amount of organic vapor which may be present at heaters down stream of waste collection tanks.

6. Evaluate elimination of HEPA filters in line to baghouse. 
MAP FACUITY, DOE-RL

WRAP 2A ACDR PRELIMINARY HAZOP REVIEW DATA SHEET

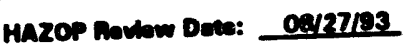

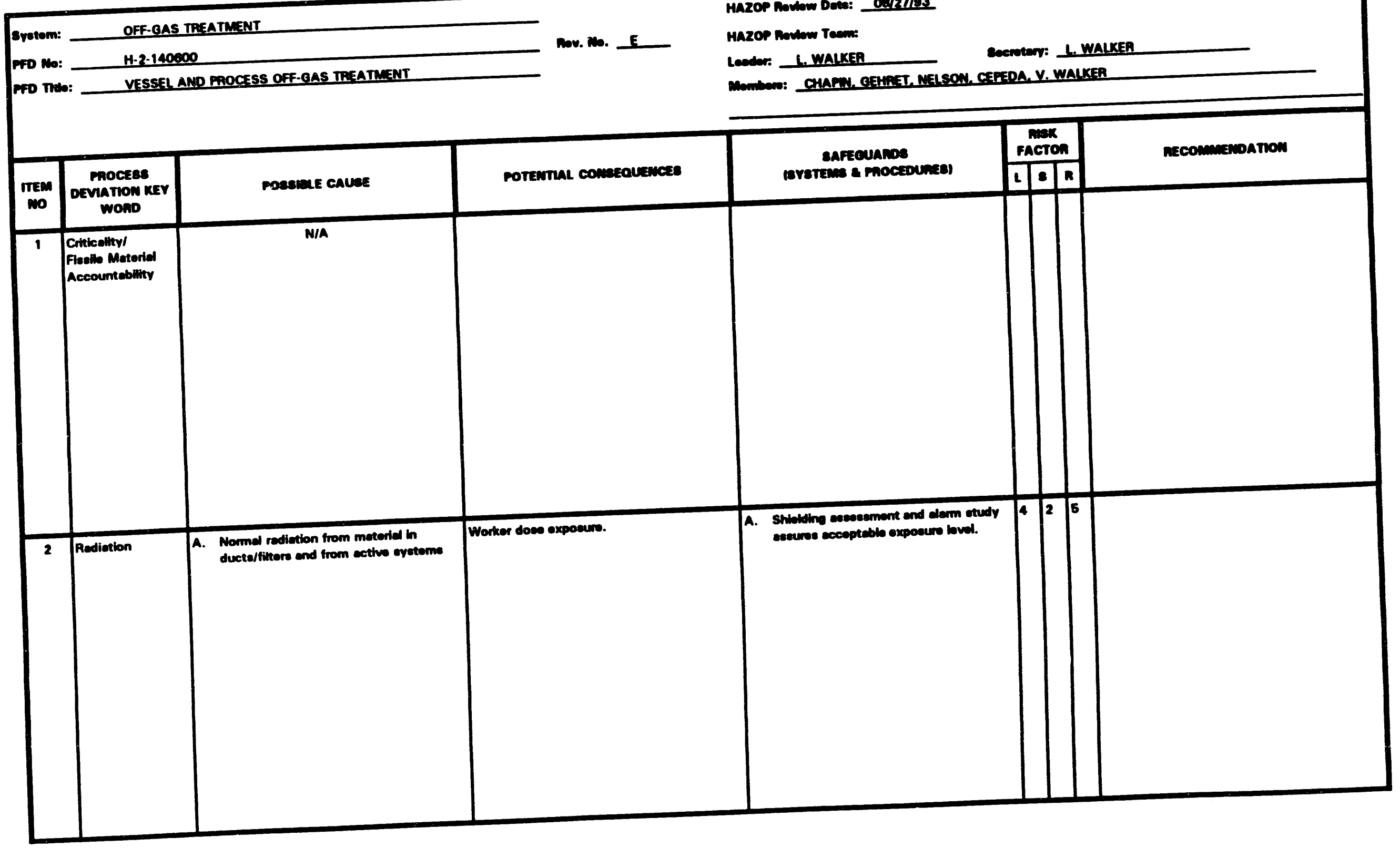



WRAP 2A ACDA PRELIMINARY HAZOPS REVIEW DATA SHEET

\begin{tabular}{|c|c|c|c|c|c|c|c|}
\hline 5 & $\begin{array}{l}\text { Contenmment } \\
\text { Brosch }\end{array}$ & No edditional hazerde idomitiod. & & & & & \\
\hline - & \begin{tabular}{|l|} 
Explocionl \\
Dotonotion
\end{tabular} & 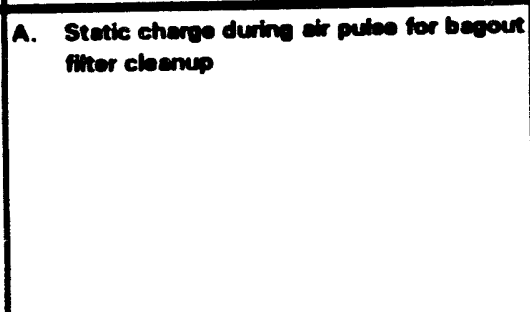 & Explocion at beathouse. & 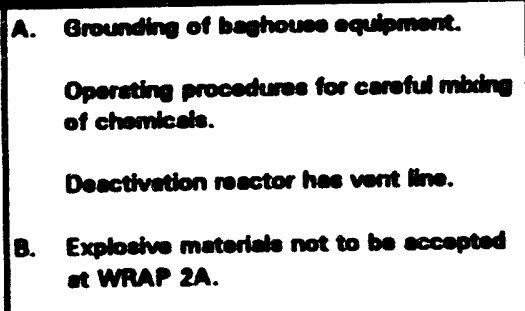 & 3 & 3 & 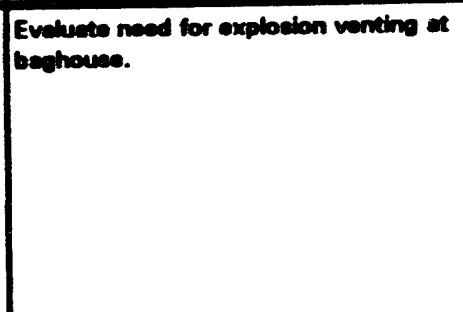 \\
\hline
\end{tabular}




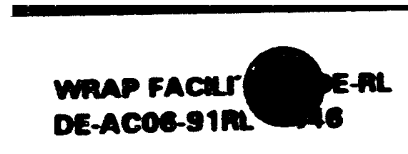

WRAP 2A ACDA PRELIMINARY HAZOPS REVIEW DATA SHEET

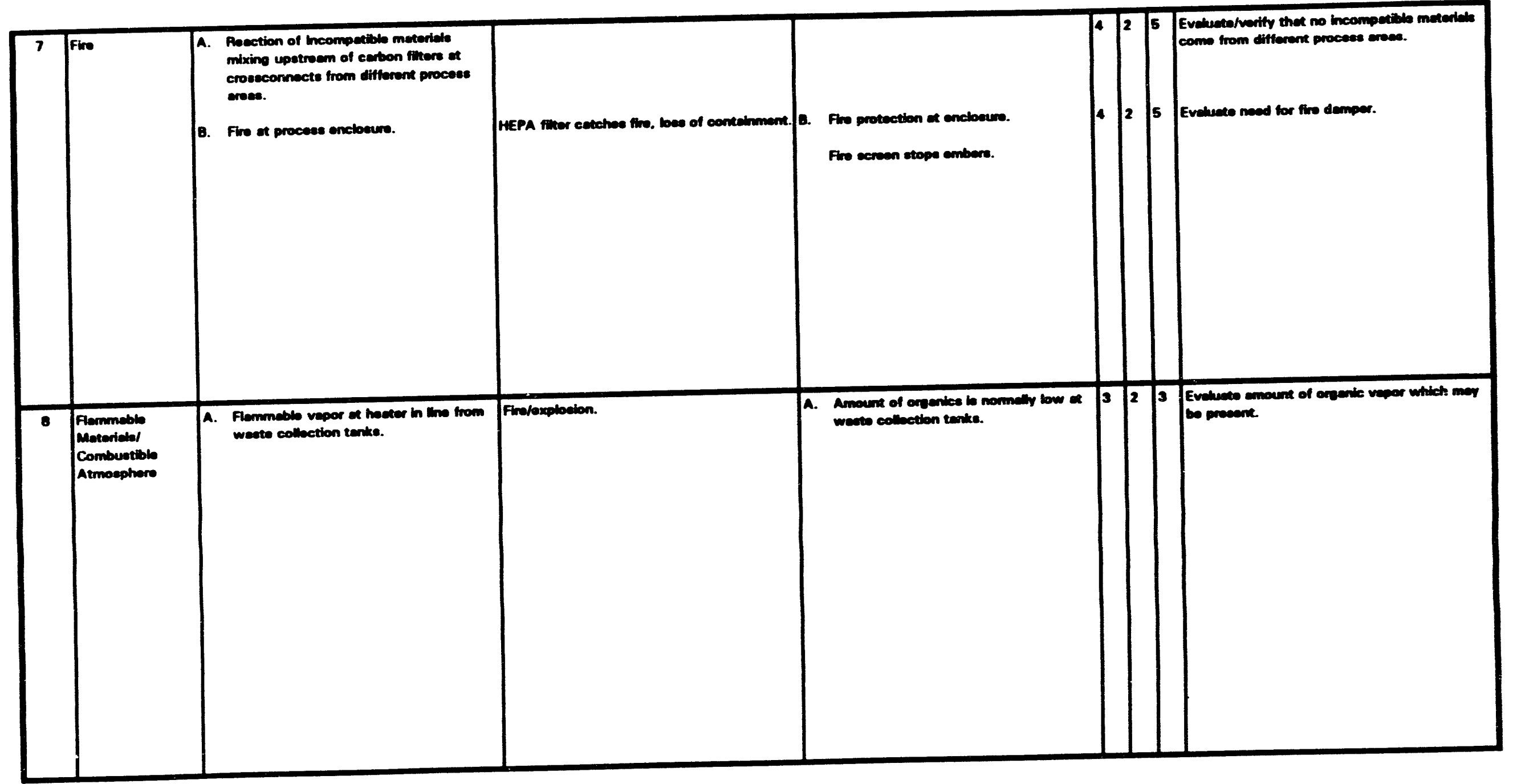


8

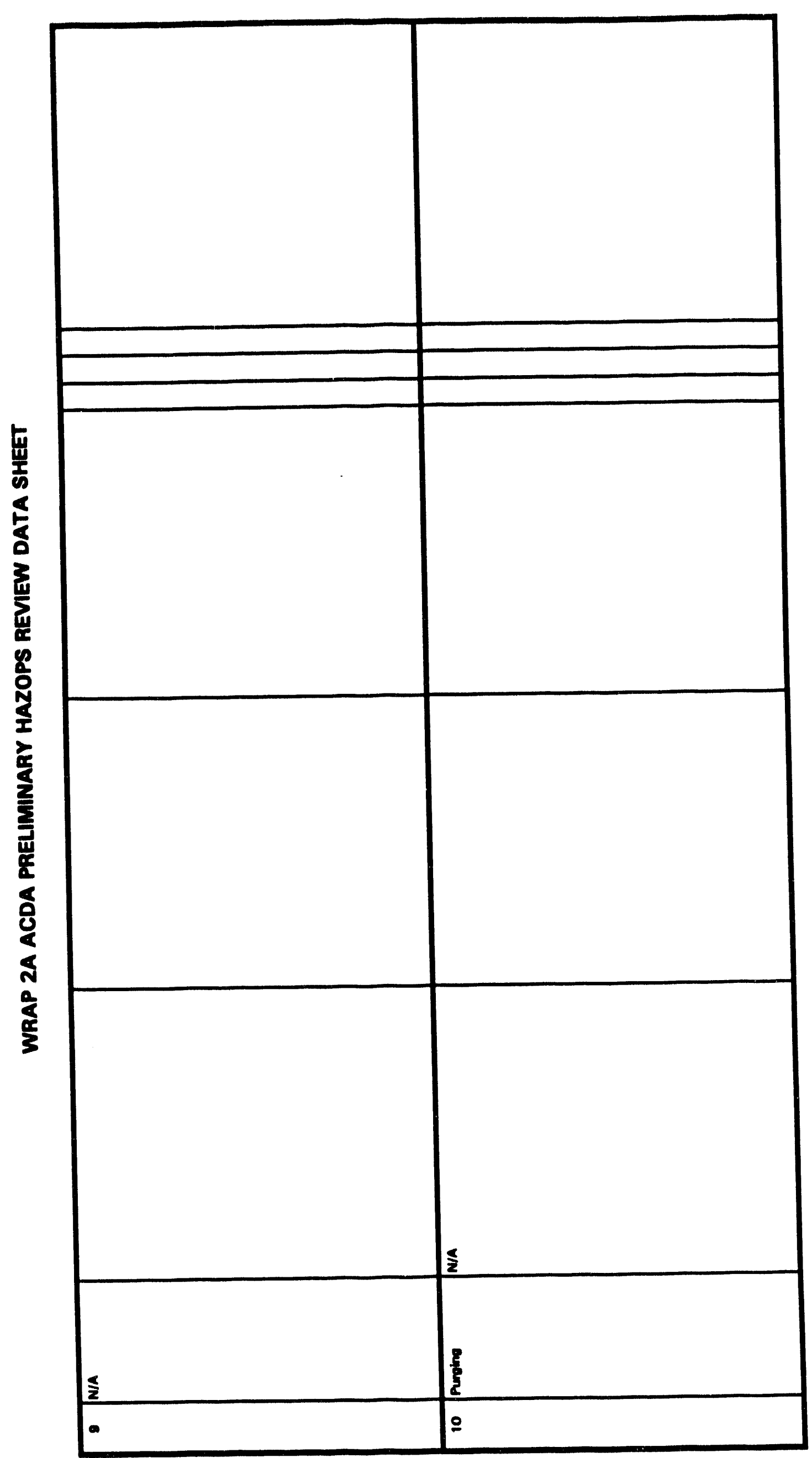



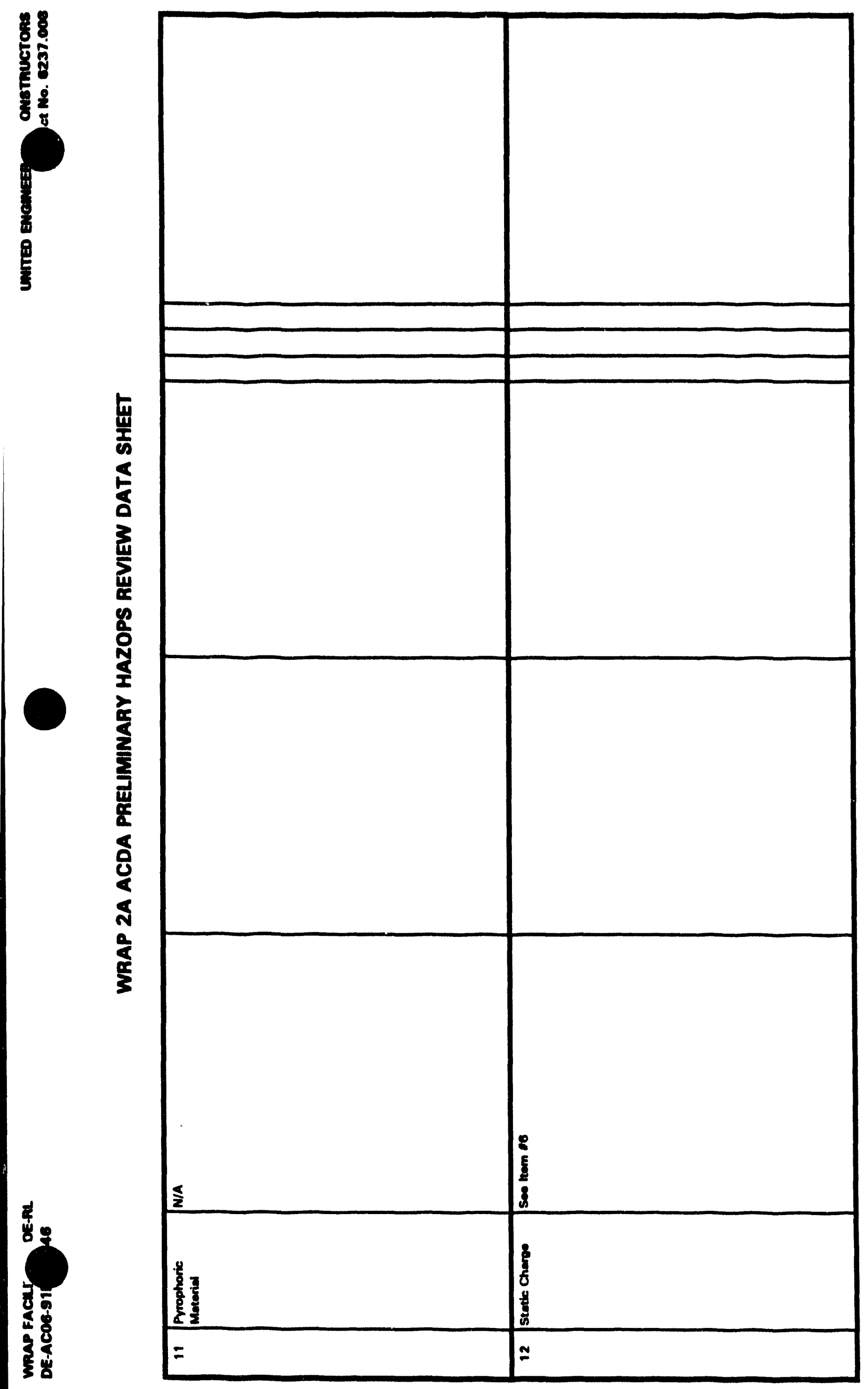


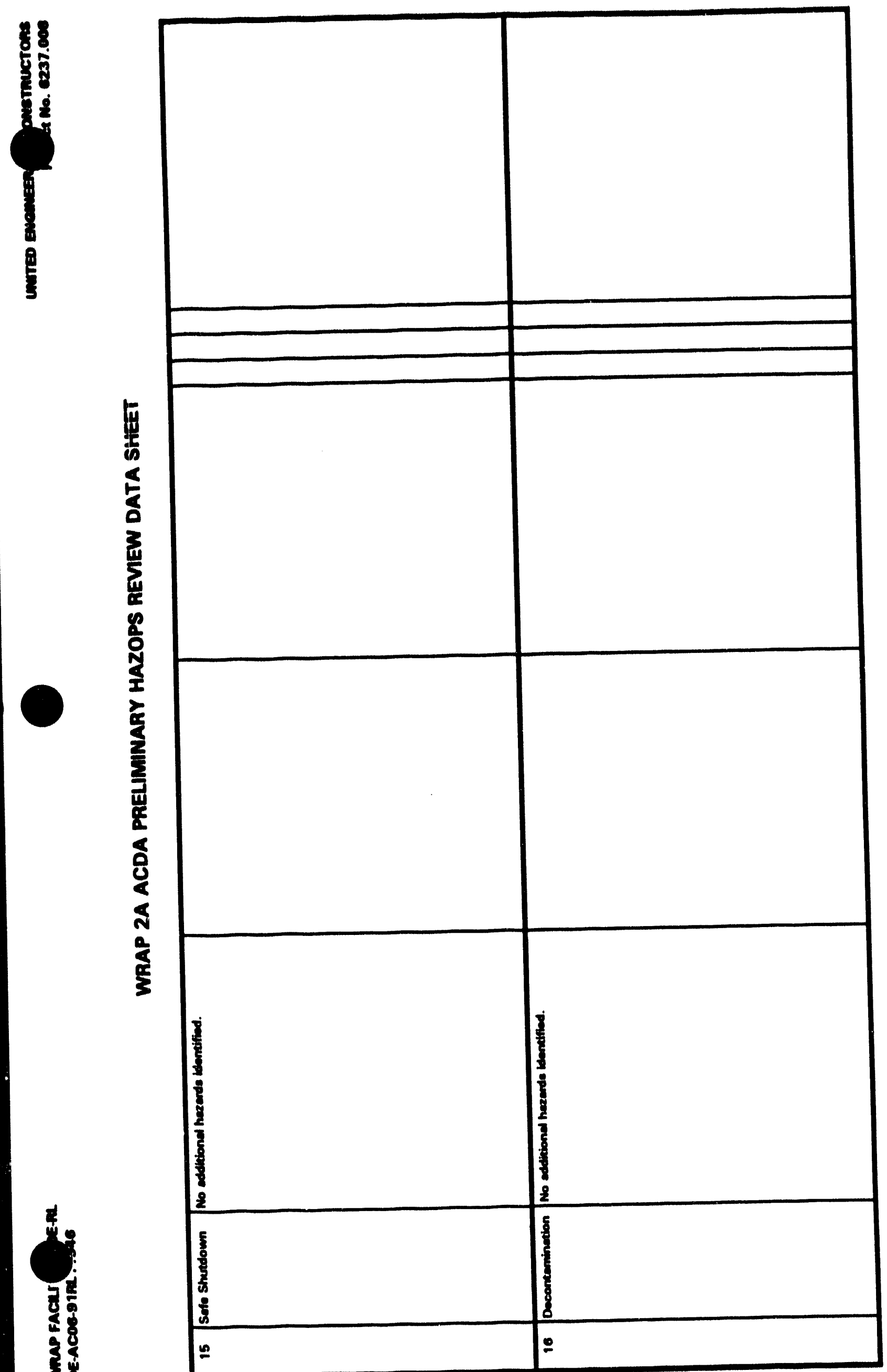

点是 
WRAP 2A ACDA PRELMINARY HAZOPS REVIEW DATA SHEET

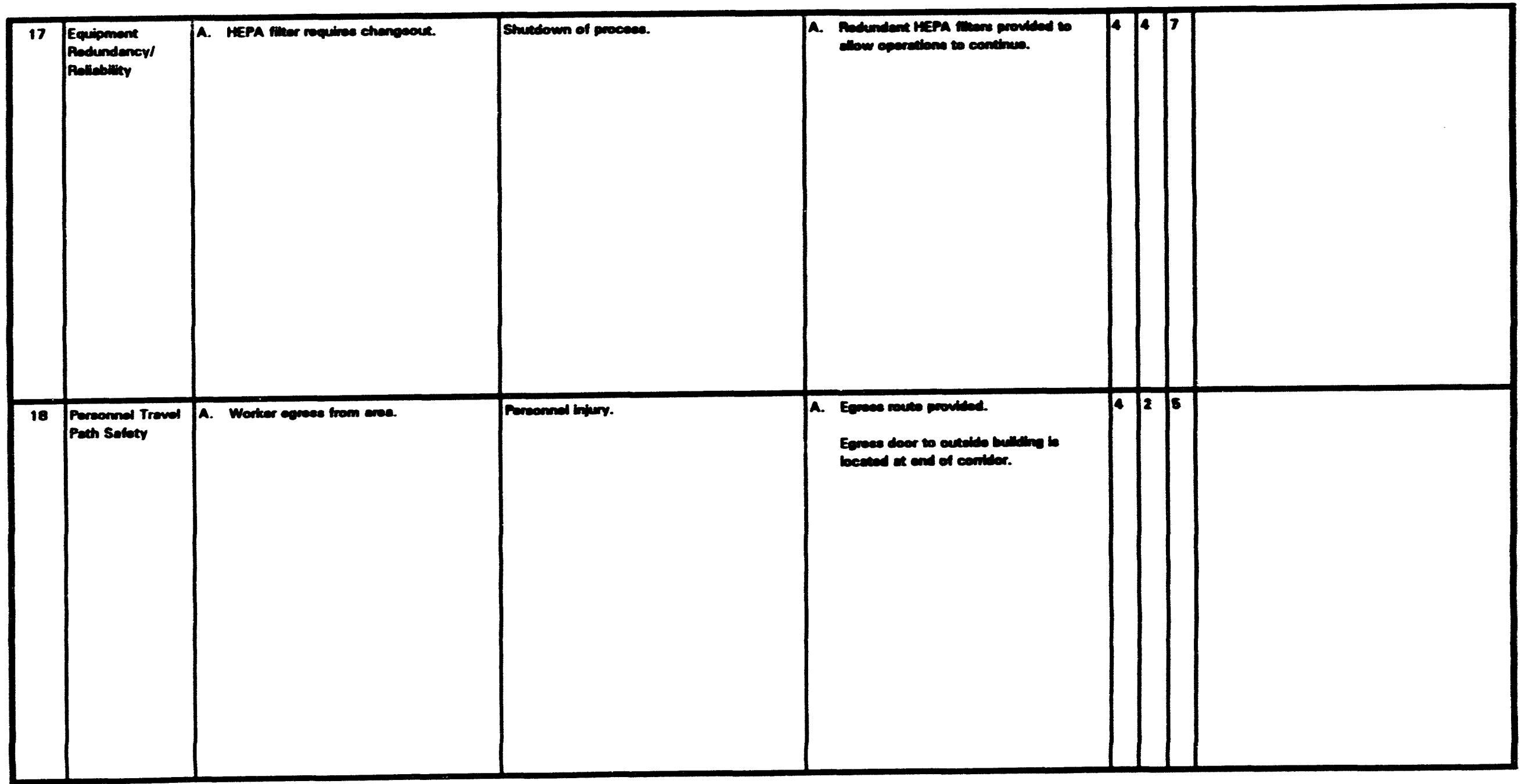


WRAP 2A ACDA PRELIMINARY HAZOPS REVIEW DATA SHEET

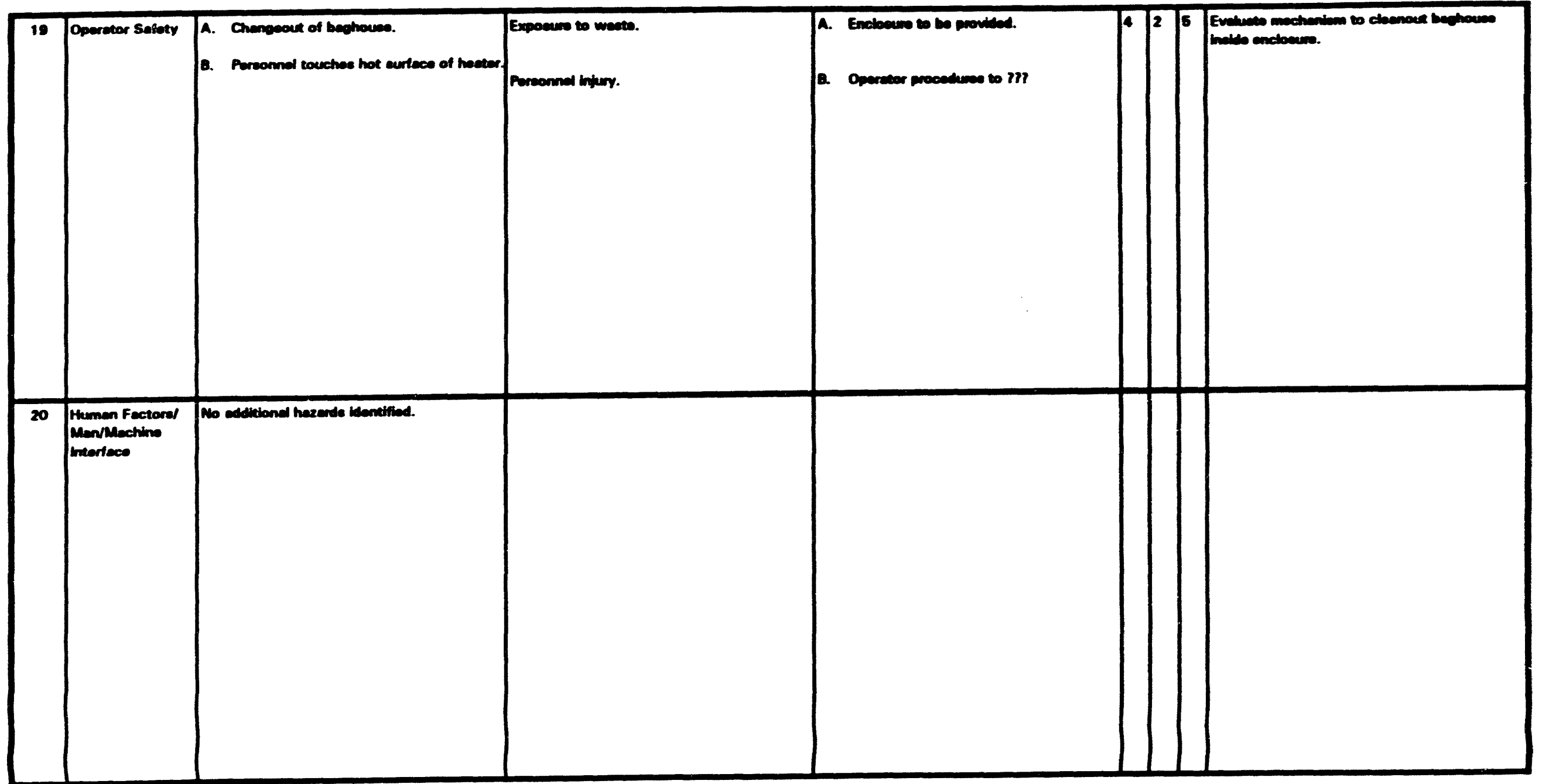


WRAP 2A ACDA PRELIMINARY HAZOPS REVIEW DATA SHEET

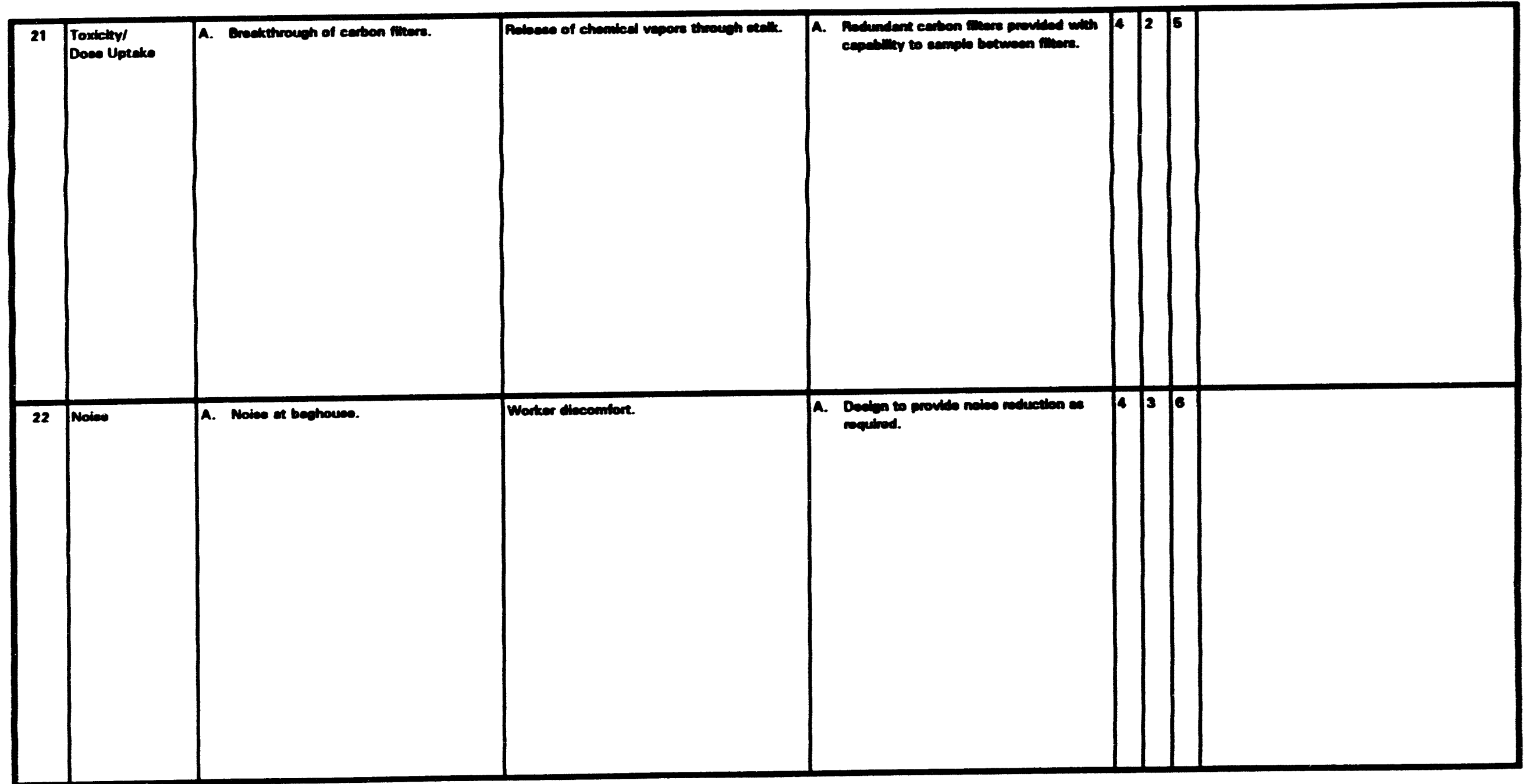




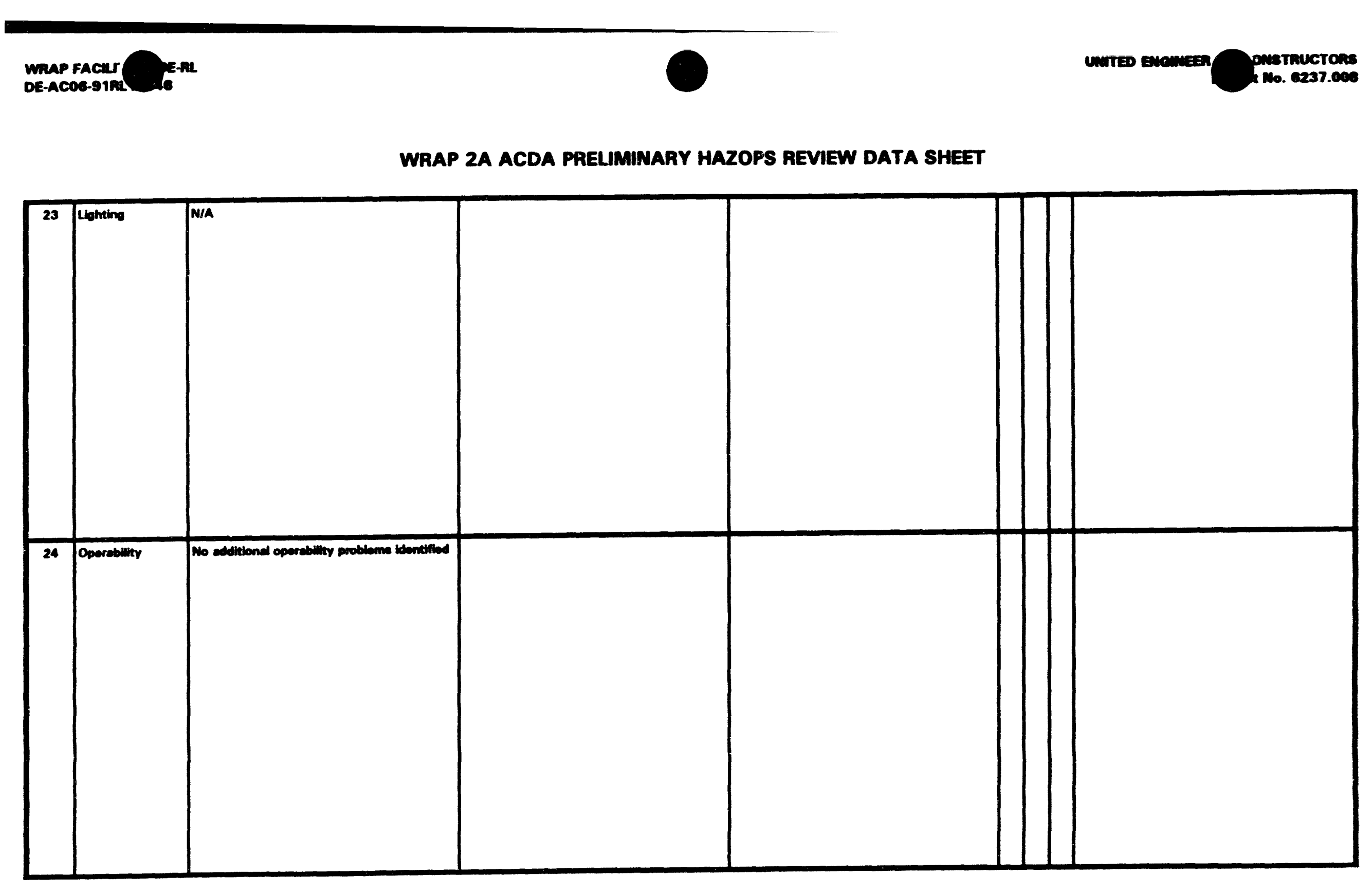

$$
=
$$


WRAP 2A ACDA PRELIMINARY hAZOPS REVIEW DATA SHEET

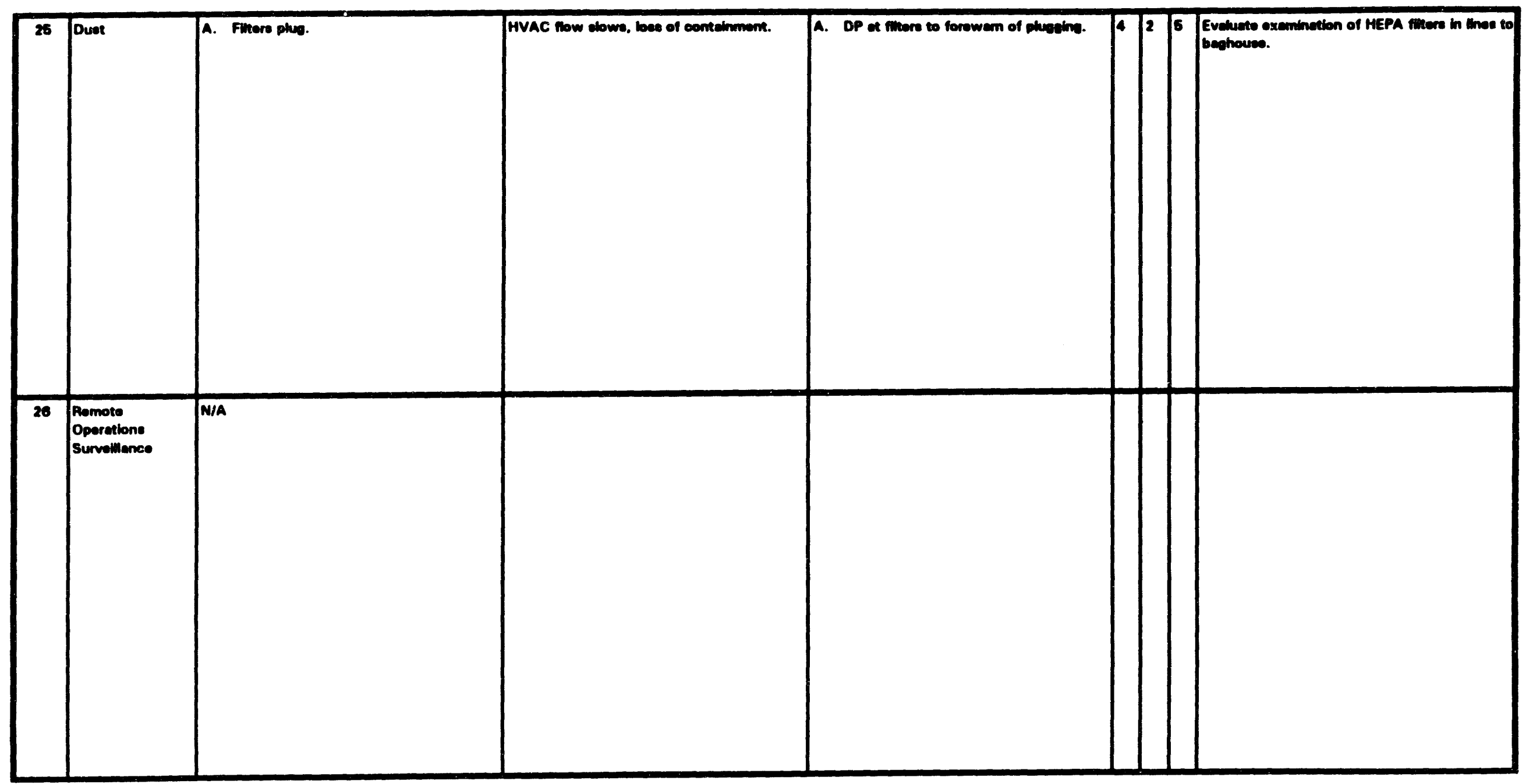




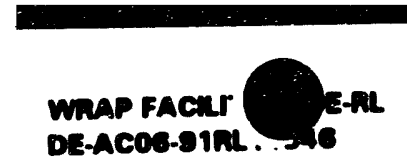

WRAP 2A ACDA PRELIMINARY HAZOPS REVIEW DATA SHEET

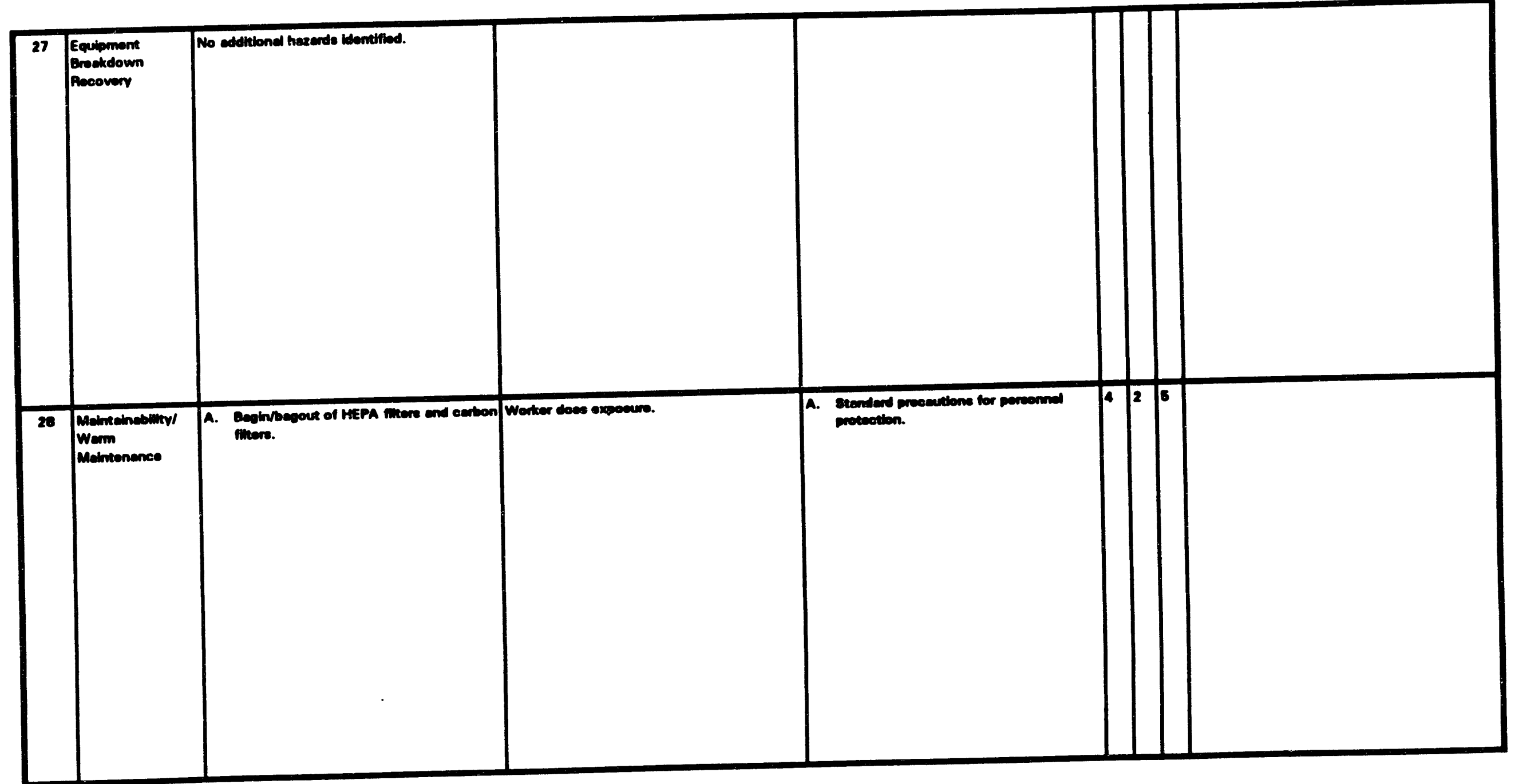


WRAP 2A ACDA PRELIMINARY HAZOPS REVIEW DATA SHEET

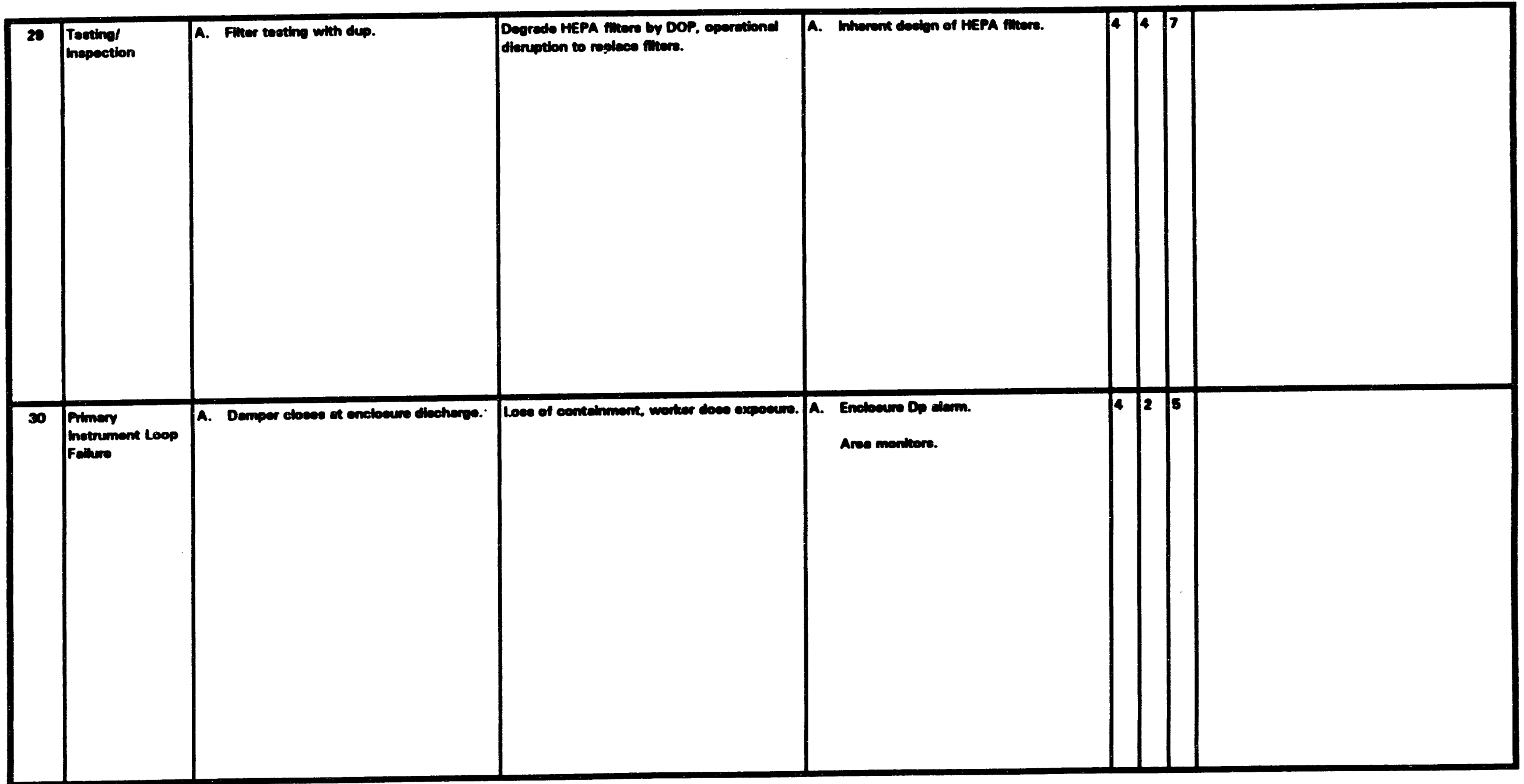




$$
\square
$$


WRAP 2A ACDA PRELIMINARY HAZOPS REVIEW DATA SHEET

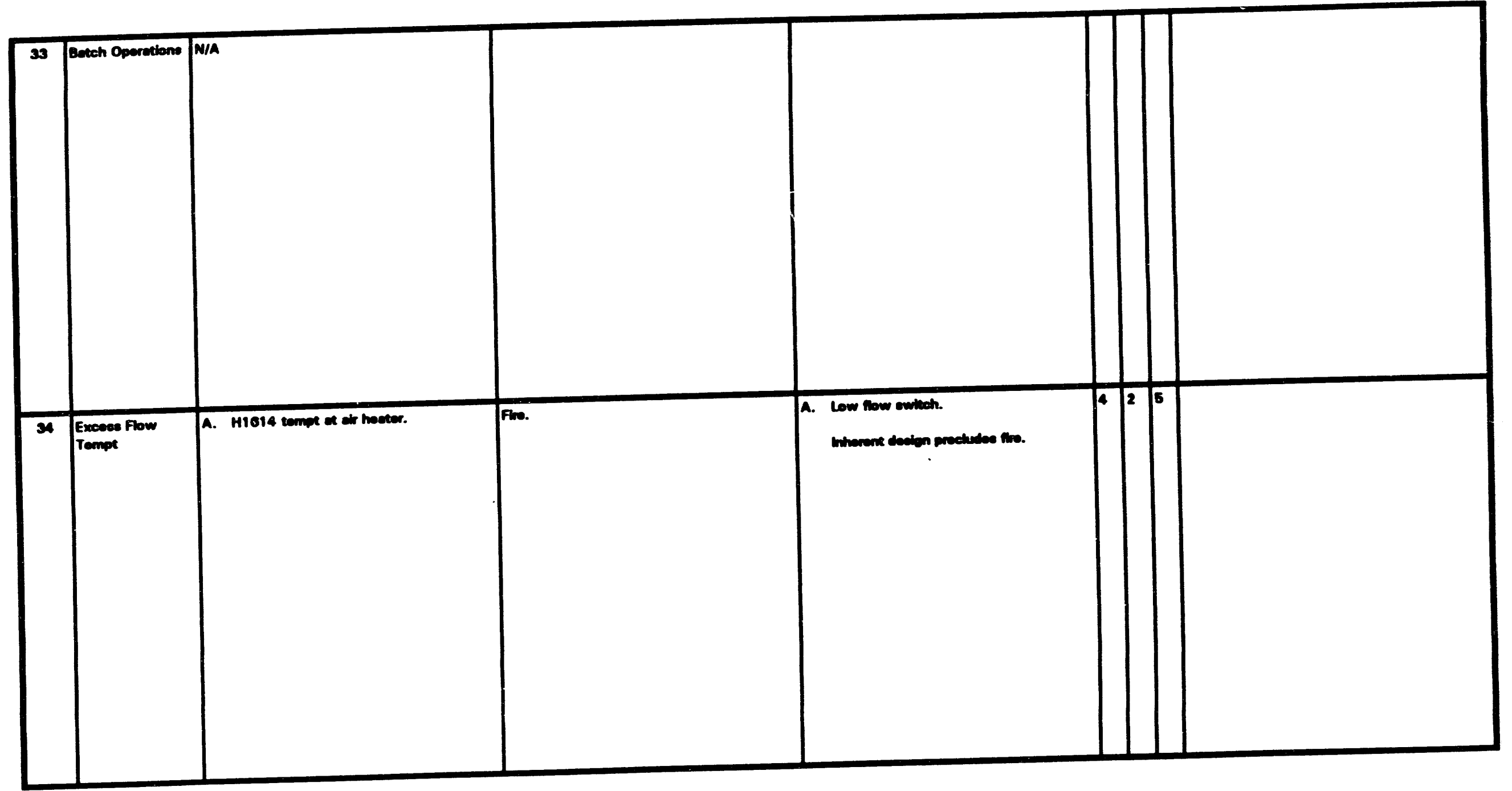


Je-ACo6-91PL 11

WRAP 2A ACDA PRELIMINARY HAZOPS REVIEW C TA SHEET

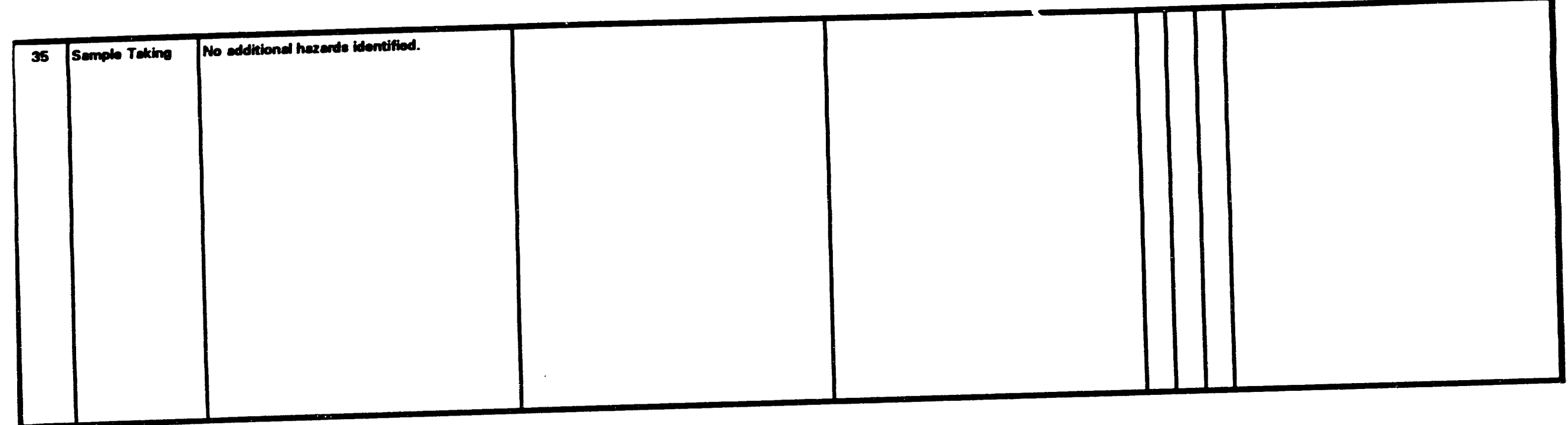


Whate

RECEIVING

AND

PROCESSING FACILITY

\section{TrT: ACoR TME AND MOTION SAMLATION}

Rovidion: 0

Submittod to:

Uiving staTes

DAPARTMENT Of Euser

Fichland, Washington

Prepared by:

Unirrob evoinenese

a constrauctons

A Roytreon Compeny

Whenen Operecions 
map racily, Douse

units ruavuans a constwuotons

TIME AND MOTION SIMULATION

Prepared by:

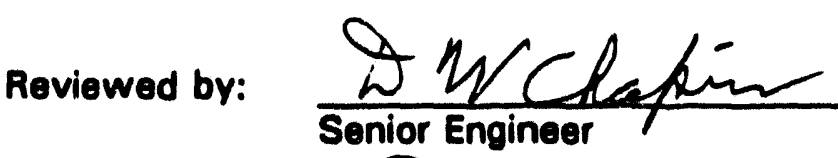

Approved by:

Approved by:

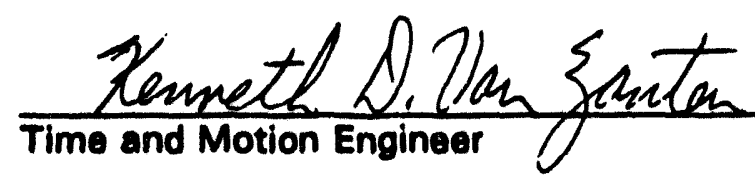

Time and Motion Engineer
Date: $1 / 10 / 94$

Date: $1 / 10 / 44$

Date: $1 / 10 / 94$

Date: $/ 10 / 04$

Project Manager

WRAPOA73

01/10/94

Pop 1 


\section{IABLE OF CONTENTS}

\section{Page}

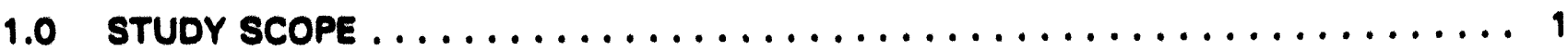

2.0 MODEL DESCRIPTION ............................ 1

3.0 STUdY BASIS $\ldots \ldots \ldots \ldots \ldots \ldots \ldots \ldots \ldots \ldots \ldots \ldots \ldots \ldots \ldots \ldots$

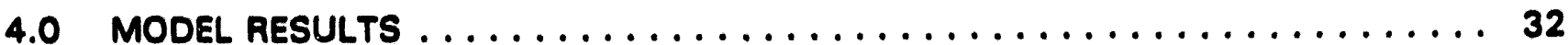


WRAP 2A

\section{PLANT THROUCHPUI TIME AND MOTION SIMULATION}

\subsection{TUDY 8COPE}

1. A WITNESS TIme and Motion model will be doveloped and run to dotermine if the WRAP $2 A$ plant throughput requirements of 29,000 CF per year can be met in one shift per day, assuming an overall plant availability of 70 percent or 175 avallable operating days per year. The WITNESS model flow diagram (shown on SK-643 attached) shows the key process functions (machine and buffers) and modes of transportation (vehicles, elevators and conveyors) to be used in the model. The model is not intended to be an exact replicate of the WRAP 2A ACDR design, but rather a top lovel summary where, for example, several process functions can be combined into a single WITNESS machine with a combined cycle time.

2. The WITNESS model will be run in four modes of operation: (1) Debris - Vibro Grout line operating in parallel with the Sludge/Particulate - Agitated Grout line, (2) Debris - Vibro Grout line operating in parallel with the Sludge/Particulate - Polyethylene Extruder line, (3) the Special Waste area and (4) the Box Breakdown area. The first two modes of operation will be run to determine if the two lines operating in parallel can meet the 29,000 CF per year throughput requirements. The last two modes of operation will be run to determine if the predicted operating times for the various campaigns in the Special Waste and Box Breakdown areas can meet the operating times targeted in the FDC and SDRD.

\subsection{MODEL DESCRIPTION}

1. The WITNESS model shown on SK-643 uses automated guided vehicles (AGV1, AGV2) and forklift truck (FORK) to transport waste drums and wasteboxes from the W112 storage area to WRAP 2A, to transport new empty drums and empty product containers from the new container storage area to WRAP $2 A$ and to transport product containers filled with treated waste and 55 gallon drums filled with repacked waste from WRAP 2A back to W112. Vehicle AGV2 will carry 2 waste drums at one time to the special waste, particulate/sludge and debris processing lines where the 2-drum "unit" is converted to two individual drums using "production machines" SWSPLT, PSSPLT and DSPLT. Vehicle AGV1 will carry two new empty 55-gallon drums at a time from the new container storage area to the drum loadout stations at the box breakdown cell and to the debris processing line for filling with particulate matter screened from the debris. After the drums are repacked with waste and returned to the loading conveyors, AGV1 will transport the filled drums to W1 12 for interim storage and eventual processing in WRAP 2A. The model does not include the depalletizing of drums of new or waste drums coming to the WRAP 2A plant or the palletizing of drums leaving the WRAP $2 A$, as these requirements were added late in model development and time constraints prevented their inclusion. These steps will be added in Title I design. 
2. New empty product containers are delivered to WRAP $2 A$ by a fork lift truck (FORK) and pass via convoyors through a sot of airlocks. Empty product containers can be sent on demand to the following areas to recoive processed wasto or mixtures of processed waste and grout or processad waste and polyethylono:

\author{
8. Box Breakdown Waste Repackaging Loadout (BOXLDCON) \\ b. Compacted Empty Drums Loadout (PUCKLOAD) \\ c. Dabris Loadout (DLOADS) \\ d. Vibro Grout Station Loadout (DVGROUT) \\ - Agltated GroutWaste Loadout (PSACROUT) \\ 1. Extruded PolyothylenoMasto Losdout (PSPOLYMR) \\ g. Special Waste Shredded Material Loadout (SWLOADS) \\ h. Special Waste Treated Bottle Loadout (SWLOADT)
}

3. After immobilization or encapsulation of the waste with grout or polyethylene (except compacted empty drums which are sent in a product container directly to the cure storage area for temporary storage (TEMPSTOR) before shipment to W112), the filled product containers are sent to the cure storage area (CUREOUT) for 48 hours to allow the grout/waste mixture to cure and the polyethylene/waste mixture to cool down and solidify before shipment by the FORK vehicle to W112.

4. Waste drums from W112 are delivered to the special waste drum storage area (SWIN), the particulate/sludge drum storage area (PSIN) or the debris drum storage area (DEBRISIN) by vehicle AGV2. For each processing line, a similar mode of transportation is used to deliver full drums to the processing area, and return used empty drums to the empty drum compactor (ECOMPACT). A conveyor transports a full drum through an airlock to an olevator (modeled as a vohicle) which lifts the full drum to the delidding/processing level of that processing line. A conveyor transports the full drum to the delidding station where the drum lid clamps are cut and the lid removed. The drum then enters the processing area and the contents are tipped onto a sorting table. The empty drum is returned to the delidding area where the lid is reattached to the drum and the drum is pushed off (via a conveyor) to a transfer car (TRANSCAR) which transports the drum to an empty drum compactor. After compaction, the compacted drum is loaded into a product container. Since the compactor and compacted drum load-out station are located at elevation above grade, an elevator is used to transport empty product containers up to the load-out station and when the product container is filled with 22 compacted drums, the container is relidded and the elevator returns the filled product container to grade level and transported via conveyors to the temporary storage area (TEMPSTOR) for eventual transport to W112.

5. In the debris processing line, drum contents are tipped onto a sorting table (DSORT) to remove non-shreddable items which are loaded directly into a product container (DLOADS) which has been delidded at the loadout station. Particulates are removed via screening and loaded into 55 gallon drums. The full drums are transported via conveyors and an elevator (the same elevator that transports waste drums up to the processing area) to grade level and vehicle AGV1 transports the full drums to W1 12 for interim storage and eventual treatment in WRAP 2A. The remainder of the drum contents are shredded (DSHRED) along with oversized material from the particulate/sludge processing line sorting table (DSORT). Product containers filled with shredded debris are then moved to the vibro grout station (DVGROUT) where grout is added while vibrating the container. Containers filled with waste and grout are then relidded and sent via conveyors to the cure storage 
area (CUAEOUT) for 48 hours before boing tranaported via the fork lift truck (FORK) to W112. Product containers holding repacked box breakdown waste or waste from the special waste processing line are queued on the conveyor leading to the vibro grout station and are also vibro grouted on a first come first served basis.

6. In the particulate/sludge processing line, drum contents are tipped onto a sorting table and screened (PSSORT). Overaized material is sent (via a gravity chute) to the debris shredder (DSHRED). The remainder of the material is crushed (PSCRUSH) in preparation for mixing with grout in an agitated mixer or for blending with molten polyothylene in an extruder. Waste that is compatible with grout immobilization is sent directly to the agitated grout mixer (PSAGAOUT) where the waste is mixed with wot grout and then poured into empty product containers. Waste that is best suited for polyethylene immobilization is first dried to remove residual moisture (PSDRYER) and then sent to the polyethylene extruder where the waste is mixed with molten polyethylene and extruded into empty product containers (PSPOLYMR). Containers filled with waste/grout or waste/polyethylene mixtures are then sent to the cure storage area (CUREOUT) via conveyors prior to shipment to W112. The model does not include the grout equipment washout steps, but does reduce the daily operating time per shift from $\mathbf{5 . 5}$ to $\mathbf{5 . 0}$ hours to take this into account.

7. In the special waste processing line, bottles of liquid waste are manually removed and either sampled or sent directly to treatment. The drum contents are then tipped onto a sorting table (SWSORT) where additional bottles are removed. Bottles of elemental mercury are sent directly to the treatment area (SWTREAT) for amalgamation. Amalgamated mercury bottles are loaded into product containers (SWLOADT) and sent to the vibro grout station (DVGROUT) for grout macro encapsulation. Bottles containing chemical waste are sampled in one of five sampling stations (SWSAMPL1, SWSAMPL2, SWSAMPL3, SWSAMPL4 and SWSAMPL5). After sampling, the bottles are stored (SWSTORIN) for 10 days while waiting for sample results from the laboratory. When sample results are available, the bottles are treated in one of five treatment stations. Five sampling and treatment stations (SWTREAT1, SWTREAT2, SWTREAT3, SWTREAT 4 and SWTREAT5) are needed to process an expected 22 bottles of chemical waste per shift. Since the sampling and treatment activities may actually be done in the same location, the model was designed so only one activity at a time (i.e. sampling or treating) could take place at each of the five stations. During treatment, in which the waste may be neutralized or deactivated and either absorbed onto an absorbent or immobilized by grouting, the volume of treated waste increases, doubling the number of bottles holding treated waste.

The treated bottles are loaded into the product containers using bottle racks(SWLOADT) and sent to the vibro grout station (DVGROUT) for grout encapsulation. Packing material and mercury contaminated solids are shredded (SWSHRED). Inert material is loaded directly into product containers (SWLOADS). Mercury contaminated material is retorted to remove the elemental mercury and the residue is loaded into product containers (SWLOADS). The product containers holding shredded material or mercury evaporation residue are sent to the vibro grout station (DVGROUT) for grout encapsulation. The elemental mercury is sent to the treatment area (SWTREAT) for amalgamation and placement in product containers (SWLOADT) and eventual macro encapsulation with grout at the vibro grout station (DVGROUT). 
8. Waste boxes and 85 or 110 gallon drums are sent to the box breakdown (BOXBREAK) ares by the FORK vehicle. Boxes or drums are received by two conveyors in series which pass through a set of airlocks. Inside the box breakdown area, the boxes or drums are broken down by remotely operated equipment and the waste is repackaged in either 58 gallon drums or product containers.

85 gallon drums are returned to the W112 storage area whore they would be gathered by type of waste and eventually (not in the model) campaigned through the WRAP 2A plant. Product containers will be sent to the vibro grout station for grout addition and then to the cure storage area (CUREOUT). 


\subsection{STUDY BASIS}

1. The model assumes a facility availability of 70 percent or 175 operating days per year.

2. The model assumes the material handling system (vehicles, conveyors and buffers) operates for 7 hours por shift, the vibro grout and agitated grout systems operate for 5 hours per shift and the rest of the WRAP 2A plant operates for 5.5 hours per shift. The grout systems are assumed to need an additional 30 minutes at the end of the shift for cleanup so the shift time was reduced from 5.5 to 5.0 hours. The model will be run on a one shift per day basis.

3. Labor is not included in the model except in the special waste area. Here five operators are assumed to alternate between five sampling stations and five chemical treatment stations to allow only five of the ten stations to operate at a time. The shift patterns of the labor are included which takes into account the break times and change times for labor. If it is determined in the model development that two functions (machines) cannot operate simultaneously (as noted above for special waste), both machines will be assigned the same operator so that only one machine can operate at any given time.

4. Sampling of incoming waste drums and sampling of outgoing product containers is not included in the model (although sampling of bottles is included in special waste). Sampling will be included in the Time and Motion model of WRAP $2 A$ during Title I Design.

5. The flow rates of waste drums and waste boxes into the WRAP 2A plant are based on a FDC/SDRD requirement of 29,000 CF per year. To simplify model operations and avoid undue complexity, streams with similar treatments will be lumped together in the model. This reduces the number of streams to the following:

\section{Debris and Sludoe/Particulate}

Stream DVG Drums processed in the debris line and vibro grouted

Stream SPG Drums processed in the sludge/particulate line and grouted (agitated)

Stream SPP

Drums processed in the sludge/particulate line and polyethylene extruded

\section{Soecial Waste}

Stream

Stream 51A Elemental

Stream 5 A3 Heterogeneous Mercury

Stream 5A2 Mercury Chemicals

\section{Ireatment}

Bottles - Amalgamation; Vibro Grout

Packing - Mercury Evaporation, Vibro Grout

Mercury Evaporation; Vibro Grout

Recovered Mercury - Amalgamation; Vibro Grout

Bottles - Chemical Treatment; Vibro Grout

Packing - Mercury Evaporation; Vibro Grout

Recovered Mercury - Amalgamation; Vibro Grout 


\section{Box Breakdown}

Stream DVGBOX Boxes containing debris that are broken down and repacked in new 55 gallon drums. Drums are sent back to W112 in the model.

Stream SPGBOX Boxes containing sludge/particulate that are broken down, shredded and repacked in now $\mathbf{5 5}$ gallon drums. Drums are sent back to W112 in the model.

Steam FAILPROD Product containers that have failed quality tests and need to be reworked and product containers that require destructive examination will be broken down and repacked in new 55 gallon drums. Drums are sent back to W112 in the model.

Stream OVERPACK Leaky or damaged 55 gallons of waste overpacked in 85 gallon drums. These will be broken down and repacked in new $\mathbf{5 5}$ gallon drums. Drums are sent back to W112 in the model.

Stream $\mathbf{5 C 1}$

Overweight drums (over 1000 lbs.) containing lead that have the lead repacked in product containers and the drum shells size reduced and repacked in new 55 gallon drums. Product containers are sent to vibro grout and drums are sent back to W112 in the model.

In Table 1, the FDC/SDRD waste volume and drum requirements (assuming 7.4 CF per drum) are given for the debris and sludge/particulate lines. Two runs will be made using these three streams:

- Debris/vibro grout and sludge/particulate (agitated) grout lines will be run in parallel to confirm that the debris/vibro grout line can process 11,600 CF per year and the sludge/particulate line (using grout) can process $17,400 \mathrm{CF}$ per year.

- Debris/vibro grout and sludge/particulate using polyethylene extrusion will be run in parallel to confirm that the debris/vibro grout line can process 11,600 CF per year and the sludge/particulate line using polyethylene extrusion can process $17,400 \mathrm{CF}$ per year.

In Table 2, the waste volume and drum requirements for the special waste line as given by WHC in a $12 / 4 / 93$ fax are given as well as the operating days per campaign. The model will be run for the three campaigns by inputting the number of drums of each and running the model to determine how many days are predicted by the model for each campaign. Model results will be compared to campaign requirements. 


\section{IABLE1}

DEBRIS AND SLUDGE/PARTICULATE OPERATIONS

\begin{tabular}{|c|c|c|c|}
\hline Stream No. & Treatmont & $\begin{array}{c}\text { Weate Volums } \\
\text { CFrYear }\end{array}$ & Drumaryoar \\
\hline \multicolumn{4}{|l|}{ Sludoa/Particulate } \\
\hline $\begin{array}{c}1 A \\
1 B \\
1 C \\
1 D 1 \\
2 C \\
7 \\
9 A\end{array}$ & $\begin{array}{l}\text { Strean SPG } \\
\text { Shudge/Particulate - Grout }\end{array}$ & 17,400 & 2,351 \\
\hline $\begin{array}{l}2 A \\
2 B\end{array}$ & $\begin{array}{l}\text { Stream SPP } \\
\text { Sludoe/Particulate - Polyethylene }\end{array}$ & 17,400 & 2,351 \\
\hline & TOTAL SLUDGEPARTICULATE & 17,400 & 2,351 \\
\hline Debris & $\begin{array}{ll}8 \\
\end{array}$ & 2 & \\
\hline $\begin{array}{l}102 \\
9 B \\
\end{array}$ & $\begin{array}{l}\text { Stream DVG } \\
\text { Debris - Vibro Grout } \\
\end{array}$ & 11,600 & 1,568 \\
\hline 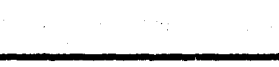 & TOTAL DEBAUS & 11,600 & 1,568 \\
\hline & TOTAL PLANT & 29,000 & 3.919 \\
\hline
\end{tabular}

Notes: 1. Drum Volume $=7.4 \mathrm{Cu} f t$

2. Either Stream SPG (Sludge/Particulate -Grout) or Stream

SPP (Sludge/Particulate- Polyethylene) will be included in the Model, but not both streams at the same time 
TABLE?

SPECIAL WASTE OPERATIONS

\begin{tabular}{|c|l|c|c|}
\hline Stream No. & Treatment & $\begin{array}{c}\text { Waste Volume } \\
\text { CF/Year }\end{array}$ & Drums/Year \\
\hline 5 E1 $\begin{array}{l}\text { Elemental } \\
\text { Mercury }\end{array}$ & $\begin{array}{l}\text { Bottles - Amalgamation, Vibro } \\
\text { Grout } \\
\text { Packing - Mercury Evaporation, } \\
\text { Vibro Grout }\end{array}$ & 130 \\
\hline 5 A3 Heterogeneous \\
$\begin{array}{l}\text { Mercury } \\
\text { Chercury Evaporation, Vibro Grout } \\
\text { Recovered Mercury - } \\
\text { Amalgamation, Vibro Grout }\end{array}$ & 560 & 76 \\
\hline 5 Mercury & $\begin{array}{l}\text { Bottles - Chemical Treatment, } \\
\text { Vibro Grout } \\
\text { Packing - Mercury Evaporation, } \\
\text { Vibro Grout } \\
\text { Recovered Mercury - } \\
\text { Amalgamation, Vibro Grout }\end{array}$ & 80 & 11 \\
\hline $\begin{array}{l}\text { Stream SWCT } \\
-5 \text { C2 Lead Chemicals } \\
-9 \text { Contained \& } \\
\text { Absorbed Liquids }\end{array}$ & $\begin{array}{l}\text { Bottles - Chemical Treatment, } \\
\text { Vibro Grout } \\
\text { Packing - Shred, Vibro Grout }\end{array}$ & 1185 & 162 \\
\hline
\end{tabular}

Drum Volume $=7.4 \mathrm{Cu} \mathrm{ft}$.

Note: During the campaign time when special waste is operating, the throughput requirements for debris are reduced by the amount of special waste processed, so as to maintain an overall plant throughput of 29,000 CF per year.

REQUIRED OPERATING TIMES FOR SPECIAL WASTE CAMPAIGNS

\begin{tabular}{|c|c|c|}
\hline Campaign & Stroam & Campaign Duration, Shifts \\
\hline Elemental Mercury & 5A1 & 12 \\
\hline Heterogeneous Mercury & $5 A 3$ & 50 \\
\hline \multirow{2}{*}{$\begin{array}{l}\text { Chemicals/Contained Liquids } \\
\text { (5A2, 5C2 and 9C) }\end{array}$} & $5 A 2$ and SWCT & 113 \\
\hline & Total & 175 \\
\hline
\end{tabular}

In Table 3, the box and drum requirements are given for the box breakdown cell. The five feed streams to this area are given below, as well as the projected time to complete each campaign. As with special waste, model results will be compared with target values to see if the operating shifts per campaign are being met. 
PROJECTED OPERATINO TIMES FOR BOX BREAKDOWN CAMPAICNS

\begin{tabular}{|l|l|c|}
\hline \multicolumn{1}{|c|}{ Campaign } & \multicolumn{1}{|c|}{ Containers/Year } & \multicolumn{1}{|c|}{$\begin{array}{c}\text { Projected Time to } \\
\text { Complote Campaign }\end{array}$} \\
\hline Stream DVGBOX & 30 Boxes & 45 Shifts \\
\hline Stream SPGBOX & 10 Boxes & 15 Shifts \\
\hline Stream FAILPROD & 24 Product Containers & 48 Shifts \\
\hline Stream OVERPACK & 100 Drums & 50 shifts \\
\hline Stream 5C1 (Overweight) & 10 Drums & 5 Shifts \\
\hline & Total & 163 Shifts \\
\hline & Contingency & 12 Shifts \\
\hline & Available Shifts Por Year & 175 Shifts \\
\hline
\end{tabular}

6. The flow rate of waste drums, waste boxes and product containers within the plant and the flow rate of product containers produced by the plant will be based on the process flow diagrams and process design bases for eight functional areas of the plant which are shown in Table 4. While the flow rates per shift of drums, boxes or containers used in the WITNESS model may not exactly match the numbers given in the process flow diagrams. the increase or decrease in waste volume or number of drums, boxes or containers as waste progresses through the WITNESS model will be based on the relative increase or decrease in volume and waste "containers" as given in the process flow diagrams.

7. Vehicles: The model uses four types of vehicles: two automated guided vehicles (AGV1 and AGV2), a forklift truck (FORK), a transfer car (TRANSCAR) and four elevators (ELEV1, ELEV2, ELEV3, and ELEV4). The speed (both loaded and unloaded), acceleration and deceleration and loading and unloading times for these vehicles were based on information gathered from vendors during the WRAP 1 Title II design and are given below:

$\begin{array}{lllll} & \text { AGVs } & \text { EORK } & \text { TRANSCAR } & \text { ELFVS } \\ \text { Speed, Loaded } & 193.0 \mathrm{FPM} & 183.6 \mathrm{FPM} & 210 \mathrm{FPM} & 33 \mathrm{FPM} \\ \text { Speed, Unloaded } & 193.0 \mathrm{FPM} & 183.6 \mathrm{FPM} & 210 \mathrm{FPM} & 33 \mathrm{FPM} \\ \text { Time Dolay, Acceleration } & 0.045 \mathrm{~min} & 0.10 \mathrm{~min} & 0.10 \mathrm{~min} & 0.10 \mathrm{~min} \\ \text { Time Delay, Decoleration } & 0.045 \mathrm{~min} & 0.10 \mathrm{~min} & 0.10 \mathrm{~min} & 0.10 \mathrm{~min} \\ \text { Losding Time } & 0.25 \mathrm{~min} & 0.75 \mathrm{~min} & 0.25 \mathrm{~min} & 0.25 \mathrm{~min} \\ \text { Unloeding Time } & 0.25 \mathrm{~min} & 0.42 \mathrm{~min} & 0.25 \mathrm{~min} & 0.25 \mathrm{~min}\end{array}$

The speed of the AGVs (2.2 mph or 193.6 FPM) is based on vendor information. The speed of the automated guided fork lift truck (FORK) was assumed to be the same speed as the AGVs. The time delays and loading and unloading times for the AGVs were based on vendor information. The time delays and loading and unloading times for the FORK were based on a manually operated fork lift truck. The speeds, time delays and loading and unloading times for the transfer car and the four elevators were based on the automatic stacker/retriever system (ASRS). The horizontal speed of the ASRS of 210 FPM was used for the transfer car and the vertical speed of 33 FPM of the ASRS was used for the elevators. The lengths of the vehicle tracks for AGVs and FORK were assumed using a distance of 400 feet from W112 to WRAP 2A and 65 feet from new container storage to WRAP 2A. The elevator vertical lifts (tracks) were assumed to be $\mathbf{4 0}$ feet to the debris processing line, 40 feet to the particulate/sludge processing line and 50 feet to the special waste processing line. 
TABLE 3

BOX BREAKDOWN OPERATIONS

\begin{tabular}{|c|c|c|c|}
\hline Stream No. & Treatment & $\begin{array}{c}\text { Food Waste } \\
\text { Containord } \\
\text { Year }\end{array}$ & $\begin{array}{l}\text { Repacked Waste } \\
\text { Containers/Yoar }\end{array}$ \\
\hline $\begin{array}{l}\text { Stream DVGBOX } \\
\text { - } 102 \text { Misc. Waste } \\
\text { - 98 Heterogeneous } \\
\text { Solids/Debris }\end{array}$ & $\begin{array}{l}\text { Break box and } \\
\text { contents apart, repack } \\
\text { box contents and } \\
\text { exterior in drums ( } 30 \\
\text { Drums/Box) }\end{array}$ & 30 Boxes & 900 Drums \\
\hline $\begin{array}{l}\text { Stream SPGBOX } \\
\text { - 9A Particulate/Sludge }\end{array}$ & $\begin{array}{l}\text { Break box and } \\
\text { contents apart, shred } \\
\text { box contents and } \\
\text { repack box contents } \\
\text { and exterior in drums } \\
\text { (22 Drums/Box) }\end{array}$ & 10 Boxes & 220 Drums \\
\hline $\begin{array}{l}\text { Stream FAILPROD } \\
\text { - } 12 \text { Failed Product Containers } \\
\text { - } 12 \text { Product Containers for } \\
\text { Destructive Examination }\end{array}$ & $\begin{array}{l}\text { Break container and } \\
\text { contents apart, repack } \\
\text { container contents } \\
\text { and exterior in drums } \\
\text { (14 Drums/Product } \\
\text { Container) }\end{array}$ & $\begin{array}{l}24 \text { Product } \\
\text { Containers }\end{array}$ & 336 Drums \\
\hline $\begin{array}{l}\text { Stream OVERPACK } \\
\text { - Overpacked } 55 \text { gallon drums } \\
\text { in } 85 \text { gallon drums }\end{array}$ & $\begin{array}{l}\text { Remove } 55 \text { gallon } \\
\text { drums from } 85 \text { gallon } \\
\text { drum, repack drum } \\
\text { contents in drums, } \\
\text { size reduce used } 55 \\
\text { and } 85 \text { gallon drums } \\
\text { and repack in drums } \\
\text { (2.32 repacked } \\
\text { Drums Waste Drums) }\end{array}$ & 100 Drums & 232 Drums \\
\hline $\begin{array}{l}\text { Stream } 5 \mathrm{Cl} \\
\text { - Overweight elemental lead } \\
\text { drum (assumed weight of } \\
1460 \text { (bs) }\end{array}$ & $\begin{array}{l}\text { Remove lead from } \\
\text { drum and place in } \\
\text { product container } \\
\text { (maximum weight of } \\
4400 \text { lbs per } \\
\text { container. Size } \\
\text { reduce used drums } \\
\text { and repack in drums. }\end{array}$ & 10 drums & $\begin{array}{l}4 \text { Product } \\
\text { Containers } \\
4 \text { Drums }\end{array}$ \\
\hline
\end{tabular}

8. Conveyors: The model uses several types of conveyors for drums, waste boxes and product containers. Cycle times (defined as the time to move one part length) depends on the size of the drum, box or container, the speed of the conveyor, and the presence of other conditions (such as airlocks). 


\section{TABLE 4}

PROCESS BASIS FOR WRAP 2A WITNESS MODEL

\begin{tabular}{|c|c|c|}
\hline PROCESS DESIGN BASIS & DWO No. & DWG TILE \\
\hline - Material Handling Internal Transport & H-2-140644 (Sheets 1 and 2) & Material Handling Internal Transport \\
\hline - Particulate/Sludge Processing System & H-2-140628 (Sheet 1) & Sludge/Particulate Processing \\
\hline - Empty Drum Compaction & H-2-140628 (Sheot 2) & Empty Drum Compaction \\
\hline - Debris Processing System & H-2-140628 (Sheet 3) & Debris Processing \\
\hline - Box Breakdown & H-2-140628 (Sheet 4) & Box Breakdown \\
\hline - Special Waste Processing System & $\begin{array}{l}H-2-140649 \\
H-2-140650\end{array}$ & $\begin{array}{l}\text { Special Waste - Size Reduction } \\
\text { Special Waste - Pretreatment }\end{array}$ \\
\hline - Grout Immobilization & $\begin{array}{l}H-2-140637 \text { (Sheets } 1 \text { and 2) } \\
H-2-140638\end{array}$ & $\begin{array}{l}\text { Vibro Grout System } \\
\text { Sludge/Particulate Grout System }\end{array}$ \\
\hline - Polyethylene Polymer & $H-2-140641$ & Polyethylene Encapsulation \\
\hline
\end{tabular}

Equipment general arrangement drawing H-2-140599 was used to determine the physical lengths of conveyors and vehicle tracks within the WRAP 2A Plant. 


\section{Drum Conveyors}

$\begin{array}{ll}\text { Part Length } & =2 \text { feet } \\ \text { Speed } & =30 \text { feet/minute } \\ \text { Cycle Time } & =\frac{2 \text { feet }}{30 \text { feet/minute }}\end{array}$

For drums passing through airlocks, a time of 0.80 minutes was added to the total travel time.

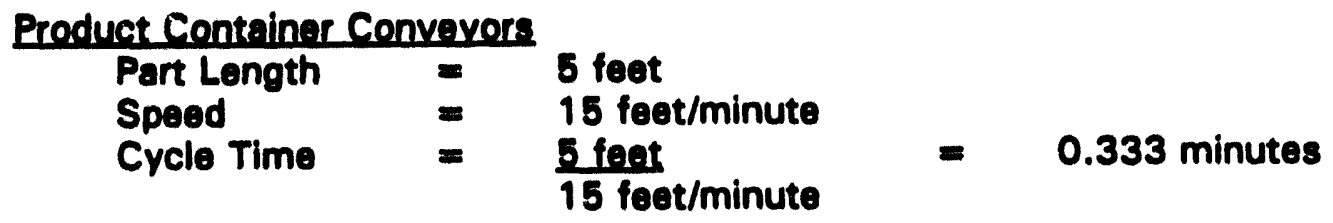

For product containers passing through airlocks, a time of 1.0 minutes was added to the total travel time. For delidding or relidding a product container, a time of 3.0 minutes was added to the total travel time. For clamping the lid on a product container, a time of 4.0 minutes was added to the total travel time.

\section{Box Conveyors}

For the box conveyors passing through airlocks, a conveyor time of 1.0 minutes was assumed.

For drums, boxes, or containers passing by a bar code reader, a conveyor time of 1.0 minutes was added to the total travel time.

The length of the conveyors used in the model was based on general arrangement drawing H-2-140599.

\section{Processing Times}

Cycle times for functional activities (machines) in the WITNESS model will be based orr the following:

a. For activities which are similar to those found in the WRAP 1 design, cycle times in the WRAP Model 1 Detailed Design Report, Section 4.5 Plant Throughput Time and Motion Analysis, will be used.

b. For activities which are similar to those found in the WRAP 2A CDR design but are not found in the WRAP 1 design, cycle times from the WRAP 2A CDR Report, Appendix I, Plant Throughput Functional Analysis, will be used.

c. For activities which are not similar to any activities in either WRAP 1 or WRAP 2A CDR designs, the best available engineering judgement will be used by UE\&C/BNFL engineers.

The cycle times for the operational steps in the WITNESS Model shown in SK-643 are given in Tables 5 through 10. 
10. Container and Drum Volumes

Waste Drum or Repacked Drum Volume $=7.4 \mathrm{Cu} f t$

Product Container Net Volume $=60 \mathrm{Cu} f t$

11. Based on process flow diagram information, the ratio of product container produced per inlet feed drums used in the WITNESS model is given below:

Dabria and Sludoe/Particulate

Dobris-Vibro Grout

8.11 drums per Product Container

Sludge/Particulate-Agitated Grout

2.36 drums per Product Container

Sludge/Particulate-Polyethylene Extrusion

5.07 drums per Product Container

Special Waste Shredded/Repacked Material

Stream 5 A1

Stream 5A3

6 drums per Product Container

Stream 5A2

7.6 drums per Product Container

Stream SWCT.

6 drums per Product Container

9 drums per Product Container

Soecial Waste Treated Bottles

Amalgamated Mercury

50 bottles per Product Container

Chemically Treated..

196 bottles per Product Container

Empty Compacted Drums

22 compacted drums per Product Container

Where decimal fractions are used to determine the number of drums per Product Container, a random number generator is used in the WITNESS model to determine the integer number of drums for each individual Product Container.

Assumes $90 \%$ packing material, or $6.66 \mathrm{ft}^{3}$ per drum.

-. Assumes the number of treated bottles is twice the number of sampled, untreated bottles. 
TABLE 8

PRODUCT CONTANNER TRANBFERS

\begin{tabular}{|c|c|c|c|}
\hline $\begin{array}{l}\text { OPERATION } \\
\text { STEP NO. }\end{array}$ & OPERATIONAL STEP DESCAIPTION & $\begin{array}{l}\text { WITNESS } \\
\text { CODE }\end{array}$ & $\begin{array}{l}\text { TIME } \\
\text { (MINUTES) }\end{array}$ \\
\hline 1. & $\begin{array}{l}\text { NFW EMPTY PRODUCT CONTAINEAS } \\
\text { Load now ompty product containers into } \\
\text { new container atorage }\end{array}$ & NEWCON & - \\
\hline 2. & $\begin{array}{l}\text { Unload container from storage to forklift } \\
\text { truck }\end{array}$ & UNLOADC & 10.0 \\
\hline 3. & $\begin{array}{l}\text { Transfer container via forklift to WRAP } 2 A \\
\text { inlet product container conveyor }\end{array}$ & FORK & VARIES \\
\hline 4. & $\begin{array}{l}\text { Transfer container via conveyor through } \\
\text { airlock and bar code reader }\end{array}$ & CCON1 & 2.0 \\
\hline $\mathbf{6}$. & $\begin{array}{l}\text { Transfer container via conveyor through } \\
\text { second airlock }\end{array}$ & CCON2 & 1.0 \\
\hline 6. & Holding station for now container (conveyor) & CCON3 & VARIES \\
\hline 7. & $\begin{array}{l}\text { Transfer container via conveyors to box } \\
\text { breakdown load-out }\end{array}$ & $\begin{array}{l}\text { CCON4 AND } \\
\text { CCON5 }\end{array}$ & VARIES \\
\hline 8. & $\begin{array}{l}\text { Transfer container via conveyors to } \\
\text { compacted empty drum load-out elevator }\end{array}$ & $\begin{array}{l}\text { CCON3, CCON6, } \\
\text { CCON7 AND } \\
\text { CCON8 }\end{array}$ & VARIES \\
\hline 9. & $\begin{array}{l}\text { Transfer container via conveyors to debris } \\
\text { vibro grout load-out }\end{array}$ & $\begin{array}{l}\text { CCON7, CCON9 } \\
\text { CCON12 AND } \\
\text { CCON13 }\end{array}$ & VARIES \\
\hline 10. & $\begin{array}{l}\text { Transfer container via conveyors to } \\
\text { sludge/particulate grout load-out }\end{array}$ & $\begin{array}{l}\text { CCON12, } \\
\text { CCON15 AND } \\
\text { CCON16 }\end{array}$ & VARIES \\
\hline 11. & $\begin{array}{l}\text { Transfer container via conveyors to } \\
\text { sludge/particulate polyethylene load-out }\end{array}$ & $\begin{array}{l}\text { CCON15 } \\
\text { CCON18 AND } \\
\text { CCON19 }\end{array}$ & VARIES \\
\hline 12. & $\begin{array}{l}\text { Transfer container via conveyors to special } \\
\text { waste shredded material load-out }\end{array}$ & $\begin{array}{l}\text { CCON18, } \\
\text { CCON21 AND } \\
\text { CCON22 }\end{array}$ & VARIES \\
\hline 13. & $\begin{array}{l}\text { Transfer container via conveyors to special } \\
\text { waste treated waste (bottle) load-out }\end{array}$ & $\begin{array}{l}\text { CCON21, } \\
\text { CCON23, } \\
\text { CCON24, } \\
\text { CCON26 AND } \\
\text { CCON27 }\end{array}$ & VARIES \\
\hline
\end{tabular}


TABLE 8

PAODUCT CONTANNER TRANBFERS

\begin{tabular}{|c|c|c|c|}
\hline $\begin{array}{l}\text { OPERATION } \\
\text { STEP NO. }\end{array}$ & OPERATIONAL STEP DESCAIPTION & $\begin{array}{l}\text { WITNESS } \\
\text { CODE }\end{array}$ & $\begin{array}{l}\text { TIME } \\
\text { (MINUTES) }\end{array}$ \\
\hline 14. & $\begin{array}{l}\text { EILLED PAODUCT CONTANEASEROM } \\
\text { CUAE } \\
\text { STORACE OR TEMPORARY STORACETO } \\
\text { W112 } \\
\text { CUre storage or temporarY storage }\end{array}$ & $\begin{array}{l}\text { CUREOUT or } \\
\text { TEMPSTOR }\end{array}$ & $\begin{array}{l}840.0(2 \\
\text { DAYS) or } 30.0\end{array}$ \\
\hline 15. & $\begin{array}{l}\text { Transfer container via conveyor from cure } \\
\text { storage through airlock and bar code reader }\end{array}$ & CCON33 & 2.0 \\
\hline 16. & $\begin{array}{l}\text { Transfer container via conveyor through } \\
\text { second airlock }\end{array}$ & CCON34 & 1.0 \\
\hline 17. & Transfor via forklift truck to W112 & FORK & VARIES \\
\hline 18. & Store containers in W112 & W112CON & \\
\hline
\end{tabular}


TABLE 8

DERAISNIBRO OROUT

\begin{tabular}{|c|c|c|c|}
\hline $\begin{array}{l}\text { OPERATION } \\
\text { STEP NO. }\end{array}$ & OPERATIONAL STEP DESCRIPTION & $\begin{array}{c}\text { WITNESS } \\
\text { CODE }\end{array}$ & $\begin{array}{c}\text { TIME } \\
\text { (MINUTES) }\end{array}$ \\
\hline 1. & Load dobris drums into W112 & W1 12DEB & - \\
\hline 2. & Unioad 2-drum unit from W1 12 to AGV & UNLOADD & 2.0 \\
\hline 3. & $\begin{array}{l}\text { Transfor 2-drum unit via AOV to dobris } \\
\text { processing area }\end{array}$ & AQV2 & VARIES \\
\hline 4. & $\begin{array}{l}\text { Transfor 2-drum unit via conveyor to storage } \\
\text { area (includes bar code reading) }\end{array}$ & C1DEB & 1.5 \\
\hline 5. & Convert 2-drum unit to 2-drums & DSPLT & NIL \\
\hline 6. & Store debris drums in storage area & DEBAISIN & VARIES \\
\hline 7. & $\begin{array}{l}\text { Tranafer drum via conveyor from storage area } \\
\text { to elevator }\end{array}$ & C3 & 1.5 \\
\hline 8. & $\begin{array}{l}\text { Transfer drum via elevator to debris processing } \\
\text { line }\end{array}$ & ELEV1 & VARIES \\
\hline 9. & $\begin{array}{l}\text { Transfer drum via conveyor from elevator to } \\
\text { delid/relid station }\end{array}$ & C4 & 1.0 \\
\hline 10. & Delid drum & DELID & 7.0 \\
\hline 11. & $\begin{array}{l}\text { Transfer delidded drum to sorting table, tip } \\
\text { contents onto table, and roturn drum to delid } \\
\text { Irelid station }\end{array}$ & DENTRY & 7.0 \\
\hline 12. & Place clamps in drum and relid drum & DRELID & 4.0 \\
\hline 13. & Sort and screen drum contents & DSORT & 7.0 \\
\hline $14 . \cdots$ & $\begin{array}{l}\text { Load particulates ( } 5 \% \text { ) into drum (includes } \\
\text { drum delidding and relidding) }\end{array}$ & DLOAD55 & 15.0 \\
\hline $15 . \cdots$ & $\begin{array}{l}\text { Transfer empty product container via conveyor } \\
\text { to shredder load-out }\end{array}$ & CCON13 & VARIES \\
\hline 16. & $\begin{array}{l}\text { Close shredder hatch, purge with nitrogen and } \\
\text { shred shreddable material }\end{array}$ & DSHRED & 11.0 \\
\hline 17. & $\begin{array}{l}\text { Transfer non-shreddable material to product } \\
\text { container }\end{array}$ & $\begin{array}{l}\text { DSORT TO } \\
\text { DLOADS }\end{array}$ & NIL \\
\hline 18. & $\begin{array}{l}\text { Delid and relid product container at shredder } \\
\text { load-out }\end{array}$ & DLOADS & 6.0 \\
\hline
\end{tabular}

-.. See Steps $1(a)$ to 18(a) in Table 6 for Particulate Drum Transfers

.... See Table 5 for Product Container Transfers. 
TABLE 8

DEBRISNIBRO CAOUT

\begin{tabular}{|c|c|c|c|}
\hline $\begin{array}{l}\text { OPERATION } \\
\text { STEP NO. }\end{array}$ & OPERATIONAL STEP DESCRIPTION & $\begin{array}{l}\text { WITNESS } \\
\text { CODE }\end{array}$ & $\begin{array}{l}\text { TIME } \\
\text { (MINUTES) }\end{array}$ \\
\hline 19. & $\begin{array}{l}\text { Tranafor dobris filled product container via } \\
\text { conveyor to vibro grout station }\end{array}$ & CCON14 & VARIES \\
\hline 20. & $\begin{array}{l}\text { Dolid product container, fill product container } \\
\text { with grout, vibrate and relid product container. }\end{array}$ & DVGAOUT & 26.0 \\
\hline 21. & $\begin{array}{l}\text { Transfer vibro grouted product container via } \\
\text { conveyors to cure storage (includes } 4 \text { minutes } \\
\text { to clap lid on product container on CCON } 11 \text { ) }\end{array}$ & $\begin{array}{l}\text { CCON11, } \\
\text { CCON3OA, } \\
\text { CCON28A, } \\
\text { CCON28A, } \\
\text { CCON26A AND } \\
\text { CCON28 }\end{array}$ & VARIES \\
\hline 22. & $\begin{array}{l}\text { Cure vibro grouted product containars in cure } \\
\text { storage } \\
\text { Delivery of Emoty se. Gallon Drums and } \\
\text { ElemovaL of Particulate Materia Lvia Drums }\end{array}$ & CUREOUT & $\begin{array}{l}840.0 \\
\text { (2 DAYS) }\end{array}$ \\
\hline $1(a)$ & $\begin{array}{l}\text { Load empty } \mathbf{5 5} \text { gallon drums into new } \\
\text { container storage }\end{array}$ & NEWDRUM & - \\
\hline $2(a)$. & Unload 2-drum unit from storage to AGV & UNLDE55 & 2.0 \\
\hline $3(a)$. & $\begin{array}{l}\text { Transfer 2-drum unit via AGV to debris } \\
\text { processing area }\end{array}$ & AGV1 & VARIES \\
\hline $4(a)$ & $\begin{array}{l}\text { Transfor 2-drum unit via conveyor to storage } \\
\text { area ( includes bar code reading) }\end{array}$ & CIDEB & 1.5 \\
\hline $\mathbf{5}(\mathbf{a})$ & Convert 2-drum unit to 2-drums & DSPLT & NIL \\
\hline $6(a)$. & Store empty drums in storage area & DEBSEIN & VARIES \\
\hline $7(a)$. & $\begin{array}{l}\text { Transfer empty drum via conveyor from } \\
\text { storage area to elevator }\end{array}$ & C3 & VARIES \\
\hline $8(\mathbf{a})$ & $\begin{array}{l}\text { Transfor empty drum via elevator to first level } \\
\text { (20 feet) }\end{array}$ & ELEV1 & VARIES \\
\hline $\mathbf{g}(\mathbf{a})$ & $\begin{array}{l}\text { Transfer empty drum via conveyor from } \\
\text { elevator to particulate load-out station }\end{array}$ & cC4 & VARIES \\
\hline $10(a)$. & $\begin{array}{l}\text { Load particulates }(5 \%) \text { into drum (includes } \\
\text { drum delidding and relidding) }\end{array}$ & DLOAD55 & 15.0 \\
\hline $11(a)$. & $\begin{array}{l}\text { Transfer particulate filled drum via conveyor to } \\
\text { elevator }\end{array}$ & $\operatorname{CC} 4 A$ & VARIES \\
\hline $12(a)$. & Transfer drum via elevator to grade & ELEV1 & VARIES \\
\hline
\end{tabular}


TADUE 8

DERAISMIERO GROUT

\begin{tabular}{|c|c|c|c|}
\hline $\begin{array}{l}\text { OPERATION } \\
\text { STEP NO. }\end{array}$ & OPERATIONAL STEP DESCRIPTION & $\begin{array}{l}\text { WITNESS } \\
\text { CODE }\end{array}$ & $\begin{array}{l}\text { TIME } \\
\text { (MINUTES) }\end{array}$ \\
\hline $13(0)$. & $\begin{array}{l}\text { Transfor drum via conveyor from dovator to } \\
\text { storage area }\end{array}$ & C3A & VARIES \\
\hline $14(a)$. & $\begin{array}{l}\text { Join } 2 \text { particulate fillod drums into on 2-drum } \\
\text { unit }\end{array}$ & DJOIN65 & 2.0 \\
\hline $15(a)$. & $\begin{array}{l}\text { Transfor 2-drum unit via conveyor through } \\
\text { airlock (includes barcode reading) }\end{array}$ & CIDEBA & 1.5 \\
\hline $18(a)$. & Transfor 2-drum unit via AGV to W112 & AGV1 & VARIES \\
\hline $17(a)$. & Convert 2-drum unit to 2 drums & LOADF58 & 2.0 \\
\hline $18(a)$. & Store drums in W112 & W112DRUM & VARIES \\
\hline
\end{tabular}


TABLE 7

SLUDGE/PARTICULATE CROUT OR

8LUDGEAPARTICULATE POLYETHYLENE ENCAPSULATION

\begin{tabular}{|c|c|c|c|}
\hline $\begin{array}{l}\text { OPERATION } \\
\text { STEP NO. }\end{array}$ & OPERATIONAL STEP DESCRIPTION & $\begin{array}{l}\text { WITNESS } \\
\text { CODE }\end{array}$ & $\begin{array}{l}\text { TIME } \\
\text { (MINUTES) }\end{array}$ \\
\hline 1. & Load drums into W112 & W112ps & - \\
\hline 2. & Unload 2-drum unit from W112 to AGV & UNLOAD PS & 2.0 \\
\hline 3. & $\begin{array}{l}\text { Transfer 2-drum unit via AGV to sludge/ } \\
\text { particulate processing area }\end{array}$ & AGV2 & VARIES \\
\hline 4. & $\begin{array}{l}\text { Transfer 2-drum unit via conveyor to storage } \\
\text { area (includes bar code reading) }\end{array}$ & C1PS & 1.5 \\
\hline 5. & Convert 2-drum unit to 2 drums & PSSPLT & NIL \\
\hline 6. & Store drums in storage area & PSIN & VARIES \\
\hline 7. & $\begin{array}{l}\text { Transfer drum via conveyor from storage area } \\
\text { to elevator }\end{array}$ & C6 & 1.5 \\
\hline 8. & $\begin{array}{l}\text { Transfer drum via elevator to sludge/particulate } \\
\text { processing line }\end{array}$ & ELEV2 & VARIES \\
\hline 9. & $\begin{array}{l}\text { Transfer drum from olevator to delid/relid } \\
\text { station }\end{array}$ & $C 7$ & 1.0 \\
\hline 10. & Delid drum & PSDELID & 7.0 \\
\hline 11. & $\begin{array}{l}\text { Transfer delidded drum to sorting table, tip } \\
\text { contents into table, and return drum to } \\
\text { delid/relid station }\end{array}$ & PSENTRY & 7.0 \\
\hline 12. & Place clamps in drum and relid drum & PSRELID & 4.0 \\
\hline 13. & Sort and screen dsum contents & PSSORT & 10.0 \\
\hline 14. & $\begin{array}{l}\text { Transfer oversized material }(5 \%) \text { to debris } \\
\text { shredder }\end{array}$ & $\begin{array}{l}\text { PSSORT TO } \\
\text { DSHRED }\end{array}$ & NIL \\
\hline 15. & $\begin{array}{l}\text { Crush remaining drum contents } \\
\text { Aaitated Grout }\end{array}$ & PSCRUSH & 5.0 \\
\hline $16(a) \cdot$ & $\begin{array}{l}\text { Transfer empty product container via conveyor } \\
\text { to grout load-out station }\end{array}$ & CCON16 & VARIES \\
\hline $17(a)$. & Store waste in tank ( 4 drums) & PSGSTOR & VARIES \\
\hline 18(a). & Transfer waste to batch mixing tanks & PSGO & 5.0 \\
\hline
\end{tabular}

- See Table 5 for Product Container Transfers 
TABLE 7

SLUDGE/PARTICULATE GROUT OR

SLUDGE/PARTICULATE POLYETHYLENE ENCAPSULATION

\begin{tabular}{|c|c|c|c|}
\hline $\begin{array}{l}\text { OPERATION } \\
\text { STEP NO. }\end{array}$ & OPERATIONAL STEP DESCRIPTION & $\begin{array}{l}\text { WITNESS } \\
\text { CODE }\end{array}$ & $\begin{array}{l}\text { TIME } \\
\text { (MINUTES) }\end{array}$ \\
\hline $19(a)$. & $\begin{array}{l}\text { Mix waste ( } 4 \text { drums) and grout in batch mixing } \\
\text { tanks (includes } 20 \text { minutes for tank cleaning) }\end{array}$ & $\begin{array}{l}\text { PSGMIX1 and } \\
\text { PSGMIX2 }\end{array}$ & 40.0 EACH \\
\hline $20(a)$. & $\begin{array}{l}\text { Delid product container, fill container with } \\
\text { waste/grout mixture and relid container }\end{array}$ & PSAGROUT & 26.0 \\
\hline $21(a)$. & $\begin{array}{l}\text { Transfer agitated grout product container via } \\
\text { conveyors to cure storage (includes } 4 \text { minutes } \\
\text { to clamp lid on product container on CCON 17) }\end{array}$ & $\begin{array}{l}\text { CCON17, } \\
\text { CCON29A, } \\
\text { CCON28A, } \\
\text { CCON26A AND } \\
\text { CCON25 }\end{array}$ & VARIES \\
\hline & Polvethvlene Encapsulation & & \\
\hline 16(b)." & $\begin{array}{l}\text { Transfer empty product container via conveyor } \\
\text { to polyethylene load-out station }\end{array}$ & CCON19 & VARIES \\
\hline $17(b)$. & Dry waste ( 2 drums per batch) in dryer & PSDRYER & $\begin{array}{l}\text { 40.0 PER } \\
\text { BATCH }\end{array}$ \\
\hline 18(b). & $\begin{array}{l}\text { Process waste/polyethylene in polyethylene } \\
\text { extruder and fill product container (includes } 6 \\
\text { minutes for delidding and relidding of product } \\
\text { container) }\end{array}$ & PSPOLYMR & 81.0 \\
\hline
\end{tabular}

See Table 5 for Product Container Transfers 
TABLE 8 SPECIAL WASTE

\begin{tabular}{|c|c|c|c|}
\hline $\begin{array}{l}\text { OPERATION } \\
\text { STEP NO. }\end{array}$ & OPERATIONAL STEP DESCRIPTION & $\begin{array}{l}\text { WITNESS } \\
\text { CODE }\end{array}$ & $\begin{array}{c}\text { TIME } \\
\text { (MINUTES) }\end{array}$ \\
\hline 1. & Load drums into W1 12 & W112SW & - \\
\hline 2. & Unload 2-drum unit from W112 to AGV & UNLOADSW & 2.0 \\
\hline 3. & $\begin{array}{l}\text { Transfer 2-drum unit via AGV to special waste } \\
\text { processing area }\end{array}$ & AGV2 & VARIES \\
\hline 4. & $\begin{array}{l}\text { Transfer 2-drum unit via conveyor to storage } \\
\text { area (includes bar code reading) }\end{array}$ & C1sw & 1.5 \\
\hline 5. & Convert 2-drum unit to 2 drums & SWSPLT & NIL \\
\hline 6. & Store drums in storage area & SWIN & VARIES \\
\hline 7. & $\begin{array}{l}\text { Transfer drum via conveyor from storage area } \\
\text { to elevator }\end{array}$ & C10 & 1.5 \\
\hline 8. & Transfer drum via elevator to special waste & ELEV3 & VARIES \\
\hline 9. & $\begin{array}{l}\text { Transfer drum via conveyor from elevator to } \\
\text { delid/relid station }\end{array}$ & C11 & 1.0 \\
\hline 10. & Delid drum & SWDELID & 7.0 \\
\hline 11. & $\begin{array}{l}\text { Transfer delidded drum to sorting table, } \\
\text { manually remove bottles from drum, tip } \\
\text { remaining contents onto table, and return drum } \\
\text { to delid/relid station }\end{array}$ & SWENTRY & 15.0 \\
\hline 12. & Place clamps in drum and relid drum & SWRELID & 4.0 \\
\hline 13. & $\begin{array}{l}\text { Manually remove additional items from sorting } \\
\text { table and tip remaining table contents into } \\
\text { shredder }\end{array}$ & SWSORT & 15.0 \\
\hline 14.• & $\begin{array}{l}\text { Transfer empty product container via conveyor } \\
\text { to shredded waste load-out }\end{array}$ & CCON22 & VARIES \\
\hline $15 .^{\bullet}$ & $\begin{array}{l}\text { Transfer empty product container via conveyor } \\
\text { to treated waste (bottle) load-out }\end{array}$ & CCON27 & VARIES \\
\hline $16(a)$. & $\begin{array}{l}\text { Stream } 5 A 1 \text { (Elemental Mercury) } \\
\text { Generates } 2 \text { bottles of mercury (ELEMHG) per } \\
\text { drum (from sorting table) }\end{array}$ & SW5A1 & NIL \\
\hline
\end{tabular}

- See Table 5 for Product Container Transfers 
TABLE 8

SPECIAL WASTE

\begin{tabular}{|c|c|c|c|}
\hline $\begin{array}{l}\text { OPERATION } \\
\text { STEP NO. }\end{array}$ & OPERATIONAL STEP DESCRIPTION & $\begin{array}{l}\text { WITNESS } \\
\text { CODE }\end{array}$ & $\begin{array}{l}\text { TIME } \\
\text { (MINUTES) }\end{array}$ \\
\hline $17(a)$. & Amalgamate mercury in bottle & SWTREAT & $\begin{array}{l}60.0 \\
\text { (PER BOTTLE) }\end{array}$ \\
\hline $18(a)$. & $\begin{array}{l}\text { Delid product container, lower rack of bottles } \\
\text { into container, raise hoist and relid container }\end{array}$ & SWLOADT & 16.0 \\
\hline 19(a). & $\begin{array}{l}\text { Close shredder feed hopper door, nitrogen } \\
\text { purge shredder and shred waste }\end{array}$ & SWSHRED & 16.0 \\
\hline 20(a). & $\begin{array}{l}\text { Load shredder material ( } 2 \text { drums) into mercury } \\
\text { evaporator, nitrogen purge, retort at } 450^{\circ} \mathrm{F} \text {, } \\
\text { cool to } 120^{\circ} \mathrm{F} \text { and unload evaporator }\end{array}$ & SWEVAP & $\begin{array}{l}330.0 \\
\text { (24 HOURS) }\end{array}$ \\
\hline 21(a). & $\begin{array}{l}\text { Delid product container, load evaporator } \\
\text { residue into product container and relid } \\
\text { container }\end{array}$ & SWLOADS & 10.0 \\
\hline & Stream 5 A3 (Heterogeneous Mercurv) & & \\
\hline $16(b)$. & $\begin{array}{l}\text { Close shredder feed hopper door, nitrogen } \\
\text { purge shredder and shred waste }\end{array}$ & SWSHRED & 16.0 \\
\hline 17(b). & $\begin{array}{l}\text { Load shredded material ( } 2 \text { drums) into mercury } \\
\text { evaporator, nitrogen purge, retort at } 450^{\circ} \mathrm{F} \text {, } \\
\text { cool to } 120^{\circ} \mathrm{F} \text { and unload evaporator }\end{array}$ & SWEVAP & $\begin{array}{c}330.0 \\
\text { (24 HOURS) }\end{array}$ \\
\hline 18(b). & $\begin{array}{l}\text { Delid product container, load evaporator } \\
\text { residue into product container and relid } \\
\text { container }\end{array}$ & SWLOADS & 10.0 \\
\hline 19(b). & $\begin{array}{l}\text { Generates elemental mercury (ELEMHG) from } \\
\text { mercury evaporator (1 bottle per } 12 \text { drums) }\end{array}$ & SWEVAP1 & NIL \\
\hline 20(b). & Amalgamate mercury in bottle & SWTREAT & 60.0 \\
\hline 21 (b). & $\begin{array}{l}\text { Delid product container, lower rack of bottles } \\
\text { into container, raise hoist and relid container }\end{array}$ & SWLOADT & 16.0 \\
\hline & $\begin{array}{l}\text { Stream 5A2 (Mercury Chemicals) and } \\
\text { Stream SWCT (5C2-Lead Chemicals and } \\
\text { 9C-Contained \& Absorbed Liavids }\end{array}$ & & \\
\hline 16(c). & $\begin{array}{l}\text { Generates } 14.375 \text { bottles of chemicals } \\
\text { (CHEMBOT) per drum of waste (from sorting } \\
\text { table) }\end{array}$ & SWCT1 & NIL \\
\hline
\end{tabular}


TABLE 8

SPECIAL WASTE

\begin{tabular}{|c|c|c|c|}
\hline $\begin{array}{l}\text { OPERATION } \\
\text { STEP NO. }\end{array}$ & OPERATIONAL STEP DESCRIPTION & $\begin{array}{l}\text { WITNESS } \\
\text { CODE }\end{array}$ & $\begin{array}{c}\text { TIME } \\
\text { (MINUTES) }\end{array}$ \\
\hline $17(c)$. & $\begin{array}{l}\text { Sample bottle contents at } 1 \text { of } 5 \text { parallel } \\
\text { sampling stations }\end{array}$ & $\begin{array}{l}\text { SWSAMPL1, } \\
\text { SWSAMPL2, } \\
\text { SWSAMPL3, } \\
\text { SWSAMPL4 AND } \\
\text { SWSAMPL5 }\end{array}$ & $\begin{array}{l}\text { 10.0 EACH } \\
\text { STATION }\end{array}$ \\
\hline $18(c)$. & $\begin{array}{l}\text { Store sampled bottles in sample storage for } 10 \\
\text { days while waiting for sample results }\end{array}$ & SWSTORIN & $\begin{array}{l}4200.0 \\
\text { (10 DAYS) }\end{array}$ \\
\hline $19(c)$. & $\begin{array}{l}\text { Deactivate and grout chemicals in bottles and } \\
\text { generate } 2 \text { bottles of treated chemicals } \\
\text { (TREATBOT) per bottle of untreated chemicals } \\
\text { in } 1 \text { of } 5 \text { parallel treating stations }\end{array}$ & $\begin{array}{l}\text { SWTREAT1, } \\
\text { SWTREAT2, } \\
\text { SWTREAT3, } \\
\text { SWTREAT4 AND } \\
\text { SWTREAT5 }\end{array}$ & $\begin{array}{l}\text { 60.0 EACH } \\
\text { STATION }\end{array}$ \\
\hline $20(c)$. & $\begin{array}{l}\text { Cure bottles in bottle storage for } 10 \text { days while } \\
\text { waiting for TCLP results }\end{array}$ & SWTCLP & $\begin{array}{c}4200.0 \\
\text { (10 DAYS) }\end{array}$ \\
\hline $21(c)$. & $\begin{array}{l}\text { Delid product container, lower rack of bottles } \\
\text { into container, raise roist and relid container }\end{array}$ & SWLOADT & 16.0 \\
\hline & Stream 5 A2 (Mercury Chemicals) & & \\
\hline $22(c)$. & $\begin{array}{l}\text { Close shredder feed hopper, nitrogen purge } \\
\text { shredder and shred waste }\end{array}$ & SWSHRED & 16.0 \\
\hline $23(c)$. & $\begin{array}{l}\text { Load shredded material ( } 2 \text { drums) into mercury } \\
\text { evaporator, nitrogen purge, retort at } 450^{\circ} \mathrm{F} \text {, } \\
\text { cool to } 120^{\circ} \mathrm{F} \text { and unload evaporator }\end{array}$ & SWEVAP & $\begin{array}{l}330.0 \\
\text { (24 HOURS) }\end{array}$ \\
\hline $24(c)$. & $\begin{array}{l}\text { Delid product container, load evaporator } \\
\text { residue into product container and relid } \\
\text { container }\end{array}$ & SWLOAD & 10.0 \\
\hline $25(c)$. & $\begin{array}{l}\text { Generates elemental mercury (ELEMHG) from } \\
\text { mercury evaporator (1 bottle per } 12 \text { drums) }\end{array}$ & SWEVAP1 & NIL \\
\hline $26(c)$. & Amalgamate mercury in bottle & SWTREAT & $\begin{array}{l}60.0 \\
\text { PER BOTTLE }\end{array}$ \\
\hline $27(c)$. & $\begin{array}{l}\text { Delid product container, lower rack of bottles } \\
\text { into container, raise hoist and relid container. } \\
\frac{\text { Stream SWCT (5C2-Lead Chemicals and }}{\text { 9c-Contained \& Absorbed Liquids) }}\end{array}$ & SWLOADT & 16.0 \\
\hline $22(d)$. & $\begin{array}{l}\text { Close shredder feed hopper, nitrogen purge } \\
\text { shredder and shred waste }\end{array}$ & SWSHRED & 16.0 \\
\hline
\end{tabular}


TABLE 8

SPECIAL WASTE

\begin{tabular}{|c|c|c|c|}
\hline $\begin{array}{l}\text { OPERATION } \\
\text { STEP NO. }\end{array}$ & OPERATIONAL STEP DESCRIPTION & $\begin{array}{l}\text { WITNESS } \\
\text { CODE }\end{array}$ & $\begin{array}{l}\text { TIME } \\
\text { (MINUTES) }\end{array}$ \\
\hline $23(d)$. & $\begin{array}{l}\text { Delid product container, load shredded material } \\
\text { into container and relid container }\end{array}$ & SWLOADS & 10.0 \\
\hline & Iranafer Product Containers to Vibre Grout & & \\
\hline 30. & $\begin{array}{l}\text { Transfer product containers containing } \\
\text { shredded material via conveyors to vibro grout } \\
\text { station }\end{array}$ & $\begin{array}{c}\text { CCON22A, } \\
\text { CCON23, } \\
\text { CCON24, } \\
\text { CCON26, } \\
\text { CCON28, } \\
\text { CCON29, } \\
\text { CCON30, } \\
\text { CCON31, } \\
\text { CCON32, CCON7, } \\
\text { CCON9 AND } \\
\text { CCON10 }\end{array}$ & VARIES \\
\hline 31. & $\begin{array}{l}\text { Transfer product container containing treated } \\
\text { chemicals (bottles) via conveyors to vibro grout } \\
\text { station }\end{array}$ & $\begin{array}{c}\text { CCON27A, } \\
\text { CCON28, } \\
\text { CCON29, } \\
\text { CCON30, } \\
\text { CCON31, } \\
\text { CCON32, CCON7, } \\
\text { CCON9 AND } \\
\text { CCON10 }\end{array}$ & VARIES \\
\hline & Vibre Grout Product Containers & & \\
\hline 32. & $\begin{array}{l}\text { Delid product container, fill product container } \\
\text { with grout, vibrate and lid product container }\end{array}$ & DVGROUT & 26.0 \\
\hline 33. & $\begin{array}{l}\text { Transfer vibro grouted product container to } \\
\text { cure storage (includes } 4 \text { minutes to clamp lid } \\
\text { on container on CCON 11) }\end{array}$ & $\begin{array}{l}\text { CCON11, } \\
\text { CCON30A, } \\
\text { CCON29A, } \\
\text { CCON28A, } \\
\text { CCON26A AND } \\
\text { CCON25 }\end{array}$ & VARIES \\
\hline 34. & $\begin{array}{l}\text { Cure vibro grouted product containers in cure } \\
\text { storage }\end{array}$ & CUREOUT & $\begin{array}{l}840.0 \\
\text { (2 DAYS) }\end{array}$ \\
\hline
\end{tabular}


TABLE 9

EMPTY DRUM COMPACTION AND LOADOUT

\begin{tabular}{|c|c|c|c|}
\hline $\begin{array}{l}\text { OPERATION } \\
\text { STEP NO. }\end{array}$ & OPERATIONAL STEP DESCRIPTION & $\begin{array}{l}\text { WITNESS } \\
\text { CODE }\end{array}$ & $\begin{array}{l}\text { TIME } \\
\text { (MINUTES) }\end{array}$ \\
\hline 1. & $\begin{array}{l}\text { Transfer empty drum via conveyor from debris } \\
\text { relid station (DRELID) to transfer car }\end{array}$ & C5 & 0.5 \\
\hline 2. & $\begin{array}{l}\text { Transfer empty drum via conveyor from } \\
\text { sludge/particulate relid station (PSRELID) to } \\
\text { transfer car }\end{array}$ & C8 & 0.5 \\
\hline 3. & $\begin{array}{l}\text { Transfer empty drum via conveyor from special } \\
\text { waste relid station (SWRELID) to transfer car }\end{array}$ & $\mathrm{C} 12$ & 0.5 \\
\hline 4. & $\begin{array}{l}\text { Transfer empty drum via transfer car to empty } \\
\text { drum compactor }\end{array}$ & TRANSCAR & VARIES \\
\hline 5. & $\begin{array}{l}\text { Compact empty drum and place in product } \\
\text { container }\end{array}$ & ECOMPACT & 7.0 \\
\hline 6." & $\begin{array}{l}\text { Transfer empty product container via conveyor } \\
\text { to container elevator }\end{array}$ & CCON8 & 1.333 \\
\hline 7. & $\begin{array}{l}\text { Transfer empty product container via elevator } \\
\text { to load-out level }\end{array}$ & ELEV4 & VARIES \\
\hline 8. & Delid, relid and clamp product container & PUCKLOAD & 10.0 \\
\hline 9. & $\begin{array}{l}\text { Transfer full product container via conveyor } \\
\text { from loadout level to grade }\end{array}$ & ELEV4 & VARIES \\
\hline 10. & $\begin{array}{l}\text { Transfer full product container via conveyor to } \\
\text { temporary storage }\end{array}$ & $\begin{array}{c}\text { CCON8A, } \\
\text { CCON9, CCON12, } \\
\text { CCON15, } \\
\text { CCON18, } \\
\text { CCON21, } \\
\text { CCON23, } \\
\text { CCON24 AND } \\
\text { CCON25 }\end{array}$ & VARIES \\
\hline 11. & $\begin{array}{l}\text { Store full product container temporarily for } \\
\text { transfer to W112 }\end{array}$ & TEMPSTOR & 30.0 \\
\hline
\end{tabular}

- See Table 5 for Product Container Transfers 
TABLE 10

BOX BREAKDOWN - DRUM TRANSFERS

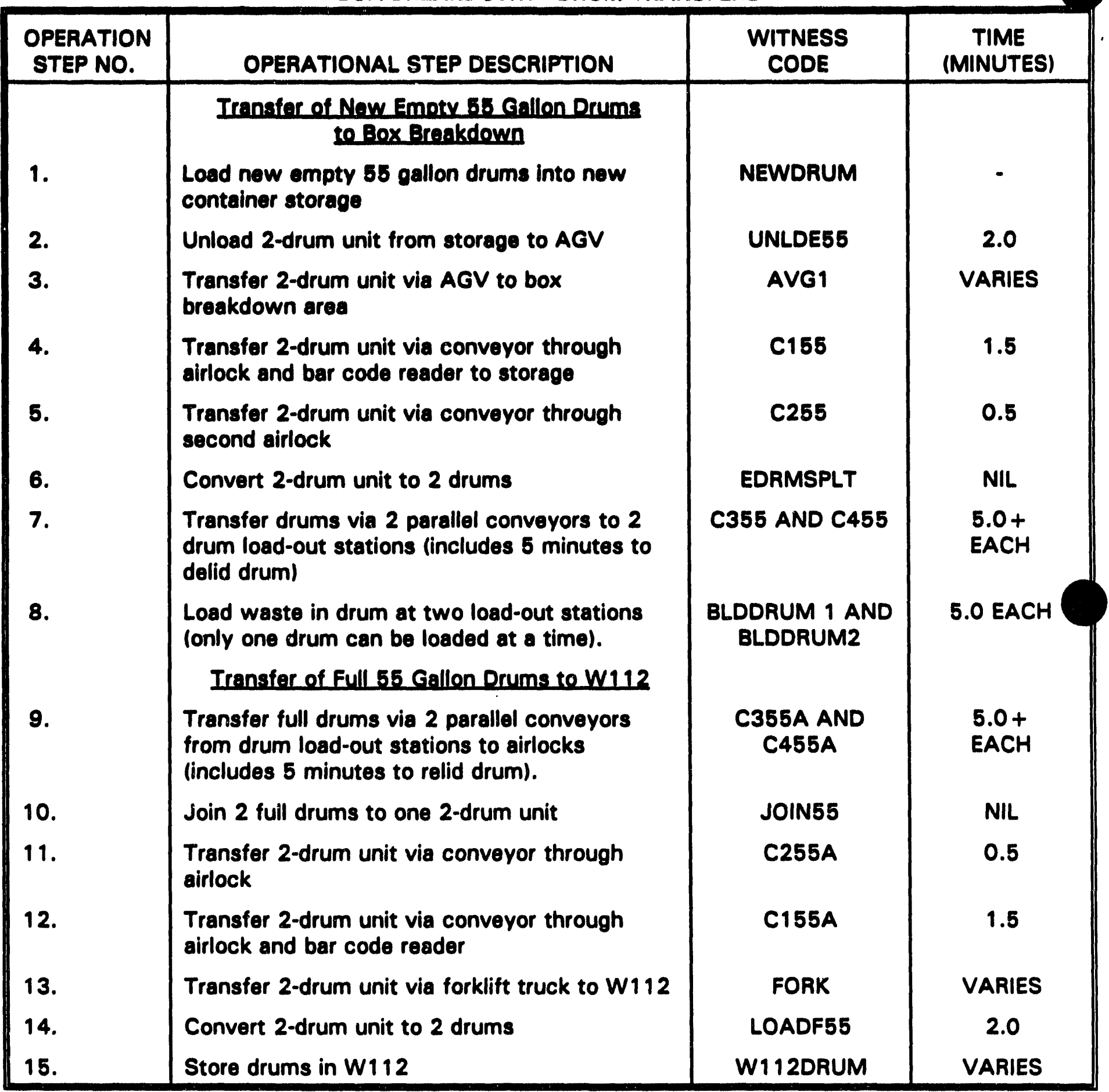


TABLE 10

BOX BREAKDOWN - BOXES

[Boxes Containing Dobris (DVOBOX) and

Sludge/Particulate (SPOBOX)]

\begin{tabular}{|c|c|c|c|}
\hline $\begin{array}{l}\text { OPERATION } \\
\text { STEP NO. }\end{array}$ & OPERATIONAL STEP DESCRIPTION & $\begin{array}{l}\text { WITNESS } \\
\text { CODE }\end{array}$ & $\begin{array}{l}\text { TIME } \\
\text { (MINUTES) }\end{array}$ \\
\hline & BOXes (DVGBOX and SPGBOX) & & \\
\hline 1. & Load boxes into W112 & w11280x & - \\
\hline 2. & Unload box from W1 12 to forklift truck & UNLOADBX & 2.0 \\
\hline 3. & $\begin{array}{l}\text { Transfer box via forklift truck to box } \\
\text { breakdown area }\end{array}$ & FORK & VARIES \\
\hline 4. & $\begin{array}{l}\text { Transfer box via conveyor through airlock and } \\
\text { bar code reader }\end{array}$ & CBOX1 & 2.0 \\
\hline 5. & $\begin{array}{l}\text { Transfer box via conveyor through second } \\
\text { airlock }\end{array}$ & $\mathrm{CBO} \times 2$ & 1.0 \\
\hline 6. & $\begin{array}{l}\text { Transfer box via conveyor into box breakdown } \\
\text { cell }\end{array}$ & CBOX3 & 0.333 \\
\hline & Boxes Containing Debris (DVGBOX) & & \\
\hline 7. & $\begin{array}{l}\text { Remove box lid and size reduce box exterior. } \\
\text { (Generates } 30 \text { drums of waste (including box } \\
\text { contents) to be repacked in new empty } 55 \\
\text { gallon drums) }\end{array}$ & BOXBREAK & 90.0 \\
\hline 8.• & $\begin{array}{l}\text { Load waste in drums at two load-out stations } \\
\text { (only one drum can be loaded at a time). }\end{array}$ & $\begin{array}{l}\text { BLDDRUM1 AND } \\
\text { BLDDRUM2 }\end{array}$ & $\begin{array}{l}5.0 \\
E A C H\end{array}$ \\
\hline & Boxes Containing Sludge/Particulate (SPGBOX) & & \\
\hline $7(a)$. & $\begin{array}{l}\text { Remove box lid and size reduce box exterior. } \\
\text { (Generates } 22 \text { drums of waste (including box } \\
\text { contents) to be repacked in new empty } 55 \\
\text { gallon drums) }\end{array}$ & BOXBREAK & 90.0 \\
\hline 8(a). & Shred box contents & BBSHRED & $\begin{array}{l}\text { 5.0 PER } \\
\text { DRUM } \\
\text { EQUIVALENT }\end{array}$ \\
\hline 9(a). & $\begin{array}{l}\text { Load waste in drums at two load-out stations } \\
\text { (only one drum can be loaded at a time). }\end{array}$ & $\begin{array}{l}\text { BLDDRUM1 AND } \\
\text { BLDDRUM2 }\end{array}$ & $\begin{array}{l}5.0 \\
E A C H\end{array}$ \\
\hline
\end{tabular}

- See Table 10 Box Breakdown - Drum Transfers 
TABLE 10

BOX BREAKDOWN - PRODUCT CONTAINERS

(Includes falled product containars and product comtainors undergoing destructive examination)

\begin{tabular}{|c|c|c|c|}
\hline $\begin{array}{l}\text { OPERATION } \\
\text { STEP NO. }\end{array}$ & OPERATIONAL STEP DESCRIPTION & $\begin{array}{l}\text { WITNESS } \\
\text { CODE }\end{array}$ & $\begin{array}{c}\text { TIME } \\
\text { (MINUTES) }\end{array}$ \\
\hline & Produat Containars (FAlLPAOD) & & - \\
\hline 1. & Load product containers into W1 12 & W112Box & $\cdot$ \\
\hline 2. & $\begin{array}{l}\text { Unload product containers from W112 to } \\
\text { forklift truck }\end{array}$ & UNLOADBOX & 2.0 \\
\hline 3. & $\begin{array}{l}\text { Transfer product container via forklift truck to } \\
\text { box breakdown area }\end{array}$ & FORK & VARIES \\
\hline 4. & $\begin{array}{l}\text { Transfer product container via conveyor } \\
\text { through airlock and bar code reader }\end{array}$ & CBOX1 & 2.0 \\
\hline 5. & $\begin{array}{l}\text { Transfer product container via conveyor } \\
\text { through second airlock }\end{array}$ & CBOX2 & 1.0 \\
\hline 6. & $\begin{array}{l}\text { Transfer product container via conveyor into } \\
\text { box ureakdown cell }\end{array}$ & CBOX3 & 0.333 \\
\hline 7. & $\begin{array}{l}\text { Remove product container lid and size reduce } \\
\text { container contents and exterior }\end{array}$ & BOXBREAK & $\begin{array}{l}330.0 \\
(1 \text { SHIFT) }\end{array}$ \\
\hline 8.• & $\begin{array}{l}\text { Load waste in drums at two load-out stations } \\
\text { (only one drum can be loaded at a time) }\end{array}$ & $\begin{array}{l}\text { BLELRUM1 AND } \\
\text { BLDDRUM2 }\end{array}$ & $\begin{array}{c}5.0 \\
\text { PER DRUM }\end{array}$ \\
\hline
\end{tabular}

- See Table 10 Box Breakdown - Drum Transfers 
TABLE 10

BOX BREAKDOWN - OVERPACKED DRUMS

\begin{tabular}{|c|c|c|c|}
\hline $\begin{array}{l}\text { OPERATION } \\
\text { STEP NO. }\end{array}$ & OPERATIONAL STEP DESCRIPTION & $\begin{array}{c}\text { WITNESS } \\
\text { CODE }\end{array}$ & $\begin{array}{c}\text { TIME } \\
\text { (MINUTES) }\end{array}$ \\
\hline & Overnacked Drums (OVERPACK) & & \\
\hline 1. & Load drums into W112 & W11280X & - \\
\hline 2. & Unload 2-drum unit from W112 to forklift truck & UNLOADBX & 2.0 \\
\hline 3. & $\begin{array}{l}\text { Transfer } 2 \text {-drum unit via forklift truck and box } \\
\text { breakdown area }\end{array}$ & FORK & VARIES \\
\hline 4. & $\begin{array}{l}\text { Transfer 2-drum unit via conveyor through } \\
\text { airlock and bar code reader }\end{array}$ & CBOX1 & 2.0 \\
\hline 5. & $\begin{array}{l}\text { Transfer 2-drum unit via conveyor through } \\
\text { second airlock }\end{array}$ & CBOX2 & 1.0 \\
\hline 6. & $\begin{array}{l}\text { Transfer } 2 \text {-drum unit via conveyor into box } \\
\text { breakdown cell }\end{array}$ & CBOX3 & 0.333 \\
\hline 7. & $\begin{array}{l}\text { Convert 2-drum unit into } 2 \text { drums and delid } \\
\text { both drums (one drum at a time) }\end{array}$ & OVERSPLT & 10.0 \\
\hline 8. & $\begin{array}{l}\text { Convert } 100 \text { overpacked drums into } 232 \\
\text { drums of material suitable for repacking in new } \\
\text { empty } 55 \text { gallon drums }\end{array}$ & $\begin{array}{l}\text { DRUMLD1 AND } \\
\text { DRUMPACK }\end{array}$ & $\begin{array}{l}120.0 \text { PER } \\
\text { OVERPACK }\end{array}$ \\
\hline 9.• & $\begin{array}{l}\text { Load material into drums at two load-out } \\
\text { stations (only one drum can be loaded at a } \\
\text { time) }\end{array}$ & $\begin{array}{l}\text { BLDDRUM1 AND } \\
\text { BLDDRUM2 }\end{array}$ & $\begin{array}{l}\text { 5.0 PER } \\
\text { DRUM }\end{array}$ \\
\hline
\end{tabular}

- See Table 10 Box Breakdown - Drum Transfers 
TABLE 10

BOX BAEAKDOWN - OVEAWEIOHT DAUMS

\begin{tabular}{|c|c|c|c|}
\hline $\begin{array}{l}\text { OPERATION } \\
\text { STEP NO. }\end{array}$ & OPERATIONAL STEP DESCRIPTION & $\begin{array}{l}\text { WITNESS } \\
\text { CODE }\end{array}$ & $\begin{array}{l}\text { TIME } \\
\text { (MINUTES) }\end{array}$ \\
\hline & Ovarwaiaht Drume (Stream BCy) & & \\
\hline 1. & Load drums into W112 & W11280X & $\cdot$ \\
\hline 2. & $\begin{array}{l}\text { Unload one drum at a time (assumed to be } \\
1460 \text { lbs esch) from W112 to forklitt truck }\end{array}$ & UNLOADBX & 2.0 \\
\hline 3. & $\begin{array}{l}\text { Transfer overweight drum via forklift truck to } \\
\text { box breakdown area }\end{array}$ & FORK & VARIES \\
\hline 4. & $\begin{array}{l}\text { Transfor drum via conveyor through airlock and } \\
\text { bar code reader }\end{array}$ & CBOX1 & 2.0 \\
\hline 5. & $\begin{array}{l}\text { Transfer drum via conveyor through second } \\
\text { airlock }\end{array}$ & CBOX2 & 1.0 \\
\hline 6. & $\begin{array}{l}\text { Transfer drum via conveyor to box breakdown } \\
\text { cell }\end{array}$ & CBOX & 0.333 \\
\hline 7. & $\begin{array}{l}\text { Convert drum into } 2 \text { "exterior pieces" that will } \\
\text { be repacked into drums }\end{array}$ & OVERSPLT & 10.0 \\
\hline 8. & $\begin{array}{l}\text { Convert each drum into two "interior (drum } \\
\text { contents) pieces". (Includes time to load } \\
\text { product container) }\end{array}$ & DRUMSC1 & $\begin{array}{l}\text { 60.0 PER } \\
\text { "EXTERIOI } \\
\text { PIECE" }\end{array}$ \\
\hline 9.• & $\begin{array}{l}\text { Transfer new empty product container via } \\
\text { conveyors to box breakdown load-out }\end{array}$ & $\begin{array}{l}\text { CCON4 AND } \\
\text { CCON5 }\end{array}$ & VARIES \\
\hline 10. & $\begin{array}{l}\text { Delid and relid product container } 15 \text { "interior } \\
\text { pieces of lead" are loaded into one product } \\
\text { container) }\end{array}$ & BOXLDCON & 6.0 \\
\hline 11. & $\begin{array}{l}\text { Transfer filled product container vis conveyors } \\
\text { to vibro grout station }\end{array}$ & $\begin{array}{c}\text { CCON5A, } \\
\text { CCON4A, } \\
\text { CCON6, CCON7, } \\
\text { CCON9 AND } \\
\text { CCON10 }\end{array}$ & VARIES \\
\hline 12. & $\begin{array}{l}\text { Delid product container, fill product container } \\
\text { with grout, vibrate and relid product container }\end{array}$ & DVGROUT & 26.0 \\
\hline
\end{tabular}

- See Table 5 for Product Container Transfers 
TABLE 10

DOX BAEAKDOWN - OVEAWEIOHT DAUMS

\begin{tabular}{|c|c|c|c|}
\hline $\begin{array}{l}\text { OPERATION } \\
\text { STEP NO. }\end{array}$ & OPERATIONAL STEP DESCRIPTION & $\begin{array}{l}\text { WITNESS } \\
\text { CODE }\end{array}$ & $\begin{array}{l}\text { TIME } \\
\text { (MINUTES) }\end{array}$ \\
\hline 13. & 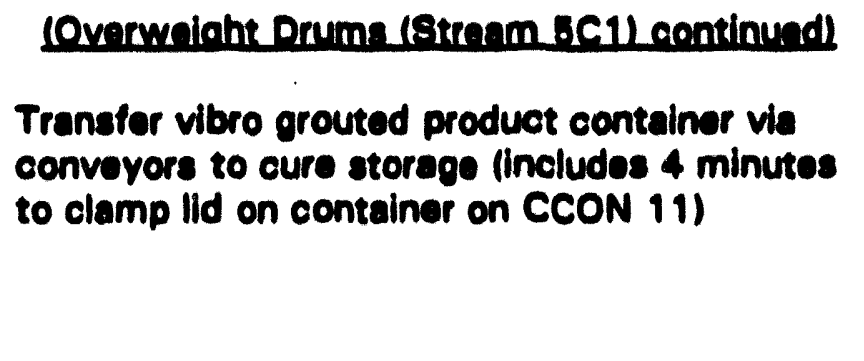 & $\begin{array}{l}\text { CCON11, } \\
\text { CCON3OA, } \\
\text { CCON29A, } \\
\text { CCON28A, } \\
\text { CCON26A AND } \\
\text { CCON2S }\end{array}$ & VARIES \\
\hline 14. & $\begin{array}{l}\text { Cure vibro grouted product containers in cure } \\
\text { atorage }\end{array}$ & CUREOUT & $\begin{array}{l}840.0 \\
\text { (2 DAYS) }\end{array}$ \\
\hline $15 .^{\circ}$ & $\begin{array}{l}\text { Load "exterior pieces" into drums at two load- } \\
\text { out atations (5 "oxterior ploces" are loaded into } \\
\text { one empty } 58 \text { gallon drum) }\end{array}$ & $\begin{array}{l}\text { LDRMBC11 AND } \\
\text { LDRMBC12 }\end{array}$ & 5.0 EACH \\
\hline
\end{tabular}

- See Table 10 Box Breakdown - Drum Transfers 


\subsection{MODIL RESULTS}

1. The WITNESS Model (W2AACDR.MOD) for the WRAP 2A plant was run for four modes of operation: (1) Dobris-Vibro Grout in parallel with sludge Particulare-Agitated Grout, (2) Debris-Vibro Crout in parallel with Polyothylene Extrusion, (3) Spocial Waste and (4) Box Breakdown. The results for the first two modes of operation are given below in Tablo 11.

\section{TAOLE 11}

WRAP 2 A WTHEs Model Rosutiv for Parallel Operation of Debols and Sludge/Partoulate Proceseing Unas

\begin{tabular}{|c|c|c|c|c|}
\hline & \multirow{2}{*}{$\begin{array}{c}\text { FDC/BDAD } \\
\text { BEOUIREMFNTS } \\
\text { CENEAR }\end{array}$} & \multicolumn{2}{|c|}{ WITNFSS MODFLRFSULTS } & \multirow{2}{*}{$\begin{array}{c}\text { PEACENT OF } \\
\text { FDC/SDAD } \\
\text { REOUUREMFNTS }\end{array}$} \\
\hline & & CENEAR & DAUMSNYEAR & \\
\hline Debris-Vibro Grout & 11,600 & 16,824 & 2287 & $146 \%$ \\
\hline $\begin{array}{l}\text { Sludge/Particulate- } \\
\text { Grout }\end{array}$ & 17.400 & 18.974 & 2564 & $109 \%$ \\
\hline TOTALS & 29.000 & 38,898 & 4851 & $124 \%$ \\
\hline Debris-Vibro Grout & 11,600 & 16,924 & 2287 & $146 \%$ \\
\hline $\begin{array}{l}\text { Sludge/Particulate- } \\
\text { Polyethylene }\end{array}$ & 17.400 & 18.974 & 2564 & $109 \%$ \\
\hline TOTALS & 29.000 & 35,898 & 4881 & $124 \%$ \\
\hline
\end{tabular}

2. For parallel operations of the Debris-Vibro Grout line and the Sludge/Particulate line using Agitated Grout, the model predicts that the Debris line can process 16,924 CF per year of waste while the Sludge/Particulate line can process 18,974 Ci per year. These estimates exceed the FDC/SDRD requirements of 11,600 CF per year for the Debris line and 17,400 CF per year for the Sludge/Particulate line.

3. Likewise, for parallel operations of the Debris-Vibro Grout line and the Sludge/Particulate line using Polyethylene Extrusion, the model predicts that the Debris line can process 16,924 CF per year of waste while the Sludge/Particulate line can process 18,974 CF per year. These model runs show no difference in predicted flow rates, indicating the primary factor in determining the maximum throughput for each processing line is the method of inputting drums into the processing line the method is identical for both lines) and not the processing steps within each line. Also, the model runs indicate that the operation of the Debris line does not influence the throughput of the Sludge/Particulate line and vice versa. 
4. In prelliminary model runs, operation of the Sludge/Particulate line for $\mathbf{5 . 5}$ hours per shift with the Polyethylene Extruder indicated that this processing scheme could only process about 18,000 CF per year of waste, or about 87 percent of the FDC/SDRD requirement. At first, it was felt that the polyethylene extruder was the bottleneck in this processing line, and indeed, throughput could be mot (18,850 CF par year) if the time to operate the extruder was increased from 3.5 to 7.0 hours. However, after more detailed analyais it was dotermined that the dryer time of 30 minutes per drum was also limiting production. Consequantiy, after some trial and error runs, the dryer size was increased to hold 2 drums at a time and the drying time for exch 2 drum batch was increased to 40 minutes. This had a significant effect on increasing throughput for the Sludge/Particulate line and consequently became the basis for the present dryer design. The throughput was obtained by keeping the operating time for the Polyethylene Extruder at 5.5 hours.

b. In the Sludge/Particulate line when operating with Agitated Grout, throughputs were obtained by operating the grout equipment for only 5.0 hours per shift. This was done to simulate the need to stop the grout equipment 30 minutes before the end of a shift to allow for cleaning of the grout equipment to prevent buildups of grout deposits on the walls of the equipment.

6. In the Special Waste area, a slightly different approach was used to compare model results with FDC/SDRD requirements. Here, a specified number of operating shifts were allowed for each of three types of Special Waste: 5A1 - Elemental Mercury, 5A3 Heterogeneous Mercury and a combination of 5A2, 5C2 and 9C Streams representing Mercury and Lead Chemicals and Contained and Absorbed Liquids. A comparison of the FDC/SDRD time requirements with the WITNESS Model results is shown in Table 12. For Stream 5A1 - Elemental Mercury, the WITNESS Model predicts a processing time of 9.4 shifts compared to the 12 shifts allowed by the FDC and SDRD. For Stream 5A3 Heterogeneous Mercury, the WITNESS Model predicts a processing time of 38.4 ehifts compared to the 50 shifts allowed by the FDC and SDRD. For the combined Streams 5 A2 - Mercury Chemicals, 9C2 - Lead Chemicals and 9C - Contained and Absorbed Liquids the FDC/SDRD allowed 113 operating shifts while the WITNESS model predicted 114.3 shifts are needed to sample and treat all bottles of liquid waste. If the time for all TCLP results is included, the time increases to 124.4 shifts. These model predictions are based on using five combination sampling/treating stations, where only sampling or only treating can take place at any given time. If four combination sampling/treating stations are used, the WITNESS model predicts a campaign time of 140.6 shifts to process bottles of liquid waste. 


\section{STREAMNO.}

5A1 Elemental Mercury

5 A3 Heterogeneous Mercury

5 A2 Mercury

Chemicals

and

Stream SWCT 19C2 - Lead Chemicals \& 9C - Contained \& Absorbed Liquids) TOTALS
TABLE 12

WRAP 2 A WTINESS Modd Reaults for Specid Weste Processing Line

\section{OPERATING SHIFTS PER CAMPAIGN}

\section{WASTE VOLUME CFNEAR}

130

560

80

1185

1955

\section{WASTE CONTAINERS DRUMSTYEAR}

18

76

11
WITNESS
EDC/SDRD REOUIREMENTS

12

50

38.4

9.4
MODEL

RESULTS

162

267

175

162.1

$\bullet$

Assumes:

All bottles of liquid waste have been sampled and treated, but are still waiting for TCLP results. If the time for all TCLP results is included, the operating time for Contained and Absorbed Liquids is predicted by the model to be 124.4 shifts. The model predicts 24.0 bottles per shift can be processed in the Special Waste area assuming 5 dual sampling/treating stations are used. If 4 dual sampling/treating stations are used, the model predicts 19.2 bottles per shift can be processed in a campaign time of $\mathbf{1 4 0 . 6}$ shifts. 
7. In the Box Breakdown Area, an approach similar to Special Waste was used to compare FDC/SDRD time requirements for five types of feed streams with results from the WITNESS Model. This comparison is shown in Table 13. For the two box streams containing Debris (DVGBOX) and Sludge/Particulate (SPGBOX), about 1.5 shifts per box were targeted per box. For the box stream containing Debris (30 Boxes per year), the WITNESS Model predicted an operating time of 40.0 shifts, or about 5 shifts less than the target of 45 shifts. For the box stream containing Sludge/Particulate (10 Boxes per year), the WITNESS Model predicted an operating time of 10.7 shifts, or about 4.3 shifts less than the target of 15 shifts. About 90 minutes were allowed to break open a box and size reduce the box exterior once the box was emptied. About 15 minutes were allowed per drum to delid, fill and relid a drum. Delidding and relidding were assumed to take place simultaneously at the two drum load-out stations, but only one drum at a time could be filled.

8. For the combined stream (FAILPROD) which contains failed product containers (12 per year) and product containers undergoing destructive examination (12 per year) being processed in the Box Breakdown area, about 2.0 shifts per product container were assumed to be needed for processing, or a total of 48 shifts. The WITNESS Model predicted about 36.0 shifts to process the product containers, or about 12.0 shifts less than the target amount. One shift was allowed in the model to breakdown and shred a product container, with the remaining time spent in repacking the waste in $\mathbf{5 5}$ gallon drums and transporting these drums to W112.

9. Overpacked $\mathbf{5 5}$ gallon drums in $\mathbf{8 5}$ gallon drums (OVERPACK) are also processed in the Box Breakdown Area. Two overpacked drums per day were assumed to be handled in the Box Breakdown area. For the annual requirement of 100 drums, the WITNESS Model predicts 49.6 days are required to process the drums or an almost exact agreement with the target of $\mathbf{5 0}$ days. The model was set up assuming two overpacked drums at a time could be delivered to the Box Breakdown area. A processing time of 2 hours per overpacked drum was used in the model, plus the time to repack the waste in new empty 55 gallon drums. The processing time also includes the time to size reduce the feed 55 gallon and $\mathbf{8 5}$ gallon drums and repack them in new $\mathbf{5 5}$ gallon drums.

10. Finally, 10 overweight drums (containing lead) per year are also processed in the Box Breakdown area. Two overweight drums per day were also expected to be processed in this area. The WITNESS model predicts that 4.3 days are required to process this waste, or slightly less than the 5 days that were targeted. Again, about 2 hours were assumed in the model to process each drum (which includes the time to size reduce the feed drum), plus the time to repack the waste in product containers and size reduce the feed drums and repack them in new empty $\mathbf{5 5}$ gallon drums. Overweight drums were assumed to weigh 1460 pounds, which is the maximum expected. About four product containers (maximum load weight of 4400 pounds) and 4-55 gallon drums are assumed to be filled by the 10 overweight drums.

11. The annual production rates of product containers and repacked 55 gallon drums is shown in Table 14. When the Debris-Vibro Grout line is operated in parallel with the Sludge/Particulate line using Agitated Grout, the WITNESS Model predicts 1539 Product Containers and 128 repacked 55 gallon drums (particulate from the debris line) are produced. This includes 220 product containers used to hold compacted empty drums (each product container was assumed to hold 22 compacted drums). When the DebrisVibro Grout line is operating in parallel with the Sludge/Particulate line using the Polyethylene Extruder, the WITNESS model predicts 980 product containers and 128 repacked 55 gallon drums are produced. Again, this includes 220 product containers filled with compacted drums. 
TABLE 13

WRAP $2 A$ WITNESS Model Result for Box Breakdown Area

\section{CAMPAIGN}

Stream DVGBOX

(Dobris in Boxes)

Stream SPGBOX

(Sludge/Particulate in Boxes)

Stream FAILPROD

(Failed Product Containers

and Product Containers for

Destructive Examination)

Stream OVERPACK

(Overpacked 55 Gallon

Drums in 85 Gallon Drums)

Stream $5 \mathrm{C1}$

(Overweight Drums

Containing Lead)

\section{CONTAINERSNFAR}

30 Boxes

10 Boxes

24 Product Containers

100 Drums

10 Drums

TOTALs

Contingent Shifts

TOTAL SHIFTS PER YEAR
OPERATING SHIFTS PER CAMPAIGN

PRO.JECTED

45

WITNESS MODEL.

BESULTS

40.0

15

10.7

48

36.0

50

49.6

\section{3}

140.6

163

34.4

175.0 
TABLE 14

WRAP $2 A$ WITNESS Model Results for Annual Production of Product Containere and Repacked Drums

Debris-Vibro Grout

Sludge/Particulate - Grout

Compacted Empty Drums

Debris-Vibro Grout

Sludge/Particulate - Polyethylene

Compacted Empty Drums

\section{SPECIAL WASTE}

Stream 5A1 Elemental Mercury Stream 5 A3 Heterogeneous Mercury

Stream 5 A2 Mercury Chemicals Stream SWCT 15C2- Lead Chemicals and 9C - Contained \& Absorbed Liquids)

Compacted Empty Drums

BOX BREAKDOWN

Debris in Boxes (DVGBOX)

Sludge/Particulate in Boxes (SPGBOX)

Failed \& Dest. Exam. Product Containers (FAILPROD)

Overpacked Drums (OVERPACK)

Overweight Drums (5C1)
TOTALS

PRODUCT CONTAINERSNFAR 282 1037 220

TOTALS

TOTALS

TOTALS

1639

282

478

220

980

Shredded Material \& Compacted Drums

3

10

2

18

$\frac{12}{45}$

PRODUCT CONTAINERS NEAR

\section{PRODUCT CONTAINERSMEAR}

Ireated Bottles

1 (Amalgamated Mercury)

26 (Treated Chemicals)

27

REPACKED 55 GALLON DRUMSNEAR

$\begin{array}{cc}-. & 900 \\ -. & 220 \\ \ldots & 336 \\ 4 & 232 \\ 4 & \frac{4}{1692}\end{array}$


12. The WITNESS model predicts that $\mathbf{7 2}$ product containers are produced annually when the Special Waste enclosure is operating. This includes about 33 product containers holding shredded packing material or shredded material that has been processed in the Mercury Evaporator. One product container was assumed to hold 50 bottles of amalgamated mercury and 26 product containers were predicted to hold bottles of treated (deactivated and immobilized) chemicals. Each product container was assumed to hold 196 bottles of treated chemicals. Twelve product containers containing compacted drums were also produced.

13. In the Box Breakdown area, only 4 product containers were produced (repacked lead from overweight drums) and 1692 repacked 55 gallon drums. Of these drums, 900 drums were produced from repacking boxes containing debris, 220 drums were produced from repacking boxes containing sludge/particulate, 336 drums were produced from reprocessed failed product containers and product containers undergoing destructive examination, 232 drums were produced from repacking of overpacked drums and 4 drums were produced from repacking of size reduced drums that were overweight.

14. The estimated size of the cure storage area for grout or polyethylene encapsulated waste and for sampled and treated bottles in the Special Waste enclosure is shown in Table 15. Two scenarios are presented for the worst case situations in cure storage:

Scenario A: Debris-Vibro Grout and Sludge/Particulate using Agitated Grout are operating in parallel plus both Special Waste and Box Breakdown are operating.

In this scenario, based on the WITNESS model predictions for product containers generated by the WRAP $2 A$ plant, an average of 15.81 product containers should be in cure storage at any given time. The WITNESS model predicts an average of 15.73 product containers and a maximum of 21 product containers.

Scenario B: Debris-Vibro Grout and Sludge/Particulate using the Polyethylene Extruder are operating in parallel plus both Special Waste and Box Breakdown are operating.

In this scenario, an average of $\mathbf{9 . 4 3}$ product containers should be in cure storage at any given time. The WITNESS Model predicts an average of 9.37 product containers and a maximum of 13 product containers.

15. In the Special Waste Enclosure, sampled bottles are stored for 10 days waiting for laboratory results. An average of 142 sampled bottles are expected at any given time based on a total of 2487 sampled bottles. The WITNESS Model predicts an average of 219 bottles and a maximum of 498 bottles. This discrepancy is caused by the bottles having a predicted storage time of 15.4 days versus 10 days. The increased storage time is caused by the difference in sampling time (10 minutes) compared to treatment time 160 minutes) per bottle of waste. It should be noted that each of the five sampling/treatment stations is operated by one operator, meaning that either sampling or treating can take place at any given time, but not both.

16. The calculated average storage time for treated bottles (stored for 10 days while waiting for TCLP results) is 284 bottles, based on a total of 4974 treated bottles (double the number of untreated, sampled bottles). The WITNESS Model predicts an average of 284 bottles and a maximum of 510 bottles for this storage area. 
TABLE 15

WRAP 2A WITNEsS Model Predictions

Of Product Container and Special Waste (Bottles) Storage Requirements

\section{CURE STORACE (2 DAYs Storage)}

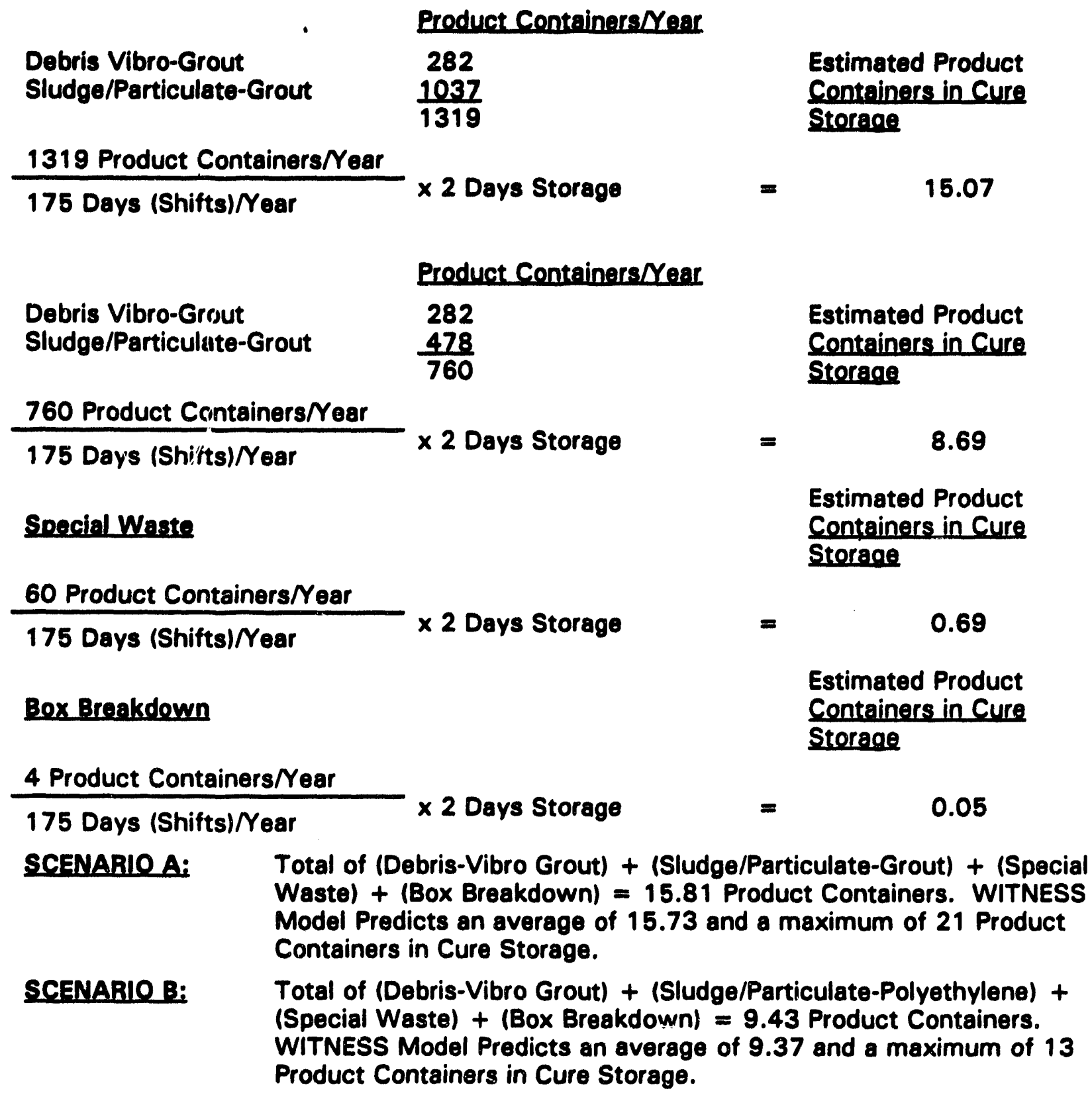


TABLE 15

WRAP 2A WITNESS Model Predictions

Of Product Container and Special Waste (Bottles) Storage Requirements

TEMPORARY STORACE FOR

PRODUCT CONTANERS CONTANINC COMPACTED EMPTY DRUMS

\begin{tabular}{|c|c|c|c|}
\hline ' & & Estimated & $\begin{array}{l}\text { Product Containers in } \\
\text { Iemporary Storage }\end{array}$ \\
\hline $\begin{array}{l}\text { 232 Product Containers Year } \\
175 \text { Days (Shifts)/Year }\end{array}$ & $x$ & $\frac{30 \text { Minutes }}{420 \text { Minutes/Day }}$ & 0.09 \\
\hline
\end{tabular}

WITNESS Model predicts an average of 0.10 and a maximum of 1 product Container in Temporary Storage.

SPECIAL WASTE

Storage of Sampled Bottles 2487 Bottles/ear
Estimated Sampled

Bottles in Storaoe

X 10 Days Storage

284 Sampled Bottles

WITNESS Model predicts an average of 219 and a maximum of 498 Sampled bottles in Storage.•

Storage of Treated Bottles Awaiting TCLP Results

4974 Bottles/Year..

175 Days (Shifts) Year

$=284$ Sampled Bottles

WITNESS Model predicts an average of 284 Treated Bottles and a maximum of 510

Treated Bottles in Storage.

The reason for the difference between the calculated average of 142 sampled bottles in storage versus the WITNESS Model prediction of 179 sampled bottles is that the sampled bottles actually average about 15.4 days in storage. This extra 5.4 days is caused by the sampled bottles having to wait for an available treatment station, since the sampling time of 10 minutes per bottle is less than the treatment time of 60 minutes por bottle.

-. The number of treated bottles is assumed to be twice the number of untreated bottles. 


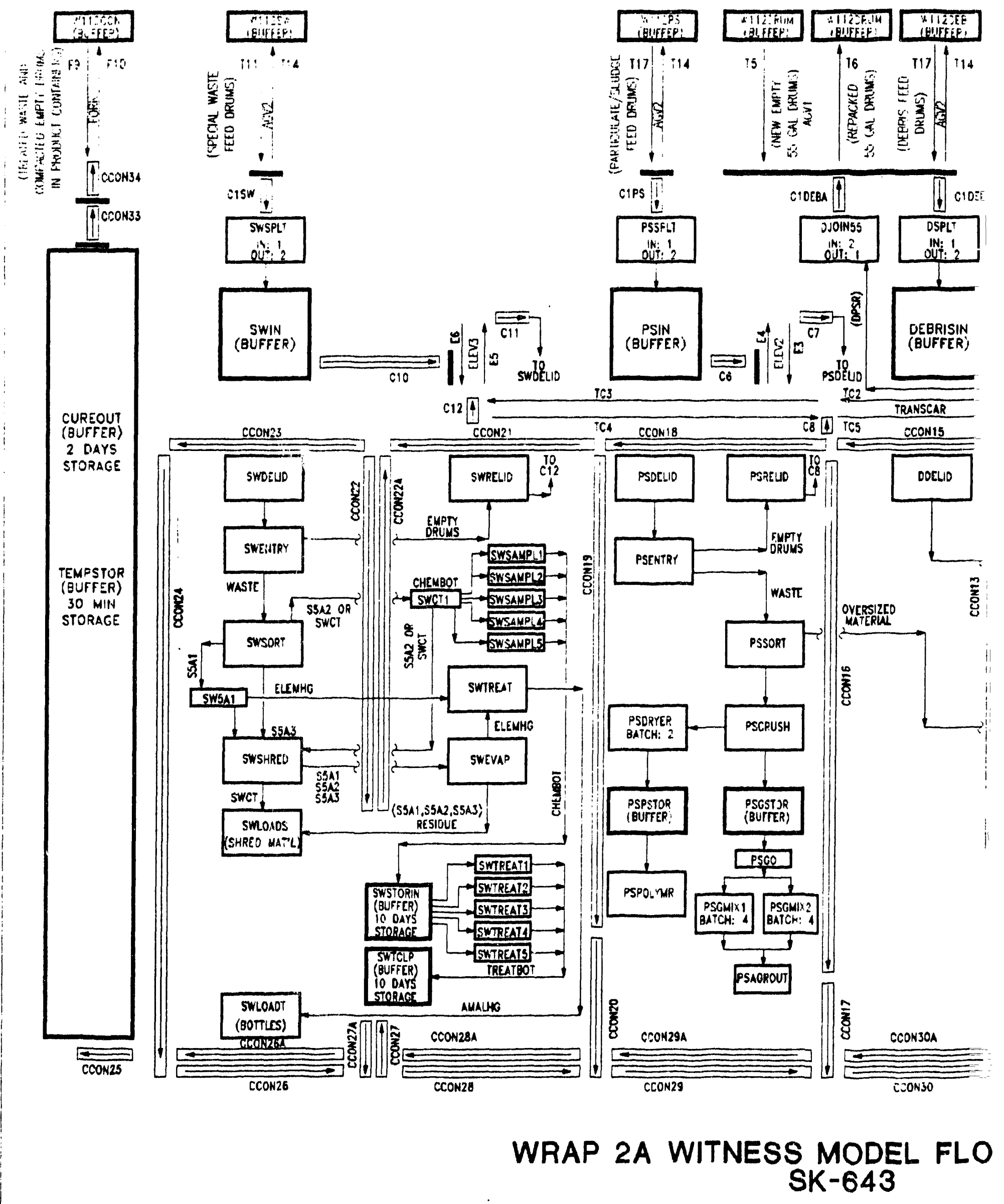



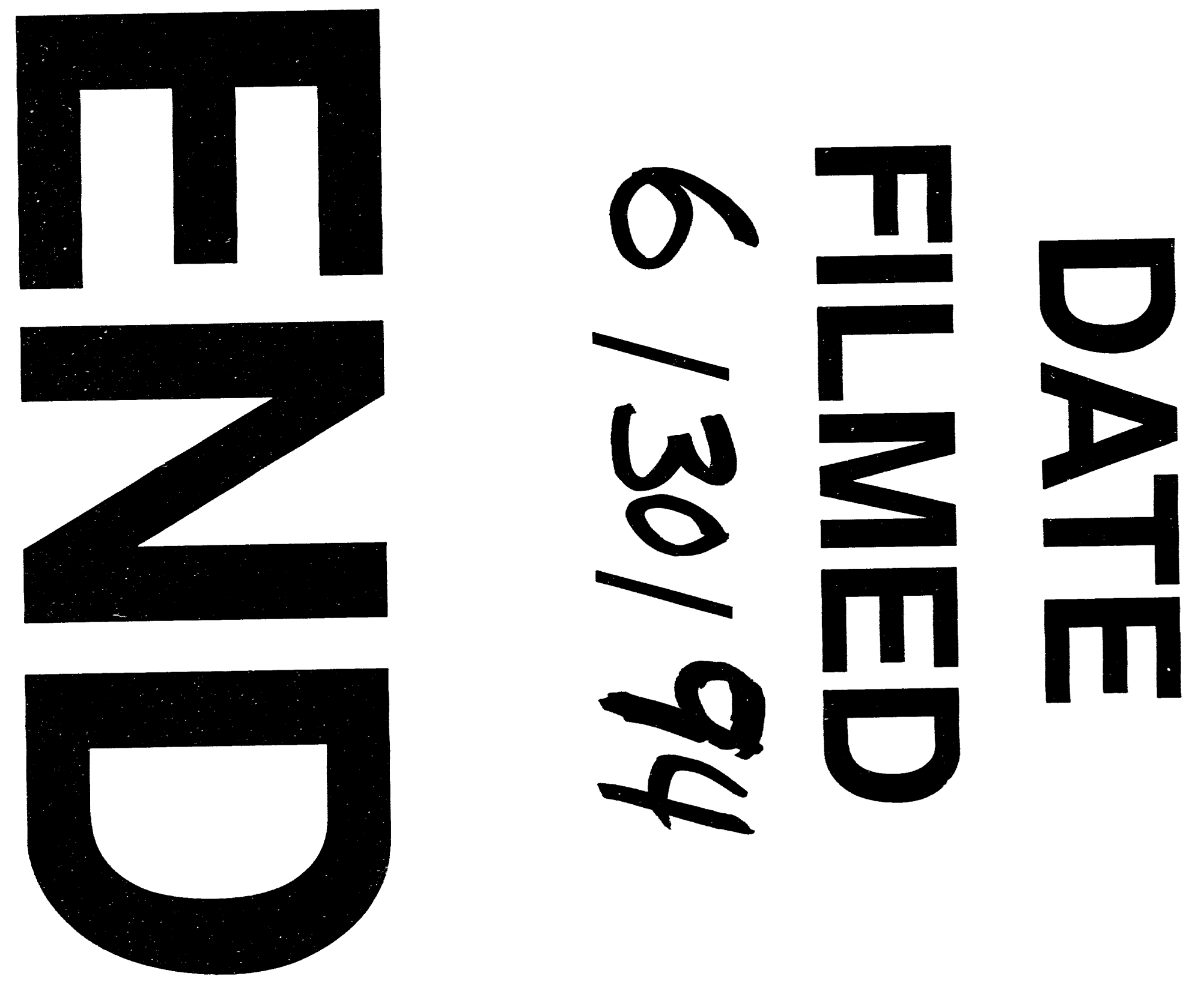
